\title{
(1)
}

UNIVERSIDAD PERUANA DE CIENCIAS APLICADAS

FACULTAD DE ARQUITECTURA

CARRERA DE ARQUITECTURA

\section{NUEVO TERMINAL PESQUERO Y COMPLEJO \\ CULTURAL DE LA GASTRONOMIA PERUANA EN PUCUSANA}

\author{
TESIS \\ Para optar el Título Profesional de Arquitecto \\ Autor: \\ María José Padilla Privat (0000-0002-0881-2826) \\ Asesor de Tesis \\ Arq. Pilar Mercado Neumann (0000-0003-2983-1046)
}




\section{RESUMEN}

El proyecto Nuevo Terminal Pesquero y Complejo Cultural de la gastronomía peruana en Pucusana, consta de cuatro tipologías, Terminal pesquero, Mercado de pesca, Mercado Gastronómico y finalmente Espacios culturales, estos últimos espacios están distribuidos en todo el proyecto ya que servirán para poder entender lo que pasa en cada espacio y darle un enfoque cultural a toda la experiencia. El recorrido se realizará a través de rampas, las cuales permitirán al usuario un recorrido optimo ascendente hasta el gran mirador.

La propuesta nace de la necesidad de repotenciar el sector y darle una personalidad clara que perdure en el tiempo. La propuesta arquitectónica en el primer nivel es dejar la planta libre para poder entender la actividad pesquera que se realiza en Pucusana, para ello no hay muros que tapen las visuales hacia el mar y cuenta con una plaza de interacción la cual tiene mobiliario paisajístico además cuenta con murales gráficos donde te explica la flora y fauna local.

En el segundo nivel se encuentra el mercado de pesca el cual se accede atreves de una rampa que es la continuación del malecón existente, En este espacio se podrá comprar el pescado fresco y en el recorrido ver la actividad del terminal pesquero que se está realizando, la planta cuenta con dobles alturas y balcones. Además de los espacios culturales que guiaran el recorrido y espacios de talleres prácticos para aprender a cocinar. En el tercer nivel se encuentra el mercado gastronómico y plaza gastronómica, en estos espacios el usuario puede comprar el plato que sea distributor contemplando el paisaje, entendiendo el gran valor culinario que los peruanos caracterizan y que Pucusana representa.

Finalmente, en el cuarto nivel se encuentra el mirador paisajístico, el cual consta de un sistema de rampas y mobiliario para poder contemplar el lugar y reflexionar sobre la experiencia, comprendiendo el gran valor que caracteriza.

Palabras claves: Mercado, Gatronómico, Cultural, Pucusana, Terminal pesquero, Artesanal 


\section{ABSTRACT}

The New Fishing Terminal project and cultural complex of Peruvian cuisine in Pucusana, consists of four types, Fishing Terminal, Fishing Market, Gastronomic Market and finally Cultural Spaces, these last spaces are distributed throughout the project as they will serve to understand what what happens in each space and give a cultural focus to the whole experience. The route will be made through ramps, which will allow the user an optimal path up to the great viewpoint.

The proposal arises from the need to repower the sector and give it a clear personality that lasts over time. The architectural proposal in the first level is to leave the floor free to understand the fishing activity that takes place in Pucusana, for it there are no walls that block the visuals towards the sea and it has an interaction plaza which has landscaped furniture. with graphic murals where he explains the local flora and fauna.

In the second level is the fishing market which is accessed through a ramp that is the continuation of the existing boardwalk. In this space you can buy fresh fish and in the tour see the activity of the fishing terminal that is being made, the plant has double heights and balconies. In addition to the cultural spaces that will guide the tour and spaces for practical workshops to learn how to cook.

In the third level is the gastronomic market and gastronomic plaza, in these spaces the user can buy the plate that is distributor contemplating the landscape, understanding the great culinary value that the Peruvians catheterize and that Pucusana represents.

Finally, on the fourth level there is the scenic viewpoint, which consists of a system of ramps and furniture to be able to remain contemplated the place and reflecting on the experience, understanding the great value that characterizes.

Keyswords : Market, Gastronomic, Pucusana, Cultural, Fishing terminal, Artisan 


\section{TABLA DE CONTENIDO}

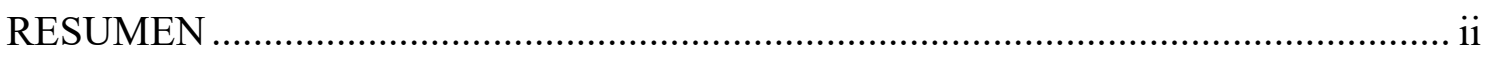

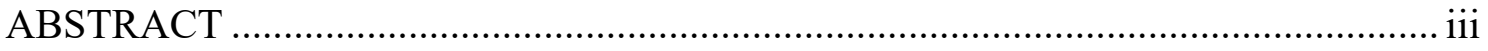

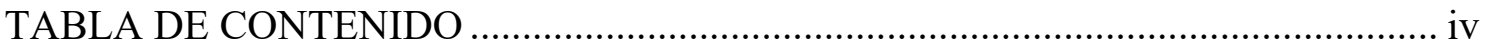

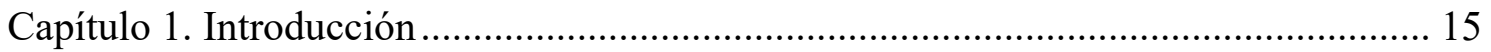

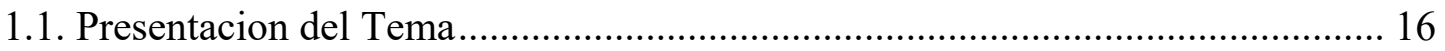

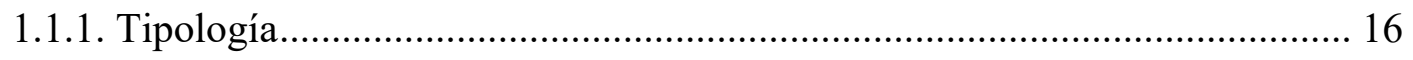

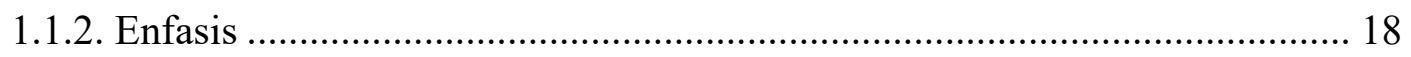

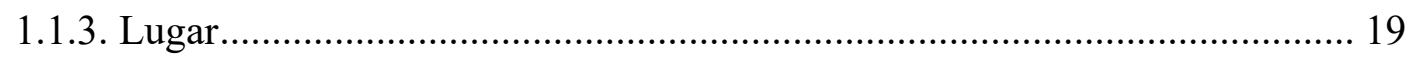

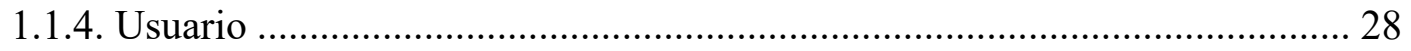

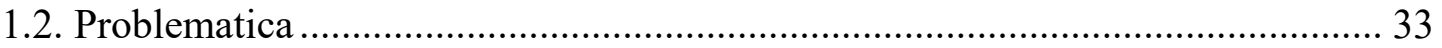

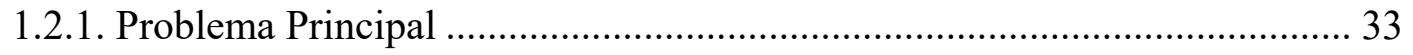

1.2.2. Problemas Especificos ........................................................................... 34

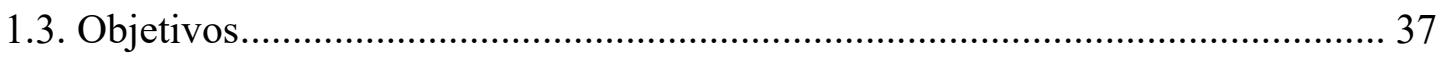

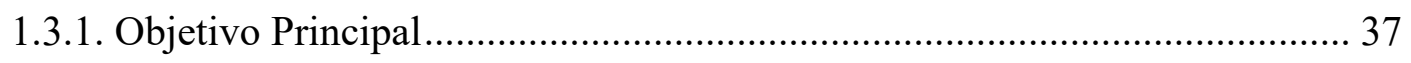

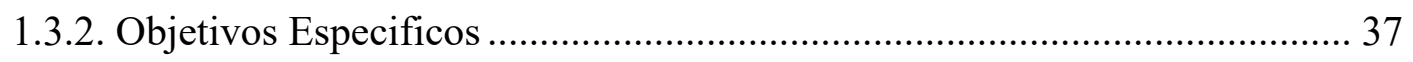

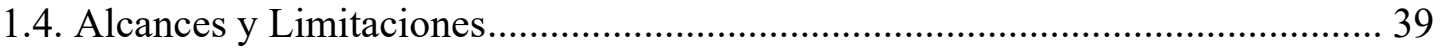

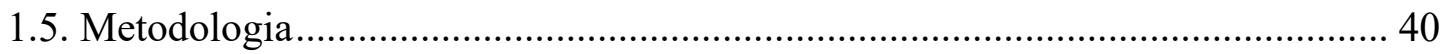

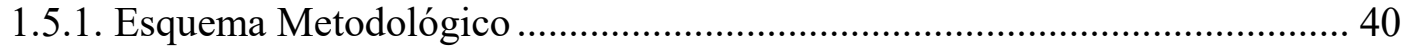

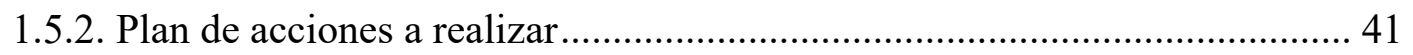

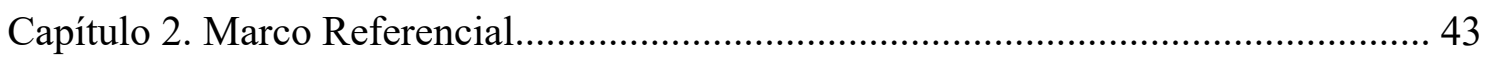

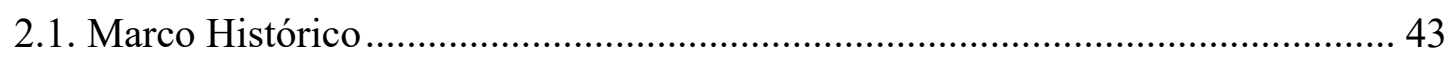

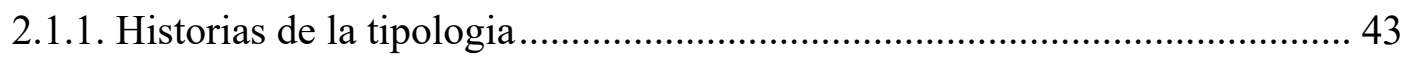

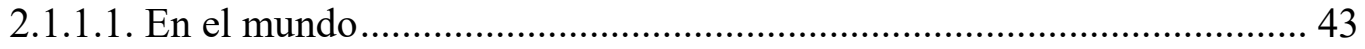

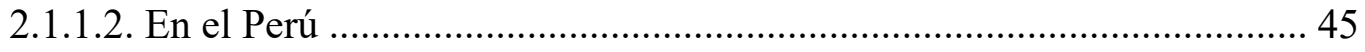

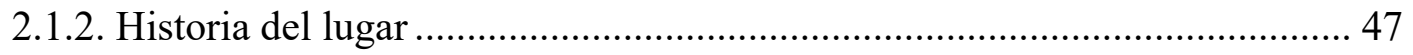

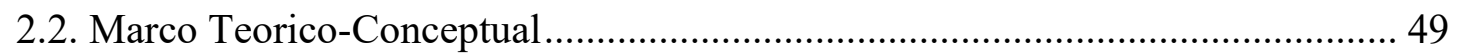

Capítulo 3. Análisis de los Proyectos Referenciales .................................................... 57

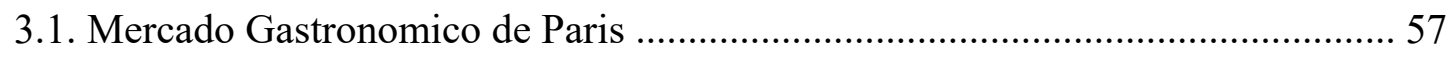

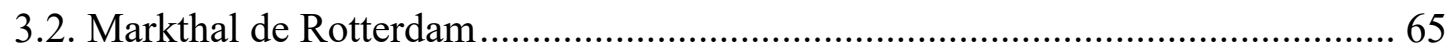

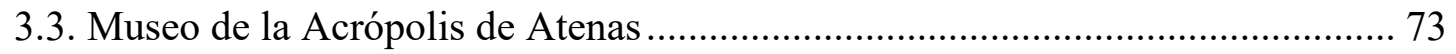




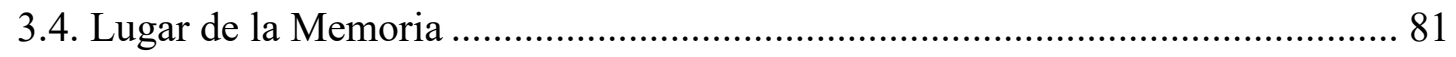

3.5. Cuadro Comparativo de los Proyectos ................................................................ 89

3.6. Otros Proyectos Referenciales......................................................................... 93

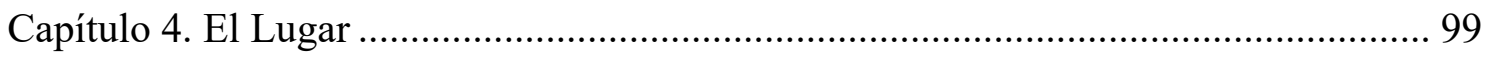

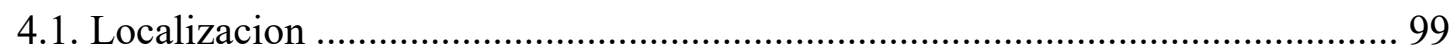

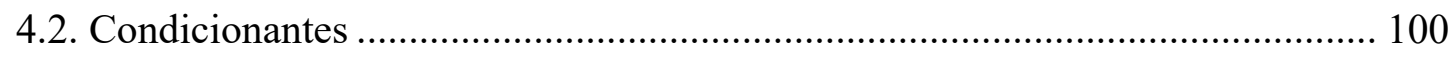

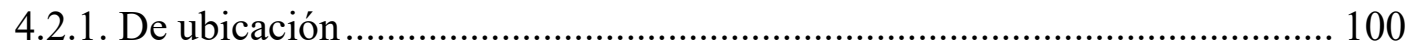

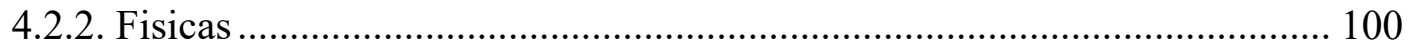

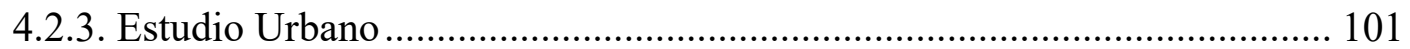

4.2.3.1. Zonificacion y usos de suelo ........................................................... 101

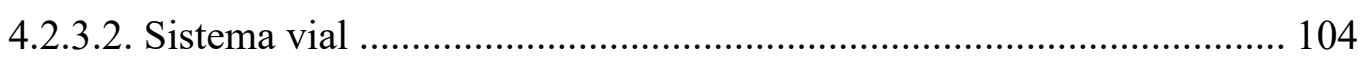

4.2.3.2.1. Vias expresas, semi- expresas, arteriales, colectoras y locales .... 104

4.2.3.2.2. Transporte publico................................................................... 105

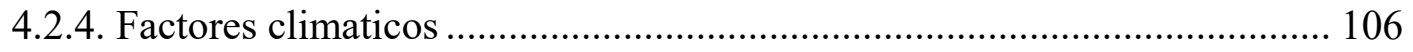

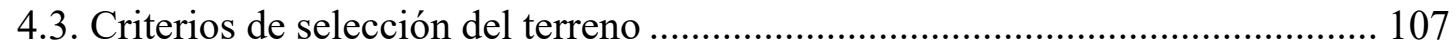

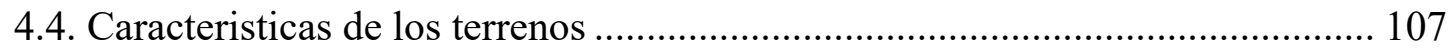

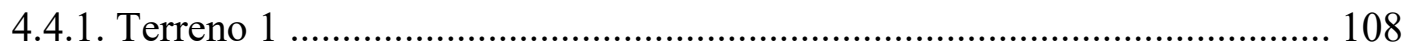

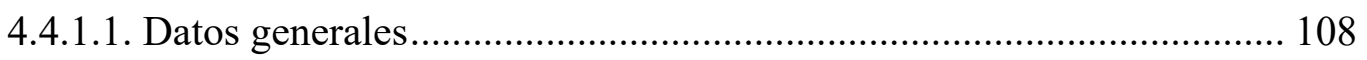

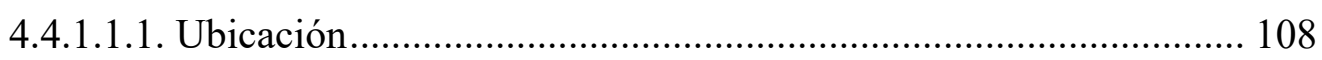

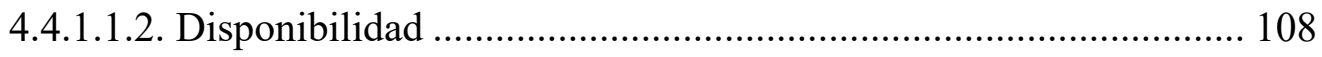

4.4.1.1.3. Situacion y conexión con la ciudad .............................................. 108

4.4.1.2. Parametros urbano - arquitectonicos............................................... 109

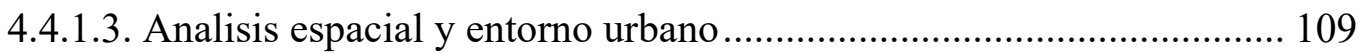

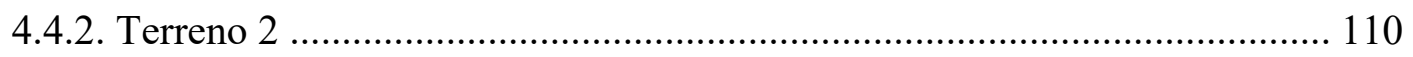

4.4.2.1. Datos Generales ............................................................................ 110

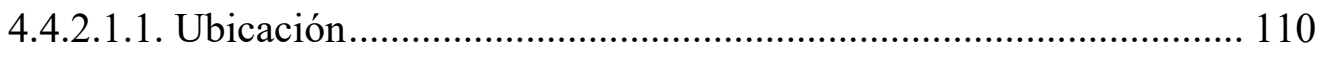

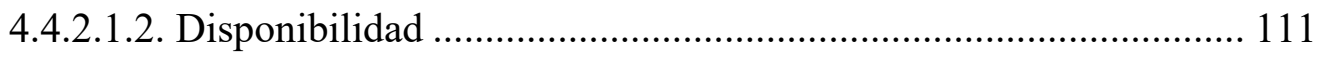

4.4.2.1.3. Situacion y conexión con la ciudad .............................................. 111

4.4.2.2. Parametros urbano - arquitectonicos................................................ 111

4.4.2.3. Analisis espacial y entorno urbano .................................................. 112

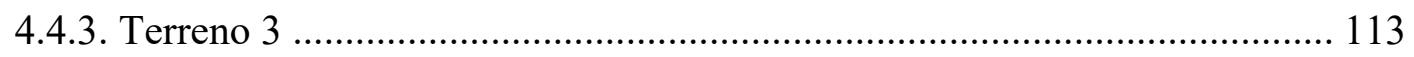

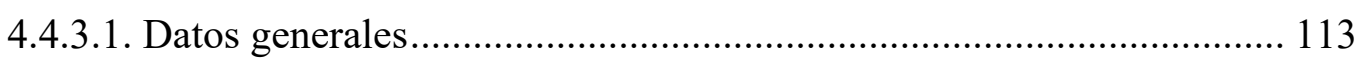

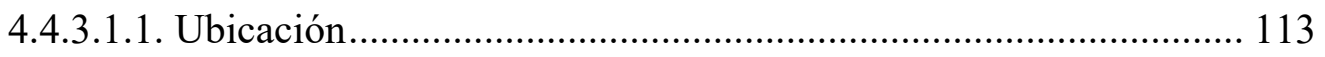

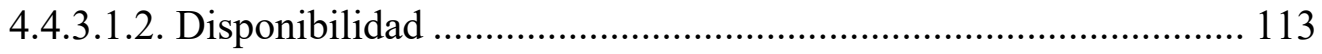


4.4.3.1.3. Situacion y conexión con la ciudad 113

4.4.3.2. Parametros urbano - arquitectonicos ............................................... 114

4.4.3.3. Analisis espacial y entorno urbano................................................. 114

4.5. Cuadro de valoracion de los terrenos según criterio ........................................ 115

4.6. Cuadro de ventajas y desventajas de los 3 terrenos......................................... 116

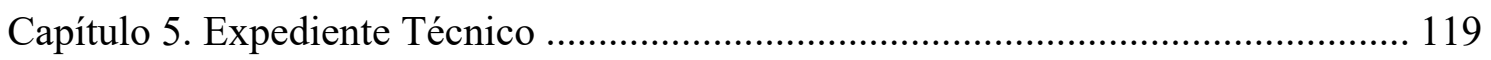

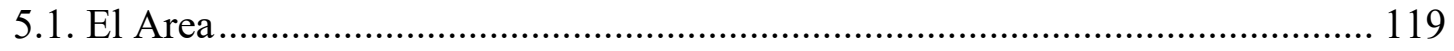

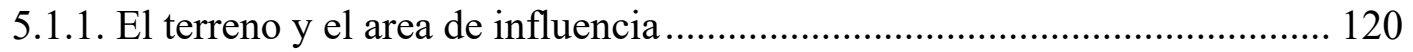

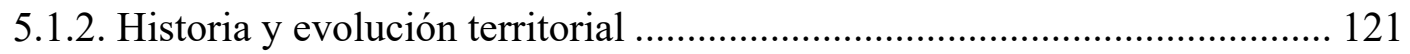

5.1.3. Zonas protegidas e intagibles, zonas de proteccion paisajista................... 123

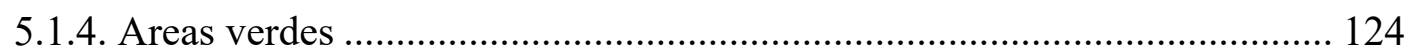

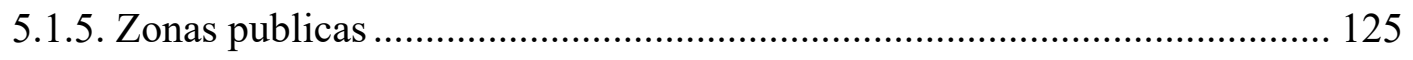

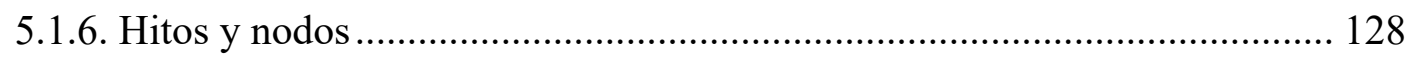

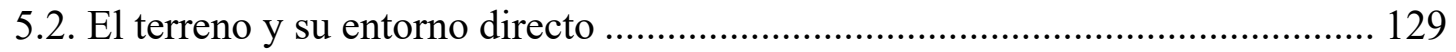

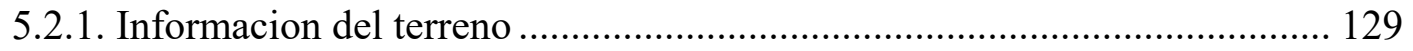

5.2.1.1. Ubicación, propiedad y situacion ....................................................... 129

5.2.1.2. Area, orientacion y topografia ........................................................ 130

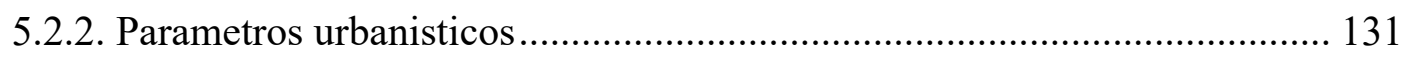

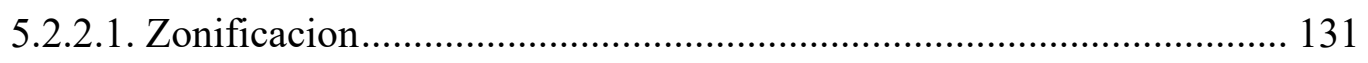

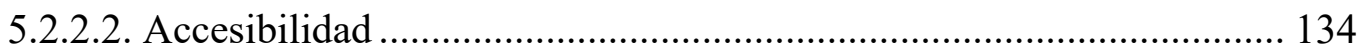

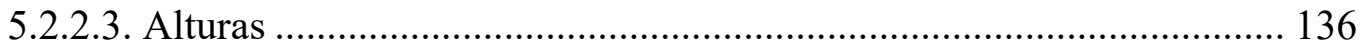

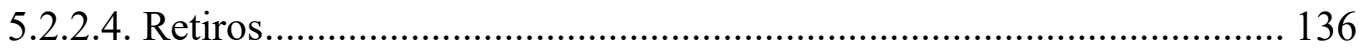

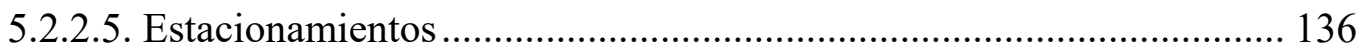

5.2.2.6. Compatibilidad de usos de suelo ..................................................... 136

5.2.2.7. Especificaciones normativas.......................................................... 136

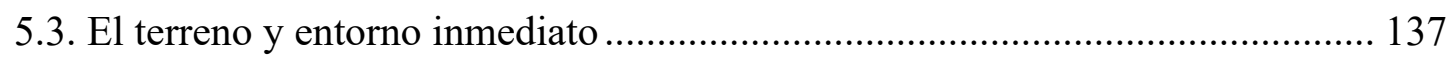

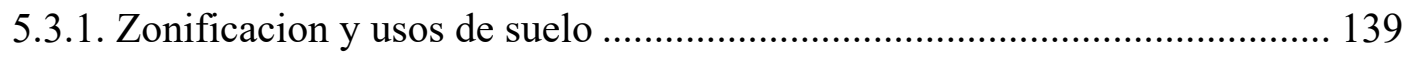

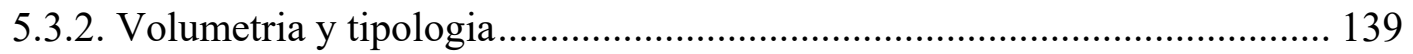

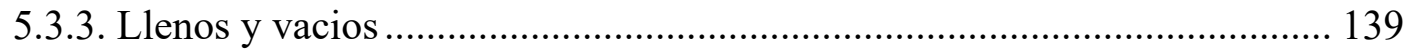

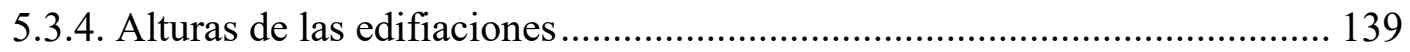

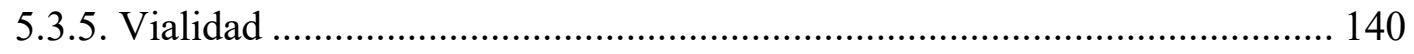

5.3.6. Circulaciones peatonales, alamedad, plazas, etc. .................................... 141

5.3.7. Levantamiento, secciones de vias y veredas ........................................ 143 
5.3.8. ¿Qué problemas, condición o condicionantes del entorno debe resolver el proyecto?

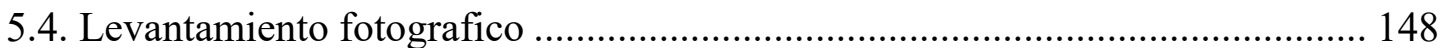

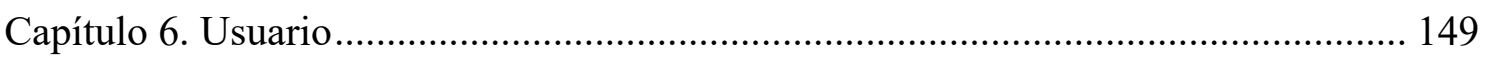

6.1. Definición de los Usuarios ............................................................................. 149

6.1.1. Informacion Cuantitativa ........................................................................ 150

6.1.1.1. Numero y tipos de usuario............................................................... 153

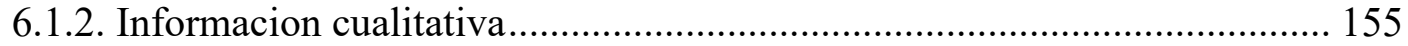

6.1.2.1. Flujos y necesidades del Usuario ..................................................... 155

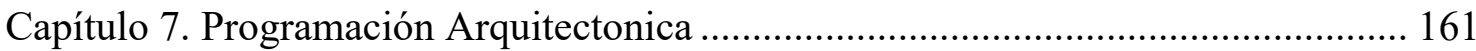

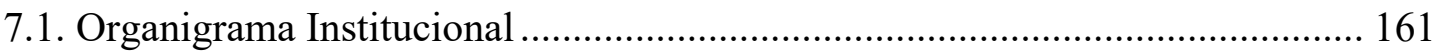

7.2. Definicion de Paquetes Funcionales............................................................. 162

7.2.1. Diagramas de interrelación entre paquetes funcionaes............................. 162

7.2.2. Cercanias y lejanias de los ambientes y paquetes funcionales .................. 162

7.3. Organigrama de los Paquetes Funcionales ...................................................... 163

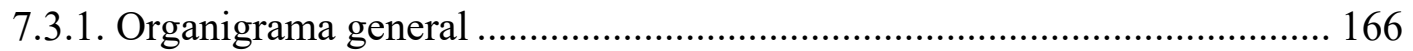

7.4. Analisis de Normativa aplicable al Proyecto.......................................................... 166

7.5. Estudio de Antropometria y Mobiliario General............................................... 170

7.6. Analisis Cuantitativo y Cualitativo de los Espacios Funcionales ...................... 171

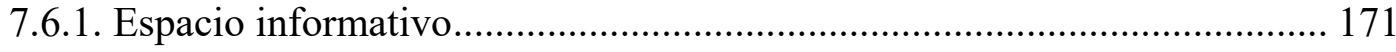

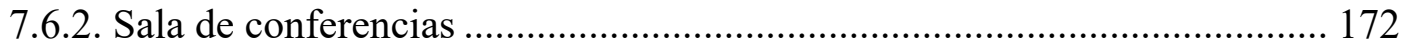

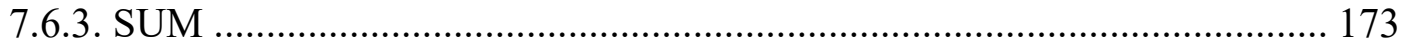

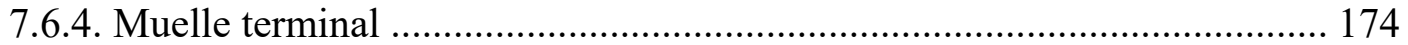

7.6.5. Mostrador mercado de pesca ................................................................... 175

7.6.6. Mostrador del mercado gastronomico ........................................................ 176

7.6.7. Cocina del mercado gastronomico .......................................................... 177

7.6.8. Zona de carga y descarga........................................................................ 178

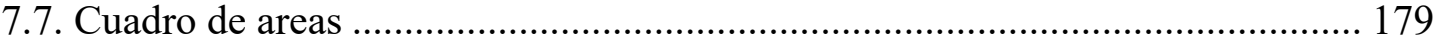

7.7.1. Listado y número de personas por ambiente ........................................... 179

7.7.2. Area por ambiente, por paquete funcional y area total construida ............. 180

7.8. Cuadro resumen de areas por paquete funcional y area total construida........... 181

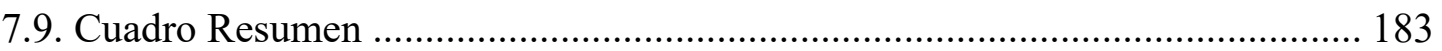

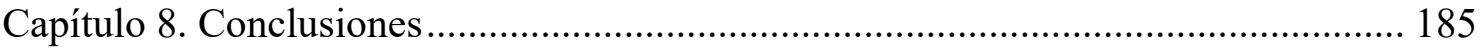

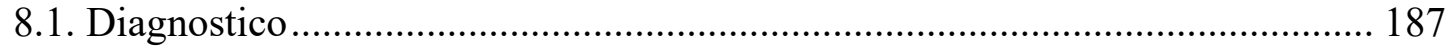




\section{INDICE DE TABLAS}

Tabla 1 : Estadistica del nivel educativo de la población del distrito de Pucusana. 31

\section{INDICE DE FIGURAS}

Figura 1 : Vista aerea de la zona pueblo de Pucusana. 18

Figura 2 : Mapa de guia de lugares importantes del recorrido hacia el proyecto............ 20

Figura 3 : Avenida principal, hacia el pueblo de Pucusana - etapa 1 ............................. 20

Figura 4 : Avenida principal, hacia el pueblo de Pucusana - etapa2 ............................ 21

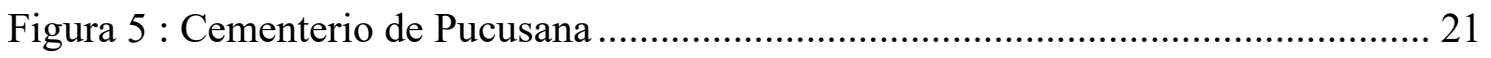

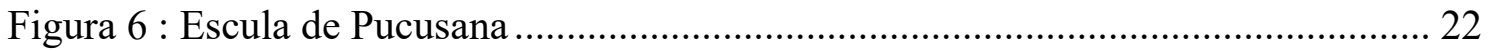

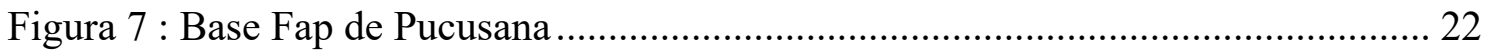

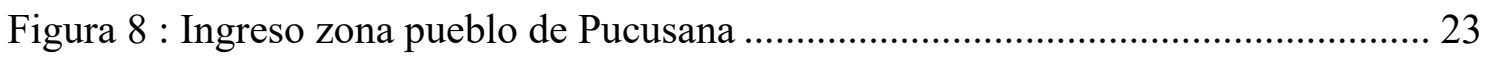

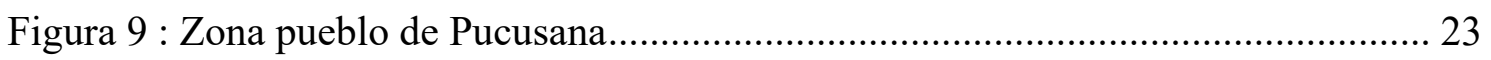

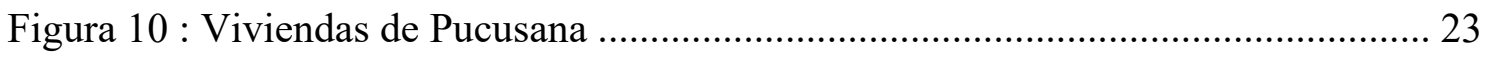

Figura 11 : Borde hacia la Bahía de Pucuana................................................................. 24

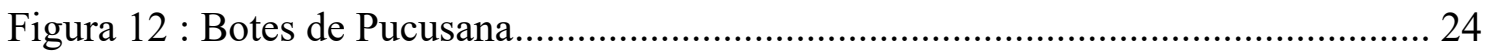

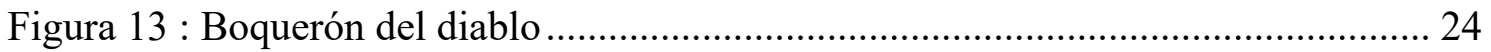

Figura 14 : Zonificación del distrito de Pucusana ........................................................... 25

Figura 15 y 16: Pescadores de la Bahía de Pucusana en los ochentas y los noventas... 26

Figura 17 : Contaminación en el malecón del pueblo de Pucusana ................................ 26

Figura 18 : Espacios públicos del pueblo de Pucusana ................................................ 27

Figura 19 : Zona de llegada y salida del pueblo de Pucusana ....................................... 28

Figura 20 : Viviendas en la zona de llegada y salida del pueblo de Pucusana............... 28

Figura 21 : Cuadro estadístico de los sexos en la población de Pucusana ...................... 29

Figura 22: Comparativo de población economicamente activa del distrito de Pucusana29

Figura 23 : Ingreso al Mercado de Pucusana................................................................... 30

Figura 24 : Pesca artesanal en el distrito de Pucusana ................................................... 31

Figura 25 : Espacios comerciales en el malecón de Pucusana ...................................... 32

Figura 26 : Embarcaciónes turisticas de la bahía de Pucusana....................................... 32 
Figura 27: Vendedores ambulantes del pueblo de Pucusana.......................................... 34

Figura 28: Puestos ambulantes en las veredas del pueblo de Pucusana ......................... 35

Figura 29: Venta ambulatorio en el malecón de Pucusana.............................................. 36

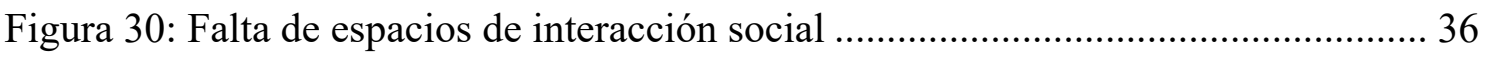

Figura 31: Primeras viviendas del pueblo de Pucusana ............................................... 47

Figura 32: Primeros veraneantes y pescadores del pueblo de Pucusana ........................ 48

Figura 33: Gráficas de los bordes por Kevin Lynch..................................................... 50

Figura 34: Ciudades refrentes de Acupuntura Urbana .................................................. 53

Figura 35: Modelo descripitivo de percepcion y comportamiento segun Downs .......... 54

Figura 36: Esquema de caparazones percepctivos de Moles y Rohmer......................... 55

Figura 40: Ruta de tránsito por el Marketlab de Paris ................................................... 57

Figura 39: Ruta de bicileta por el Marketlab de Paris ................................................. 57

Figura 41: Ruta de transporte público por el Marketlab de Paris................................. 57

Figura 38: Terreno Marketlab de Paris......................................................................... 57

Figura 37: Mapa Localizador - Marketlab de Paris ....................................................... 57

Figura 42: Entorno historico Marketlab de Paris ................................................................ 58

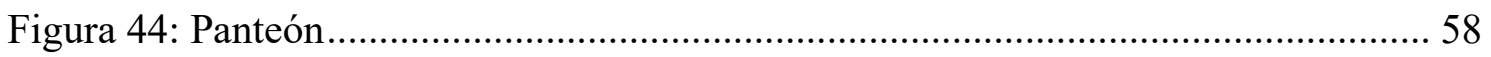

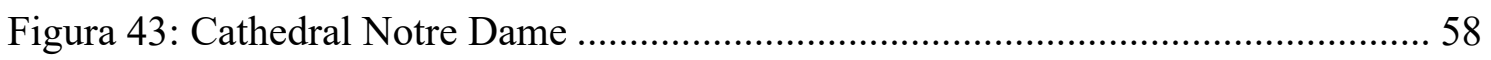

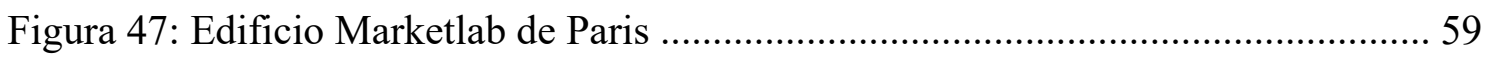

Figura 45: Bocetos Marketlab de Paris ........................................................................ 59

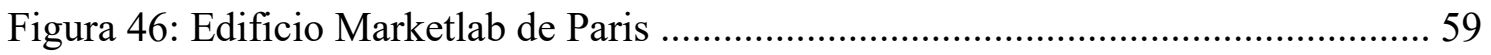

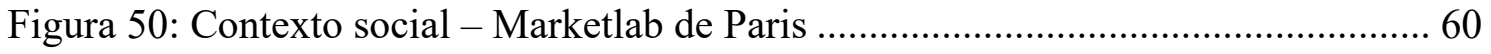

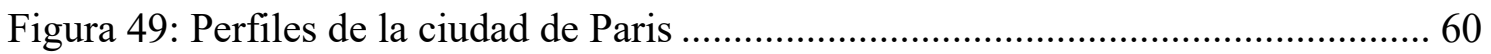

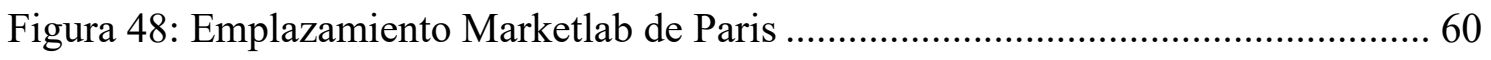

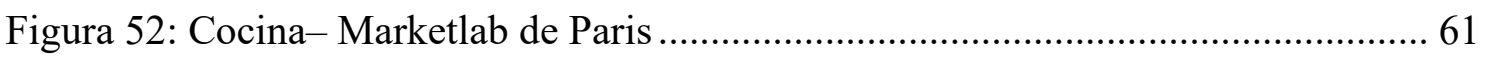

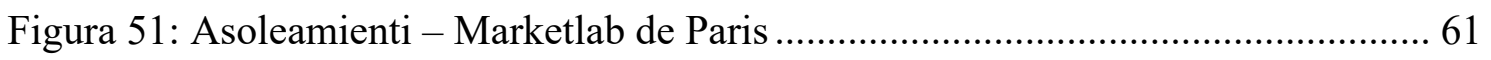

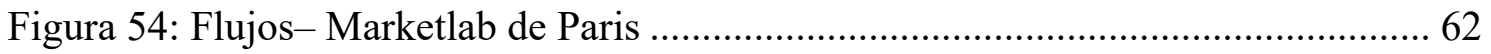

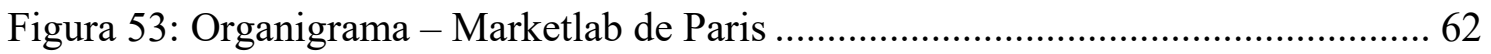

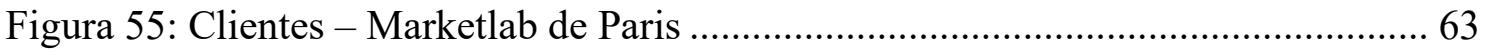

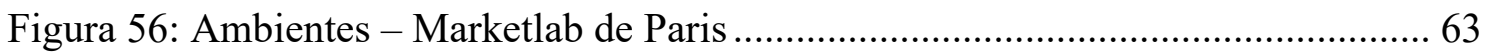

Figura 57: Tecnología del biohuerto - Marketlab de Paris .............................................. 64

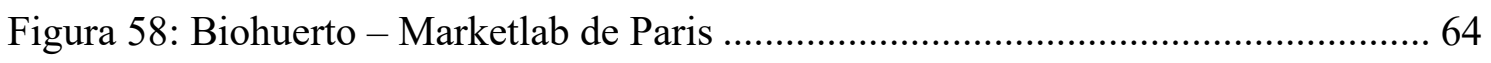

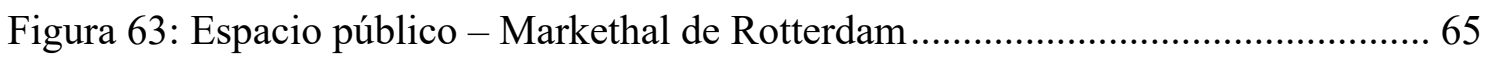

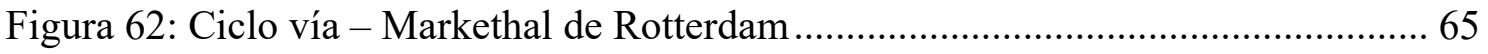


Figura 61: Transito - Markethal de Rotterdam 65

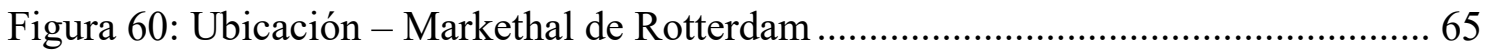

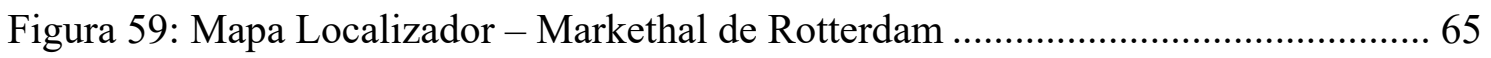

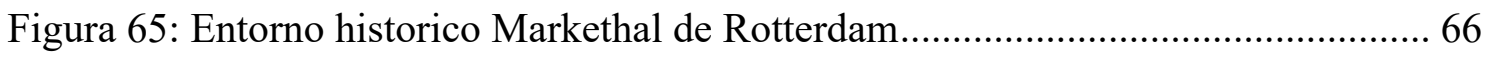

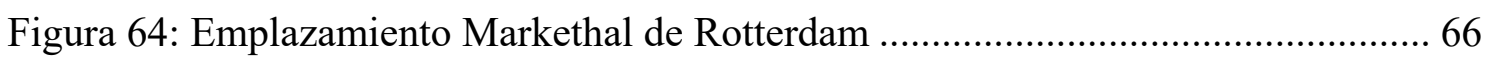

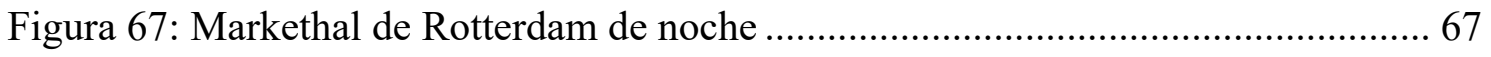

Figura 66: Vista de las viviendas del Markethal de Rotterdam...................................... 67

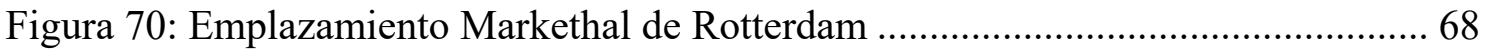

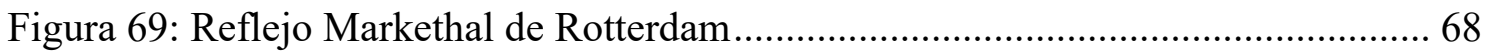

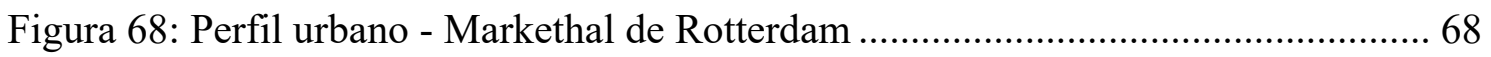

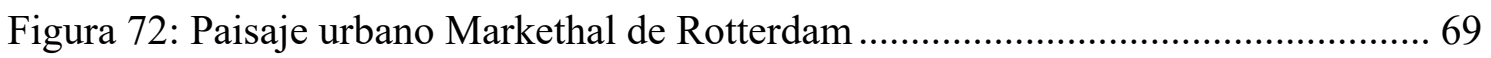

Figura 73: Vista panorámica interna del Markethal de Rotterdam ................................ 69

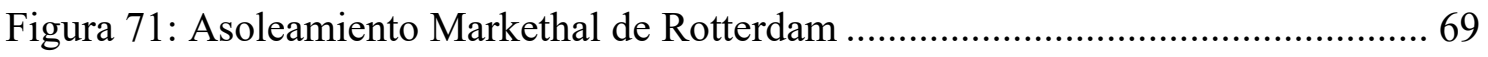

Figura 75: Escaleras Markethal de Rotterdam ............................................................. 70

Figura 74: Circulaciónes Markethal de Rotterdam....................................................... 70

Figura 78: Tipologías Markethal de Rotterdam ........................................................ 71

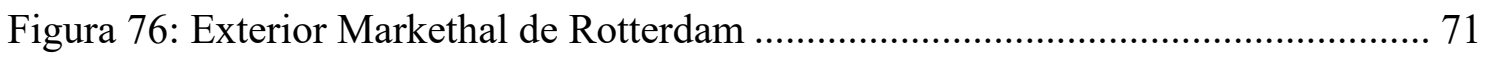

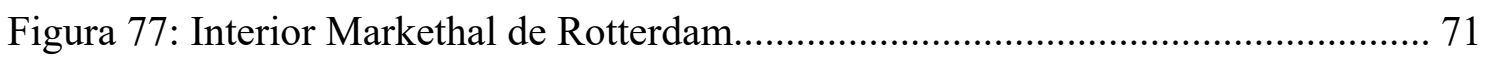

Figura 81: Vistas Markethal de Rotterdam............................................................. 72

Figura 80: Modulacón estructral Markethal de Rotterdam ......................................... 72

Figura 79: Construcción Markethal de Rotterdam ….................................................. 72

Figura 84: Transporte público Museo de la Acrópolis de Atenas ................................... 73

Figura 85: Calles colindantes del Museo de la Acrópolis de Atenas ............................. 73

Figura 86: Vista de la colina del Museo de la Acrópolis de Atenas............................... 73

Figura 83: Terreno Museo de la Acrópolis de Atenas ................................................... 73

Figura 82: Mapa Localizador - Museo de la Acrópolis de Atenas ............................... 73

Figura 88: Entorno historico del Museo de la Acrópolis de Atenas.............................. 74

Figura 87: Nexos Museo de la Acrópolis de Atenas ......................................................... 74

Figura 89: Concepto gráfico del Museo de la Acrópolis de Atenas............................... 75

Figura 90: Vista aerea Museo de la Acrópolis de Atenas.............................................. 75

Figura 91: Historia y arquitectura - Museo de la Acrópolis de Atenas ......................... 75

Figura 93: Sistema vial - Museo de la Acrópolis de Atenas ......................................... 76

Figura 94: Museo de la Acrópolis de Atenas de noche ................................................ 76

Figura 92: Relación con la ciudad - Museo de la Acrópolis de Atenas.......................... 76 
Figura 97: La escala del Museo de la Acrópolis de Atenas .......................................... 77

Figura 98: Reflejos del Museo de la Acrópolis de Atenas ........................................... 77

Figura 96: Visuales desde el Museo de la Acrópolis de Atenas................................... 77

Figura 95: Asoleamiento Museo de la Acrópolis de Atenas .......................................... 77

Figura 100: Historia contenida de la Acropolis de Atenas - exterior ............................ 78

Figura 99: Historia contenida de la Acropolis de Atenas - interior................................ 78

Figura 101: Volumetría - Museo de la Acropolis de Atenas ........................................ 79

Figura 103: Vistas - Museo de la Acropolis de Atenas ................................................. 80

Figura 102: Ssitema constructivo - Museo de la Acropolis de Atenas ........................... 80

Figura 108. Vias peatonales Lugar de la memoria .................................................. 81

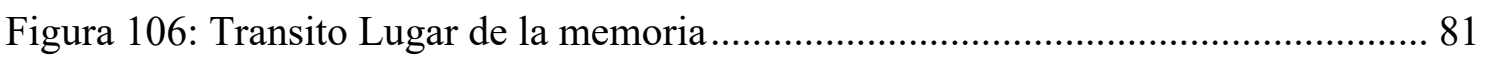

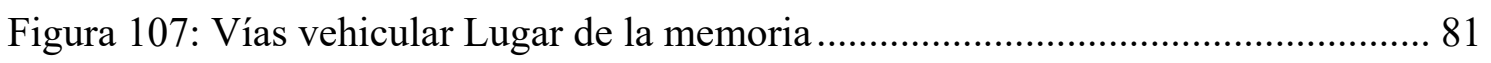

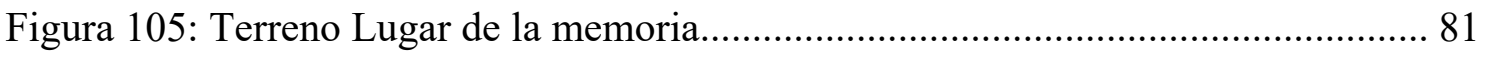

Figura 104: Mapa Localizador - Lugar de la memoria ................................................. 81

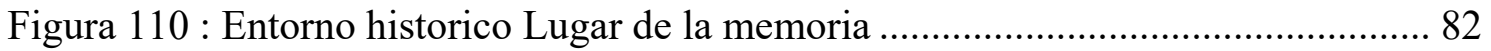

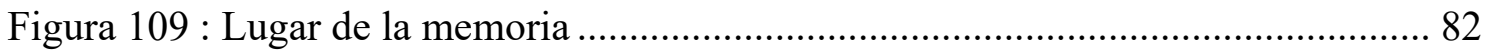

Figura 113 : Enfoques naturales del Lugar de la memoria......................................... 83

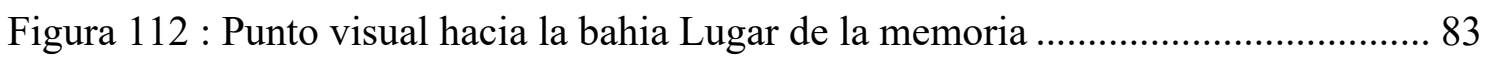

Figura 111 : Conceptualización Lugar de la memoria ............................................... 83

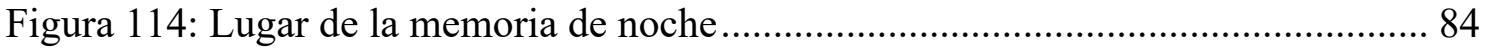

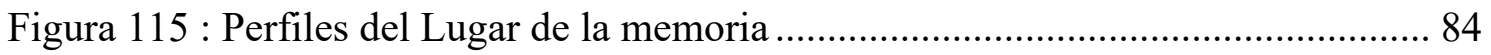

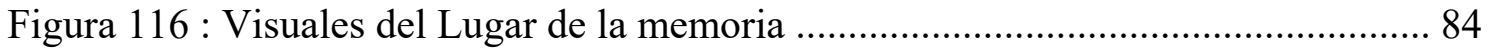

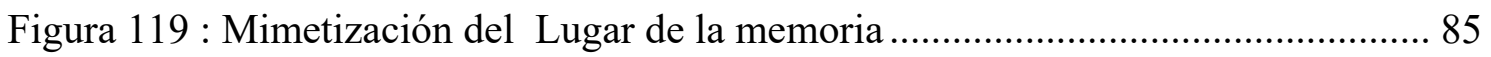

Figura 118 : Punto focal del Lugar de la memoria ..................................................... 85

Figura 117 : Asoleamiento Lugar de la memoria ...................................................... 85

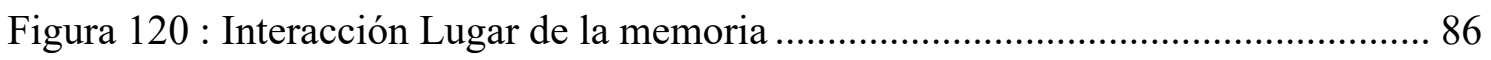

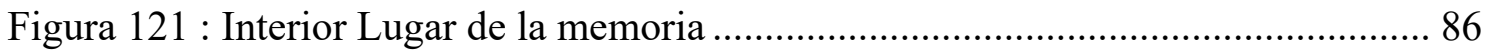

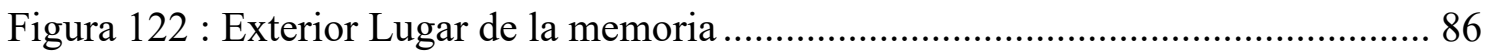

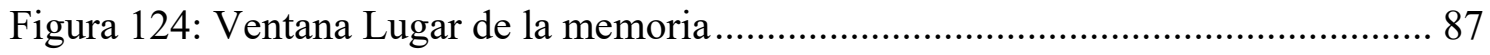

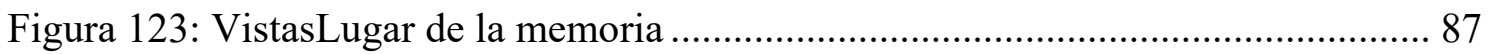

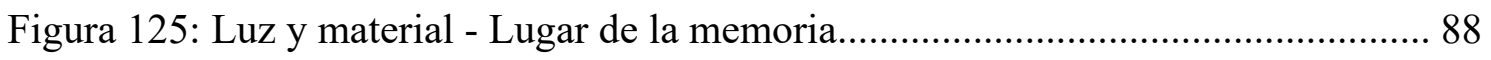

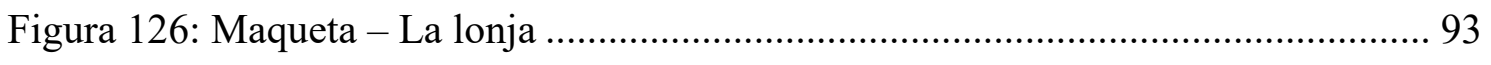

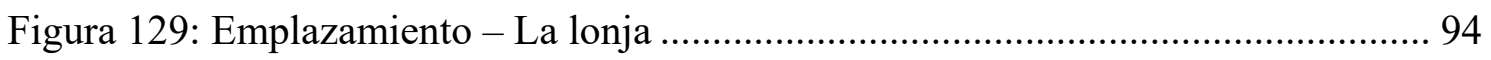

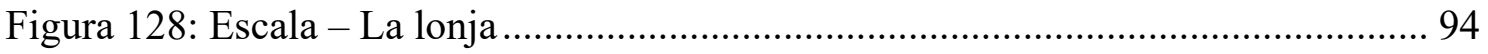




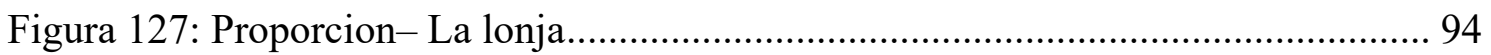

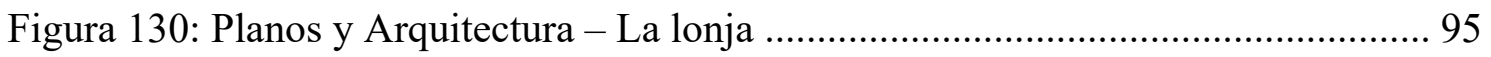

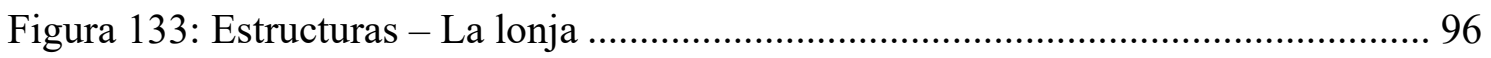

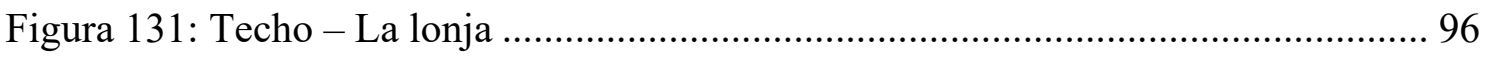

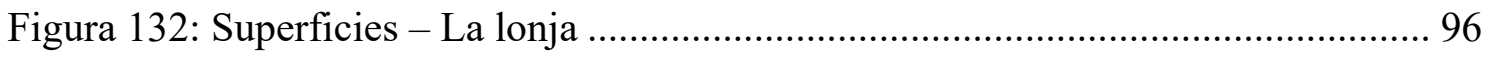

Figura 135: Conversaciónes trascendentes - Mistura ….............................................. 97

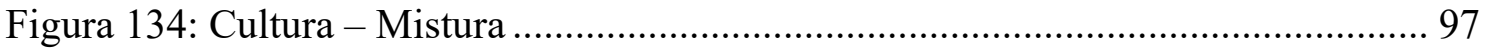

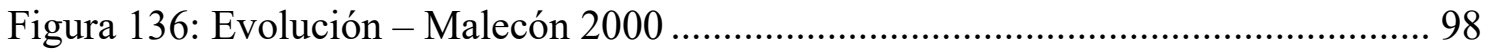

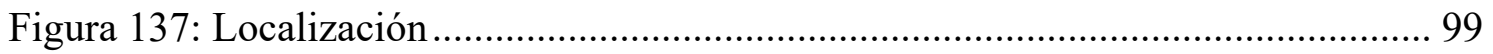

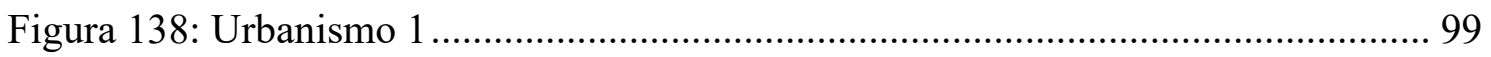

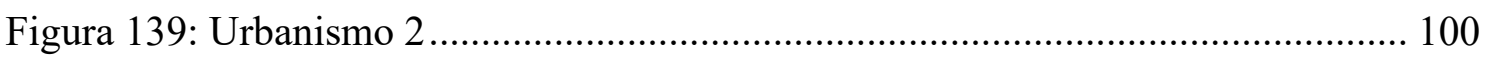

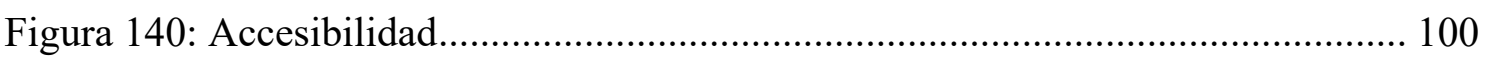

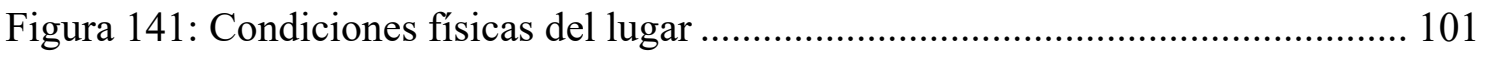

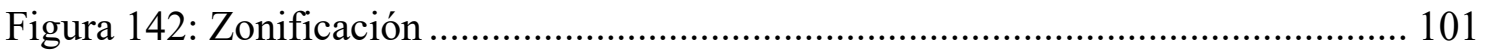

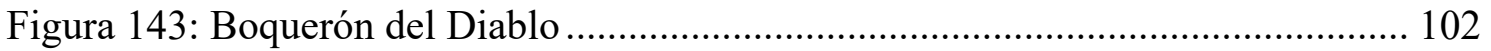

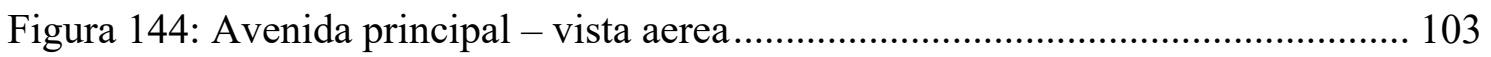

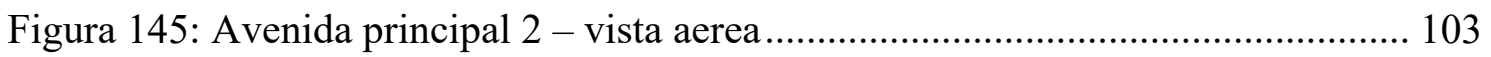

Figura 146. Vias expresas, semi- expresas, arteriales, colectoras y locales .................. 104

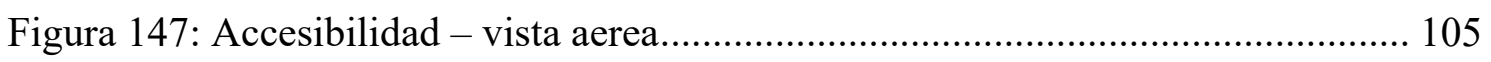

Figura 148: Accesibilidad - fotos de las vias de acceso ........................................... 105

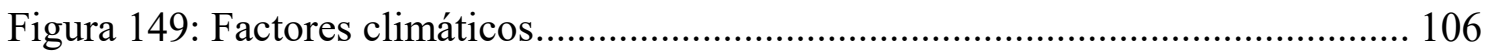

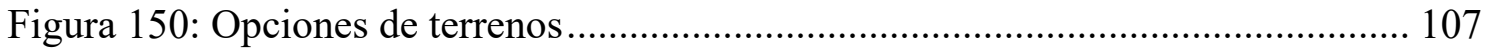

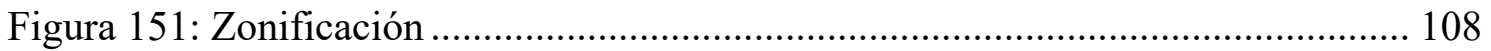

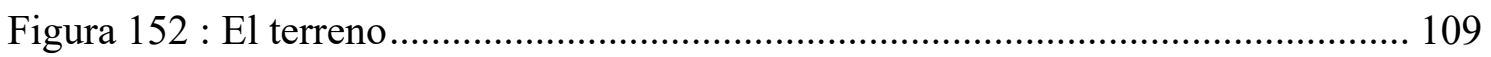

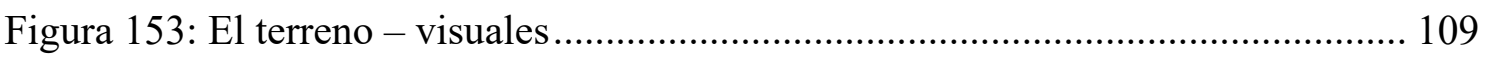

Figura 154 y 155: Embarcaciones y pescadores artesanales ..................................... 109

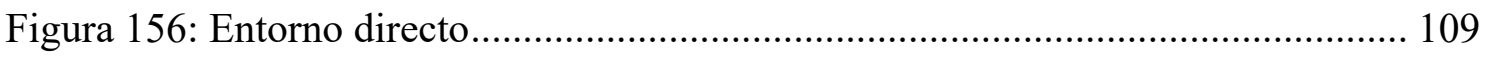

Figura 157: Pescadores en el Terminal pesquero artesanal ........................................ 110

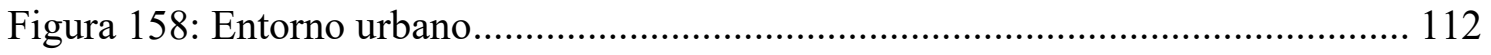

Figura 159: Techos precarios - Mercado de abastos.................................................. 112

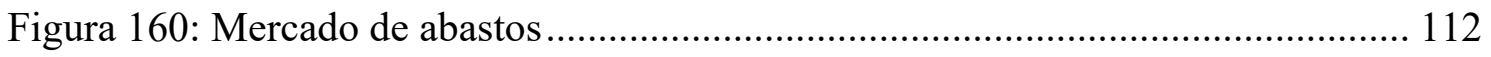

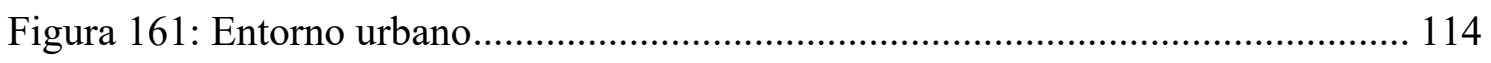

Figura 162: Terminal pesquero - Toma aerea..................................................... 120

Figura 163: Terminal pesquero y malecón - Toma aerea ........................................ 121 
Figura 164: Terminal pesquero y zona urbana - Toma aerea

Figura 165: Pueblo de Pucusana - Toma aerea........................................................... 123

Figura 166: Ingreso zona pueblo de Pucusana - Toma aerea....................................... 124

Figura 167. Gáfica muestra el déficit de áreas verdes en Pucusana ............................ 125

Figura 168: Zonas publicas del pueblo de Pucusana - Toma aerea ........................... 125

Figura 169: Los espacios públicos se incrementan no solo en cantidad sino en escala 125

Figura 170: Acceso al melecón - Toma aerea.......................................................... 126

Figura 171. Mapa donde se muestra los 3 posibles terrenos ..................................... 126

Figura 172: Terminal pesquero y malecón - Toma aerea......................................... 128

Figura 173: Mercado de abastos - Toma aerea ............................................................ 129

Figura 174: Boquerón del diablo - Toma aerea ....................................................... 129

Figura 175: Malecón, Terreno y embarcaciónes - Toma aerea .................................. 132

Figura 176. Mapa muestra malecón exclusivo de poeatones ...................................... 133

Figura 177. Mapa de alturas, muestra las viviendas de 2 hasta 5 pisos....................... 135

Figura 178: El terreno y el borde hacia el mar - Toma aerea .................................. 137

Figura 179: Playa del pueblo de Pucusana - Toma aerea ........................................... 137

Figura 180. El terreno y el entorno inmediato .......................................................... 138

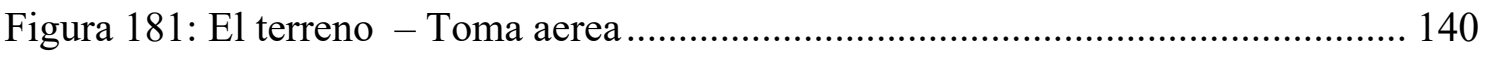

Figura 182: Edificios colindantes al terreno - Toma aerea ...................................... 140

Figura 183: Terreno en zoom (toma aerea) y vista del terminal ................................ 141

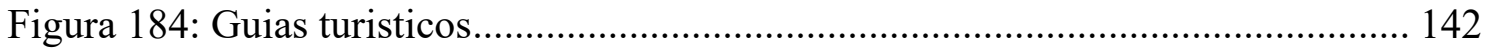

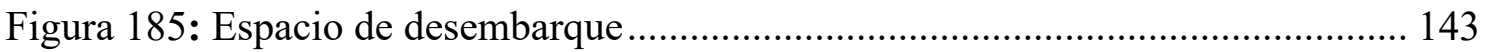

Figura 186: Camión de transporte - Terminal Pesquero ............................................... 143

Figura 187: Acceso a las Ninfas - Toma aerea .......................................................... 143

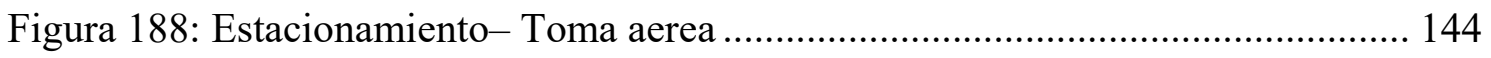

Figura 189: Patio de maniobras - Toma aerea ......................................................... 144

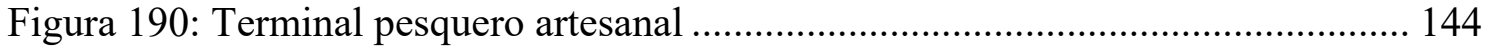

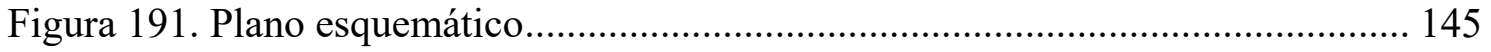

Figura 192: Patio de maniobras - carga y descarga …................................................. 146

Figura 193: Descarga Terminal pesquero artesanal ..................................................... 147

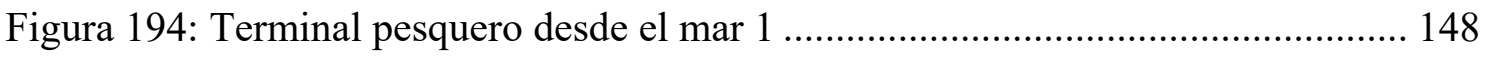

Figura 195: Terminal pesquero desde el mar 2 ...................................................... 148

Figura 196: Terminal pesquero desde el mar 3 .................................................... 148

Figura 197. Radio de influencia del lugar en el contexto urbano ................................ 150 


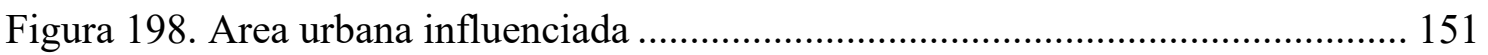

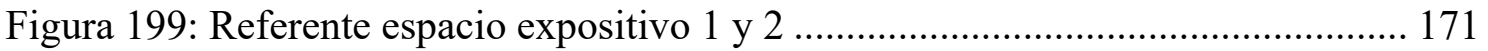

Figura 200: Referencia de sala de conferencias y detalle de butacas .......................... 172

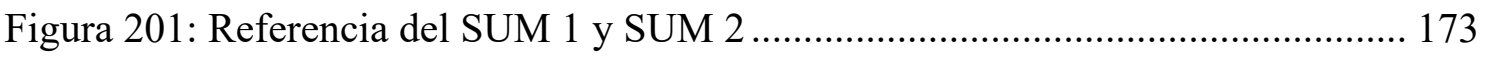

Figura 202: Referencia de Muelle de terminal ........................................................ 174

Figura 203: Referencia de Mercado de Pesca ........................................................ 175

Figura 204: Referencia de Mercado Gatronomico - comedor, puestos y espacialidad 176

Figura 205: Referencia - Cocina del Mercado Gatronomico ..................................... 177

Figura 206: Referencia - Patio de Carga y descarga Mercado Gatronomico .............. 178

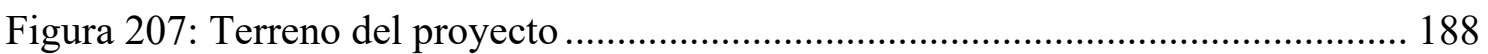




\section{Capítulo 1. Introducción}

En el Perú y en el mundo, la cocina peruana está en la boca de todos. Su variedad de sabores, hacen de ella una comida única e incomparable. Sus logros obtenidos en los últimos años han sido la prueba de ello, entrando al mapa de la mejor gastronomía mundial y ser fuerza motriz e impulsadora hacia el desarrollo y autoestima nacional. ${ }^{1}$

Así como en tiempos remotos los creyentes construían catedrales, iglesias o santuarios para contemplar sus creencias, la gastronomía peruana también debe profesar sus tradiciones en espacios de culto. Existen, huariques, picanterías, restaurantes, entro otros espacios que transmiten cultura e identidad. Es por ello que en pleno boom gastronómico peruano, los arquitectos debemos aportar y diseñar propuestas innovadores que permitan representarla.

Se sabe que los mercados, además de sus diseños, también aportan cultura e historia y es que, como señalan los arquitectos Córdova y Machicao y el periodista y gastrónomo Raúl Vargas, los mercados siempre fueron y deben seguir siendo centros de encuentro e intercambio de la gente. Las grandes cocinas del mundo entero, no solo han difundido sus sabores, sino también su cultura, diseño y con ello su identidad.

Lima, la ciudad capital del Perú, se encuentra situada en la costa central del país, a orillas del océano Pacífico. Como afirma el urbanista y arquitecto peruano Manuel de Rivero. Lima es una ciudad difícil de entender. En primer lugar, presenta un grande problema de centralismo, el 80 porciento de la población es inmigrante o hijo de inmigrante lo cual afirma que Lima no es una ciudad de una tradición, sino de muchas. Los contrastes culturales son notables no solo socialmente sino espacialmente y esta interrelación constante en muchos casos ha generado desconfianza y por ende sectarismo a lo largo de la ciudad.

En segundo Lugar, el trasporte y el área en el cual nos movilizamos no está controlado, los trabajos y universidades entre otros se juntan en un solo centro generando densidades muy altas que se escapan de control. Por la oferta y demanda, nuevos centros comerciales han ido desarrollándose en los bordes de la ciudad, generando nuevas y futuras centralidades, sin embargo aun se encuentra fraccionado, los museos, universidades, e

\footnotetext{
${ }^{1}$ Cfr. Apega (2014)
} 
instituciones que generen nuevos desarrollos periféricos, no han sido planteados aún. Se debe entender a Lima como una ciudad conformada por ciudadanos y no por consumidores, donde los espacios de culto y de interación social profesen nuestras costumbres y tradiciones.

Finalmente, el turismo de igual manera, que el crecimiento de la ciudad, se ha visto aislado y desarticulado en su conjunto. El turismo y recorrido turístico en Lima no alberga la amplia gama de atractivos interculturales, las perisferias se han quedado aisladas y se estan viniendo a menos con el tiempo.

Es por ello que se plantea realizar en el distrito de Pucusana, distrito limite al sur de Lima Metropolitana, cuenta con mucho potencial para ser valorado y repotenciarlo para ser un foco turistico de difusión gastronómica, el proyecto propuesto: TERMINAL PESQUERO Y CUMPLEJO CULTURAL DE LA GASTRONOMÍA PERUANA será una propuesta para ello, generando un recorrido cultural y culinario, en el cual, los locales, peruanos y extranjeros puedan ser testigos de la diversidad cultural que los Peruanos presentan. La gastronomía moviliza a millones de peruanos, refuerza su orgullo e identidad por su cultura y diversidad. ${ }^{2}$

\subsection{Presentacion del Tema}

\subsubsection{Tipología}

Se plantea realizar un TERMINAL PESQUERO Y COMPLEJO CULTURAL DE LA GASTRONOMIA PERUANA EN PUCUSANA. Debido a su cercanía con la capital y belleza natural, el distrito de Pucusana ofrecerá un complejo articulado, el cual por medio del recorrido se podrá entender y valorar el lugar, desde sus orígenes hacia su desarrollo entendiéndolo como una oportunidad hacia el desarrollo. La arquitectura propuesta en el recorrido del proyecto será el hilo conductor de dicha experiencia, permitiendo entender la actividad culinaria local desde la extracción hasta el consumo.

Primero, se plantea re organizar la zona del malecón y muelle de pescadores. Lugar donde se originó el distrito y en el cual se encuentra la mejor vista de la actividad que la caracteriza, la pesca artesana. Este sector del distrito debido a su demanda hoy en dia no funciona como terminal artesanal, se propone recuperarlo y darle un valor agregado

\footnotetext{
${ }^{2}$ Grupo La República digital (Septiembre 12, 2013)
} 
turistico interconectado con el resto de la ciudad y con la actividad que caracteriza. En la temporada de verano y a la necesidad de los locales por obtener una actividad adquisitiva, se ha ido desarrollando desordenadamente y sin ningún control de las autoridades. Encontrándose en mal estado, con un amplia variedad de puestos culinarios informales y temporales.

Se buscara entender el malecón y muelle en su conjunto, con infraestructura necesaria para que el visitante pueda valorar la identidad de Pucusana.

Segundo, de acuerdo al crecimiento descontrolado distrital, se plantea realizar un recorrido desde la zona del malecón (orígenes) hacia la zona emergente del distrito (futuro). Por medio de esta trama, vehicular y peatonal, el visitante será testigo de la evolución distrital. Dentro del trascurso del recorrido habrán puntos de inflexión estratégicos con servicios e infraestructura determinada, que harán que el visitante enfatice su experiencia hacia el reconocimiento del lugar e identidad gastronómica que caracteriza.

Tercero, el recorrido propuesto llegará a su fin con el nuevo Terminal Pesquero y Complejo Cultural, planteado como el punto de interacción cultural y social. Con una gran plaza en la planta baja, con espacios de difusión gastronómica que permitan la interacción entre los visitantes, generando un dinamismo espacial en su conjunto, consecuente con lo anteriormente experimentado.

La gastronomía permite introducir a los turistas en el patrimonio cultural e histórico de los destinos mediante la degustación, la vivencia y la compra. Tres aspectos fundamentales para la experiencia gastronómica que vivirá Pucusana. Permitirá aproximarse a la cultura de un modo más vivencial y participativo.

“Antigua bahía de pescadores Pucusana nos trae el olor del mar y también de la historia “ - Documental a la vuelta de la esquina. ${ }^{3}$

“Con la modernización de las ciudades, con la globalización, empezamos a recibir y comprar cosas con demasiados envoltorios, demasiado preparadas, en espacios con demasiados acabados. Ya no vemos las cosas en su estado original. Por eso la nostalgia de ver productos, frutas, verduras, carnes, pescados en estado natural nos atrae. [...]" - Jaime Lerner ${ }^{4}$

El mercado de pesca respetara la identidade del lugar y reflejara la tradicional de Pucusana en todo momento. Se busca atreves de el generar una reflexión positiva de lo

\footnotetext{
${ }^{3}$ Documental ala vuelta de la esquina (2011) $14 \mathrm{~min}$

${ }^{4}$ LERNER Jaime, Acupuntura Urbana (2005).
} 
importante que es la gastronomía en nuestro país, valorando nuestras costumbres, tradiciones y tendencias hacia un mejor futuro.

\subsubsection{Enfasis}

El énfasis del proyecto es que el complejo propuesto sea entendido como una unidad articulada. En la cual las diferentes partes que la conforman, "No compitan, se complementen".

El énfasis estará propuesto como arquitectura como metabolismo, el cual estará en constante relación tanto con los espacios del proyecto mismo como con el sitio en el cual se encuentra y las conexiones planteadas en él-

Se trabajará en dos escalas, la escala macro en la cual se vera el planteamiento general del sector a desarrollar para el mejoramiento distrital y la escala micro en la cual se trabajara cada parte del proyecto, de la misma manera, en constante interacción complementaria hacia el desarrollo de nuevas oportunidades, de difusión cultural y gastronomica.

Figura 1 : Vista aerea de la zona pueblo de Pucusana

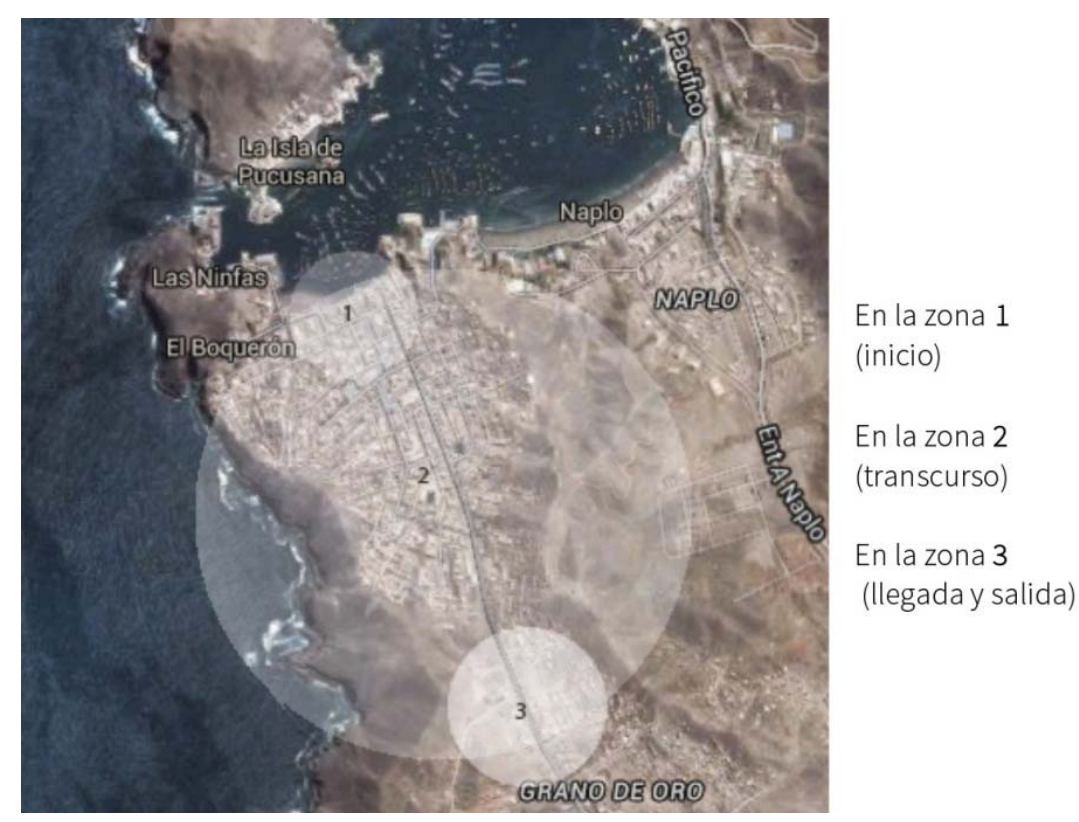

Fuente: Google maps

La teoría de la acupuntura urbana planteada por Jaime Lerner, será una alternativa bastante coherente con el planteamiento propuesto. 
"Siempre tuve la ilusión y la esperanza de que con un pinchazo de aguja sería posible curar las enfermedades. El principio de recuperar la energía de un punto enfermo o cansado por medio de un simple pinchazo tiene que ver con la revitalización de ese punto y del área que hay a su alrededor.“ - Jaime Lerner ${ }^{5}$

Estos puntos deberán ser experimentados por los visitantes y deben estar planteados bajo un concepto, en este caso gastronómico. La arquitectura en esos espacios debe estar en relación y complementar la experiencia.

“... el hombre crea a la arquitectura y la arquitectura crea al hombre, todo esto a través de las percepciones que vive a lo largo de su existencia(...) El ser humano que es el que vive la experiencia sensorial, por el otro la arquitectura que provoca esta experiencia, y las percepciones que los relacionan uno por que las vive y la otra porque las crea." - Rita Brushi6

\subsubsection{Lugar}

Pucusana es un distrito de Lima, se encuentra ubicado entre los kilómetros 54 y 68 de la Panamericana sur, aproximadamente a una hora de la capital. Limita con el distrito de Santa María por el lado norte y por el lado sur con el distrito de Chilca y presenta una extensión de 46000 km2 según el ultimo censo en el año 2007.

Respecto a su ubicación geográfica, el clima en Pucusana es desértico subtropical, con una temperatura promedio anual de 17 grados centígrados, siendo esta una temperatura muy agradable para el residente y turista que recorre el distrito.

La accesibilidad al distrito es a atreves de la autopista Panamericana Sur luego atraviesa una vía larga la cual ofrece un paisaje bastante amigable y de reconocimiento del territorio. Con granes espacios libres y cerros que enfatizan el camino hacia el mar.

\footnotetext{
${ }^{5}$ LERNER Jaime, Acupuntura Urbana (2005).

${ }^{6}$ BRUSCHI, Rita Material de Apoyo de la Ficha no1, Segundo Bachiderato. (2009)
} 
Figura 2 : Mapa de guia de lugares importantes del recorrido hacia el proyecto
1. Entorno
2. Entorno
3. Cementerio
4. Entrada a Naplo
5. Escuela
6. Base Fap
7. Entorno
8. Zona antigua
9. Malecón

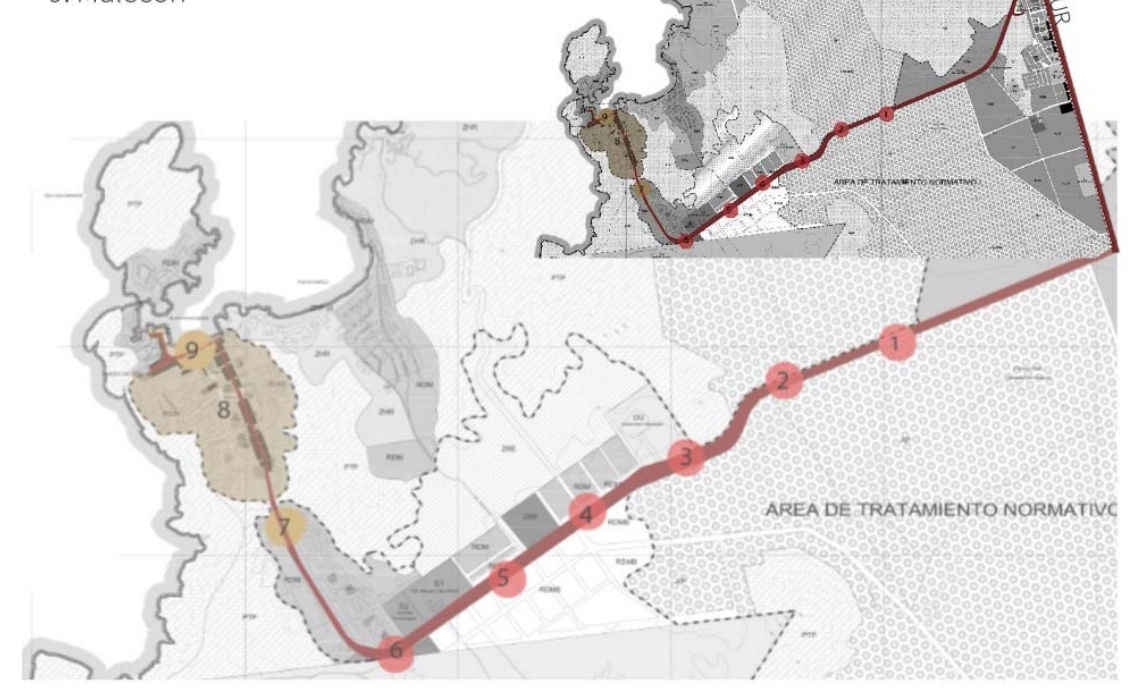

Fuente : Elaboración Propia

La secuencia espacial se analizara iniciando en la Panamericana Sur hacia la bahía de Pucusana.

La avenida que se conecta con la carretera mantiene una escala menor de dos direcciones. En su recorrido se puede apreciar el entorno paisajista que presenta amplios espacios desérticos en sus fronteras y escasa vegetación. En el fondo de la visual se simula una vegetación con cerros de altura moderada y algunas viviendas.

Figura 3 : Avenida principal, hacia el pueblo de Pucusana - etapa1

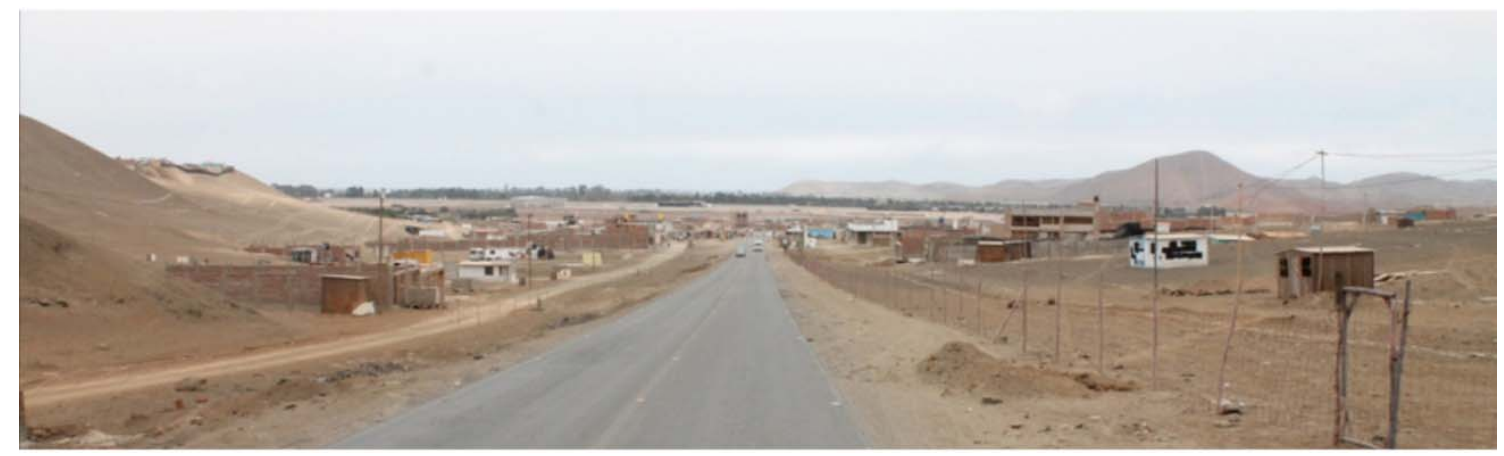

Fuente : Propia 
En la vía hay una curva que es importante analizar pues es la primera visual que te permite recocer el distrito e identificar ciertos usos, luego de atravesarla se encontraran infrestructura, como un cementerio, una escuela y una base Fap.

Figura 4 : Avenida principal, hacia el pueblo de Pucusana - etapa2

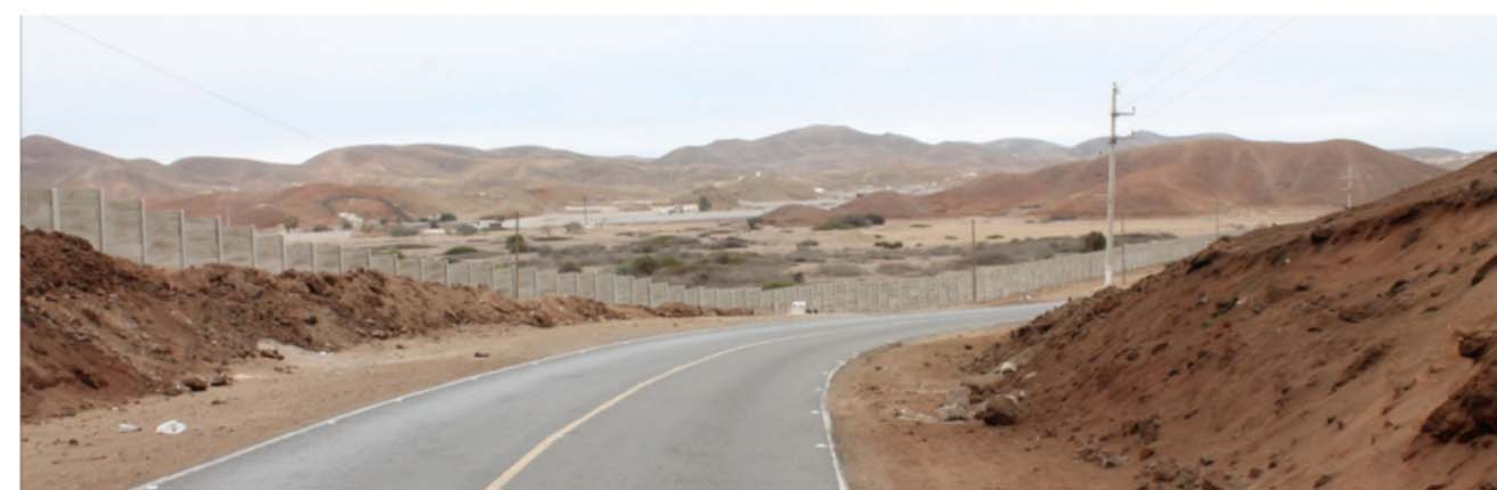

Fuente : Propia

El cementerio distrital si bien cuenta con el servicio propiamente dicho, se encuentra desarticulado de la trama urbana y no tiene un espacio publico en el cual los visitantes puedan disfrutar y por las noches es bastante peligroso ya que no hay mayor control en la zona. Se encuentra aislado entre cerros y las viviendas y comercios están alejados.

Figura 5 : Cementerio de Pucusana

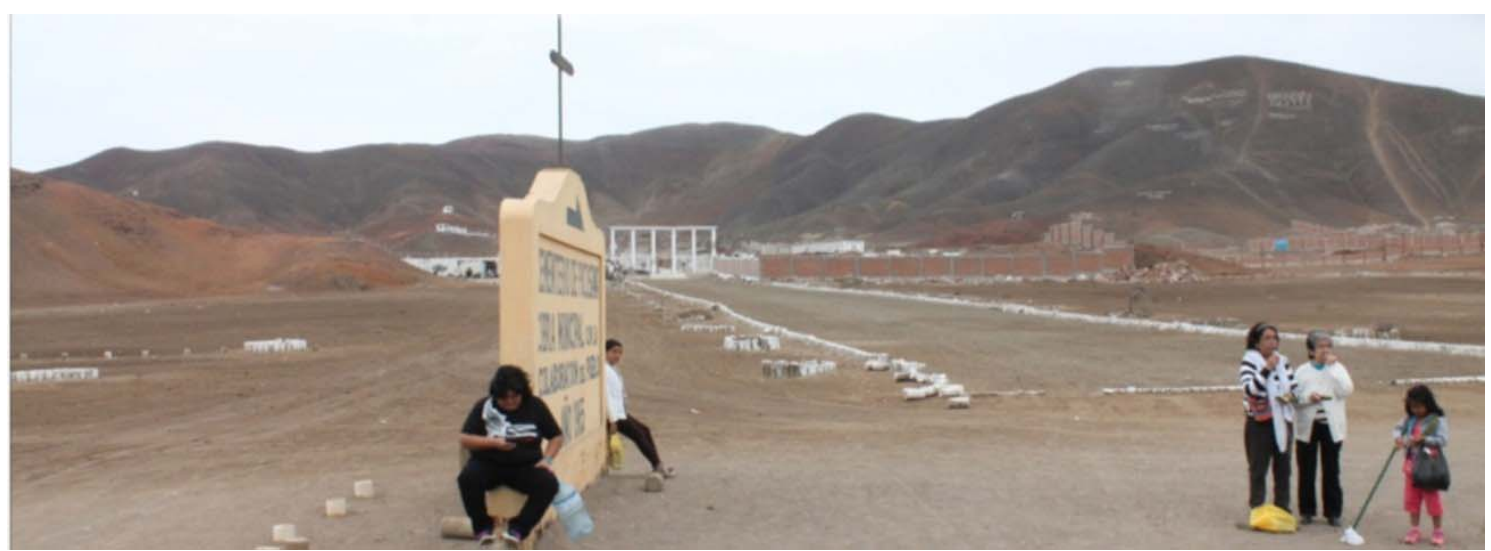

Fuente : Propia

Continuando con el recorrido en dirección al mar y malecón distrital perpendicular a la vía se abre una calle que se conectara con el balneario de Naplo, Playa característica del distrito de Pucusana en la cual los veraneante pasan las temporadas de verano disfrutando de las tranquilas aguas que la litoral presenta. 
A unos 200 metros aproximadamente, aparece una escuela y con ella viviendas en su entorno. Se encuentra retirada de la avenida y bordeada por un gran muro que lo aislar de su contexto, proporcionándole cierta protección y seguridad.

Figura 6 : Escula de Pucusana

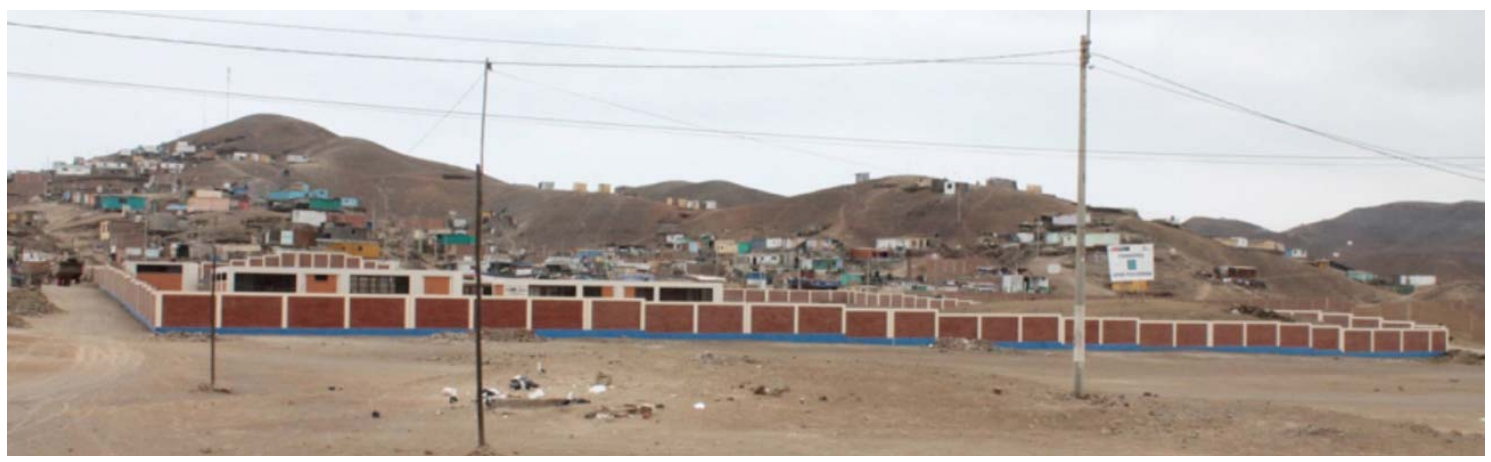

Fuente : Propia

Finalmente antes de ingresar a la vía directa en dirección al mar, previa al curva se encuentra la base Fap con una escultura de una avioneta que le da un valor agregado al sitio y le permite al visitante reconocerlo. Presenta un gran muro en su perímetro y tres palmeras en su fachada, siendo esta la única vegetación que a lo largo del recorrido se pudo identificar.

Figura 7 : Base Fap de Pucusana

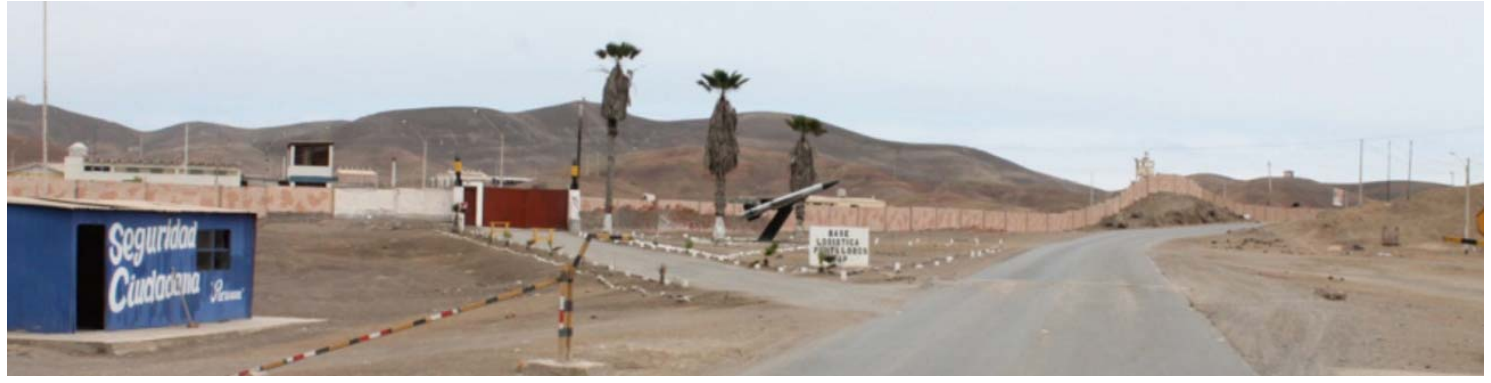

Fuente : Propia

Es en este punto que la propuesta a desarrollar comenzara su recorrido, si bien es la LLEGADA a la parte histórica de Pucusana, también es el de SALIDA, continuaremos con la secuencia del recorrido de la Panamericana hacia el mar para no per la ilación pero a lo largo del desarrollo este punto también será denominado como ZONA 3. 
Figura 8 : Ingreso zona pueblo de Pucusana

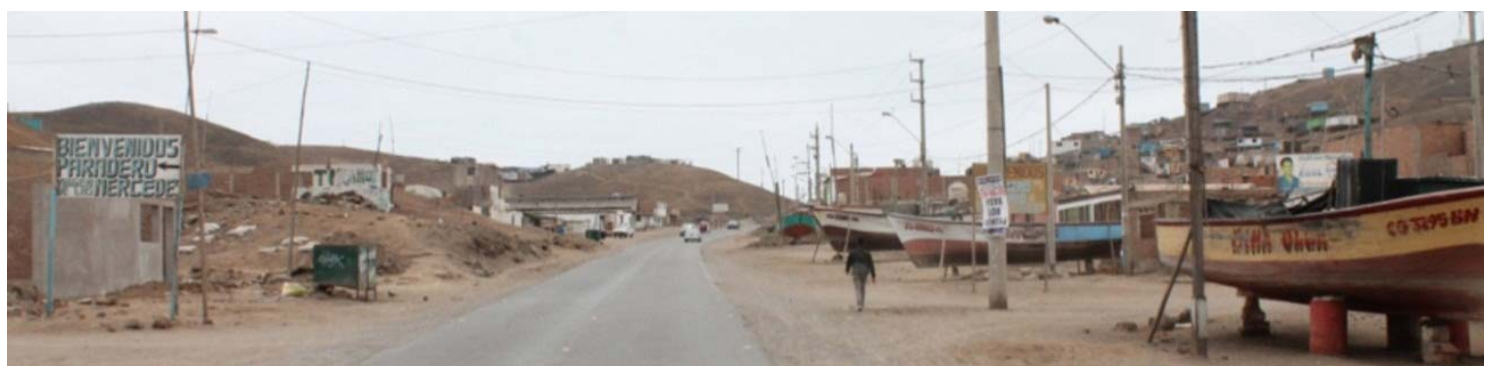

Fuente : Propia

Luego de atravesar el gran punto de llegada enmarcado por los cerros que enfocan el recorrido hacia la bahía del distrito, este punto se encuentra a una altura mayor y te permite reconocer el lugar con una visual panorámica, es la avenida principal, la avenida lima la que permitirá la conexión directa al malecón del distrito y lugar de gran identidad para todos los pobladores que la conforman.

Figura 9 : Zona pueblo de Pucusana

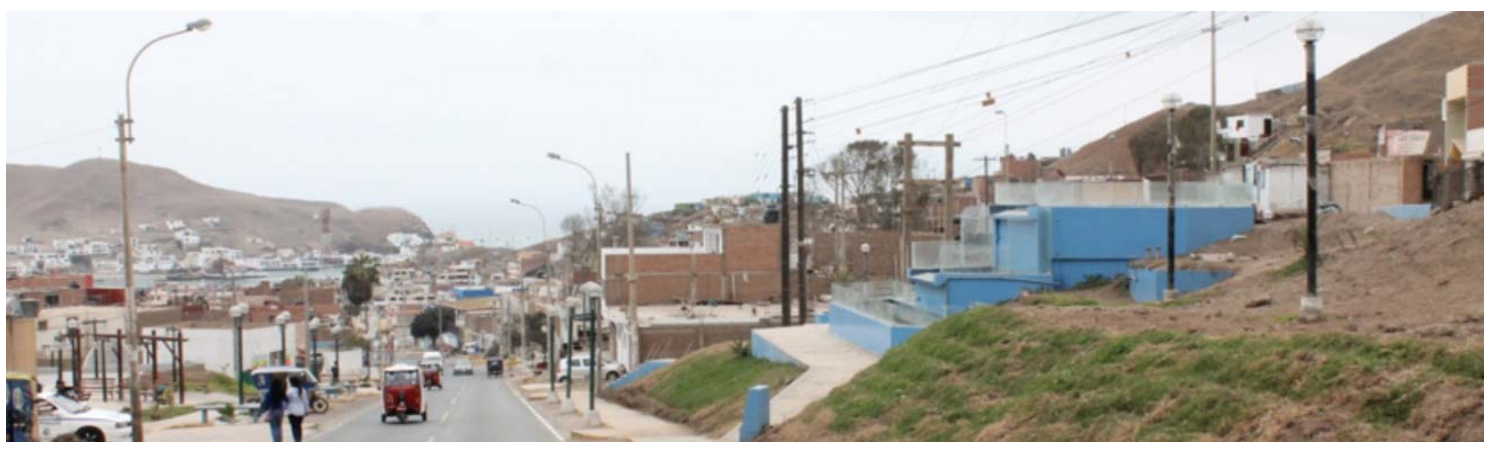

Fuente : Propia

Una característica importante del distrito es el gran colorido que las viviendas presentan. Estos colores son los mismos que los pobladores usan al pintar sus embarcaciones, aspecto importante a tener en cuenta para el díselo del nuevo planteamiento.

Figura 10 : Viviendas de Pucusana

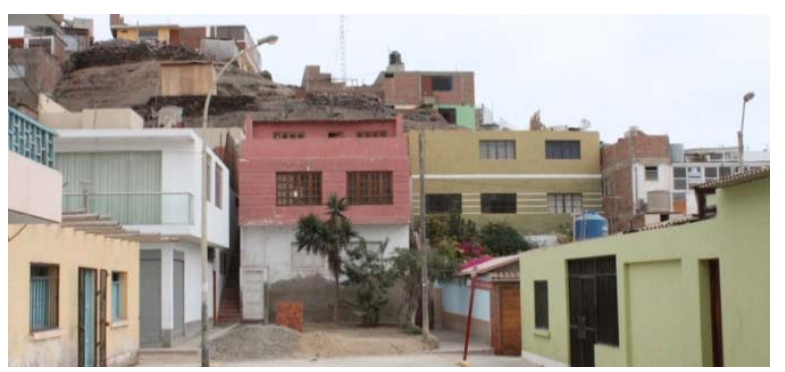

Fuente : Propia 
Como punto final, se encuentra el malecón del distrito el cual se ubica borde de la bahía $\mathrm{y}$ todos los visitantes reconocen e identidad por su gran actividad pesquera que la caracteriza. Las embarcaciones presentan un aspecto particular con frases emblemáticas y coloridos que pintan el paisaje conformado por la bahía y cerros en sus bordes.

Figura 11 : Borde hacia la Bahía de Pucuana

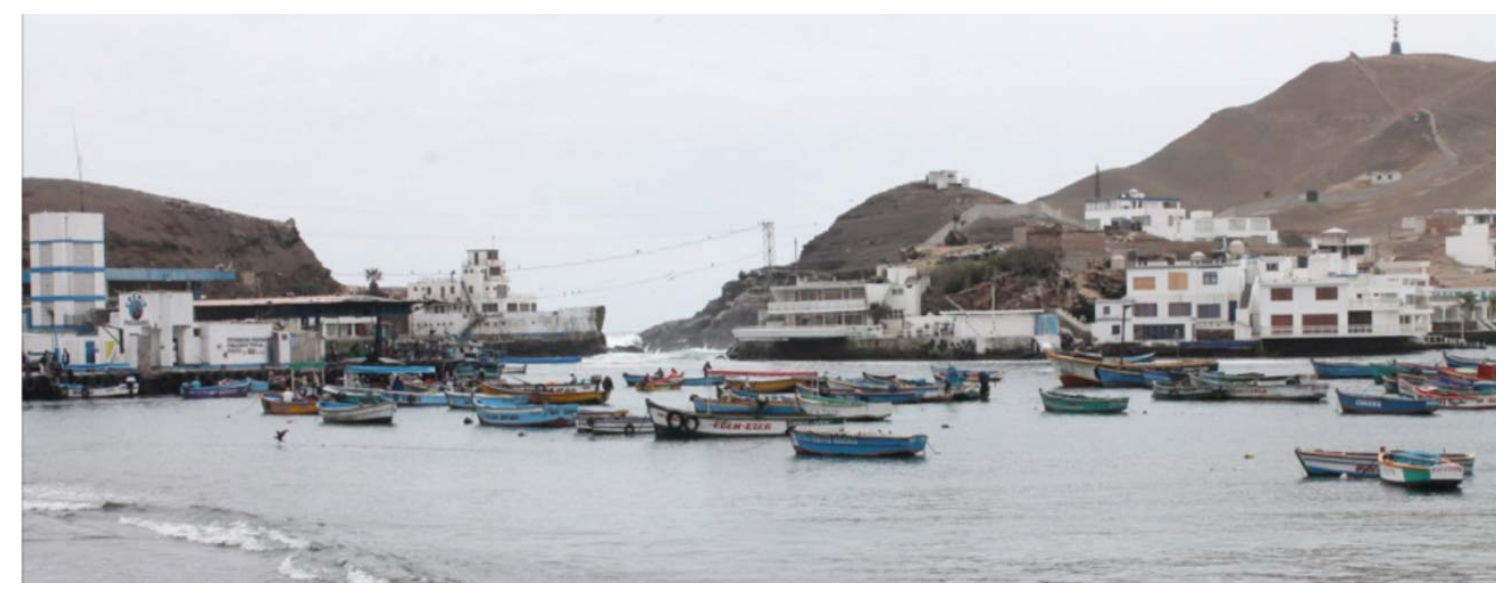

Fuente : Propia

Figura 12 : Botes de Pucusana

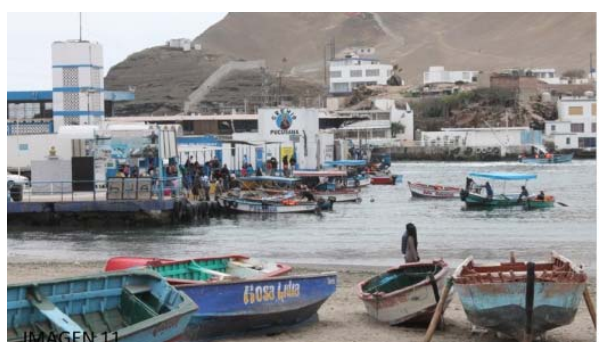

Si bien la actividad pesquera es la principal actividad distrital, muchas embarcaciones están descuidadas y ocupan grandes espacios de la playa, invadiendo los usos que el distrito ofrece.

Fuente : Propia

Figura 13 : Boquerón del diablo

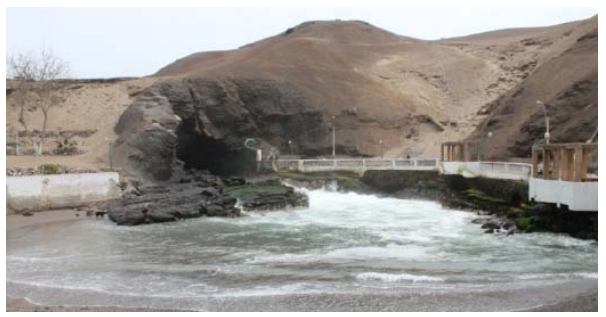

El boquerón del Diablo es un lugar que se llega a través del malecón y que es de gran atractivo turístico, en su periferia se encuentran restaurantes y comercio en general.

Fuente : Propia

Una gran parte del uso de suelo del distrito de Pucusana es de tratamiento paisajista, los cerros que envuelven el distrito y que acompañan el paisaje urbano hacen de este distrito un distrito único con una identidad particular. 
Cuenta con varias playas como la playa Naplo, Pelicanos, La quita, enrte otras, además cuenta con una zona de tratamiento paisajista, zona arqueológica, cementerio y otros atractivos distritales.

Los recursos naturales que presenta el distrito son notales y podrían ser una gran fuente de atractivo turístico en el territorio. Presenta un entorno paisajista notable, paisajes naturales con una gran variedad de contrastes y accidentes geográficos que permiten mimetizar la belleza del mar con los acantilados de los cerros. Además el mar del sur con oleadas notables y el mar del lado norte con sus aguas tranquilas entre la caleta y la bahía protegida por una isla Galápagos complementan el contraste desde otra perspectiva.

Figura 14 : Zonificación del distrito de Pucusana
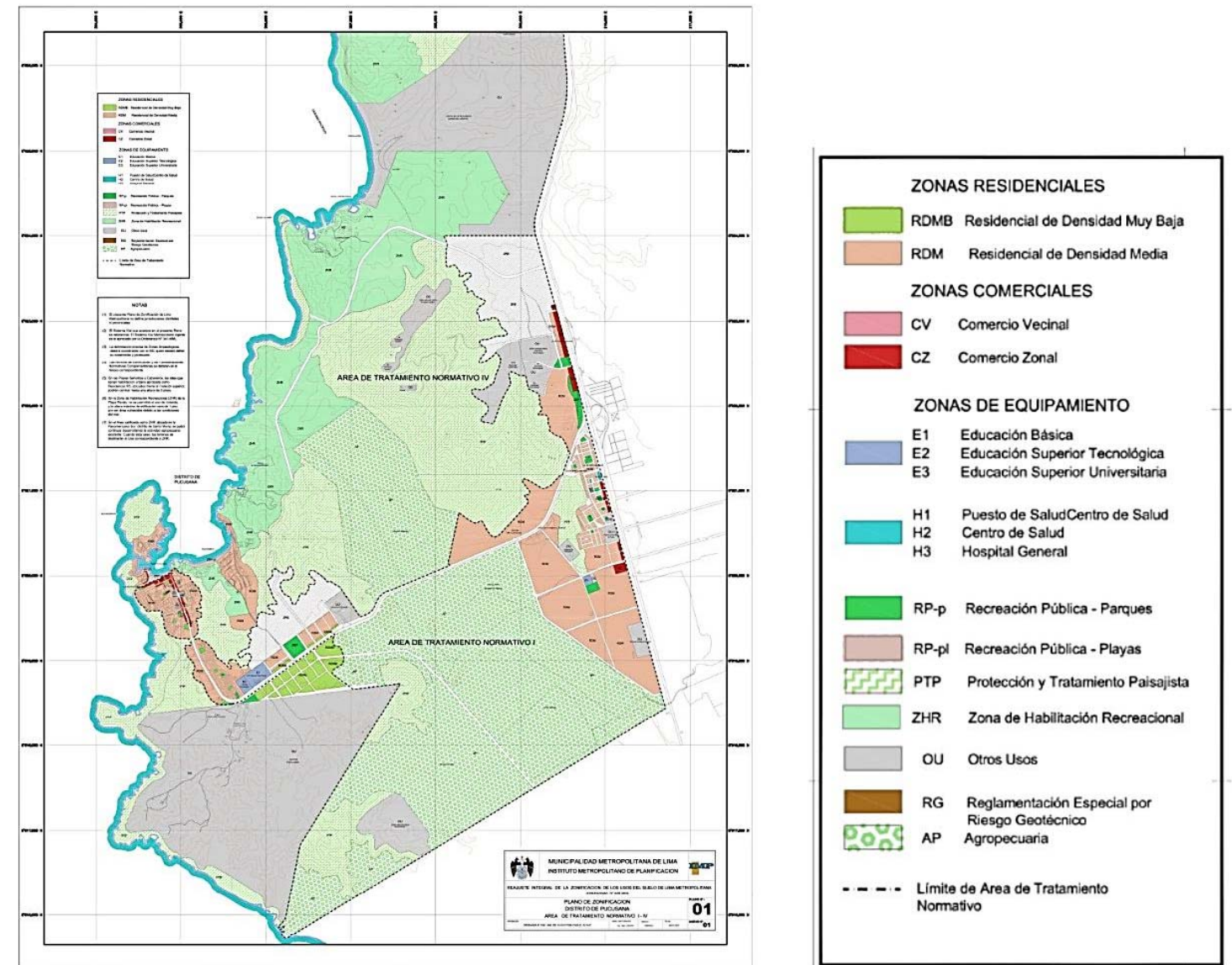

Fuente : Municipalidad de Pucusana

El distrito de Pucusana se encuentra en una zona sísmica con el resto de la ciudad, debido a su cercanía con el mar también es una zona que podría estar afectada ante un supuesto tsunami.

Debido a la humedad que se registra en la zona muchas viviendas se encuentran con grietas y las pinturas levantadas, puntos a tomar en cuenta ante el próximo planteamiento 
a realizar. Se analizará a mayor detalle la zona de intervención a lo largo del informe según el énfasis de la propuesta, a continuación se mencionaran algunas anotaciones importantes para el entendimiento de la propuesta.

\section{$\underline{\text { En la zona } 1 \text { (inicio) }}$}

Pucusana se inicio como "puerto natural" del antiguo poblador de chilca por sus tranquilas aguas. Además su principal actividad hasta la actualidad es la pesca artesanal, actividad que se realiza en el muelle y que es la principal fuente económica distrital. Y de gran tradición en los habitantes del distrito.

Figura 15 y 16: Pescadores de la Bahía de Pucusana en los ochentas y los noventas

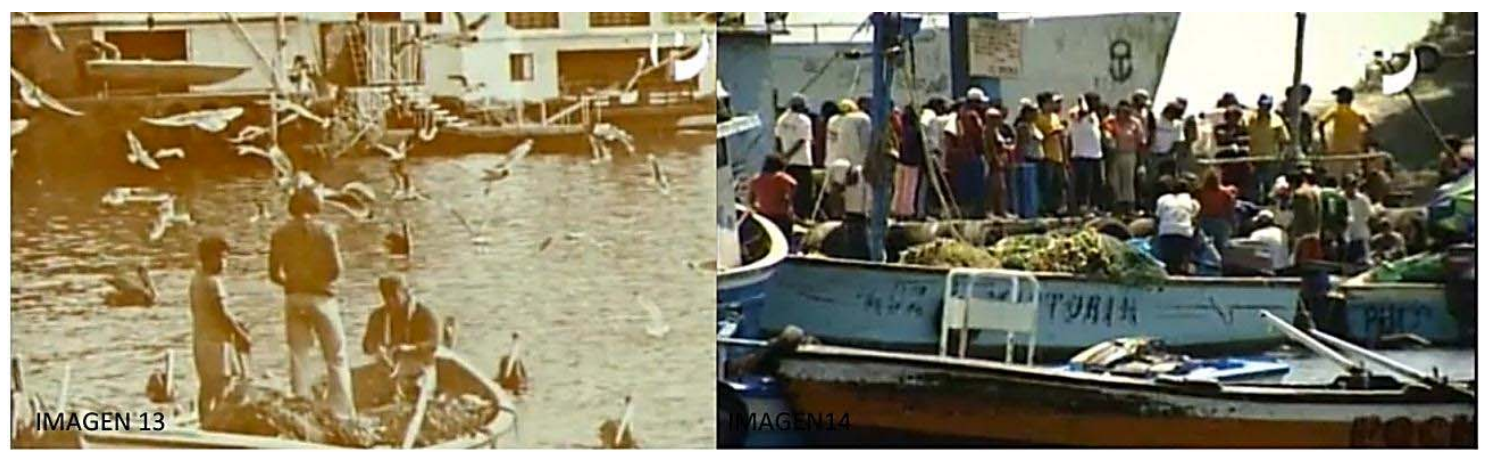

Fuente: Documental a la vuelta de la esquina

El entorno directo del muelle cuenta con infrestructura y servicios que han ido desarrollándose de forma informal y han generado que el paisaje de la bahía este rodeado de puestos de comida improvisados y de otros comercios informales en general.

Figura 17 : Contaminación en el malecón del pueblo de Pucusana

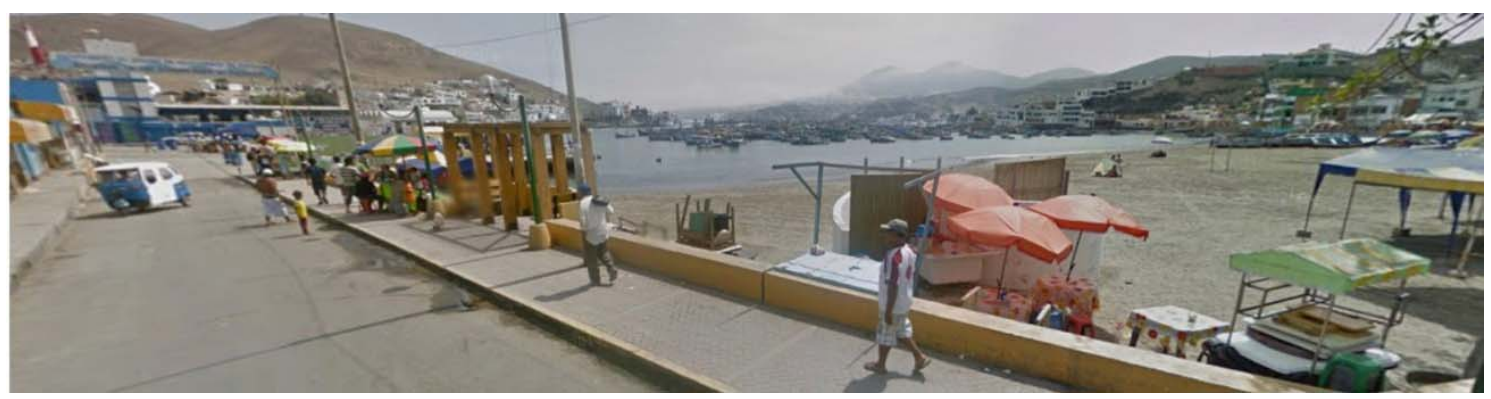

Fuente : Propia

La contaminación panorámica debido a la falta de planificación ante este desarrollo debe ser tomada en cuenta para la buena ejecución del proyecto a realizar. Además la densidad que se ha generado al redor del puerto ha producido un centralismo distrital desarticulado en su conjunto, en el cual los servicios e infrestructura se encuentran sectorizados. 
El visitante podrá conocer los distintos atractivos que el distrito presenta, será testigo del proceso de la pesca artesanal, desde su extracción, el modo en el cual se realiza y los procesos que se deben realizar para la venta y consumo de esta.

\section{En la zona 2 (transcurso)}

Los espacios libres del distrito también han sido ocupados por puestos ambulatorios, los locales se ha ocupado de acuerdo a la necesidad económica y comercial y de han dejado de lado los espacios de interacción social dignos de los habitantes y visitantes. Ocurriendo lo mismo que en Lima, pero en menor escala.

En el tema cultural y recreacional el distrito no cuenta con una buena infrestructura que mantenga activa la zona durante todo el año que sean estos atractivos turísticos que integren el distrito con mayor oportunidades.

Figura 18 : Espacios públicos del pueblo de Pucusana

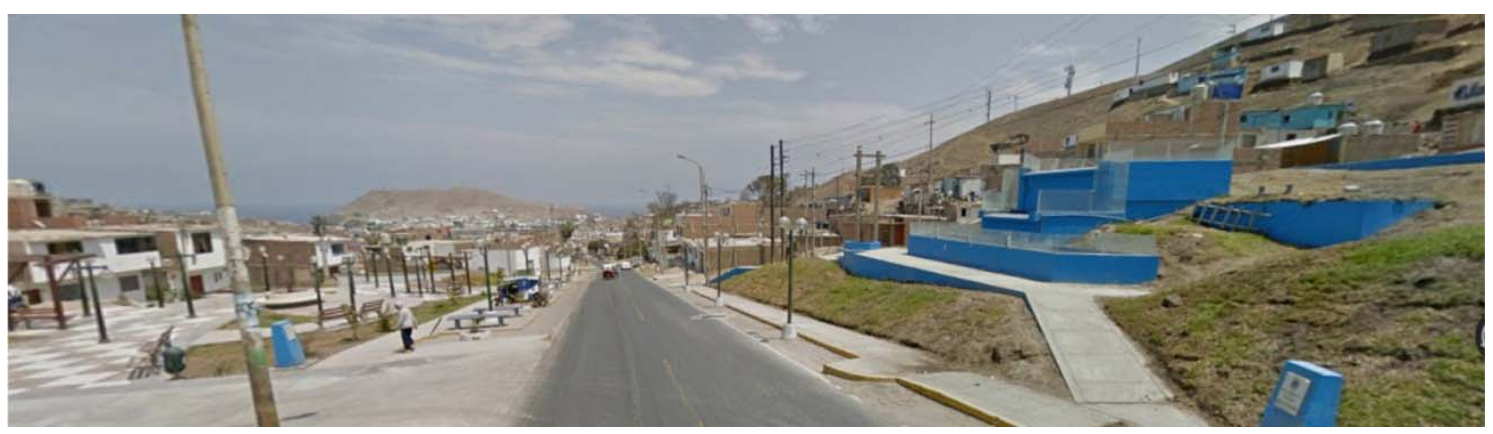

Fuente : Propia

Pucusana presenta un entorno paisajista notable, paisajes naturales con una gran variedad de contrastes y accidentes geográficos que permiten mimetizar la belleza del mar con los acantilados de los cerros. Estos contrastes serán enfocados en el recorrido para un mayor entendimiento del entorno.

El borde directo de la trama propuesta, vemos que hay muchos restaurantes, estos servirán para articular el distrito en su conjunto en torno a la gastronomía y se complementaran con espacios de interacción social y de indagación cultural en coherencia con la secuencia planteada.

Estos nuevos puntos serán nuevos nodos articuladores hacia la expansión distrital en torno a la gastronomía en todas sus direcciones.

\section{En la zona 3 (llegada y salida)}

En esta zona se plantea realizar el mercado gastronómico con espacios de difusión cultural de la gastronomía en el Perú. Esta área será entendida como el punto de llegada al distrito 
y el punto de salida del distrito. Para que eso ocurra se deben prever los espacios correspondientes para que el flujo sea el correcto.

Figura 19 : Zona de llegada y salida del pueblo de Pucusana

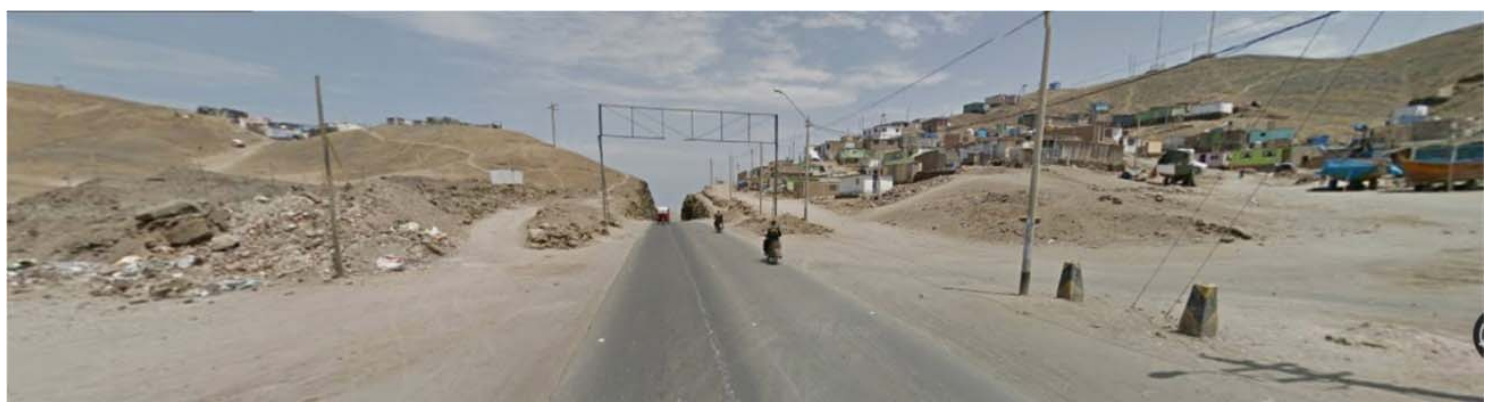

Fuente : Propia

Se encuentra previo al cerramiento de los cerros que se abren hacia la trama propuesta, el lugar paisajista por si solo da a entender el objetivo; por ello, la arquitectura a plantear debe relacionarse con el entorno natural, sublimándolo y no compitiendo.

Figura 20 : Viviendas en la zona de llegada y salida del pueblo de Pucusana

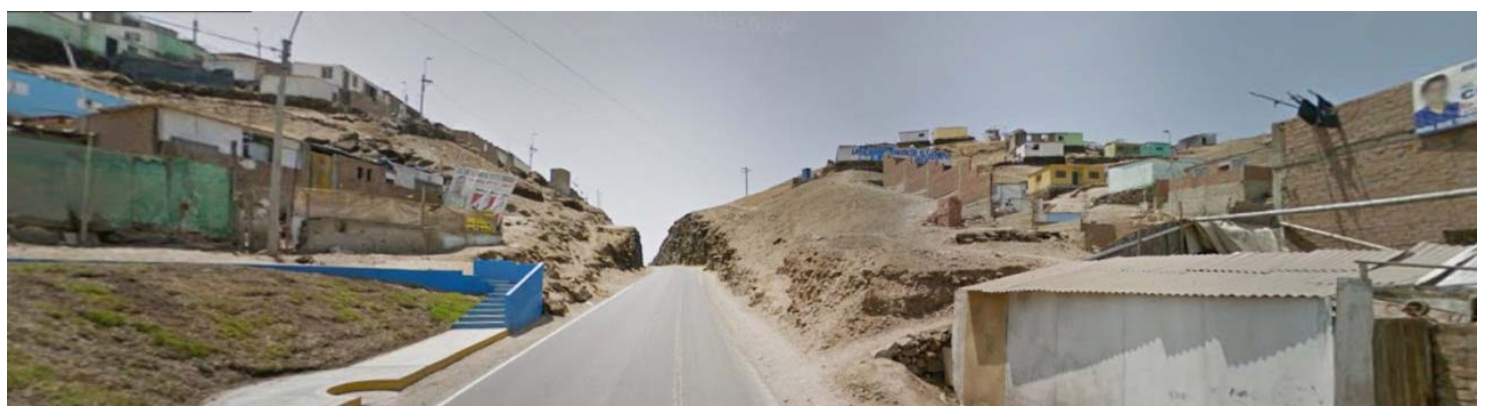

Fuente : Propia

Esta zona es de suma importante para el desarrollo pues será el punto de inflexión que te abrirá las puertas hacia una introspección de sus orígenes y de igual manera hacia un reconocimiento de oportunidades hacia el futuro.

\subsubsection{Usuario}

El distrito de Pucusana es uno de los más pobres de Lima Metropolitana. Según los datos del Instituido Nacional de Estadísticas e informática (INEI) del año 2007, el distrito cuenta con una población de 10633 habitantes. El 42\% de su población es pobre, evaluando la pobreza monetaria y no monetaria. ${ }^{7}$

\footnotetext{
${ }^{7}$ PLAN DE DESARROLLO DE PUCUSANA, Municipalidad de Pucasana (2007-2010). Pg 27
} 
De los 10.633 habitantes de Pucusana, 5.261 son mujeres y 5.372 son hombres. Por lo tanto, el 50,52 por ciento de la población son hombres y el 49,48 mujeres. ${ }^{8}$

Figura 21 : Cuadro estadístico de los sexos en la población de Pucusana

\section{POBLACION}

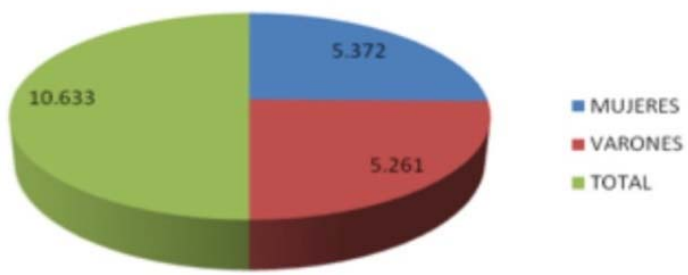

Fuente: Municipalidad de Pucusana

Si comparamos los datos de Pucusana con los del departamento de Lima concluimos que ocupa el puesto 61 de los 171 distritos que hay en el departamento y representa un 0,1259 $\%$ de la población total de ésta. A nivel nacional, Pucusana ocupa el puesto 456 de los 1.833 distritos que hay en Perú y representa un $0,0388 \%$ de la población total del país. ${ }^{9}$ Un alto porcentaje de la población del distrito entre el $40 \%$, viven directamente de la pesca artesanal y de su consumo, mientras que el resto además realizan actividades comerciantes relacionadas a la venta directa de pescados o mariscos.

Figura 22: Comparativo de población economicamente activa del distrito de Pucusana

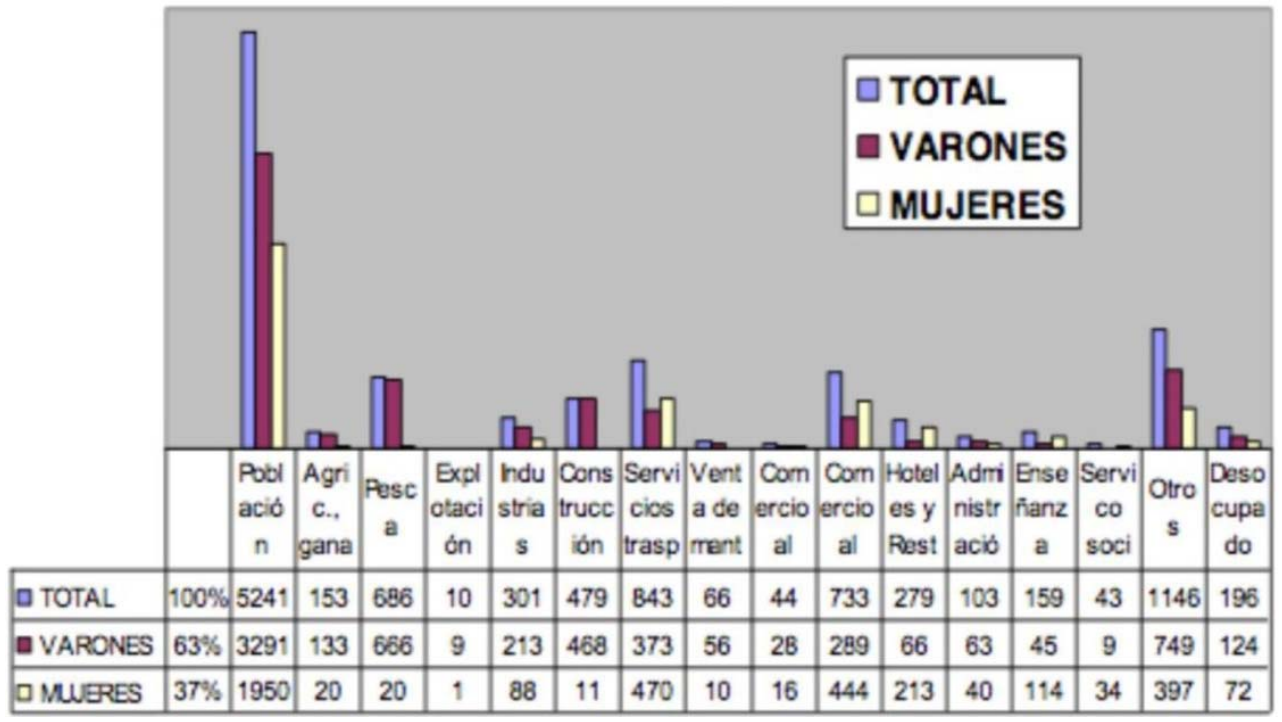

Fuente: Municipalidad de Pucusana

El comercio en el distrito como vemos en la tabla es alto, muchos de los locales del distrito se dedican a la venta de productos en el mercado municipal. Si bien el mercado en un

\footnotetext{
${ }^{8}$ PLAN DE DESARROLLO DE PUCUSANA, Municipalidad de Pucasana (2007-2010). Pg 13

9 PLAN DE DESARROLLO DE PUCUSANA, Municipalidad de Pucasana (2007-2010). Pg 43
} 
lugar de encuentro social e interacción entre los habitantes. Este mercado se encuentra aislado y no permite la correcta interacción entre ellos, los espacios libres son muy angostos y es usado como un lugar de consumo excluso ante.

Alrededor de el se han realizado otras actividades también relacionadas al comercio volviendo la calle la plaza del mercado. Los usuarios no tienen un espacio destinado para dicha actividad.

Figura 23 : Ingreso al Mercado de Pucusana

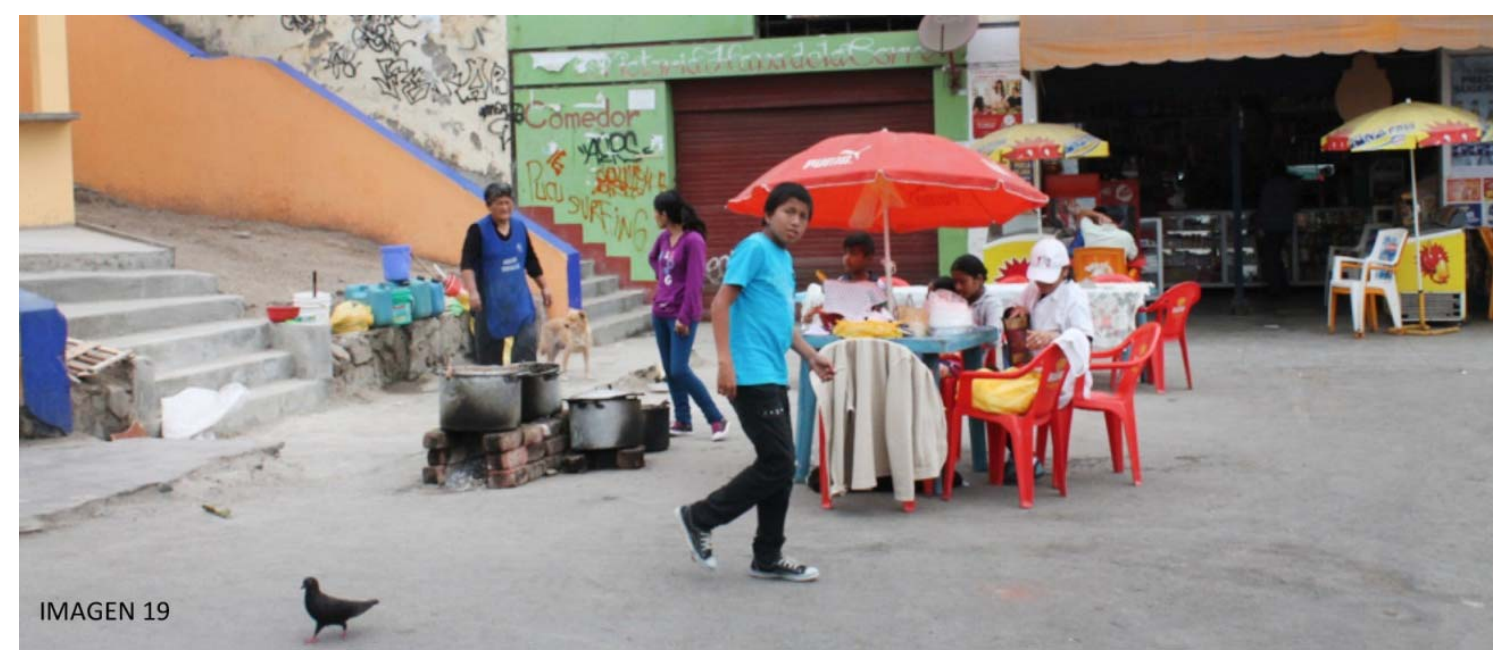

Fuente : Propia

Del total de los habitantes del Distrito de Pucusana, el $86.44 \%$ han tenido educación. La antiguas generaciones que hoy en día la conforman no han tenido educación superior e incluso en algunos casos no han tenido ni educación primaria. Situación que puede ser indicadora de la deficiencia de nuevos proyectos o planteamientos que permitan desarrollar el distrito además de la pesca artesanal. ${ }^{10}$

\footnotetext{
${ }^{10}$ PLAN DE DESARROLLO DE PUCUSANA, Municipalidad de Pucasana (2007-2010). Pg 14
} 
Tabla 1 : Estadistica del nivel educativo de la población del distrito de Pucusana

\begin{tabular}{|l|r|r|r|r|r|r|}
\hline \multicolumn{1}{|c|}{ Descripción } & Total & $\begin{array}{r}6-14 \\
\text { años }\end{array}$ & $\begin{array}{r}15-29 \\
\text { años }\end{array}$ & $\begin{array}{c}\text { 30 a } 44 \\
\text { años }\end{array}$ & $\begin{array}{c}45 \text { a } 64 \\
\text { años }\end{array}$ & $\begin{array}{c}65 \text { a más } \\
\text { años }\end{array}$ \\
\hline sin nivel & 176 & 21 & 29 & 36 & 46 & 44 \\
\hline Educación Inicial & 152 & 140 & 11 & 1 & & \\
\hline Primaria & 4821 & 1440 & 226 & 306 & 544 & 305 \\
\hline Secundaria & 597 & 404 & 2025 & 1271 & 625 & 105 \\
\hline $\begin{array}{l}\text { Sup. No Universitaria } \\
\text { incompleta }\end{array}$ & 466 & 320 & 190 & 80 & 7 \\
\hline $\begin{array}{l}\text { Sup. No Universitaria } \\
\text { completa }\end{array}$ & 255 & 163 & 203 & 94 & 6 \\
\hline $\begin{array}{l}\text { Superior Universitaria } \\
\text { incompleta }\end{array}$ & 347 & 126 & 74 & 48 & 7 \\
\hline $\begin{array}{l}\text { Superior Universitaria } \\
\text { completa }\end{array}$ & 9244 & 2005 & 2976 & 2235 & 1539 & 489 \\
\hline Total & & 76 & 154 & 102 & 15 \\
\hline
\end{tabular}

Fuente: Municipalidad de Pacusana

Según las entrevistas realizadas en el distrito de pucusana se anoto que los trabajadores que realizan la labor de la pesca artesanal desde la extracción hasta el consumo, muchos de ellos son los padres de familia y los jóvenes hoy en día se dedican a la comercialización de esta.

Figura 24 : Pesca artesanal en el distrito de Pucusana

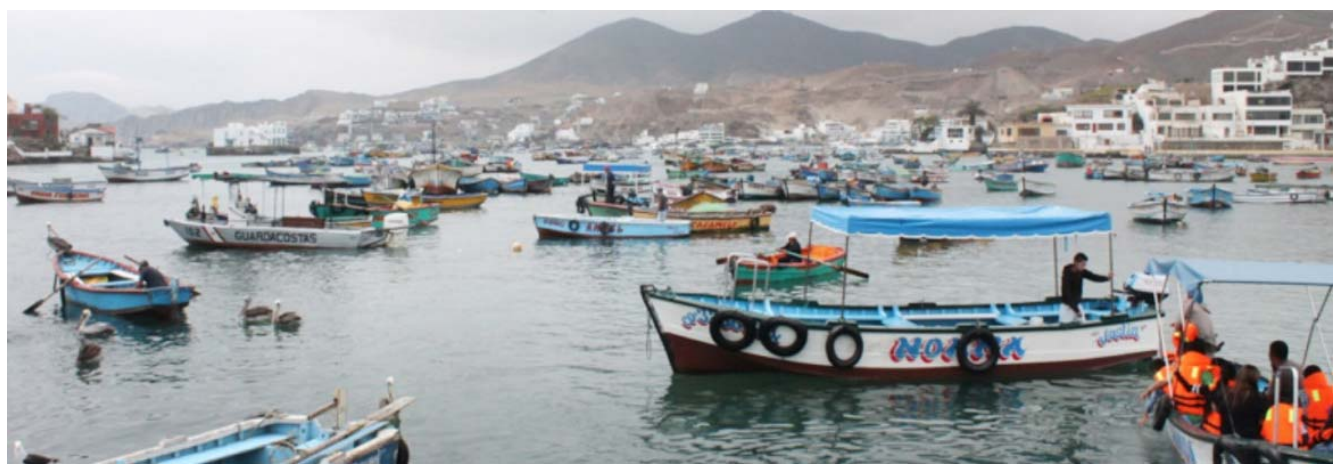

Fuente : Propia

Muchas viviendas del distrito presentan características inadecuadas para ser habitables. Una población equivalente a $29.5 \%$ son las que viven en ellas. Se han identifico viviendas con rejas y con cierto tipo de cerramiento, lo cual indica que hay desconfianza en la zona y los usuarios deben protegerse ante ello.

En el distrito, se puede apreciar durante los casi nueve meses de temporada baja (meses de otoño hasta la primavera) un bajo movimiento de flujo de turistas locales y residentes veraneantes. Por ello, muchos comercios, hostales, restaurantes, no se preocupan o esmeran en brindar el servicio requerido. 
Figura 25 : Espacios comerciales en el malecón de Pucusana

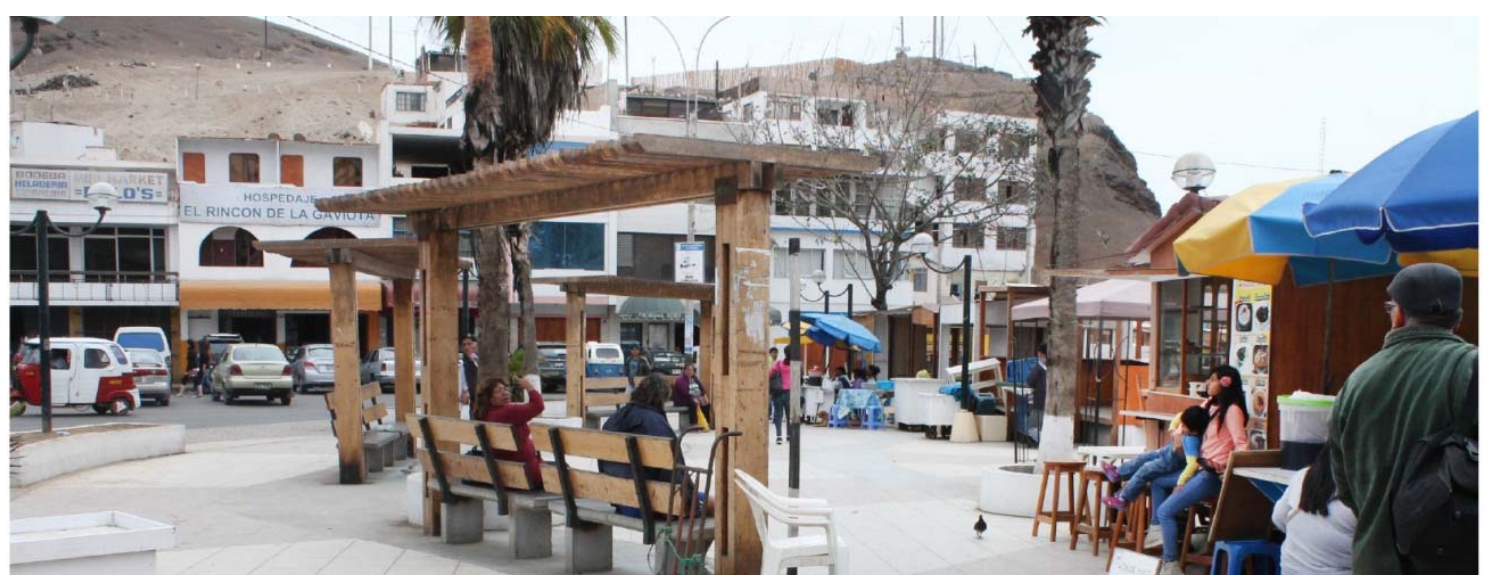

Fuente : Propia

Si bien la pesca artesanal es la gran actividad adquisitiva que tiene el distrito, el turismo de esta también es importante. Durante todo el año el turismo marítimo se lleva acabo y los turistas pueden disfrutar del entorno natural que Pucusana presenta.

Figura 26 : Embarcaciónes turisticas de la bahía de Pucusana

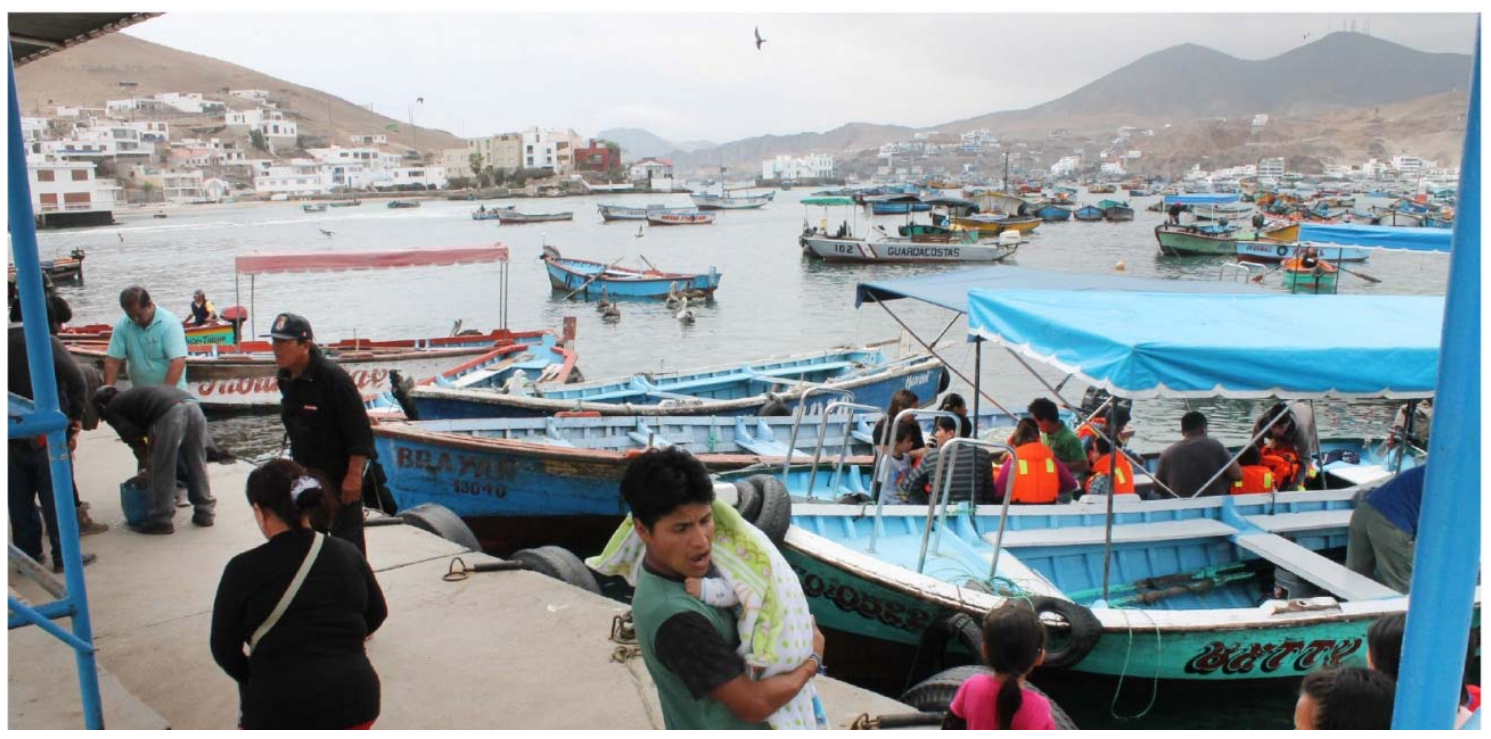

Fuente : Propia

El proyecto plantea que los residentes de Pucusana, los peruanos mismos y extranjeros puedan ser testigos de la gastronomía que el distrito les ofrece durante todo el año. Es por ello que el diseño urbano estará diseñado para que la experiencia sea la optima.

"Del mismo modo en que la medicina necesita la interacción entre el médico y el paciente, en el urbanismo también es necesario hacer que la ciudad reaccione. Tocar un área de tal modo que pueda ayudar a curar, mejorar, crear reacciones 
positivas y en cadena. Es necesario intervenir para revitalizar, hacer que el organismo trabaje de otro modo. [...]" - Jaime Lerner

$\underline{\text { El público objetivo }}$

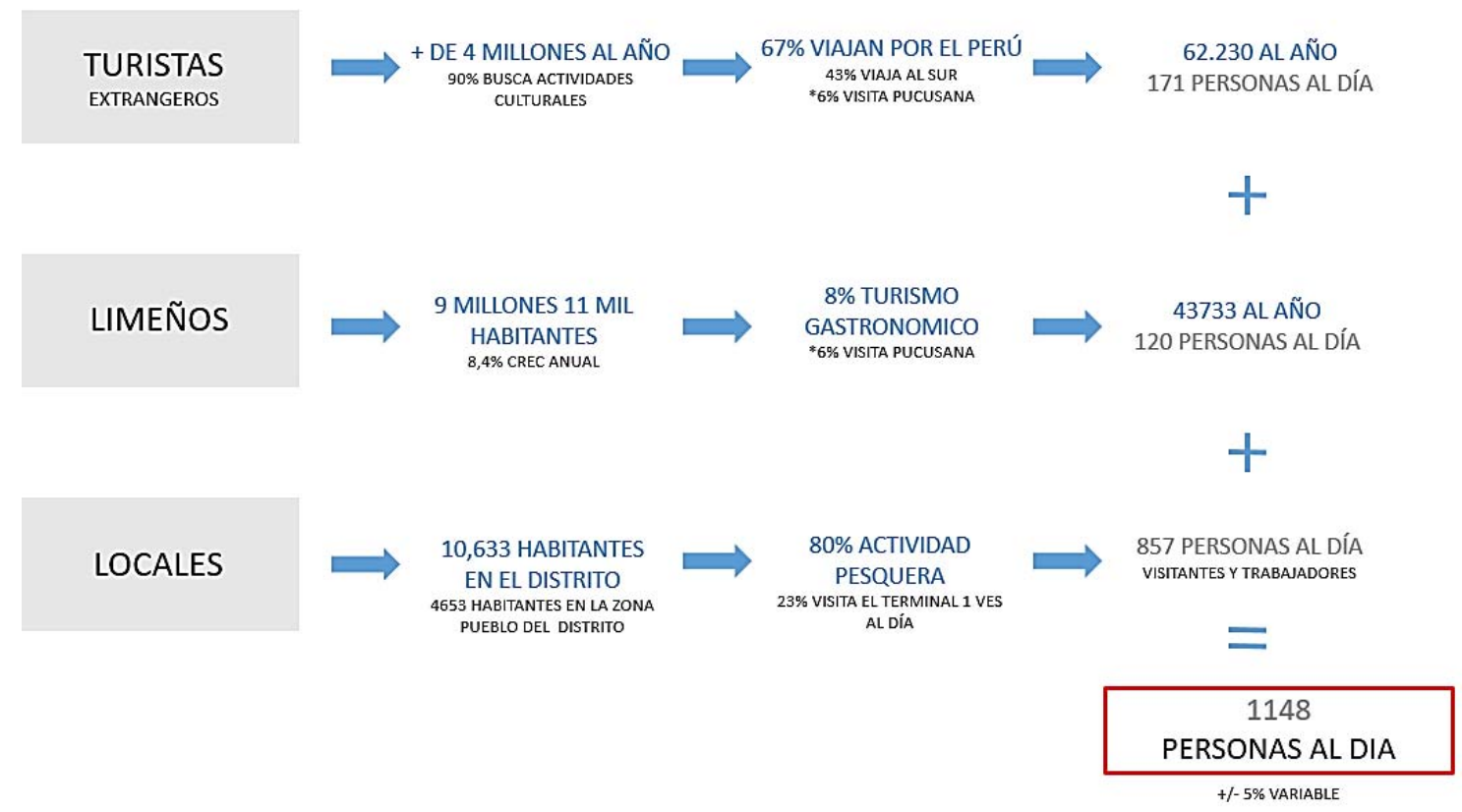

\subsection{Problematica}

\subsubsection{Problema Principal}

La ciudad de Lima a través de los años ha ido desarrollándose de acuerdo a su evolución económica. Con el boom industrial de los ochentas, la ciudad se vio sometida a un gran crecimiento, el cual no tuvo un planteamiento claro de desarrollo. Es por ello que la zona centro de la ciudad se vio afectada, densificándose y generando un gran centralismo en la ciudad.

En Pucusana ha ocurrido lo mismo que en Lima pero en menor escala. Los habitantes de esta zona no cuentan con servicios ni infrestructura que les permita quedarse y seguir progresando. La pesca artesanal es principalmente su única fuente económica y el desarrollo del distrito se ha generado a través de ella y alrededor de esta.

El distrito ha crecido sin un orden planificado desarticulando su conjunto, el trasporte de igual manera no es claro y por ende el visitante no llega a conocerlo de la manera que debería, reconociendo sus atractivos y valorando el área como una potencia hacia el desarrollo y de gran identidad cultural. 


\subsubsection{Problemas Especificos}

- La pesca artesanal que se realiza en Pucusana ha sido un tradición, atractivo turístico y fuente económica característica de este sector. Sin embargo esta actividad tiene un tiempo determinado y debido a la escases de peces y moluscos ha hecho que el progreso en este ámbito no sea constante, dificultando la mejore en la calidad de vida de los hogareños.

- El crecimiento económico distrital es casi nulo, presenta una mala calidad en los servicios y hay una mínima presencia de inversión en la actividad pesquera. Se han establecido puestos de comida y de venta culinaria en el muelle pero esta actividad sigue siendo insuficientes económicamente.

- El publico consumidor es temporal ya que su público es principalmente veraneante. No existe un plan de turismo y la señalización de las atracciones turísticas naturales son escasas. Lo cual dificulta el entendimiento del sitio y tu atractivo turístico disminuye.

Figura 27: Vendedores ambulantes del pueblo de Pucusana

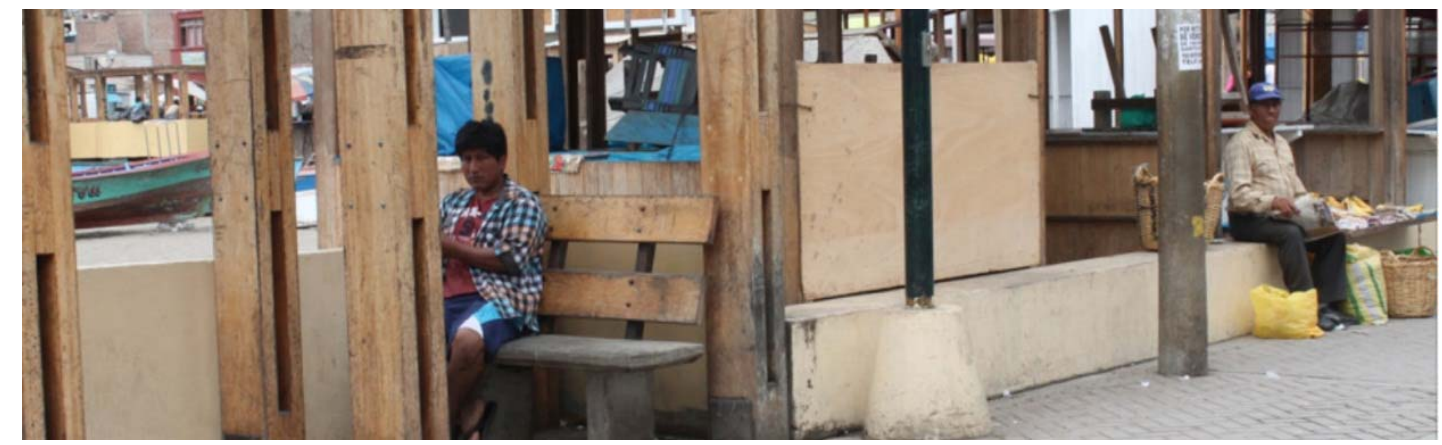

Fuente : propia

- Poca efectividad en el gobierno municipal para ampliar las normal y sancionar la informalidad, de igual manera, el distrito presenta poca presencia de personal policial u nula presencia de bomberos.

- Fala de infrestructura para estacionamientos y peatones.

- Falta se servicios higiénicos en todo el distrito.

- No existe un catastro detallado de las casas de residentes estacionarias de la Honda, Pelicanos, Quipa, Minkamar, Naplo, Pucusana, Isla y Ninfas. 
- Es notable que cada día el comercio ambulatorio y la manipulación de los productos adquiridos a través de la pesca artesanal, la cual pone en peligro la vida de personas que sin tener conocimiento, la consumen y en muchos casos contraen enfermedades.

- Poco desarrollo productivo comercial e industrial en la zona. Distrito de muchas tradiciones y con falta de inversión.

- Población distrital con un nivel educativo bajo, educación secundaria y superior escaza.

- Necesidades de educación básica y técnica con limitada infrestructura.

- Carencia de servicios básicos (agua y desagüe) para atender las a un 55\% de la población.

Figura 28: Puestos ambulantes en las veredas del pueblo de Pucusana

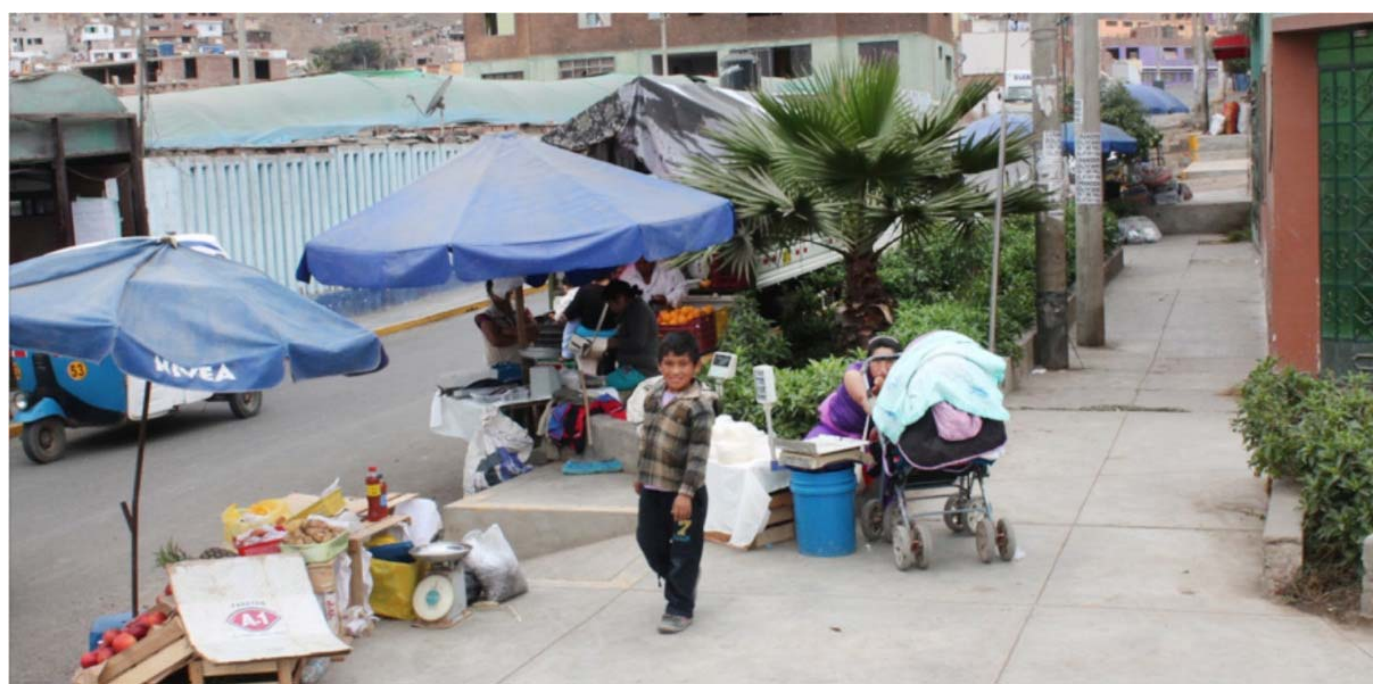

Fuente : propia

- Transporte público automotriz inadecuado para brindar servicios con calidad y seguridad a la población.

- Actividades recreativas y de actividades deportivas limitadas en la zona, la municipalidad no incentiva a sus habitantes a que las realicen, ni les ofrecen actividades recreacionales.

- Enfermeda.es en el distrito debido a la baja conciencia sanitaria

- La carencia de un proyecto de manejo de residuos sólidos limitan el servicio del recolecto de basura. 
- Población con poco conciencia de ciudad ecológico, dañan el entorno con basura y no son consientes de lo importante que es mantener el entorno limpio no solo para salud sino para el turismo y esparcimiento en él

- Altos índices de delincuencia, pornografía y drogadicción, los mecanismos se seguridad no son efectivos y los índices no se han podido controlar ni disminuir.

- Comercio informal y crecimiento en torno a el a lo largo de los años.

Figura 29: Venta ambulatorio en el malecón de Pucusana

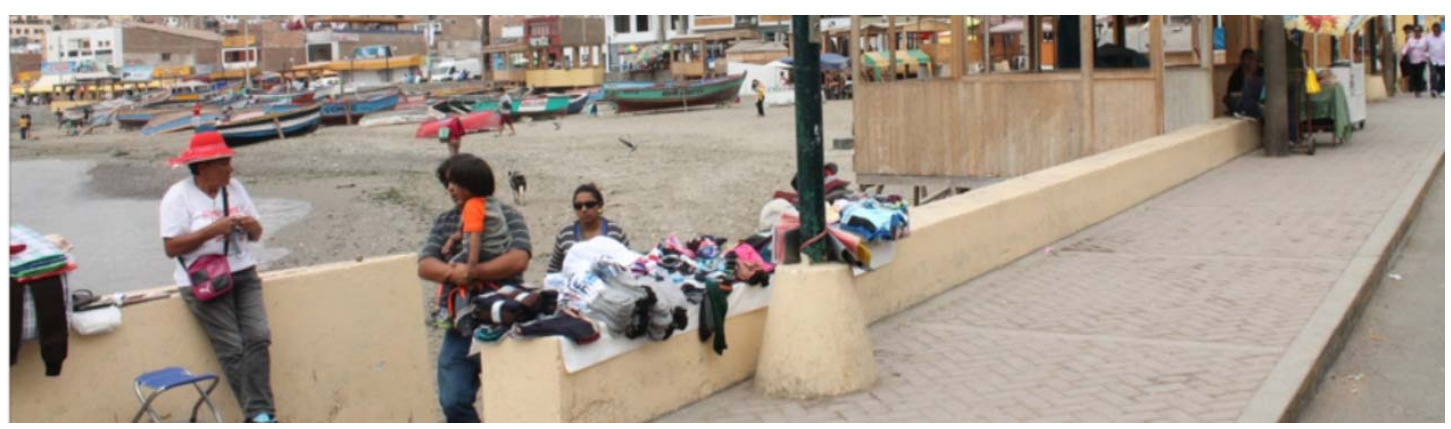

Fuente : propia

- Zona con riesgo de maremotos, terremotos en general desastres naturales que podrían dañar el distrito notablemente.

- Espacio públicos mal equipados y sin un planteamiento integrado con sus alrededores, el espacio en muchos casos se encuentra aislado y no se integra con el distribuido en general.

- Espacio público de interacción limitado, no permite la interacción de la sociedad. .

Figura 30: Falta de espacios de interacción social

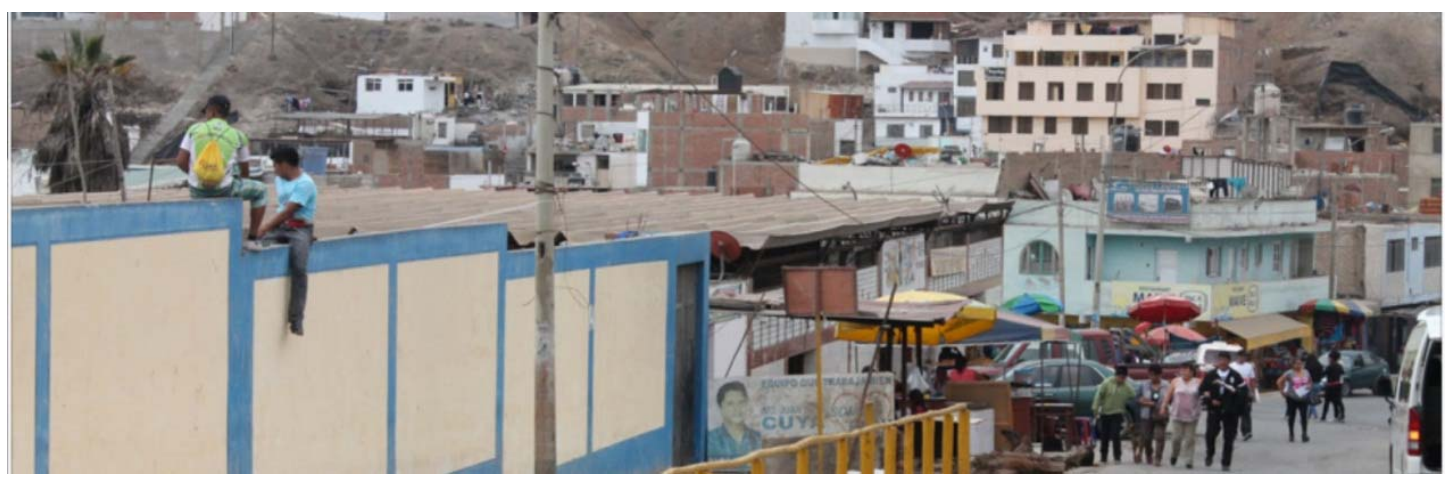

Fuente : propia 


\subsection{Objetivos}

\subsubsection{Objetivo Principal}

El objetivo principal ante la problemática anteriormente mencionada es articular el distrito de Pucusana en su conjunto, dotándolo de nuevas infrestructura y servicios que lo reintegren y que estén en constante relación. Entender el distrito según su historia, sus tradiciones en la pesca artesana, los atractivos culinarios que presenta y las oportunidades gastronómicas a desarrollar.

\subsubsection{Objetivos Especificos}

- Hacer que la pesca artesanal sea el principal atractivo del sector, implementarlo con buena infrestructura, la cual permita que su ejecución y desenvolvimiento sea el óptimo y que la tradición no se pierda en el trascurso de la actividad.

- Ofrecer servicios interconectados que se complementen con el resto, de modo tal que todo el distrito ofrezca una variedad de alternativas culturales y gastronómicas las cuales favorezcan al turismo en la zona, en general.

- Influir en un público constante durante todo el año, el recorrido gastronómico permitirá re activar el sector e implementar su turismo. Los servicios que se ofrecerán en el distrito complementarios a él, generaran ingresos significativos para el progreso de este.

- Implementar la espacialidad, infrestructura y funcionamiento del Terminal Pesquero existente, rescatando espacios y funcionándolos con nuevos diseños. Regenerarlo para la demanda del sector y de los futuros visitantes.

- El mercado gastronómico, tendrá productos nativos del Perú que por medio del plato gastronómico se podrán disfrutar siendo los visitantes testigos de la variedad gastronómica Peruana y reflexionar sobre lo experimentado luego de las percepciones obtenidas en su recorrido.

- Organizar la zona del muelle con nuevos puestos gastronómicos, los cuales estén conectaos y el publico pueda recorrerlos mientras reconoce el lugar.

- Identificar los puntos estratégicos del distrito y potenciarlos para que sirvan de nuevos nodos articuladores del distrito. 
- Establecer y formalizar en forma continua convenios de cooperación técnica financiera con entidades privadas, $\mathrm{ONG}$, entidades públicas e internacionales para la ejecución del Proyecto del PDC.

- El Terminal pesquero y muelle de pescadores será reconocido por el visitante y podrá ser testigo de la actividad que se realiza y ser testigos del proceso.

- Se plantean nuevos puntos de turismo en el cual el turista puede acudir para un mayor conocimiento distrital.

- Se plantean analizar los espacios públicos y repotenciarlos para que los habitantes puedan interactuar.

- El punto de llega y de salida será un punto estratégico de la puesta pues dará la primera imagen del planteamiento a desarrollar.

- El mercado como identidad cultural será un emblema a tener en cuenta en toda la conceptualización de la propuesta contara con espacios de difusión gastronómica.

- Se entenderá el mercado como lugar de encuentro con una plaza que englobe el contexto y que n compita ni con el resto del distrito ni con el paisaje que lo conforma, se complementaran en todo momento.

- Por medio del análisis de las vías se propondrán nuevas accesibilidades y recorridos que harán del distrito un distrito mas fácil de entender con señalización actualizada y dinámica apta para todas las edades en la comprensión.

- A atreves del proyecto todos los turistas peruanos, extranjeros y publico en general podarán ser testigos de la oportunidad gastronómica que el Perú presenta.

- Promover la participación de la población organizada para que aporten con recursos financieros, materiales o de mano de obra en la ejecución de los proyectos de su circunscripción o los que incidan en su bienestar.

- Gestionar la cooperación de los organismos públicos y privados competentes para lograr su participación efectiva en la ejecución de los proyectos contenidos en el Plan del Desarrollo Concertado Distrital.

- Plantear proyectos con participación poblacional de la mano con organismo públicos, con el fin de trabajar en el ámbito urbano y así repotenciar el sector desde un ámbito local y participativo de la población misma y del publico en general. 
- La avenida Lima es el eje principal del distrito este no se encuentra bien diferenciado del resto de las avenidas y calles, la infrestructura del borde no responde a la jerarquía urbanística que debería presentar.

- El ingreso de Pucusana debe ser reconocido desde el exterior y atreves del recorrido entender el distrito, el cartel de bienvenido a Pucusana debe ser el gran ingreso para todo el publico y así promover el turismo con un orden lógico.

\subsection{Alcances y Limitaciones}

Se busca identificar los puntos clave y característicos del distrito de Pucusana, y interconectarlos para poder optimizar la propuesta correctamente, siendo esta coherente con su contexto, sin competir sino mas bien complementarse.

La trama busca entender el distrito desde sus orígenes con la identidad pesquera que caracteriza, valorando las oportunidades que el distrito ofrece, resaltando sus tradiciones y evolución hasta la actualidad. Se plantea complementar los infraestructuras con las existentes de modo tal que los residentes se sientan identificados y entiendan la propuesta con una visión positivo, buscando mejorar la calidad de la experiencia turística del visitante y con ello mejorar el entorno como un punto de inversión tanto para el distrito como la expansión hacia el sur de lima.

Se busca llegar a un publico variado, con edades diversas y con intereses diferentes, el espacio ofrecerá un recorrido cultural enfocado en la gastronomía y en la principal actividad económica y de desarrollo que ha tenido y tiene el distrito: el terminal pesquero. Se busca complementar la actividad con un recorrido cultural, y fomentar el turismo en el sector.

La evolución del distrito se ha generado sin ningún orden y muchos de los lotes no se han respetado y hay una deficiencia de espacios libres, lo que ha generado que los habitantes se tengan que movilizar principalmente al muelle o mercado para poder interactuar con el resto de los habitantes del distrito.

Falta un catastro actualizado que limita el desarrollo. Para una buena ejecución se debe realizar los mapeos correspondientes para la optima precisión de la información.

Los espacios culturales que se ubicaran dentro de la trama propuesta serán complementarios a los espacios que ya se encuentran en el distrito. En todo momento la tradición será tomada en cuenta, usándolo como recursos para enfatizar los objetivos. 
Además, el proyecto debe contar con una comunicación vial vehicular y peatonal la cual permita su optimo desenvolvimiento en el recorrido de la experiencia.

Conectar el distrito con el resto del País, dar a conocer sus orígenes y comprender que si bien Pucusana forma de Lima, muchas de sus tradiciones tienen que ver con el resto del país y su desarrollo estuvo ligado a los habitantes de Chilca.

\subsection{Metodologia}

\subsubsection{Esquema Metodológico}

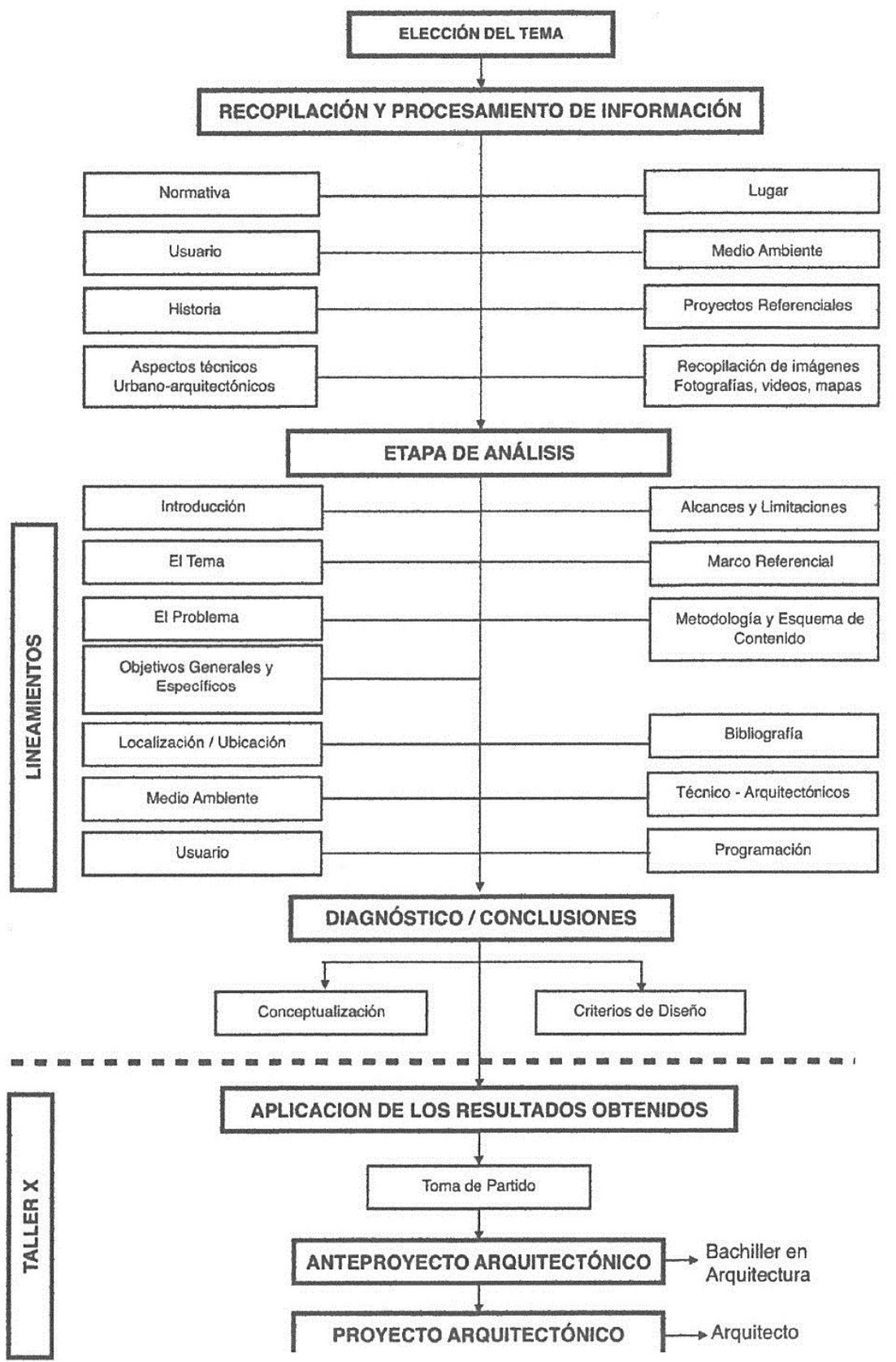




\subsubsection{Plan de acciones a realizar}

Debido al gran centralismo que Lima presenta, los bordes de la ciudad se encuentran desolados y sin mayores oportunidades hacia el progreso es por ello que se propuso como parte de la estrategia de hacer un foco cultural, y turístico en torno en la gastronomía en el borde de la ciudad, regenerando este sector hacia su expansión con el resto de la ciudad. Entendiendo este como una conexión y no una barrera.

Para la selección del lugar, se procedió a analizar los distintos bores que presentaba la ciudad desde el norte hasta el sur, siendo la actividad por coincidencia, la actividad pesquera.

Luego de visitar los lugares se anoto que la pesa artesanal y lo que esta actividad conlleva podía ser una gran oportunidad de desarrollo y de atractivo turístico en distrito, la ciudad $\mathrm{y}$ en el mundo. Es por ello que se propuesto desarrollar el proyecto en torno a la gastronomía peruana y en su en la misma actividad, que le brinda al sector una identidad particular.

A continuación del análisis de los tres lugares se escogió el distrito de Pucusana para desarrollar el proyecto. En el distrito de santa Maria del mar Gastón acuario de la mano con la universidad católica del Perú están planteando realizar una universidad gastronómica en los próximos años, es por ello que se propuso realizar el proyecto ahí para que ambas actividades se complementen y todo el sector sur de lima tenga una identidad gastronómica característica.

"El grupo de accionistas está liderado por Gastón Acurio. La idea de la PUCP es participar directamente en la implementación de este proyecto. Va a ser una asociación privada. Queremos entrar a competir con las mejores universidades del mundo en los campos de gastronomía, hotelería y turismo." - Carlos Fosca ${ }^{11}$

Pucusana además del problema anteriormente mencionado, en una menor escala el distrito en su conjunto presentaba el mismo problema del centralismo y es por ello que se analizo el distrito y se propuesto intervenirlo en tres grandes puntos.

En primer lugar el lugar tradicional, el muele de pescadores, luego una trama que reactivará el distrito en torno al gastronomía con puntos estratégicos para que eso ocurra y finalmente en el lugar de llegada y de salida del distrito se propone un mercado gastronómica con espacios de cultura gastronómica para que los visitantes puedan ser testigos de las oportunidades que esta ofrece.

\footnotetext{
${ }^{11}$ Diario el Comercio (2014) 1 de diciembre: 13:31
} 
Se busca a través de este análisis por medio de distintos recursos, como libros, informes, internet, información grafica, históricos visitas y consultas, llegar a un amplio análisis del área y del proyecto a realizar. Se tiene muy presente la identidad que el distrito caracteriza, sus tradiciones y su contexto. Lo que se pretende es subliminar el distrito dotándolo de nuevas actividades que le permitan darse a conocer y explotar los grandes atractivos que presenta.

Si el proyecto es realizado correctamente con los objetivos ejecutados y según lo previsto, el Complejo cultural de gastronomía peruana en Pucusana será un atractivo para el mundo y todos querrán ser testigos de la experiencia gastronómica que el Perú presenta y que todos debemos estar orgullos de ello. 


\section{Capítulo 2. Marco Referencial}

\subsection{Marco Histórico}

\subsubsection{Historias de la tipologia}

\subsubsection{En el mundo}

Existen tres momentos trascendentales en la historia de la gastronomía en el mundo. La primera hace dos millones y medio en África, cuando se inicio debido a una superviviendo básica e alimentación con la matanza de animales, se incorporaron porciones de carne animal en la dieta dejando de lado la exclusiva dieta vegetariana, esta nueva tendencia y descubrimiento hizo que el sistema del cuerpo humano procese la comida distinto dándole vitaminas y nuevos beneficios nutriciones a las personas. Aumentando sus capacidades y permitiéndoles vivir y realizar sus actividades de una mejor manera.

El segundo fue hace millones de años cuando de descubrió el fuego y se entendió como un medio de cocción y de nuevo modo de consumir la comida, si bien los alimentos eran extraídos y consumidos este proceso de preparación genero nuevos aportes a la gastronomía, no solo era la comida, sino los olores los sabores y la degustación lo que también tomo valor.

El último hace muy poco tiempo hace doce mil años cuando el hombre propuso cultivar plantas para su propio consumo con un método se superveniencia económica al igual que el criadero de animales, ya no era solo para vivir sino también para obtener recursos económicos con él y con ello nació la agricultura y la ganadería como fuentes principales de alimentos. En un principio el intercambio fue por truque, luego ya de formaron empresas y organizaciones que promovieron el comercio e un ámbito mas globales.

Al principio se utilizaban las cuevas para poder cocinar, luego los fogallones y otra tecnologías que de acuerdo al tiempo y necesidades se realizaban. En la actualidad las tecnologías han avanzado mucho y los nuevos aporten creativos han hecho del ala gastronomía un nuevo medio de expresión e innovación. 
Luego de la revolución francesa muchos cocineros de la alta sociedad y de la nobleza tuvieron que buscar nuevos trabajos ya que la crisis era muy grande. Se vieron obligados a abrir nuevos restaurantes y poder dar a conocer sus sabores culinarios. ${ }^{12}$

En el siglo XIX, cuando nació la ciencia culinaria. Cocineros como Urbain Dubois proponen la importancia de la ciencia en la cocina. ${ }^{13}$ Un gran aporte en este momento fue el de Joseph Favre, ya que propuso nuevas recetas, ilustraciones y fotografías de la gastronomía en general y la ofreció al público.

Auguste Escoffier, reorganizo con una nueva estructura la cocina clásica sintetizándola propuso nuevas recetas generando así un atractivo en la innovación de esta para la época y para el publico consumir en general

Benjamin Thomson, aplico los descubrimientos científicos en la cocina, innovo en términos de temperaturas de colocación y en la manera de sentir los alimentos, propuso nuevas texturas y propuso nuevos platos que en el momento marcaron tendencia.

La física en la gastronomía se llevo a cabo con el aporte del físico de Oxford, Nicholas Kurti, él tenía un gran interés por la comida e hizo investigaciones y aportes en la gastronomía, fue quien creo los rellenos pasteleros como el merengue, propuso nuevos métodos de presentación pastelera, de igual manera los rellenos de los dulces sin afectar su cobertura fue propuesta por él, utilizo la aguja hipodérmica para hacerlo.

En 1988 a término "gastronomía molecular" para referirse a la aplicación de los principios científicos a la comprensión y la mejora de la preparación de alimentos a pequeña escala. La innovación culinaria ha traspasado barreras, ha entrado en el hogar de todos y todos en la actualidad estamos en búsqueda de nuevos lugares para probar nuevas alternativas de gastronomía.

Se ha comprendido la importancia y el sentido que esta tiene en la cultura en la actualidad, los cinco sentidos se despiertan en su sabores y presentaciones siendo este un momento memorable.

Actualmente para el Perú y e mundo la gastronomía es un gran medio de interacción cultural y de reconcomiendo de identidad, la gente reconoce los orígenes de los alimentos y las mezclas que estas conllevan en sus platos de acuerdo a la cultura que ha influido en el país.

\footnotetext{
${ }^{12}$ ALCUBILLA, Julio. Enciclopedia Gourmet (2015)
}

${ }^{13}$ ALCUBILLA, Julio. Enciclopedia Gourmet (2015) 
Además la gastronomía en la actualidad es enseñada en distintas universidades del mundo, las trasformaciones que han generado en las personas han sido notables y muchos quieren aprender de ello para seguir generando nuevos aportes.

Las transformaciones tan radicales que se están produciendo en nuestra alimentación son, así, una consecuencia de la aceleración de la historia y de la globalización del mercado alimentario.

La globalización de sus productos y del mercado de los alimentos en general, desde su producción y consumo ha hecho que los ciudadanos se sientan libres de expresar sus tradiciones en sus sabores, y con ello un gran atractivo turístico en torno a él, ha hecho que los ciudadanos se sientan libres y puedan reflejar su identidad, la cual todos deben reconocer.

“Quiero saber el porqué la cocina aquí es algo más que cocina, que es ...lo que hace que este país sea único en el mundo* - Ferran Adria ${ }^{14}$

\subsubsection{En el Perú}

Los tiempos precolombinos (hasta 1532)

Cuando llegaron los españoles, con su llegada trajeron importantes usos y costumbres en el ámbito culinario, trajeron la cebolla y el ajo que combinados con el ají peruano, son hoy de los ingredientes mas utilizados en los platos peruanos.

El limón también fue originario de esa época si bien fue producida en el Perú luego y cambiada su forma el origen llega con los españoles. El cual es hoy en día uno de los ingredientes mas reconocibles de un plato típico peruano que se llama cebiche.

Los vinos, también los trajeron los españoles, debido alas distintas temperaturas que presenta el Perú la vid, fue mutando y nuevos tipos de esta se fueron generando, produciendo nuevos sabores, texturas y colores.

En los primeros encuentros entre los nativos peruanos con los españoles, el modo de pago o recompensa ante cualquier acuerdo pactado era atreves del trueque, la papa y el maíz eran de los elementos mas frecuentes en dicha actividad.

La repostería peruano tuvo gran desarrollo en este periodo, el mana y el alfajor eran los dulces mas frecuentes de la época, se preparaban de distintas maneras y fueron innovando en su ejecución.

\footnotetext{
${ }^{14}$ Ferran Adria: cocinero español considerado por muchos como el mejor chef del mundo.
} 
Los esclavos africanos también influyeron en los sabores que hoy nos caracterizan, ya que fueron ellos quienes comenzaron a cocinar para las grandes masas de trabajadores de la época, una manera fácil y rápida de hacerlo era por medio de brasas y de salteados con fuego, lo cual hacia que la comisa tenga mayor circulación. Los guisos también eran ofrecidos a la servidumbre.

Es ese omento los platos criollos como los anticuchos, el cau cau o el chicharon fueron los platos mas emblemáticos de la época.

\section{Los tiempos republicanos (Desde 1821)}

A la independencia, mucha migraciones se generaron en la ciudad de Lima, con ello las tradiciones los nuevos habitantes fueron plasmadas en la sociedad, y la dinámica culinaria atravesó grandes cabios

Una de las grandes fusiones de la época llego con la migración de los chinos a mediados del siglo XIX, el fuego fuerte en sus salteados y los sabores dulces en los plantos principales fue algo innovador para el momento. De igual manera el arroz, el cual hoy en día es un importante acompañamiento de muchos platos se origino en este periodo.

Otra migración notable fue la de los italianos, las pastas y los pasteles fueron traídos con ellos, de igual la manera la tradición del panetón en la navidad fue implantada en la sociedad por ellos, la cual hasta ahora se realiza y se genera como un momento de interacción y de compartir en un momento tan importante.

Finalmente la migración japonesa, propuso alternativas de alimentos crudos con cortes peliculares que hicieron de ella una comida que causo mucha tendencia en la sociedad, ya que no solo era la comida sin cocción sino el modo de comerlo como el implemento de los palitos de madera como un nuevo utensilio. La técnica del corte fue fusionada con la sazón del limón que ya se utilizaba en el país es por ello que se propuso el famoso tiradito como una nueva alterativa a esta nueva tendencia.

\section{$\underline{\text { La cocina peruana en el mundo actual }}$}

Al finalizar el siglo XX e inicios del XX1, la cocina peruano comenzó a volverse mas común en la sociedad y popular en 1 mundo entero. En la cumbre internacional, fusión Madrid del 2006, la ciudad de Lima, capital del Perú, fue nombrada capital gastronómica de América. Luego de ese nombramiento Lima estaba en la mirada de muchos países del mundo y de nuevos proyectos que extranjeros gastronómicos que pronto llegarían al país. 
La gastronomía en el Perú, es actualmente una marca en el mundo y es un icono de identidad que todo peruano debe reconocer y sentirse orgulloso de que sea así.

El Perú presenta una gran variedad de insumos y de sabores, que por medio de su historia, tradiciones e innovaciones ha hecho de ella un recurso trascendental para el desarrollo del país.

La gastronomía peruana refleja los orígenes d el agente, el modo en el que viven, interactúan y se desenvuelven. Este si es bien canalizado podría ser un gran foco de atractivo turístico para el mundo, algo que ya ha sido apuntado por grandes figuras peruanas como el reconocido chef peruano Gastón Acurio, quien tiene actualmente notables proyectos en torno a la gastronomía.

\subsubsection{Historia del lugar}

Pucusana en la actualidad es un tradicional balneario que además presenta un puerto natural con caleta de pescadores. Su nombre, Pucusana, significa sopladero.

En 1876, en el censo, se determino que los pobladores de chilca, poblado colindante con el distrito, iban en burro a pescar a Pucusana en busca de alimentos, poco apoco con el tiempo se fueron estableciendo y conociendo las oportunidades que la zona les presentaba.

En 1917, las primeras casas de cobijo para los pescadores, fueron construidas. En 1920 se construyo la primera casa formal, la familia residió por primera ves en ese territorio, la familia de Santos Jacobo, nacido en chilca, fue quien estableció su primera casa en el actual balneario del sur, y luego de el se fueron generando los primeros indicios del próximo frecuentado balneario.

Figura 31: Primeras viviendas del pueblo de Pucusana

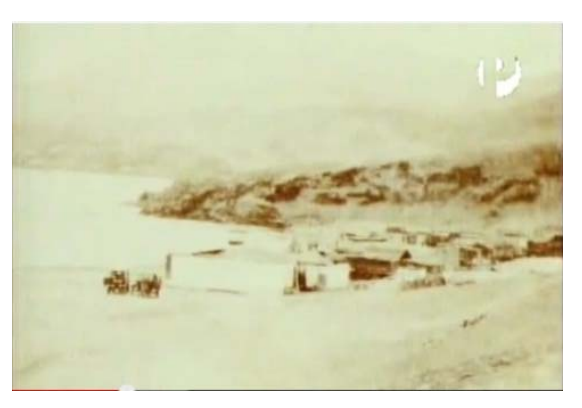

En torno de las viviendas se construyo posteriormente la ciudad. Debido a la ineficiencia de la llega del agua esta desarrollo no puedo evolucionar de la mejor manera y en 1928 los primeros negocios de trasporte e agua llegaron a la zona primero con barriles y luego en camiones, esto

Fuente: Documental a la vuelta de la esquina 
ayuda a estimular el progreso de la zona y a su ves el económico de los comerciantes. ${ }^{15}$ Hasta 1929, los habitantes que habían llegado a Pucusana por sus aguas tranquilas y puerto característico natural de pesca artesanal, eran chilcanos. Hasta que llego el señor Shoders, un alemán que construyo su casa ahí y con el llevo el primer automóvil y a través de el conoció el pueblo.

En 1930 y 1935, las primeras residencias veraniegas fueron construidas en las islas galápagos. En ese mismo año la carretera Panamericana Sur se estaba llevando a cabo y puso en evidencia las oportunidades positivas que tenia Pucusana.

Parte de los residentes fueron los jóvenes de la asociación cristiana, quienes levantaron campamentos de verán. Los promotores de dicha actividad tenían que proporcionarle alimentos preparados a los jóvenes para poder seguir realizando sus actividades, es por ello se generó la primera tienda bodega.

Figura 32: Primeros veraneantes y pescadores del pueblo de Pucusana
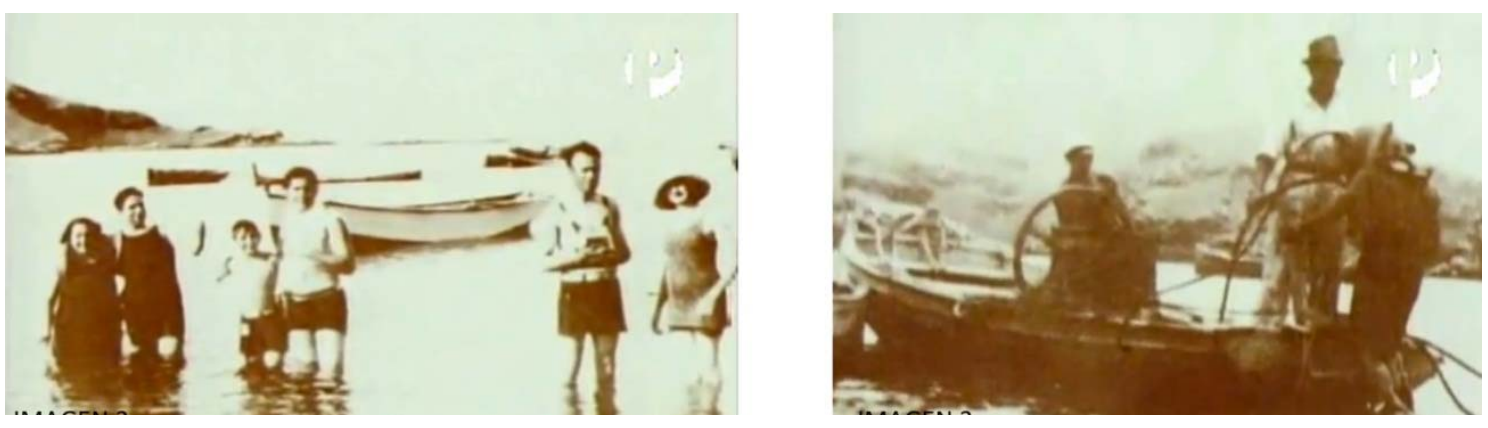

Fuente : Propia

En 1940 aparecieron los primeros restaurantes y a su ves los hoteles que complementaban el recorrido turístico y esparcimiento en él. De modo tal que la economía fue progresando en el sector y el balneario fue un emblemático lugar atractivo y de esparcimiento turístico. Hasta 1940, se contaban con aproximadamente 30 familias de pescadores establecidas y con actividades comerciales que ayudaban su desarrollo. En 1943 se convirtió en distrito, y con el plan regulador el cual impulso en la venta de nuevos terrenos.

La carretera al sur de lima termino su ejecución en 1951, y con el nuevas residencias fueron creando las viviendas que hoy Pucusana posee, la playas de Naplo, las ninfas fueron las playas de la elite social mas alta de Lima que venían en temporadas de verano a relajarse y a compartir en familia las vacaciones, eran casas temporales de compartir.

${ }^{15}$ ORREGO Juan Luis, Historia del Perú, America Latina y el mundo. Siglo XIX Y XX (2009) 
Finalmente en 1953, la instalación de servicios de agua y a su ves de desagua ayudaron el desarrollo del sector en muchos aspectos, marco un momento importante para el distrito hacia el progreso de modo tal que en los años 50 , el distrito ya contaba con un paisaje característico urbano con una personalidad geográfica, de pueblo tradicional de pescadores. Se plantearon servicios de salud para los habitantes de recreación y de esparcimiento a su ves los nuevos comercios en torno al turismo fueron aumentando, personas de todas partes iban a Pucusana a ser testigos del gran potencial que presenta. Muchas construcciones caracterizaron el distrito como lo son la plaza de armas, el nuevo Mercado, el malecón Can Martin, el nuevo puerto y muelle de pescadores, y as u ves la avenida lima que conectaba todo el distrito en su conjunto, Pocos a poco el distrito se fue articulando pudiendo así recorrerlo en la actualidad sin ningún problema.

\subsection{Marco Teorico-Conceptual}

\section{PESCA ARTESANAL}

La pesca artesanal es un tipo de actividad pesquera que utiliza técnicas tradicionales con poco desarrollo tecnológico. La practican pequeños barcos en zonas costeras a no más de 10 millas de distancia, dentro de lo que se llama mar territorial.

Se mantiene en regiones poco desarrolladas donde la producción es escasa y sirve básicamente para el autoconsumo; solo una pequeña parte se destina al mercado. Para este tipo de pesca se utilizan Yariksas que extraen gran cantidad de especies de peces, mariscos, moluscos y crustáceos. ${ }^{16}$

\section{TURISMO GASTRONOMICO}

El turismo gastronómico es una forma de turismo, donde el interés está puesto en la gastronomía y cultura culinaria del país que se visita.

El turismo gastronómico es un instrumento que ayudara al posicionamiento de los alimentos regionales. En los últimos años, están adquiriendo cada vez más importancia en el mundo, pues se han convertido en una pieza clave para el posicionamiento de los alimentos regionales.

Este turismo se puede definir como las visitas a productores primarios y secundarios de alimentos, festivales gastronómicos, restaurantes y lugares específicos donde la

\footnotetext{
${ }^{16}$ https://es.wikipedia.org/wiki/Pesca artesanal
} 
degustación de platos y la experimentación de los atributos de una región especializada en la producción de alimentos es la razón principal para la realización del viajes

\section{CENTRALISMO URBANO}

Es cuando los usos de una ciudad se centran en en punto, se canalizan todas las infraestructuras en torno a él y las funciones ase ramifican según su recorrido. Podría ser beneficioso en muchos casos pero por general es descontrol de este podría generar sectarismo en el conjunto urbano generando un solo punto de atención aislando y dejando de lado el resto del lugar.

\section{CLASES DE CENTRALISMO}

a) Centralismo puro: que el ejercicio de las competencias del órgano central se lleva a cabo de forma exclusiva y total.

b) Centralismo desconcentrado: cuando todo está basado en la decisión de un cuerpo administrativo o de una persona.

\section{BORDES}

Los bordes son los elementos lineales que el observador no usa o considera sendas. Son los límites entre dos fases, rupturas lineales de la continuidad, como playas, cruces de ferrocarril, bordes de desarrollo, muros. Constituyen referencias laterales y no ejes coordinados. Estos bordes pueden ser vallas, más o menos penetrables, que separan una región de otra o bien pueden ser suturas, líneas según las cuales se relacionan y unen dos regiones. Estos elementos fronterizos, si bien no son tan dominantes como las sendas, constituyen para muchas personas importantes rasgos organizadores, en especial en la función de mantener juntas zonas generalizadas, como ocurre en el caso del contorno de una ciudad trazado por el agua o por una muralla. 17- Lynch, Kevin

Figura 33: Gráficas de los bordes por Kevin Lynch
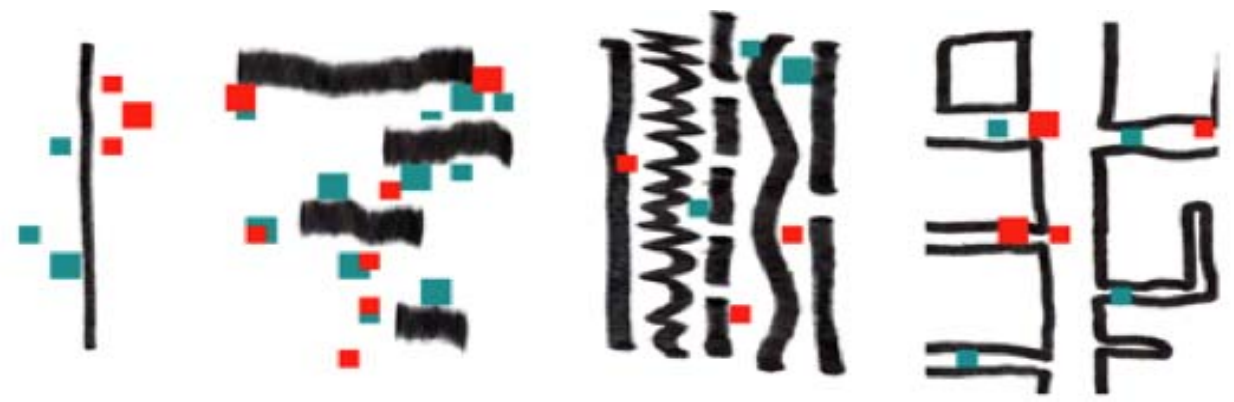

\footnotetext{
${ }^{17}$ LYNCH, Kevin, “LA IMAGEN DE LA CIUDAD”, ed. Gili, SA, Barcelona, 1984/1998.
} 
Fuente: LYNCH, Kevin, "LA IMAGEN DE LA CIUDAD”.

\section{DESPLAZAMIENTOS}

Los desplazamientos en la ciudad de deben a los espacios diseñados para esto ocurra, el trasporte por un lado hace que la gente recorrida las vías para llegar a sus dentinos.

También los espacios públicos han hecho que los habitantes interactúen en el y de un espacio en el cual la gente se interrelaciona. Los desplazamientos en lima generalmente son debido al consumo, la falta de ligares públicos de ocio, descanso y reconocimiento del lugar son escasos.

El problema se debe a desorción de los usos sociales y las formas físicas que estas presentan, en muchos casos de debe a la falta del entendimiento del entorno y al mal funcionamiento de las instituciones para entender la ciudad y plantear recorridos concretos, efectivos y funcionales.

\section{$\underline{\text { TERRITORIO }}$}

El concepto de territorio es consecuencia de la delimitación espacial de un proceso de apropiación de una parte de la superficie terrestre por un grupo social. Esta definición tiene sus referentes en caracteres deducidos de la Antropología, Sociología, Psicología, etc. Pero también podemos encontrar la vinculación del término al dominio jurídico, y éste actúa en la expresión "ordenación del territorio".

Porque un territorio no es sólo un trozo de espacio apropiado por un grupo social, sino que corresponde a una extensión espacial ordenada por este grupo con una unidad de funcionamiento donde vendrán los "actores" (estado, colectividad territorial, empresa, grupo o individuo) con sus percepciones y sus estrategias. El territorio es el espacio de una sociedad; es pues un "espacio de vida". ${ }^{18}$

\section{$\underline{\text { EL LUGAR }}$}

Supone una sólida correspondencia entre formas, actividades y significados, con una marcada estabilidad espacio-temporal que brinda identidad, memoria y referencia a la sociedad. El lugar tiene un fuerte efecto organizador del espacio urbano generando una topología que facilita la comprensión y valoración de la ciudad. Además, la existencia de un sistema de lugares significativos, asociados a formas relevantes y usos pertinentes que brinda a la ciudad una dimensión de totalidad, un sistema complejo pero integrado.

\footnotetext{
${ }^{18}$ BRUSCHI, Rita Material de Apoyo de la Ficha no1, Segundo Bachiderato. (2009)
} 
Cada lugar público conforma un núcleo de centralidad material y simbólica (la plaza, la escuela, la calle principal) que territorializa el espacio urbano generando una topología de continuidades perceptivas, cognitivas y valorativas que alcanza a la sociedad en su conjunto. ${ }^{19}$

El lugar es un concepto clave en la geografía actual. Adquiere un valor que deriva de la percepción que de él tienen sus habitantes y del significado que le han atribuido. El lugar adquiere una dimensión subjetiva, se convierte en imagen individual, se modela de acuerdo a los valores e intereses de las personas.

El espacio en general, en abstracto, se transforma en un mosaico de lugares, con atributos asignados por los individuos. Éstos proporcionan a cada lugar un signo propio. Son espacios vinculados a la existencia de cada individuo, a sus experiencias particulares, a su relación personal con el entorno, a la percepción que del mismo tiene, de acuerdo con condiciones culturales y personales. ${ }^{20}$

\section{ESPACIO PÚBLICO}

El espacio publico de debe a la existencia del lugar en el tiempo y la experiencia que ha tenido en el. A través de el la realidad cotidiana se va influenciando en torno a la sociedad y determina situaciones en el contexto de su vida en el lugar o ciudad.

Al articulare correctamente estos espacios públicos el esparcimiento en el determinado lugar hace de el un recorrido formidable y de reconocimiento. El espacio publico muchas veces determina si el sector es seguro o no y se te permite recórrelo con tranquilidad.

En muchos casos viene de la mano con temas específicos subjetiva de percepción pero a la ves el buen diseño de este como un espacio abierto y mobiliario optimo permiten que el usuario lo experimente de la mejor manera según el planteamiento y la ciudad pueda ser entendida como un conjunto, con espacios de distintas jerarquías y usos.

\section{ARTICULACION URBANISTICA}

La articulación urbanística no debería aislarse en ningún caso, el principal objetivo de esta en transformar e integrar la ciudad. Las articulaciones pueden estar presentadas de distintas formas y en diversos puntos de la ciudad. Lo importante de ello es que debe ser una estrategia de movimiento y de relación de movimientos entre varios componentes que influyen la ciudad, por lo tanto la articulación resume los tejidos urbanos y los

\footnotetext{
${ }^{19} \mathrm{http}: / / \mathrm{www} . v i t r u v i u s . c o m . b r /$ revistas/read/arquitextos/07.081/269/es

${ }^{20} \mathrm{http} / / / \mathrm{www} . r e d u a m b i e n t a l . e d u . u y / \mathrm{wp}$-content/uploads/2009/12/01-material-extra.pdf
} 
trasforma en paisajes entendidos por los usuarios y reconocidos en la ciudad como puntos de movimiento y de flujos de diferentes velocidades y frecuencias. ${ }^{21}$

Articulaciones lineales o trenzas urbanas: Conectan los vínculos de mayor y mejor desarrollo marcando una línea directa y sin obstáculos.

Articulaciones focales o urdimbres urbanas: Sintetizan los puntos del tejido urbano, y los vinculan, generan permeabilidad en distintas escalas.

Articulaciones nodales o bisagras urbanas: Potencian el lugar, conectan movimientos y lo concentran, son puntos estratégicos de orden. Son entendidos como ejes motrices de movilidad. (Costanera, vías de FFFCC, Avenidas).

Figura 34: Ciudades refrentes de Acupuntura Urbana
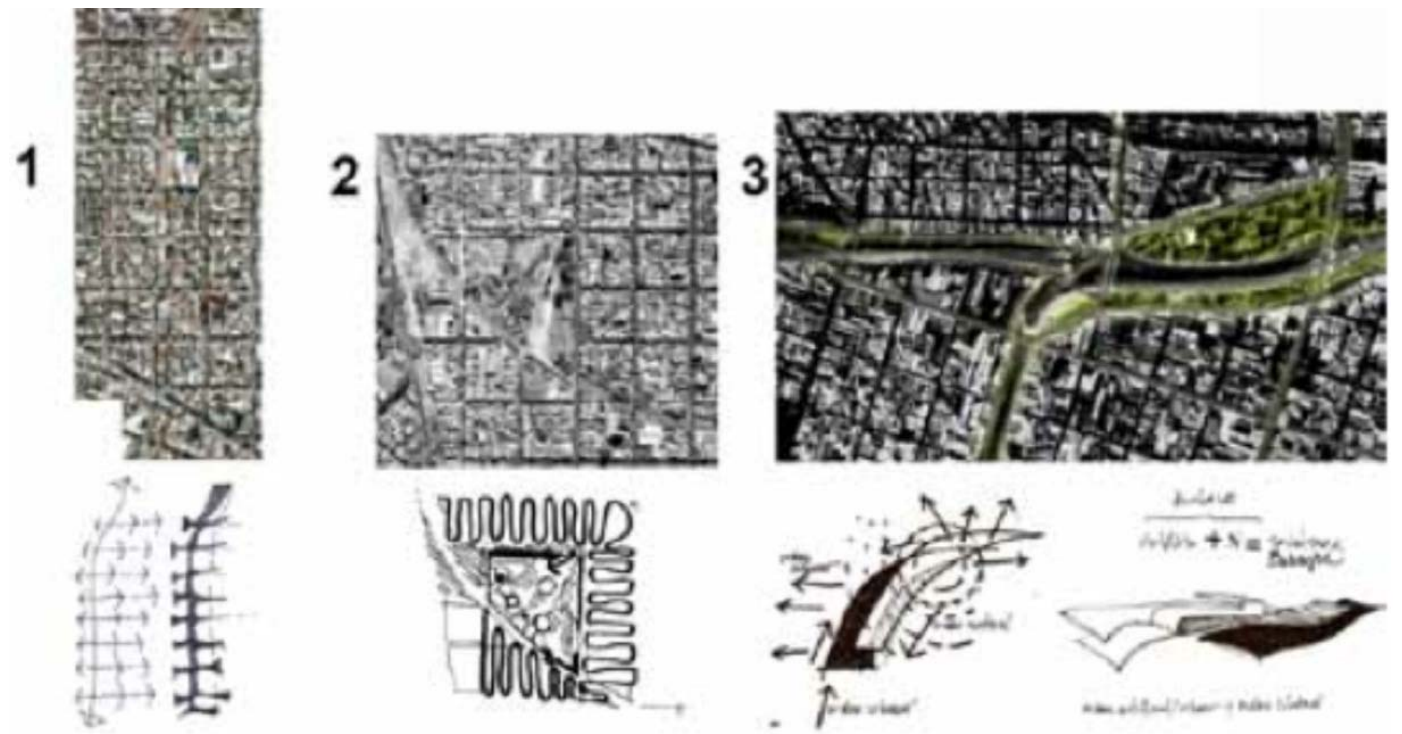

Fuente: Gráficas de los bordes por Kevin Lynch

\section{ACUPUNTURA URBANA}

La acupuntura urbana es un método que sustenta sus técnicas con el metabolismo mismo del cuerpo humado, detecta puntos estratégicos y los conecta con distintos puntos para así ir sanando la ciudad. Se busca comprender la ciudad como un ser vivo, el cual se mueve, el cual se relacione y debe estar en constante retroalimentación para su optimo esparcimiento, es por ello que esta tecnología plantea analizar la ciudad dense ese punto dentro de un inteligencia colectiva de la sociedad que la conforma.

Se promueve localización de núcleos y puntos clave que generaran una mejor ciudad. De deben identificar las distintas partes que la conforman para poder detectar esos puntos y

\footnotetext{
${ }^{21} \mathrm{http}: / /$ www.habitatinclusivo.com.ar/revista/wpcontent/uploads/2013/02/la articulacion como estrategia proyectual.pdf
} 
para ello se necesita un análisis detallado de su conjunto. No se busca hacer grandes cambios sino cambios específicos claves para su evolución y desarrollo.

\section{NODOS URBANOS}

Harold Carter explica los nodos de la ciudad como puntos de interacción sociales vehiculare y de las distintas ordenes que la ciudad presenta. el habitante cuando los identifica puede entender la ciudad, su comportamiento y desplazamiento, es muchos casos en esos puntos se encuentran centros comerciales o edificaciones que generen nuevos comercios colindantes, ya que conllevan un gran flujo de personas y de circulación frecuente.

\section{PERSEPCION}

La percepciones de las personas son subjetivas están relacionadas con lo aprendido en su infancia, las experiencias que hayan tenido en general en todos los momentos de su vida. Las respuestas ante las distintas situaciones son reflejo de dicha experiencia aprendida, la relación del entorno también es influyente en dicha experiencia ya que adquiere valores significativos en su percepción.

Veamos a continuación, el modelo descriptivo de percepción y comportamiento según Downs.

Figura 35: Modelo descripitivo de percepcion y comportamiento segun Downs

\section{PERCEPCIÓN}

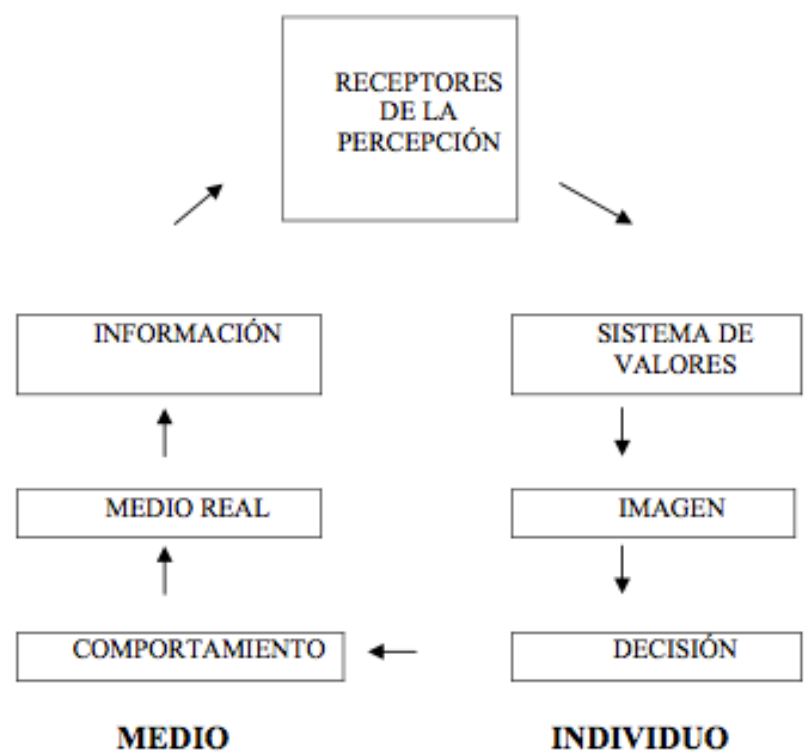

Fuente: Internet : www.usal.edu.ar/archivos/geousal/otros/nodos.pdf 


\section{SISTEMA DE VALORES DE PERSEPCIÓN}

Según A. Moles y E. Rohmer, el ser humano reconoce ocho envolturas o caparazones de la percepción que son: $(5){ }^{22}$

El cuerpo en particular: el cual limita el sitio en contacto con el resto.

El gesto inmediato: se da de modo inmediato y en muchos casos inconsciente ante una reacción de alguna llamada de atención.

La habitación: lugar mas intimo de relación con uno mismo

La casa o departamento: lugar donde nos rodeamos de gente con la que hemos crecido en muchos casos nuestros familiares,

El barrio: es el espacio donde nos hemos desarrollado y que nos sentimos reconocidos.

Sabemos su historia y evolución, lo denominamos como nuestro territorio, y ha sido un espacio de gran influencia en la actualidad.

La ciudad centrada: conocida como el lugar de concentración de servicios e infraestructuras en la que conocemos a algunos extraños. Se puede circular en el observando los detalles que presenta y se debe tener cuidado ya que resulta algo desconocido.

La región: es un espacio delimitado que puede ser reconocido pero también da una sensación de inseguridad ya que resulta muy amplio y la sociedad suele ser diferente a lo que comúnmente vemos. Con costumbres y culturas destinas que interactuar en un espacio delimitado.

El vasto mundo: Nos ayuda a ubicarnos en relación al conjunto, nos hace dársenos cuenta de lo excepcional y lo nuevo.

Figura 36: Esquema de caparazones percepctivos de Moles y Rohmer

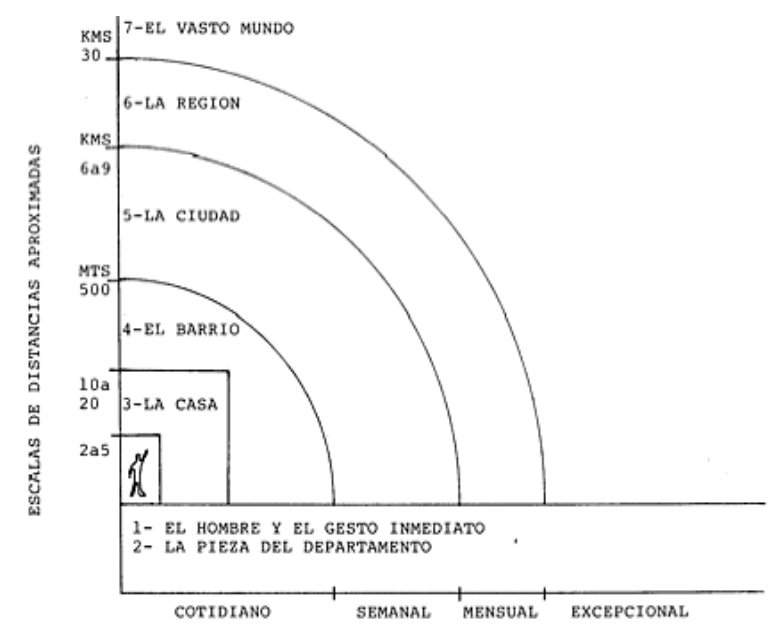

${ }^{22}$ http://www.usal.edu.ar/archivos/geousal/otros/nodos.pdf 
Fuente: Internet : www.usal.edu.ar/archivos/geousal/otros/nodos.pdf 


\section{Capítulo 3. Análisis de los Proyectos Referenciales}

\subsection{Mercado Gastronomico de Paris}

NFORMACION GENERAL

En el año 2012, ARCHMEDIUM organizó un concurso de arquitectura para estudiantes con el objetivo de crear un nuevo centro gastronómico.

NOMBRE

Paris Marketlab

AUTOR

BAVS Arq

(Batista.Amador.Varandas Santana)

AREA OCUPADA: $560 \mathrm{M} 2$

AREA TOTAL COSTRUIDA: 3920 M2

La ciudad de Paris, es el destino turistico más popular del mundo, al rededor de 42 millones de visistantes extrangeros lo vissitan al año

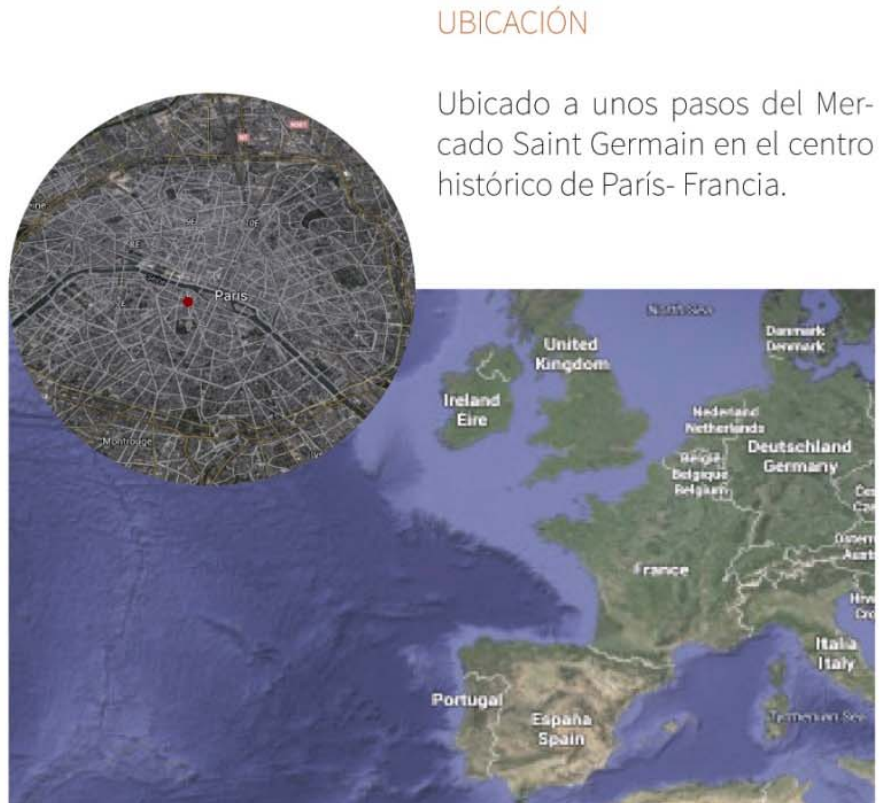

Figura 37: Mapa Localizador - Marketlab de Paris Fuente: Google Earth

Saint Germain es una zona historica notable en la ciudad en la cual se encuentran muchos atractivos turisticos. La cercania del mercado de Saint Germain con la propuesta ha generado que todo el sectorr cultural y comercial se interelacione y sea recoconocido en su conjunto como un lugar cultural y de interacción social. La buena proximidad de sus potenciales historicos y la buena organizacion de sus vías ha hecho de esta una zona atractiva de exparsimiento. TERRENO

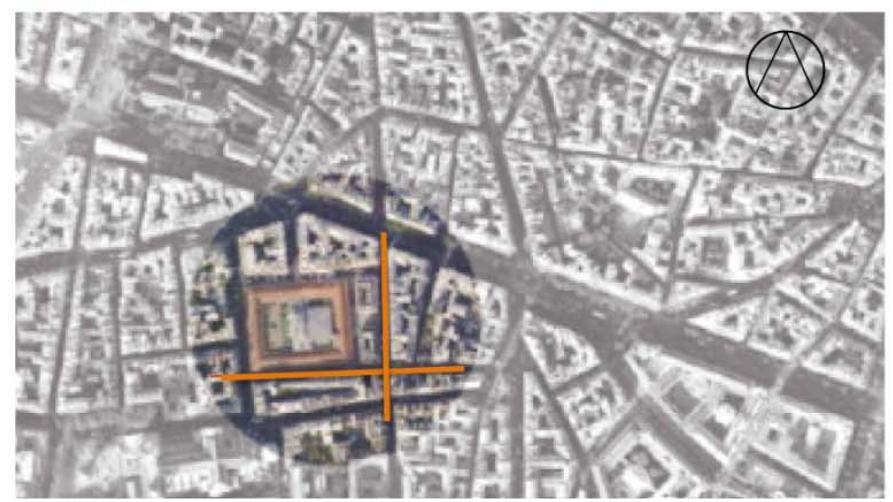

Figura 38: Terreno Marketlab de Paris Fuente: Elaboración propia

El Marketlab tiene dos calles que marcan el ingreso, hacia el sur, Rue Lobineau y hacia el oeste Rue de Seine hacia, ambas con comercio en la planta baja permitiendo así su integración con el sitio e interlacionarse.en el recorrido.

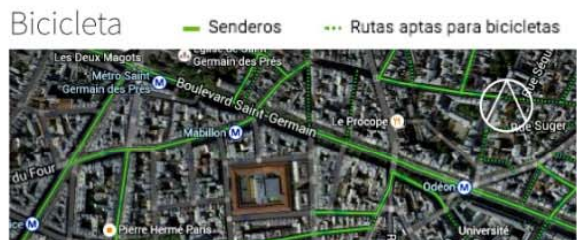

Figura 39: Ruta de bicileta por el Marketlab de Paris

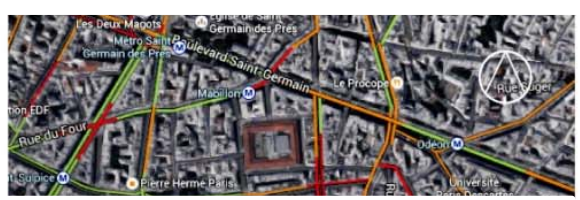

Figura 40: Ruta de tránsito por el Marketlab de Paris

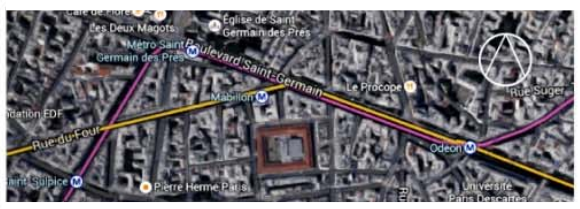

Figura 41: Ruta de transporte público por el Marketlab de Paris

Fuente : Google Earth 


\section{ANTECEDENTES HISTORICOS}

\section{EVOLUCIÓN HISTÓRICA}

La evolución hisorica del lugar, ha sido muy importante para la ciudad en general. Saint Germain es considerado como el mayor centro comercial a cielo abierto del oeste parisino. Además a lo largo de su historia, por ser una ciudad militar en años anteriores es conciderado, un lugar emblematico en la actualidad.

\section{INTEGRACIÓN CON SU ENTORNO HISTÓRICO}

El lugar, direcciona el diseño a considerar los tejidos urbanos históricos de la ciudad, de moda tal que la identidad del sitio no se deja de lado. En su entorno se encuentran varios edificios importantede para la ciudad, con gran atractivo túristico.

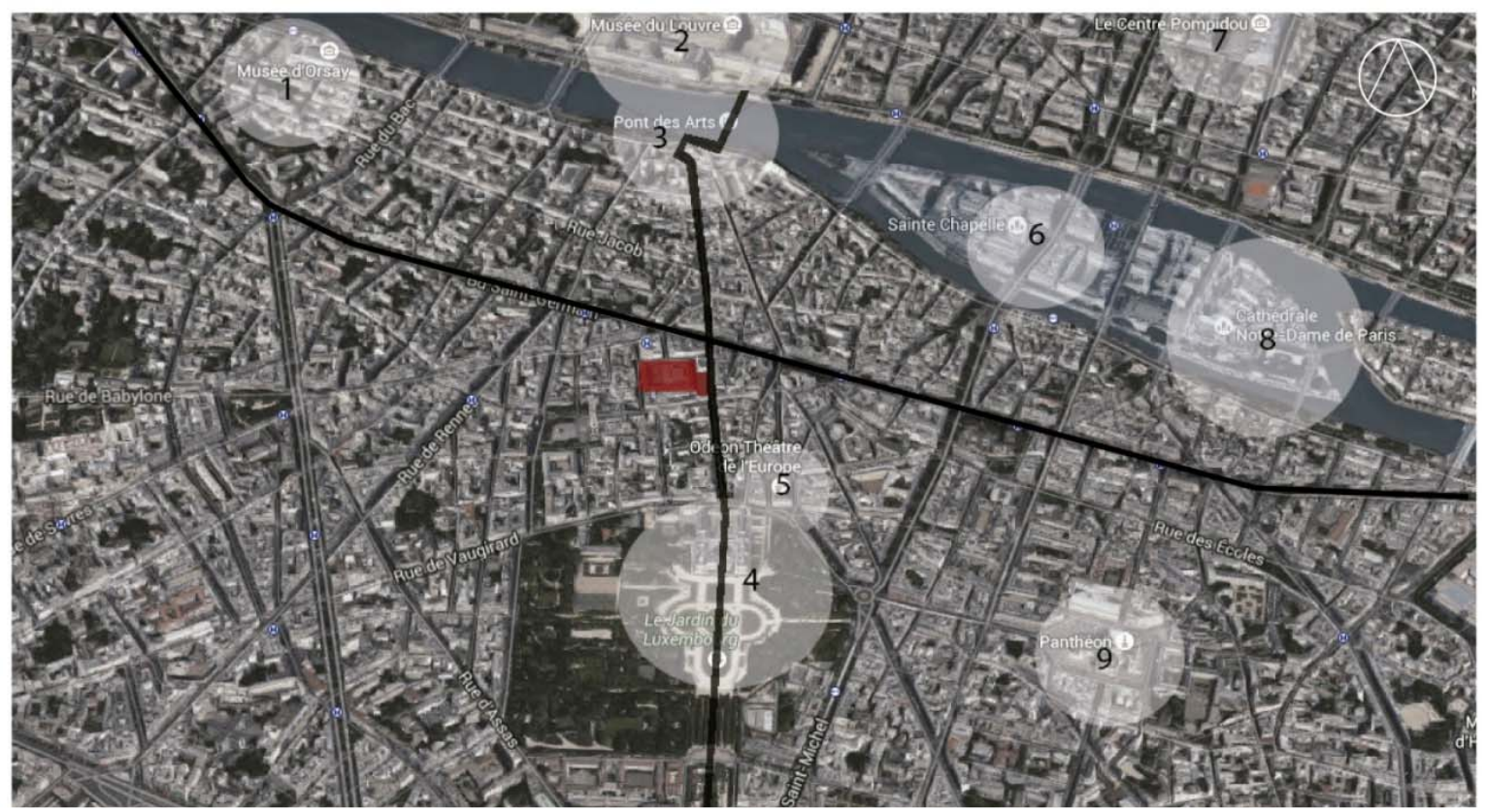

Figura 42: Entorno historico Marketlab de Paris Fuente: Elaboración propia

2- LOUVRE

3- PONT DES ARTS

4 - JARDIN DU LUXEMBURGOURG
6 - THEATRE DU CHATELET

7 - CENTRO POMPIDOU

8- CATHEDRALE NOTRE DAME DE PARIS

9 - PANTEÓN

IDENTIFICACION DE EDIFICACIONES Y AMBIENTES URBANO - ARQUITECTONICO

Cathedral Notre - Dame

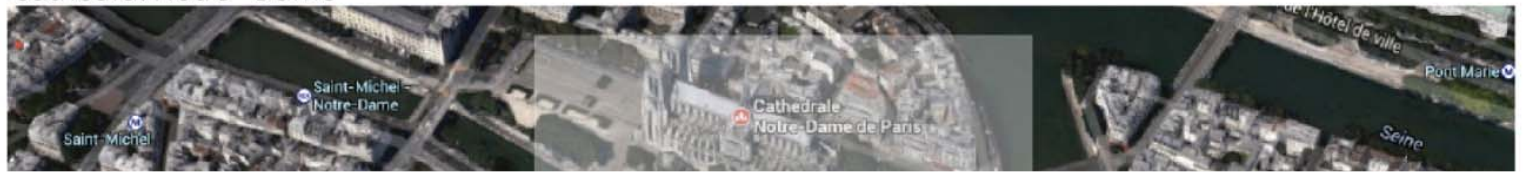

Figura 43: Cathedral Notre Dame

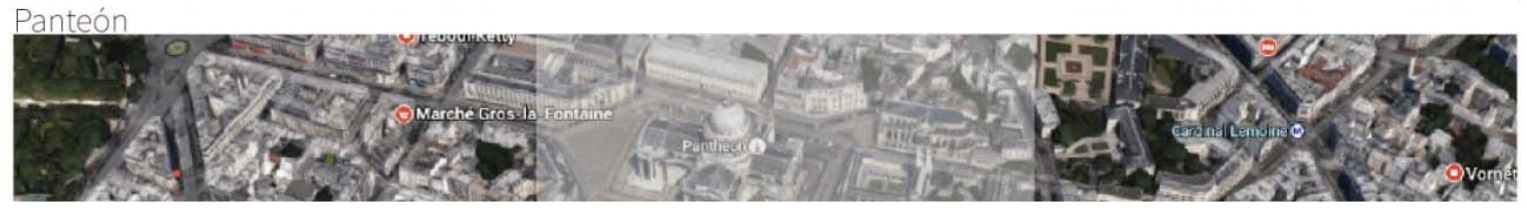

Figura 44: Panteón

Fuente: Google Earth 


\section{CONCEPTUALIZACIÓN DE LA PROPUESTA}

Proceso de conceptualización<smiles>CC(C)C1CC2CCCC1C2</smiles><smiles>Brc1ccccc1</smiles><smiles>Cc1ccccc1N1C2CC1C1C=CC2C1</smiles>

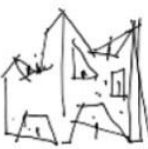
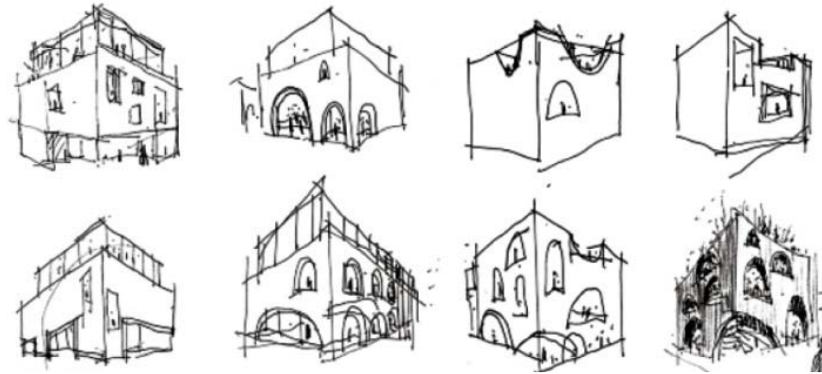

Figura 45: Bocetos Marketlab de Paris Fuente : Archdaily

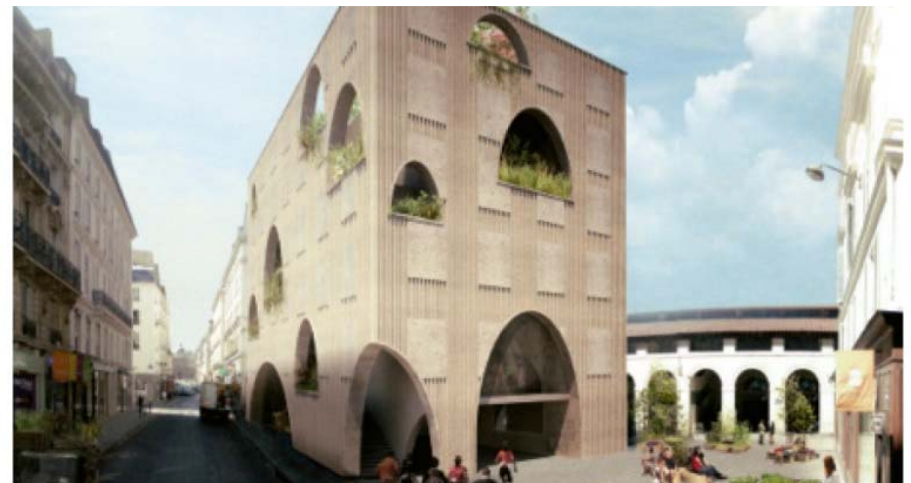

Figura 46: Edificio Marketlab de Paris Fuente: Archdaily

\section{RELACIONES ESPACIALES URBANO -}

\section{ARQUITECTONÓNICO}

Se plantea un camino público continuo, desde la planta baja hasta la superior, siempre en relacion con el exterior.

El edificio por sus aberturas en la planta baja y ventanas a lo largo del edificio ha hecho que la experiencia del recorrido no se aisle del contexto territorial en ningun momento.

El mercado, genera un espacio cubierto que se convierte en un paseo arquitectonico en continuacion al espacio público de los alrededores.

Desde el interior como del exterior se aprecian las actividades que se realizan y todos pueden ser testigos de ello.

METODOLÓGICA

\section{PROCESO DE DISEÑO}

La propuesta detrás de este Marketlab es la de un lugar donde la creación gastronómica no convencional se lleve a cabo, donde el acto de cocinar puede ser visto como un estado mental y una forma artística de expresión, con el objetivo de dar a aconocer el arte gastronómico que se está explorando y desarrollando

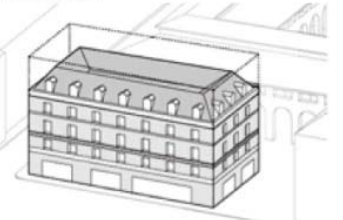

Edificio Antiguo

Se elimina la parte superior del edificio para constriir el marketlab.

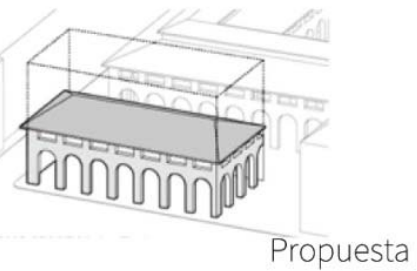

Se adapta la planta baja con una propuesta mas permeable.

Se reinterpretan los arquetipos de la ciudad: la grilla de Haussmann, la tipología del mercado y la idea del jardín comestible en la parte superior.

1- Espacio abierto en la parte baja, como continuacion a la plaza que bordea el edificio.

2- Amplio recorrido por medio de rampas que permiten conectar el exterior con el interior y el interior con el exterior.

3. Parte superior con gran visual hacia la ciudad, en la cual se encuentra un jardín comestible el cual enfatiza la identidad gastronomica del proceso productivo que esta conlleva.

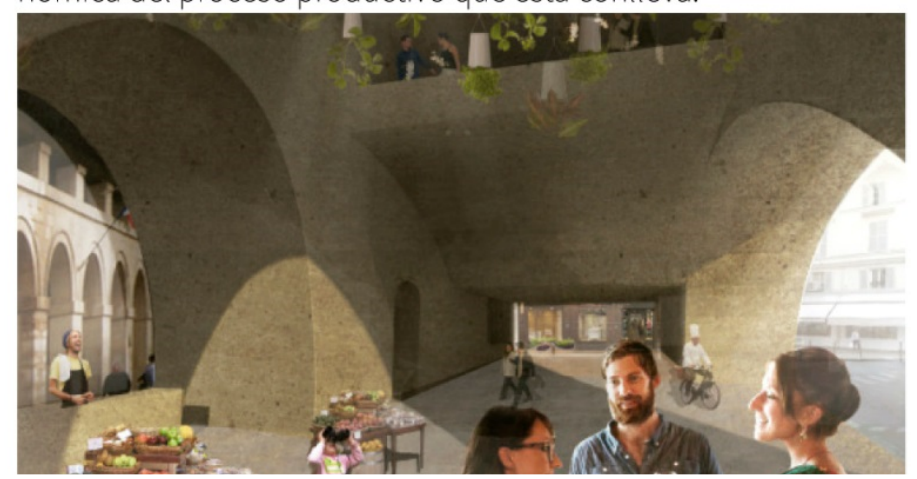

Figura 47: Edificio Marketlab de Paris

Fuente: Archdaily 


\section{ENTORNO}

\section{SISTEMA VIAL}

El sistema vial en su conjunto está bastante bien aticulado.

El trasporte público es eficiente y tiene varias estaciones cerca que permiten su optima accesibilidad, la mas cercana es la Saint Germain des Près y Mobillon.

Por otro lado la escala de la ciudad es bastante amigable para el patón, con espacios diseñados para el ocio y para disfrutar del barrio con valores historicos, culturales y artisticos que enfatizan la identidad parisina.
AREAS LIBRES

El proyecto del Marketlab esta rodeado de una gran plaza comercial de interacción comercial, cultural y social.

\section{CIRCULACIONES VEHICULARES Y PEATO-} NALES.

Las ciculaciónes del sitio estan bien diseñadas con espacios para el peatón diferenciadas de los vehiculos logrando así su optimo recorrido y expersimiento.

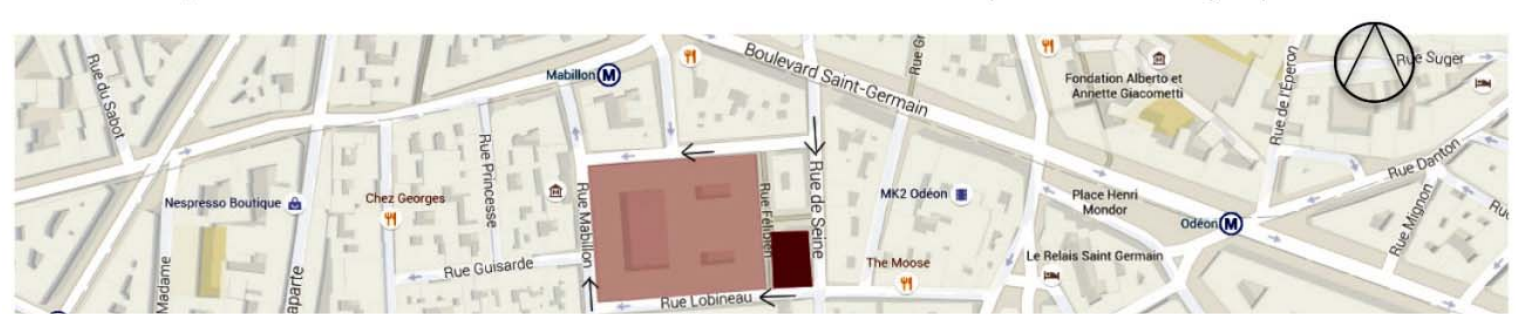

Figura 48: Emplazamiento Marketlab de Paris

Fuente: Elaboración propia

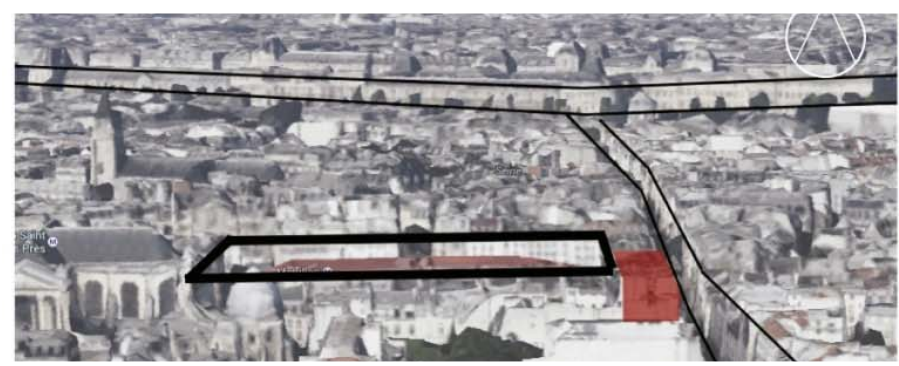

Figura 49: Perfiles de la ciudad de Paris Fuente: Elaboración propia
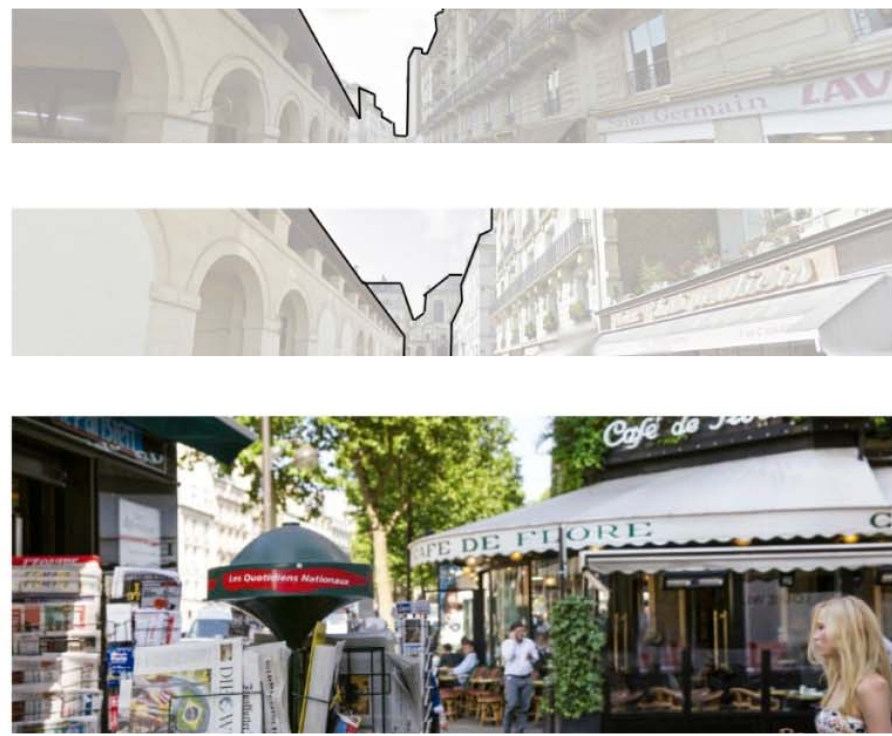

Figura 50: Contexto social - Marketlab de Paris Fuente: Archdaily
PERFIL URBANO

El perfil de la zona es bastante parejo, en las grandes avenidad las alturas son generalmente constantes e incluso el diseño de las fachadas es similar.

\section{ZONIFICACIÓN}

El proyecto se encuentra en una zona comercial.

\section{EDIFICIOS DEL ENTORNO}

Los edificios del entorno, presentan comercio relacionado al ambito culinario en las plantas bajas, lo cual complementa la experiencia gastronómica que el proyecto plantea.

Las edificaciones presentan entre tres y 5 pisos. Las alturas no son tan drásticas. y resulta amigable el exparisimineto.

\section{CONTEXTO SOCIAL, ECONOMICO Y CUL- TURAL}

El barrio SaintGermain-des-Prés es uno de los lugares más destacados de la vida intelectual y cultural Parisina, debido a los grandes atractivos turisticos que lo conforman 


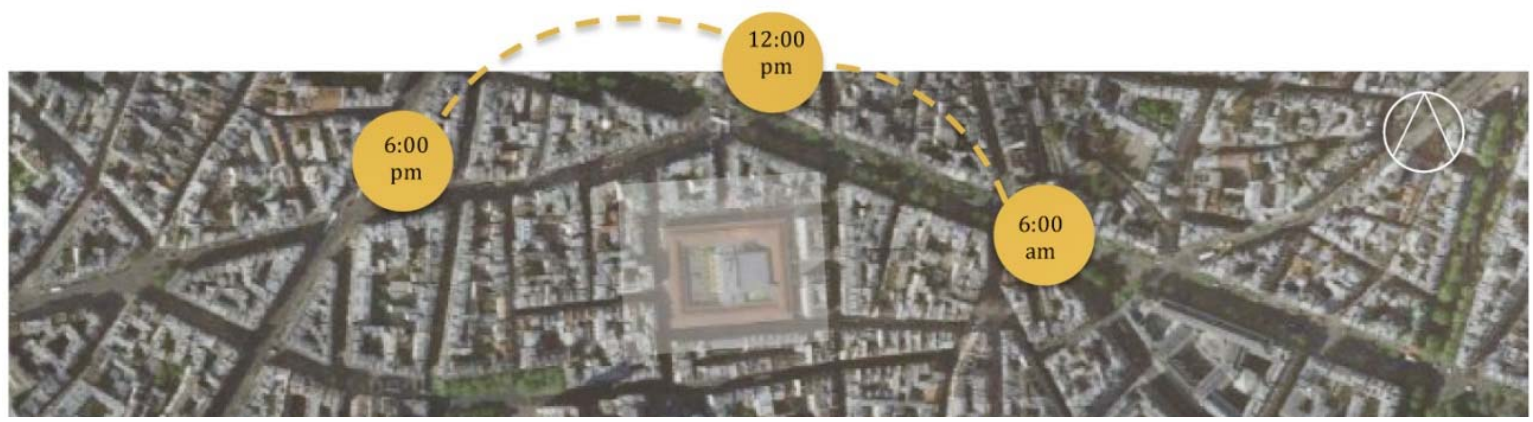

Figura 51: Asoleamienti - Marketlab de Paris

Fuente: Elaboración propia

ANALISIS CLIMATOLOGICO

- Las temperaturas en verano pueden superar los $30^{\circ} \mathrm{C}$ ocasionalmente y son frecuentes las tormentas.

- En la primavera y el primer mes del otoño las temperaturas son suaves pero con días de lluvia.

- La segunda parte del otoño y todo el invierno es frío, con lluvias y nieve.

CLIMA

El clima de París presenta precipitaciones algo abundantes aunque no excesivas, con una media aproximada de $636 \mathrm{~mm}$ y está repartida a lo largo de todo el año de forma regular.

PAISAJE

El paisaje que atraviesa el visistante en su recorrido esta en contante relación con su entorno. Un entorno comercial en relación a la gastonomía. El recorrido inicia en la parte baja en donde se encunetra el mercado relacionado al espacio publico, a traves de el se asciende por medio de rampas que en todo momento enfocan las actividades que realizan alli. Los paisajes del edificio enfatizar el llugar en el cual se encuentra y la influencia que tiene en él.

Al finalizar el recorrido en la parte superior, el espacio se abre a la ciudad por medio de un techo descubierto con un jardin comestible, haciendo referencia al origen de este proceso gastronomico y siendo reconocido por toda la sociedad la ciudad.

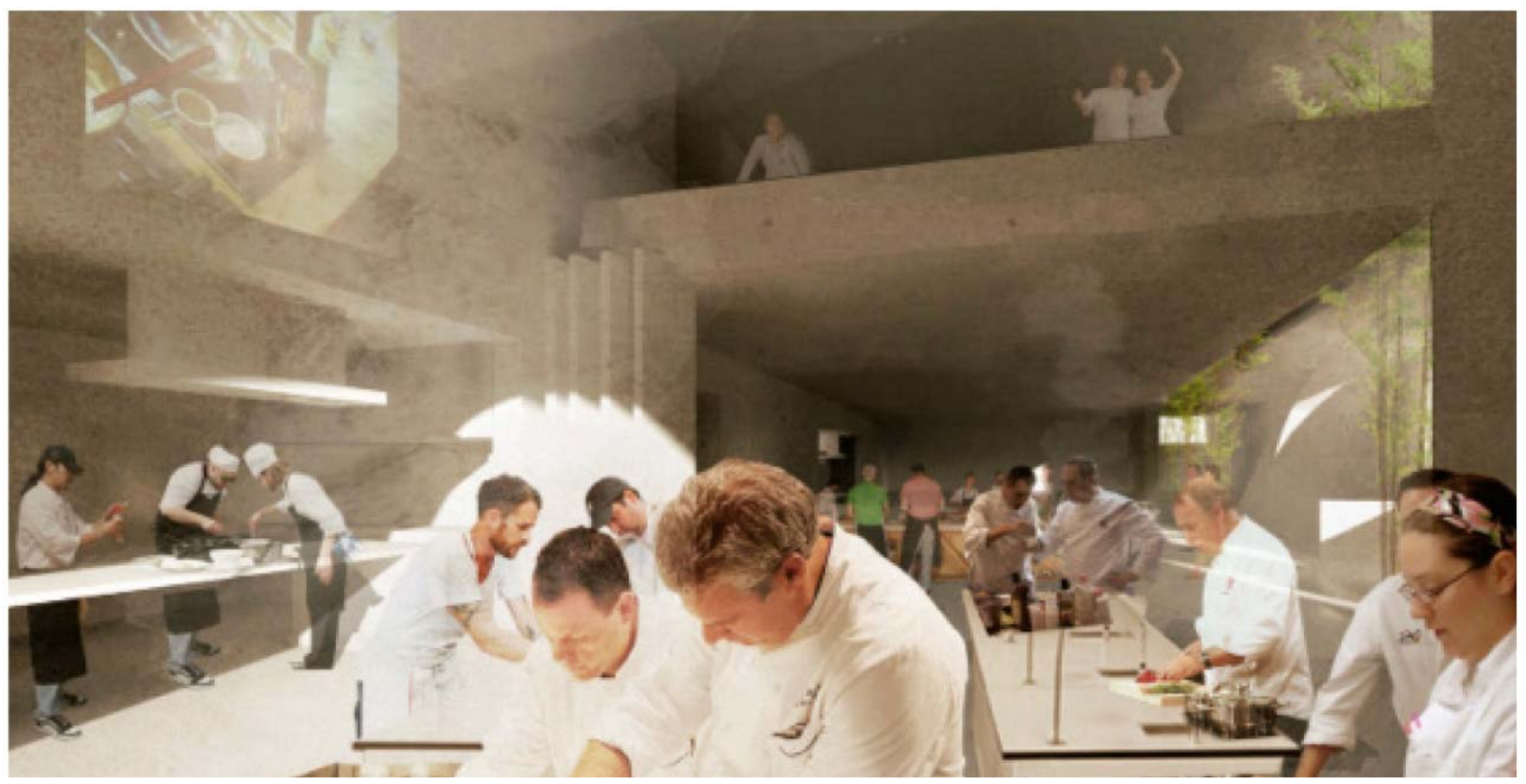

Figura 52: Cocina- Marketlab de Paris

Fuente: Archdaily 


\section{ASPECTOS FUNCIONALES}

\section{PAQUETES FUNIONALES}

El edificio presenta paquetes funcionales que estan relacionados con la gastronomía.

La zona administrativa se encunetra en la primera planta junto con el mercado, la ubicacion de esta es por medio de una pequeña recepción que brinda informacion a los visistantes acerca del edificio.

La zona de sevicios esta ubicada cerca de las circulaciones y dentro de los espacios de talleres de los alumnos.

En la planta baja, por tener la función de mercado, los sevicios seben satisfacer las necidades de dica actividad teniendo servicios en la planta baka tambien con baños tanto para hombres como para mujeres.

En medio del edificio se plantea un auditorio con un aforo moderado de los alumnos que acudiran ahi. Con una proximado de 200 personas.

Finalmente luego de finalizar el recorrido y de haber atravezado todos los espacios del Marketlab, el espacio se abre hacia la ciudad con un espacio que tiene la funcion de ser un huerto en el cual los alumnos pueden cultivar sus insumos de trabajo.
ORGANIGRAMA E INTERLACIONES

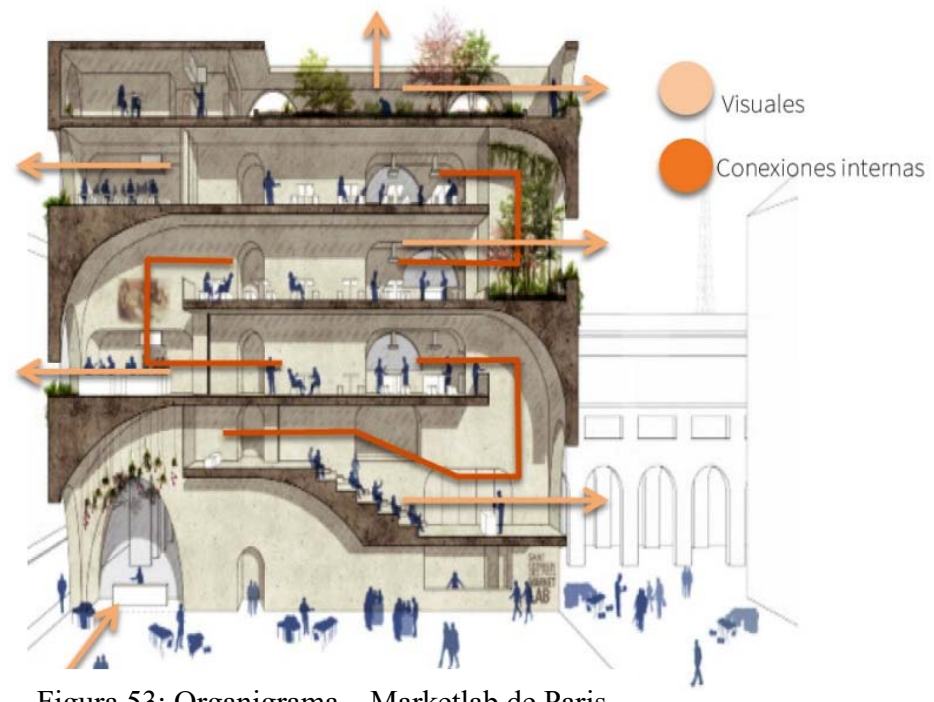

Figura 53: Organigrama - Marketlab de Paris

CERCANIAS Y LEJANIAS FUNCIONALES

El espacio interior esta diseñado para generar interacción entre los estudiantes, por medio del aprendizaje y la degustación. Sin perder la identidad que el lugar caracteriza

Los espacios son flexibles y permiten relacionarse unos con otros, la arquitectura planteada con dobles alturas y circulaciones claras influye en su entendimineto y optimo recorrido.

Se entiende como un proyecto integrado en contante relación entre los usuarios y el espacio.

\section{CIRCULACIÓNES DIFERENCIADAS}

Las circulaciones son bastante claras. En primer lugar, el recorrido vertical llega a todos los puntos del edificio de una manera directa, desde la planta baja hasta la superior donde se puede ver la ciudad.

En segundo lugar, el recorrido horizontal inicia en la planta baja y va adcendiendo de manera secuencial respecto a los usos, siempre en constante relacion con el exterior y con llas mismas actividadades que realizan

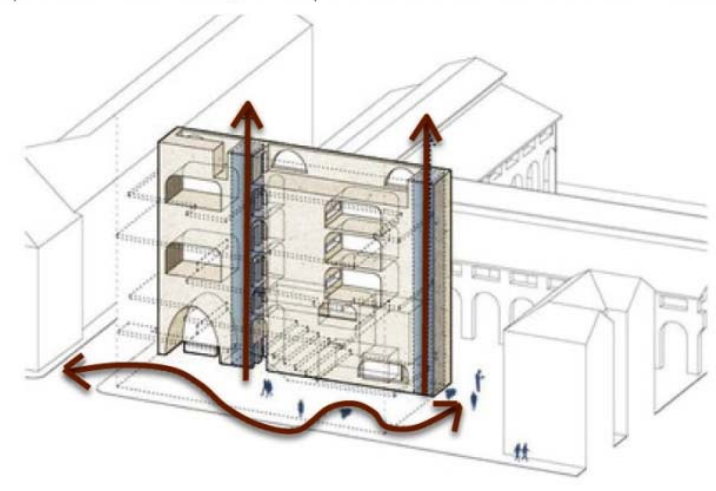

Ciculación Vertical

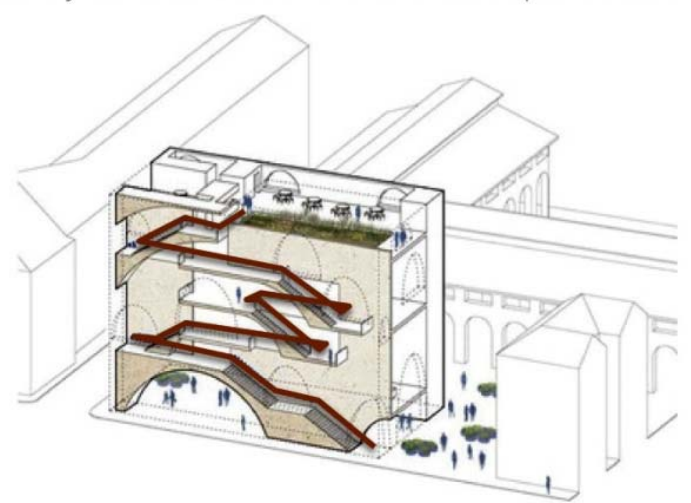

Ciculación Horizontal

Figura 54: Flujos- Marketlab de Paris

Fuente: Archdaily 


\section{PROGRAMACIÓN}

El programa busca generar una red de espacios de creación y educación gastronómica.

- zona de servicios: se encunetran distribuidas a lo largo del edificio se encuentran cerca de las escaleras y al comienzo del nuev o nivel.

- zona de talleres: se situa a lo largo de las distintas plataformas de todos los espacios. Estan relacionados por medio de una arquitectura de doble altura, comprendiendo la espacialidad como una unidad con divisiones.

- zona del comercio: ubicada en la planta baja en la cual se encunetra el mercado gastronomico.

- circulaciones, las circulaciones verticales estan ubicadas en la zona centro del edificio mientras que las horizontales atraviezan todos niveles.

\section{NUMERO DE USARIOS APROXIMADO}

Debido a su ubicación en una zona altamente turística se estima que los usarios dependiendo de las épocas de turismo varian. Un promedio es de 1500 personas. Los estudiantes por día varian entre 300 y 500 y los profesores entre 60 y 100.

Además el Marketlab preseneta un auditorio que abracara un aforo máximo de 200 personas.

Figura 55: Clientes - Marketlab de Paris

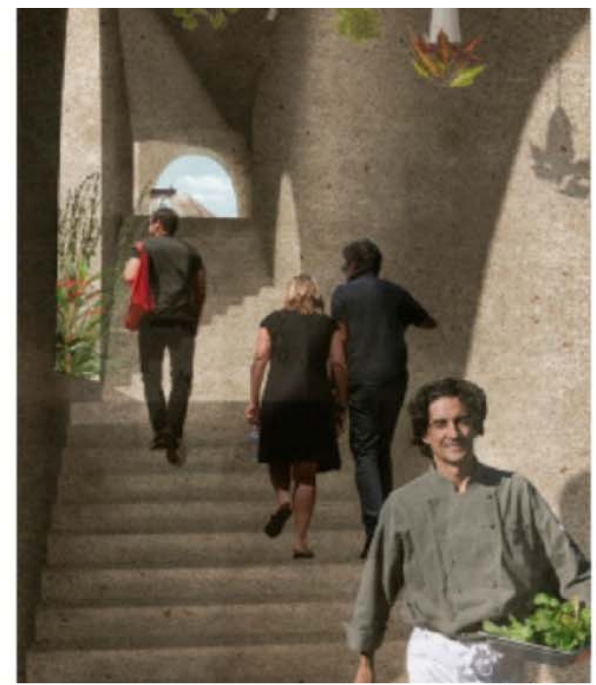

Fuente: Archdaily

\section{LISTADO DE AMBIENTES}

Figura 56: Ambientes - Marketlab de Paris Fuente: Archdaily

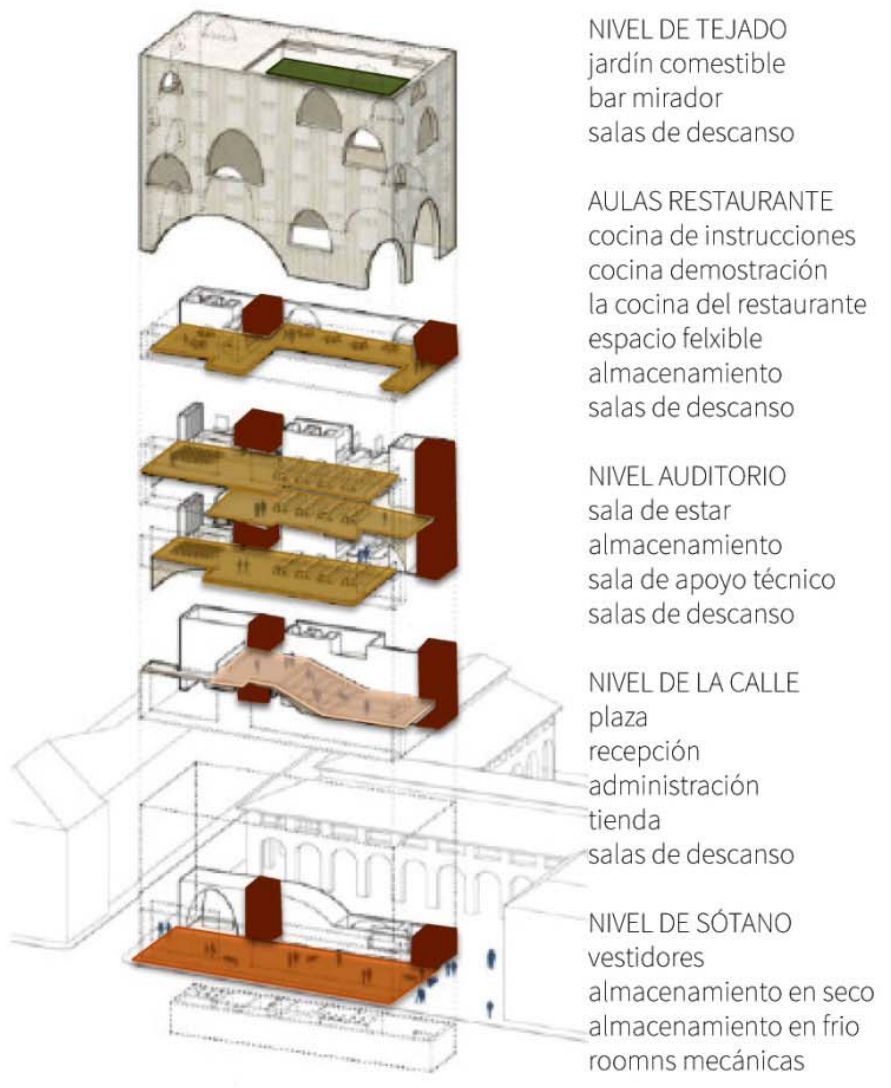

Analisis de zonas

1. zona pública - mercado

En la planta baja se plantea un espacio público en el cual se plantea el mercado gastronomico.Es un espacio trasitorio del exterior al interior y viceversa.

\section{2. zona de trabajo - talleres}

Luego de ascender por el espacio público se llega alrea de trabajo y de talleres los cuales se conectan por dobles alturas siempre conectads con el resto de espacios de trabajo y con el contexto en el que se enucnetra ubicado.

\section{3. zona huerto - identidad}

Finalmente es el espacio superior es el lugar de reconocimiento del entorno y en el cual el estduiante hace referencia al origen del proceso productivo gastronomico que se desarrollan en el edificio. Dándole un valor de identidad notable. 


\section{ASPECTOS TECNOLOGICOS}

\section{SISTEMAS CONSTRUCTUVOS}

El sistema constructivo se planteo con un concepto homogéneo con su entorno con cinco niveles con funciones difereniadas pero en constante relacion.

\section{MODULACIÓN ESTRUCTURAL}

Se prpone una fusión entre la grilla de Haussmann, la tipología del mercado y la idea del jardín comestible en la parte superior.

\section{SISTEMA DE CERRAMIENTOS}

El sistema de cerramiento si bien desde afuera se entiende como un edificio más del entorno, por su fachadaada similar a las colindantes. En el interior se desarollan una serie de espacios que no se aislan y se mantienen relacionadas de acuerdo a sus usos.

\section{MATERIALES Y ACABADOS}

"La cocina, al igual que la arquitectura, trabaja con un infinito numero de recursos creativos que hacen posible crear e innovar a partir de materiales constructivos básicos. Pero incluso usando el mas fino mármol o el mejor caviar, el éxito no se garantiza. La arquitectura, como la cocina, evoluciona y perdura en la forma de memorias, sabores y temperaturas" - Ferran Adria

\section{APLICACIÓN TECNOLOGICA}

Figura 57: Tecnología del biohuerto - Marketlab de Paris

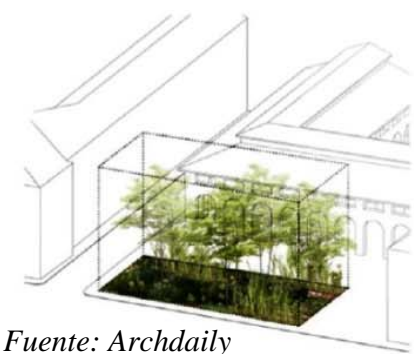

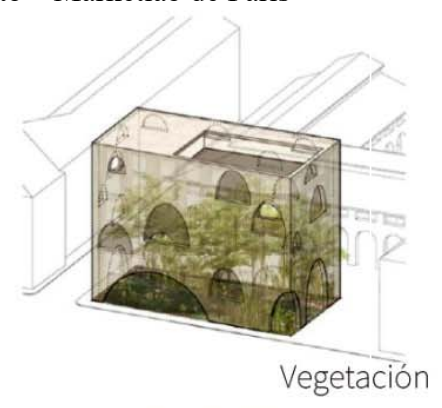

En la parte superior se encunetra el jardín comestible o huerto, el cual se abre a la ciudad, ademas la vegetacion esta propuesta desde las plantas bajas ascendiendo con el recorrido del visitante.

El ecosistema que se produce por la vegetacion genera un ambiente formidable y contribuye al medio ambiente con un sistema ecologico y sostenible.

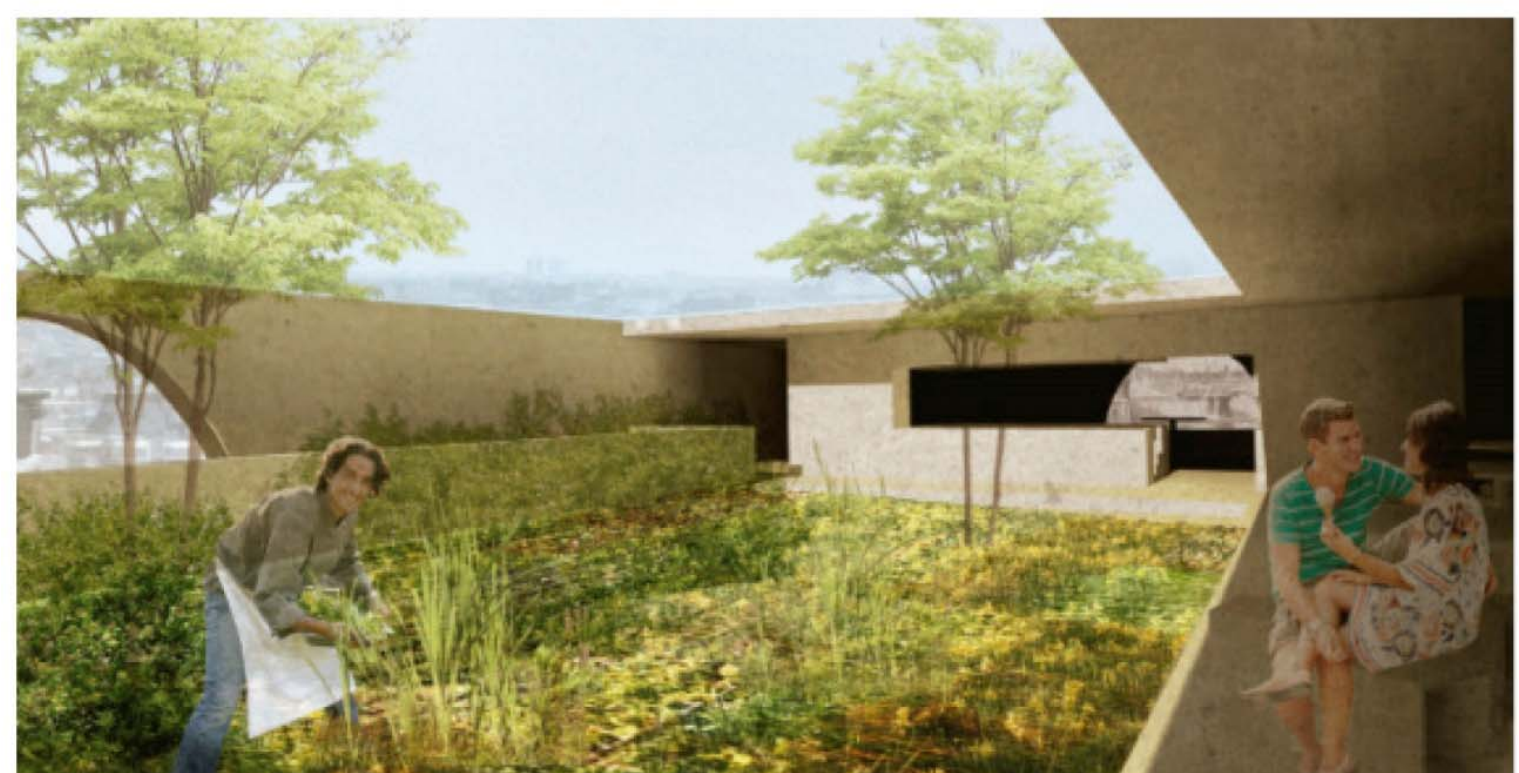

Figura 58: Biohuerto - Marketlab de Paris Fuente: Archdaily 


\subsection{Markthal de Rotterdam}

\section{INFORMACIÓN GENERAL}

AUTOR: MVRDV

Ubicación: Rotterdam, The Netherlands

Año Proyecto: 2014

AREA TERRENO:

\section{AREA CONSTRUIDA}

En octubre de 2004 el equipo de Provast desarrolladores y estudio de arquitectura MVRDV ganó un concurso organizado por la ciudad de Rotterdam para el diseño y construcción de una sala de mercado en Binnenrotte. El municipio quería ampliar el mercado al aire libre existente con una adición cubierta.

El proyecto ademas de presentar un mercado, lo funciona con vivienda, las cuales se encunetran encerrando el cerado en la parte superior, añadiendole particulares unicas al proyecto a analizar.

\section{UBICACIÓN}

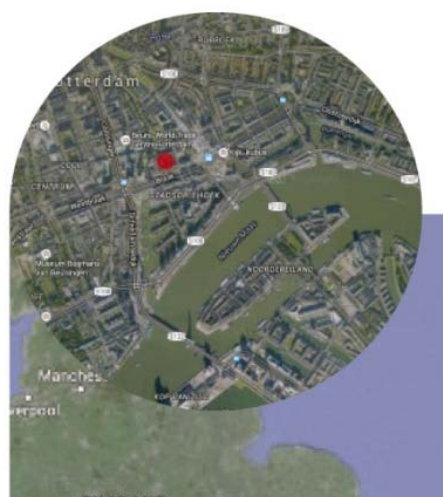

Se encuentra en la esquina de Binnenrotte con Blaak, detrás de la estación de 'Rotterdam Blaak' - Rotterdam - Paises Bajos

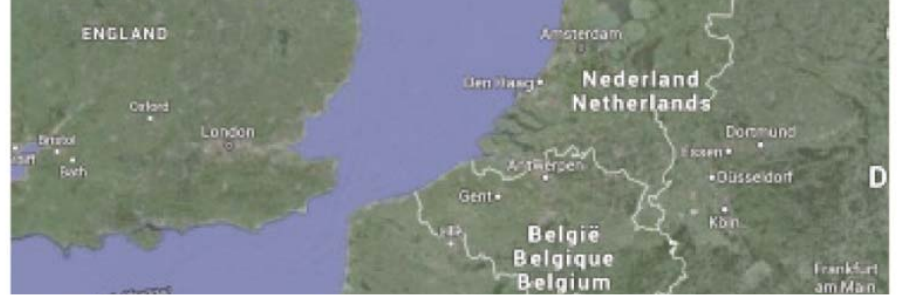

Figura 59: Mapa Localizador - Markethal de Rotterdam Fuente: Google Earth

En ningún otro lugar del mundo se encuentran bajo el mismo techo un gran mercado cubierto, tiendas de comida, restauración, un supermercado, viviendas y un parking subterráneo.. Volviendolo un proyecto revolucionario e innovador. El edificio no sigue ninguna típologia y es un gran ejemplo de propuesta arquitectonica actual.

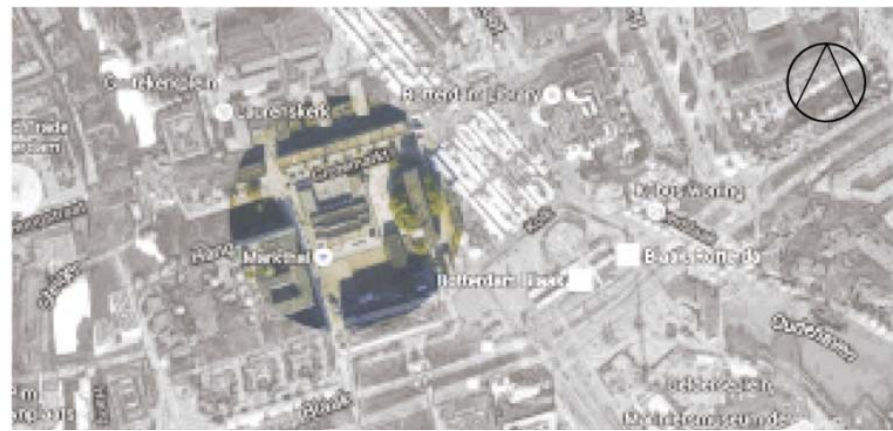

Figura 60: Ubicación - Markethal de Rotterdam Fuente: Google Earth

El mercado tiene buenas conexiones con el transporte público. La estación de tren y metro Blaak está justo al lado. Además hay paradas de varios trenvías y buses cerca.

La plaza que se encunetra previa al recinto sirve para integrar a la sociedad, permitiendo su interacción en él.Se presenta como un espacio a nivel peatonal que por su forma invita a recorrerlo.

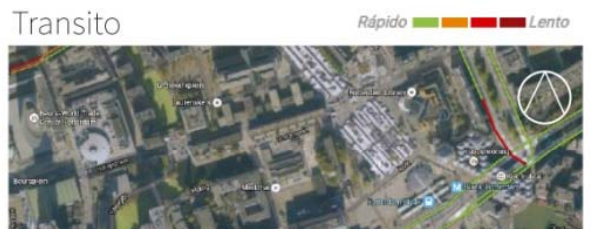

Figura 61: Transito - Markethal de Rotterdam

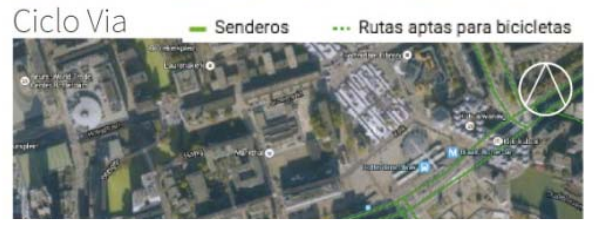

Figura 62: Ciclo vía - Markethal de Rotterdam Espacio Público

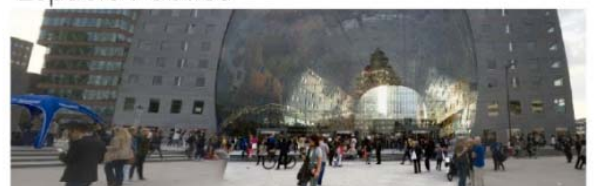

Figura 63: Espacio público - Markethal de Rotterdam Fuente : Google Earth 


\section{ANTECEDENTES HISTORICOS}

El edificio tiene raíces históricas: situado junto a la iglesia bajomedieval Laurenskerk, a orillas del antiguo río Rotte. Este río se cegó a finales del siglo XIX y se desvió para construir una línea de ferrocarril descubierta hacia la orilla sur del Mosa.

Al transformarla en un túnel subterráneo en los años 90 del siglo pasado surgió en este lugar una plaza alargada donde se celebra un mercado al aire libre dos veces por semana, es ahí donde se plantea el proyecto como un mercado techado, con viviendas en la parte superior y comercio en general.

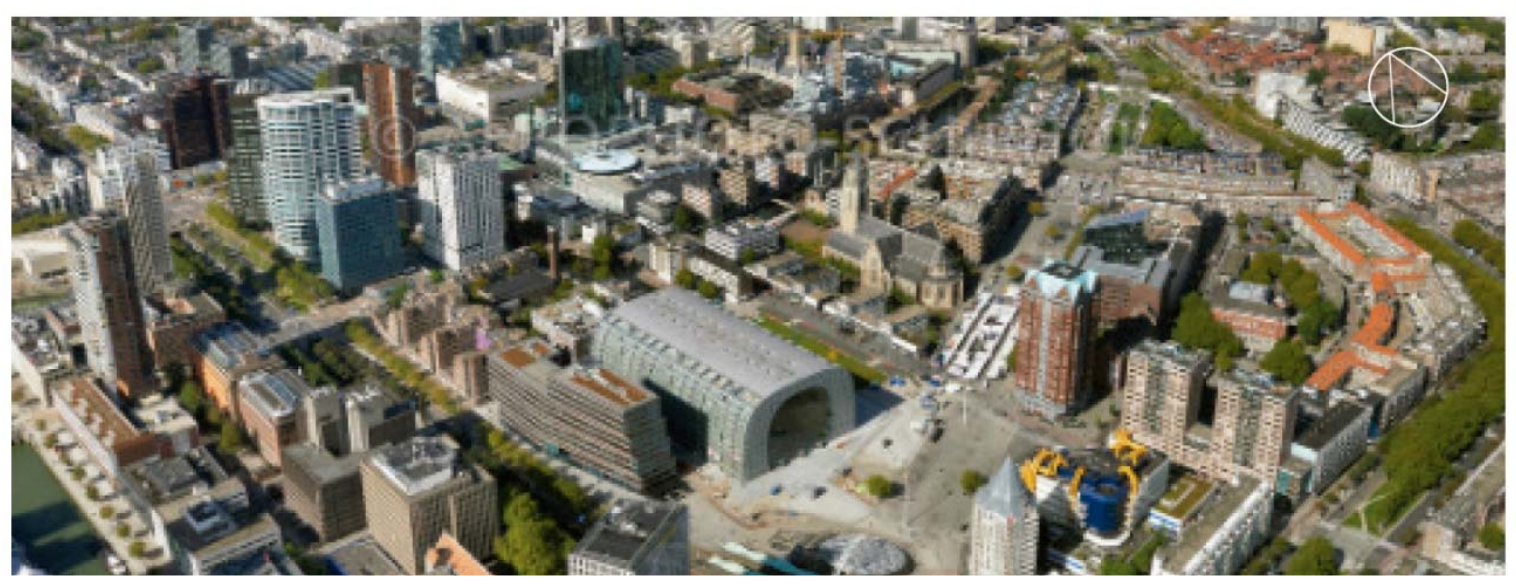

Figura 64: Emplazamiento Markethal de Rotterdam Fuente: Archdaily

El Markethall se encuentra en una zona emblemática para la ciudad, la plaza que la bordea sirve para conglomerar gentee interrelacionarla antes del ingreso al edificio. Además la forma del mercado y su colorido interior hace que no pase desaparesivido. Su gran ubicación influye en qu etodos pasen por ahí y sea un punto de gran atractivo turistico, reconocido como un icono comercial para la ciudad de Rotterdam.

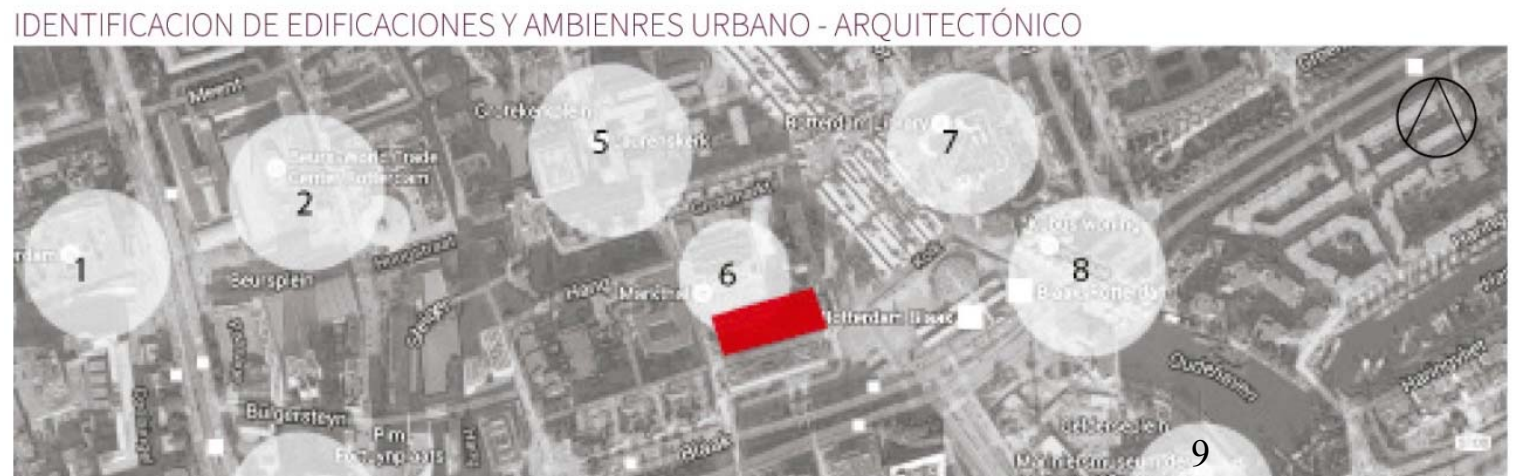

Figura 65: Entorno historico Markethal de Rotterdam Fuente: Elaboración propia

1 - DO BIJENKORF ROTTERDAM

2 - BEURS - WORLD TRADE CENTER

3 - MARITIEM MUSEUM

5 - LAURENS KERK
6- BINNENROTTE CON BLAAKE

7-ROTTERDAM LIBERY

8 - KUBUS WONING

9 - MARINIERS MUSEUM 


\section{CONCEPTUALIZACION DE PROPUESTA}

RELACIONES ESPACIALES URBANO ARQUITECTONICO

El edificio por su forma de tunel a nivel permite su amplio recorrido sin mayor dificultad.

La fachada trasparente que presenta permite la permeabilidad del edificio con el exterior y viceversa. Las formas y colores de la cobertura interior invitan al público a acercarse.

El edificio de encunetra integrado a su entorno no solo por su forma sino por la materialdiad en su fachada que se mimetiza con el contexto de los demas edificios colindantes.

El edificio presneta caracteristicas particulares que lo hacen unico ya que no sigue ninguna tendencia ni tipologia tradicional.

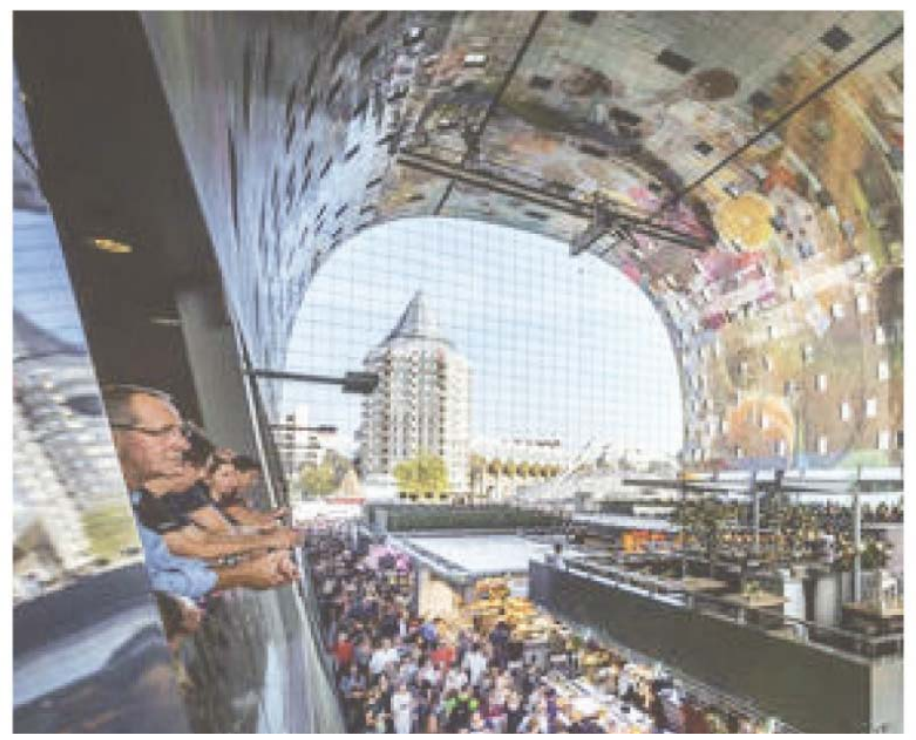

Figura 66: Vista de las viviendas del Markethal de Rotterdam Fuente: Archdaily
PROCESO DE DISEÑO

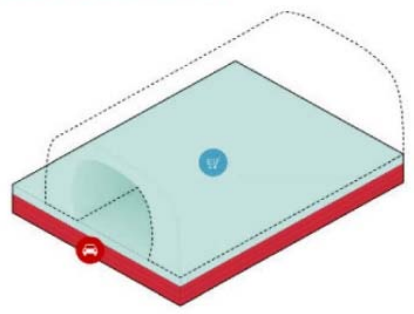

Base

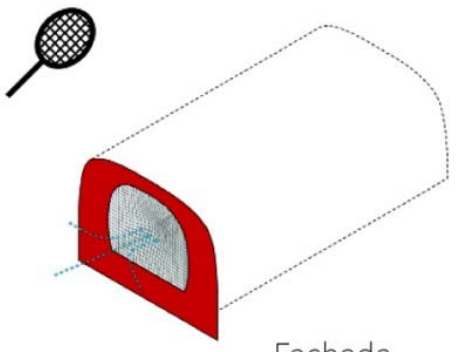

Fachada

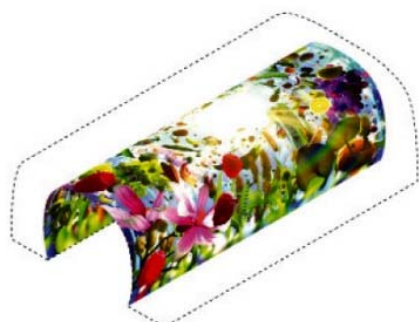

Cubierta interior

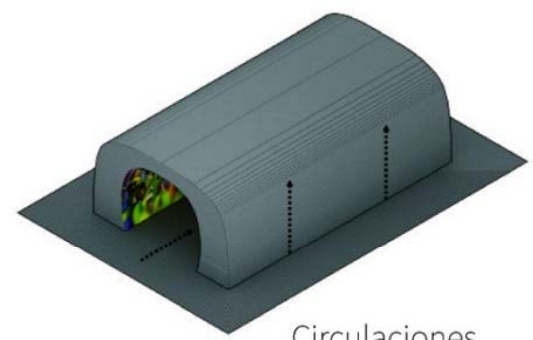

Circulaciones

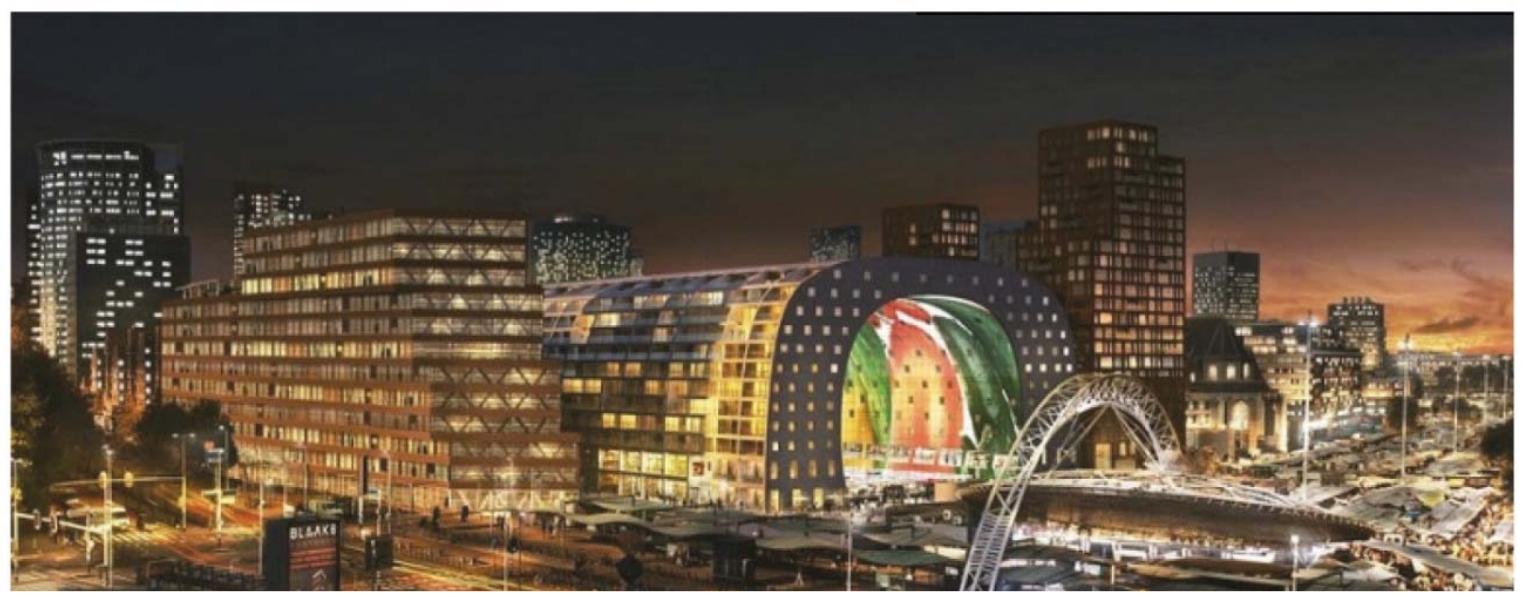

Figura 67: Markethal de Rotterdam de noche Fuente: Archdaily 


\section{ENTORNO}

\section{PERFIL URBANO}

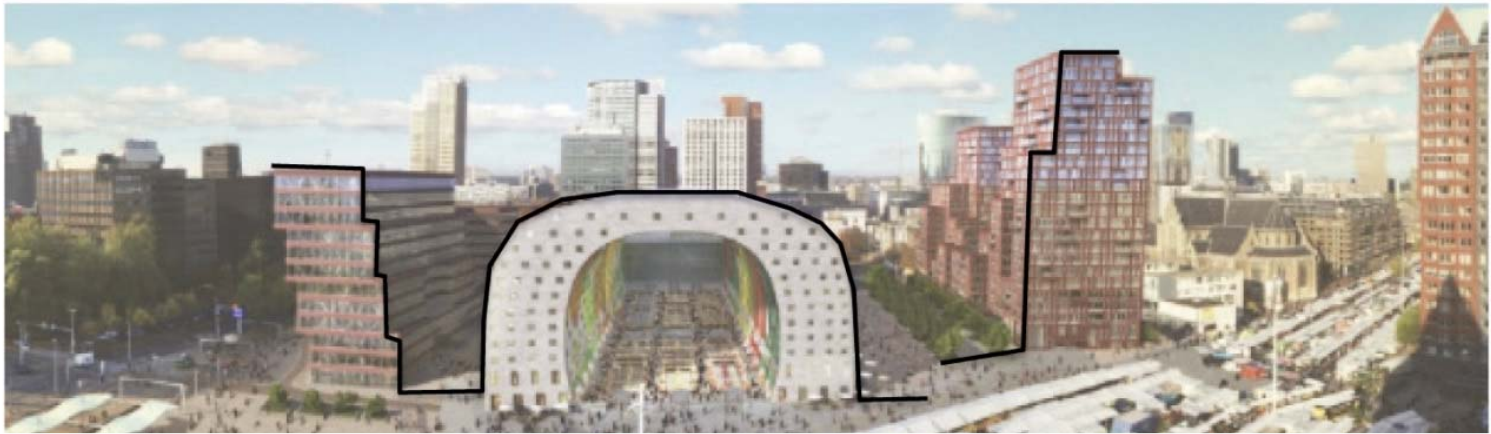

Figura 68: Perfil urbano - Markethal de Rotterdam Fuente: Elaboración propia

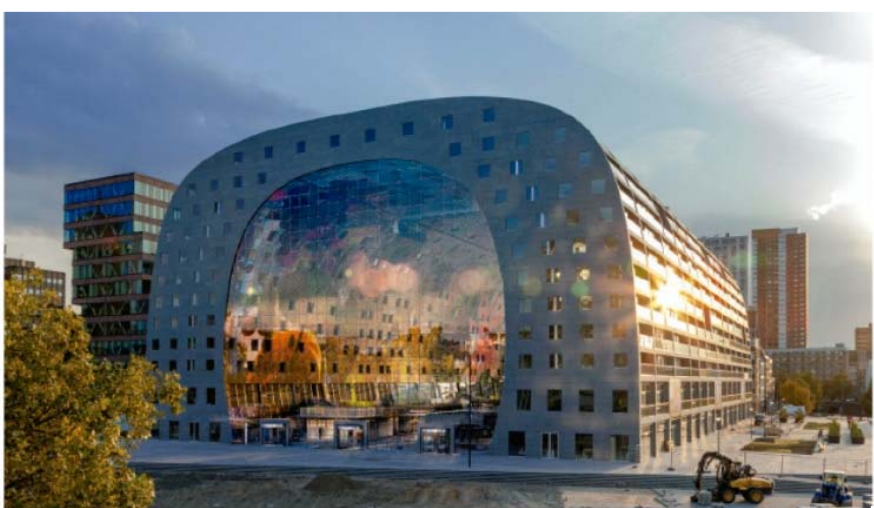

Figura 69: Reflejo Markethal de Rotterdam Fuente: Archdaily

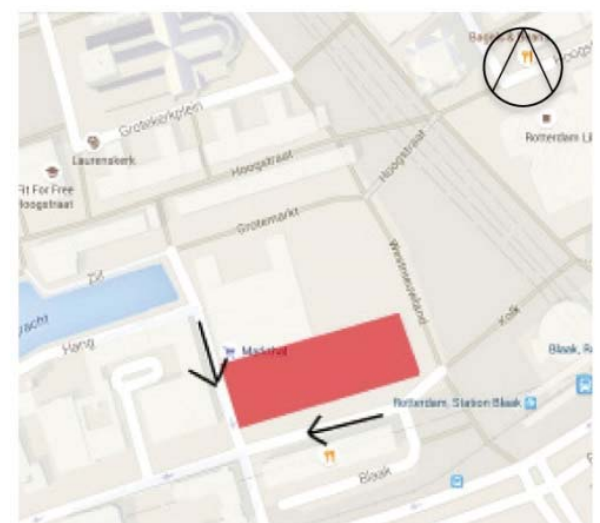

Figura 70: Emplazamiento Markethal de Rotterdam Fuente: Elaboración propia

\section{CONTEXTO SOCIAL, ECONOMICO Y CULTURAL}

A traves de la ejecucion del Markethall la zona se ha repotenciado, ha aumentado notablemente el turismo en la zona y resulta un hito para la ciudad, siendo reconocible por todos los locales y los turistas que lo vistan.

\section{ZONIFIACIÓN}

La zonificacion del edificio es comercial, y el entorno en el que se encuentra también lo es, siendo esta una zona comercial reconocible por todo el sector y la ciudad en general

\section{EDIFICACIONES DEL ENTORNO}

Las edificaciones del entorno son bastante imponentes ya que son de gran altura y de importante comercio distrital. El promedio de pisos por edificios varia entre los 10 y 20.

\section{AREAS LIBRES}

Si bien el lugar no presenta muchas areas libres verdes, hay una gran variedad de espacios publicos destinados al exparsimiento dotados de infrestuctura urbana para su correcto funcionamiento.

\section{CIRCULACIONES VEHICULARES Y PEATONALES}

Las circulaciones del entorno son notables y estan bien jerarquizadas, resulta bastante fácil acceder al edificio tanto vehicular como peatonalmente. La organizacion urbanistica de la ciudad, funciona bastante bien. 


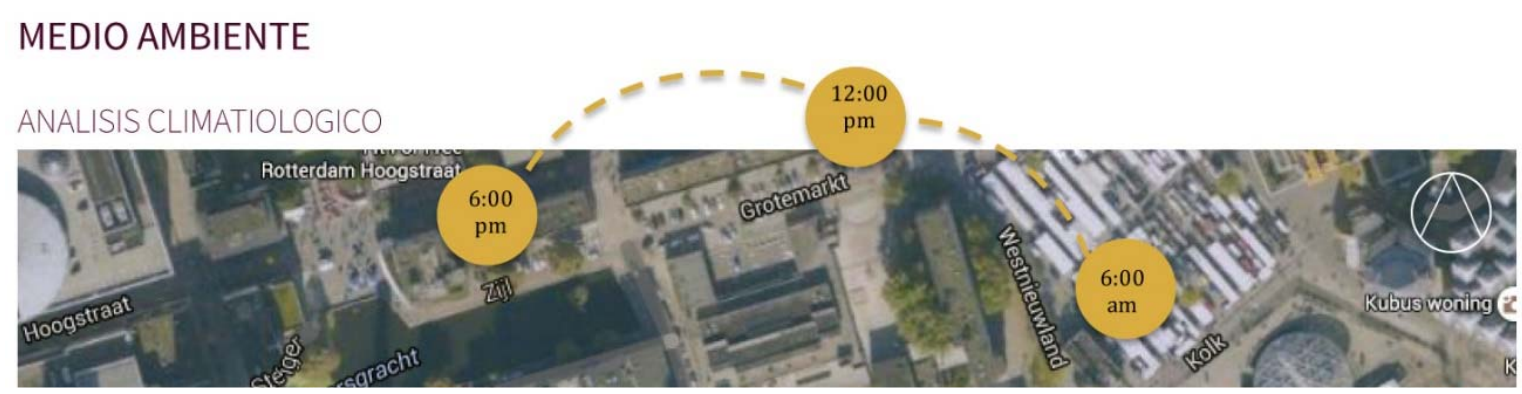

Figura 71: Asoleamiento Markethal de Rotterdam

Fuente: Elaboración propia

CLIMA

El clima es oceánico, con veranos suaves e inviernos fríos. El edificio es un espacio abierto que atrae a un público numeroso, pero cerrado en los laterales para salvar el viento y la lluvia, en donde se encuentran las viviendas.

\section{PAISAJE}

Desde el exterior el paisaje que se ve del mercado es bastante imponente no solo por su volumetría con forma de tunel y una escala que presenta sino por el colorido interior que lo carcateriza el cual es reconocible a largas distancias.

El edificio tambien tiene iluminacion noctura tanto en el interior como en el exterior llamando aun mas la atencion en el conjunto urbano.
Figura 72: Paisaje urbano Markethal de Rotterdam Fuente: Archdaily

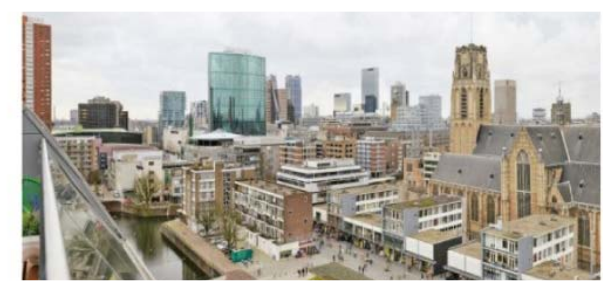

Desde el interior el paisaje, es altamente comercial, todo el conjunto del proyecto esta relaiconado con el comercio en general. Desde las viviendas se puede apreciar este comercio tanto hacia el interior como hacia el exterior.l

Ademas de la importancia del Markethall en la zona, la volumetria y particularidad que presenta en la fusion de usos ha generado que presente un paisaje arquitectonico unico e innovador que le añade un valor a la zona . Se ha planteado una nueva manera el espacio de acuerdo a sus usos y las relaciones entre ellos.

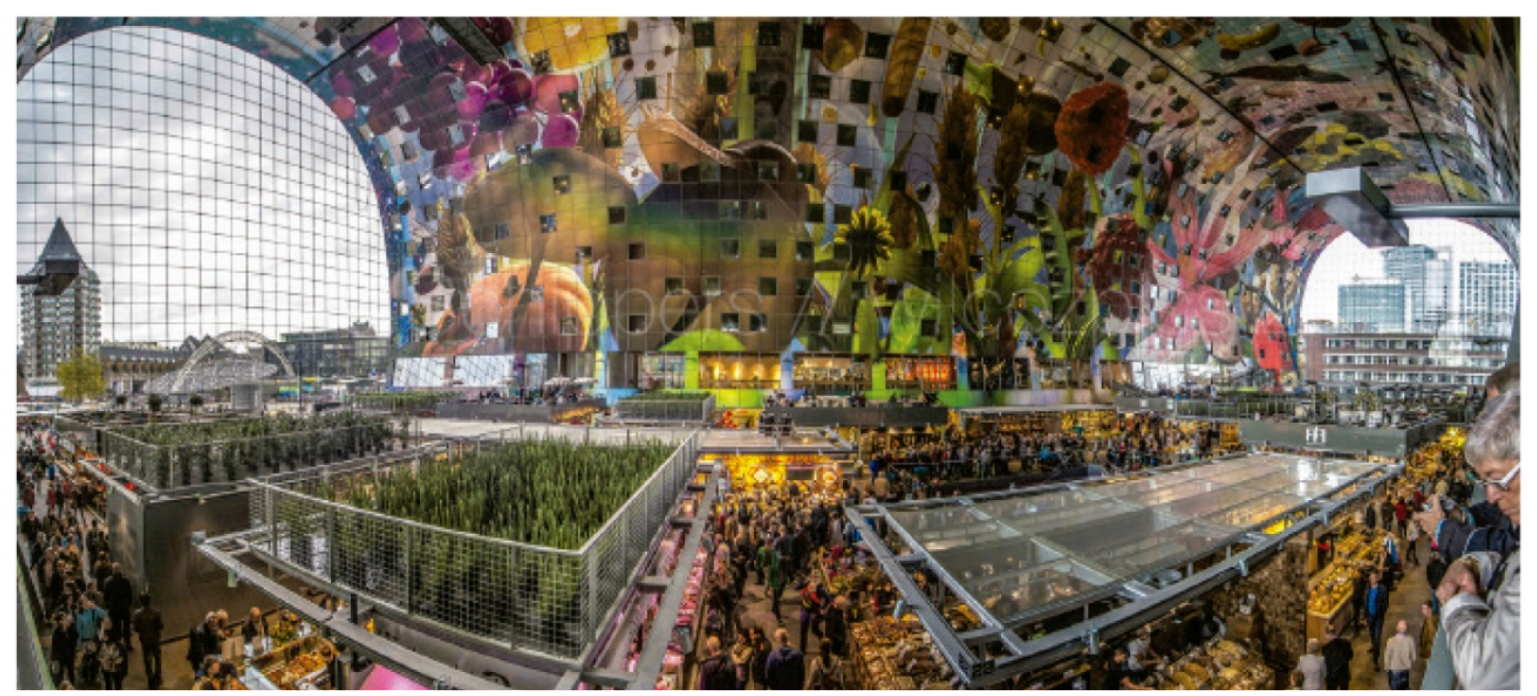

Figura 73: Vista panorámica interna del Markethal de Rotterdam Fuente: Archdaily 


\section{ASPECTOS FUNCIONALES}

PAQUETES FUNCIONES

El mercado integra diferentes funciones y las viviendas forman el tejado de la nave central, si bien son tipologias distintas, estan en constante relación espacial por este gran espacio centra.l que las fusiona.

\section{ORGANIGRAMA}

El edificio de organiza segun los usos que lo conforman, una primera zona de comercio, otra de mercado y finalente en la parte superior la de vivienda.

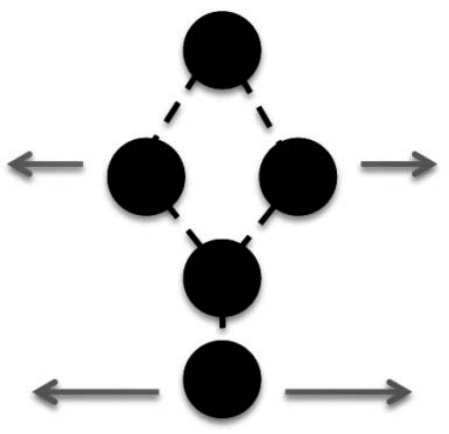

CERCANIAS Y LEJANIAS FUNCIONALES

Los espacios estan en constante relación en todo momento. En el centro el mercado se encunetra el gran nuclleo de escaleras electricas que permiten su amplio recorrido hacia el interior del edificio en donde de encunetra el comecio y el estacionamiento.

\section{CIRCULACIONES DIFERENCIADAS}

Las ciuculaciones estan bien diferencias segun los usos. El ingreso a las viviendas es por la parte exterior, en los laterales, mientras que e ingreso al mercado es por el frente encarmarcando el proyecto como la gran entrada

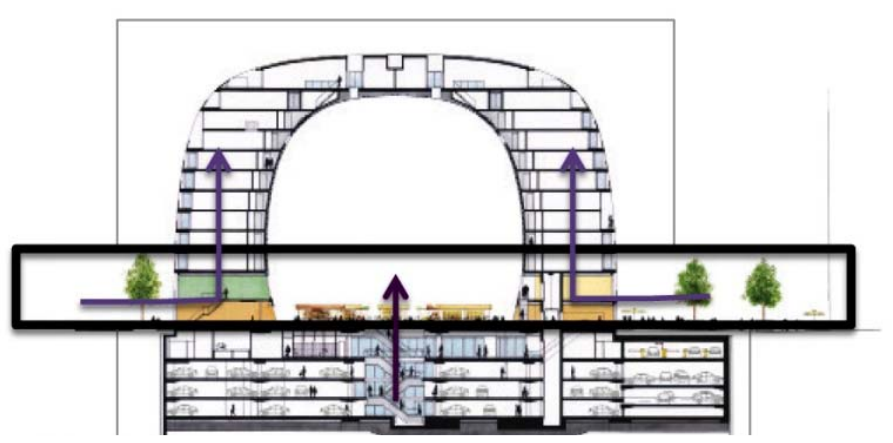

Figura 74: Circulaciónes Markethal de Rotterdam Fuente: Elaboración propia

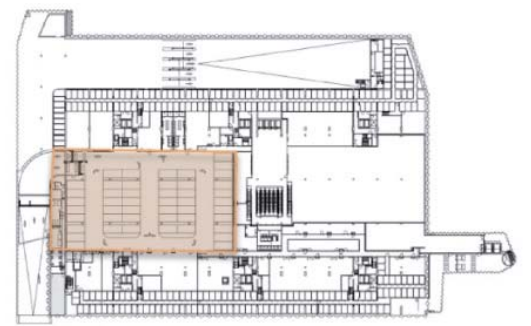

Cuenta con un estacionamiento en e sótano del edificio, el cual se conecta con la zona comercial.

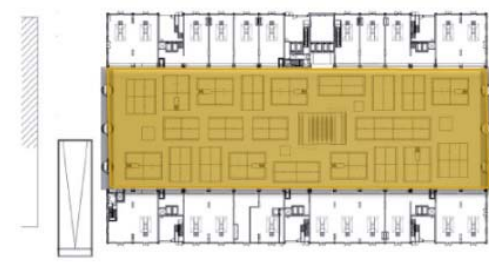

Estacionamientos y comercio

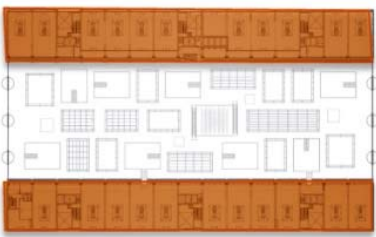

El mercado se encuentra a nivel del la calle, como un recubrimiento particular con dibujos y colores llamativos

\section{Mercado}

Se ingresa a los restaurantes desde el mercado, estos tienen ventanas que permiten su constante interacción

\section{Restaurantes}

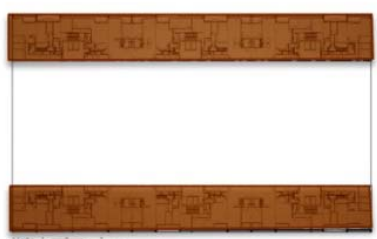

Las viviendas ubicadas en la parte superior de edificio encerrando la parte comercial. Tienen ventanas hacia el interior como hacia el exterior.

Viviendas

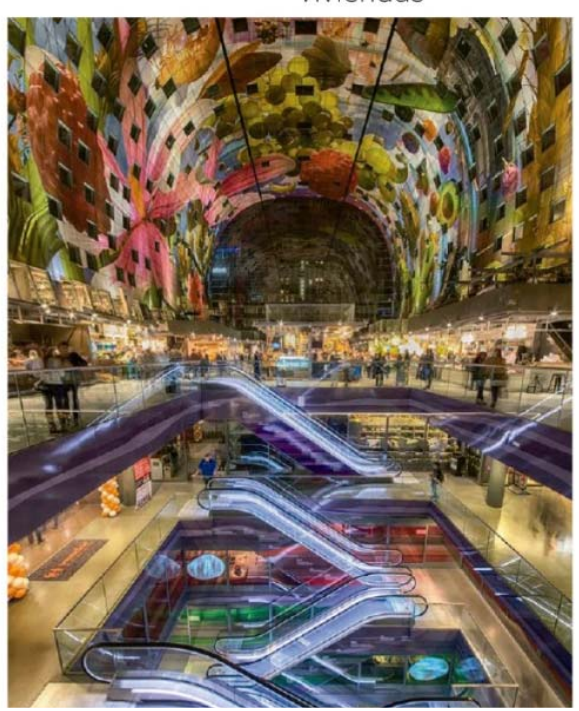

Figura 75: Escaleras Markethal de Rotterdam Fuente: Archdaily 


\section{PROGRAMACIÓN}

El proyecto incluye un mercado techado a nivel, tambien incluye 246 viviendas las cuales forman un arco por encima del área del mercado. El volumen actual del arco emerge 120 metros de largo, 70 metros de ancho y 40 metros de altura.

En los apartamentos los cuartos que requieren luz natural están situadas en el exterior. Cocinas, habitaciones y almacenamiento de comedor están colocados en el lado del mercado, de manera que establecen una conexión con este.

Figura 76: Exterior Markethal de Rotterdam

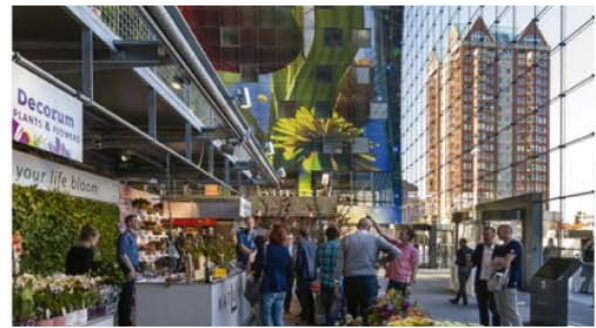

Figura 77: Interior Markethal de Rotterdam

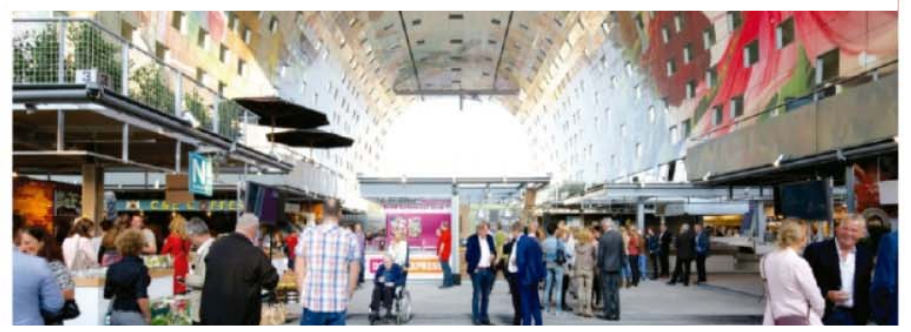

Fuente: Archdaily

\section{LISTADO DE AMBIENTES}

En las plantas baja y primera, presenta un gran mercado, con zona de restaurantes e incluso una escuela de cocina. Los pisos superiores, están formados por apartamentos de distinto tamaño, en venta o en alquiler. Se trata de 228 apartamentos que van de los 82 a los 300 metros cuadrados, con tres, cuatro o cinco dormitorios. La mitad de ellos da al mercado, mientras que la otra mitad disfruta de unas bonitas vistas a Rotterdam, con el río Mosa o el Laurenskerk. En la parte superior del arco, 24 áticos completan la oferta de alojamiento que ofrece el Markthal, con la posibilidad de trabajar, vivir y comprar en el mismo lugar.

NUMERO DE USARIOS APROXIMADO

El numero de usarios de la viviendas aproximado es de 1000 personas, y de la zona comercial varia dependiendo de la época, por logeneral bordan los 2500 visitantes por día, pero en temporadas de verano el flujo aumenta notablemente.

Figura 78: Tipologías Markethal de Rotterdam

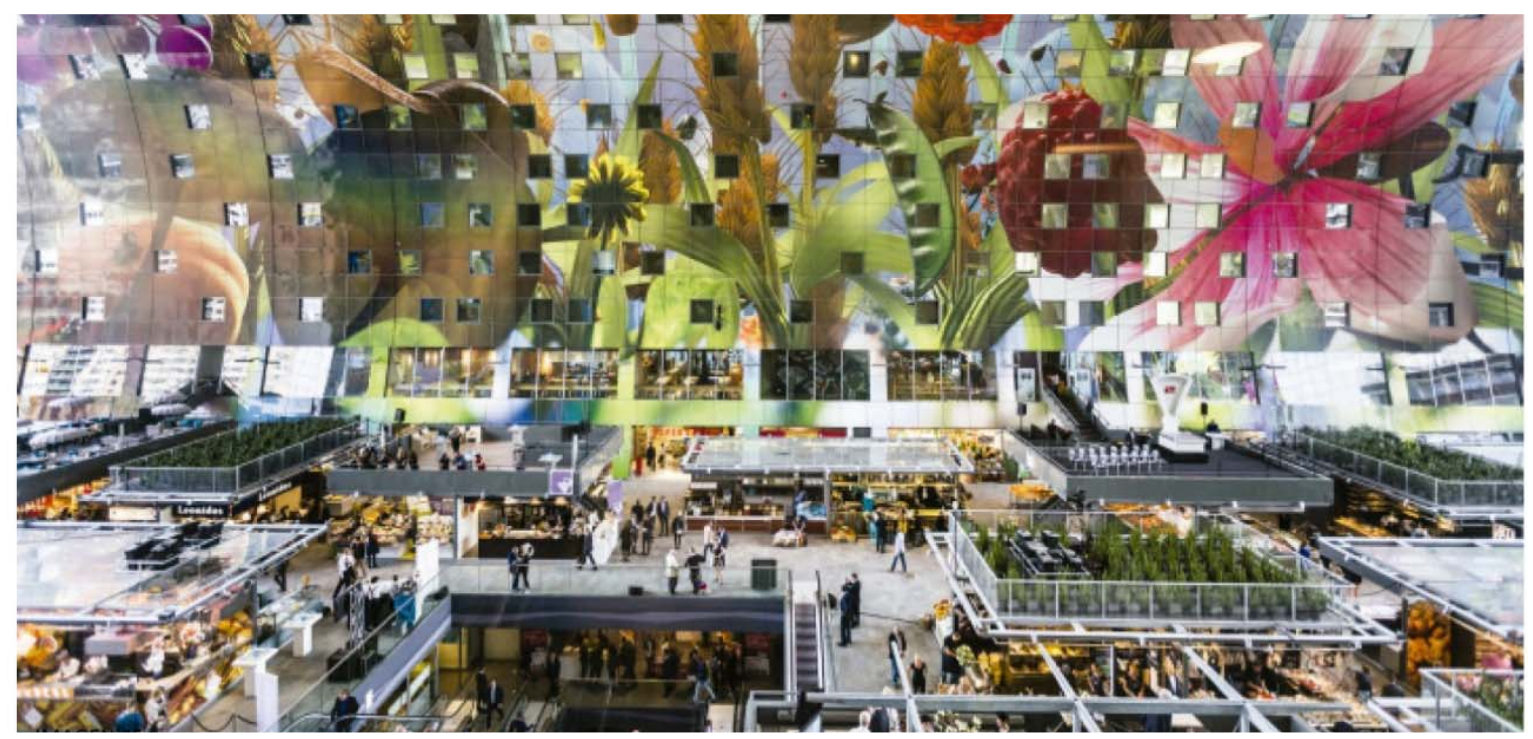

Fuente: Archdaily 


\section{ASPECTOS TECNOLÓGICOS}

\section{SISTEMAS CONSTRUCTIVOS}

Se voltear las dos placas y se plantea en la tensión de esta, el mercado con dos grandes aberturas hacia la ciudad. El volumen actual del arco surgió, a 120 metros de ancho y 40 metros de ancho y de alto.

\section{MATERIALES YACABADOS}

Se utilizo una rejilla de acero, en la fachada se cubrio con vidrio trasnparente, en el interior se utilizo un recubrimiento pintado y en el exterior piedra natural gris.

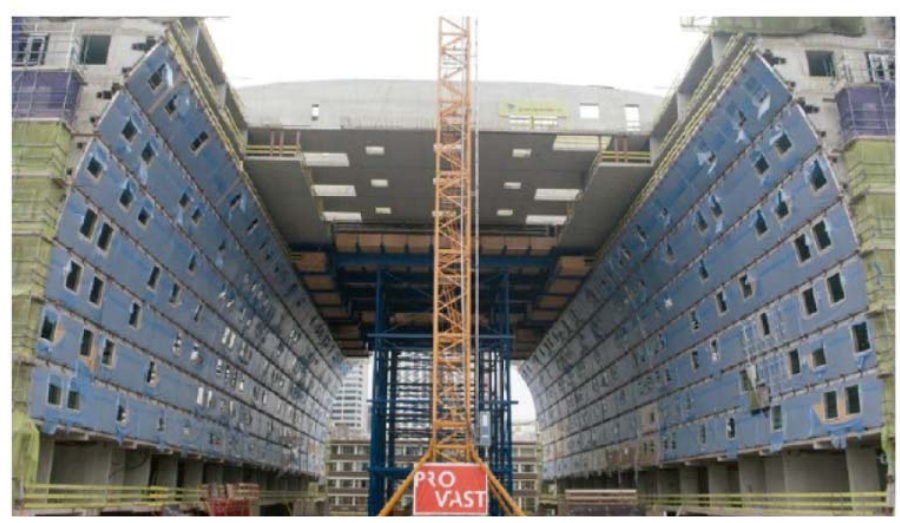

Figura 79: Construcción Markethal de Rotterdam Fuente: Archdaily

\section{SISTEMA DE CERRAMIENTO}

El Markthall tiene un sistema de cerramiento bastante particular desde el exterio con una afachada modulada por bloques y ventanas y por el interrior una pintura de frutas y flores. La fachada principal y de recorrido longitudinal esta cubierta por un gran vidrio que refleja la ciudad y que permite entender el mercado como incertado en él. Se ha tomado en cuenta el aislamento sonoro de las viviendas en relacion al mercado.

\section{MODULACIÓN ESTRUCTURAL}

Toda la estructura del edificio está hecha mediante piezas moduladas que contrastan con la inusual forma del edificio.

Figura 80: Modulacón estructral Markethal de Rotterdam Fuente: Archdaily
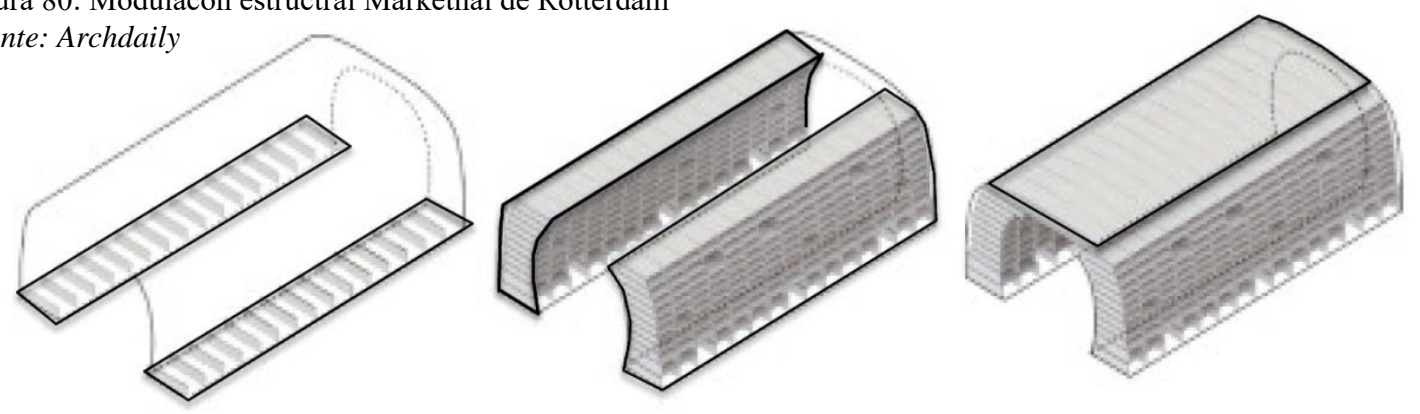

\section{APLICACIONES TECNOLOGICAS}

Para el suministro de energía se opto por una conexión con la calefacción urbana y un sistema de acumulación de calor y frío en el suelo, con la particularidad de que suministra energía a otros edificios.

Sus diferentes funciones permiten el intercambio de calor y frío. Para poder controlar todos los flujos de energía en el edificio se ha equipado con un detallado sistema de control.

En el mercado se ha instalado un panel donde los visitantes pueden ver información actualizada sobre el uso de energía y el ahorro de $\mathrm{CO} 2$ en el edificio.
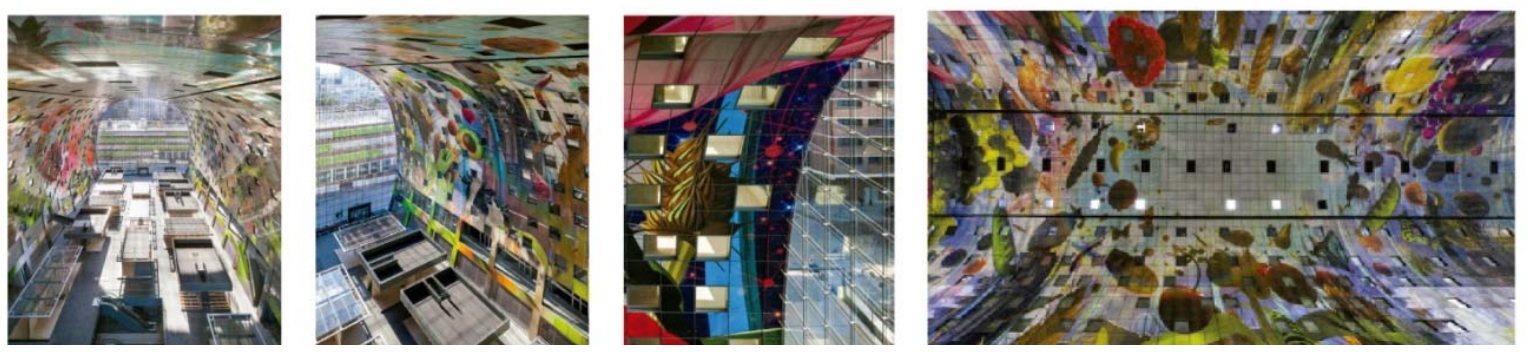

Figura 81: Vistas Markethal de Rotterdam Fuente: Archdaily 


\subsection{Museo de la Acrópolis de Atenas}

\section{INFORMACIÓN GENERAL}

NOMBRE: El Museo de la Acropolis fue construido para albergar los hallazgos arqueolgicos de colina de la Acropolis.

AUTOR: Bernard Tschumi en colaboración con Michalis Photiadis \& Associate Architects en Atenas, Grecia.

AREA COSTRUIDA: $4895.50 \mathrm{~m} 2$

AREA LIBRE: $6126.02 \mathrm{~m} 2$

AREA DEL TERRENO: $7573.32 \mathrm{~m} 2$

COSTO: 130 millones de euros
UBICACIÓN

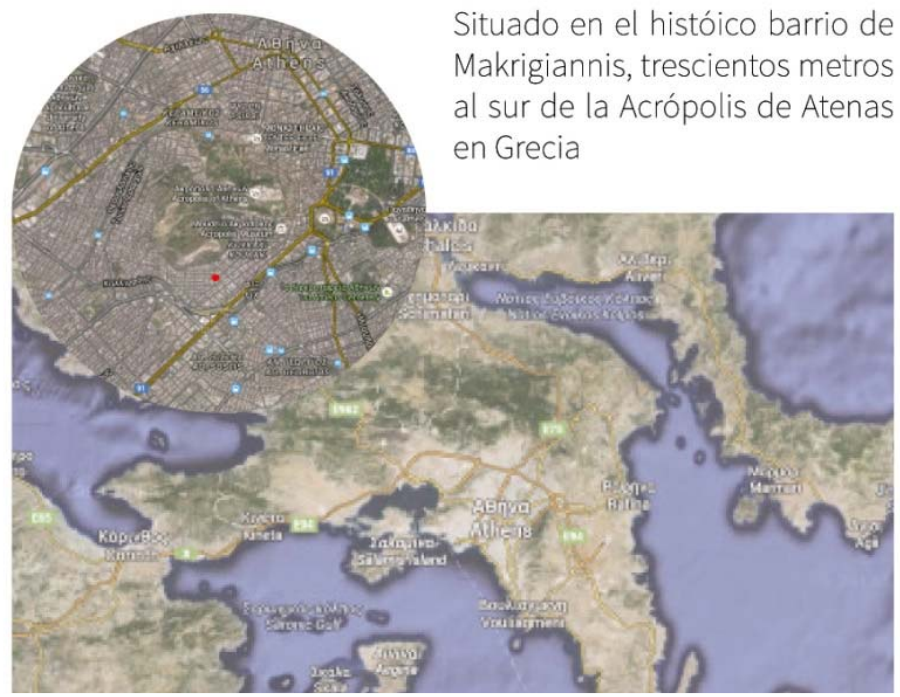

Figura 82: Mapa Localizador - Museo de la Acrópolis de Atenas Fuente: Google Earth

Desde la colina de la Acropolis de Atenas se reconoce el museo. La propuesta arquitectonica pretende recopilar la volumetria historia de la Acropolis misma y el recorrido que presentaba en este nuevo museo que le hace refrencia. Su imponente composicion arquitectónica resalta sobre todo el conjunto urbano y el resto de la ciudad, siendo reconocido como un edificio importante y que debe ser tomado en cuenta como tal.

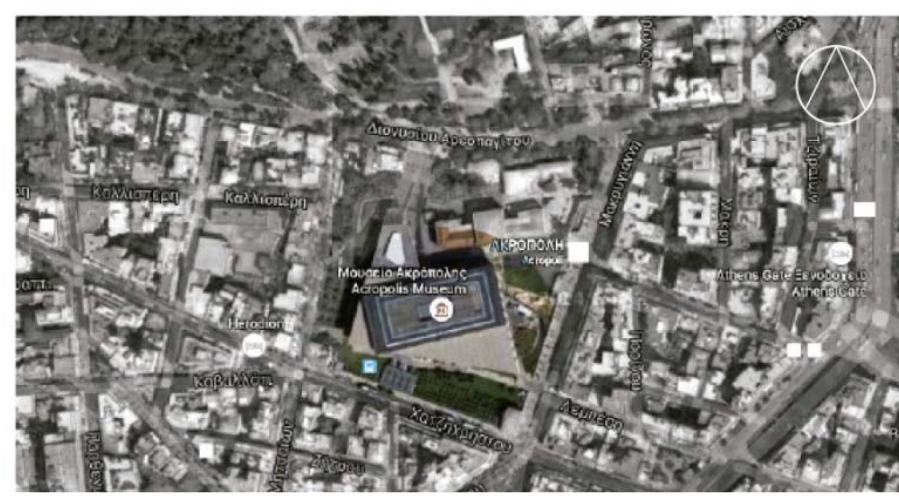

Figura 83: Terreno Museo de la Acrópolis de Atenas Fuente: Elaboración propia

La entrada principal del Museo está situada al comienzo del paseo de Dionisio Areopagita, eje principal de la red de recintos arqueológicos unificados de Atenas.
Transporte Publico

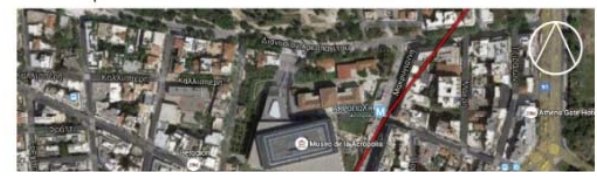

Figura 84: Transporte público Museo de la Acrópolis de Atenas

Vista de la calle

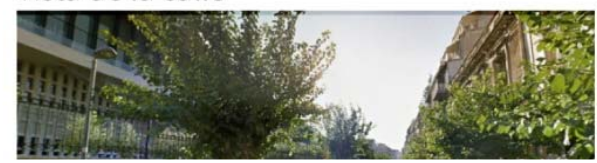

Figura 85: Calles colindantes del Museo de la Acrópolis de Atenas

visla ue id cullila de huivulis

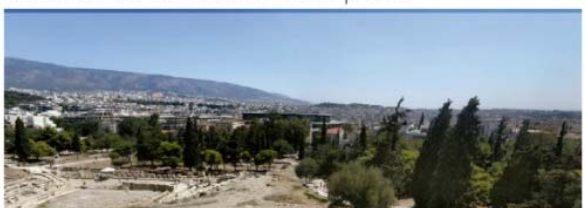

Figura 86: Vista de la colina del Museo de la Acrópolis de Atenas

Fuente : Archdaily 


\section{ANTECEDENTES HISTORICOS}

Figura 87: Nexos Museo de la Acrópolis de Atenas Fuente : Archdaily

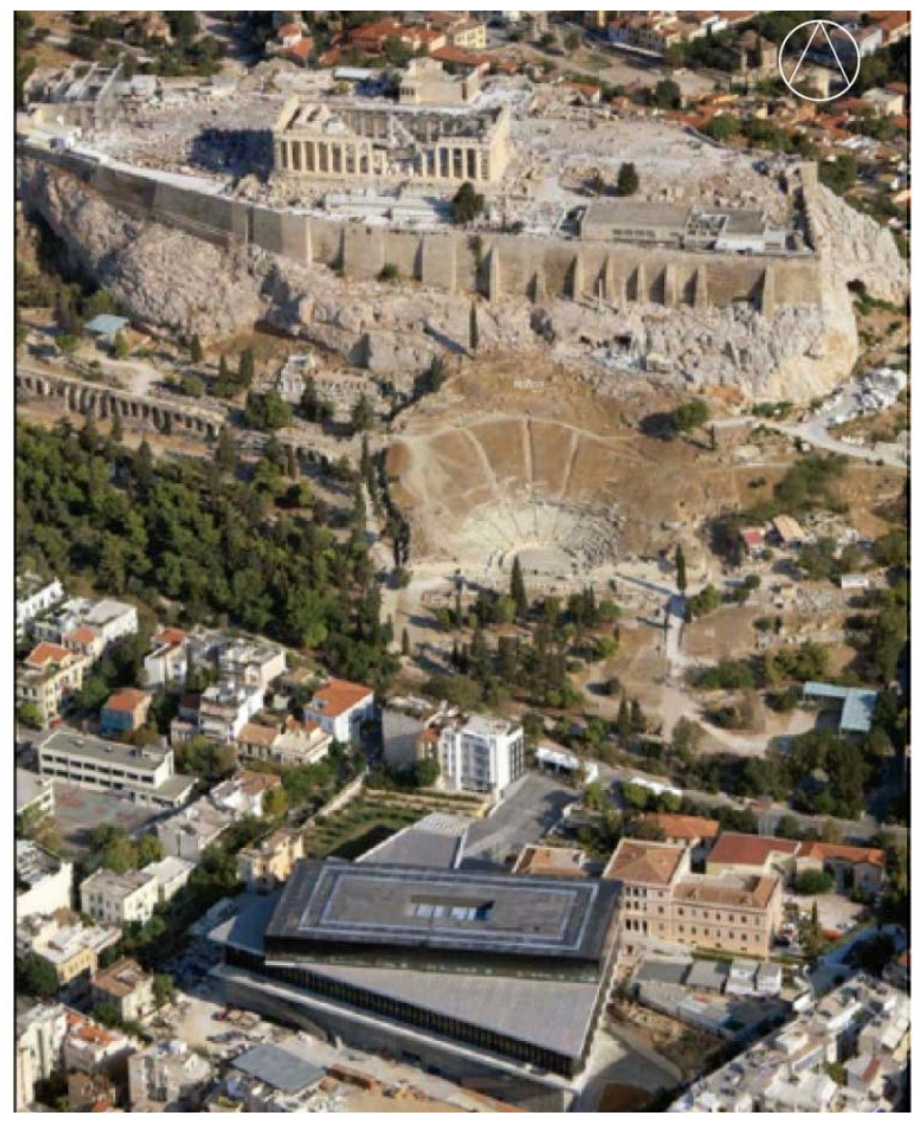

EVOLUCIÓN HISTORICA

La Acrópolis, es un símbolo de la civilización griega antigua, que data del siglo V antes de nuestra era, es uno de los lugares más visitados del mundo.

Se origino en 1833 y en 1978 ese decidió trasladar el museo fuera de la Acrópolis debido a la falta de espacios de exposición. Hubo para ello cuatro concursos. Los dos primeros, con participación de arquitectos griegos únicamente.

En 1989, se lanzó un tercer concurso, internacional esta vez, debido al descubrimiento de los restos de una antigua ciudad de Atenas, llevando a la anulación de la competición en 1999.

El cuarto concurso se realizó únicamente por invitación, siendo ganado por el estudio de Nueva York del arquitecto Bernard Tschumi, en colaboración con el arquitecto griego Michael Photiadis.

En su proyecto, los restos arqueológicos descubiertos fueron conservados e integrados en el diseño del Museo en el cual forma parte de un momento importante de la experiencia del visitante.

\section{IDENTIFICACION DE EDIFICACIONES Y AMBIENTES URBANO - ARQUITECTÓNICOS}

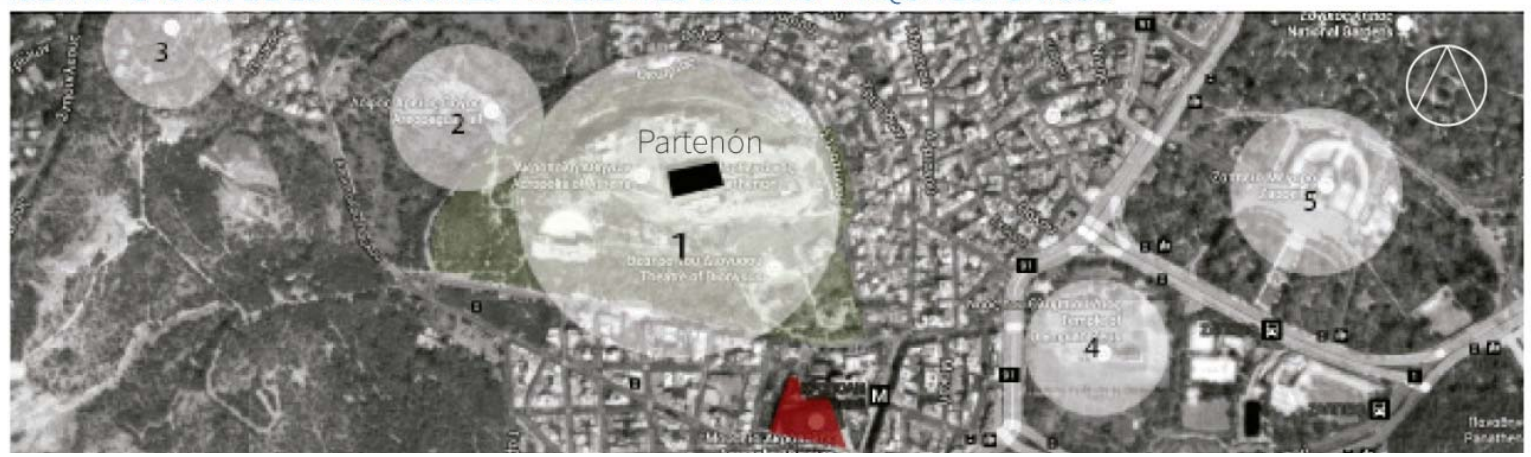

Figura 88: Entorno historico del Museo de la Acrópolis de Atenas Fuente : Archdaily

1 - ACOPOLIS DE ATHENAS

2- AREOPAGUS

3 - OBSERVATORIO NACIONAL DE ATHENAS

4- ALYMPIAN ZEUS

5 - ZAPPEION 


\section{CONCEPTUALIZACIÓN DE LA PROPUESTA}

\section{PROCESO DE DISEÑO}

El proceso de diseño dio inicio con el entendimiento de la Acropolis misma para la optima ejecución de la propuesta basada en ella.

\section{METODOLOGIA}

Se plasman las ideas principales abstraidas de la acropolis, para el dieño del nuevo museo, con una versión modernizada del complejo.
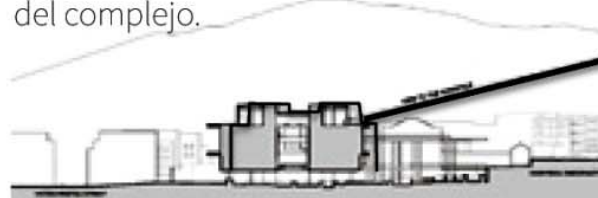

Figura 89: Concepto gráfico del Museo de la Acrópolis de Atenas Fuente : Elaboración propia

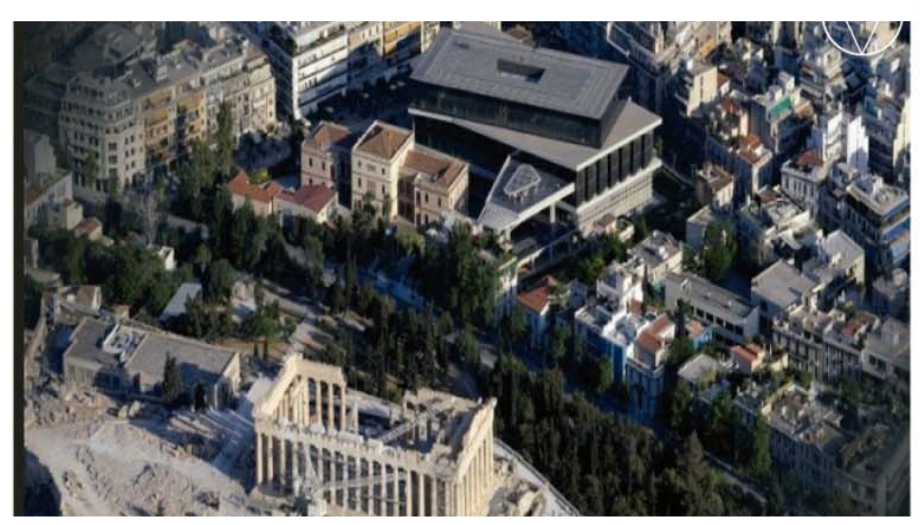

RELACIONES ESPACIALES URBANO

ARQUITONICO

Se analizan tres aspectos importantes, el primero es el visual, el segundo el de la base y el tercero la espacialidad interior.

El contacto visual es fundamental en el proyecto ya que en todo momento se relaciona con la acropolis. Es ua reinterpretacion del recinto historico, volumentricamente como urbanisticamente.

Ademas el edificio presenta excavaciones arquielogicas ubicadas en la base, influyendo a que el visistante diriga su mirada

Figura 90: Vista aerea Museo de la Acrópolis de Atenas Fuente : Archdaily

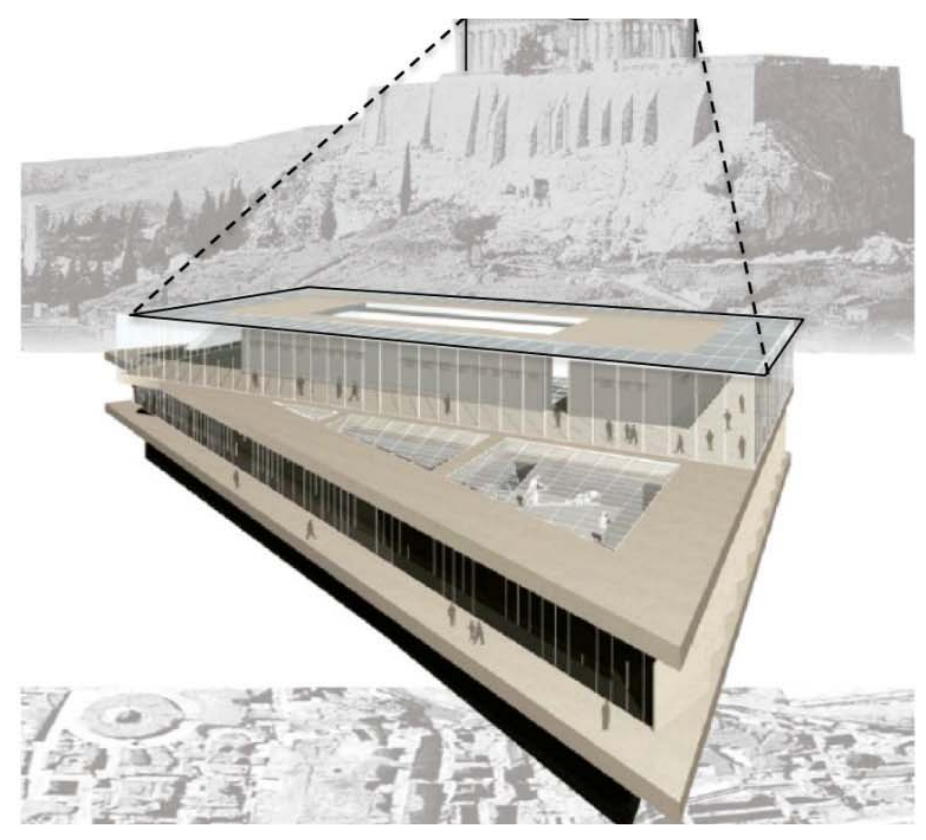
hacia el interior haciendo referencia a los origenes historicos que lo conforman.

En la base, el museo da la sensación de estar flotando, pues se halla suspendido sobre más de cien pilares.

El espacio interior mas notable del museo es la sala del Partenón, ya que presenta las mismas proporciones y orientaciones del Partenon mismo.

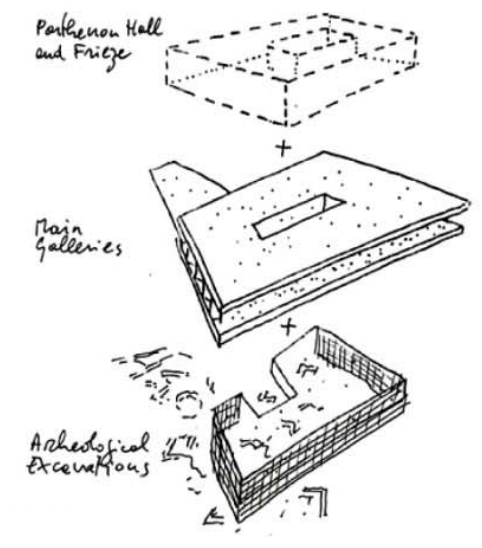

Figura 91: Historia y arquitectura - Museo de la Acrópolis de Atenas Fuente : Archdaily 


\section{ENTORNO}

RELACION CON LA CIUDAD

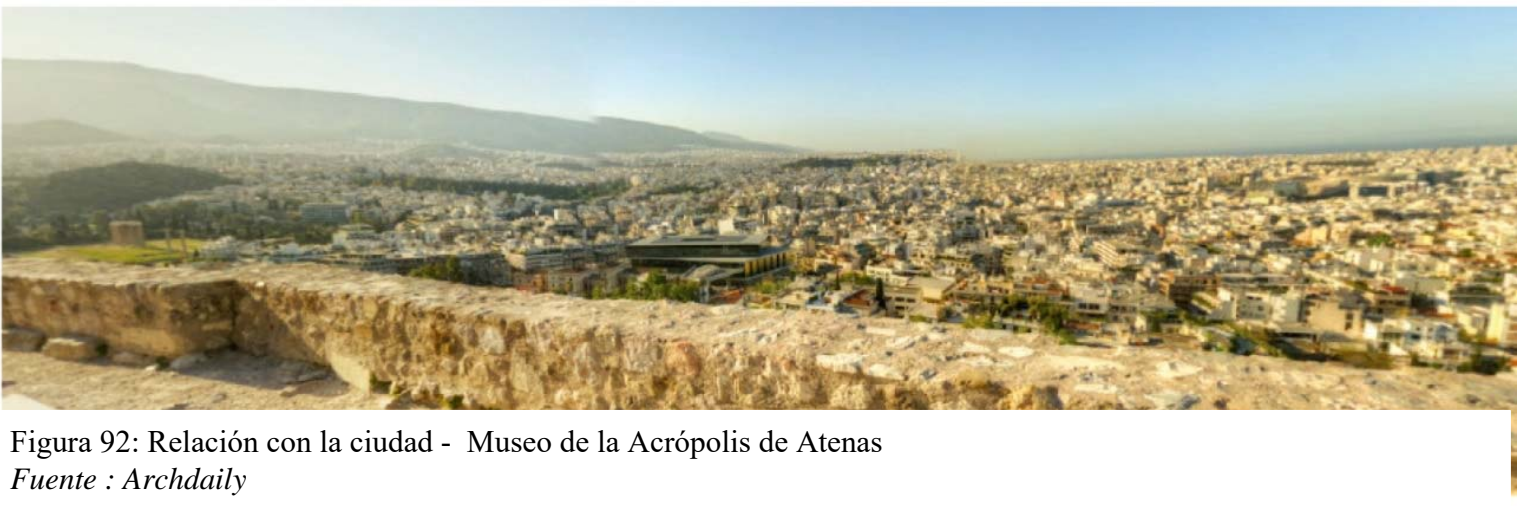

\section{PERFIL URBANO}

Se incerta muy bien en el contexto urbano, si bien la escala es bastante imponente y resalta sobre el resto, la importancia que tiene es entendida por la sociedad y respetada por su valor historico.

\section{CONTEXTO SOCIAL, ECONOMICO Y CULTURAL}

Para la sociedad el edificio es muy significativo por su valor cultural e historico. Economicamente ha sido muy favorable para la zona el turismo se ha incrementado en los ultimos años.

\section{EDIFICACIONES DEL ENTORNO}

Los edificios del entorno presentan alturas menores a la del museo sin embargo este no se encunetra aisalado, ya que en la planta baja el espacio esta suspendido sobre las ruinas reconstridas, permitiendo mimetizarse a la escala del visitante o peaton.

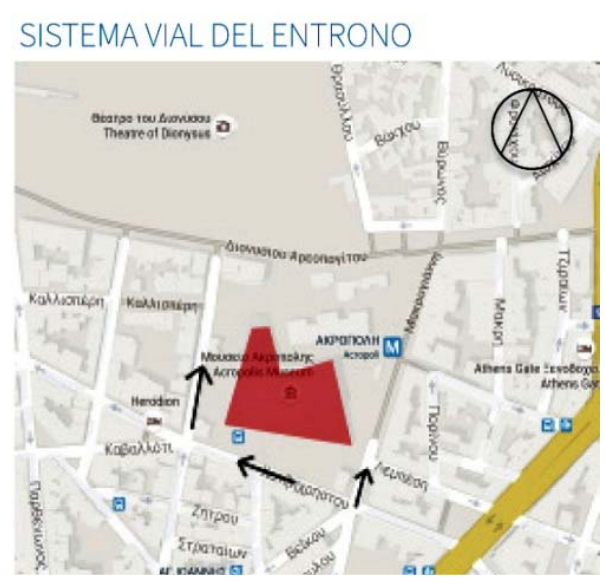

Figura 93: Sistema vial - Museo de la Acrópolis de Atenas

Fuente : Elaboración propia

\section{CIRCULACIONES VEHICULARES Y PEATONALES}

Las ciruculaciones vehiculares y peatonales estan planteadas de tal manera que se encunetren en el mismo punto de partida en el cial se incia el recorrido hacia todos los espacios del museo. Se asciende desde una rampa traspraente central y a traves de esta se recorre todo el edificio, hasta la parte superior.

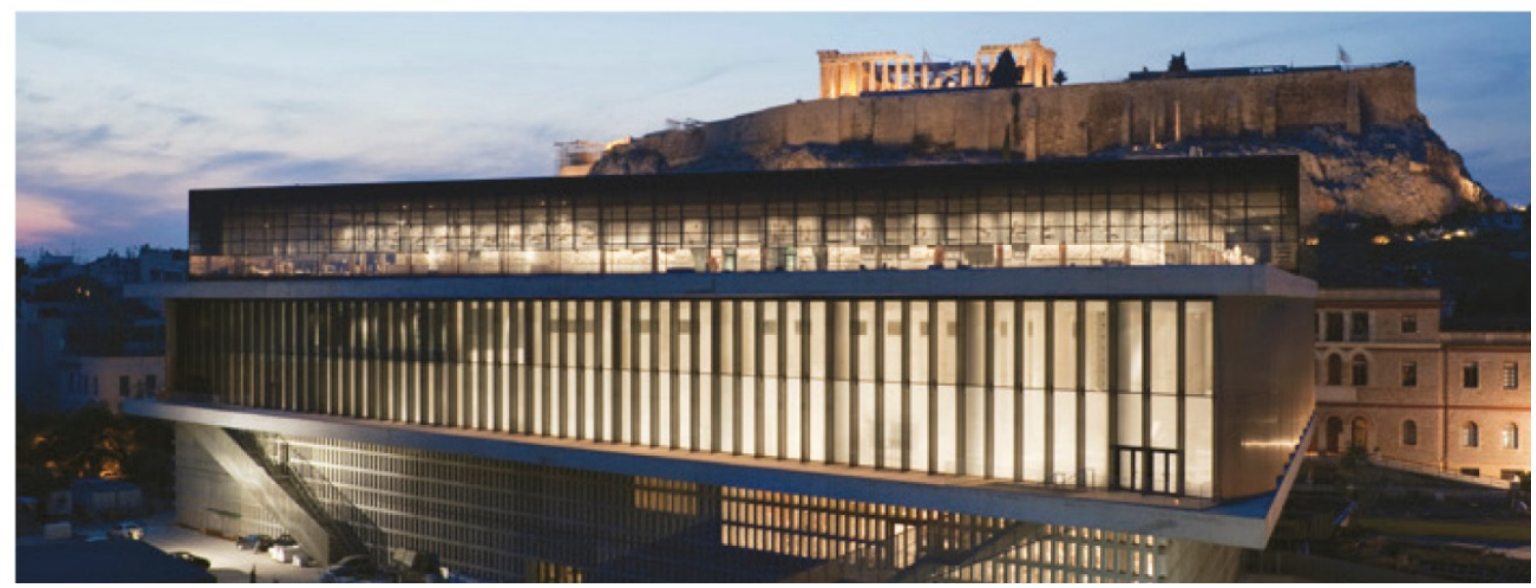

Figura 94: Museo de la Acrópolis de Atenas de noche Fuente : Archdaily 


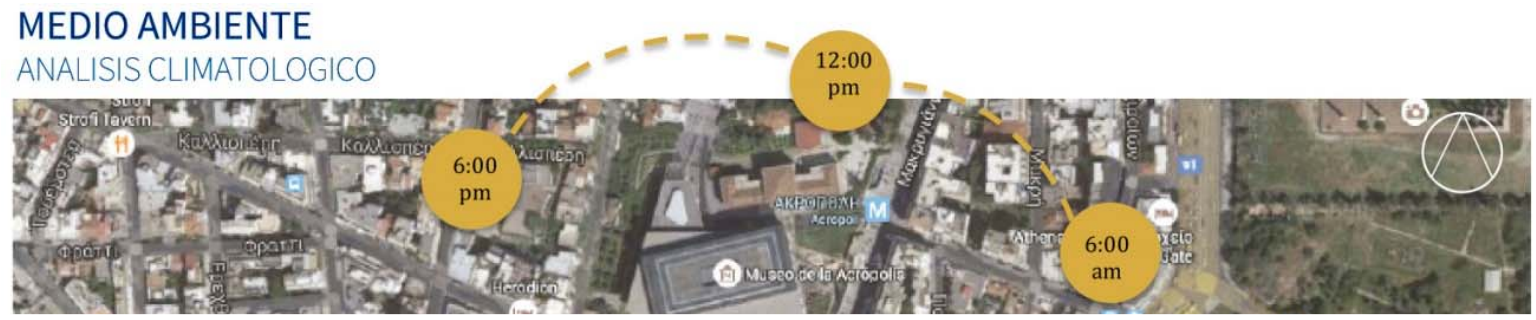

Figura 95: Asoleamiento Museo de la Acrópolis de Atenas Fuente : Elaboración propia

No hace mucho frio en invierno, pero mucho calor en verano con muchas lluvias durante el año.

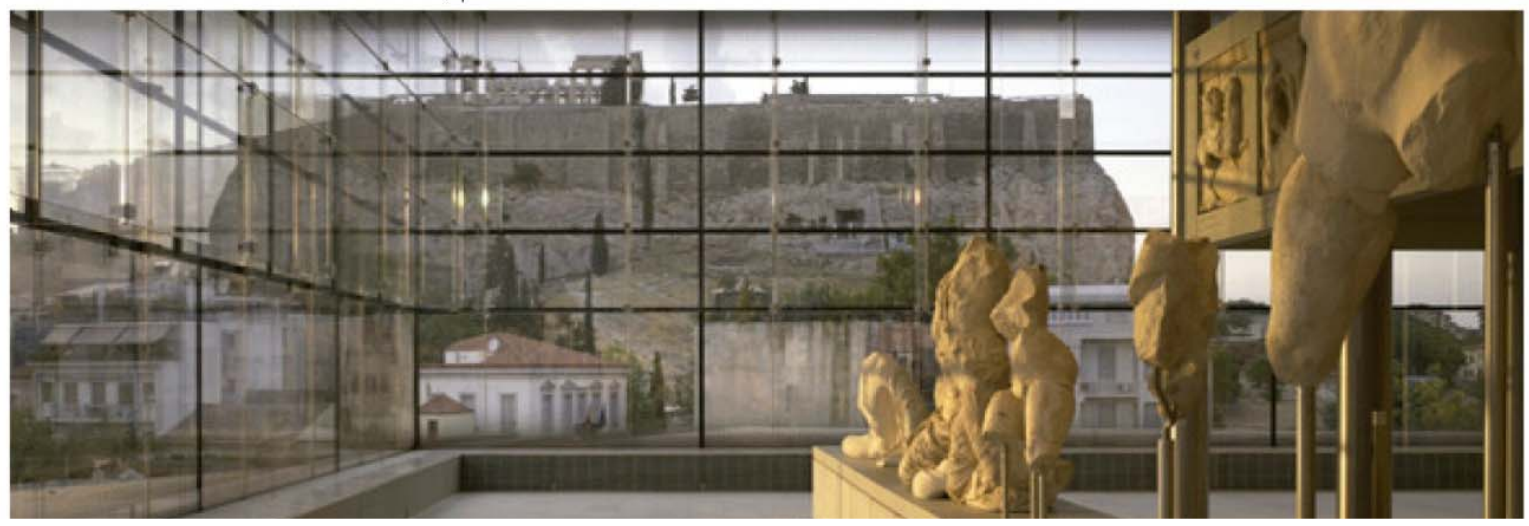

Figura 96: Visuales desde el Museo de la Acrópolis de Atenas Fuente : Archdaily

\section{PAISAJE}

El paisaje del edificio esta planteado para relacionarse con su historia y con las edificacioes modernas de la ciudad de Atenas. El museo aprovecha eso para diseñar el edificio en todo momentohaciendo referencia a su historia y a contemplación de esta. Se utiliza materiales modernos y tecnologia que por medio se la fusion de estos hace de este un edificio único e innovador, evocando al pasado con una proyección moderna.

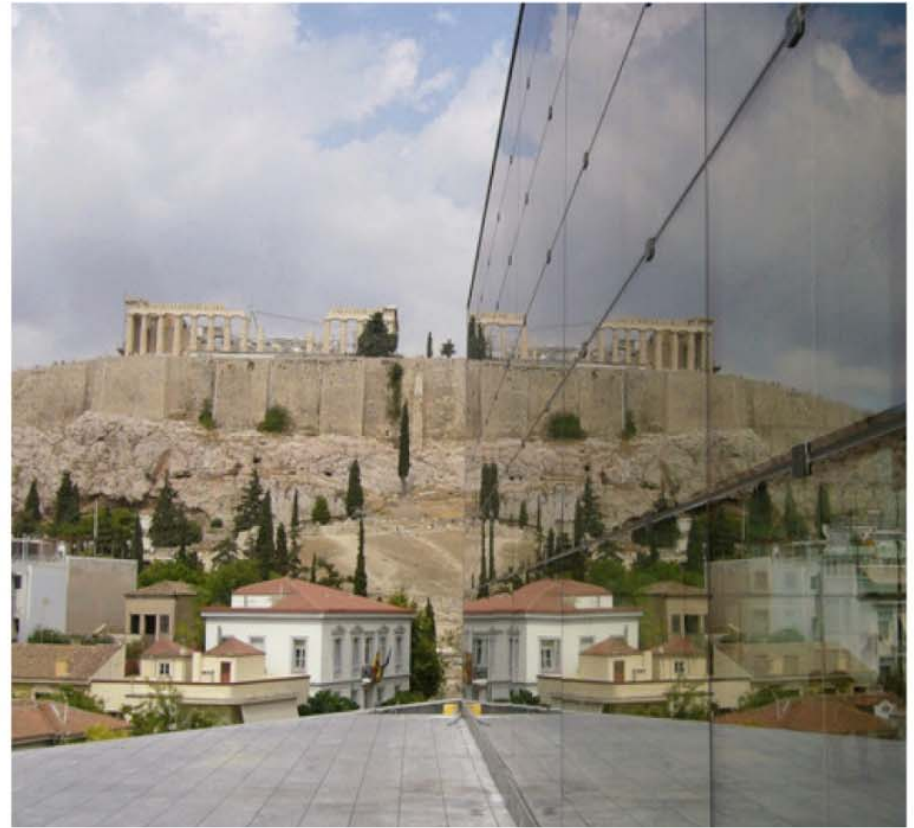

Figura 98: Reflejos del Museo de la Acrópolis de Atenas Fuente : Archdaily

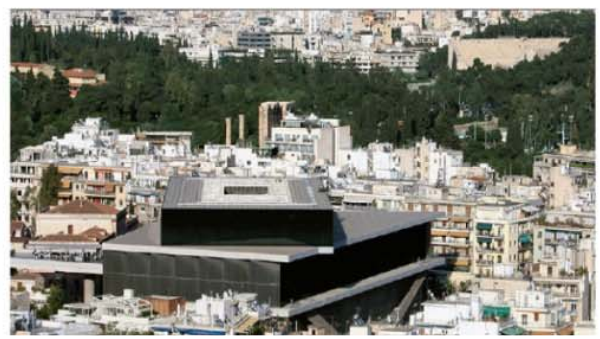

Figura 97: La escala del Museo de la Acrópolis de Atenas Fuente : Archdaily

El último piso del museo ofrece una vista de 360 grados de la Acrópolis y de la Atenas moderna.

El impacto del edificio es enorme hasta el punto que ha cambiado la fisonomía de toda una parte de la ciudad.

De noche el efecto es aún más fuerte, pues su iluminación influye a que el edificio sea reconocido en su contexto. 


\section{ASPECTOS FUNCIONALES}

PAQUETES FUNCIONALES

La zona administrativa se encuentra en la planta inferior donde se accede al edificio. La museografia se aprecia en el recorrido de las plataformas. Los sevicios se encuentran en el perímetro de la circulacion principal central.

ORGANIGRAMA E INTERRELACIONES

El volumen del edificio se artícula en su base, centro y nivel superior, diseñados en torno a las necesidades específicas de cada parte del programa.

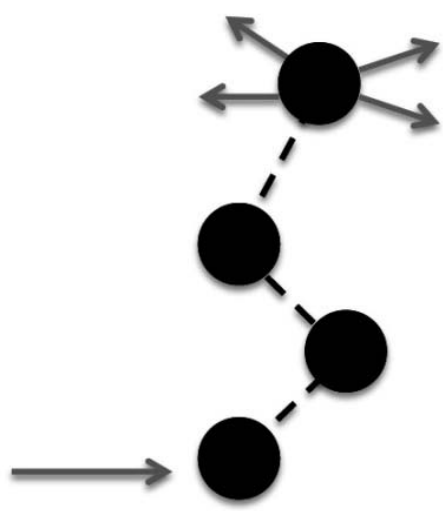

CRECANIAS Y LEJANIAS

Los espacios estan en constante relacion con su entorno historico ademas por la reconstruccion de las ruinas en la parte baja el edificio da a netender que se encunetra dentro de la historia misma y por medio del recorrido arquitectonico a experimentar de hace el entendimiento de él. Dandole un valor adicional que es reconocible por todos los que lo experimentan.
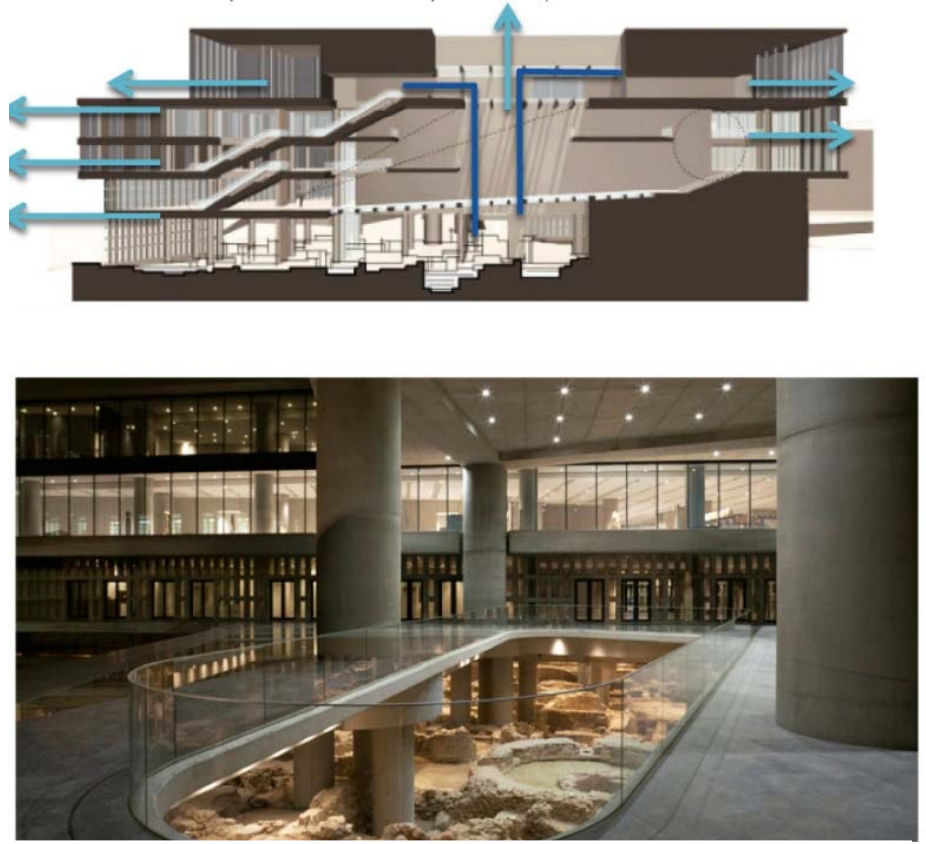

Figura 99: Historia contenida de la Acropolis de Atenas - interior Fuente : Archdaily
CIRCULACIONES DIFERENCIADAD
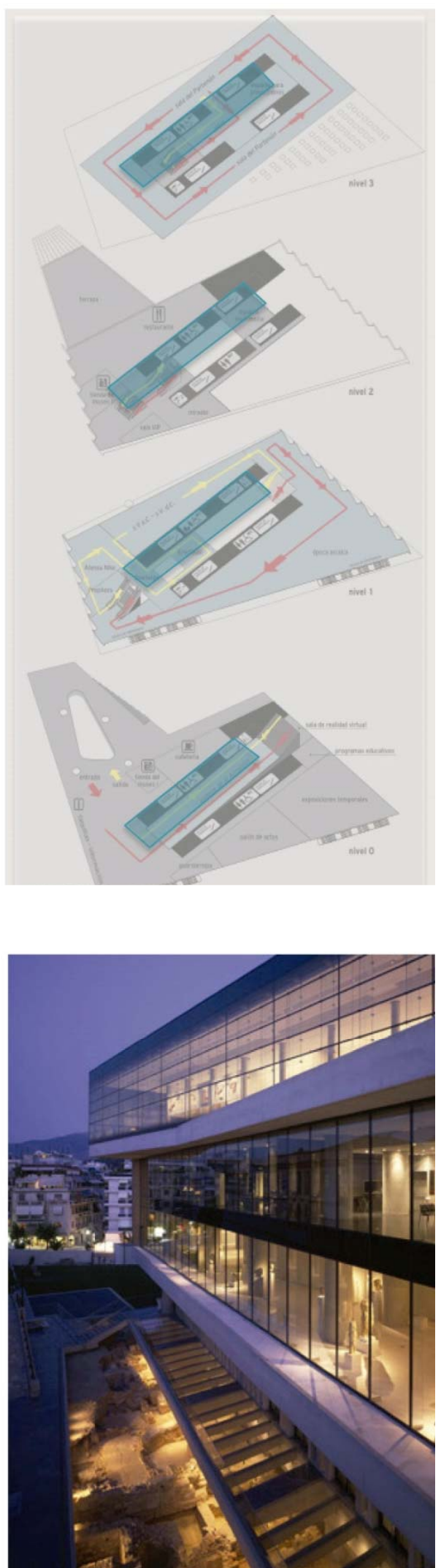

Figura 100: Historia contenida de la Acropolis de Atenas - exterior Fuente : Archdaily 


\section{PROGRAMACIÓN}

El proyecto se basa en tres conceptos que transforman las limitaciones del sitio en potencialidades: luz, movimiento, y concepto tectónico y programático.

\section{NUMERO DE USARIOS APROXIMADO}

El numero aproximado por dia en el museo es de 2000 personas, en temporadas de verano, de julio a septiembre los vistantes suelen incrementar.

Muchos turistas de distintas partes del mundo llegan al lugar para conocer la historia de la antigua acropolis expuesta enun museo moderno.

Luego de la construcion del nuevo museo, los turistas aumentaron muchisimo, consolidando la zona aun mas como un gran polo economico notable en todo Atenas no solo por el museo mismo que presenta un valor cultural e historico notable sino por las distintas actividades que se generan en torno a él

Actividades que han sido aprovechadas por los locales para consolidarse en el mercado turisitico que el sector caracteriza.

\section{NECESIDAD DE AREAS EQUIPADAS}

Todas las areas estan equipadas con la museografia respectiva de la acropolis de Atenas LISTADO DE AMBIENTES

Los ambientes del museo se relacionan por este espacio central con un gran rampa que permite su recorrido desde la zona baja hasta la superior.

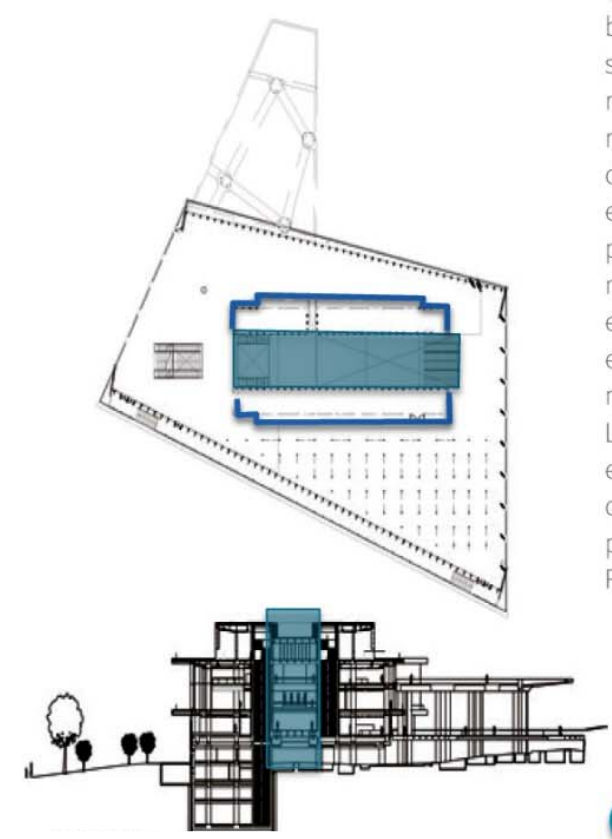

Los ambientes del museo tienen un orden bastante claro, la secuencia espacial se recorre a través de la rampa central que distribuye a los distintos espacios. Presenta una planta típica en la cual la museografía esta expuesta en todo e espacio - con modulaciones móviles. La sala mas importante es la de la parte superior que tiene la misma proporción que el Partenón de la acrópolis

Conexión interior

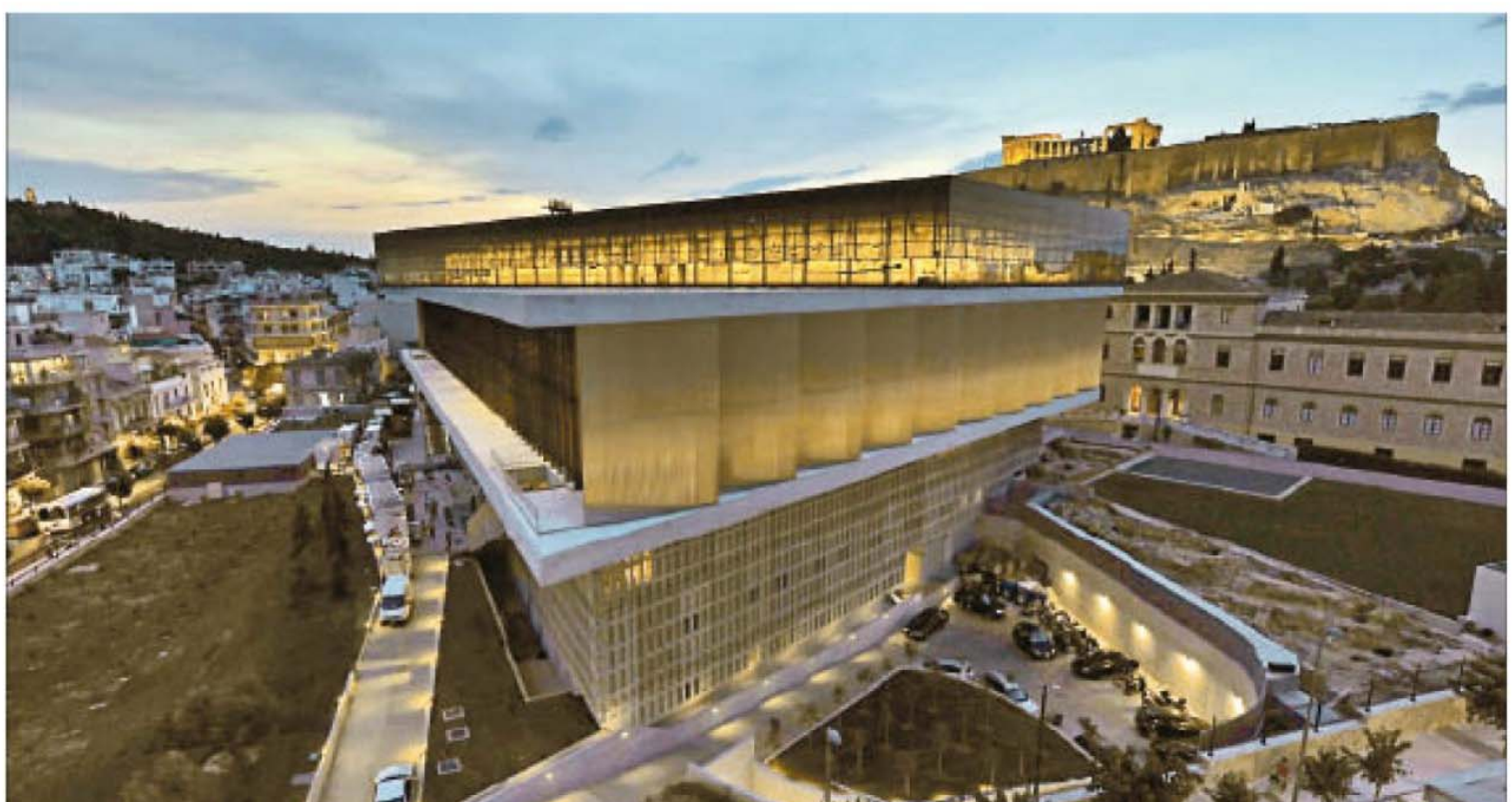

Figura 101: Volumetría - Museo de la Acropolis de Atenas Fuente : Archdaily 


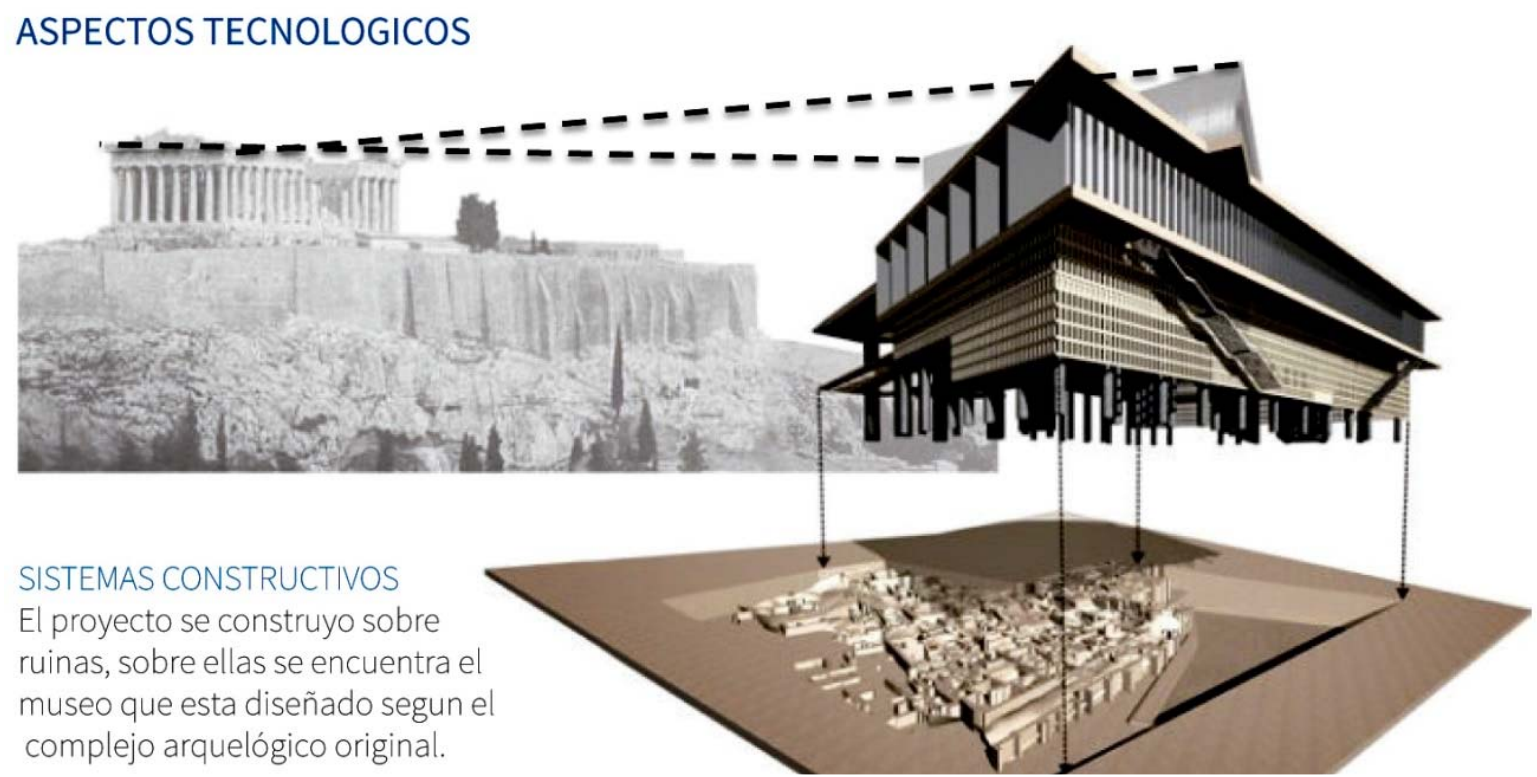

Figura 102: Ssitema constructivo - Museo de la Acropolis de Atenas Fuente : Archdaily

ESTRUCTURA

El edificio se construyó sobre una red de columnas, conservando cuidadosamente los restos arqueológicos del sitio. Los pilotes atraviesan el suelo hasta la roca firme y flotan en los rodamientos de rodillos.

MATERIALES

La construcción fue pensada en relación a la durabilidad y la resistencia al paso del tiempo, para que el edificio envejezca con gracia, a pesar del pesado volumen de tráfico de un destino turístico internacional.

Los materiales fueron seleccionados por su sencillez y sobriedad: vidrio, hormigón y mármol. La transparencia del vidrio filtra suavemente la luz a través de un proceso de serigrafía. La estructura es de hormigón armado.

APLICACIÓN TECNOLÓGICAS NO CONVENCIONALES

Los tres materiales más usados para su contrucción fueron: vidrio para las fachadas y algujos pisos, concreto para el núcleo y las estructuras, así como mármol para las galerías.
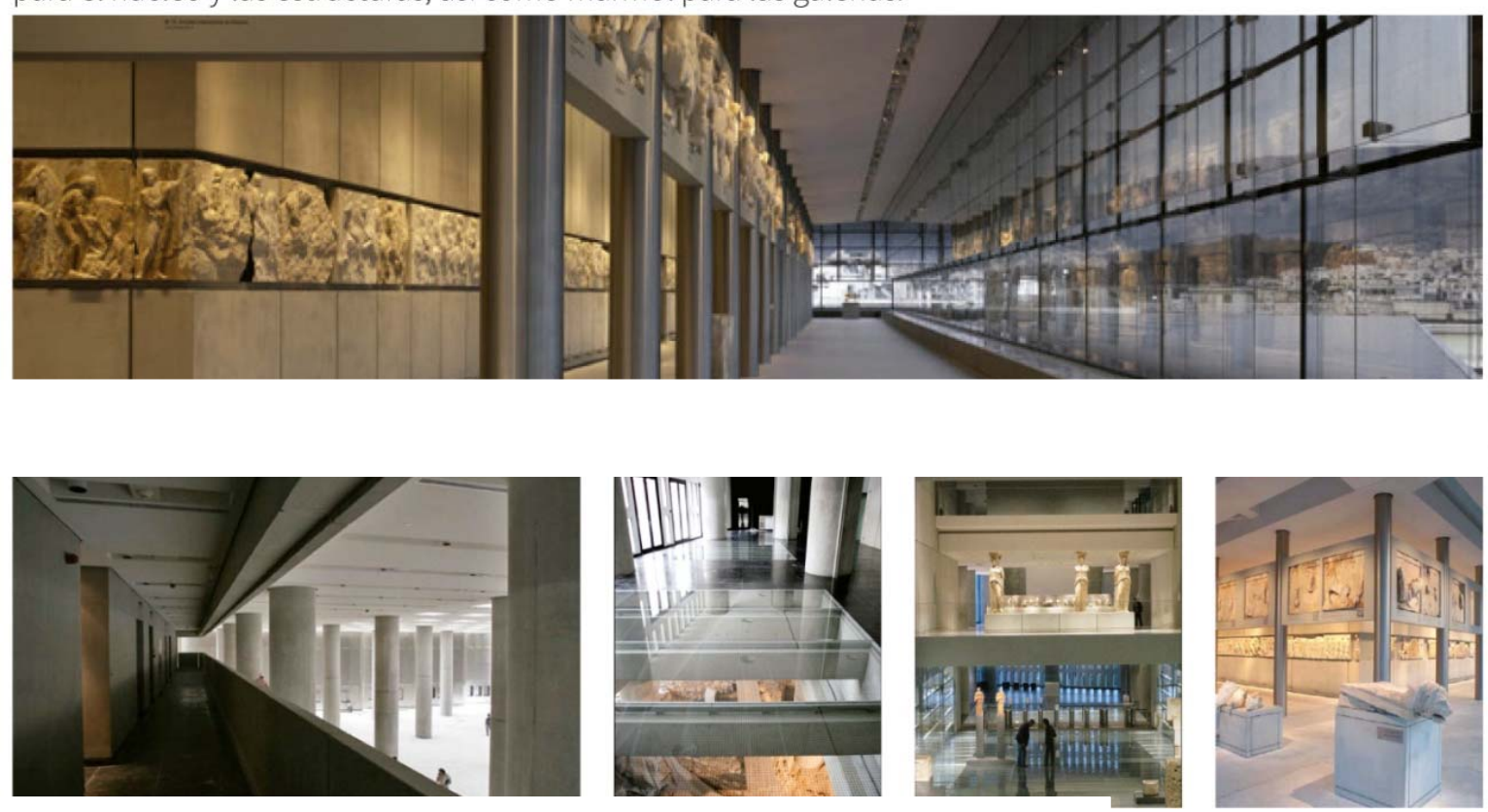

Figura 103: Vistas - Museo de la Acropolis de Atenas Fuente : Archdaily 


\subsection{Lugar de la Memoria}

\section{INFORMACIÓN GENERAL}

La Comisión de la Verdad, liderada por el escritor peruano Mario Vargas Llosa, lanzó en el 2010 un concurso nacional para la construcción de un Lugar de reconciliación de los peruanos, enfrentados durante más de veinte años en un conflicto iniciado por el movimiento terrorista

\section{NOMBRE}

Lugar de la Memoria, la Tolerancia y la Inclusión Social

\section{AUTORES}

Estudio: Barclay \& Crousse

Sandra Barclay y Jean Pierre Crousse

Asistentes: Paulo Shimabukuro, Carlos Fernandez, Rosa Aguirre, Mauricio Sialer

AREA: $4900.0 \mathrm{~m} 2$

AREA DEL TERRENO: 7,573 m2

AÑO DEL PROYECTO: 2013

\section{COSTO 8'100,000 USD}

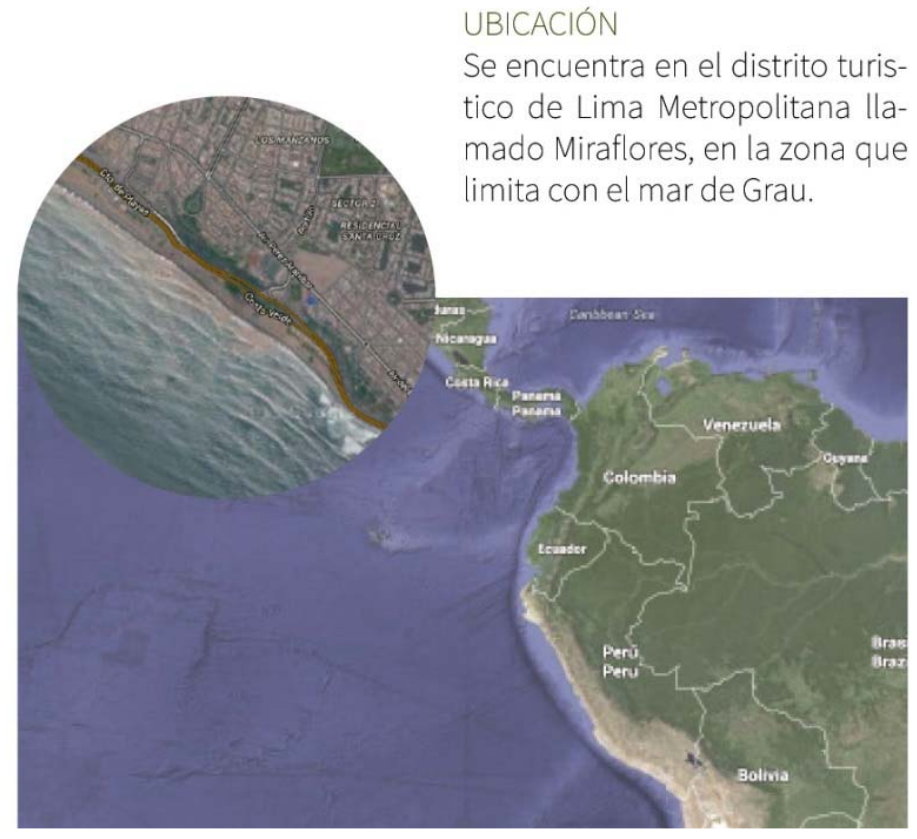

Figura 104: Mapa Localizador - Lugar de la memoria Fuente: Google Earth

El lugar de la memoria se encunetra en el límite entre la zona urbana y la zona paisajista de la costa verde de la ciudad de Lima.

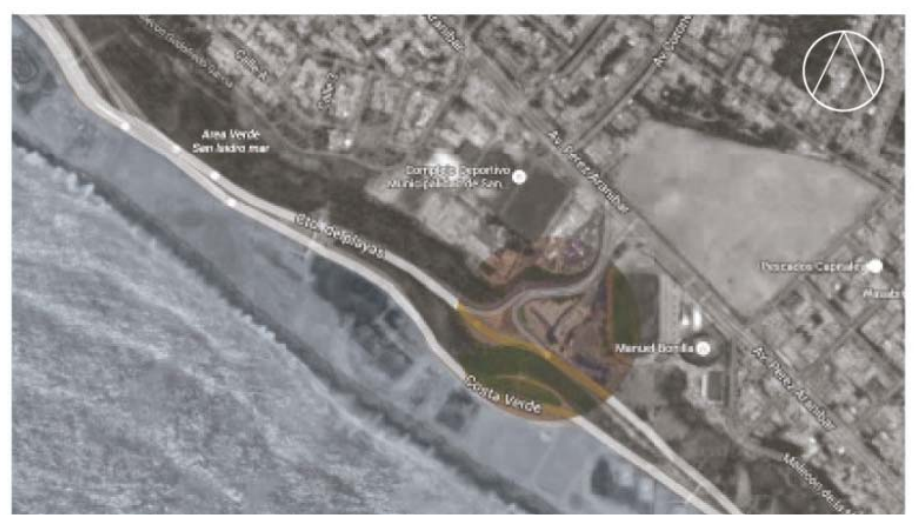

Figura 105: Terreno Lugar de la memoria

\section{Fuente: Elaboración propia}

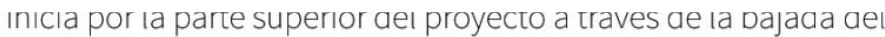
acantilado mientras que la vehicular es en la parte baja, por el circuito de playas de la costa verde de lima.

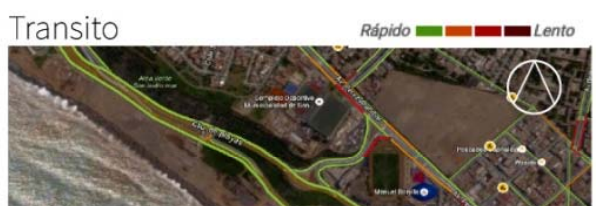

Figura 106: Transito Lugar de la memoria

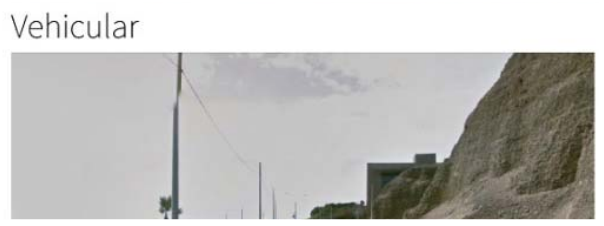

Figura 107: Vías vehicular Lugar de la memoria Peatonal

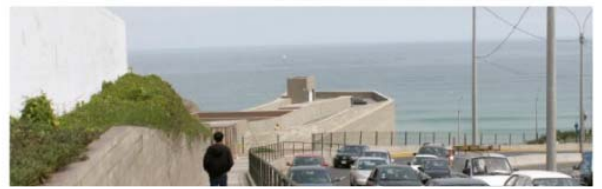

Figura 108. Vias peatonales Lugar de la memoria Fuente : Archdaily 


\section{ANTECEDENTES HISTÓRICOS}

El Museo de la Memoria de Perú, rebautizado luego como Lugar de la Memoria, la Tolerancia y la Inclusión Social es un museo que construido en la bahia de Miraflores, Lima. tiene como fin el de recordar a las víctimas del terrorismo y la historia de la guerra que se desarrolló a partir de 1980.

El edificio adquiere una dimensión notable en el territorio ya que forma parte de la costa verde siendo parte del sistema topológico de más de $10 \mathrm{Km}$ de longitud. Los espacios públicos del proyecto permiten su reconocimiento espacial con el exterior y el valor paisajista que lo influye.

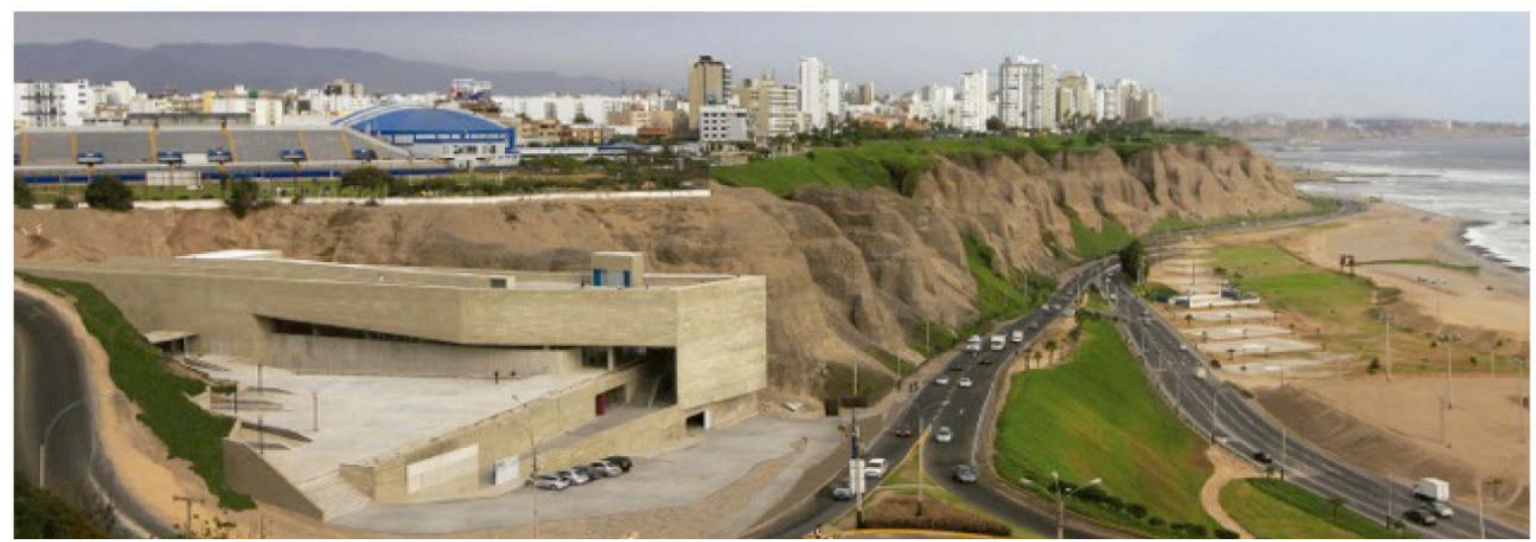

Figura 109 : Lugar de la memoria Fuente : Archdaily

INTEGRACION CON SU ENTORNO HISORICO

El proyecto, situado en los acantilados que definen la bahía de Lima, se instala cuidadosamente en la lógica de los farallones y quebradas que los componen, recuperando la memoria del lugar en su configuración física y en su materialidad ya que no se contrapone al contexto sino mas bien busca reintegrarse y subliminarlo.

IDENTIFICACIÓN DE EDIFICACIONES Y AMBIENTES URBANO ARQUITECTONICOS

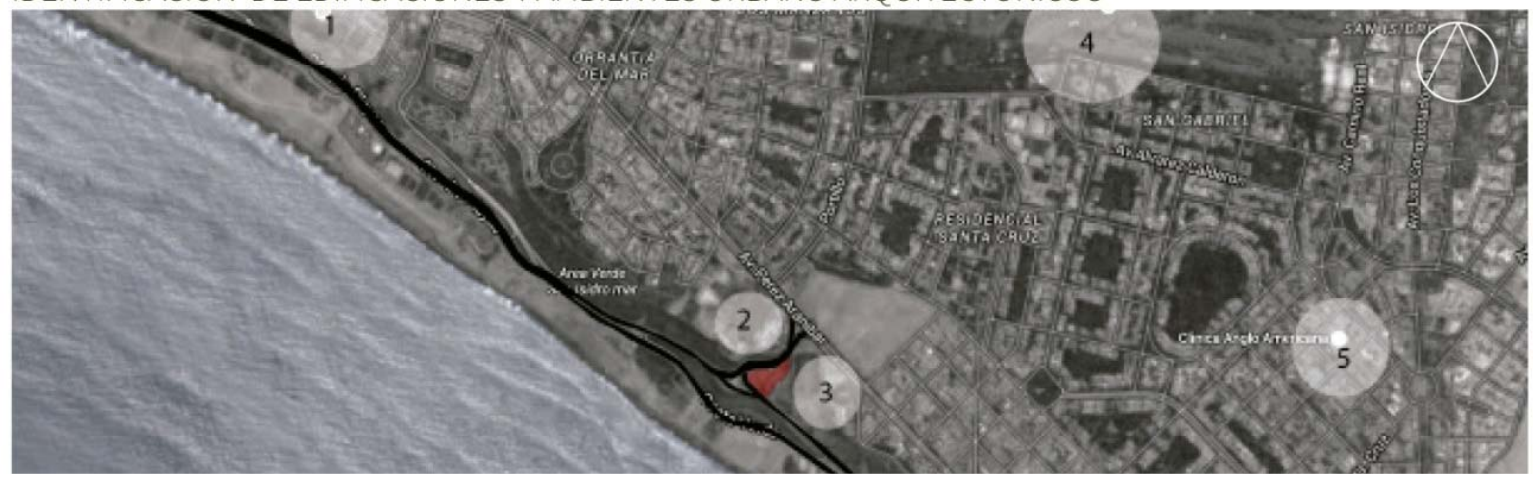

Figura 110 : Entorno historico Lugar de la memoria Fuente : Archdaily

1 - PUERICULTORIO PEREZ ARANIBAR

2 - MERCADO DE PRODUCTORES DE SANSIDRO

3. COMPLEJO DEPORTIVO DE LA MUNICIPALIDAD DE MIRAFLORES

4 - LIMA GOLF CLUB

5 - CLINICA ANGLO AMERICANA 
PROCESO DE DISEÑO
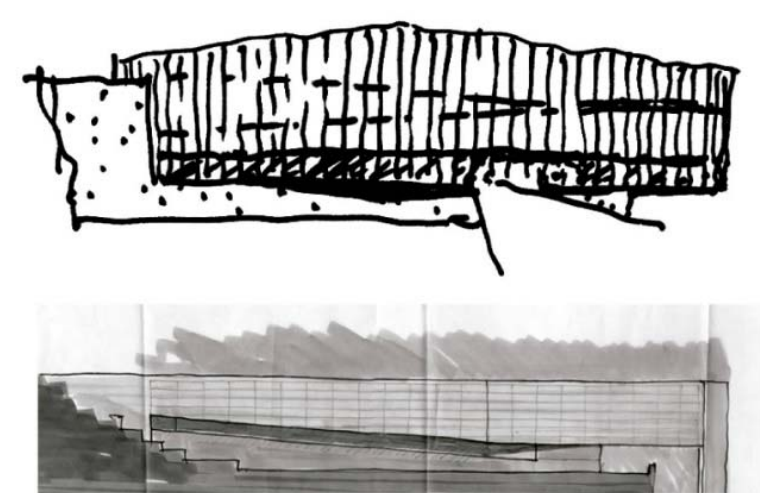

El proyecto busca insertarse armoniosamente en su contexto geográfico y urbano,.

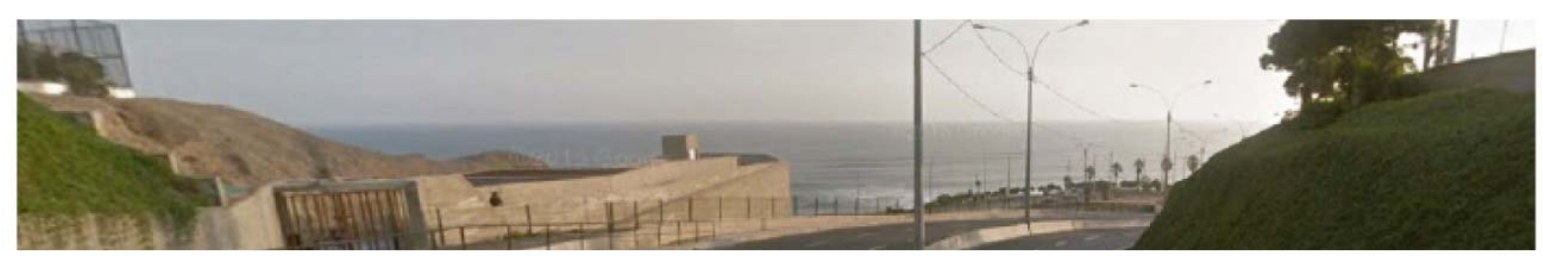

Figura 111 : Conceptualización Lugar de la memoria Fuente : Archdaily

"Yo creo que el éxito de este lugar sería si re descubrimos este horizonte con otros ojos. Con una mirada hacia el futuro, con una toma de conciencia de nuestra responsabilidad en lo que pasó, en el pasado y el compromiso para que estos hechos que ocasionaron la violencia, no se vuelvan a repetir.".

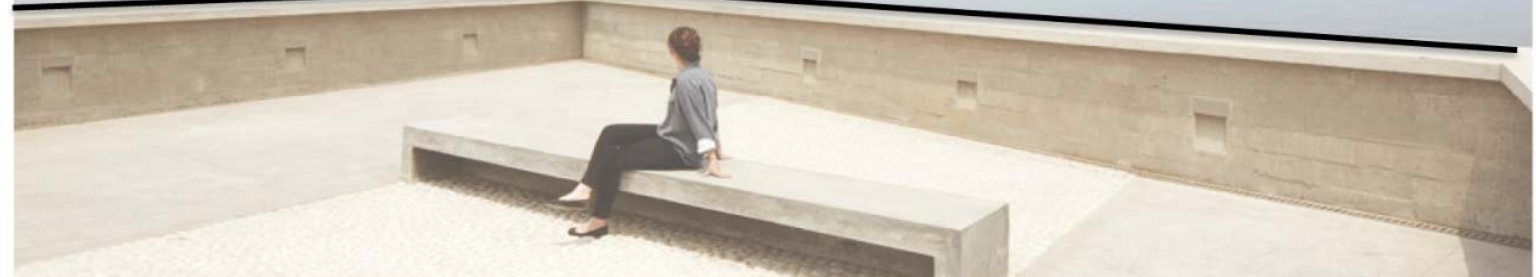

Figura 112 : Punto visual hacia la bahia Lugar de la memoria Fuente : Archdaily
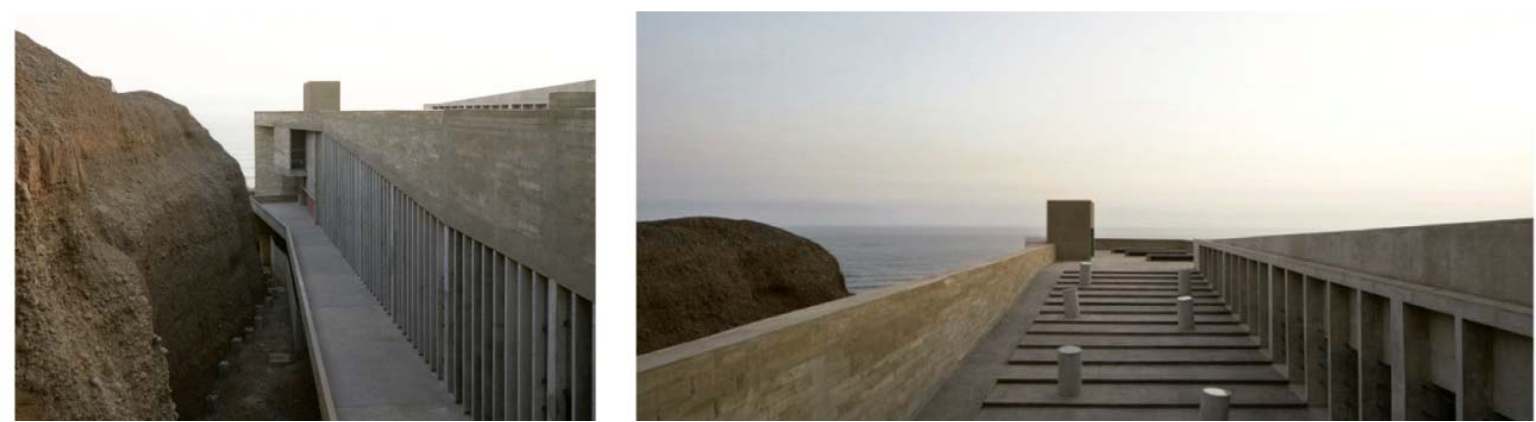

Figura 113 : Enfoques naturales del Lugar de la memoria Fuente : Archdaily 


\section{ENTORNO}

\section{RELACION CON LA CIUDAD}

El proyecto esta situado estrategicamente en un lugar de muchas tradiciones y de flujos de personas. No pasa desapersivido, se encunetra en un cruze vial de bastante tránsito.

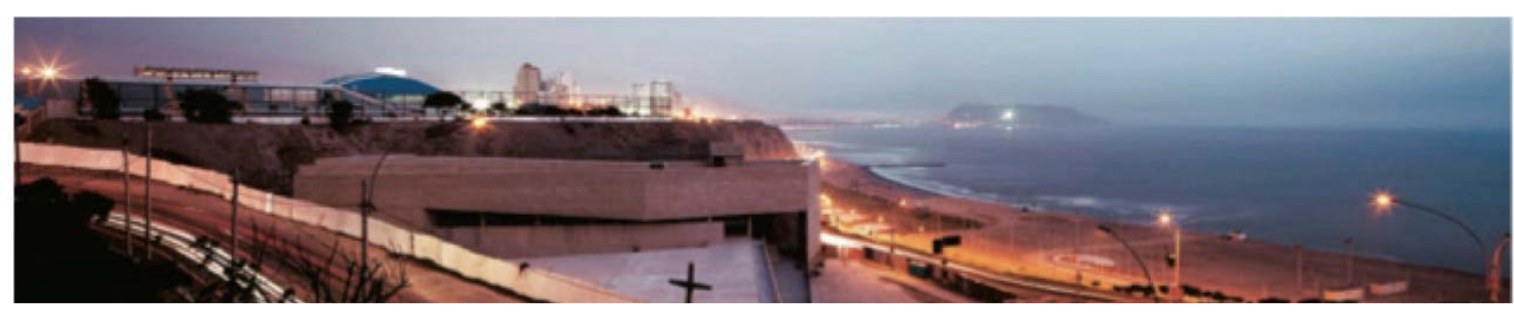

Figura 114: Lugar de la memoria de noche Fuente : Propia

\section{PERFIL URBANO}
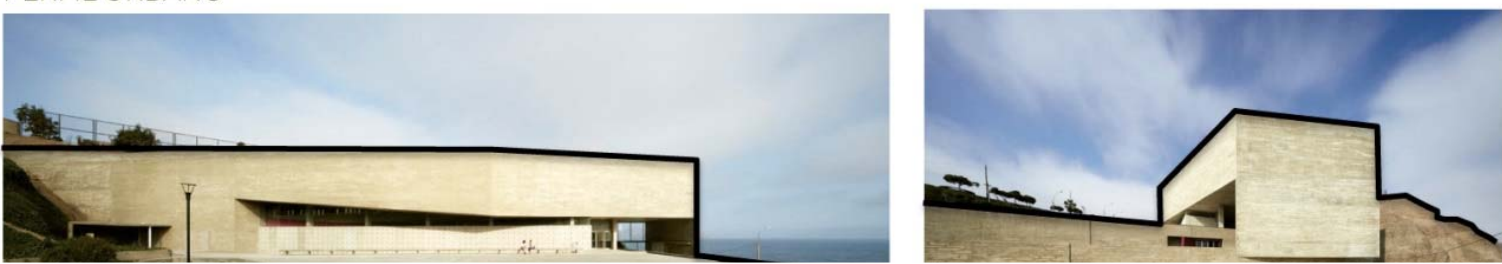

Figura 115 : Perfiles del Lugar de la memoria

Fuente : Propia

\section{CONTEXTO SOCIAL, ECONÓMICO Y CULTURAL}

La cultura peruana, ha tenido muchas influencias a lo largo de la historia,la propuesta pretende generar una instrospección acerca de sus origenes y hacer un llamado a la toma de conciencia de dicha esperiencia. Busca hacer un llamado al desarrollo aprendiendo de lo experimentado en años anteriores.
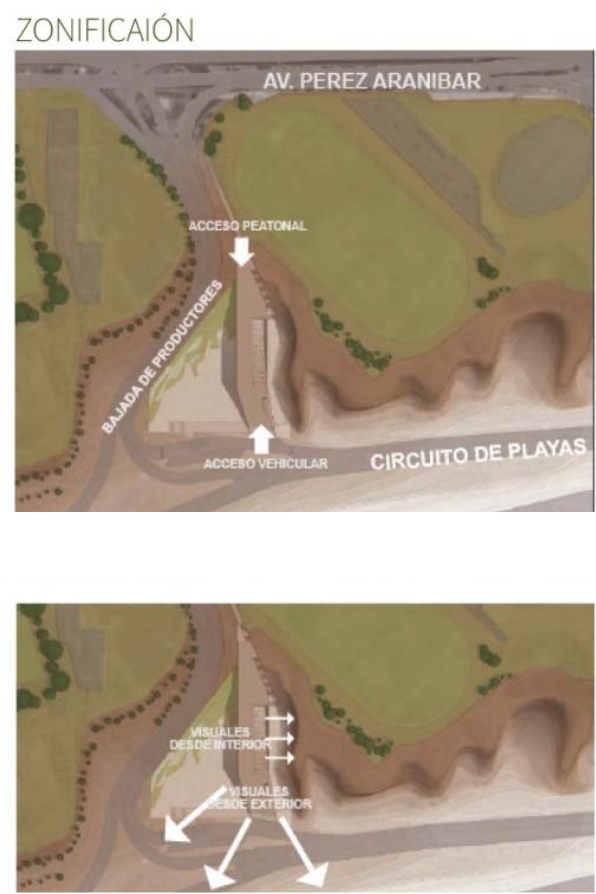

Figura 116 : Visuales del Lugar de la memoria Fuente : Propia

\section{EDIFICACIONES DEL ENTORNO}

En el entorno se encunetran edificaciones a lo largo del acantilado en la parte superior pero lo que mas resalta es el conjunto de paisajes que son aprovechados en el proyecto.

\section{SISTEMA VIAL DEL ENTORNO}

El acceso vehicular se encuentra en el nivel inferior del proyecto a través del circuito de playas de la costa verde, por ser una via rápida, solo cuenta con flujos de vehículos privados.

\section{AREAS LIBRES}

El proyecto cuenta con varias areas libres que son parte de la propuesta y del recorrido arquitectonico previsto. Como el lugar de congojo que es el espacio final, un espacio publico con una gran visual hacia el mar de grau.

\section{CIRCULACIONES VEHICULARES Y PEATONALES}

El ingreso peatonal ubicado en la cota más alta del terreno, bajando por una rampa a través de una quebrada creada entre el la naturaleza y el museo, mientras que las ciruclaciones vehiculares ingresan al edificio desde el circuito de playas de la parte inferior del provecto. 


\section{MEDIO AMBIENTE}

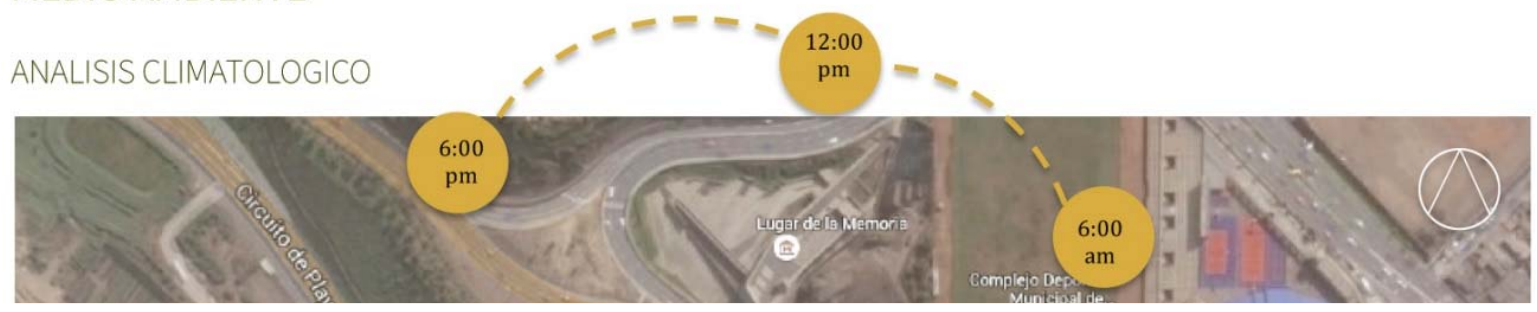

Figura 117 : Asoleamiento Lugar de la memoria Fuente : Propia

CLIMA

Lima es una ciudad con características climatisticas bastante peculiares. Lima no presenta clima drásticos, ni mucho frio ni mucho calor durante todo el año.

Presenta grandes niveles de humedad por su cercania al mary es un terreno desertico, llueve muy poco.

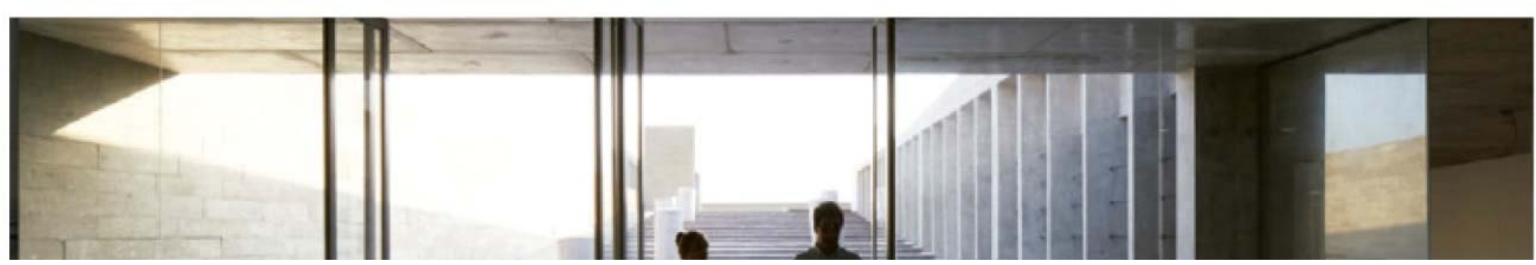

Figura 118 : Punto focal del Lugar de la memoria Fuente : Archdaily

\section{PAISAJE}

Los acantilados de la Costa Verde constituyen el patrimonio paisajista más importante de Lima. Se integra al paisaje recuperando la memoria de la Costa Verde, con su conformación de farallones y quebradas, utilizando en el proyecto sus elementos constitutivos característicos y la vegetación oriunda de carrizales permitiendo así unir la meseta de Lima con el océano, al pie del acantilado.

La volumetría del edificio simula la continuación de los acantilados de la costa verde, mimetizandose con el contexto natural del paisaje, siendo este un edificio moderno, la materialidad y la volumería ha sido prevista para que no compita con el entorno sino mas bien se complementen.

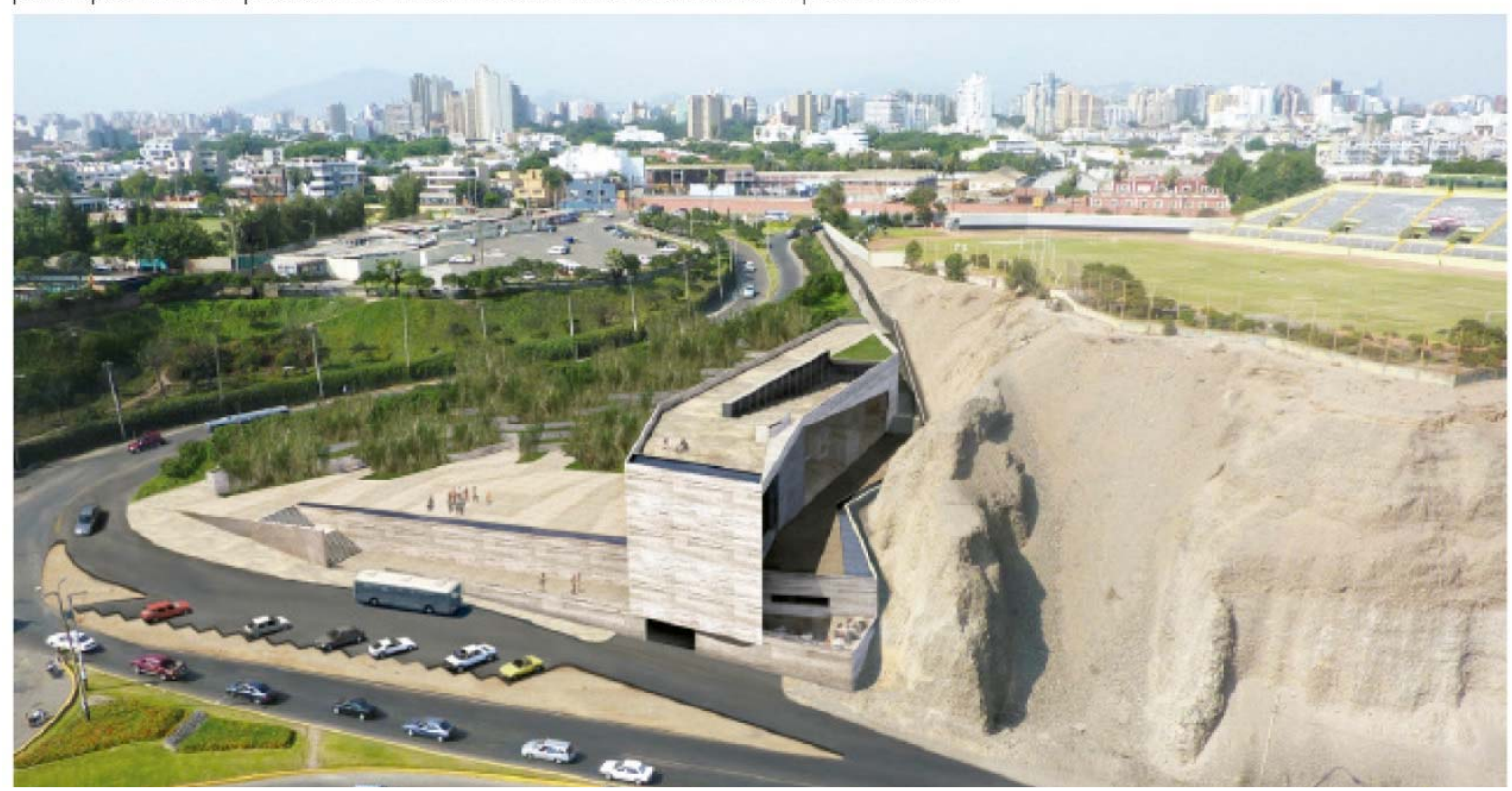

Figura 119 : Mimetización del Lugar de la memoria Fuente : Archdaily 


\section{ASPECTOS FUNCIONALES}

\section{PAQUETES FUNCIONALES}

Todo el proyecto tiene la funcion de dar a conocer esta tragedia que atraveso el Perú, el espacio se mimetiza con el entorno de modo tal que da un reconocimineto del lugar y de la historia que conlleva se funciona muy bien. En el recorrido el diseño espacial es hacia el interior el hecho de pertenecer a algo, en este caso un sitio, hace mas integro y coherente el proyecto con su localidad.

\section{ORGANIGRAMA E INTERACCION}

El edificio esta diseñado en cinco niveles, con un recorrido secuencial. Sin darte cuenta a traves de este se aciende. Las rampas permiten entender el proyecto y disfrutar de la musegrafia en su optimo desarrollo. Los espacios se complementan y la luz en los distintos espacis merminten entender el edificio como una sola unidad con diviciones de acuerdo a los usos. y lel mensaje a trasmitir.

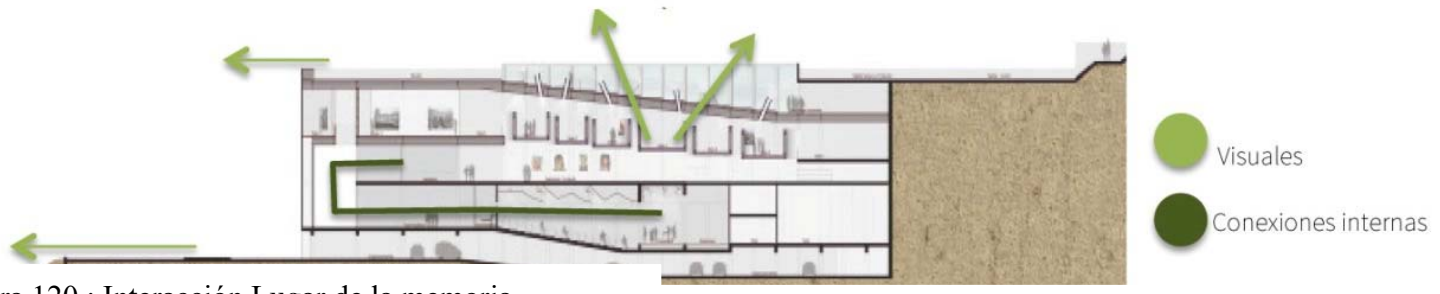

Figura 120 : Interacción Lugar de la memoria

Fuente : Elaboración propia

"Las salas de exposición con la museografía van acompañando la rampa en el recorrido. Sin casi darnos cuenta estamos subiendo hacia la luz, estamos subiendo hacia el techo. Y el techo cuando llegamos a él, resulta que no es un techo, es un nuevo suelo, es un nuevo pavimento, es un nuevo terreno que está a la altura de lima."

JP CROUSSE

\section{CERCANIAS Y LEJANIAS}

Las circulaciones del proyecto están en constante relación, son espacios amplios que se conectan generando experiencias culturales que gracias a la arquitectura se direccionan. Todos los espacios se plantean para generar una reflexión sobre lo ocurrido en el pasado que a atrvés de la arquitectura direcciona la experincia al visitante.

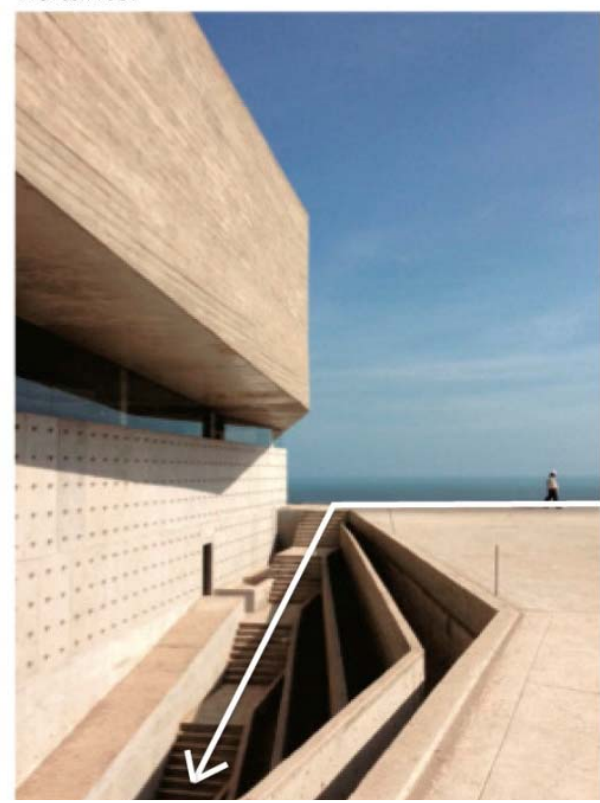

Figura 122 : Exterior Lugar de la memoria Fuente : Elaboración propia

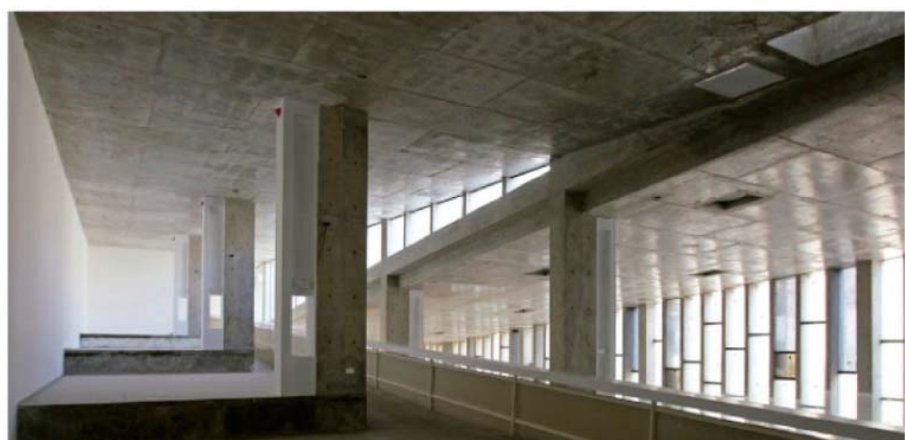

Figura 121 : Interior Lugar de la memoria Fuente : Archdaily

La circulación esta planteada por medio de un recorrido de rampas que ascendiendo hacia la gran explanada superior llamada la explanada de reconciliación.

Los ventanales ubicados hacia el sur general vistas sobre el farellón, enmarcándo e integrando conceptualmente a la exposión. La luz que ingresa se mimetiza con el entono, se mantiene una relación directa entre los espacios. 
PROGRAMACIÓN

LISTADO DE AMBIENTES

\begin{tabular}{|l|c|}
\hline \multicolumn{2}{|c|}{ PRINCIPALES CARACTERISTICAS DEL PROYECTO construida por nivel } \\
\hline \multicolumn{2}{|c|}{ Area } \\
\hline Nivel Estacionamiento & $1303.80 \mathrm{~m}^{2}$ \\
\hline Nivel Auditorio & $984.10 \mathrm{~m}^{2}$ \\
\hline Entrepiso administración & $286.50 \mathrm{~m}^{2}$ \\
\hline Nivel de Ingreso & $809.00 \mathrm{~m}^{2}$ \\
\hline Nivel Exposición & $11101.40 \mathrm{~m}^{2}$ \\
\hline Nivel Exposición 2 & $410.70 \mathrm{~m}^{2}$ \\
\hline Área del Terreno & $7573.32 \mathrm{~m}^{2}$ \\
\hline Estacionamientos & 42 en sotano \\
\hline Área Construida & 22 área libre \\
\hline Área Ocupada & $4895.50 \mathrm{~m}^{2}$ \\
\hline Área Libre & $1447.30 \mathrm{~m}^{2}$ \\
\hline Área ocupada en elevacion de \\
acantilado
\end{tabular}
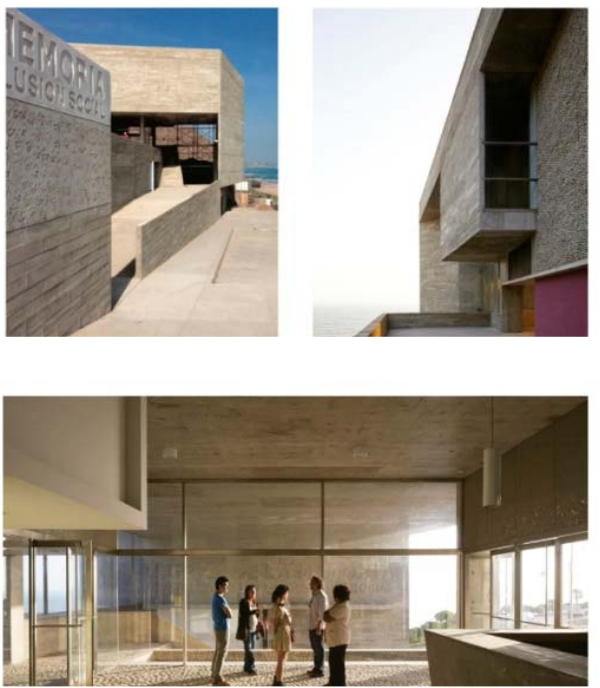

Figura 123: VistasLugar de la memoria Fuente : Elaboración propia
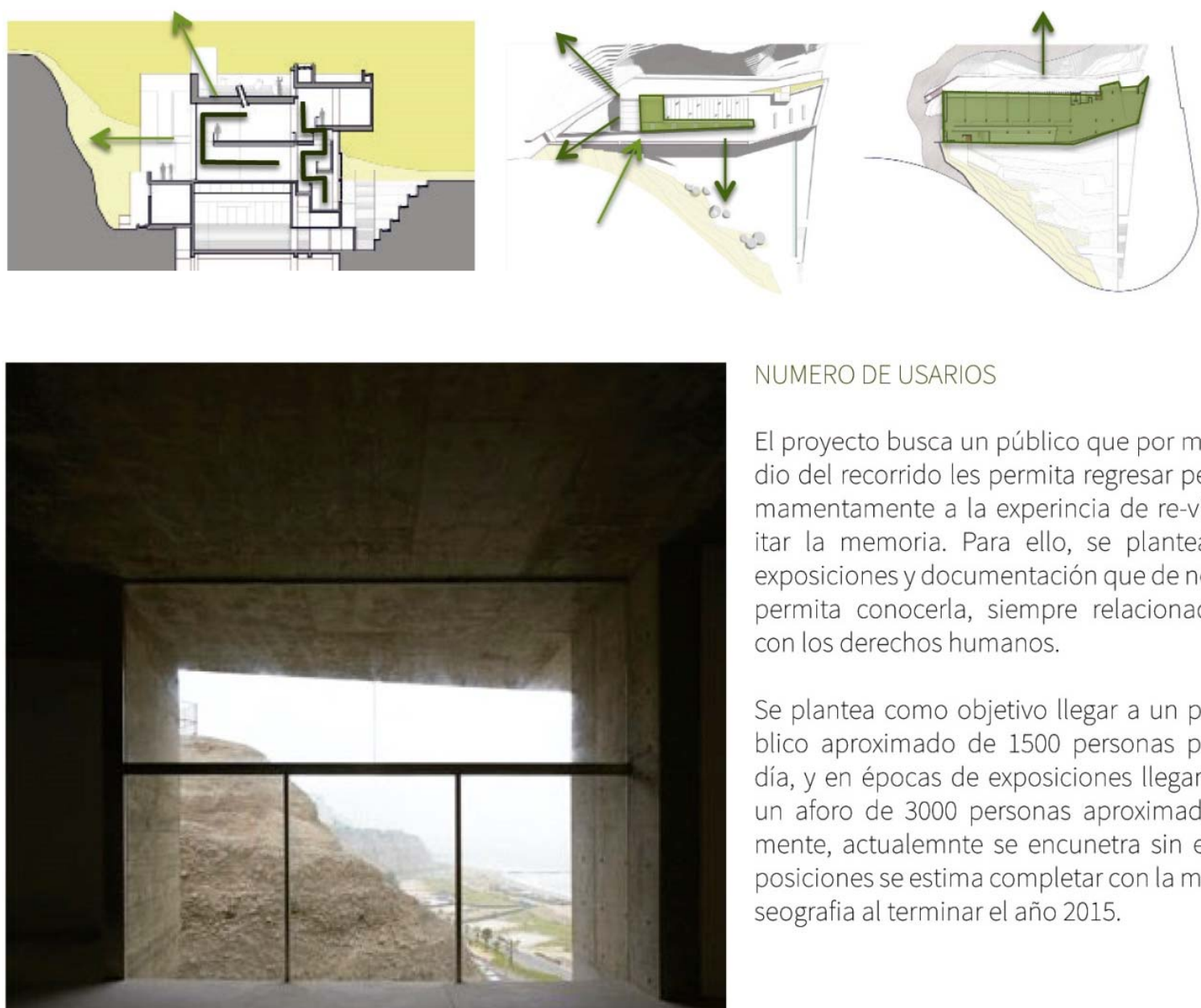

NUMERO DE USARIOS

El proyecto busca un público que por medio del recorrido les permita regresar permamentamente a la experincia de re-visitar la memoria. Para ello, se plantean exposiciones y documentación que de nos permita conocerla, siempre relacionada con los derechos humanos.

Se plantea como objetivo llegar a un público aproximado de 1500 personas por día, y en épocas de exposiciones llegar a un aforo de 3000 personas aproximadamente, actualemnte se encunetra sin exposiciones se estima completar con la museografia al terminar el año 2015.

Figura 124: Ventana Lugar de la memoria Fuente : Propia 


\section{ASPECTOS TECNOLOGICOS}

\section{SISTEMAS CONSTRUCTIVOS}

El edificio es de concreto armado, estructurado mediante columnas y vigas dispuestas ortogonalmente, conformando pórticos resistentes a cargas verticales y horizontales en ambas direcciones. Los entrepisos están estructurados como losas que se muestran de $60 \mathrm{~cm}$ de espesor con viguetas internas a cada $60 \mathrm{~cm}$ y losas de $5 \mathrm{~cm}$ en la cara superior e inferior. Asimismo, se ha usado el sistema de placas colaborantes.

\section{MODULACION ESTRUCTURAL}

Las Salas de Exposición que consisten en volúmenes con voladizos sobre la sala de exposiciones temporales, que forman cortes y dobles alturas que aluden a las profundas divisiones sociales.

Las diferentes salas son parte de un único espacio continuo y están separadas por un desnivel de piso de $45 \mathrm{~cm}$ una de otra, que corresponde al nivel de descanso de las rampas, evocando así en forma moderna los andene

\section{SISTEMA DE CERRAMIENTO}

En el proyecto hay espacios al aire libre, en interacción con el paisaje.En el interior los vitrales encierran un espacio que si bien esta delimitado, no se encunetra aislado del lugar. En todo el pryecto se reconoce el origen y la constante relación con su territorio.

\section{MATERIALES Y ACABADOS}

Los muros exteriores de las fachadas son de concreto cara vista encofrado con tablones de 8". La fachada norte del edificio cuenta con un revestimiento de paneles prefabricados de concreto. Se implementará con acabados de primera calidad. Las mampáras, ventanas y barandas son de acero inoxidable y de aluminio con vidrios templados. Los marcos y puertas de madera pintada. Los interiores son en piso de cemento pulido, cemento impreso, los muros y techos son en concreto expuesto o tarrajeados y pintados.

\section{APLICACIÓN TECNOLOGICA}

La responsabilidad con el medio ambiente es asumida por medio de dispositivos arquitectónicos simples para obtener el confort acústico y visual así como para lograr la mayor eficiencia en el consumo de agua y de energía.
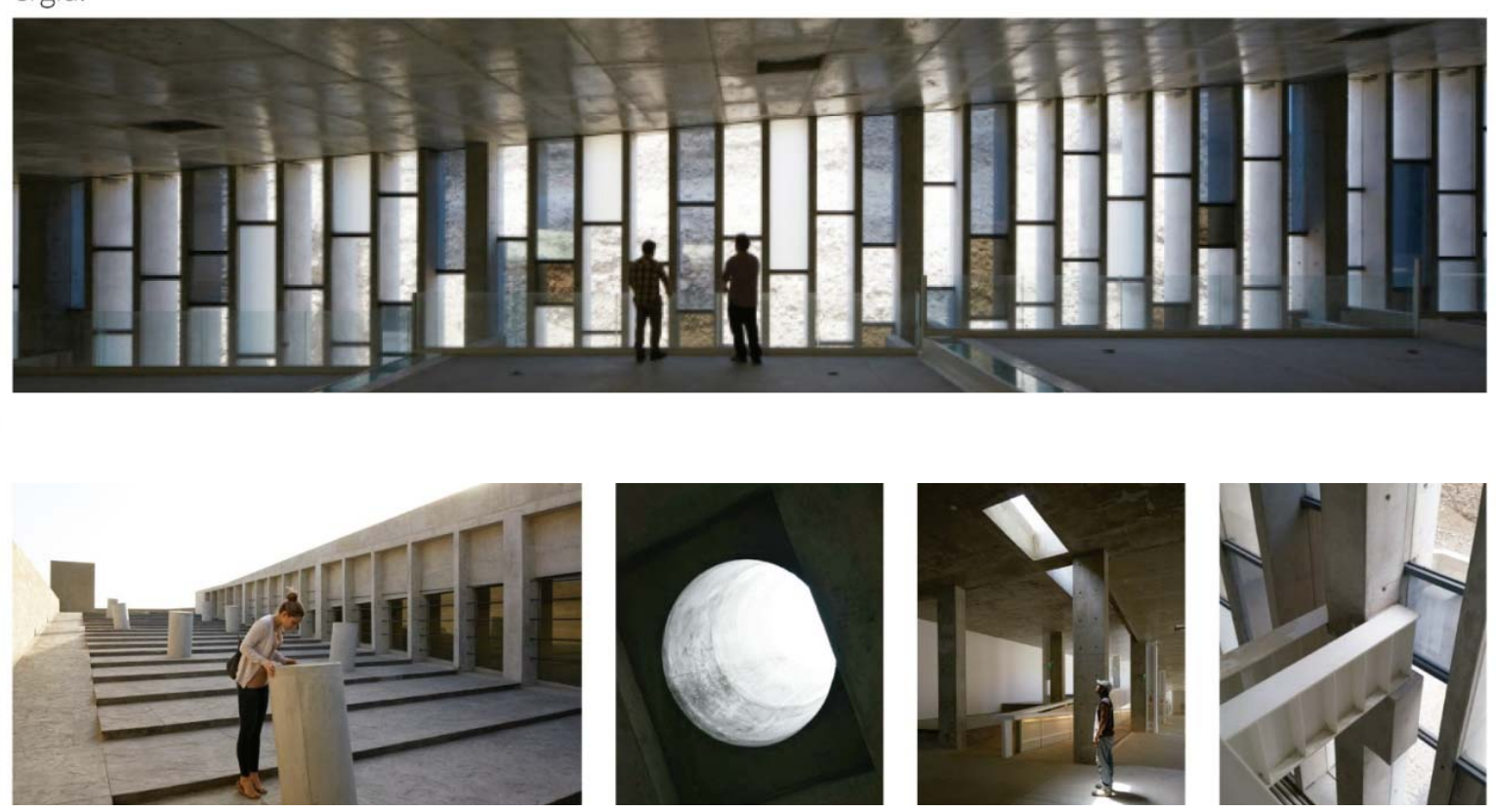

Figura 125: Luz y material - Lugar de la memoria Fuente : Propia 


\subsection{Cuadro Comparativo de los Proyectos}

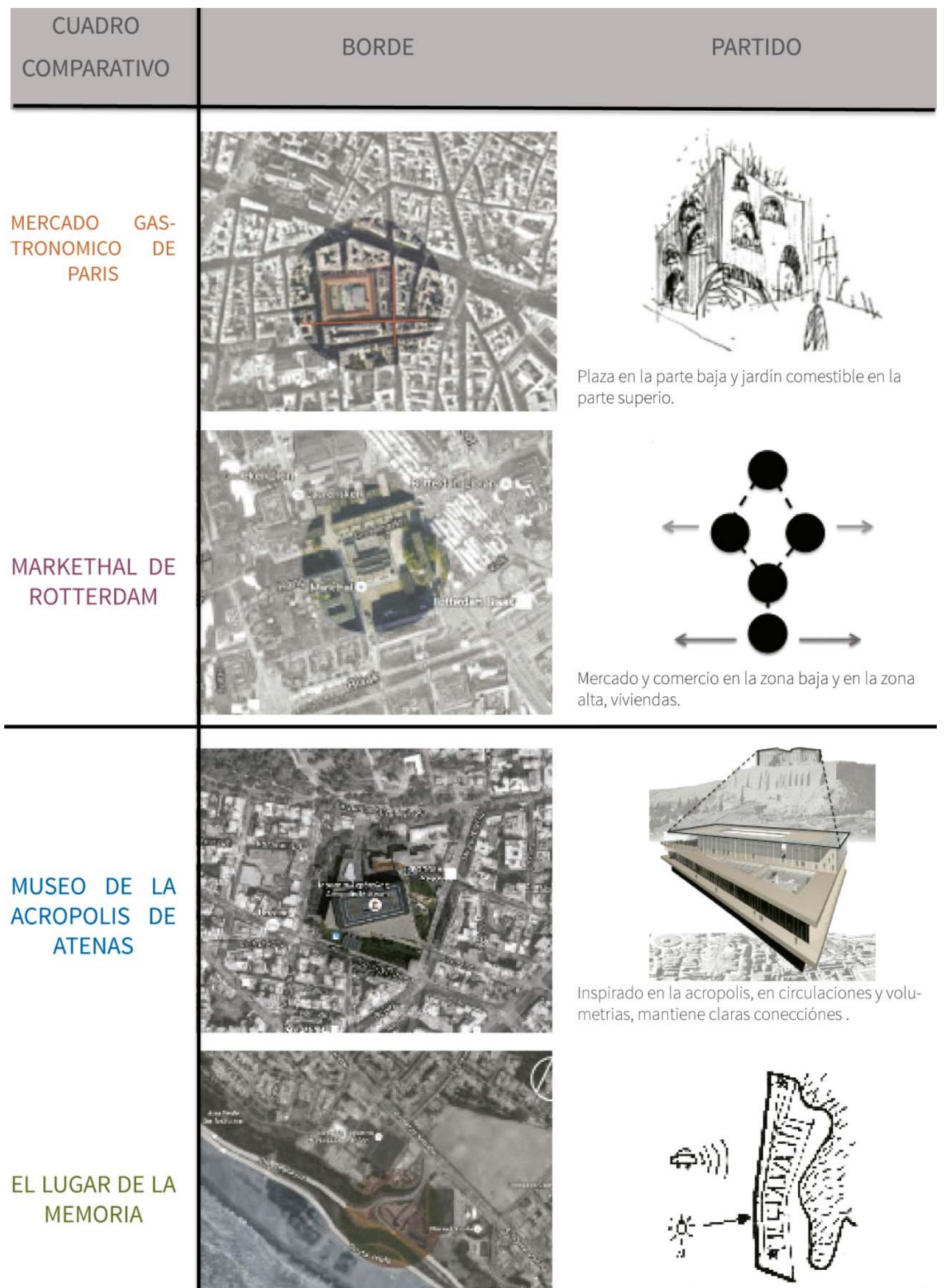

Se incerta muy bien al contexto, del oceano Pacifico y los acantilados de la costa verde. 

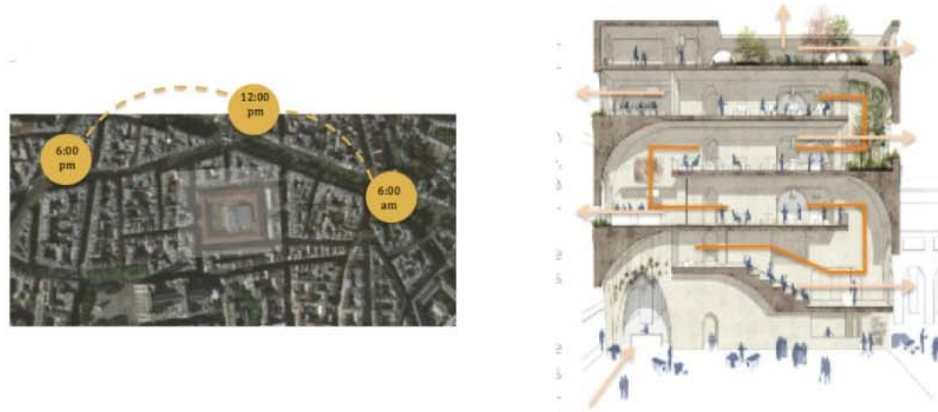

Buena orientación
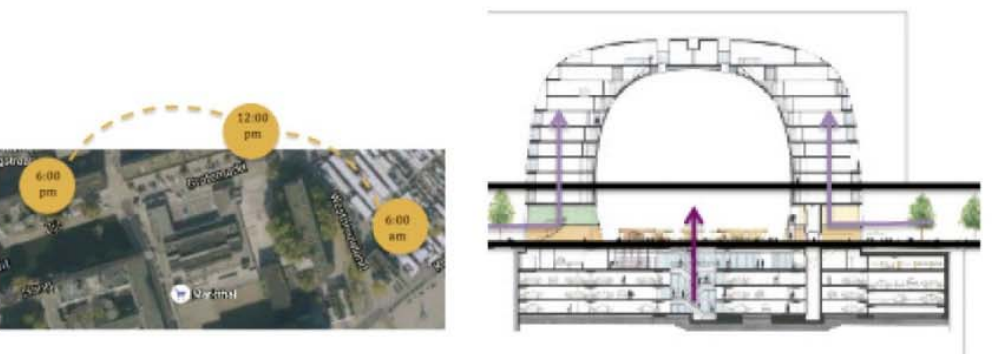

El proyecto integra muy bien el espacio con su entorno. Además plantea claras conecciones con los distintos espacios organizados verticalmente integrando los usos.

La zona del huerto en la parte superior concidero que le da un valor adicional a proyecto ya que no solo contribuye al medio ambiente sino engloba el objetivo del aprendiaje evocando siempre al origen extractivo del arte culinario y a traves de las visuales con la ciudad simula una reflexion sobre la trascendencia que este tendrá para la sociedad..

El proyecto marca una nueva manera de conceptualizar el mercado, la fusion de usos en el edificio lo hace bastante atractivo para analizar. Concidero que es un poroyecto innovador y que responde a las necesidades de la sociedad actual.

Si bien fusiona dos tipologias que son el mercado y la vivienda, al tener por circulaciones diferencias permite que los usarios de cierta forma sean distintos y su publico objetivo tambien. Ademas su volumetria imponente no pasa desapercibido y se ha vuelto un gran hito para la ciudad.

Ademas de la arquitectura muy bien lograda, con materiales contemporaneos y espacios inovadores que evocan a la historia de la acropolis. En concepto de reinter-
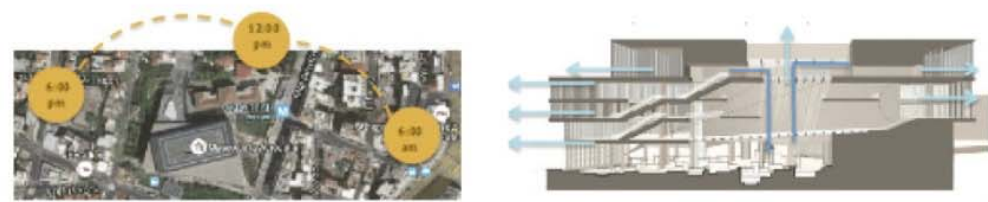
pretacion de lo existente subliminandolo y direccionando la experiencia por medio de la arquitectura, hace de este un proyecto de gran valor para la actualidad.

Las conexiones que plantea tanto visuales como espaciales son evidentes entendiendo el edificio no solo como tal sino como el contexto historico en el cual se encunetra incertado.

El proyecto se integra muy bien al entorno paisaijsta que lo engloba, ha sabido aporovechar el entorno natural como parte del recorrido del proyecto y como marcos paisajistas que la arquitectura enfatiza. Ademas de espacios con materialidades fasinantes por medio del recorrido te permiten contar de cierta forma una historia, que por medio dela buena ejecución de la luz natural el proyecto evoca a auna retrospeccion sobre el pasado generando aasi una reflexión de la identidad peruana. 


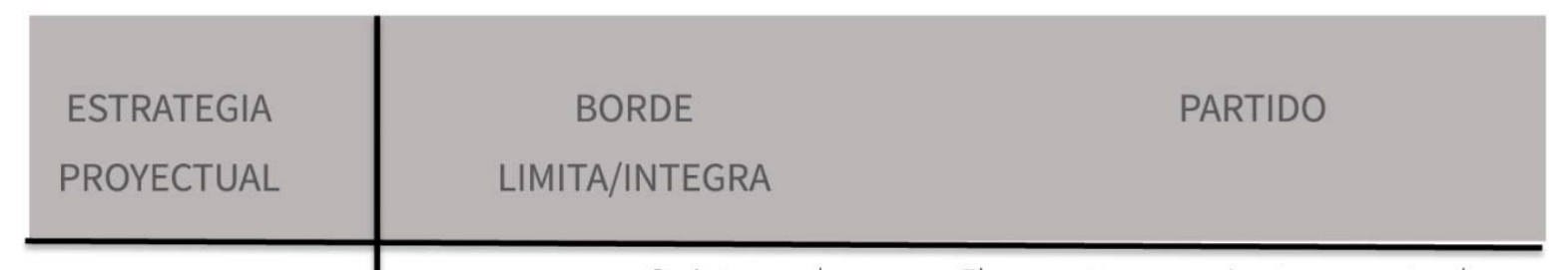

Se integra al espa- El proyecto en conjunto no pretende recio publico colin- saltar dentro del entorno, mas bien lo

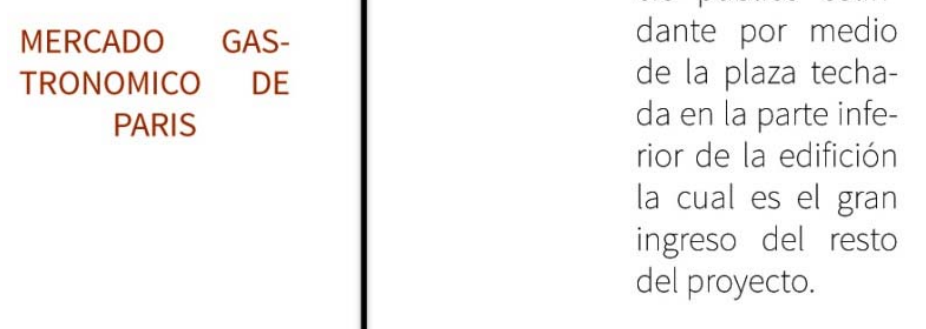

Se integra al conjunto pormedio de su volumetria con forma de "tunel", el cual permite su amplio recorrido complementa con el espacio publico en I planta baja en la cual se realiza el mercado.

\begin{tabular}{l|l} 
MARKETHAL DE & el cual permite su \\
ROTTERDAM & amplio recorrido \\
& sin mayores ob- \\
staculos.
\end{tabular}

El proyecto si busca resaltar dentro del entorno, su volumetri ay los coloridos no pasan desapercibidos, adicionalmente se le ha equipado con luces que en la noche emercan el edificio y lo hacen aun mas llamativo.

\section{MUSEO DE LA ACROPOLIS DE ATENAS}

\section{EL LUGAR DE LA MEMORIA}

Se integra notablemente con el entorno, principalmente con su entorno historico, la acropolis. El edificio esta inspirado en el y le hace referencia en todo momento espacial como volumetricamente.

Se integra muy bien al entorno principalmente paisajista. No compite con el contexto, el edificio es una vesrsion arquitectonica de los paisajes de su entorno hacia una retrospeccion de la historia peruana.

\begin{abstract}
Si biien el proyecto presenta una escala mayor notable dentro del resto de edificaciones del entorno, la importancia que este tiene en el conjunto en relacion a la zona historico hace que el edificio no se encuentre aisalado sino conectado con su origen y la sociedad lo entiende y lo valora como tal.
\end{abstract}

El lugar de la memoria se mimetiza con el acantilado de la costa verde, ademas en todo momento mantiene relacion con su entorno utilizando el paisaje para enfatizar los objetivos de reflexion en los visitantes. 
Funciona muy bien tanto desde el exterior como desde el interior. Los espacios estan relacionados y los estudiantes en ningun momento se aislan del resto de espacios del conjunto, permitiendo su aprendisaje más dinámico.
Es un proyecto muy bien logrado que funciona muy bien para la ciudad de Paris, la arquitectura de toda la ciudad esta bien lograda y se entiende como una ciudad integrada espacialment como arquitectonicamente, el edifcio no rompe por ese esteriotipo, ademas el ingreso no se encunetra aislado del conjunto resultando asi un edificio muy bien logrado que respeto su entorno y que a traves de la arquitectura enfatiza sus objetivos.

Si bien es un proyecto que establece una nueva forma arquitectonica de fusionar usos dentro de un mismo edificio, el colorido que establece en el interior me resulta un poco perturbador, si bien se necesitaba enfatizar las visuales interiores hacia la parte superior para contemplar su arquitectura, la forma misma del volumen da a anetnder el objetivo.. Su jerarquia con el conjunto ya es bastante llamativa y el colorido concidero que fue un poco ineseario.

El proyecto esta super bien logrado tanto arwuitectonicamente como en relacion con su entorno. El edificio por su volumetria, materialidad y visuales en ningun momento se encunetra aislado a su entono, ademas por tener la reconstruccion de los restos arquelogicos en la parte inferior el edificio simula estar incertado en la historia que por medio de las conexiones que mantiene con la acropolis lo corrobora.

Si bien el proyecto fue conebido como un lugar en el cual se cuente lo sucedido en la epoca del terrosimo que atraveso del Perú, resulta contradictoria en la elección del lugar para realizarlo.

Si bien el poryecto arquitectonicamente esta muy bien logrado, la propuesta pudo haber sido mejor lograda si el contexto en la que se encuentra y los restos en el enfatizan el objetivo.

\section{4}

4

proyecto tiene la funcion principa en el Perú y hacerun llamado de conciencia hacia una nueva mirada al futuro, es por ello que concidero que la arquitectura planteada en que dicha experiencia sea positiva se ha proyectado muy bien. Ademas el buen aprovochamiento del paisaje como parte del recorrido arquitectonica en notable en los dintintos espacios que el edificio presenta.

5 


\title{
3.6. Otros Proyectos Referenciales
}

\section{TERMINAL PESQUERO - LA LONJA}

\author{
URBANIZACION Y NUEVA LONJA FISTERRA
}

Se trata de actuaciones en el frente marítimo de la villa de Fisterra, en una zona de dominio público marítimo terrestre en la que confluyen la actividad portuaria y las principales actividades turísticas y de esparcimiento.

Gran parte del ámbito de intervención se encontraba ocupado indiscriminadamente por coches, construcciones auxiliares de bares y restaurantes generando Nula legibilidad de un espacio sin vistas, lugares de estancia pública, ni legibilidad en sus recorridos.

Se hacía imprescindible ordenar el tráfico rodado, el aparcamiento y la relación peatonal que tradicionalmente se producía entre el pueblo y el puerto.
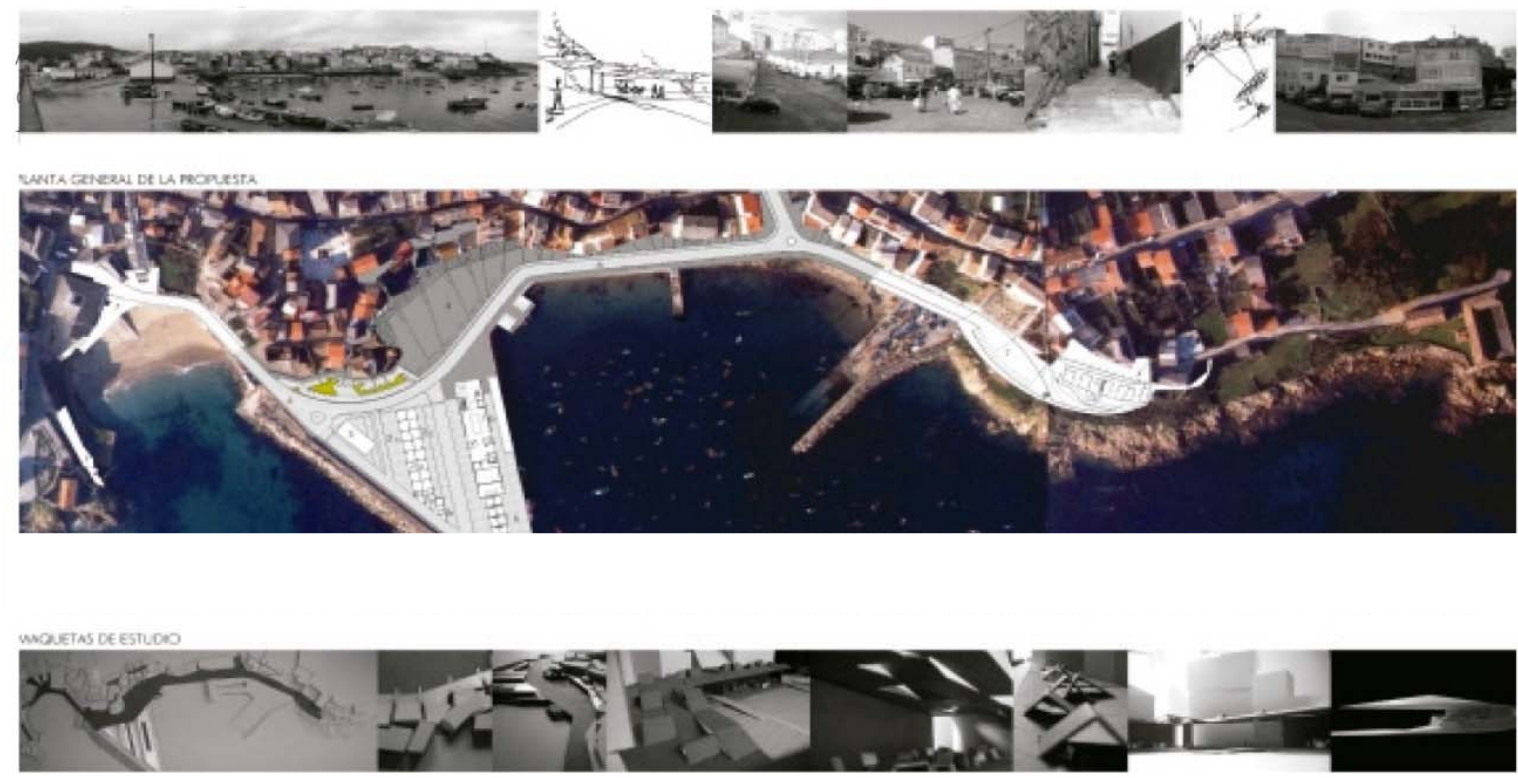

CONCEPTO

En la zona portuaria, se propuso agrupar actividades: armadores, subasta, oficinas Cofradía y Portos en un nuevo edificio, ocupando parte de las construcciones existentes. Desde un principio se maneja la idea de un contenedor ligero posado en el muelle, como un embalaje o una embarcación más.

El espacio de subasta plantea, como experiencia pionera en Galicia, la posibilidad de recibir visitantes al mismo tiempo que se realiza la actividad de lonja. Separar su recorrido de los trabajadores se convierte en un objetivo que condiciona la distribución y el programa básico de una lonja convencional, apareciendo funciones añadidas, como la información, exposición de material didáctico o la de control y tienda.

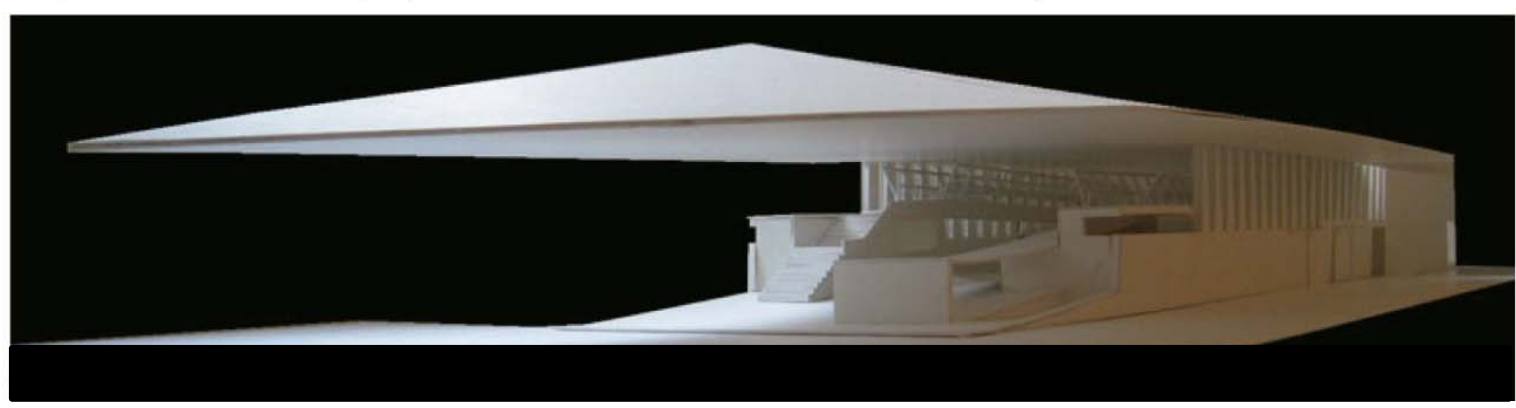

Figura 126: Maqueta - La lonja Fuente : Archdaily 
La implantación en el sitio, entre las alineaciones en ángulo de un paseo y un muelle, se resuelve aceptando su propia geometría. Así el edificio tiene muy claros su inicio y final en pico, manifestado principalmente por dos aleros de cubierta. El primero, con un vuelo máximo de 17 metros, está presente en la plaza y es el que acoge a los visitantes.

El del final, que remonta la cota del espigón, es el de la oficina de puertos, espacio administrativo y de control portuario. Entre ambos, las oficinas de la cofradía y los nuevos departamentos de armadores, cuya planta baja se retranquea del perímetro para dejar espacios de trabajo a cubierto.

Al lado de una rampa de piedra, entre embarcaciones varadas, la presencia del edificio en el muelle se va estrechando hasta desaparecer en un quiebro.
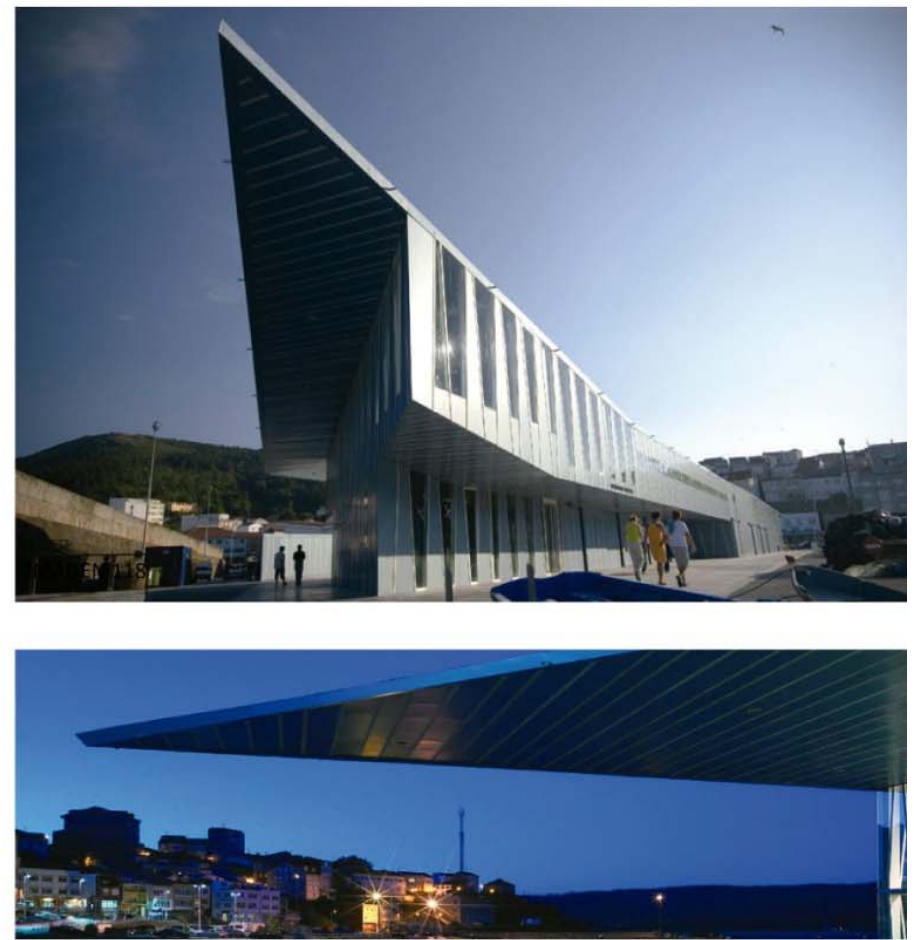

Figura 127: Proporcion- La lonja Fuente : Archdaily

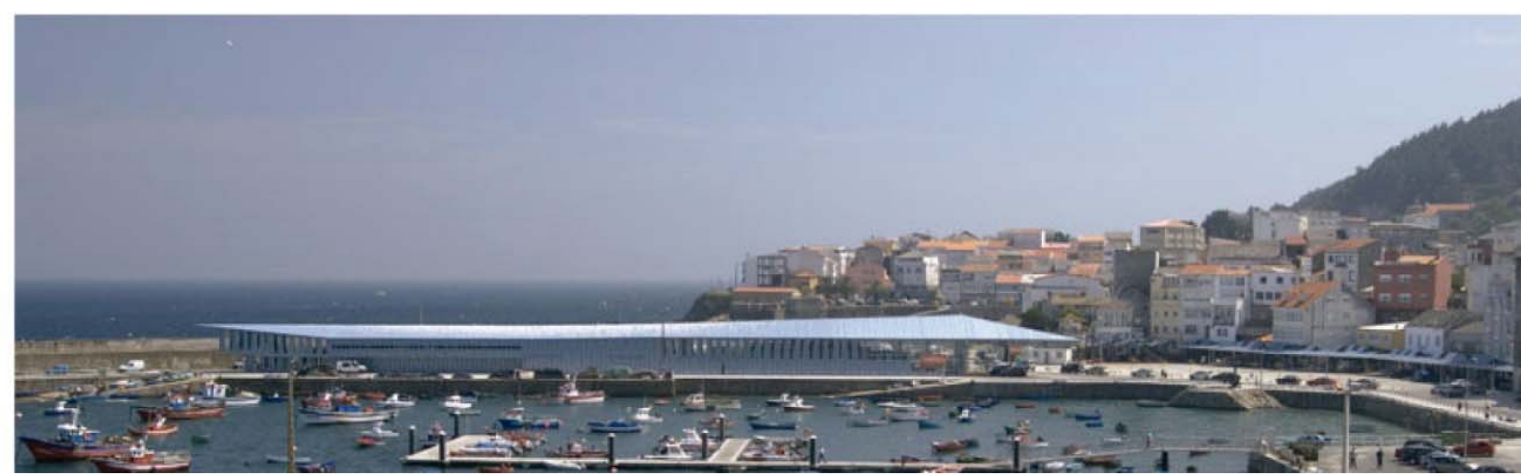

Figura 128: Escala - La lonja

Fuente : Archdaily

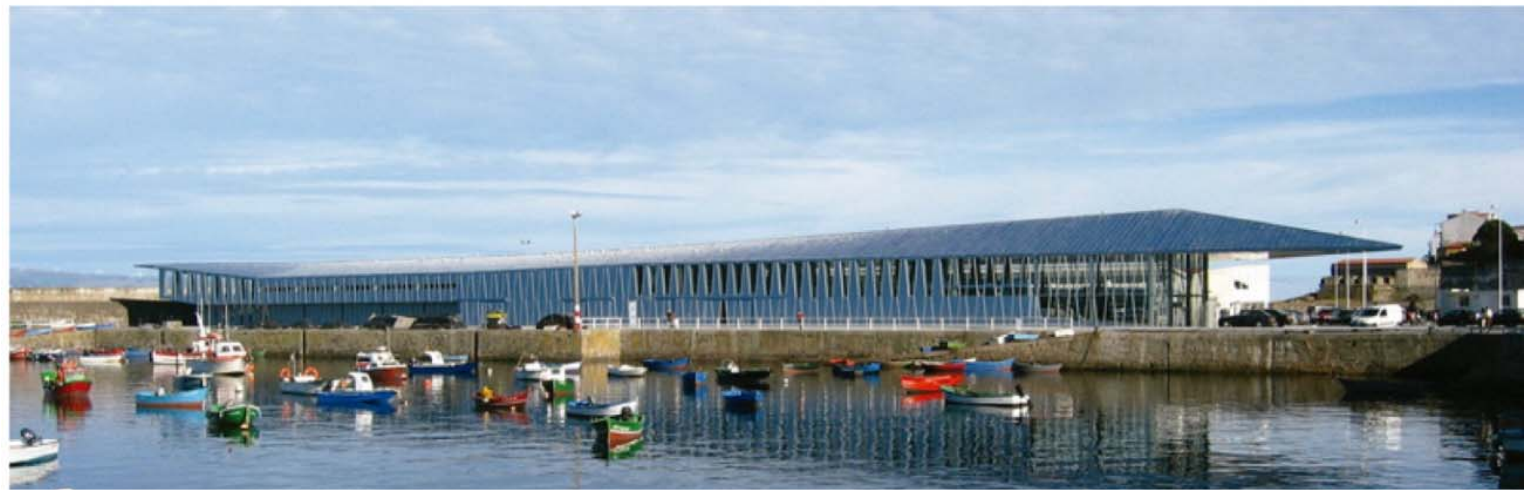

Figura 129: Emplazamiento - La lonja Fuente : Archdaily 


\section{ESQUEMAS DE FUNCIONAMIENTO}

Básicamente se plantean dos esquemas de funcionamiento muy simples que no se tocan: uno elevado para visitantes (anillo), con inicio y final en el vestíbulo, y el otro definido por la secuencia lineal a nivel de suelo de los trabajos, con accesos transversales de carga y descarga (espina).

Todo el edificio está modulado con un despiece trapezoidal de un panel de base 1.5 metros de ancho. La sustitución de piezas opacas por vidrios, tanto en planta baja como alta, define los accesos y entradas de luz, como a través de una malla. El suelo exterior, independientemente del uso que tenga, se prolonga en el interior sin discontinuidad, creando en el vestíbulo principal un espacio diferenciado de observación mediante su plegado en rampa

Las pasarelas que cruzan el recinto de exposición y venta del pescado protegen sus laterales con pantallas de vidrio inclinadas que funcionan como barreras higiénicas y sirven de soporte al material expositivo. Las dos se unen en una sala de exposiciones en la que se documentará información complementaria.

De esta manera se permite un recorrido en el que se combinan la observación de la actividad de lonja, sin interferirla, y la de documentación e información complementaria.

A continuación, integrados en el mismo volumen, se reubican los diez departamentos de armadores de la lonja antigua y, en el extremo final, la oficina de Portos, controlando la actividad portuaria.
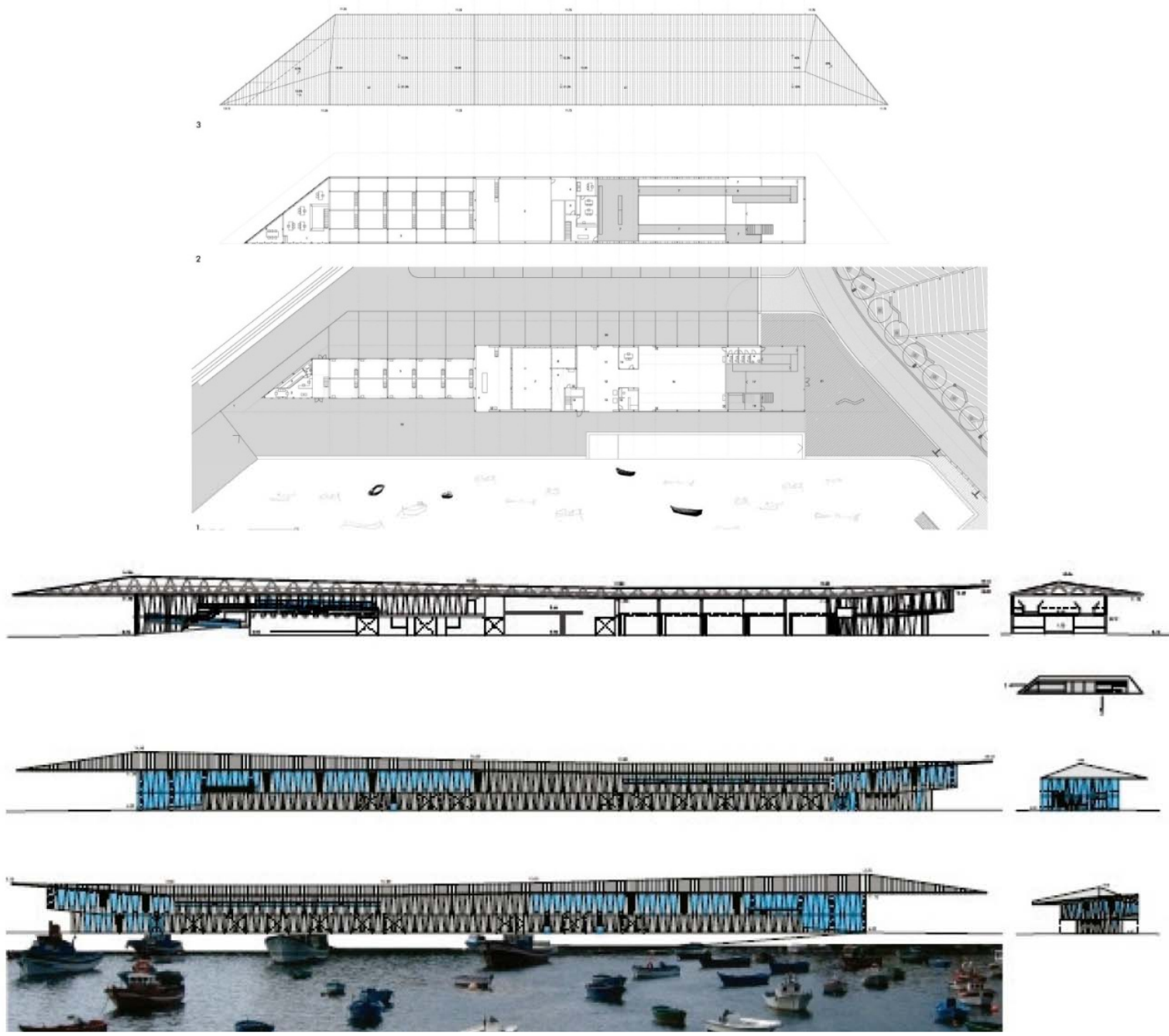

Figura 130: Planos y Arquitectura - La lonja

Fuente : Archdaily 
SUPERFICIE CONSTRUIDA

La Lonja que da cabida a los armadores y portos abarca una superficie construida de $1.880 \mathrm{~m} 2$

Espacios a cubierto $778 \mathrm{~m} 2$

Superficies urbanización:

Pavimentos de piedra $11.000 \mathrm{~m} 2$

Otros $3.545 \mathrm{~m} 2$

Zonas verdes $734 \mathrm{~m} 2$, árboles 56 uni-

dades

Aparcamiento 203 coches

Viales $9.566 \mathrm{~m} 2$ (6.021 pu + $3.545 \mathrm{po})$

Plaza y aceras $4.979 \mathrm{~m} 2$, de los cuales

$2.584 \mathrm{~m} 2$ corresponden a la plaza

Espacios cubiertos plaza $800 \mathrm{~m} 2$

Cubiertos armadores (edif.exist.) 745 m2

\section{PLAZA}

El derribo de la nave de departamentos de la antigua lonja permitió crear una gran plaza en torno a la cual situar los nuevos elementos

\section{APARCAMIENTO}

El aparcamiento tiene capacidad para 203 vehículos, de las cuales 181 son públicasy 22 para los armadores.

\section{MATERIALES}

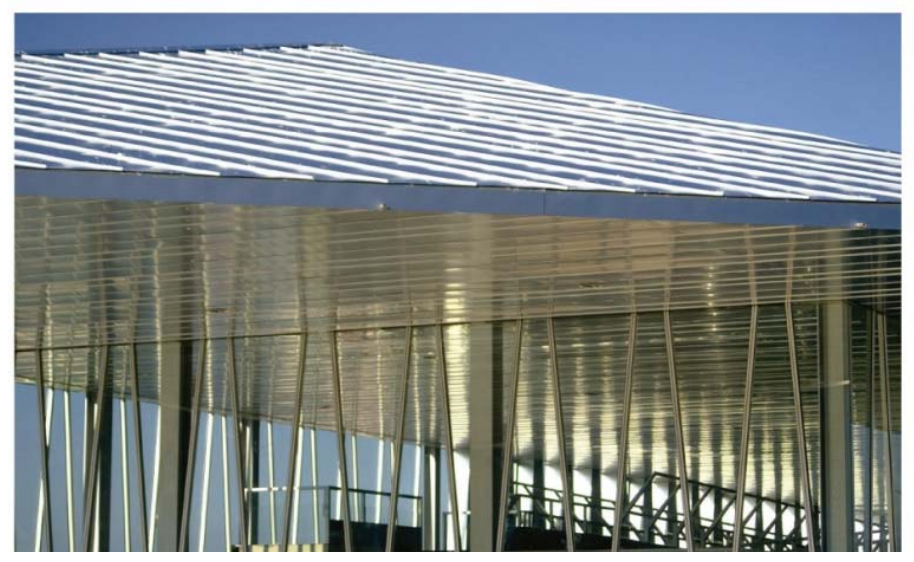

Figura 131: Techo - La lonja Fuente : Archdaily

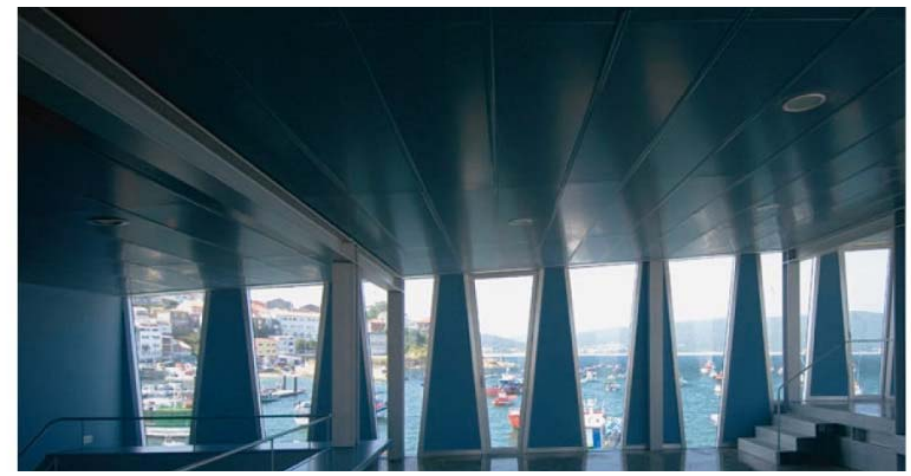

Figura 132: Superficies - La lonja Fuente : Archdaily

Estructura de cubierta malla espacial, resto mixta metálica y muros de hormigón. Los acabados de cubierta y falsos techos son de chapa de aluminio.

Las fachadas se han recubierto con panel composite aluminio con carpintería exterior de aluminio anodizado. Pavimentos de hormigón pulido, resinas y granito Cañiza en exterior. Los pavimentos de piedra cubren una superficie de 11.000 metros cuadrados.

Acero esmaltado e inoxidable en su estructura.
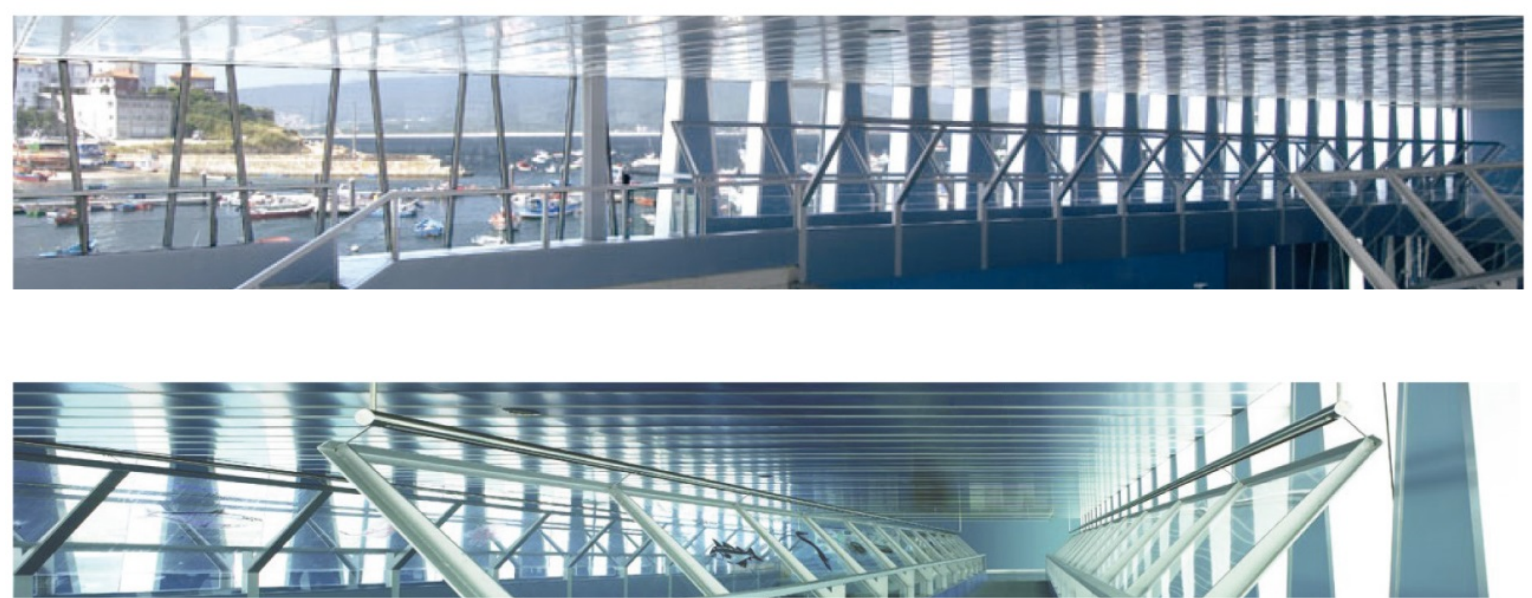

Figura 133: Estructuras - La lonja Fuente : Archdaily 


\section{MISTURA - USUARIOS}

MISTURA SOMOS TODOS

Nuestra rica biodiversidad merece un escenario especial y en Mistura lo tenemos claro; el Gran Mercado de Mistura es el recinto donde los pequeños productores de las diversas regiones del Perú se reúnen para exponer los mejores productos de nuestra tierra.

Hasta aquí llegarán alrededor de 300 agricultores de nuestra costa, sierra y selva, distribuidos en 150 stands, para ofrecernos sus quinuas de colores, papas nativas, ajíes, verduras y frutas orgánicas, además de los más deliciosos productos procesados.

Toda una celebración de esa gran despensa de la gastronomía que es la tierra peruana.

Aquí también cocineros y campesinos se darán la mano y compartirán sus conocimientos en La Cocina del Gran Mercado; donde cada día de feria un cocinero hará una demostración de cocina con un producto emblemático peruano, acompañado del agricultor que lo cosechó. La preparación será compartida con los presentes.

Según cifras de ventas, a Mistura llegaron 384,553 personas, aproximadamente un $20 \%$ más que el 2014. Los distritos más mistureros fueron San Miguel, Miraflores, Surco, Los Olivos, Cercado de Lima y San Juan de Lurigancho, pues solo en estos distritos se expendió más de cien mil entradas a la feria.
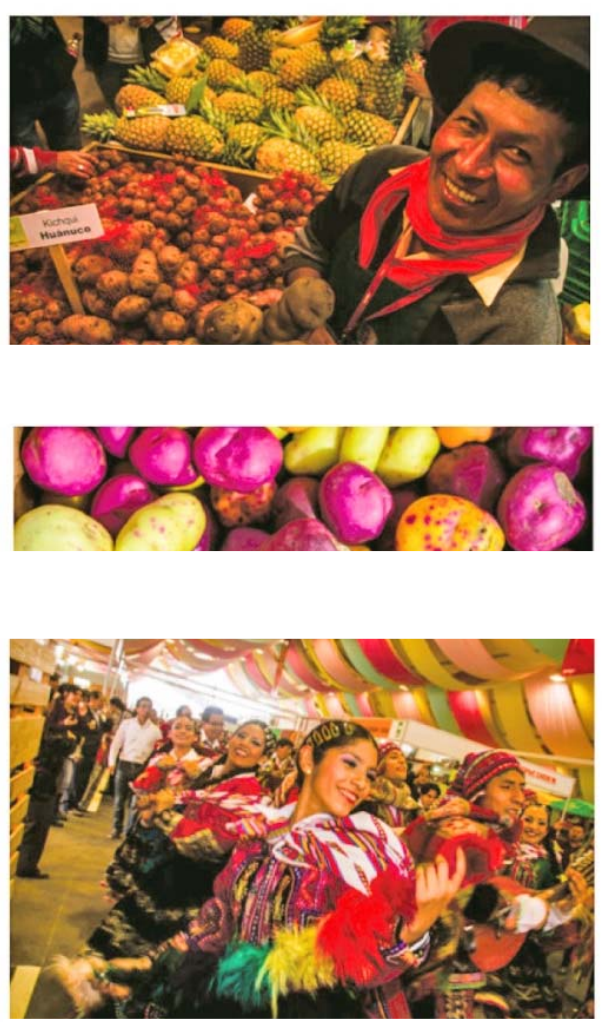

Figura 134: Cultura - Mistura Fuente : APEGA

la gastronomia hoyen dia es la actividad numero uno de reconomiento de identidad para los peruanos, desde los sabores hasta los productos. Se encuentra en las revistas mas conocidad y comentarios mas frecuentados de los altos funcionadrios culinarios del mundo entero. es fascinante como la gastronomia une el pueblo, une raicesy genera orgullo nacional. Todos los peruanos tienen la posibilidad de seguir haciendo que esto incremente que llegueaser un patrimonio nacionalygeneraractividadesqueentorno a ella. Esuna responsibildiad dejarenaltoal Perù, rescatando sus ventajas y haciendolos conocidad siendo estos nexos de desarrollo para el pais en general.

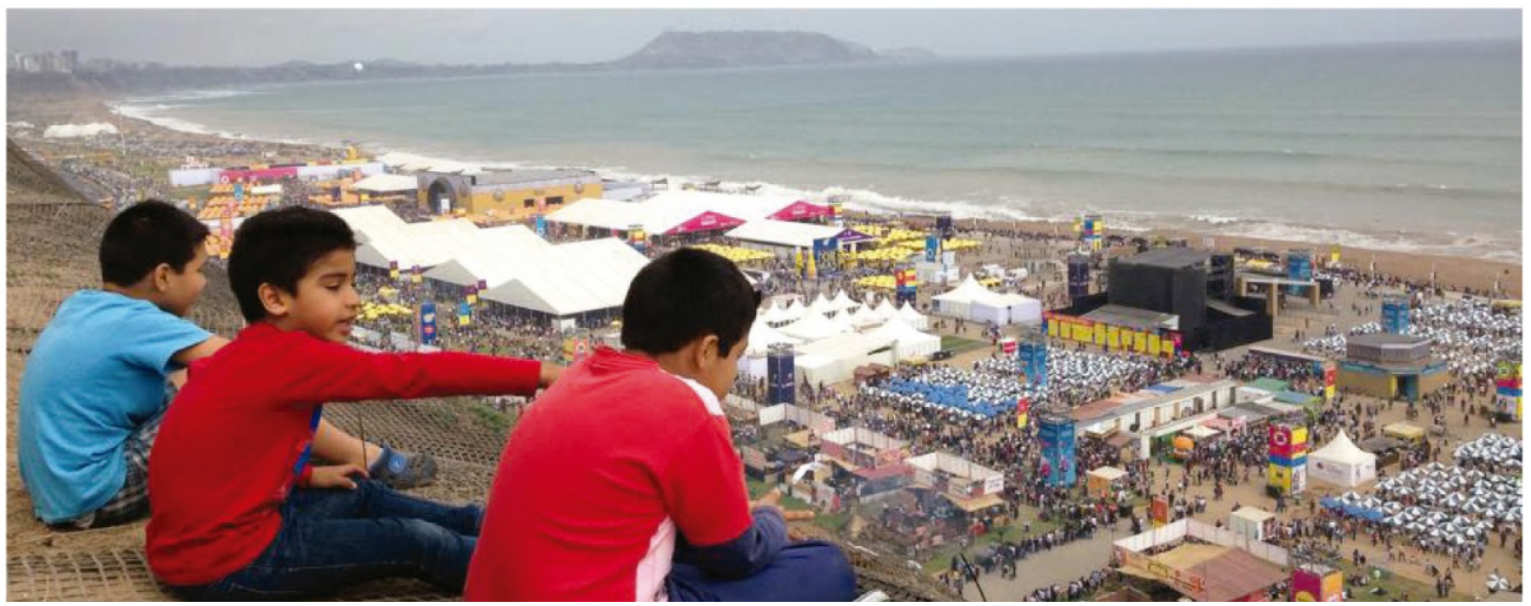

Figura 135: Conversaciónes trascendentes - Mistura Fuente : Propia 


\section{MALECON 2000 - BORDE HACIA EL MAR}

TRATAMINETO PAISAJISTA Y CULTURAL

Desde el alba es posible ver a lo largo de los 2,5 kilómetros del Malecón 2000, en el centro de Guayaquil, a decenas de personas. Unas trotan y otras realizan diversos ejercicios en grupos. También hay quienes simplemente caminan aprovechando la brisa y la tranquilidad en el inicio de la mañana. Con el pasar de las horas, el lugar se vuelve muy concurrido. Llegan turistas nacionales y extranjeros, personas que utilizan el sitio como atajo para movilizarse a algún punto del centro, delegaciones de estudiantes de escuelas o quienes desean conversar, pasear, leer o descansar bajo la sombra de un árbol del lugar.

Luego de 14 años de su remodelación y ampliación, dentro de un programa de regeneración urbana, el Malecón de la avenida Simón Bolívar se ha convertido en el principal ícono de referencia turística y de recreación de la ciudad. Según la Fundación Malecón 2000, encargada de la administración y mantenimiento de este parque recreativo de Guayaquil, mensualmente es visitado por 1600000 personas.

"El día con mayor número de visitantes es el 25 de julio con 940000 personas a tal punto que la calle del Malecón se vuelve peatonal". Ampliar La obra de regeneración marcó un antes y un después del malecón desde octubre de 1999 cuando se inauguró su primera etapa. Hasta antes del inicio de los trabajos de remodelación era un sitio abandonado en algunos sectores y peligroso.

En sus 2,5 kilómetros, los visitantes pueden ver una serie de estatuas y monumentos que se mantienen del antiguo malecón, y también con jardines. Igualmente, están los restaurantes, el centro comercial, fuentes, un cine, museo e incluso los muelles desde donde zarpan barcos con paseos turísticos. Los turistas extranjeros captan con sus cámaras los detalles del lugar, especialmente las estatuas antiguas, como los jabalíes, que son parte del lugar desde 1931, cuando se creó el Paseo de las Colonias.
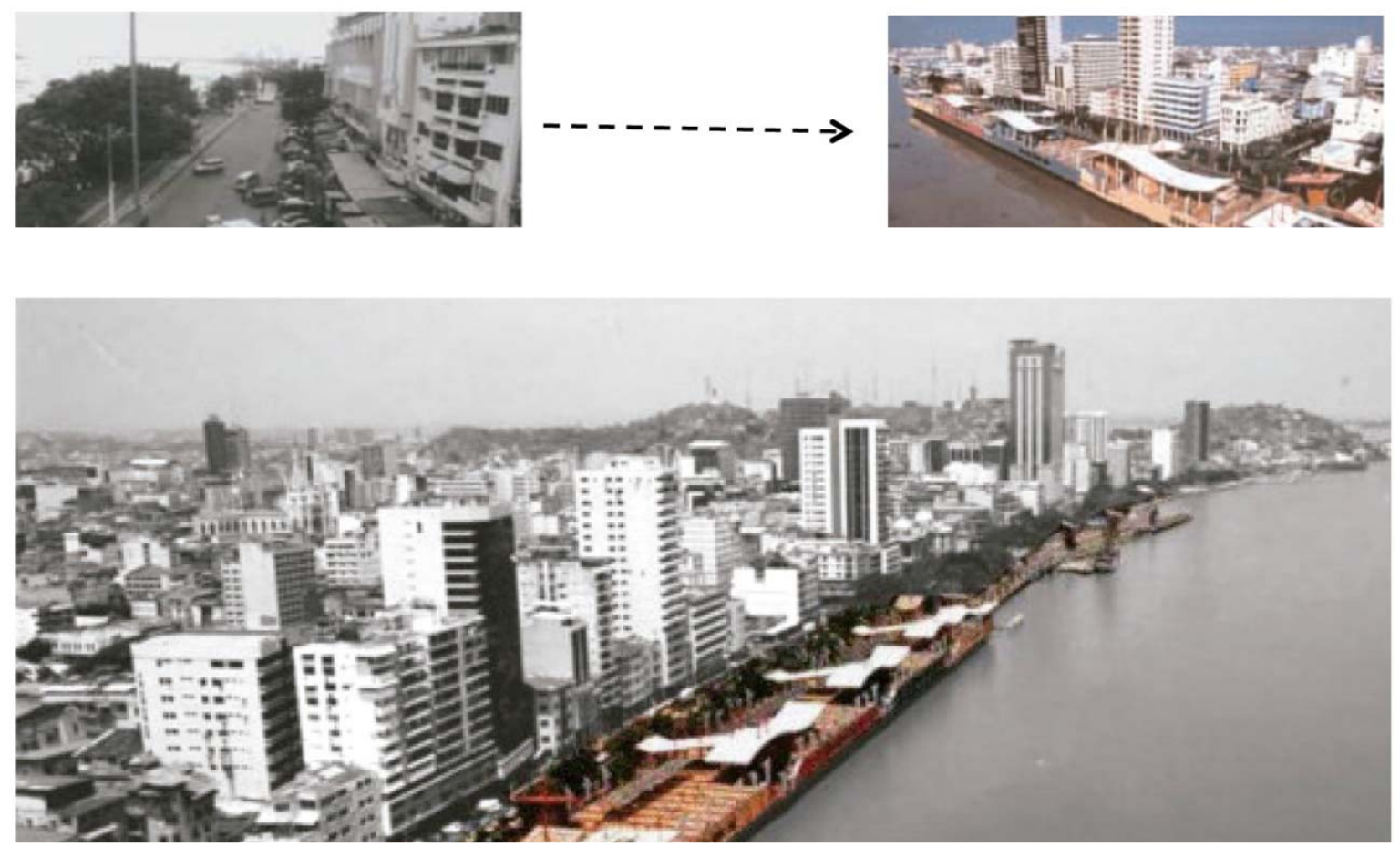

Figura 136: Evolución - Malecón 2000

Fuente : Elaboración propia 


\section{Capítulo 4. El Lugar}

\subsection{Localizacion}

Figura 137: Localización

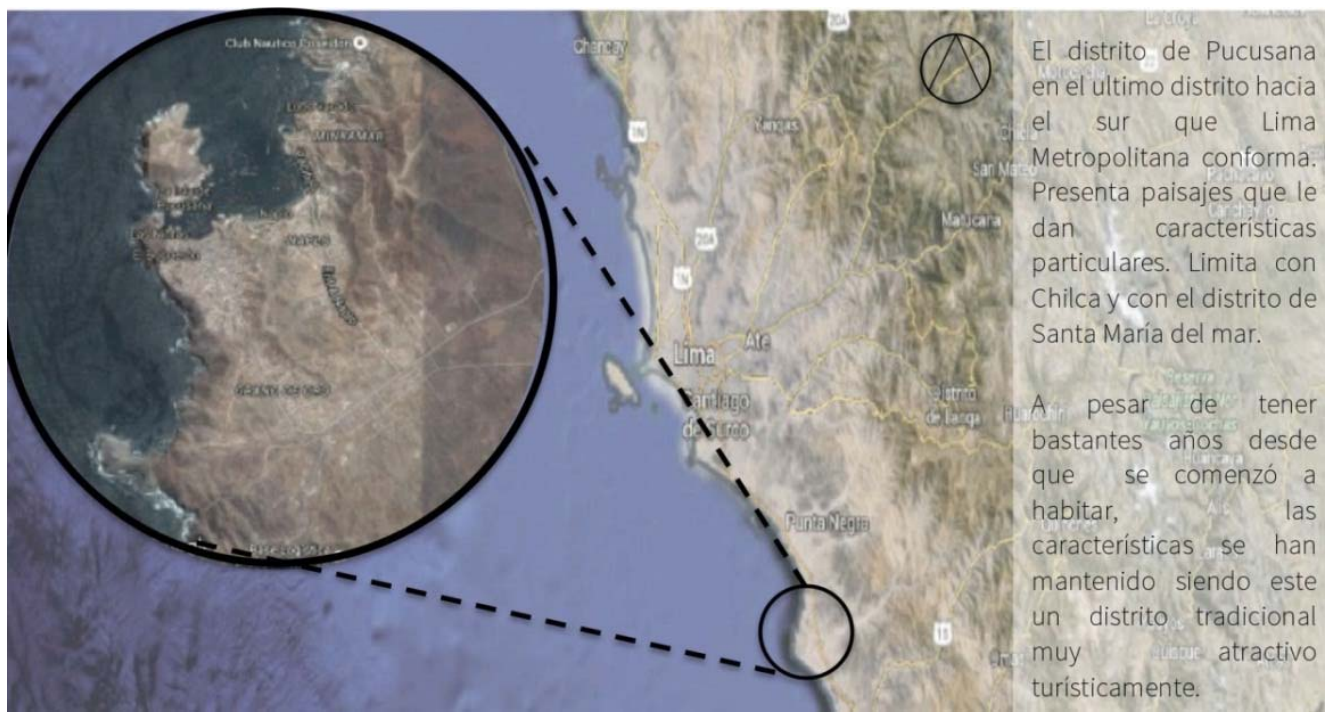

Fuente : Google Maps

Frente al malecón y como parte del distrito se encuentra una isla la cual se puede apreciar desde las alturas de los cerros que el distrito presenta.

Figura 138: Urbanismo 1

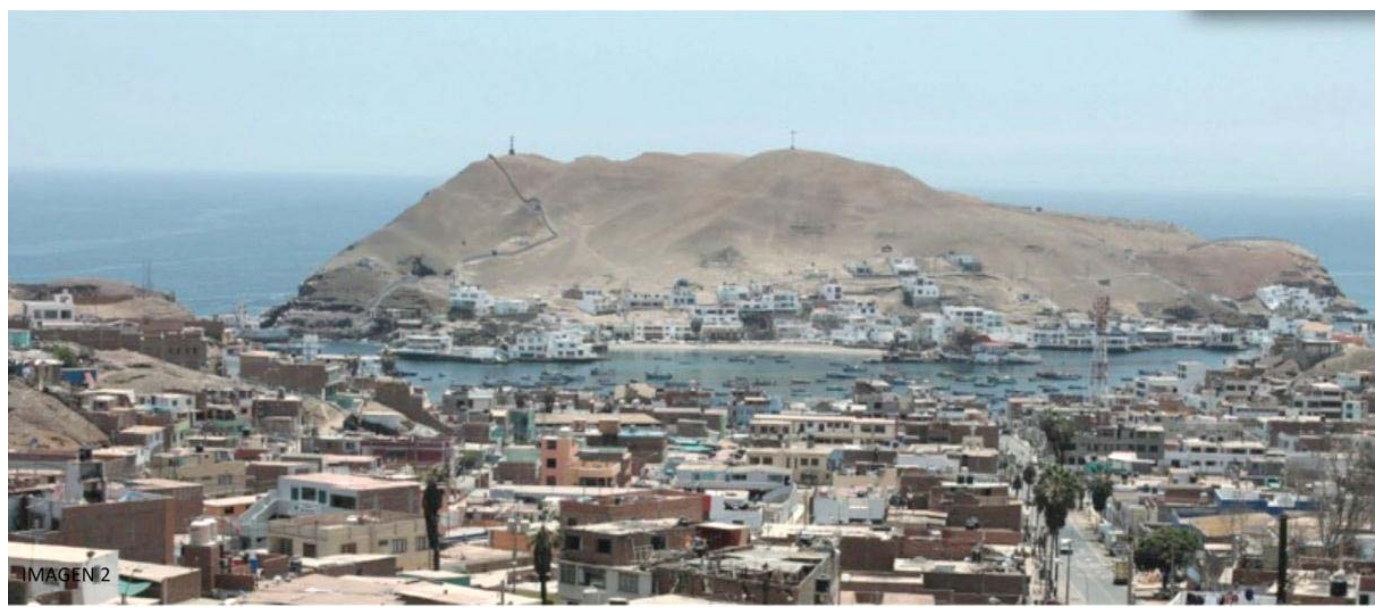

Fuente : Propia 
Figura 139: Urbanismo 2

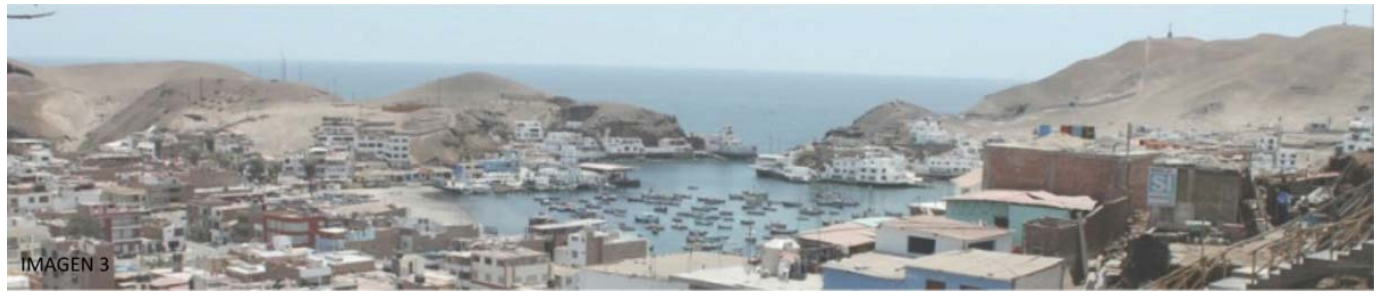

Fuente : Propia

\subsection{Condicionantes}

\subsubsection{De ubicación}

Al lugar de accede a través de la Av. Lima, que es una vía que se conecta con la Carretera Panamericana Sur, es el ultimo acceso desde esta avenida y al final del recorrido se encuentra el mar y la caleta natural que el distrito caracteriza.

Figura 140: Accesibilidad

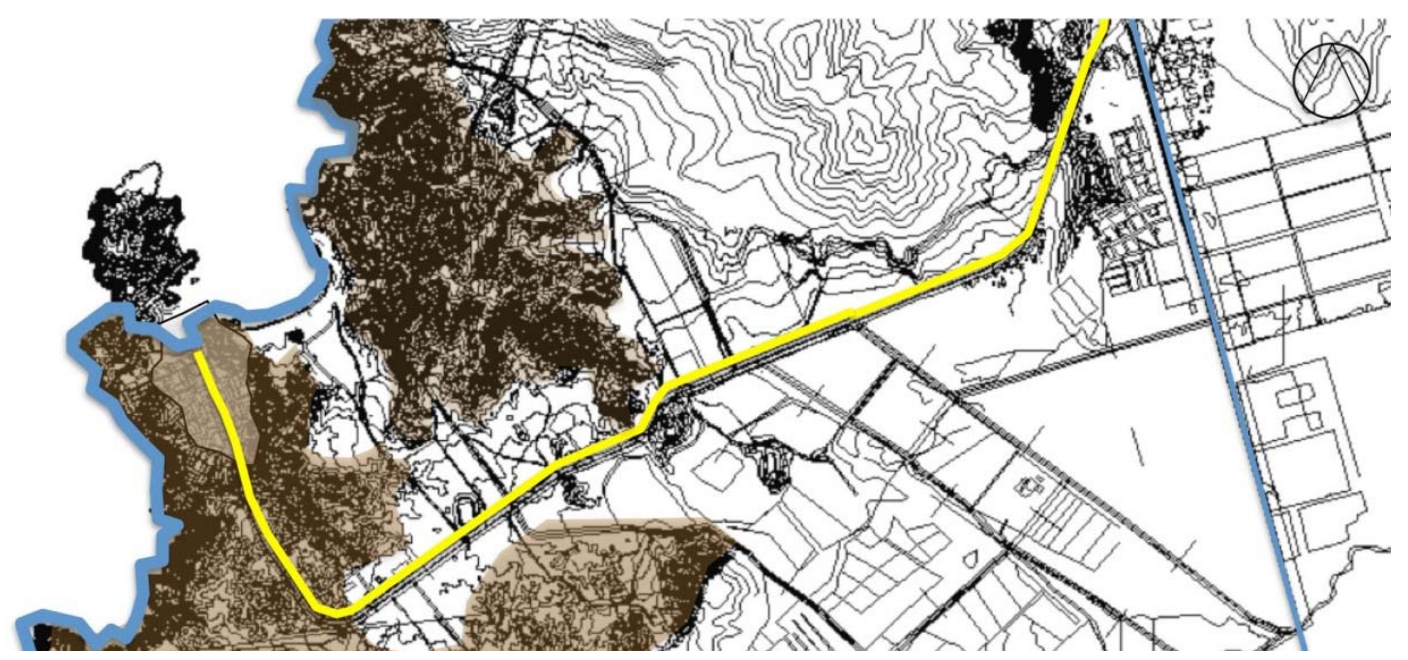

Fuente : Elaboración propia

\subsubsection{Fisicas}

Las condiciones físicas del distrito varían, presenta una topografía con cerros de altura moderada, presenta muchos paisajes naturales y el principal es el de la vista hacia la bahía. El ingreso se encuentra mayor altura que en el malecón, de modo que vas descendiendo atreves del recorrido. 
Figura 141: Condiciones físicas del lugar
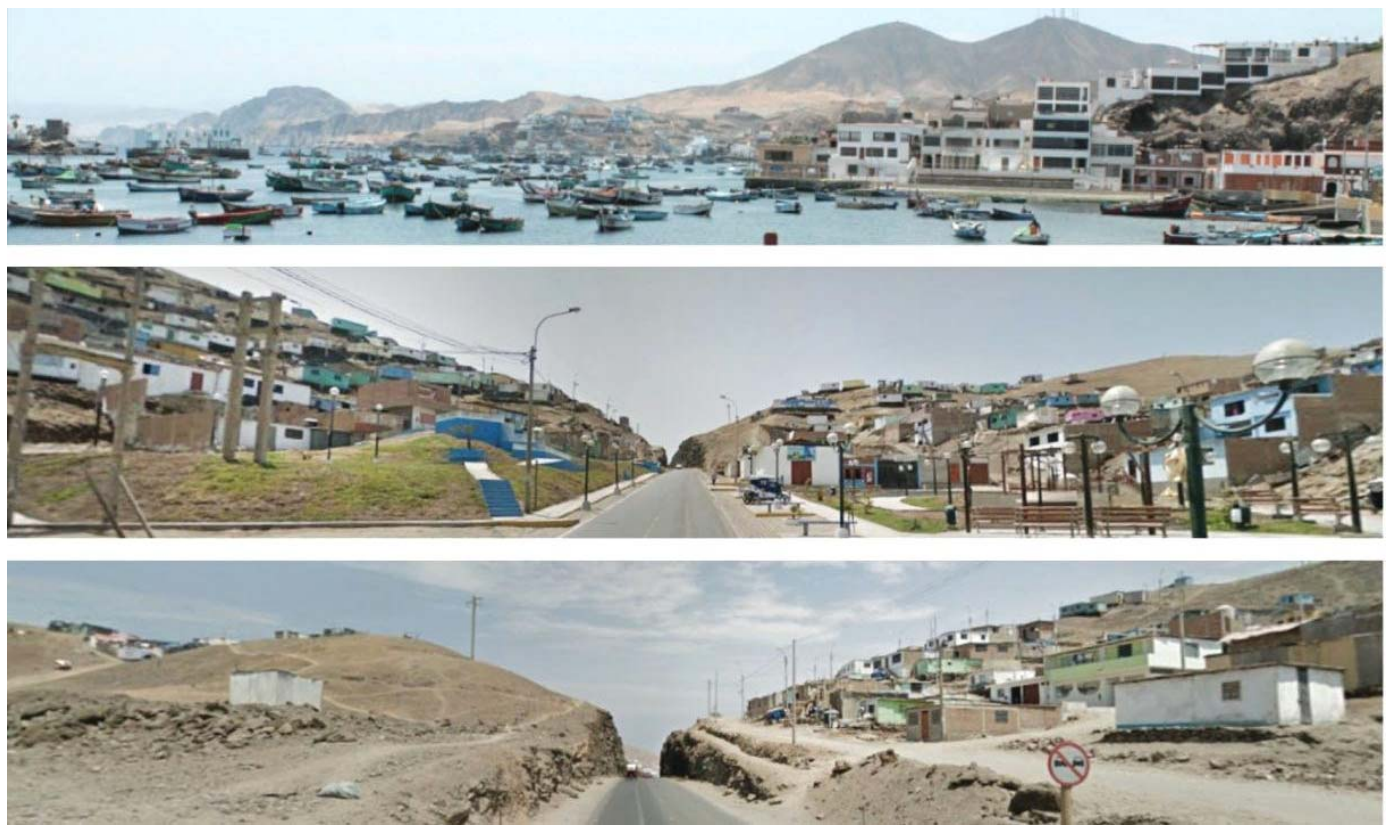

Fuente : Propia

\subsubsection{Estudio Urbano}

\subsubsection{Zonificacion y usos de suelo}

Figura 142: Zonificación

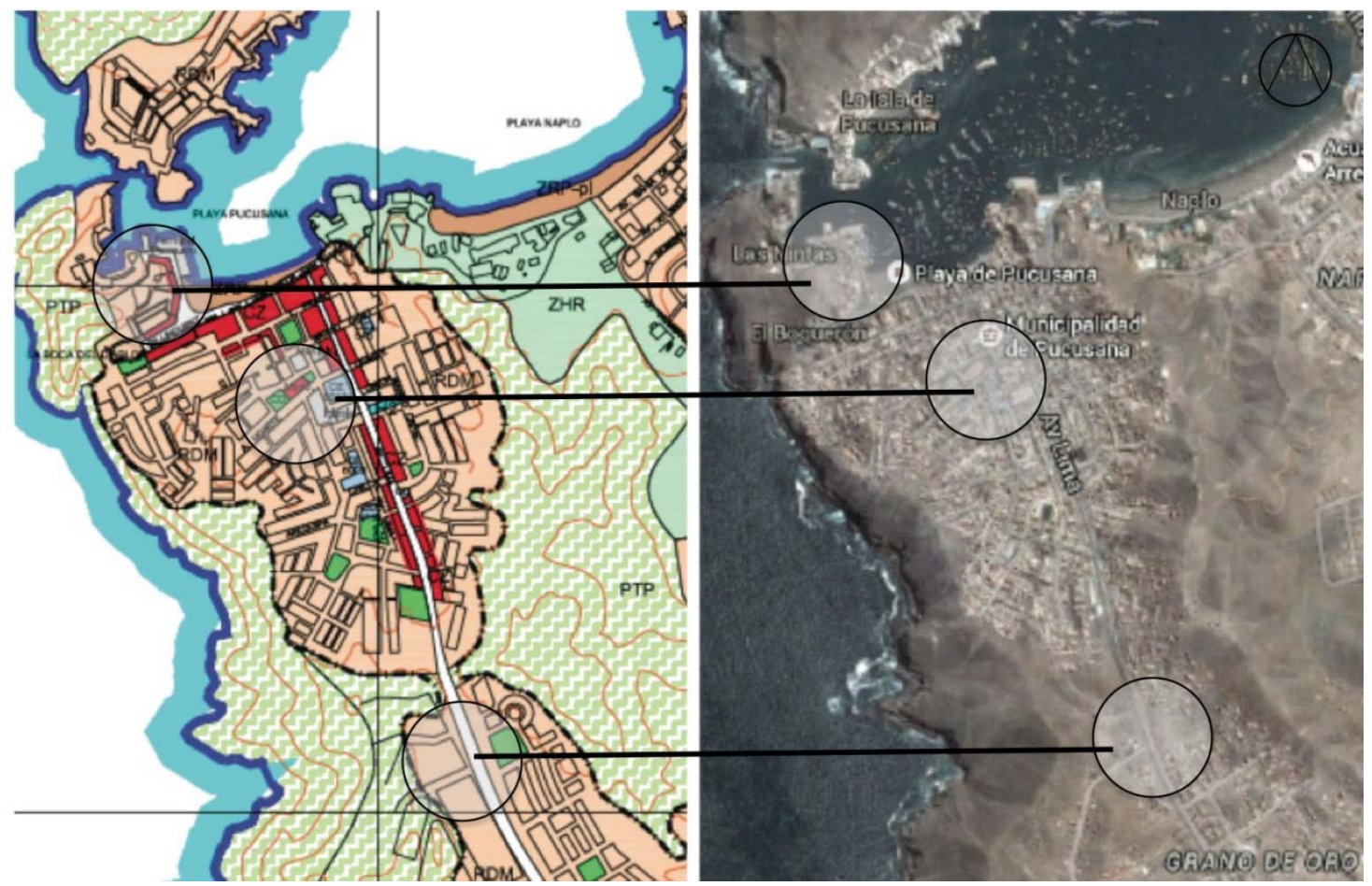

Fuente : Elaboración propia 
La zonificación del distrito no presenta mucha variedad en su conjunto, la mayor parte es de vivienda de densidad media, con permiso de comercio en el nivel uno, dos y tres.

En los limites de la avenida Lima siendo esta el eje del distrito y la vía que la conecta con el exterior. Se genera comercio local con actividades relacionadas al ámbito culinario y gastronómico.

Su actividad comercial más importante es la pesca, por lo que los restaurantes del lugar lucen los más variados platos hechos a base de productos del mar, donde destacan los cebiches, tiraditos y sudados aprovechando el paisaje para atraer a clientes de todas partes del mundo que vana visitar el distrito.Cuenta con tres playas y una isla conocida como Galápagos debido a que en los años 20 abundaban las tortugas del mismo nombre. Sin embargo, su principal atractivo es El Boquerón, formación rocosa producto de las olas que revientan en el lugar. Todo un espectáculo acuático.

Figura 143: Boquerón del Diablo
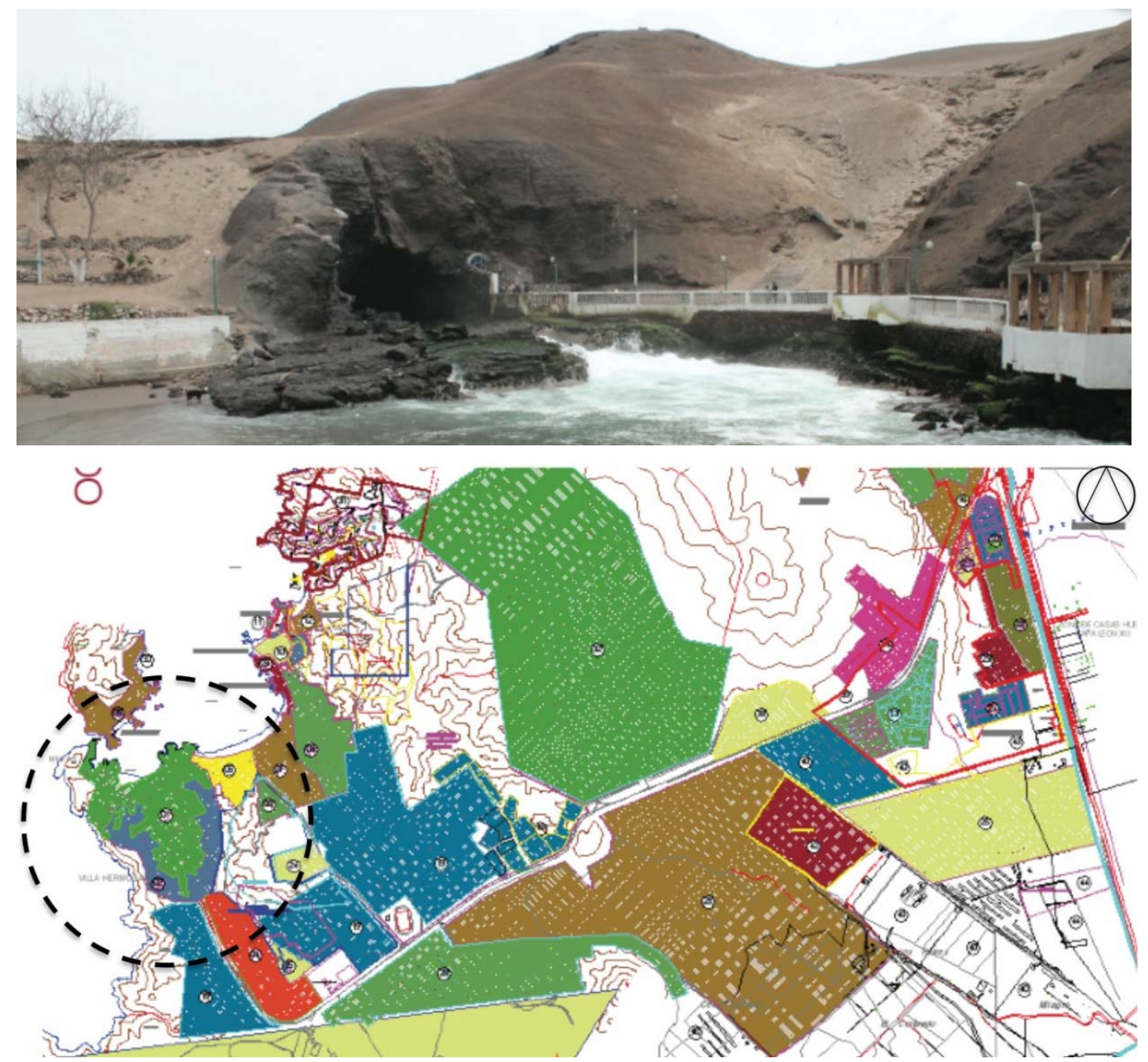

Fuente: Propia 
El distrito presenta una gran variedad de usos y de espacios destinados a distintas actividades. En los últimos años el sector se ha vuelto altamente industrial, muchos de los terrenos son de empresas importantes para el país y que ejecutaran proyectos en el terreno. Figura 144: Avenida principal - vista aerea

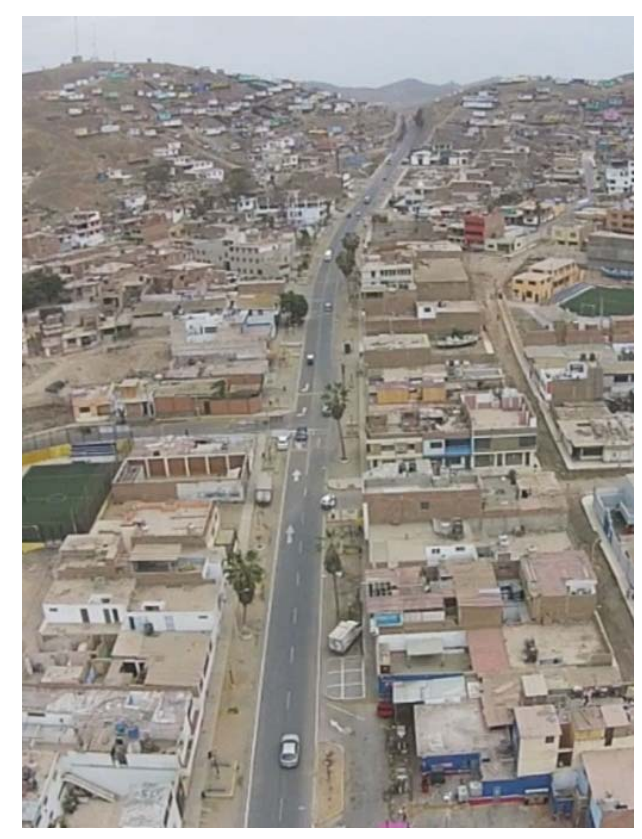

Fuente : Propia

Es por ello que es importante tener presente el valor que balneario presenta y entender las oportunidades que tiene hacia el futuro. Podría ser un poco de economía gastronómica notable de gran atractivo turístico por su entorno natural y su cercanía con la capital. Además los nuevos flujos de personas que llegaran al distrito a trabajar harán que el sector sea mas frecuentado y por ende acudan a este como esparcimiento.

Se plantea un recorrido cultural que por medio de la experiencia el visitante pueda aprender del sitio y aprovechar las oportunidades que le ofrece conociendo su origen y las oportunidades hacia el futuro.

Figura 145: Avenida principal 2 - vista aerea

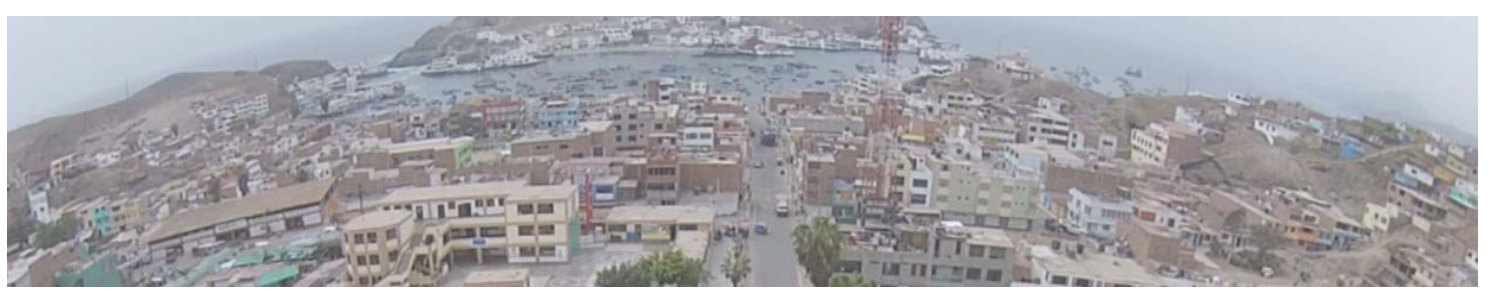

Fuente : Propia 


\subsubsection{Sistema vial}

4.2.3.2.1. Vias expresas, semi- expresas, arteriales, colectoras y locales

Figura 146. Vias expresas, semi- expresas, arteriales, colectoras y locales

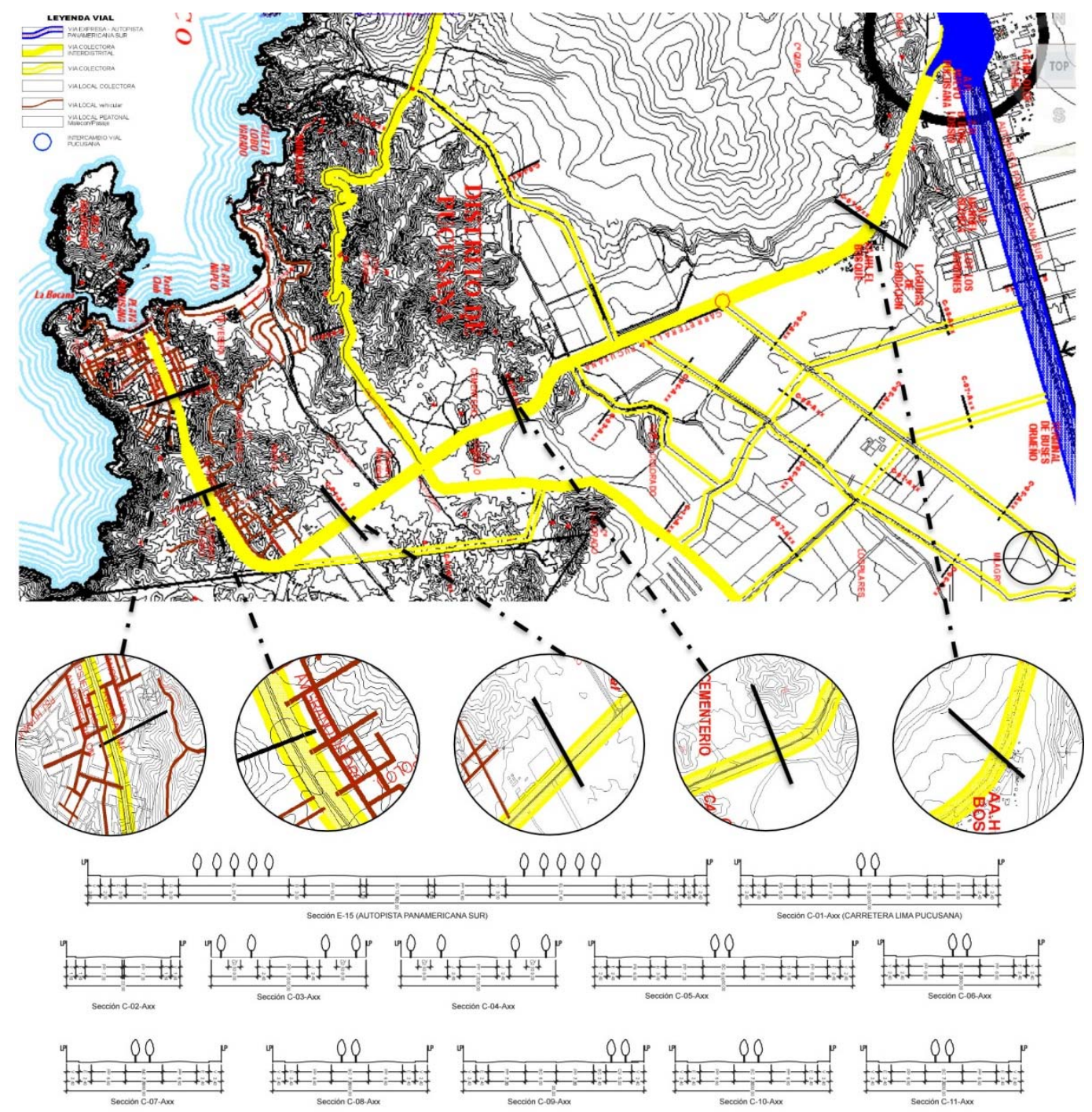

La accesibilidad al pueblo de Pucusana desde la carretera Panamericana Sur es bastante directa, la vía es de doble sentido en ambas direcciones. Las distintas vías del distrito están jerarquizada de acuerdo a al flujo que estas tienen, el orden es claro y resulta coherente con el orden vial del distrito.

El paisaje en el recorrido es desértico y en algunos momentos aparecen cierta infrestructura que simula que en los alrededores se realizan actividades, alrededor se parecían cerros de altura moderada que enmarcan y direccionan el camino y a lo lejos se puede ver el mar. También aparecen algunas viviendas establecidas en los cerros de manera provisional, se nota que no llegaron ahí por medio de invasiones. 


\subsection{Transporte publico}

Para llegar desde el centro de Lima, toma los buses que van al sur, en el paradero de la Av. Canadá con Circunvalación, y baja en el puente de Pucusana. Desde allí hay autos que llevan hasta la avenida Lima, a una cuadra de la plaza de Armas.

Figura 147: Accesibilidad - vista aerea

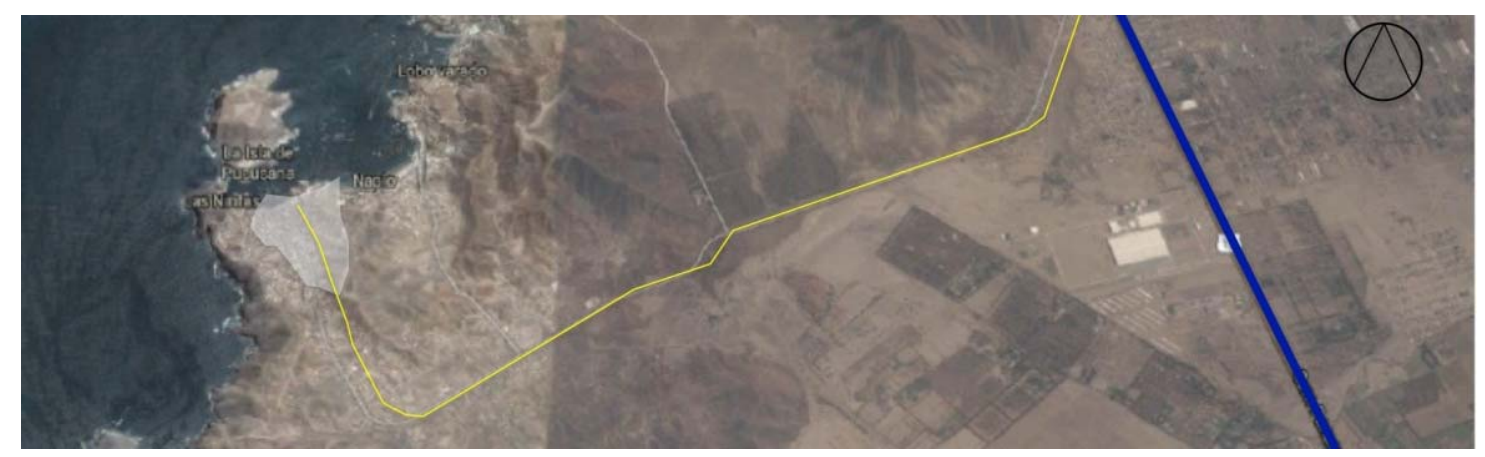

Fuente : Propia

Figura 148: Accesibilidad - fotos de las vias de acceso
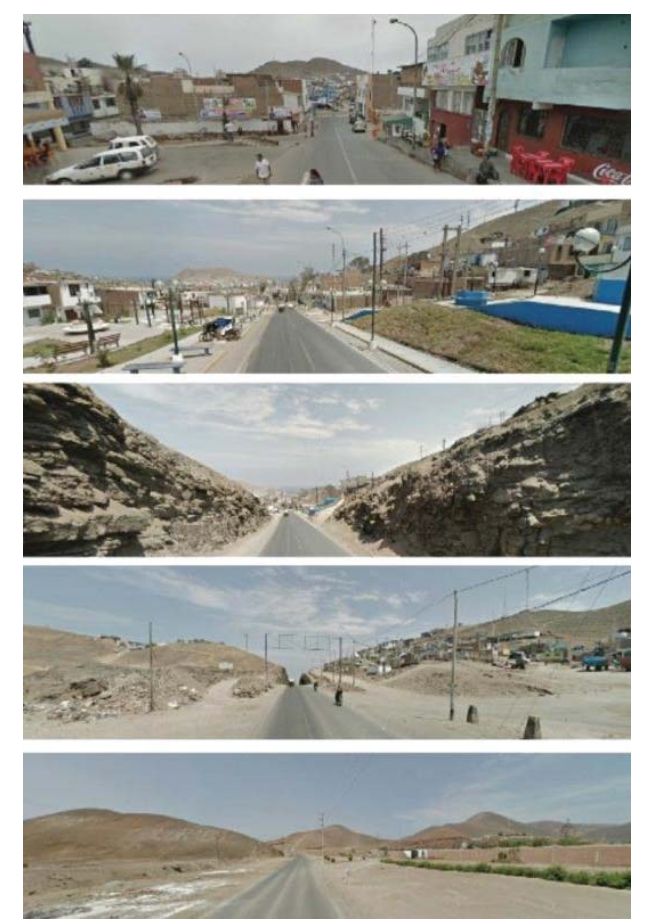

En la mayoría del distrito se aprecia comercio en la planta baja de las viviendas.

La topografía es en pendiente, siendo aparte del ingreso la cota más alta y el malecón la más baja, las visuales en el recorrido permiten el entendimiento urbano de este.

El ingreso y la salida del distrito esta enmarcada por dos cerros que enfatizan el recorrido.

En la zona externa al pueblo de Pucusana aún las viviendas son precarias $\mathrm{y}$ no hay espacios públicos, aun se entiende como un desierto que como una zona urbanizada

Desde el ingreso por la carretera el paisaje que se parecía es bastante árido con cerros que lo engloban. 


\subsubsection{Factores climaticos}

Figura 149: Factores climáticos

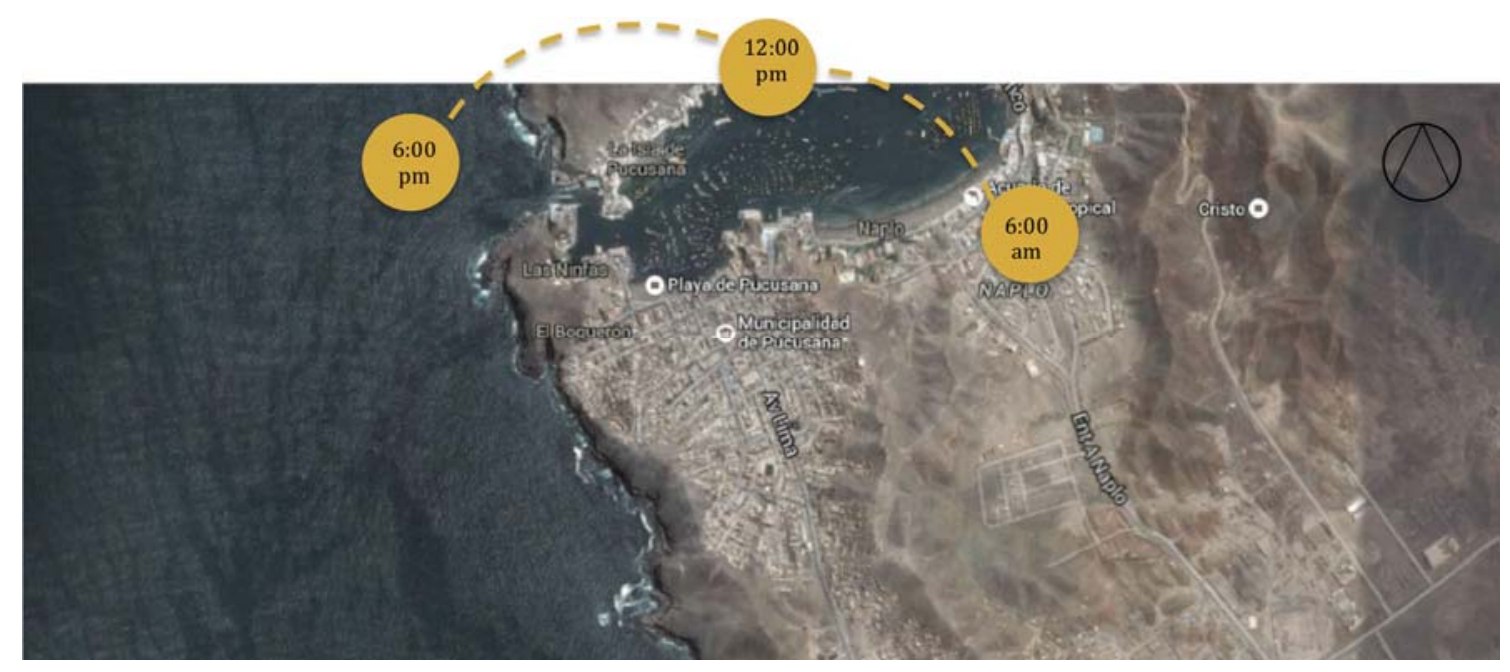

Fuente : Elaboración propia

El clima en Pucusana es un clima desértico. A lo largo del año, cayendo casi sin lluvia en Pucusana. El clima aquí es cl asificado como BWh por el systema Köppen-Geiger La temperatura media anual en Pucusana se encuentra a $19.4^{\circ} \mathrm{C}$. Hay alrededor de precipitaciones de $17 \mathrm{~mm}$. El clima en Pucusana es un clima desértico. A lo largo del año, cayendo casi sin lluvia en Pucusana. El clima aquí es clasificado como BWh por el systema Köppen-Geiger La temperatura media anual en Pucusana se encuentra a $19.4{ }^{\circ} \mathrm{C}$. Hay alrededor de precipitaciones de $17 \mathrm{~mm}$.

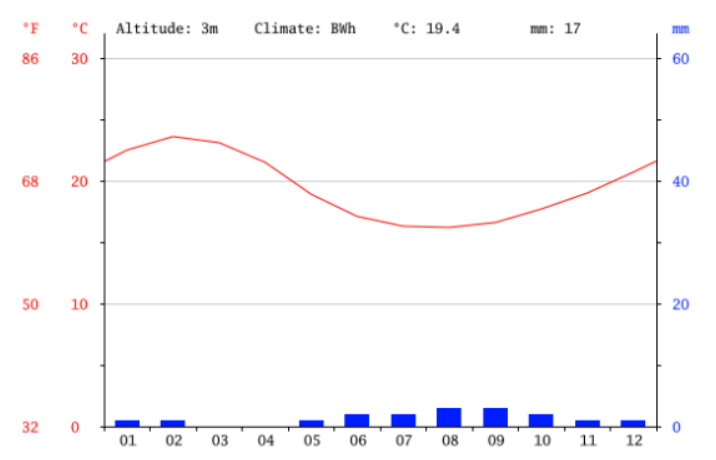

\section{DIAGRAMA DE CLIMA}

El mes más seco es marzo, con $0 \mathrm{~mm} .3 \mathrm{~mm}$, mientras que la caída media en agosto. El mes en el que tiene las mayores precipitaciones del año. 


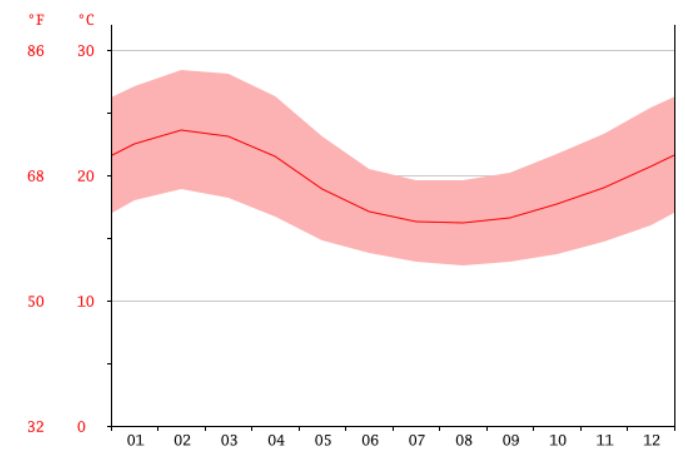

DIAGRAMA DE TEMPERATURA

El mes más caluroso del año con un promedio de $23.6{ }^{\circ} \mathrm{C}$ de febrero. El mes más frío del año es de $16.2^{\circ} \mathrm{C}$ en el medio de agosto.

\subsection{Criterios de selección del}

\section{terreno}

- Accesibilidad

- Contaminacion ambiental-sonora, visual.

- Tamaño

- Parametros

- Forma

- Compatibilidad de usos

- Orientacion

\subsection{Caracteristicas de los terrenos}

Figura 150: Opciones de terrenos

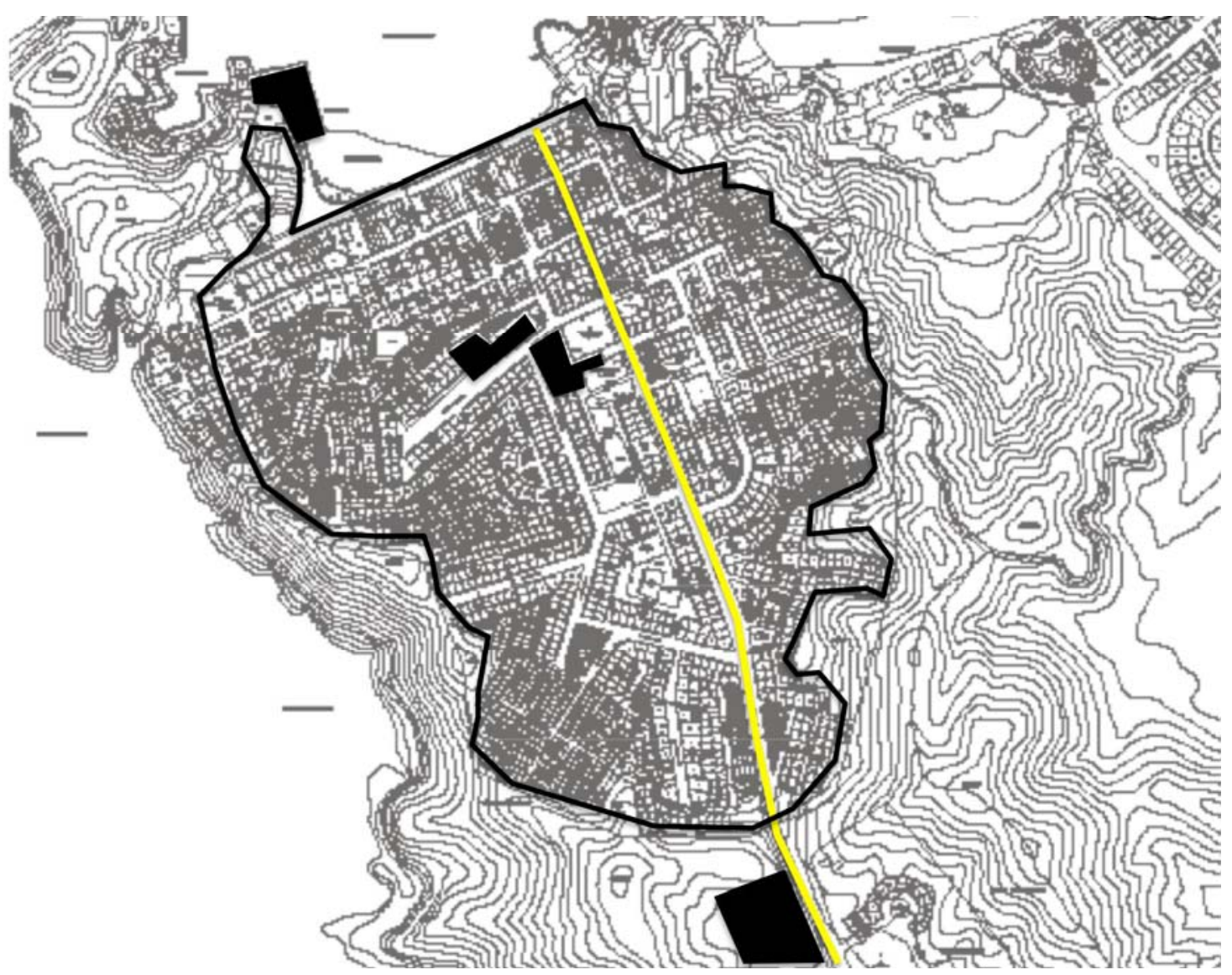




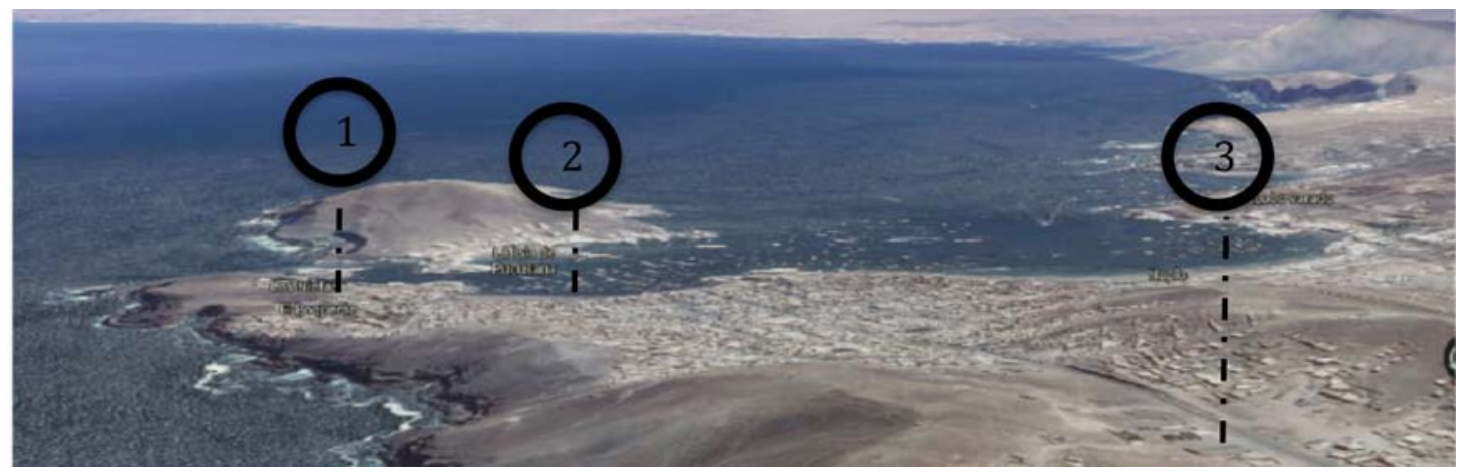

Fuente : Elaboración propia

\subsubsection{Terreno 1}

\subsubsection{Datos generales}

\subsection{Ubicación}

Figura 151: Zonificación

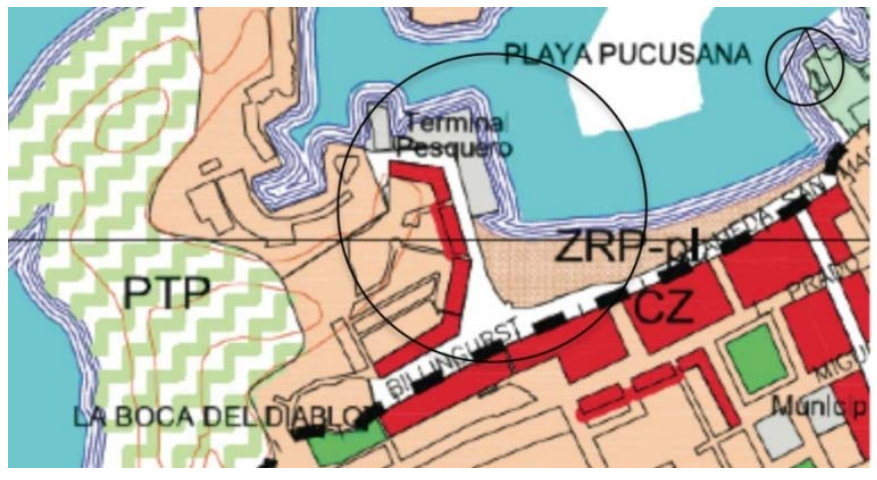

Fuente : Municipalidad de Pucusana

\subsection{Disponibilidad}

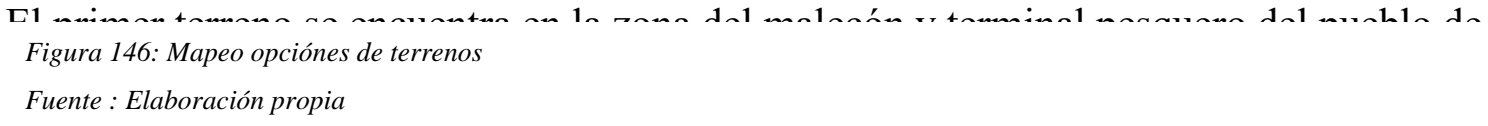

espacio y falta de control para su optima sanidad el municipio plantea mover el terminal a la zona de grano de por, dejando este espacio libre para otros osos como su zonificación demuestra y así implementar el sector en el turismo.

\subsection{Situacion y conexión con la ciudad}

El terreno limita con dos paisajes importantes, el primero el océano pacifico con el contexto tradicional que el balneario caracteriza con botes con coloridos particulares y el segundo con un paisaje urbano enfocado del pueblo, con comercio en la zona baja del malecón entorno a la gastronomía pesquera. 
Figura 152 : El terreno

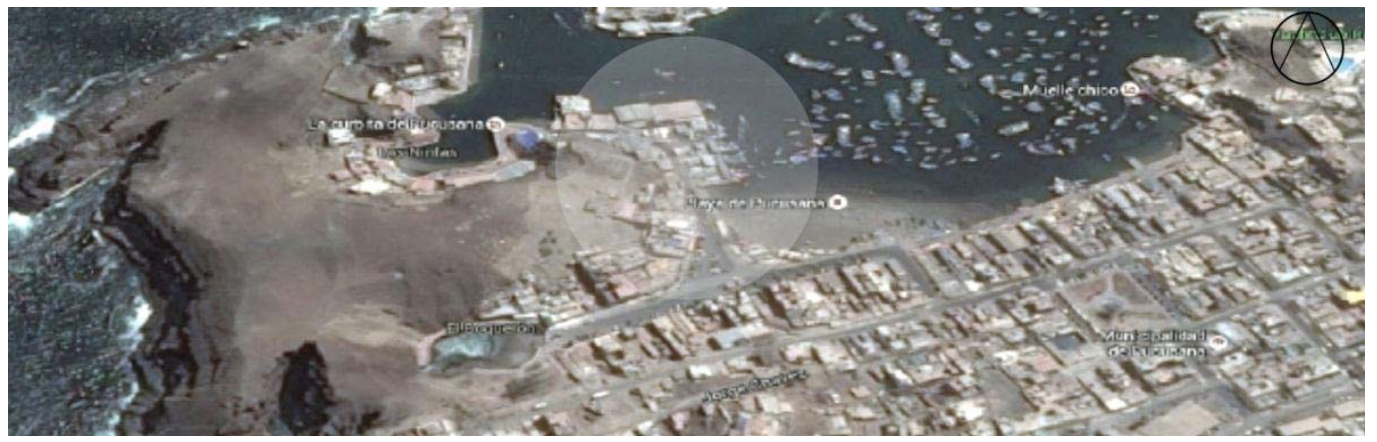

Fuente : Elaboración propia

\subsubsection{Parametros urbano - arquitectonicos}

Figura 153: El terreno - visuales
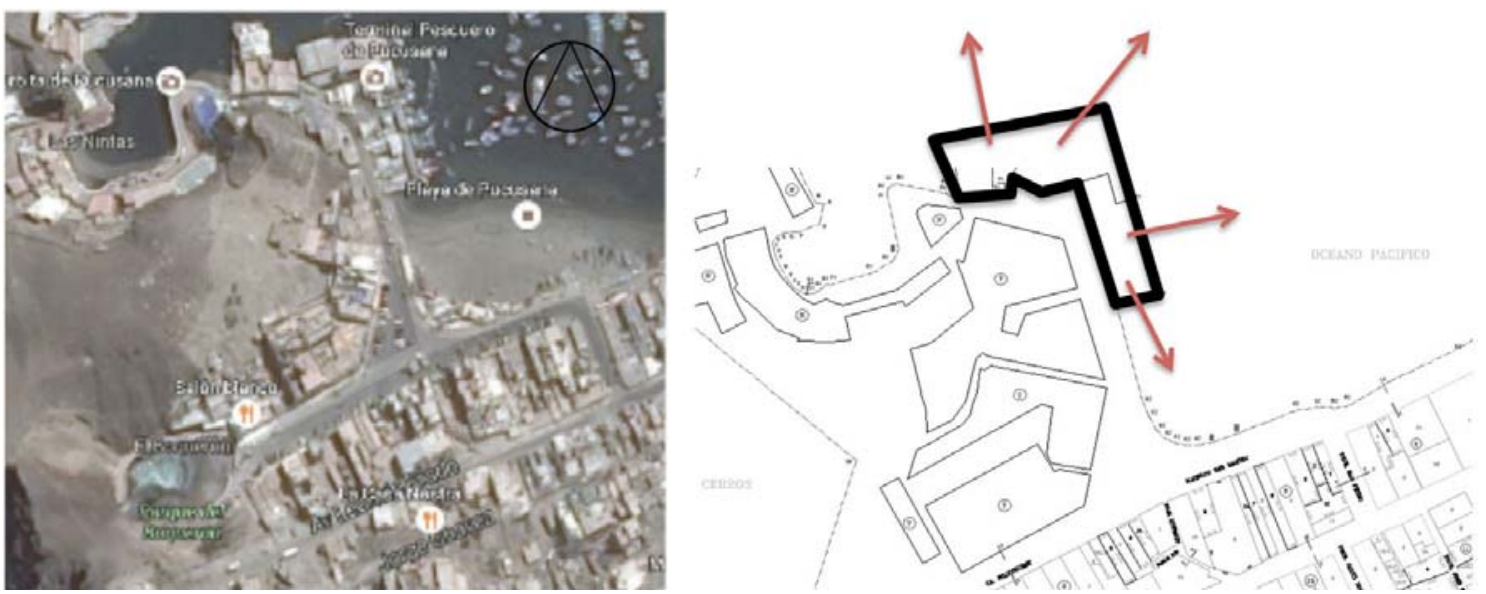

Fuente : Google Maps

\subsubsection{Analisis espacial y entorno urbano}

Figura 154 y 155: Embarcaciones y pescadores artesanales

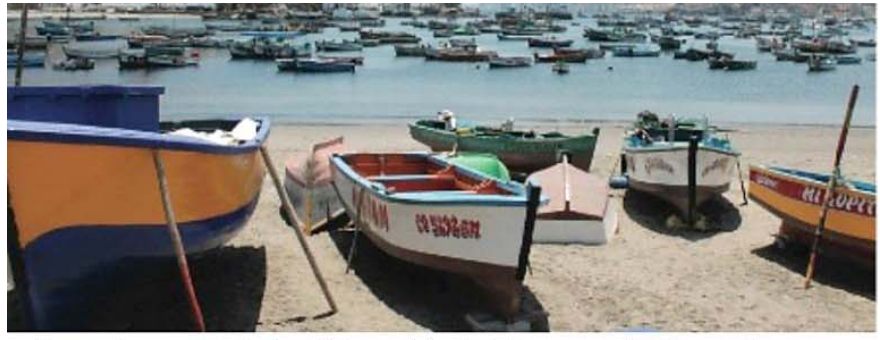

Presenta un paisaje típico del distrito en relación a la pesca artesanal. Las embarcaciones presentan coloridos particulares que le dan un valor agregado al paisaje.

Fuente : Propia

Figura 156: Entorno directo

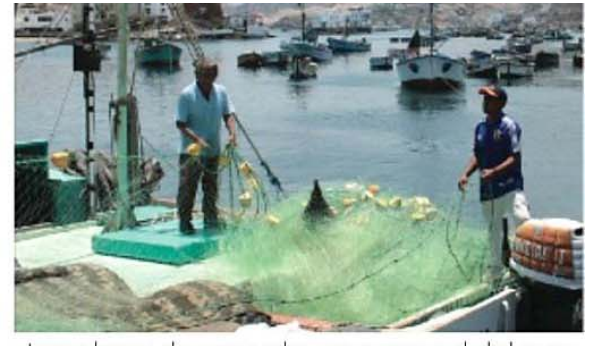

Los olores de pescado y en general del mar es notable. Hay sonidos de pelicanos y de aves en general mayormente en las mañanas y en las tardes. 

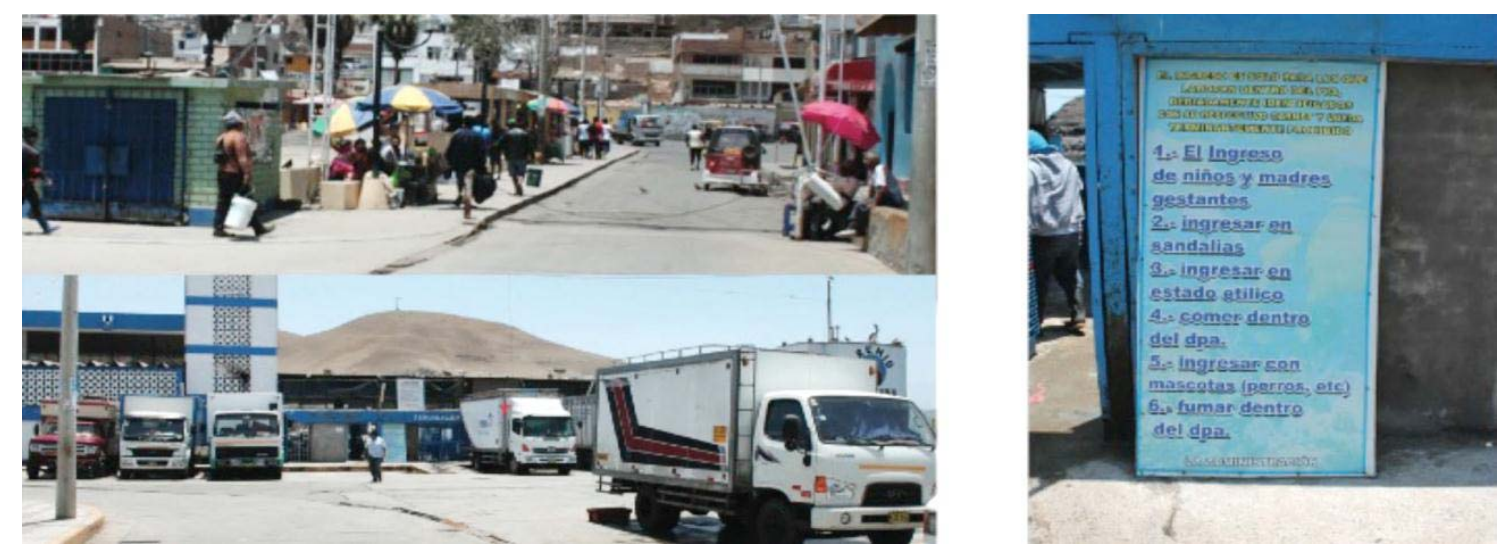

Fuente : Propia

El ingreso al terminar pesquero y la accesibilidad a el vehicularmente tiene costo. Además el espacio resulta pequeño para la demanda. Las instalaciones presenta normas de sanidad que se deben tomar en cuenta antes del esparcimiento en ellas.

Figura 157: Pescadores en el Terminal pesquero artesanal

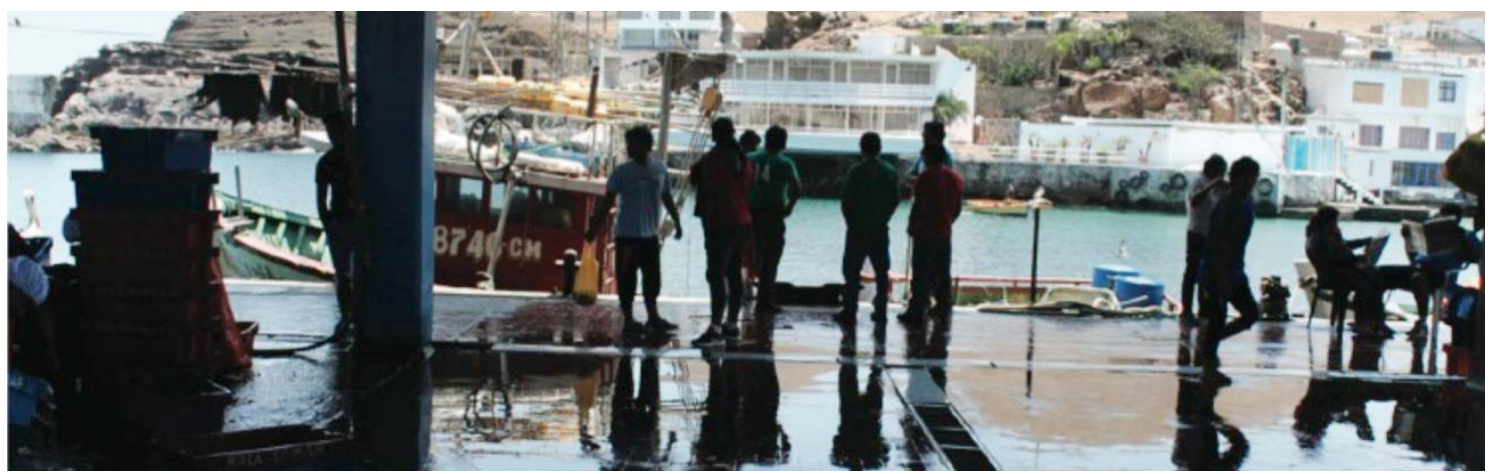

Fuente : Propia

\subsubsection{Terreno 2}

\subsubsection{Datos Generales}

\subsection{Ubicación}

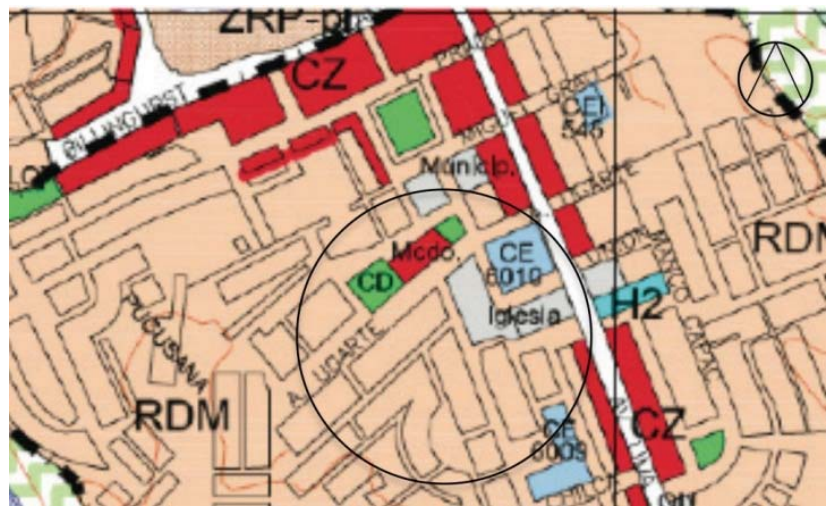




\subsection{Disponibilidad}

El segundo terreno es el mercado del distrito que se encuentra dañado y que la municipalidad lo quiere remodelar en los próximos años y también el centro comercial de al frente que se encuentra en condiciones precarias y que propiedad del estado esta insertado en pleno corazón del pueblo del distrito, se encuentra en la zona mas antigua y en torno a varias edificaciones importantes, como la municipalidad y la iglesia.

\subsection{Situacion y conexión con la ciudad}

Por estar en un punto medio en la zona tradicional del distrito, las circulaciones durando todo el día son altas. Es un punto de encuentro y de interacción que todos reconocen además por ser el mercado distrital, y el único en el conjunto hace que el sitio sea importante y sea un foco de nuevos comercios colindantes a él.

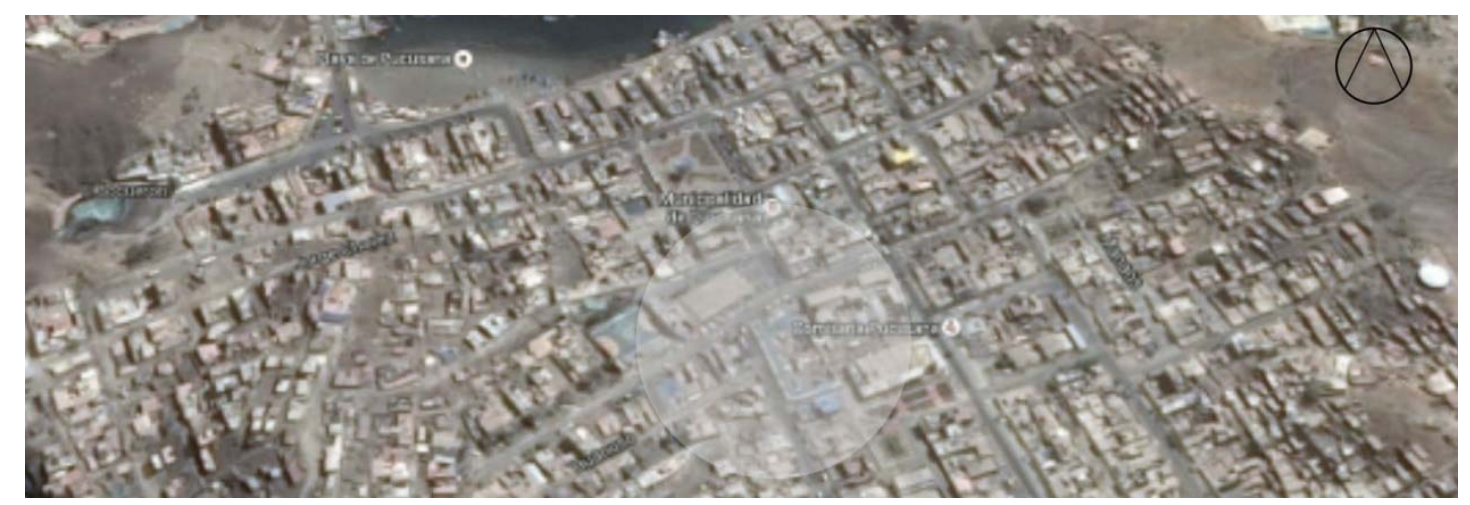

El mercado actual se encuentre entre dos calles transitadas, una de ellas en pendiente. Alrededor de este edificio hay un espacio publico, sin embargo el mal cuidado de este ha hecho que la gente lo utilice para poner mas comercio y como un espacio libre que complemente las actividades.

\subsubsection{Parametros urbano - arquitectonicos}
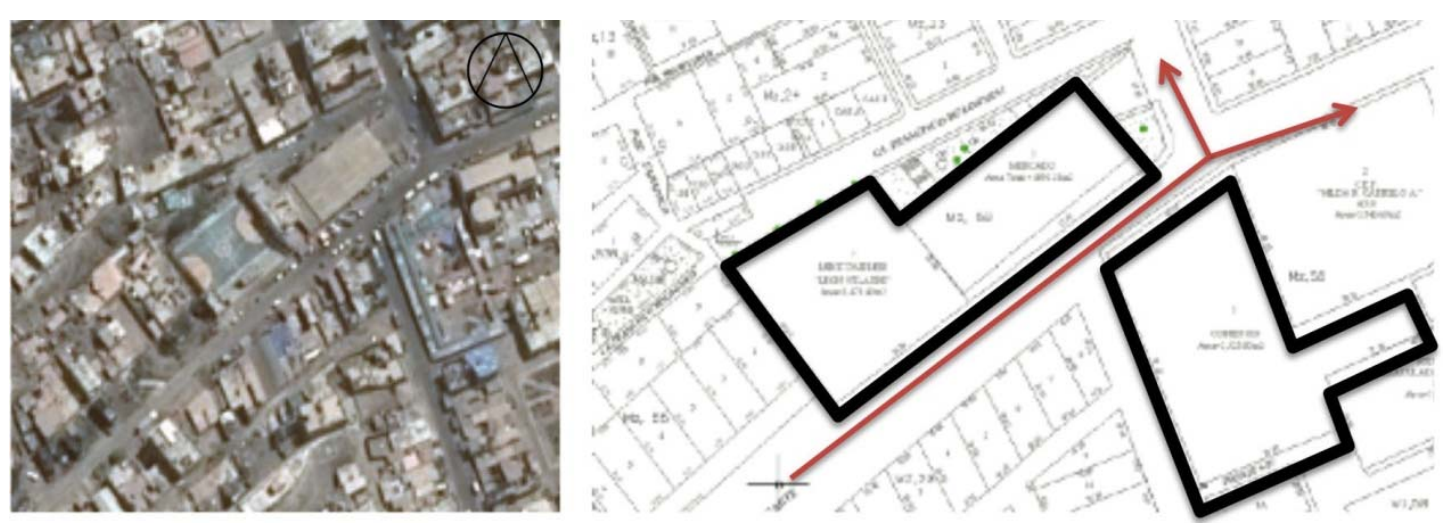


\subsubsection{Analisis espacial y entorno urbano}

Figura 158: Entorno urbano
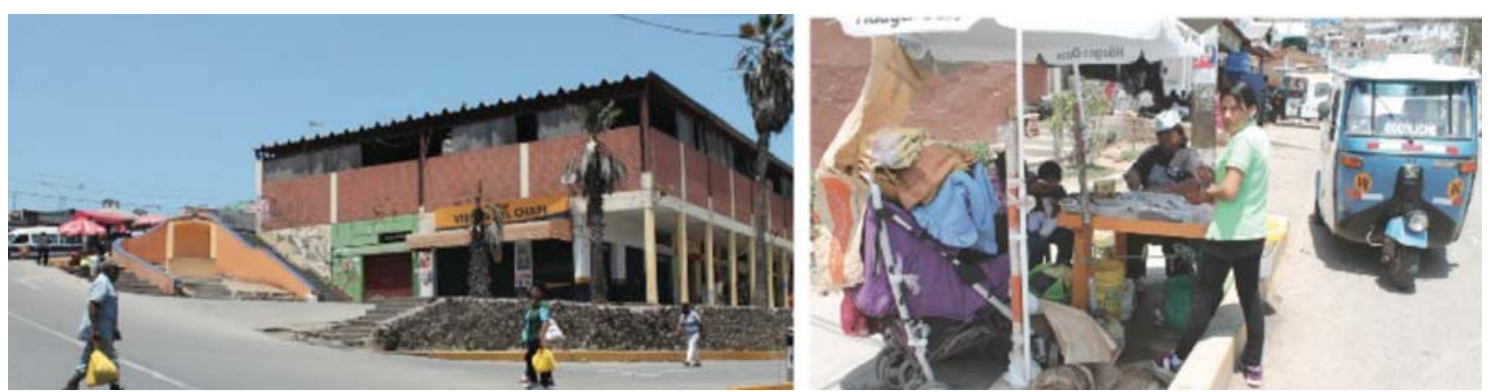

Fuente : Propia

Si bien el mercado tiene suficiente área para satisfacer a la población distrital, el espacio publico e incluso las calles han sido invadida por comercio informal. El mal equipamiento de este ha hecho que las personas busquen su propio espacio para ofrecer sus productos. Figura 159: Techos precarios - Mercado de abastos
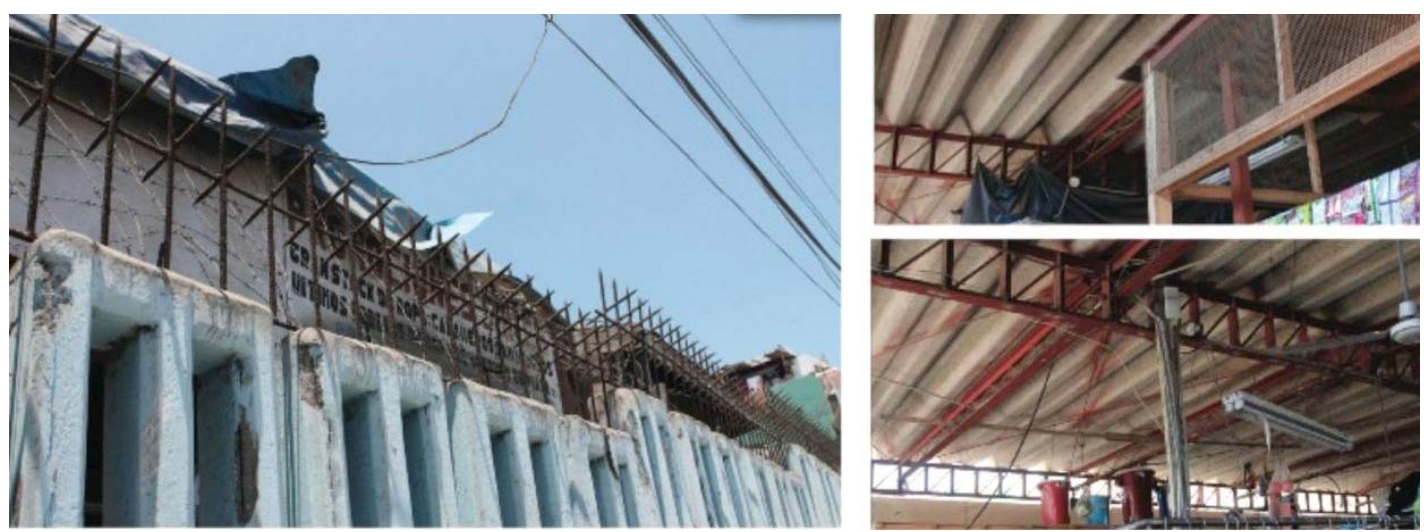

Fuente : Propia

Tanto el mercado como el centro comercial están en mal estad, las estructuras están dañadas y los recubrimientos han ido imprevistas con bolsas y techos de calamina, además las instalaciones eléctricas no han tenido un debido planteamiento y resulta peligroso por las aglomeraciones de estas en los postes.

Figura 160: Mercado de abastos 

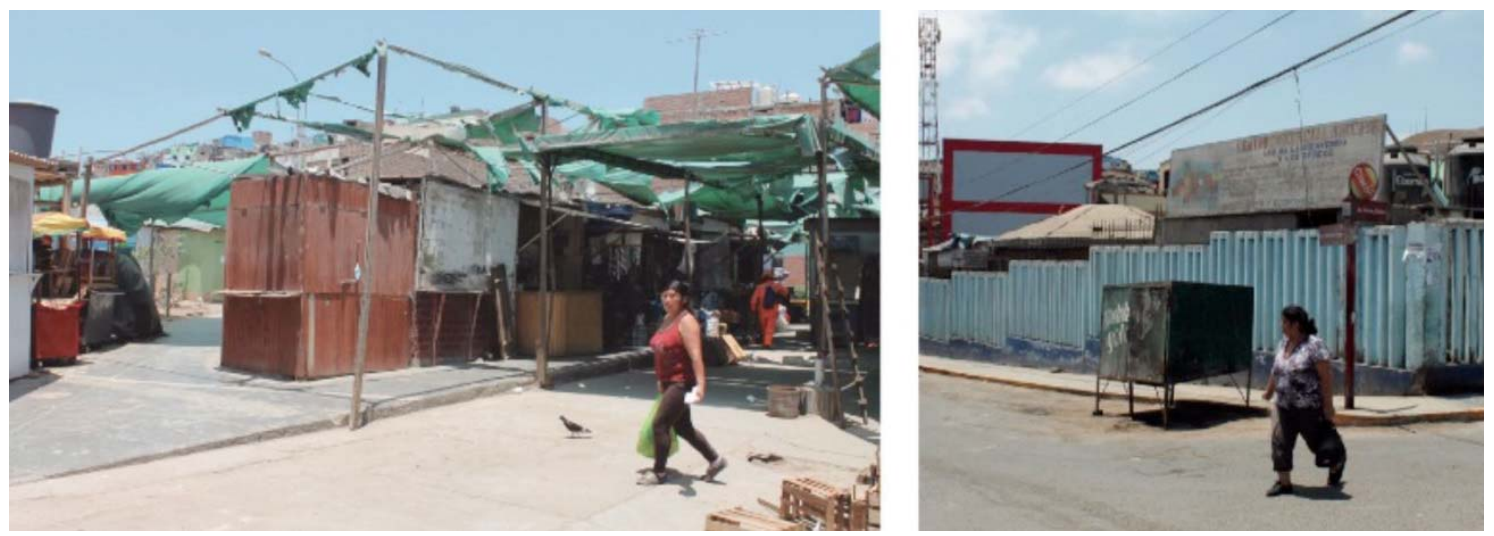

Fuente : Propia

\subsubsection{Terreno 3}

\subsubsection{Datos generales}

\subsection{Ubicación}

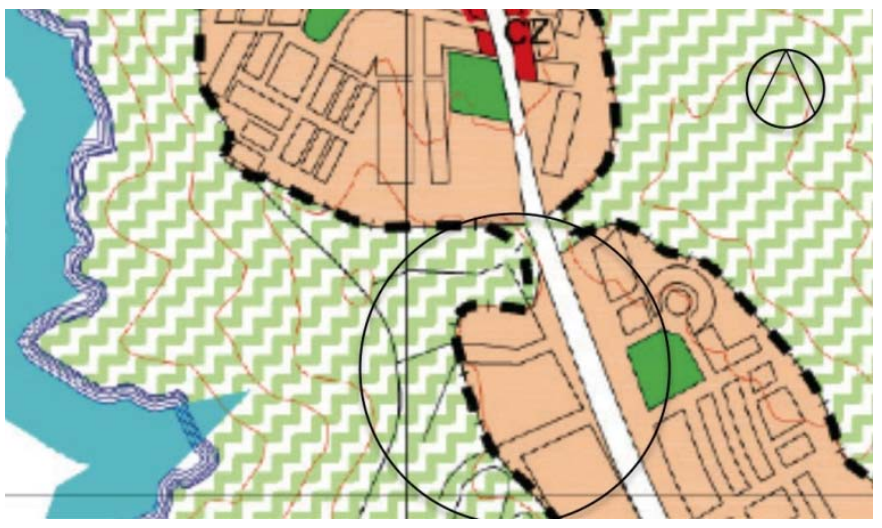

\subsection{Disponibilidad}

El tercer terreno se encuentra en el lugar de ingreso y de salida del pueblo de Pucusana, el paisaje natural y la topografía misma enmarca el ingreso marcando un recorrido interesante que podría ser un gran partido para el proyecto a desarrollar. Se encuentra colindante con la Avenida Lima que a lo largo de su extensión se conecta con la carretera.

\subsection{Situacion y conexión con la ciudad}

Es el limite entre la zona tradicional, donde el distrito se inicio y la zona de expansión y desarrollo. En el lado derecho se encuentran viviendas que recientemente han sacado su 
titulo y ya se encuentran registradas, en el lado izquierdo aun el terreno es del estado y están en busca de inversionistas para el aprovechamiento de él.

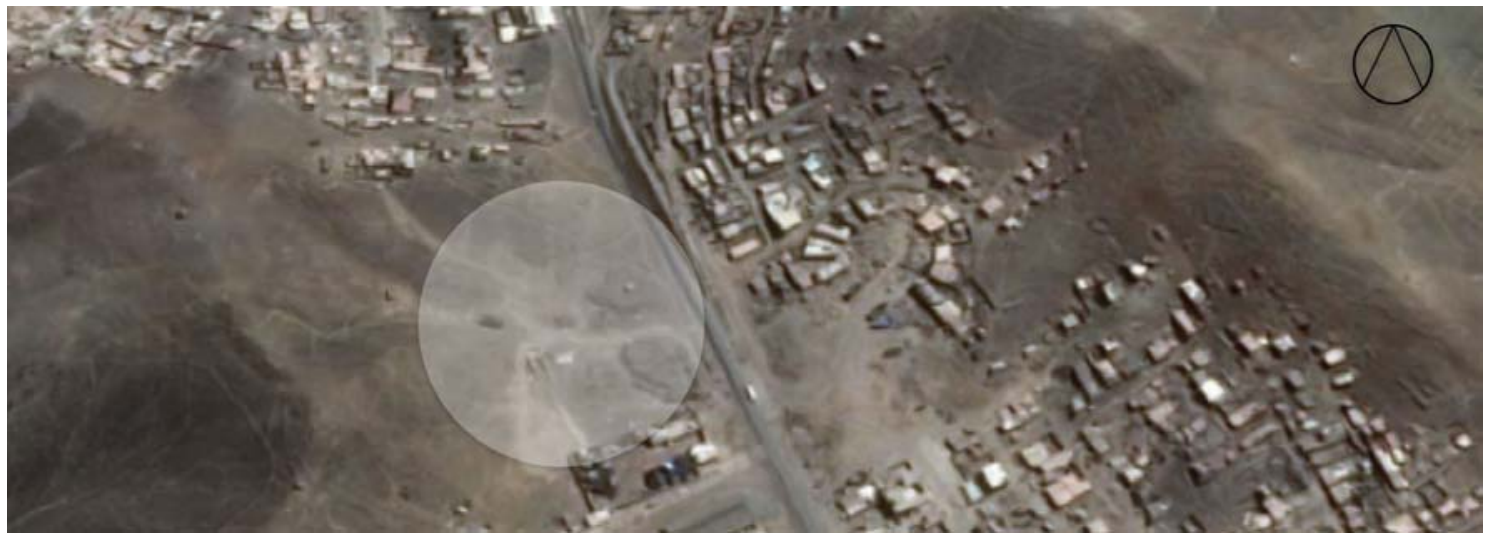

Las vistas del terreno dan la avenida principal y frente a un parque que será remodelado este año y hacia el norte el terreno enmarca el ingreso natural al pueblo de Pucusana

\subsubsection{Parametros urbano - arquitectonicos}
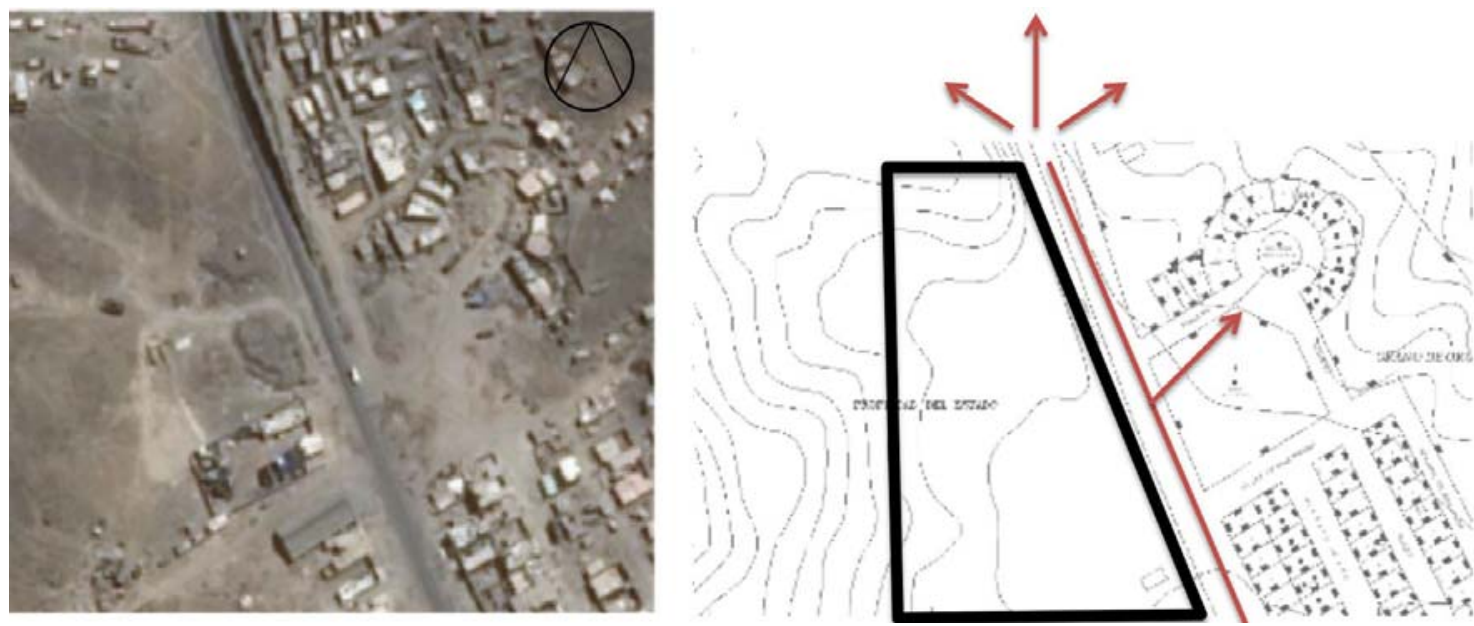

\subsubsection{Analisis espacial y entorno urbano}

Figura 161: Entorno urbano

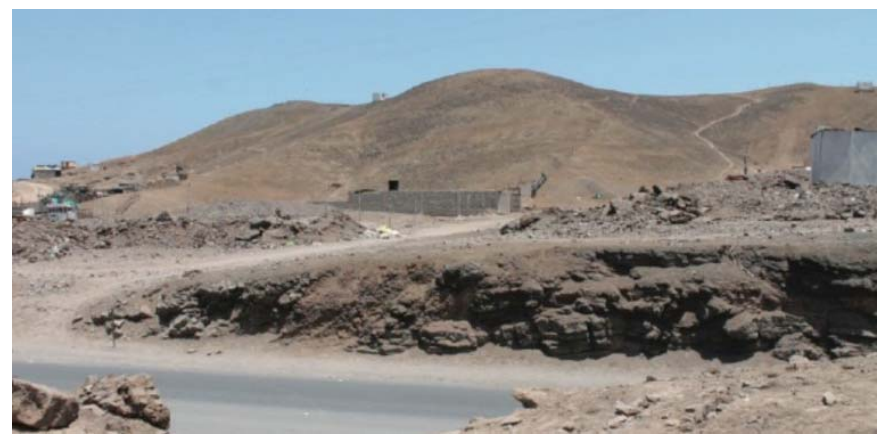

El terreno se encuentra sobre una pequeña pendiente que permite mantener una mejor visual del distrito, además por la conexión que tiene con el gran ingreso al distrito este sería aprovechado para el proyecto a realizar, evocando al origen del distrito . 

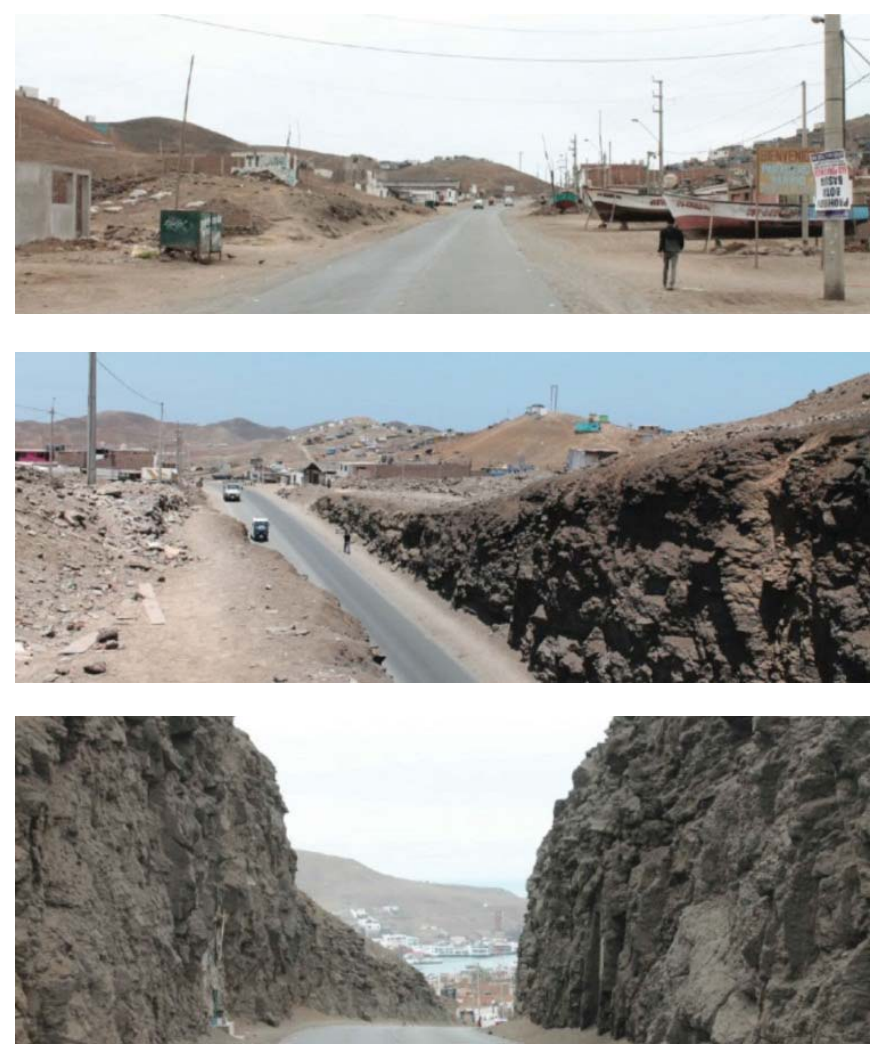

El Complejo cultural de la gastronomía peruana debe estar estratégicamente ubicad para atraer a la gente y direccionarla en la experiencia. E s por ello que se considera el lugar mas apropiado para ejecutarse.

Fuente : Propia

\subsection{Cuadro de valoracion de los terrenos según criterio}

El TERRENO 1, esta ubicado en una zona emblemática del distrito, las visuales desde la llegada a la zona del pueblo, y lugar tradicional están enfocadas en todo momento hacia ese espacio, no solo por ser el lugar donde se realiza la actividad adquisitiva mas importante del sector, la pesca artesanal, sino por su belleza paisajista siendo esta una caleta natural y puerto natural de un accidente geográfico fascinante. El terreno cuenta con visuales en todas las direcciones tanto como para la ciudad como para la bahía, Y cuenta con un área considerable para desarrollar el proyecto planteado.
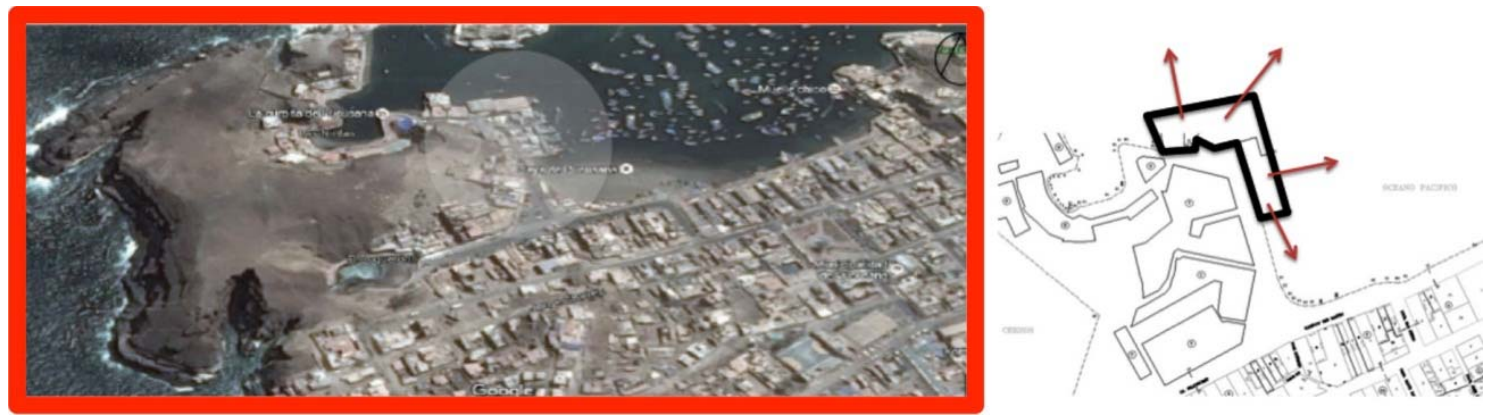
El TERRENO 2, esta ubicado en el centro de la zona pueblo, cerca de a la municipalidad, parque principal y es el lugar comercial mas representativo del sector, siendo este el único mercado de abastos dentro del distrito. La cantidad de flujos en el día es muy alta, por toda las personas que legan ahí para abastecerse de alimentos diarios. Si bien el terreno es accesible para uso comercial, la propuesta busca un recorrido cultural gastronómico y se necesitaría mas espacio necesario para poder realizar esa actividad, y como esta rodeado de vivienda resulta incoherente para realizar la propuesta.
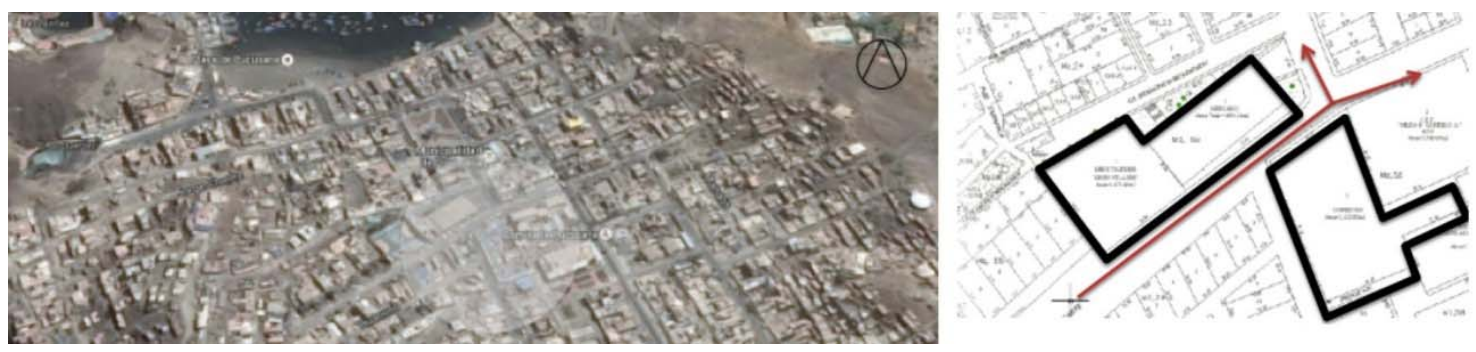

El TERRENO 3, esta ubicado en la parte inicial de la zona pueblo del distrito, si bien es el gran punto de ingreso y de salida del distrito, en los últimos años la municipalidad lo zonifico como terreno para vivienda de densidad media, aunque no haya nada ahí construido, la zonificación se debe respetar y no resulta conveniente hace un proyecto comercial y cultural en un sector delimitado para otros usos incompatibles con la propuesta.
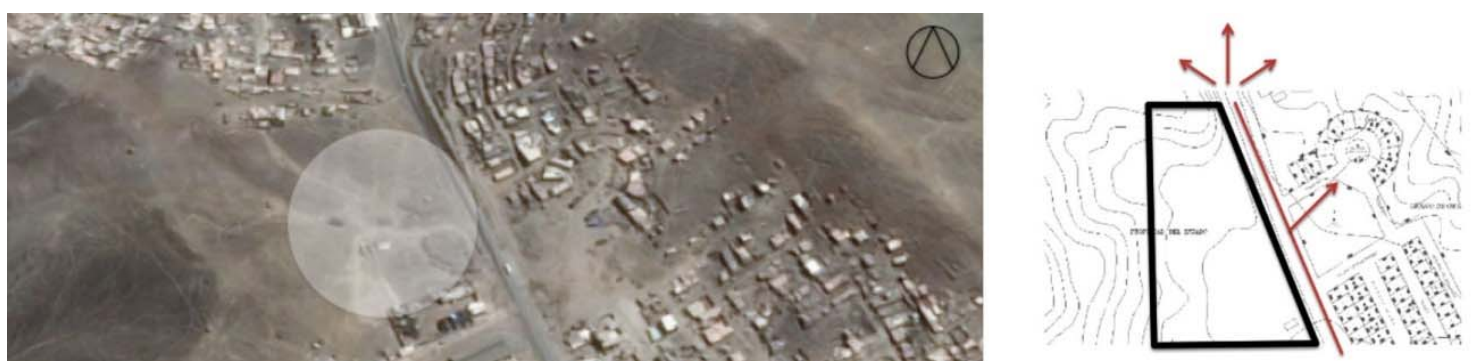

\subsection{Cuadro de ventajas y desventajas de los 3 terrenos}

\section{TERRENO 1}

\section{Ventajas}


Se encuentra en una ubicación estratégica para generar un hito en el distrito, con espacios visuales hacia todo el entono directo, tiene buenas conexiones viales con el resto del distrito y el área es accesible para el proyecto a realizar. Es un lugar que representa la identidad en la población, ya que es el

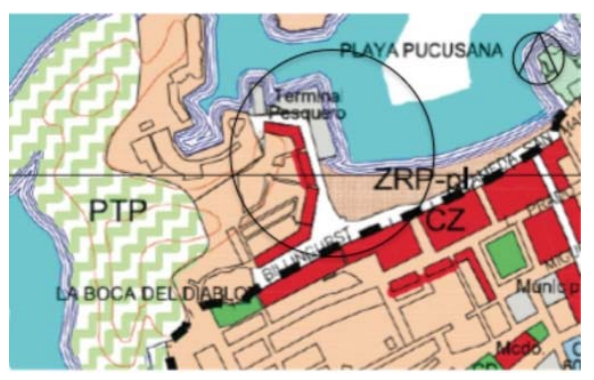
punto en donde se comenzó a desarrollar el distrito.

\section{Desventajas}

Si bien esta ubicado en una zona súper emblemática para el sector, los olores de la pesca del terminal pesquero y los sonidos de las embarcaciones para realizar sus labores, en algunos casos resulta perturbarte, en temporadas muy altas de visitantes es en este punto donde se aglomeran para realizar sus actividades turísticas y comerciales, tanto para comprar la pesca del día en el terminal o para recorrer en bote la bahía de Pucusana, se han tomado en cuenta todos los factores mencionados para la optima ejecución del proyecto.

\section{TERRENO 2}

\section{Ventajas}

El terreno 2, se encuentra emplazado en el territorio como un lugar de uso comercial, por la venta de productos y de abastos que se venden en el, sin embargo la espacialidad ya esta destinada para dicho mercado e implementarlo con un recorrido cultural

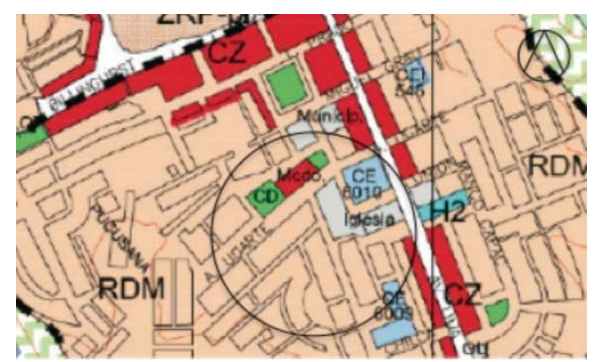
y mayor equipamiento seria invasivo para la zona. Si bien debe ser mejorado el proyecto a proponer no funcionaria en este terreno de la manera prevista.

\section{Desventajas}

Se han generado comercios informales en torno al terreno, generando un desorden en las calles, los puesto informales no han sabido respetar el espacio y en muchos casos han invadido la pista y la vereda para poder vender productos a los habitantes. La estructuras y los equipamientos son precarios y tienen problemas de seguridad en el funcionamiento y control.

\section{TERRENO 3}

\section{Ventajas}


Esta ubicado en un lugar de flujo obligado, ya que es el único acceso a la zona pueblo vehicularmente, cuenta con un entorno aun no intervenido lo que podría influir en que por medio de su desarrollo en el tiempo este lugar se vuelva un foco cultural y nuevas empresas inviertan en los terrenos colindantes.

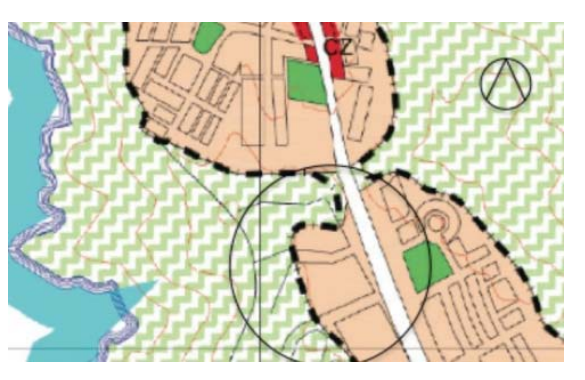

\section{Desventajas}

No cuenta con la zonificación apta para uso comercial, además en el entorno se encuentran viviendas en estado de precariedad, dándole un paisaje limitado al proyecto, ya que lo que se busca es resaltar sus cualidad y no sus debilidades. 
Capítulo 5. Expediente Técnico

\author{
5.1. El Area
}

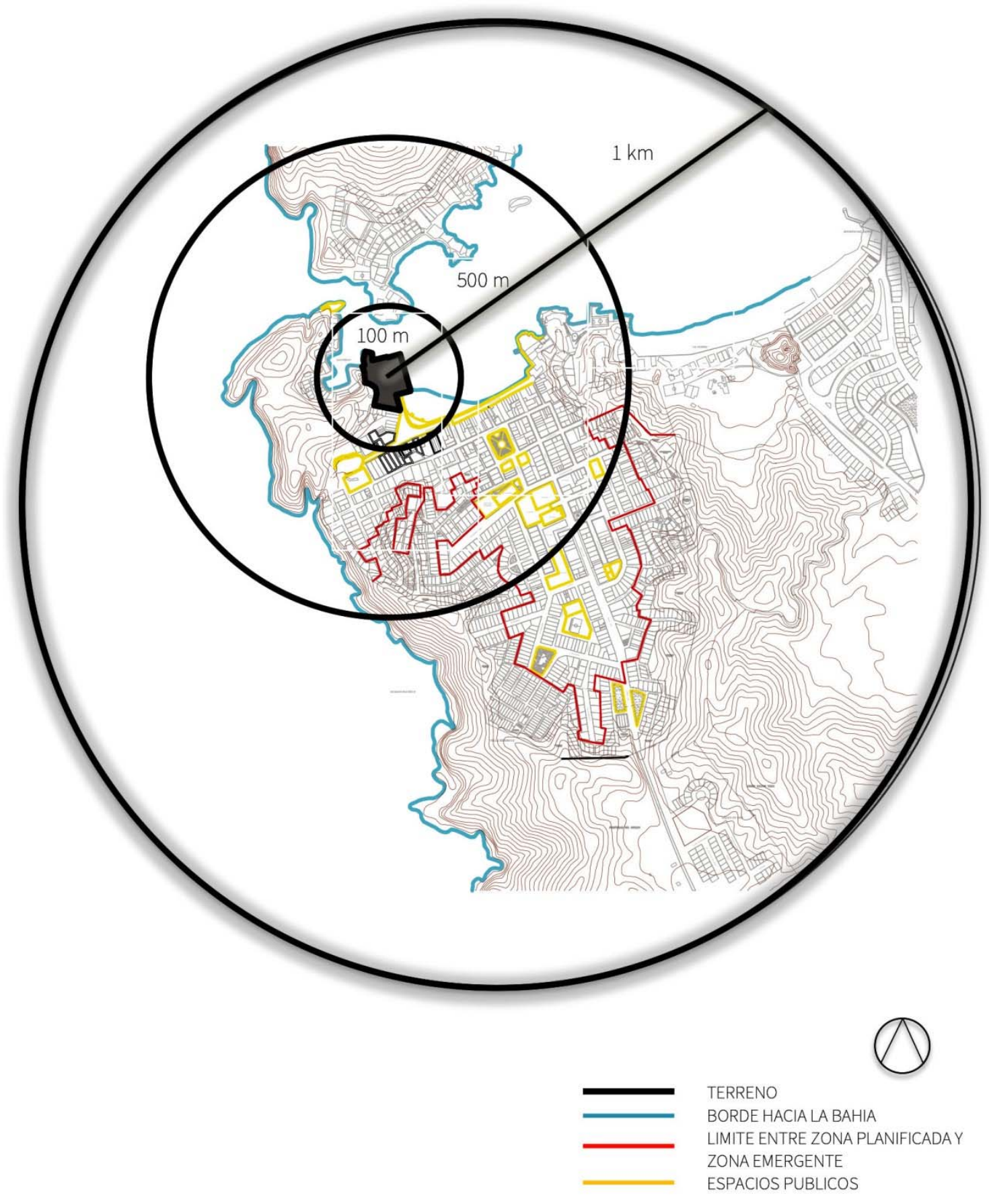




\subsubsection{El terreno y el area de influencia}

El terreno a elegir luego de lo analizado anteriormente es el terreno 1. Se analizará en tres escalas, la primera a nivel más macro abarcando $1 \mathrm{~km}$ de radio de influencia. El segundo abarcara 500 metros siendo este el entorno directo y finalmente el tercero abarcará el entono inmediato hacia el terreno

El terreno presenta la zonificación de otros usos, en el terminal y en todo su entorno se realizan varias actividades como es la del mismo terminal, la de excursiones turísticas en el malecón de pescadores y diversas actividades en la plaza, como espacio publico de interacción, de carga y descarga de las embarcaciones a flote e incluso de venta de pescado y comercio informal. Se encuentran también edificaciones de oficinas como lo son la del gremio de pescadores y la asociación de pescadores.

El terreno cuenta con un área de 7,681.82 $\mathrm{m} 2$ incluyendo el área del terminal mismo que será implementado con nueva infrestructura y espacios que hagan de este un mejor lugar tanto espacialmente como funcionalmente. Se tomará también la plaza colindante al terminal, terrenos que lo bordean y en una pequeña proporción el cerro que ayudará a tener una volumetría amigable, escalonada para tener una mejor visual hacia la bahía.

\section{ENTORNO INMEDIATO (100M)}

Figura 162: Terminal pesquero - Toma aerea

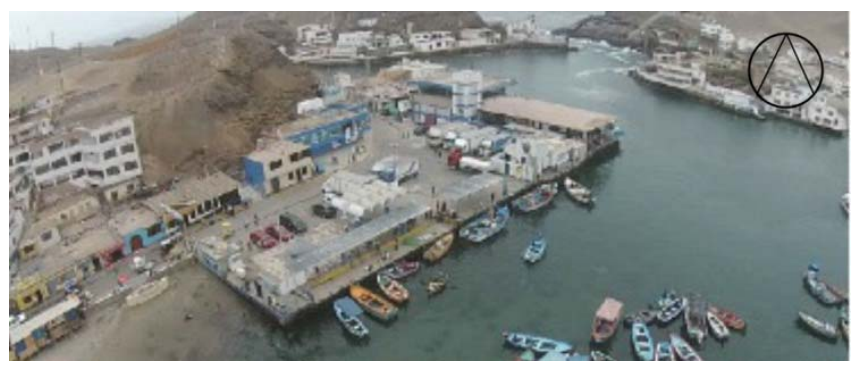

Fuente : Propia

El entorno inmediato es lo que se encuentra en el terreno mismo y todo lo que le da el valor que hoy presenta. Teniendo en cuenta las circulaciones de las personas en él como de la infrestructura y equipamiento que presenta. 


\section{ENTORNO DIRECTO $(500 \mathrm{M})$}

Figura 163: Terminal pesquero y malecón - Toma aerea

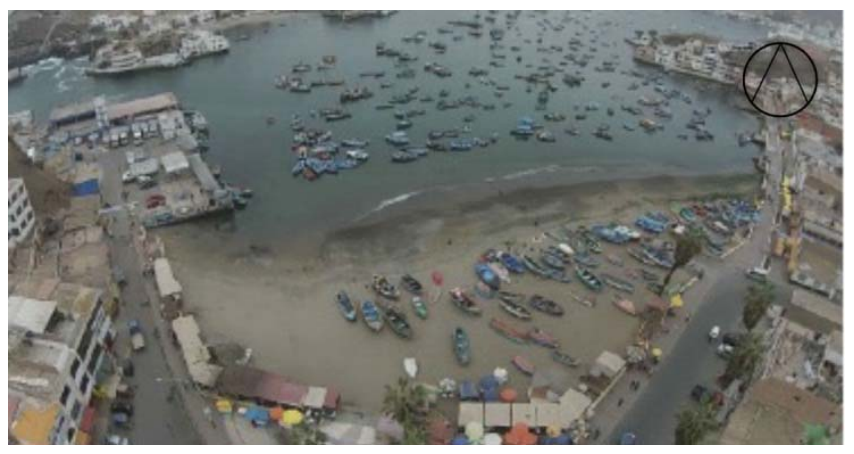

Fuente : Propia

El entorno directo es el entorno que afecta directamente al terreno y al futuro proyecto a realizar, las vías que la conectan y las distintas actividades que se generan en su entorno que influyen en su funcionamiento y que narran indicios y claves que se deben tener en cuenta a realizar a futuro, coherente con el contexto.

\section{ESCALA MACRO (1KM)}

La escala macro vendría a ser el análisis complementario al que ya se realizó anteriormente en el capítulo anterior, "EL LUGAR" analizando mas a fondo las variables que afectan directamente al proyecto y terreno colindante. Se tomar en cuneta ciertas condicionantes a tener a cuenta para el optimo proyecto a realizar.

Figura 164: Terminal pesquero y zona urbana - Toma aerea

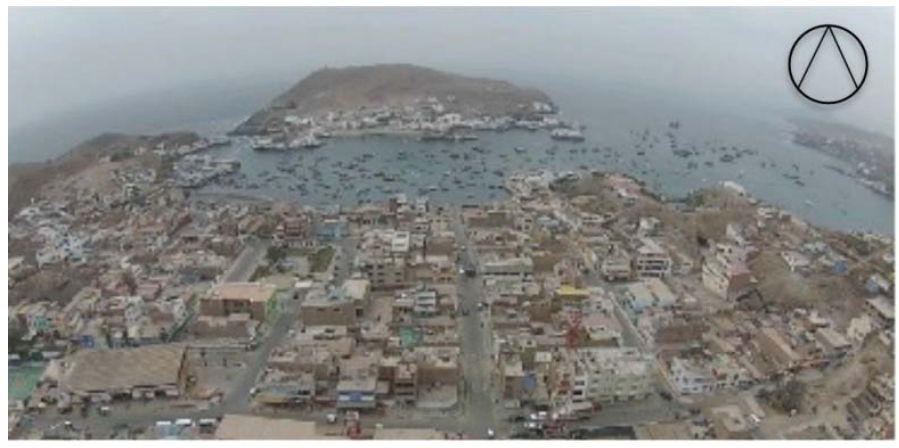

Fuente : Propia

\subsubsection{Historia y evolución territorial}

Pucusana es y siempre ha sido desde sus orígenes un lugar que se caracteriza por su actividad pesquera, las primeras construcciones habitacionales se generaron en el lugar 
debido a la actividad que se realizaba ahí y que llegaban en busca de alimentos y poco a poco se fueron asentando en torno a ella y en los lugares mas próximos siendo el borde de la bahía, hoy en día el malecón, el primer en donde se crearon viviendas y con el tiempo comercio pesquero en las plantas. Siempre se aprovecho la actividad pesquera como fuente económica, del distrito hacia el desarrollo.

Con el tiempo el distrito de fue consolidando y se planteo una trama urbana clara desde el malecón hasta el gran ingreso enmarcado por los cerros (especificaciones en el capitulo anterior). La densificación poblacional de lima fue incrementando y la falta de espacio en la zona centro genero que nuevos habitantes llegaran al distrito en busca de oportunidades ellos, se vayan asentando en las partes altas de los cerros por medio de invasiones. Estos terrenos con el tiempo se fueron formalizando siendo hoy en día, lo que denominamos como la zona emergente.

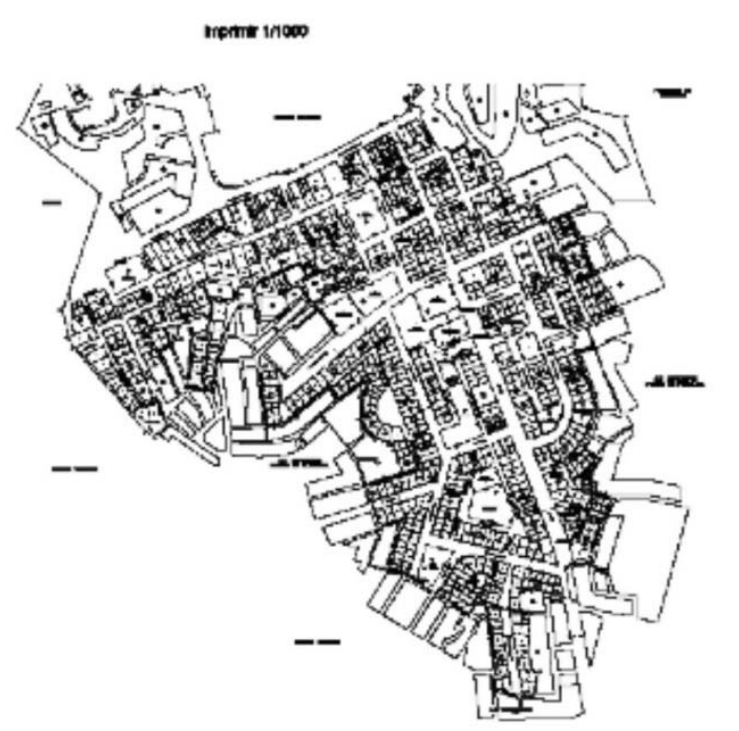

\section{ZONA PLANIFICADA}

La zona planificada presenta una trama urbana organizada y muy bien conectada, siendo la avenida Lima la principal y muchas otras que la articulan. Cada manzana presenta aproximadamente 12 viviendas y la escala no es muy grande, los terrenos son pequeños bordeando los 100 y $300 \mathrm{~m} 2$

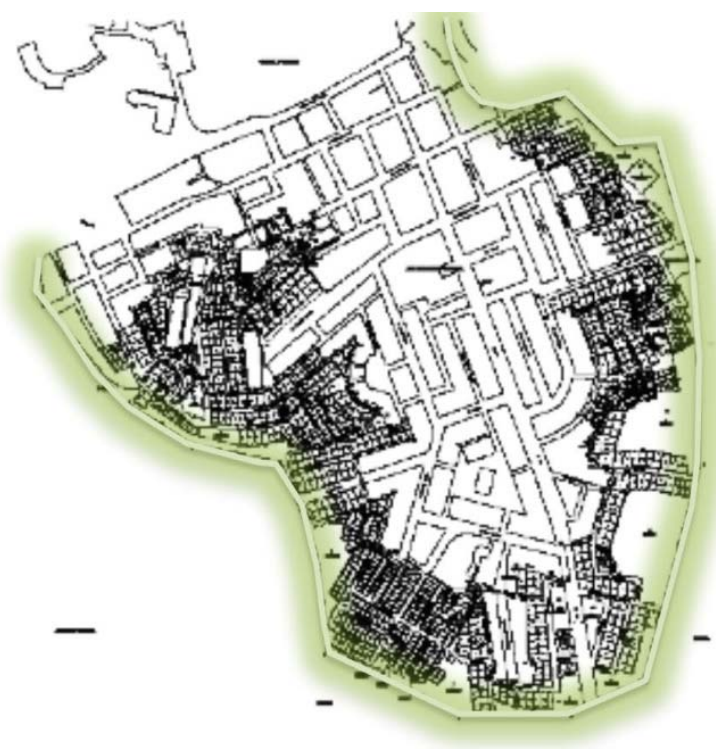

ZONA EMERGENTE

La zona emergente se fue generando en las zonas más altas de los ceros marcan el nexo entre la zona pueblo planificada $\mathrm{y}$ la zona protección y tratamiento paisajista que debe ser preservada como la norma lo especifica. 
Figura 165: Pueblo de Pucusana - Toma aerea

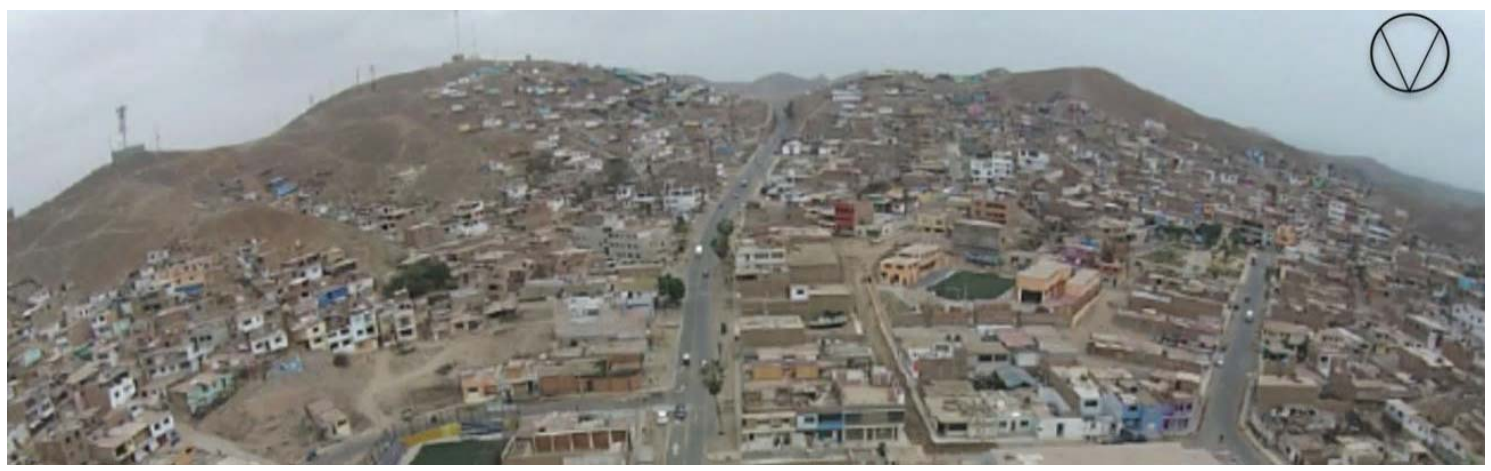

Fuente : Propia

\subsubsection{Zonas protegidas e intagibles, zonas de proteccion paisajista}

El distrito está bordeado por cerros con una altura moderada. La zonificación a delimitado el espacio denominándolo como zona de protección y tratamiento paisajista. Esta normativa pretende preservar la naturaleza y paisaje característico del distrito y mantener las vistas hacia la bahía.

A atreves de los años esta zona ha sido dañada por las invasiones que se fueron asentando en ella, pero la norma establecida con mayor detalle ha generado que se mantenga en mejo estado y que se respete. A su ves la municipalidad ha tomado mayor conciencia de la situación y están siendo más estrictos con las normativas para poder mantener un distrito correcto destacando sus importantes características que deben ser reconocidas y valoradas por todos los que lo visitan.

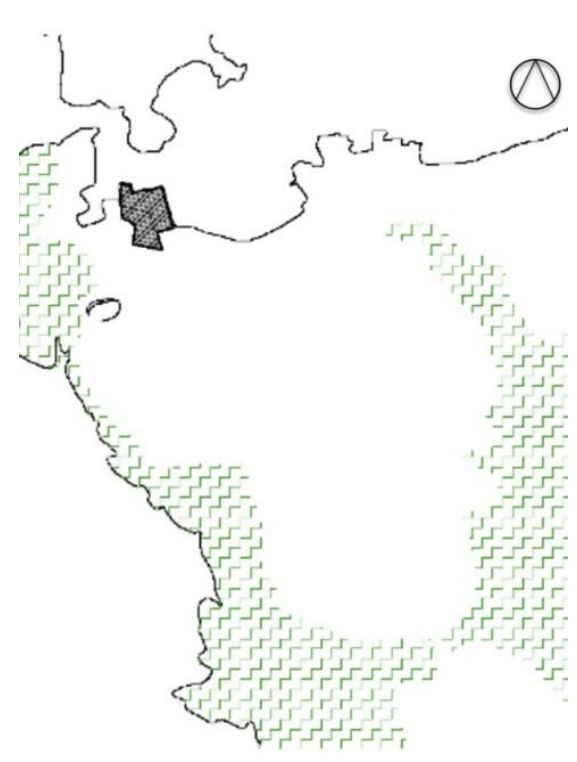

Según la normativa de la Gerencia de Desarrollo Urbano de la Municipalidad distrital de Pucusana. Los parámetros de la normativa son los siguientes:

Se permite vivienda, pero exclusivamente unifamiliar con un piso de altura, la densidad máxima es de 20 habitantes por hectárea, con un área de lote mínimo de $2500.00 \mathrm{~m} 2$ y con un área libre del 80\%.

El retiro frontal es de $3 \mathrm{~m}$ a la calle y $5 \mathrm{~m}$ a la avenida. El retiro posterior es $3 \mathrm{~m}$ con menos de $1000 \mathrm{~m} 2$. El retiro lateral es de $5 \mathrm{~m}$ con $1000 \mathrm{~m} 2$ o más y finalmente el frente normativo del lote es de $10.00 \mathrm{~m}$. 
Los estacionamientos son 2 por vivienda. -

(Parametros Urbanisticos y Edificatorios - 24 de septiembre 2015)

Figura 166: Ingreso zona pueblo de Pucusana - Toma aerea

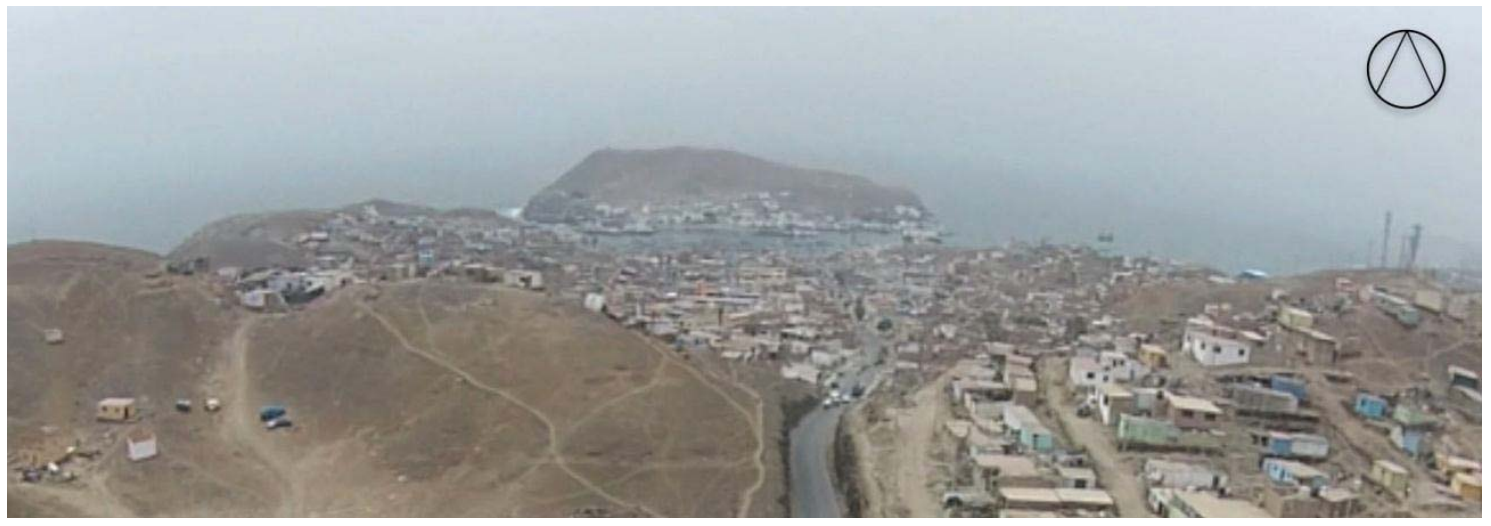

Fuente : Propia

\subsubsection{Areas verdes}

El área verde debe ser utilizado como lugar de esparcimiento y ocio, en el cual los habitantes interactúen y se relacionen entre sí. Además por la cantidad de viviendas que el distrito presenta es necesario que hayan espacios complementarios a dicha actividad. Actualmente el espacio publico y el área verde del distrito es poco y debe ser implementado como propuestas a futuro.

Los espacios determinados como área verde, son muy escasos en el distrito. Solo existe un parquet de un área considerable, el cual no es aprovechado como debería. Es utilizado de estacionamiento en

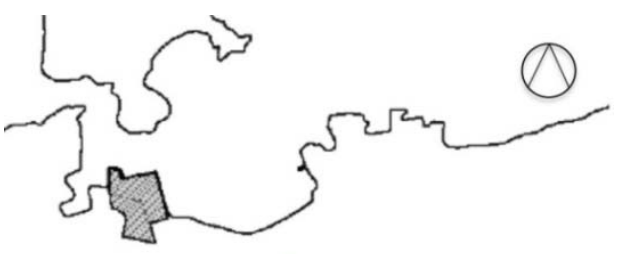
su perímetro y no presenta buenos equipamientos que atraigan a los pobladores. Es utilizado como lugar de flujo y como espacio conector entre la zona del malecón y el resto del distrito.

En el siguiente cuadro podemos apreciar los

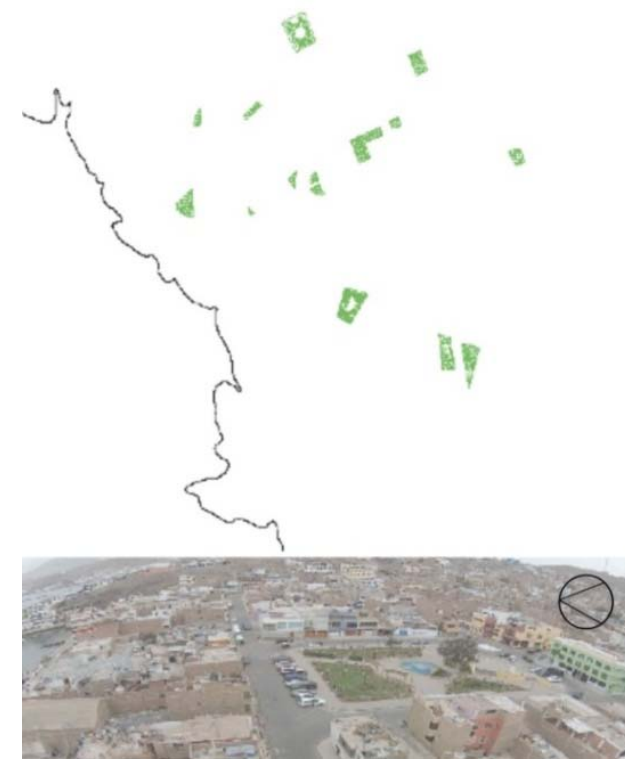
porcentajes de áreas verdes en relación a la vivienda y comercio. El área verde debería 
satisfacer a toda la población de Pucusana y no satisface ni a la cuarta parte de la población en general.

Figura 167. Gáfica muestra el déficit de áreas verdes en Pucusana

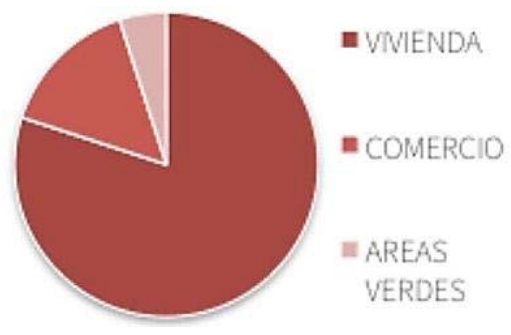

Es el parque principal del distrito con un área de $1400 \mathrm{~m} 2$, en el cual en el perímetro presenta veredas y los visitantes lo utilizan de estacionamiento. Está en el espacio e próximo a la municipalidad y gremio de pescadores.

Figura 168: Zonas publicas del pueblo de Pucusana - Toma aerea

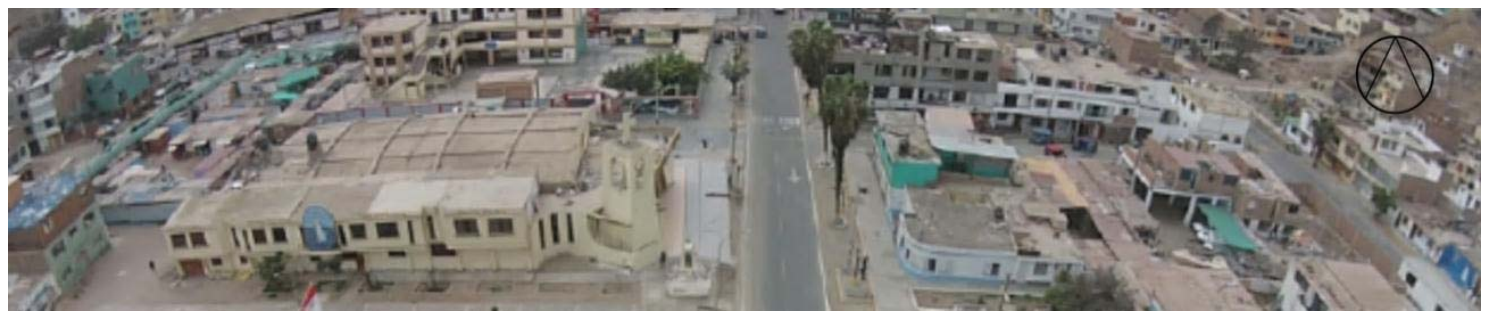

Fuente : Propia

\subsubsection{Zonas publicas}

Las zonas publicas identificadas son los espacios de interacción social y cultural con mayor influencia en el distrito, entre ellos encontramos el mismo terminal pesquero y el muelle de pescadores donde se realizan las embarcaciones turísticas por la bahía, el mismo malecón, el boquerón del diablo, el mercado, la iglesia, entre otros.

Si bien el distrito en su gran mayoría presenta una zonificación de densidad media de vivienda. Las actividad generadas en los limites de la avenida principal, la avenida lima son variadas. Se encuentran varios equipamientos de diversos usos que todos los pobladores y visitantes aprovechan y utilizan.

En el mapa de puede analizar que cerca al malecón los espacios públicos se incrementan no solo en cantidad sino en escala, la mayor aglomeración de usos y de actividades que generan ingresos económicos están cerca al terminal pesquero, siendo esta la actividad principal y de mayor importancia en el distrito.

Figura 169: Los espacios públicos se incrementan no solo en cantidad sino en escala 


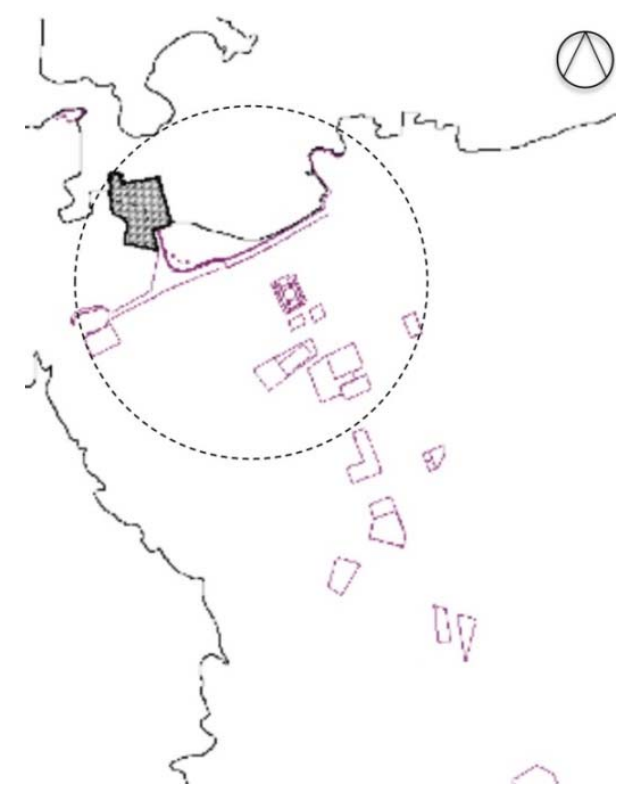

Todo el borde del malecón es de uso publico. Se puede recorrer tanto vehicular como peatonalmente, solo un tramo pequeño es exclusivo para el peatón en el cual se ubican las mejores cubicherías y restaurantes culinarios para poder disfrutar la gran variedad de peces y mariscos de la pesca del día.

El mercado y su espacio colindante es utilizado de espacio publico en el cual se realizan actividades comerciales.

Los pobladores acuden al mercado en un aproximado de 4 veces a la semana, siendo este uno de los lugares mas transcurridos del distrito y en el cual el comercio y las actividades adquisitivas tienen bastante flujo y demanda.

Al lado de este se encuentra la cancha municipal en la cual se realizan actividades culturales en fechas importantes y que todos pueden participar.

Figura 170: Acceso al melecón - Toma aerea

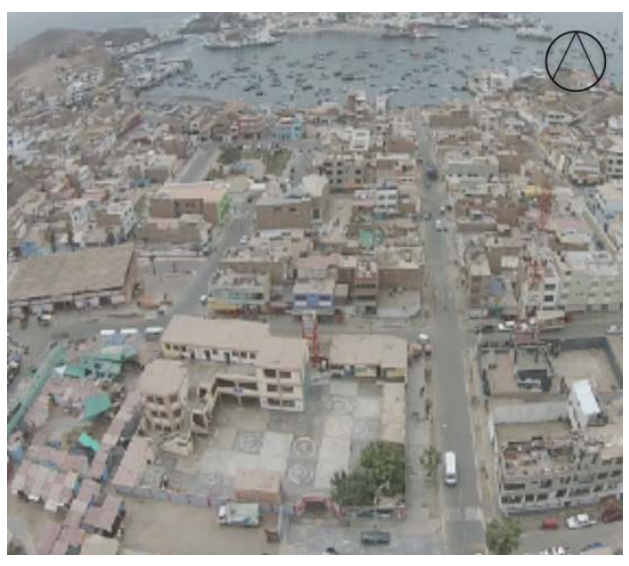

Fuente : Propia

Figura 171. Mapa donde se muestra los 3 posibles terrenos 


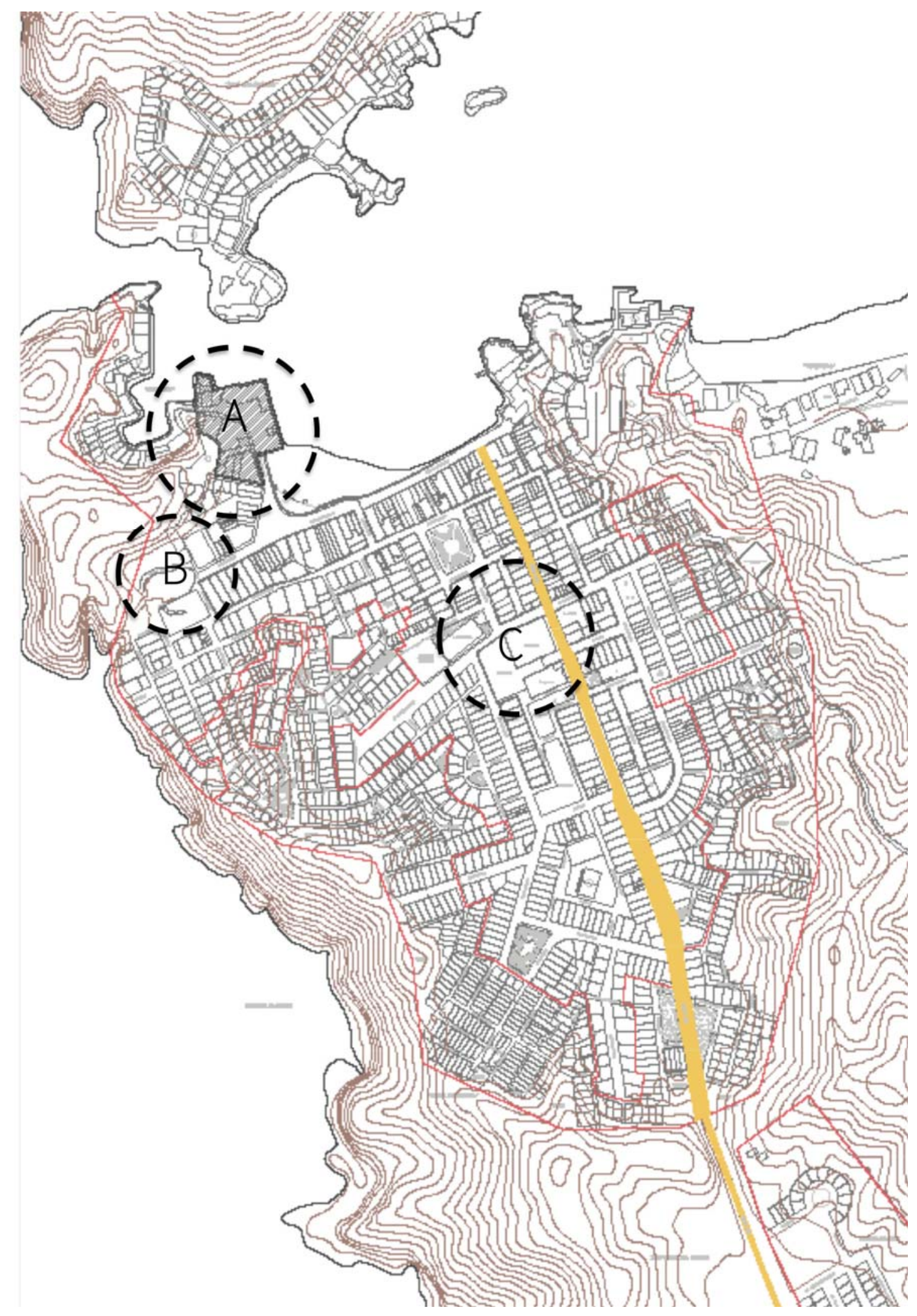




\subsubsection{Hitos y nodos}

Los hitos y nodos que el distrito presenta son varios, pero en particular se analizaran tres, siendo estos los mas importantes para la escala que se esta analizando y que tienen mayor influencia en el proyecto a desarrollar.

Es importante analizar los tres casos tanto individualmente como las relaciones que presenta entre sí para de este modo aprovechar las conexiones, similitudes y diferencias en la propuesta a desarrollar en el terminal pesquero y área colindante.

\section{A. EL TERMINAL PESQUERO}

El terminal pesquero presenta una ubicación optima, presenta visuales hacia la bahía y hacia la zona pueblo del distrito. Es un lugar con bastante recorrido diario y por la actividad que se realiza enella, es un polo económico notable.

Esta conectado al boquerón del diablo por la calle que tanto vehicular como peatonalmente es accesible en una corta distancia, el boquerón es un tractivo turístico destacable y que tiene mucha influencia turística a lo largo del año en el distrito.

Figura 172: Terminal pesquero y malecón - Toma aerea

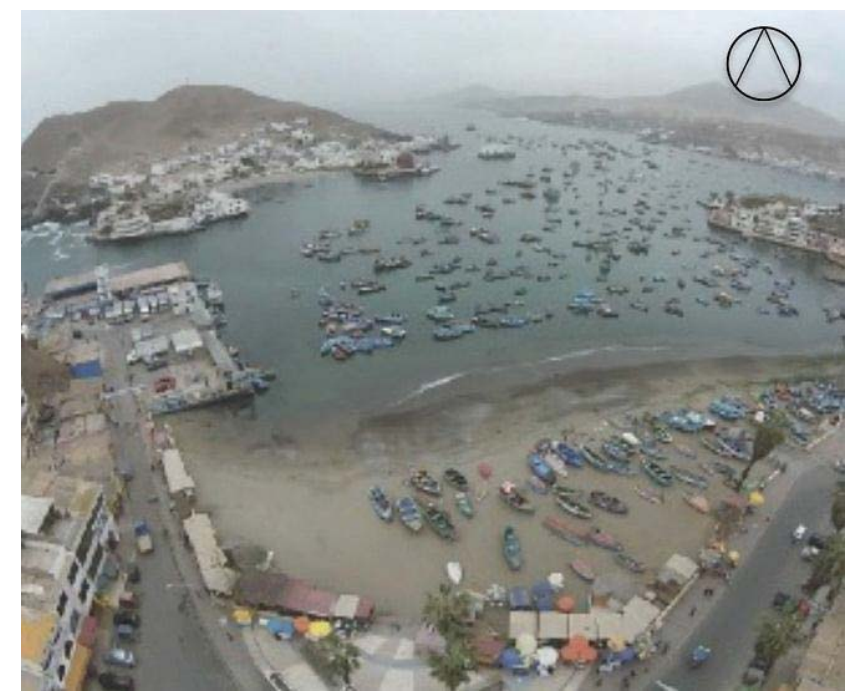

Fuente : Propia

\section{B. EL BOQUERON DEL DIABLO}

El boquerón del diablo es un lugar emblemático de Pucusana por su notable belleza natural hace que los habitantes y visitantes de sientan atraídos a visitarlo. En torno a el se ha generado actividades comerciales con puesto de comida y comercio en general que hacen de este un punto de gran influencia y flujo de personas. 
Figura 173: Mercado de abastos - Toma aerea

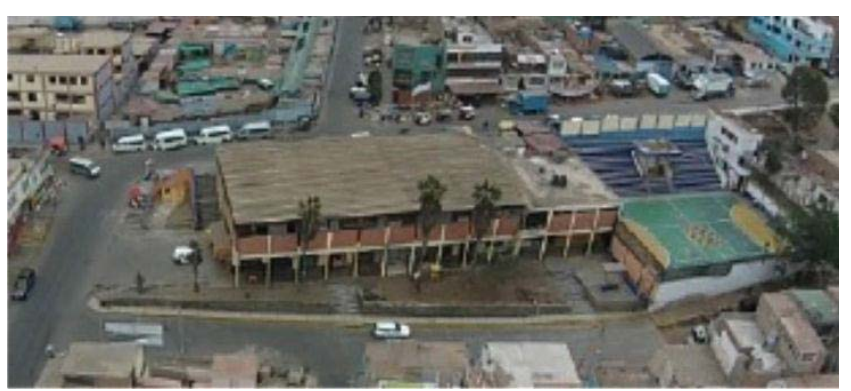

Fuente : Propia

Figura 174: Boquerón del diablo - Toma aerea

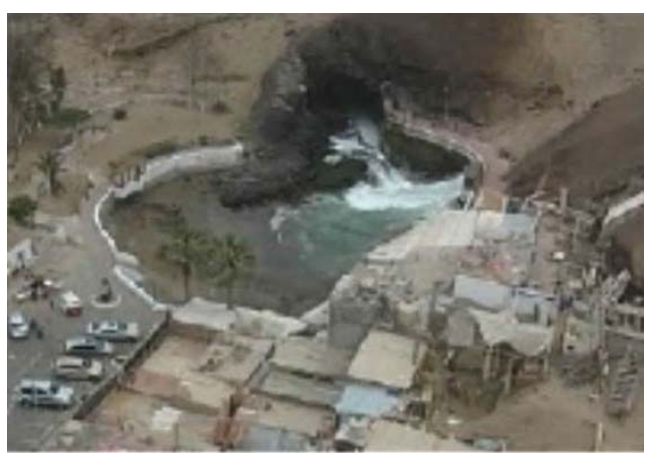

Fuente : Propia

\section{EL MERCADO DISTRITAL}

El mercado es un espacio de encuentro y de interacción entre la población del pueblo de Pucusana es uno de los lugares mas visitados en el día a día, es el único en todo el distrito y en él de encuentran todo tipo de alimentos y productos para el uso diario.

\subsection{El terreno y su entorno directo}

El entorno directo es todo lo que colinda con el terreno y lo afecta directamente, son aspectos que deben ser analizados para poder tener pistas sobre la propuesta a diseñar.

\subsubsection{Informacion del terreno}

\subsubsection{Ubicación, propiedad y situacion}

El terreno esta ubicado en el puerto natural que el distrito presenta, en el se encuentra el terminal pesquero, el muelle de pescadores, las oficinas del gremio de pescadores, entre otros además presenta una amplia plaza que conecta dichas actividades. 


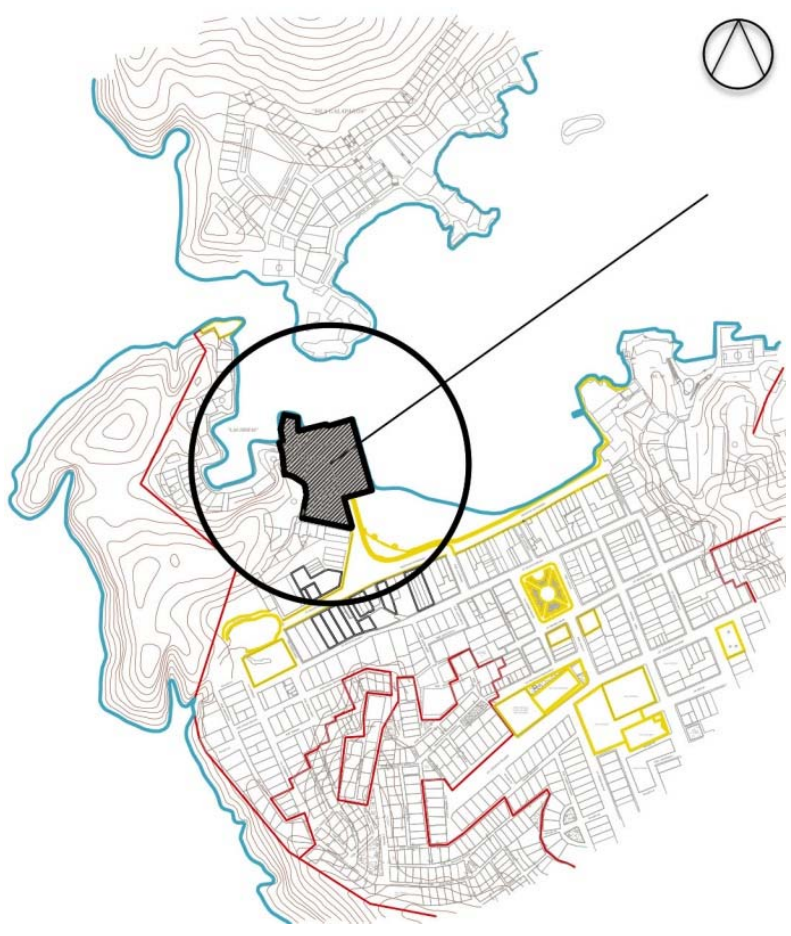

Se podría entender el terreno tanto como el comienzo del malecón, como el final de este. En la propuesta se busca entender terreno como el gran final del recorrido distrital el cual aluda a una reflexión sobre lo experimentado y que permita destacar las cualidades que el distrito presenta. El nuevo terminal pesquero y complejo cultural de la gastronomía será el proyecto que hará que eso ocurra, con espacios coherentes al contexto y a los objetivos propuestos.

\subsubsection{Area, orientacion y topografia}

Presenta un área de $7681,82 \mathrm{~m} 2$, la cual abarca parte del cerro, siendo la cota más alta de la topografía de unos 6 metros de alto, con pendiente no tan marcada que permite diseñar espacios con escalonamientos que limita con la plaza del muelle de pescadores y del terminal.

Limita por el lado oeste con la playa las Ninfas, una playa de acceso exclusivo por la misma plaza, y que el ingreso vehicular es restringido. Por el lado este se encuentra la playa misma de la zona pueblo de Pucusana y una gran vista hacia el malecón y hacia la bahía misma, a lo lejos se puede ver la playa Naplo.

Al lado sur encontramos la playa la isla, su accesibilidad es exclusiva por bote y cuenta con viviendas, en su gran mayoría de uso exclusivo en verano, en muy bien estado y con edificaciones contemporáneas que hacen de este un lugar de gran atractivo para visitar. Y finalmente al lado sur se encuentra la continuación del malecón, con comercio culinario en los limites.

A lo lejos se parecía el resto del distrito y en las zonas altas de los cerros se ven las invasiones que poco a poco se han ido formalizando. La orientación del terreno a utilizar tiene una visual de 180 grados hacia la bahía y se propondrá ser este el frente del proyecto, estando orientado según lo anterior mencionado al Nor-Este del lugar. 


\subsubsection{Parametros urbanisticos}

\subsubsection{Zonificacion}

\begin{tabular}{|c|c|}
\hline \multicolumn{2}{|c|}{$\begin{array}{l}\text { PARAMETROS URBANISTICOS Y EDIFICATORIOS } \\
\text { N044-2015-GDU/MDP }\end{array}$} \\
\hline $\begin{array}{lc}\text { Solicitante } & \vdots \\
\text { Área } & \vdots \\
\text { Ubicación } & \vdots\end{array}$ & \\
\hline $\begin{array}{l}\text { LA GERENCIA DE DESARROLLO } \\
\text { ATENDIENDO A SU SOLICITUD CERT } \\
\text { Los datos están basados a la propuest } \\
418-M M L \text { del } 21-11-02 \text {, ordenanza } 108 \\
\text { aprobados con ordenanzas } N^{\circ} 1614-M M\end{array}$ & $\begin{array}{l}\text { URBANO DE LA MUNICIPALIDAD DISTRITAL DE PUCUSANA } \\
\text { TIFICA: } \\
\text { ta de zonificación de los usos del suelo aprobado por ordenanza No } \\
86-M M L \text { del } 18-10-2007 \text { y Actualizaciones del Plano de zonificación } \\
\text { ML del } 26-07-2012 \text { y } N^{\circ} 1774 \text { del } 26-02-14 \text {. }\end{array}$ \\
\hline $\begin{array}{l}\text {-Zonificación: } \\
\text { - Area tratamiento Normativo: } \\
\text { - Usos permisibles y compatibles: }\end{array}$ & $\begin{array}{l}\text { OU (Otros Usos) } \\
\text { IV } \\
\text { Uso exclusivamente relacionados con las actividades politico- } \\
\text { administrativas, institucionales, culto y cultura y servicios en general. }\end{array}$ \\
\hline $\begin{array}{l}\text { - Densidad Normativa Máxima: } \\
\text { - Area de lote normativo: }\end{array}$ & $\begin{array}{l}\text { Será el resultante del proyecto. } \\
\text { Las edificaciones destinadas a usos educativos estarán sujetos a las } \\
\text { normatividades establecidas por el Reglamento Nacional de } \\
\text { Edificaciones, las disposiciones particulares del ministerio } \\
\text { correspondiente y otras normas técnicas de carácter nacional o } \\
\text { regional. }\end{array}$ \\
\hline $\begin{array}{l}\text { - Coeficiente de edificación: } \\
\text { - Porcentaje minimo de área libre: }\end{array}$ & $\begin{array}{l}\text { Será el resultante del Proyecto. } \\
\text { No exigible siempre y cuando se solucione adecuadamente la } \\
\text { ventilación e iluminación. }\end{array}$ \\
\hline - Alturas máxima y mínima permisibles: $L$ & $\begin{array}{l}\text { La altura de la edificación será determinada, en cada caso, en base al } \\
\text { uso propuesto y al planeamiento integral y estudio volumétrico de la } \\
\text { edificación, en relación al contexto urbano circundante y que no } \\
\text { perturbe los perfiles urbanos existentes. }\end{array}$ \\
\hline - Retiro Municipal: & $\begin{array}{l}\text { Se encuentra supeditado a las condiciones de un lote especifico, y } \\
\text { estará contemplado en el Certificado de Alineamiento. }\end{array}$ \\
\hline - Alineamiento de fachada: & $\begin{array}{l}\text { Se encuentra supeditado a las condiciones de via pública especifica, } \\
\text { y estará contemplado en el Certificado de Alineamiento. }\end{array}$ \\
\hline - Estacionamientos: & $\begin{array}{l}\text { El número de estacionamientos requeridos será determinado según lo } \\
\text { establecido por el Reglamento Nacional de Edificaciones y otras } \\
\text { disposiciones complementarias, debiendo resolverse integramente } \\
\text { dentro del lote. }\end{array}$ \\
\hline
\end{tabular}

ESPECIFICACIONES NORMATIVAS

- Considerar arborización en vías y espacios públicos, las áreas libres y retiros de lotes se trataran con predominio de áreas verdes.

SE EXPIDE EL PRESENTE CERTIFICADO DE PARAMETROS URBANISTICOS A SOLICITUD DEL INTERESADO, PARA LOS FINES QUE CONSIDEREN CONVENIENTES.

PUCUSANA, 29 de Octubre de 2015.

La zonificación es bastante amplia y no tiene muchas restricciones ni parámetros sobre el diseño a proponer.

Se tomará de referente al Reglamento Nacional de Edificaciones para poder realizar las pautas respectivas del proyecto a desarrollar.

El estacionamiento estará propuesto fuera del complejo en el lugar actual de estacionamiento con un lugar adicional de estacionamiento techado.

Se busca generar un recorrido desde el exterior, conociendo lo que el distrito presenta hasta el interior el cual estará diseñado con espacios y equipamientos necesarios que enfaticen el objetivo. 
Figura 175: Malecón, Terreno y embarcaciónes - Toma aerea

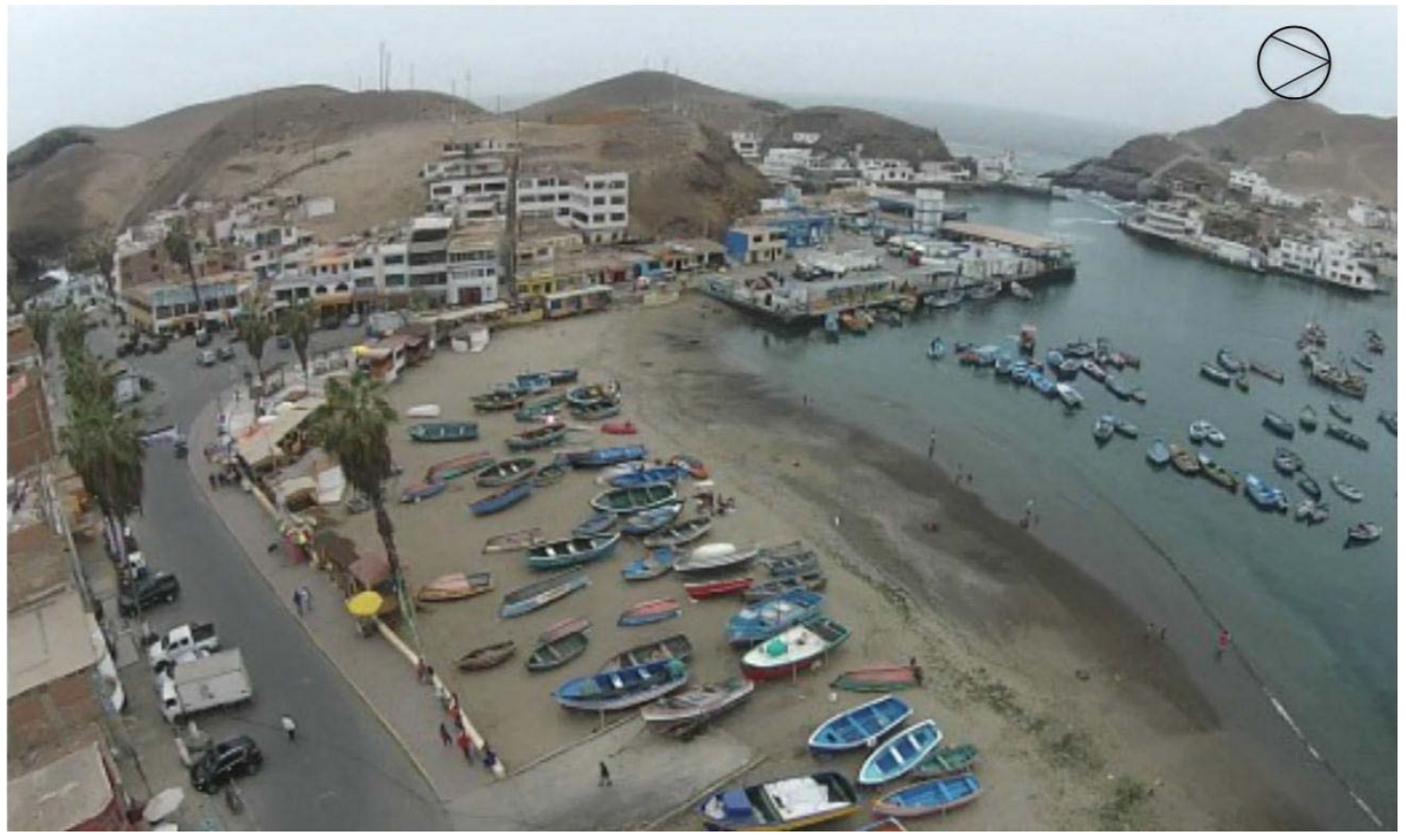

Fuente : Propia 
Figura 176. Mapa muestra malecón exclusivo de poeatones

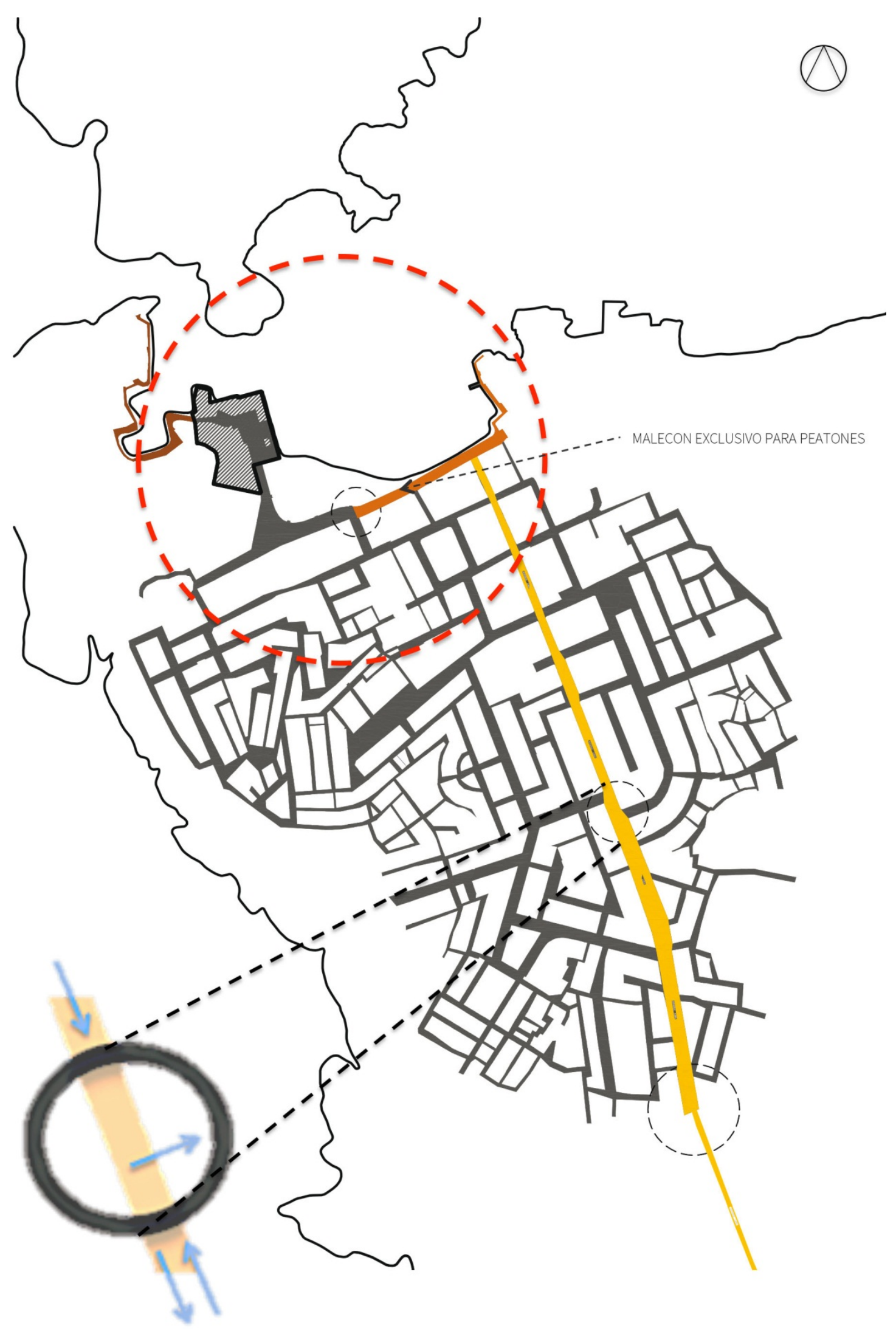




\subsubsection{Accesibilidad}

La accesibilidad a la zona pueblo del distrito es a través de una sola vía de acceso llamada la avenida Lima, esta tiene un recorrido en ambos sentidos y es presenta el espacio exclusivo para el transito motorizado, sea por combis, carros particulares taxies o mototaxis, el acceso peatonal se realiza por ahí pero la avenida no presenta la vereda correspondiente para su recorrido, es por ello que resulta peligroso.

Para llegar al terreno motorizadamente, el recorrido más frecuentado es por la avenida Lima luego hay un punto de inflación en cual se abre la vía y de llega al mercado luego se bordea el parque el cual esta al frente de la municipalidad y gremio de pescadores y finalmente se accede al malecón.

El transito es moderado durante el año y fines de semana en temporadas de verano este flujo aumenta notablemente, muchos de los visitantes acceden a el exclusivamente a través de mototaxis para evitarse el estacionamiento que es escaso en la zona.

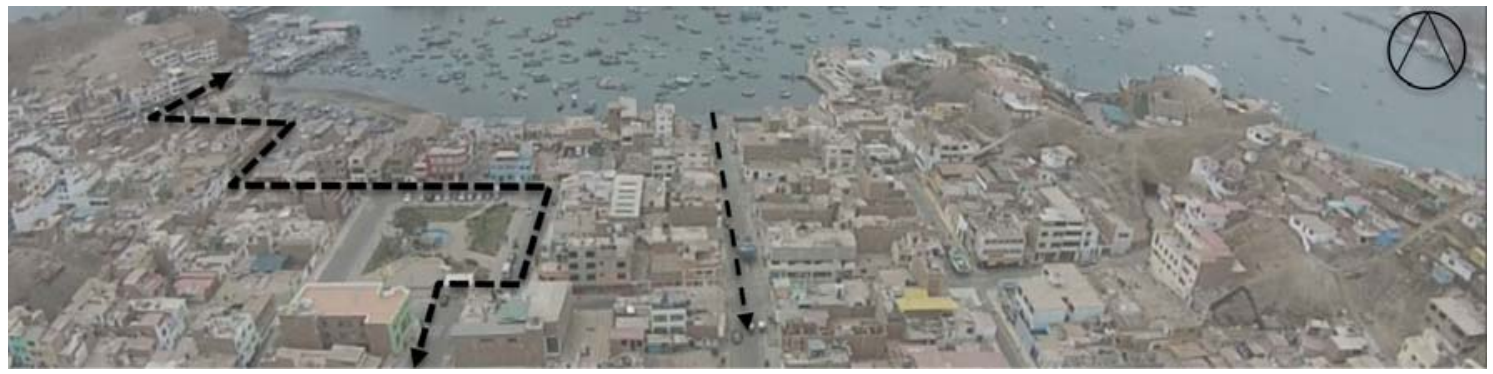

El malecón es accesible vehicular como peatonalmente, solo una zona es exclusiva para el peatón el cual presenta una alameda en la zona central con restaurantes culinarios, los cuales ofrecen al visitante y turista en general una variedad de platos de la pesca del día. Todo el borde hacia la bahía presenta comercio pero en muchos casos este es informal y se ubican donde mejor les parezca, dificultando la visual hacia el mar y dañando el potencial que el distrito presenta y que debe ser reconocido y valorado por todos los que lo recorren.
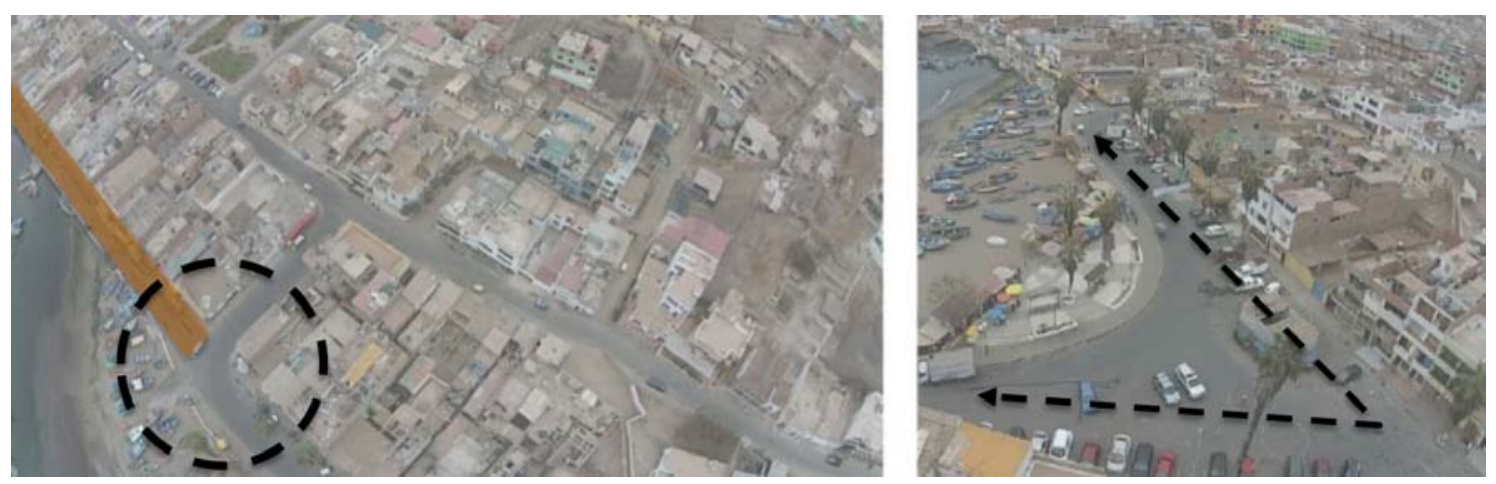
Figura 177. Mapa de alturas, muestra las viviendas de 2 hasta 5 pisos

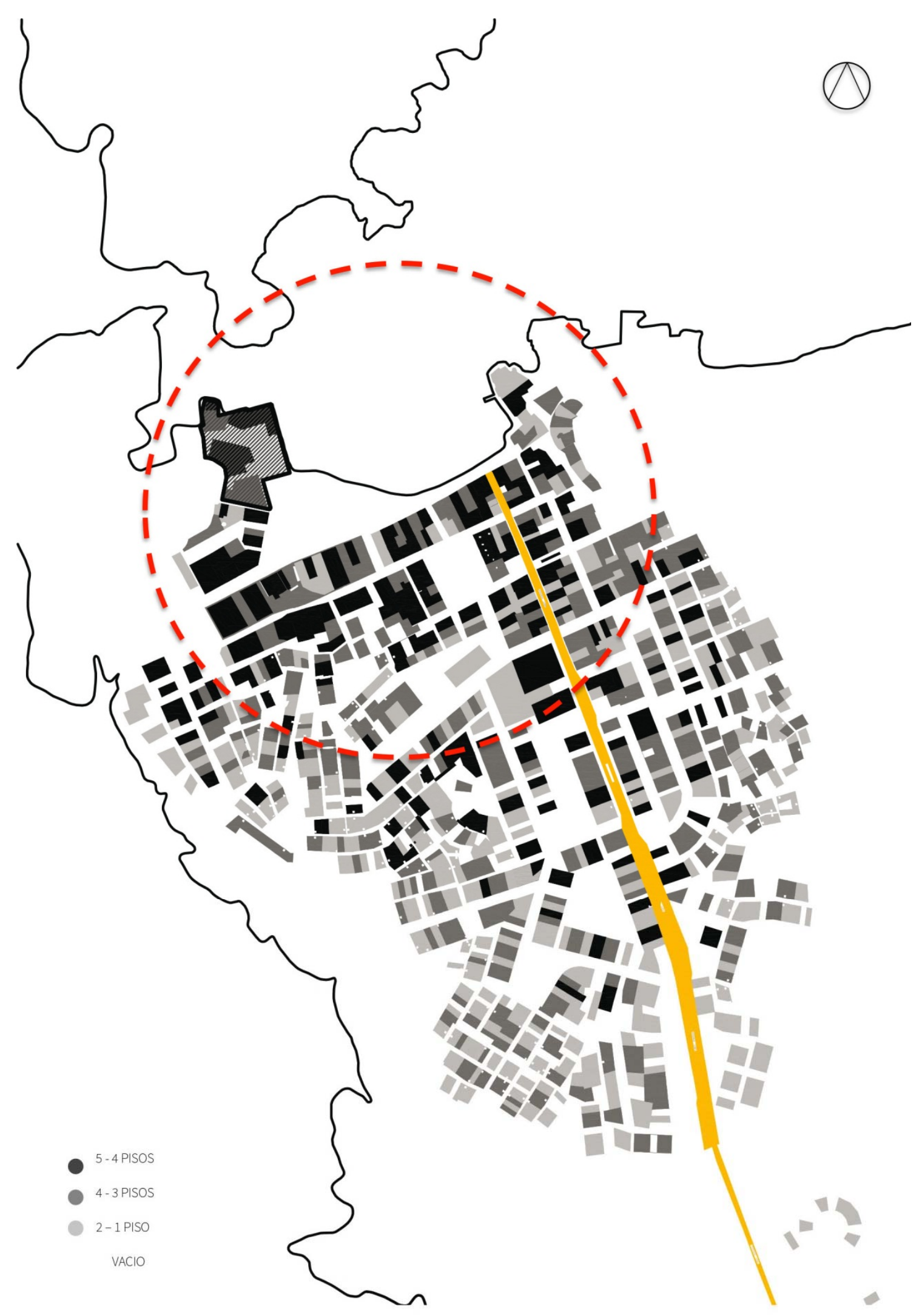




\subsubsection{Alturas}

Las alturas no son tan marcadas en el distrito en general, el numero de pisos mayor es de 6 pisos. Resulta cuestionable que en la zona próxima al malecón las edificaciones son de mayor altura. Estas edificaciones presentan comercio en las zonas bajas y vivienda $\mathrm{u}$ hostales en las pisos superiores. En el terreno en particular los edificios existentes presentan una variedad de alturas que no compiten con la escala del resto de las edificaciones de Pucusana, esto se tendrá en cuenta a la hora del diseño.

\subsubsection{Retiros}

No se han encontrado retiros en la zona cerca al terreno, todas las edificaciones están construidas al borde de la vereda o de la misma pista.

\subsubsection{Estacionamientos}

Los estacionamientos en el distrito en general en su mayoría son improvisados hay muy pocos espacios determinados para el. En particular en el cruce entre el boquerón del diablo el terminal y el malecón se encuentra el estacionamiento que tiene mayor influencia en el terreno.

\subsubsection{Compatibilidad de usos de suelo}

La compatibilidad de usos es generalmente en relacion al comercio, en la zona de comercio zonal se puede combinar con vivienda y viceversa, en el caso de otros usos (el terreno elegido) la compatibilidad de usos es mayor y tanto comercio como espacios culturales pueden ser ejecutados en él.

\subsubsection{Especificaciones normativas}

Las especificaciones normativas del proyecto a realizar serán propuestas a criterio propio, con asesoramiento del Reglamento Nacional de Edificaciones ya que la normativa municipalidad no presenta muchos parámetros. 
Figura 178: El terreno y el borde hacia el mar - Toma aerea

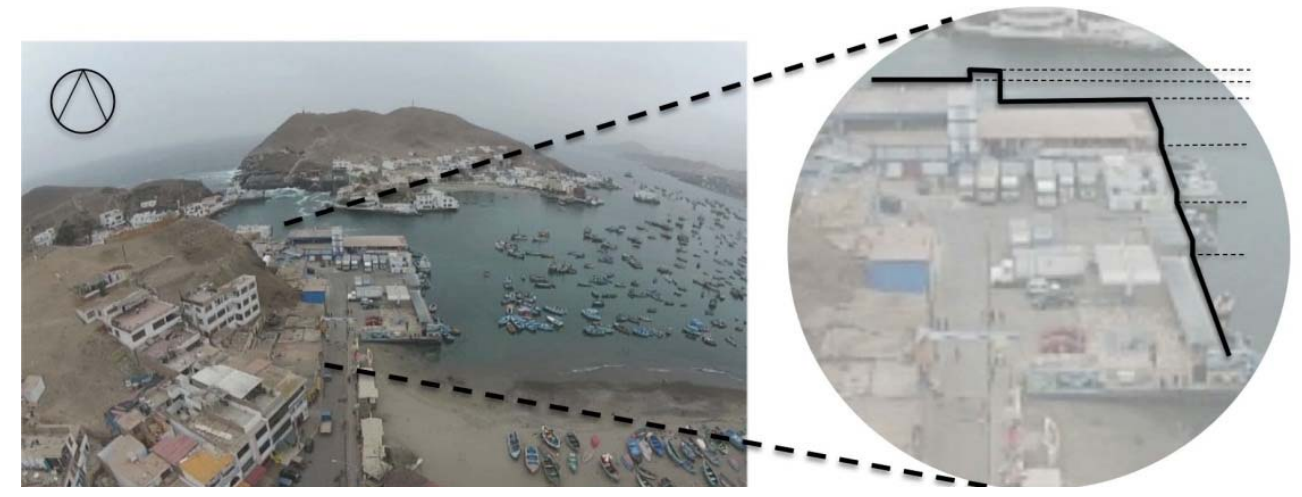

Fuente : Elaboración propia

Figura 179: Playa del pueblo de Pucusana - Toma aerea

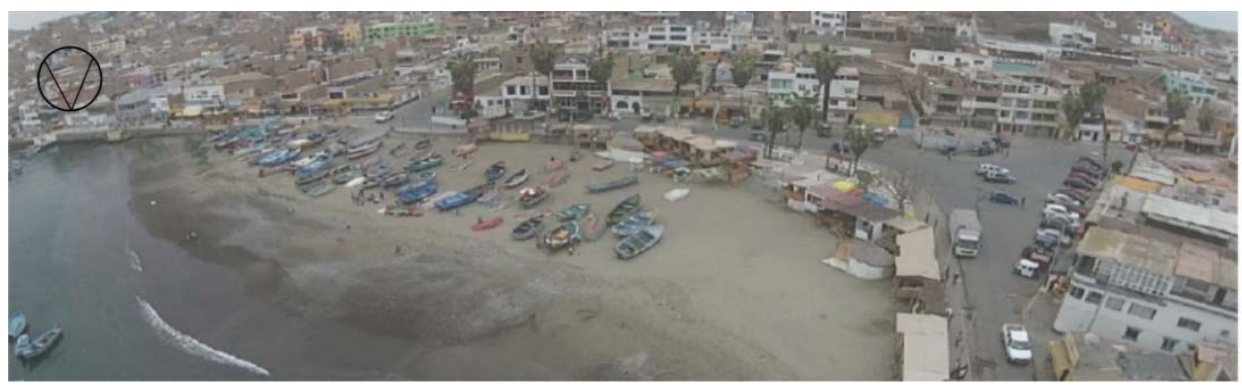

Fuente : Propia

\subsection{El terreno y entorno inmediato}

En entorno inmediato es lo que está dentro del terreno que se analizará para poder determinar el estado actual, con sus oportunidades para mejor y con las debilidades que deben ser tomadas en cuenta para el proyecto a realizar.

La forma del terreno es bastante orgánica, presenta tres frentes. Uno que está en contacto directo con la playa, el siguiente el cual da a la bahía y al muelle de pescadores y el tercero el cual da al terminal pesquero y a la playa la isla, la cual se encuentra al frente.

Las tres fachadas serán diseñadas para poder optimizar el espacio en constante relación con el entorno y poder mantener la relación directa entre ellos en todo el recorrido.

Desde el exterior hacia el interior como del interior hacia el exterior.

Se analizaran distintas variables del entorno que afectan directamente al proyecto a desarrollar. 
Figura 180. El terreno y el entorno inmediato

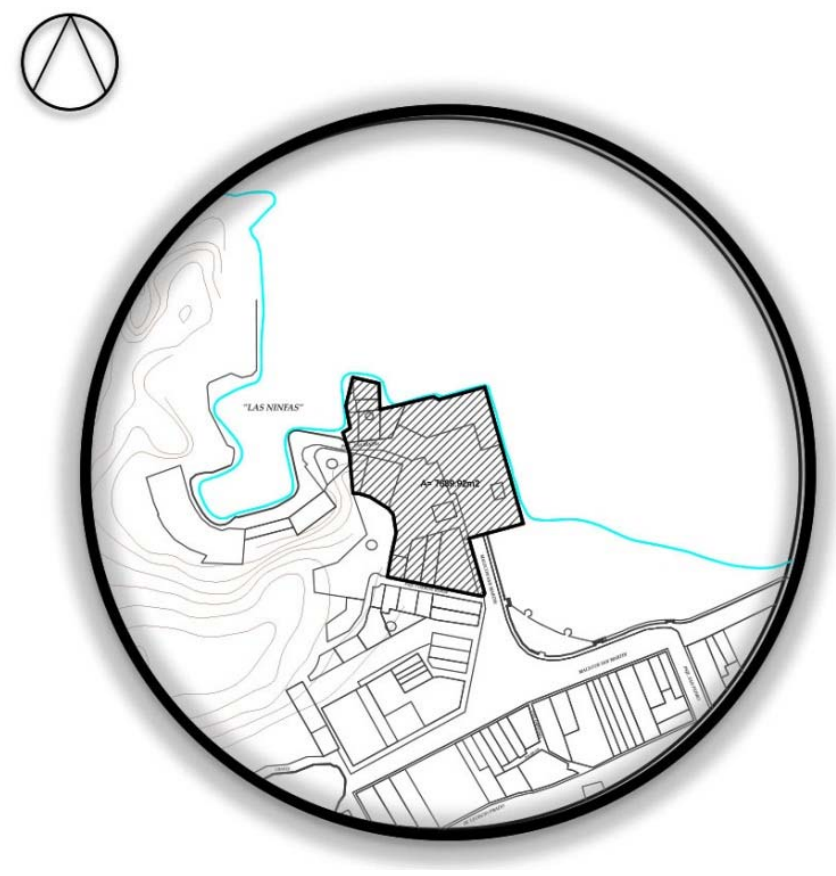

\section{$\underline{\text { VISUALES }}$}

Las visuales del proyecto dan hacia la bahía, hacia el malecón del distrito de Pucusana y hacia la ciudad misma. Se aprovecharan en su optima ejecución estos tres factores para poder realizar un proyecto acorde con el entorno.

\section{$\underline{\text { SONIDOS }}$}

Los sonidos que se perciben en el lugar varían entre el sonido de los motores de las embarcaciones y la música que los pescadores ponen en sus botes, en el

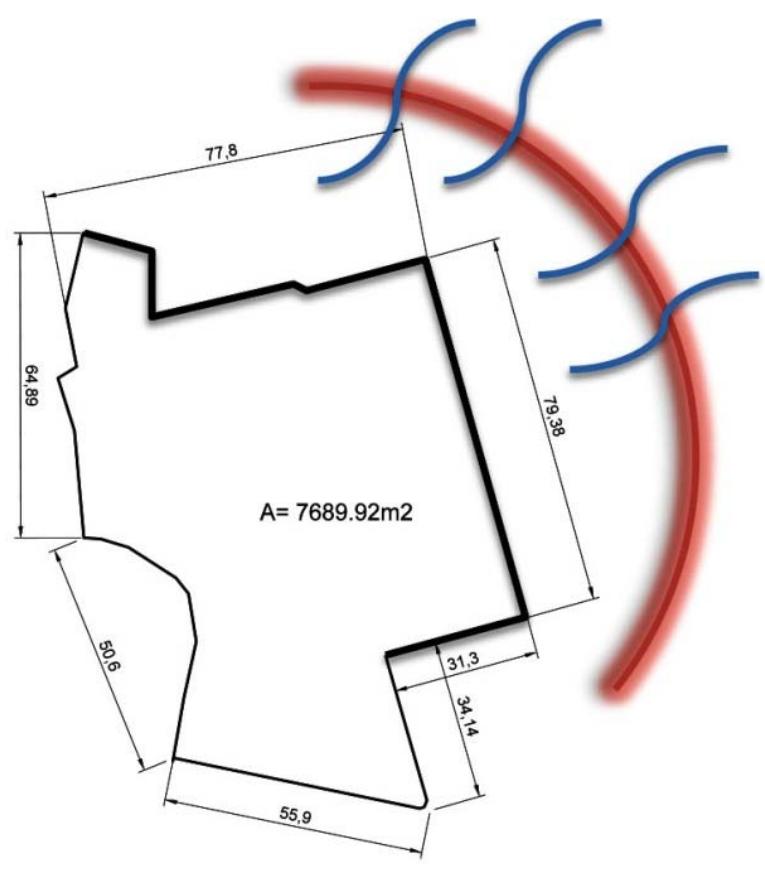
malecón se encuentran muchas mezclas de ellas desde salsa hasta música chica.

\section{OLORES}

Los olores son claves en el terreno, el olor a mar y a peces es muy influyente, por la actividad que se realiza ahí y las actividades de venta de esta, el olor es imposible no percibirlo. 


\section{$\underline{\text { FLUJOS }}$}

Los flujos en el terreno son tanto de los pescadores como de los visitantes y turistas.

\subsubsection{Zonificacion y usos de suelo}

La zonación como ya se mencionó es de usos múltiples, actualmente se realizan muchas actividades en el terreno como lo son la actividad del terminal pesquero el turismo que se realiza en la zona del malecón de pescadores, el espacio publico de interacción y edificaciones como lo son la del gremio de pescadores entre otras.

\subsubsection{Volumetria y tipologia}

La volumetría del terreno no es muy marcada y se encuentran espacios rectangulares como lo es el terminal pesquero la mayoría ha sido planteada de acuerdo a la necesidad y no con una arquitectura planeada.

\subsubsection{Llenos y vacios}

Si bien el lugar tiene bastante influencia en el distrito en el cerro aun quedan lotes sin uso y los que se encuentran están en mal estado.

El terminal cuenta con espacios improvisados que no cumplen con la normativa necesaria para el reglamento de sanidad.

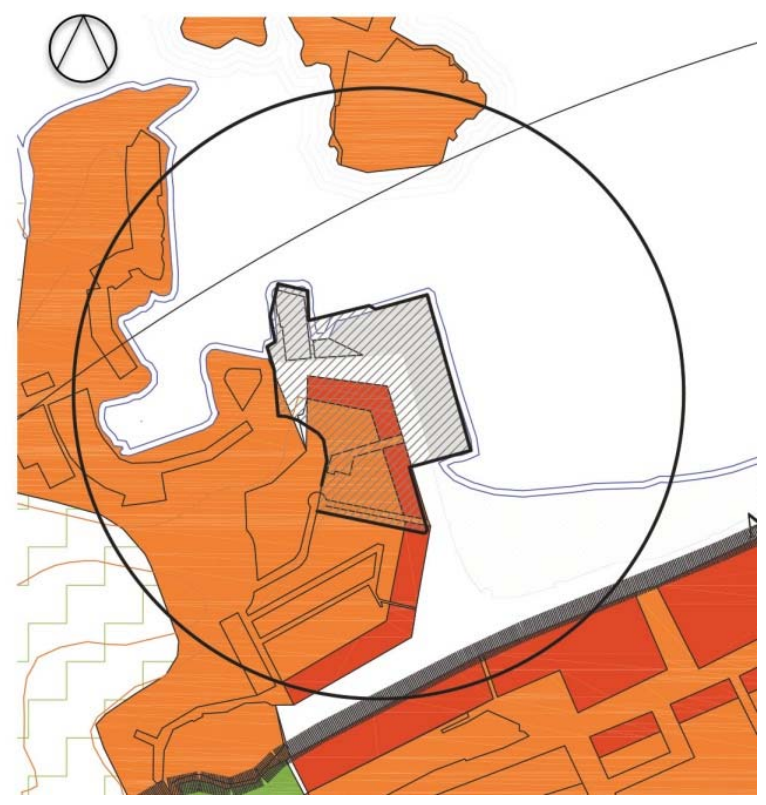

\subsubsection{Alturas de las edifiaciones}

Presenta varias alturas y en promedio es de dos metros y medio y la de las edificaciones pegadas al cerro presentan mayor altura llegando hasta los 6 metros, siendo estos de tres pisos. 
Figura 181: El terreno - Toma aerea

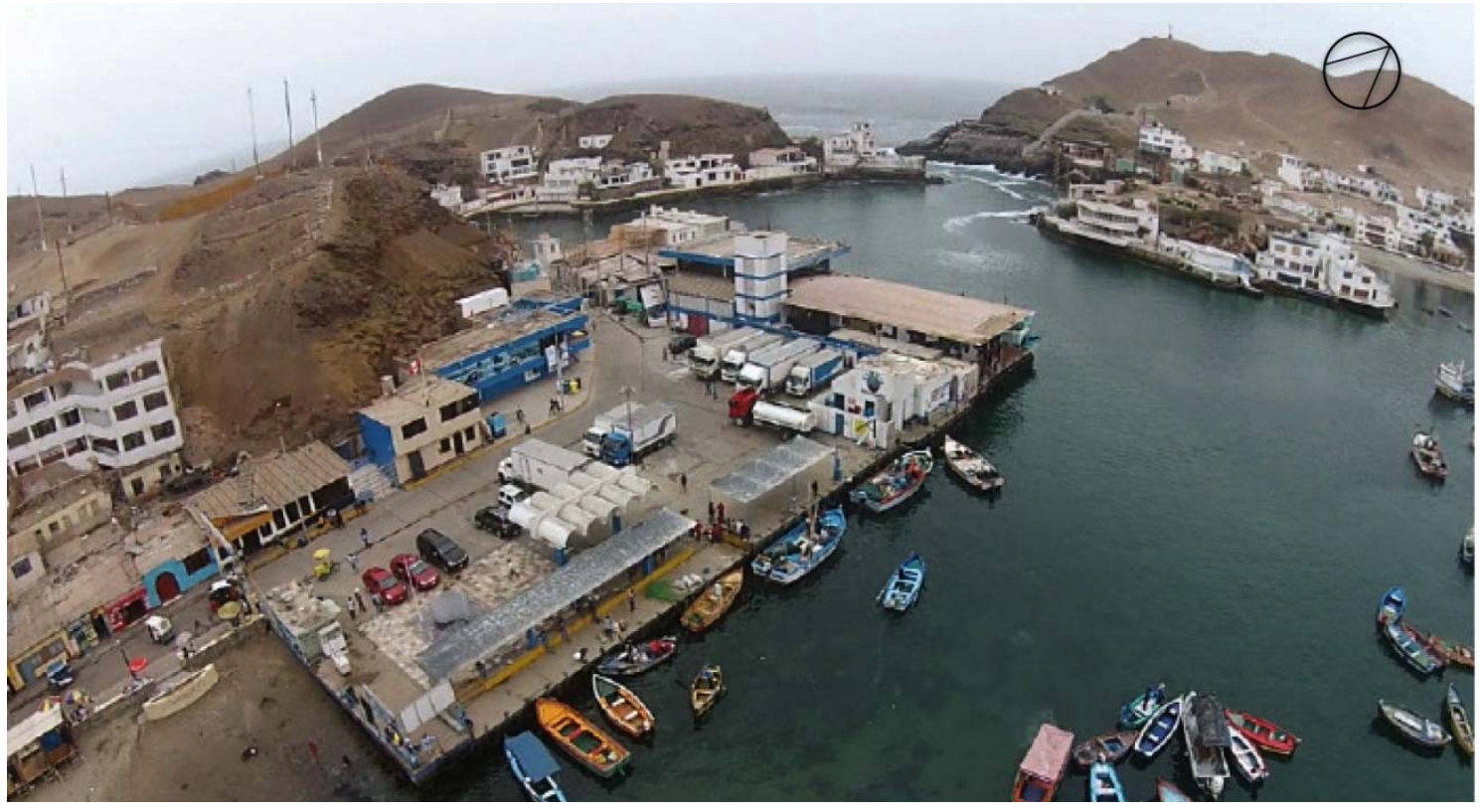

Fuente : Propia

\subsubsection{Vialidad}

La vialidad en el terreno es accesible para todos los visitantes tanto vehicular como peatonalmente, el sentido de la vía es en ambas direcciones. En el área próxima al terreno se encuentra un estacionamiento improvisado que no tiene costo en el se encuentra la mayor aglomeración de carros y transporte para acceder al terminal y muelle de pescadores ya que el espacio de estacionamiento de los mismos dentro del terreno, tiene costo.

Figura 182: Edificios colindantes al terreno - Toma aerea

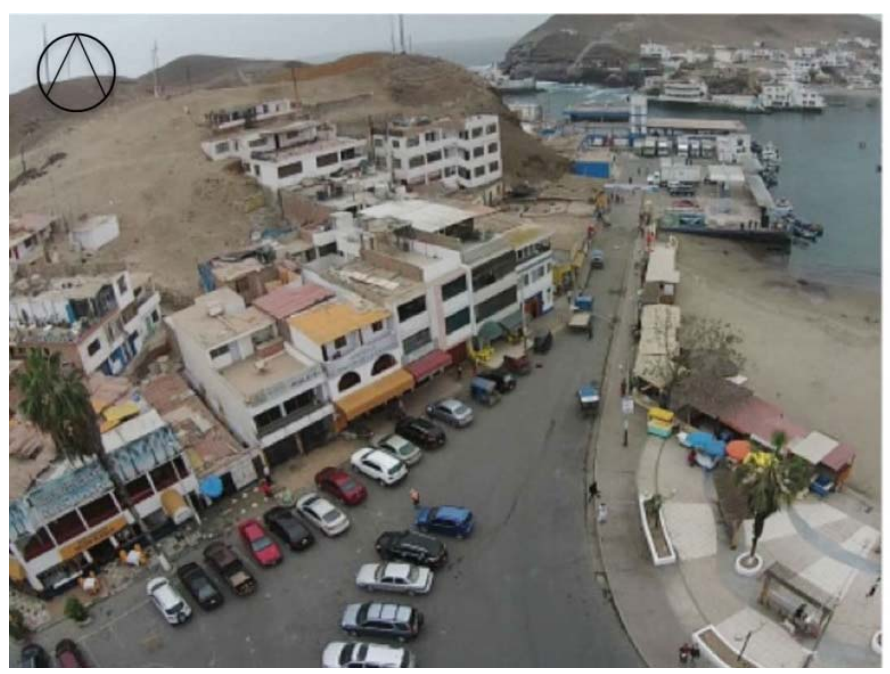

Se puede apreciar como las mototaxies dejan a los pasajeros en este espacio para que puedan disfrutan de las vistas que el distrito ofrece, este espacio conecta el terminal pesquero con el malecón y con el boquerón del diablo.

Fuente : Propia

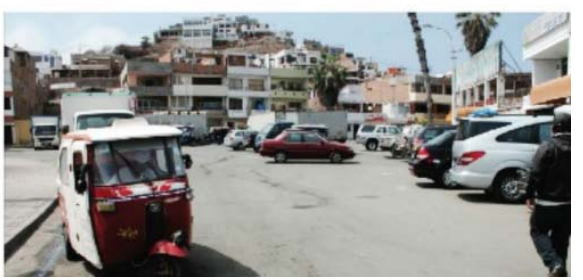


Dentro del terreno se encuentra un estacionamiento para uso publico y uso particular, cualquiera puede acceder a él, pero tiene un costo de 1 sol cincuenta el medio día. Es administrado por la asociación de pescadores con la finalidad de no hacerlo tan publico porque en ese mismo espacio es donde se embarca y la pesca del día.

Además es el espacio publico que une las edificaciones colindantes y si este esta lleno de carros el flujo seria limitado. También es el espacio previo a la playa las ninfas es el único acceso a dicha playa ya que no cuenta con acceso vehicular.

Para llegar al terminal, al muelle de pescadores, al gremio de pescadores y a los distintos edificios que el terreno presenta es necesario pasar por el espacio publico no techado, es una gran plaza que engloba el conjunto.

Figura 183: Terreno en zoom (toma aerea) y vista del terminal

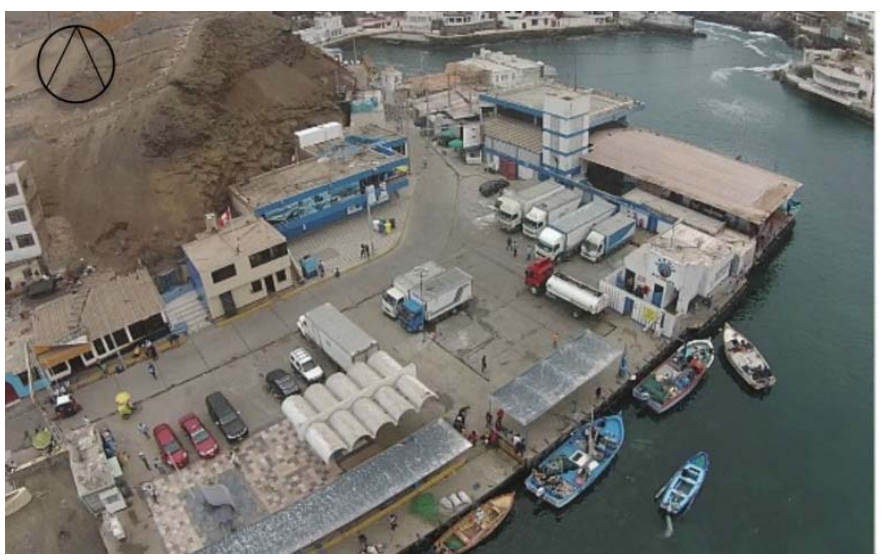

Hay un cartel que en marca la entrada y en el cual se encuentra el señor encargado de la cobranza en caso se quiera acceder motorizadamente

Fuente : Propia

\subsubsection{Circulaciones peatonales, alamedad, plazas, etc.}

Las circulaciones peatonales en el terreno son bastante fluidas, tanto por los pescadores para poder realizar sus labores diarias sino también por los turistas que llegan ahí para subirse a las embarcaciones había la bahía y poder conocer el entorno natural y paisajista que el distrito presenta. El espacio presenta mobiliario para poder sentarse y poder apreciar el lugar correctamente, sin embargo este no satisface a la demanda del turismo en el sector

Se puede apreciar un espacio al lado del muelle de pescadores el cual presenta publicad de la flora y fauna que se apreciara en el recorrido turístico en bote por la bahía.

Además cuenta con una baranda de protección debido a la altura que esta se encuentra con la playa y con el mar. 
Figura 184: Guias turisticos

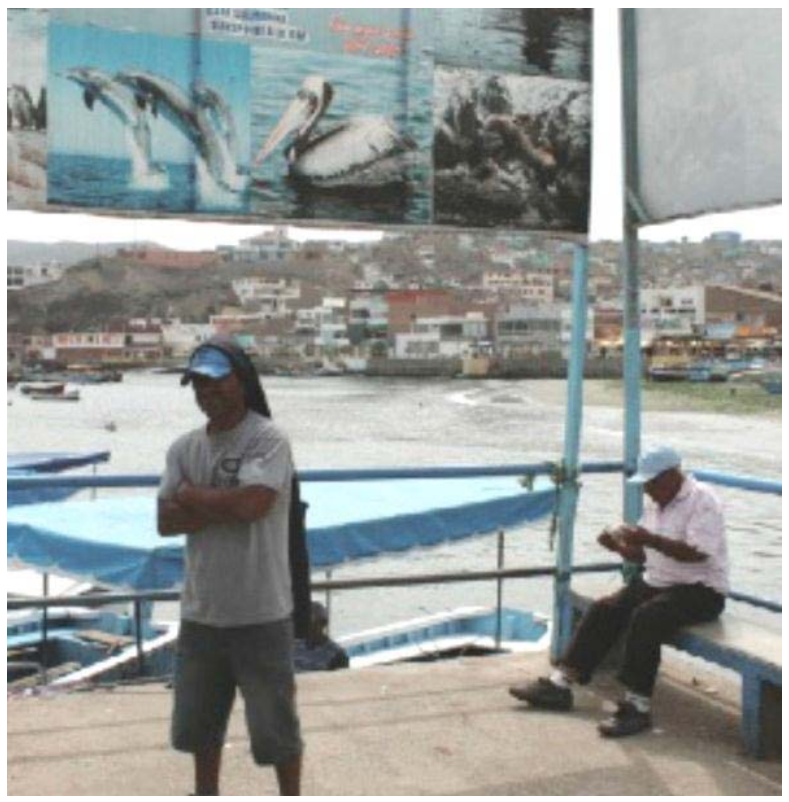

Fuente : Propia

Cuenta con mobiliario pero es escaso y la mayoría de gente que espera, espera parada o apoyada en la baranda que se encuentra en todo el perímetro hacia el mar.

El público en general, es variado tanto señores mayores como niños llegan al lugar para realizar turismo. Los domingos muchas familias van a pasar el día a buscar un día en familiar diferente disfrutando de la naturaleza.

En el espacio público se realizan muchas actividades tanto de esparcimiento del visitante como de la actividad pesquera que el terreno presenta. Además el muelle de pescadores es utilizado tanto para los pescadores para poder apoyar sus redes que luego serán embarcadas como para atender a los turistas que recorrerán la bahía.

Los pescadores mismos han apropiado el espacio y no tienen parámetros para poder mantener el orden en momentos de bastante flujo ellos se aglomeran en el espacio techado provisional y descansan conversan y hasta comen, dejando de lado el resto de actividades que realizan en el.

Es importante y debe tenerse en cuenta para la propuesta que las actividades estén determinadas tanto espacialmente como en flujos de los usuarios para que sea entendido correctamente y el visitante y publico en general pueda apreciarlo y disfrutarlo de la mejor manera 
Figura 185: Espacio de desembarque

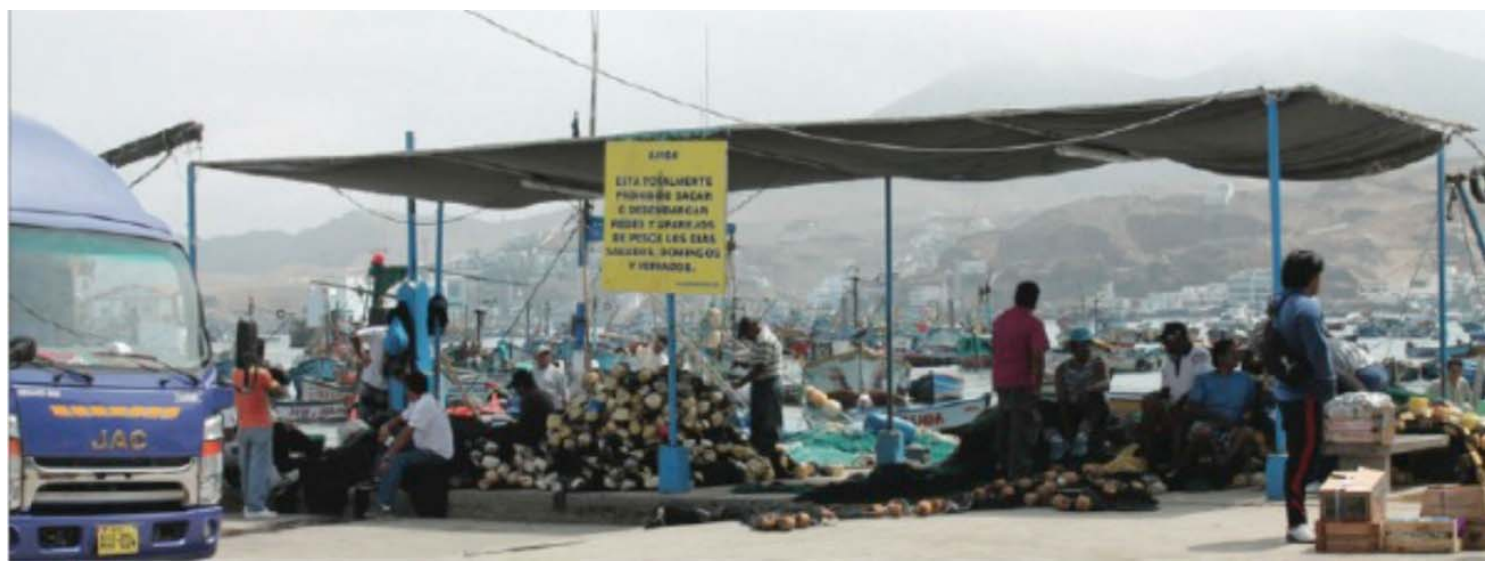

Fuente : Propia

\subsubsection{Levantamiento, secciones de vias y veredas}

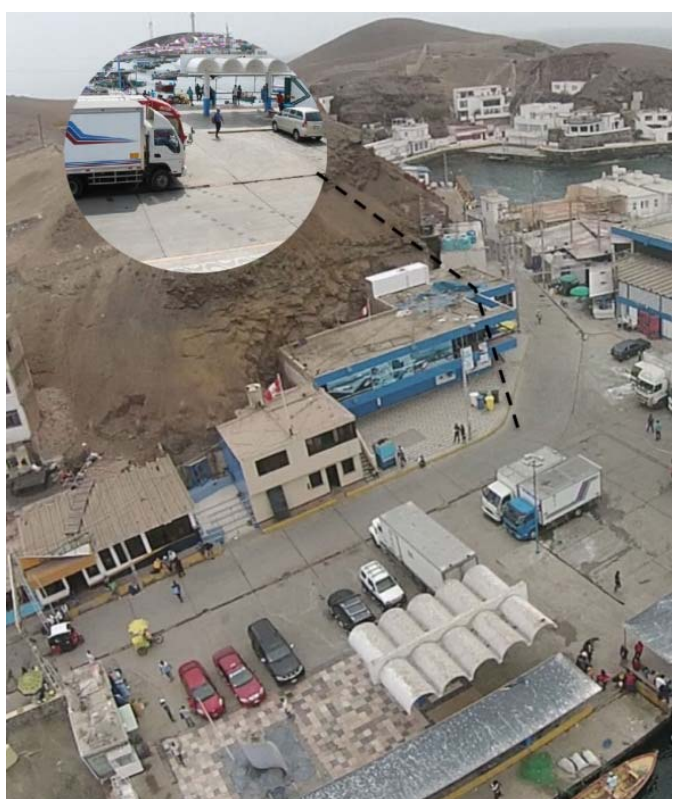

Cuenta con gran espacio, la gran mayoría no esta techado y presenta variedad de usos.

El lugar cuenta con una pista de 5 metros de ancho en el cual los camiones de carga y descarga trascurren hacia el terminal, también cuenta con un espacio techado de sombra en el cual el visitante puede esperar para ser atendido posteriormente para realizar el recorrido turístico en la bahía.

Figura 186: Camión de transporte - Terminal Pesquero Fuente : Elaboración propia

\section{EDIFICACIONES COLINDANTES}

Edificaciones que se encuentran próximas al cerro, son edificaciones que cuentan con dos a tres pisos y que realizan labores para el buen funcionamiento del de la actividad pesquera en general, tanto del terminal mismo como de pescadores particulares que salen a flote para poder obtener alimentos o comercializarlos a menor escala.

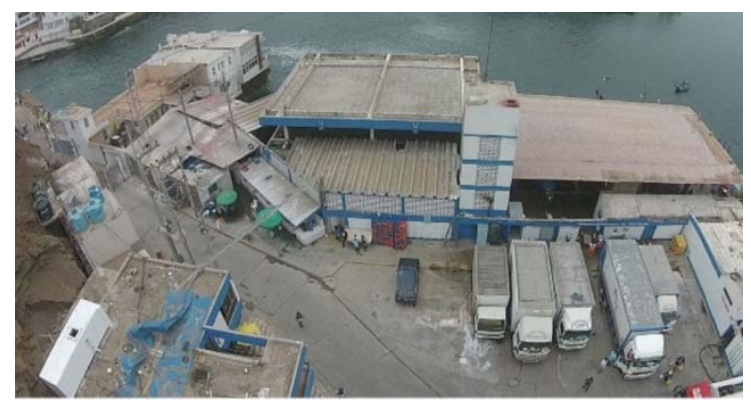

Figura 187: Acceso a las Ninfas - Toma aerea Fuente : Propia 


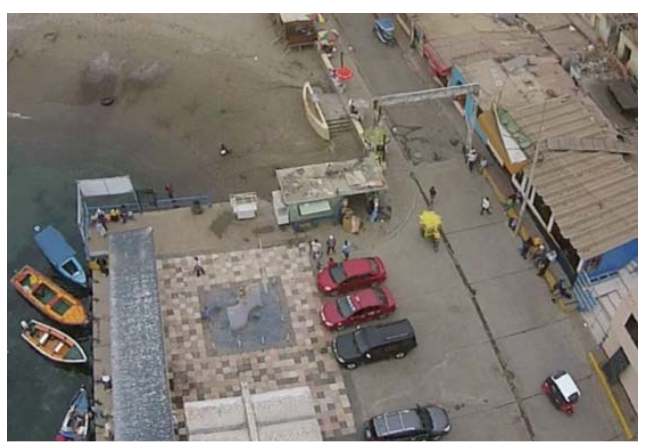

Figura 188: Estacionamiento- Toma aerea Fuente : Propia

\section{TERMINAL PESQUERO}

El terminal pesquero se encuentra en el limite con el mar y presenta un área de $600 \mathrm{~m} 2$, en el se realizan las carcas y descargas de lo obtenido en el día, también se lavan y se limpian los productos para luego comercializarlos $\mathrm{O}$ ofrecérselos al publico en general.

\section{MUELLE DE PESCADORES}

El lugar cuenta con un espacio delimitado para embarcar y desembarcar al mar, previo a este se encuentra un espacio techado de espera y que los pescadores lo utilizan como espacio de descanso. La materialidad del suelo cambia dependiendo del uso.

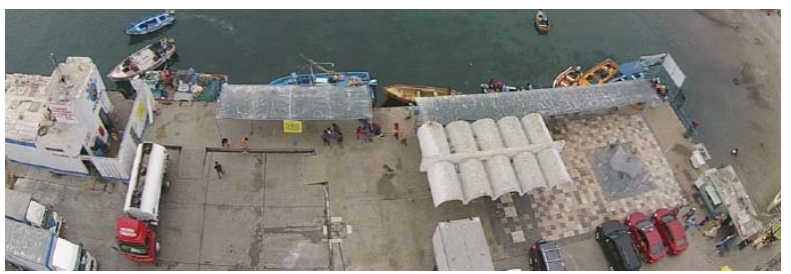

Figura 189: Patio de maniobras - Toma aerea Fuente : Propia

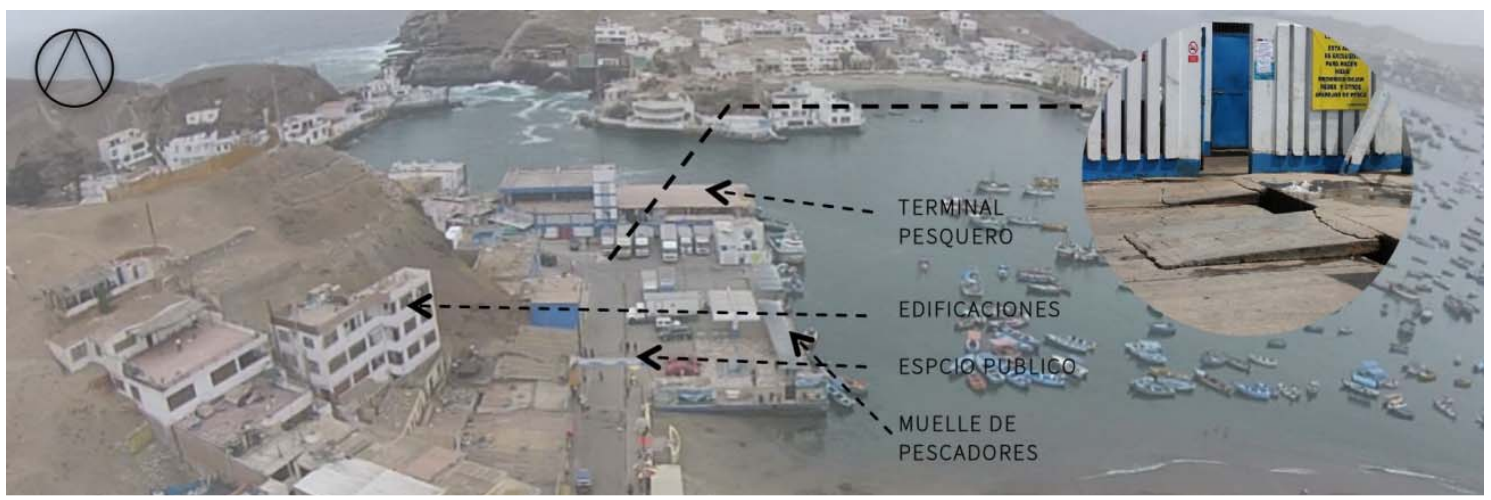

Figura 190: Terminal pesquero artesanal Fuente : Elaboración propia

Las alturas el terminal mismo y del espacio publico en relación a las edificaciones y el muelle de pescadores de puede apreciar en la imagen anterior con los énfasis necesarios para entender lo mencionado. Las alturas no son muy drástica y combinan muy bien con el entorno del distrito la escala de la edificación en Pucusana será preservada y no buscar un proyecto invasivo.

El terreno presenta una pista de 5 metros de ancho en el cual los camiones de carga y descarga trascurren hacia el terminal, el espacio al lado es del mismo material pero es 
utilizado como estacionamiento y en el medio de este hay un cambio de materialidad del suelo, a mayólicas en todo el acceso es excesivo para el peatón en el centro de este se encuentra una estatua $\mathrm{v}$ una escultura $\mathrm{y}$ al lado el lugar presenta un espacio techado de sombra en el cual el visitante puede esperar para ser atendido posteriormente para realizar el recorrido turístico en la bahía. Próximo a este espacio esta el muelle de pescadores un espacio de unos de $50 \mathrm{~m}$ largo por $5 \mathrm{~m}$ de ancho en donde se enganchan las embarcaciones y donde se sube al recorrido el visitante.

Figura 191. Plano esquemático

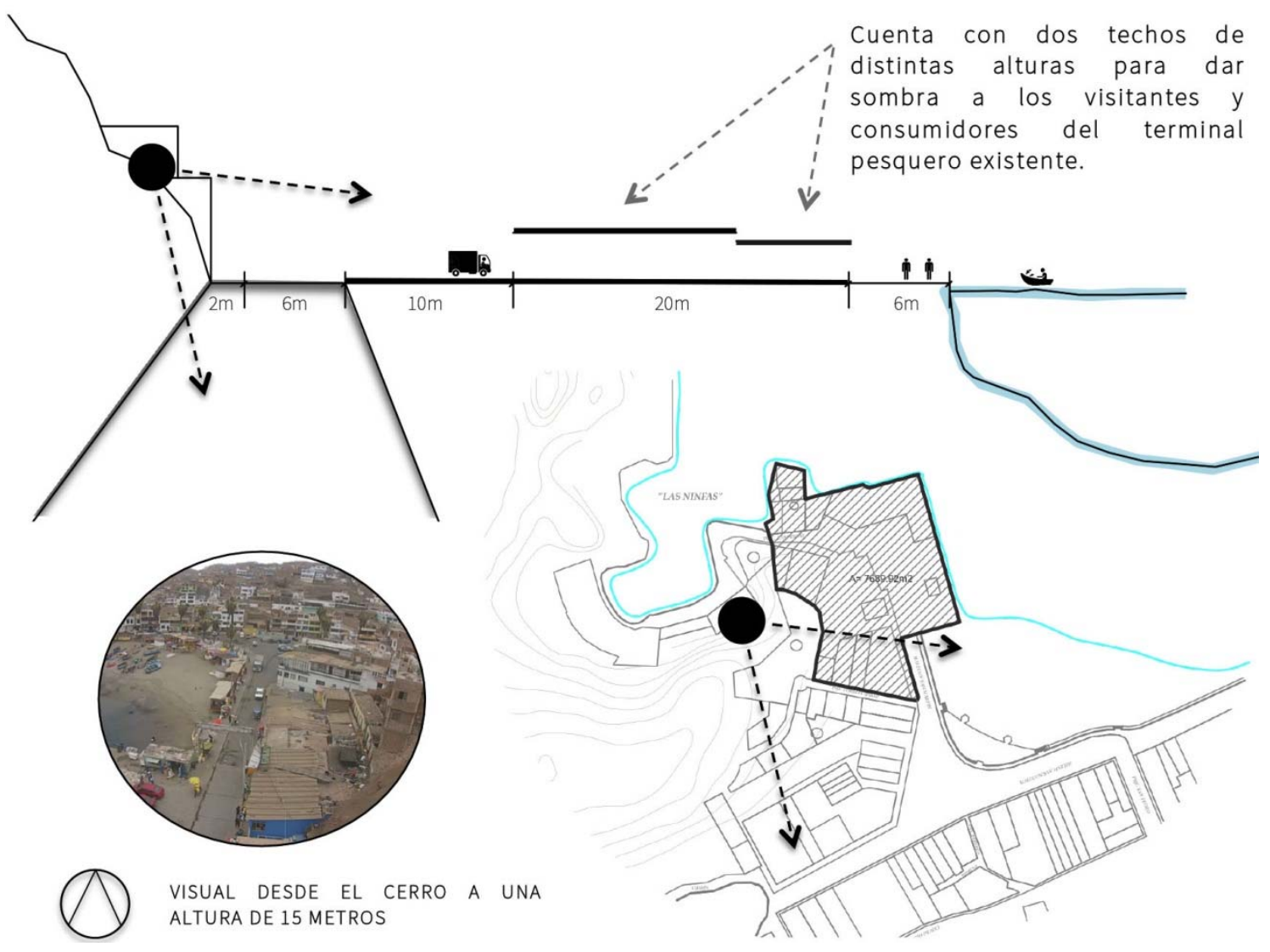

\subsection{8. ¿Qué problemas, condición o condicionantes del entorno debe resolver el proyecto?}

Se analizarán distintos problemas y condicionantes que serán tomadas en cuenta para poder realizar el proyecto correctamente, conociendo el lugar las actividades que se realizan en el y como la gente lo frecuenta para poder realizar un proyecto optimo para el entorno como para el poblador y visitante en general.

El espacio público, además ser un lugar de interacción y de estacionamiento para el muelle de pescadores y terminal pesquero, también es utilizado de lugar de descarga de 
hielo y de carga de 1 a pesca del día, además no presenta un recorrido delimitado y los pescadores los traviesan sin ningún orden. Se cruzan con las distintas actividades de el y el turista se siente invadido por la falta de orden y coherencia en sus actividades según el espacio.

Se puede observar como el hielo es descargado donde mejor lo concideren y como los pescadores están movilizando un motor de bote para llevarlo a reparar por el medio de la plaza atravesándolo e invadiendo la circulación tanto vehicular como peatonal

Figura 192: Patio de maniobras - carga y descarga
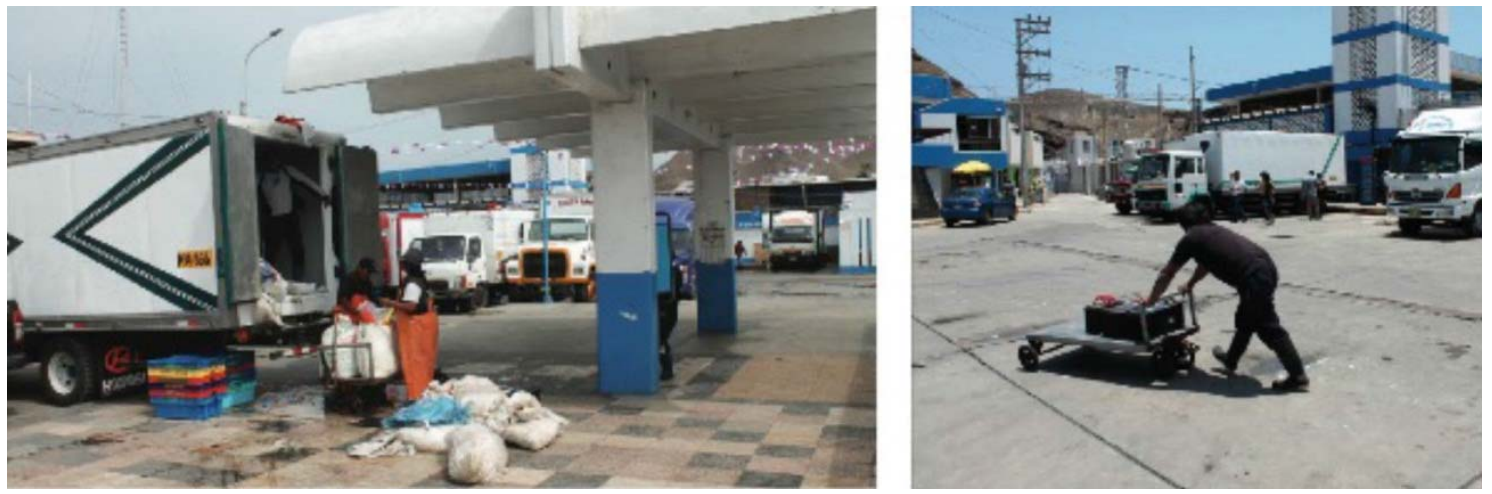

Fuente : Propio

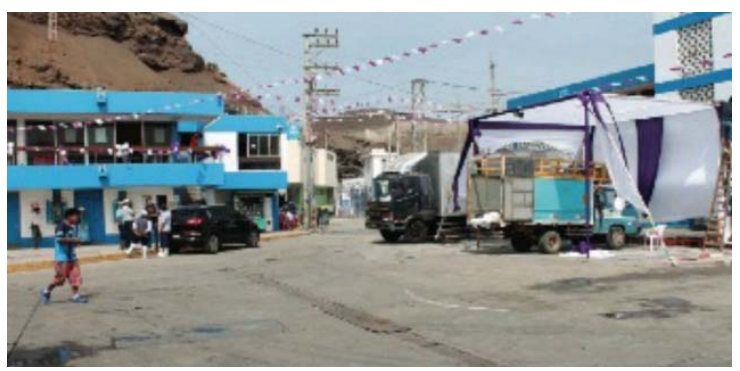

Además el espacio público en algunas fechas emblemáticas es utilizado para realizar eventos, y los trabajadores se ven obligados a detener su actividades y redistribuir los espacios de uso por los toldos y mobiliarios que el evento implica.

Estas actividades son organizadas por el gremio de pescadores, por la asociación de pescadores o por la municipalidad misma.

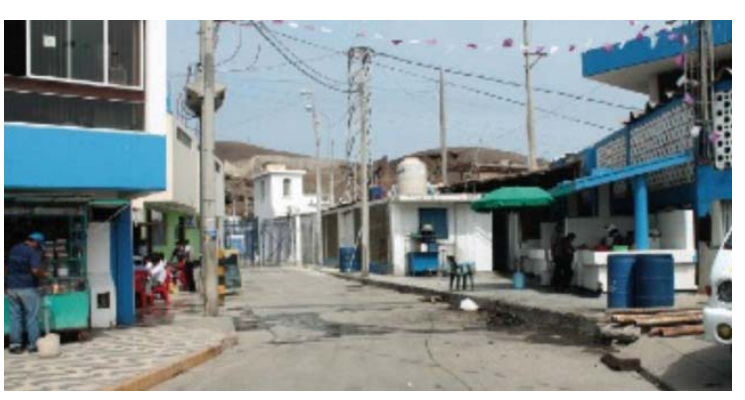

Además el lugar presenta el acceso a la playa las ninfas, siendo este el unido acceso a la playa. Se realiza atreves de una avenida chica que se conecta con la plaza y en temporadas de verano se aglomera mucha gente en ese sector. Además hay actividad comercial en su perímetro que atrae a una mayor cantidad de gente aun. 


\section{EL TERMINAL PESQUERO}

El terminal pesquero en particular presenta muchos problemas tanto espaciales como de sanidad. No cuenta con espacios delimitados para los distintos usos que este requiere, las zonas de carga y descarga son las mismas que para el lavado y pesado.

Los flujos de los trabajadores se cruzan y en muchos casas genera confusión entre ellos mismos generando conflicto y competividad entre ellos. Ya que el agarra el mejor espacio por llegar primero obtiene mas beneficios que el que se tardo mas.

La falta de orden genera que el visitante que quiera comprar la pesca del día no tenga un espacio determinado para poder apreciar la variedad de peces y mariscos que hay para poder comprar lo requerido.

Figura 193: Descarga Terminal pesquero artesanal
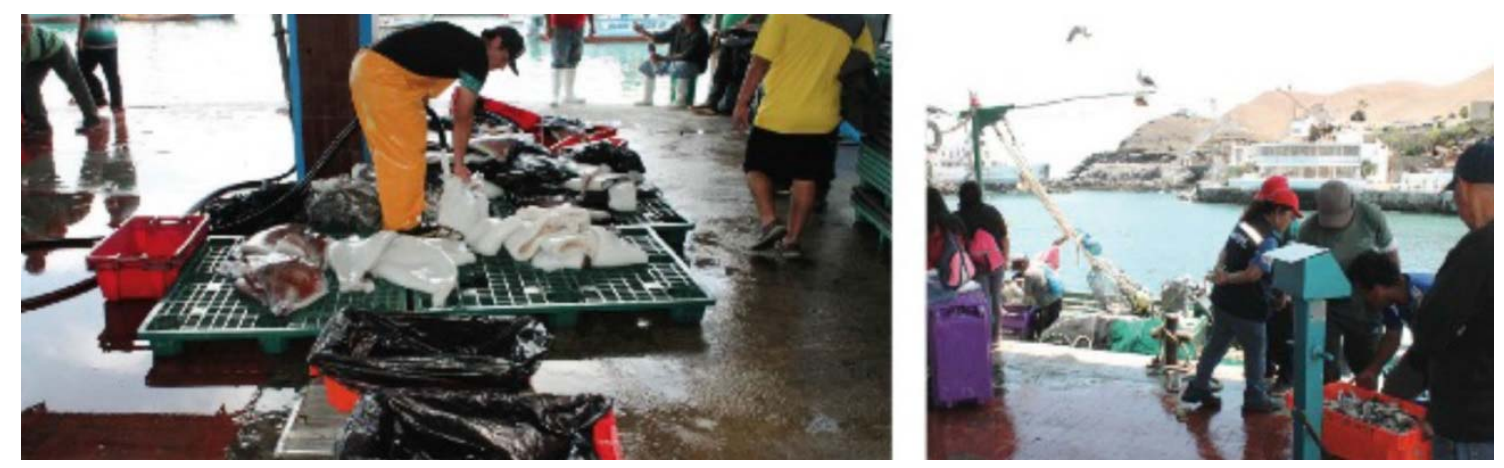

Fuente : Propio

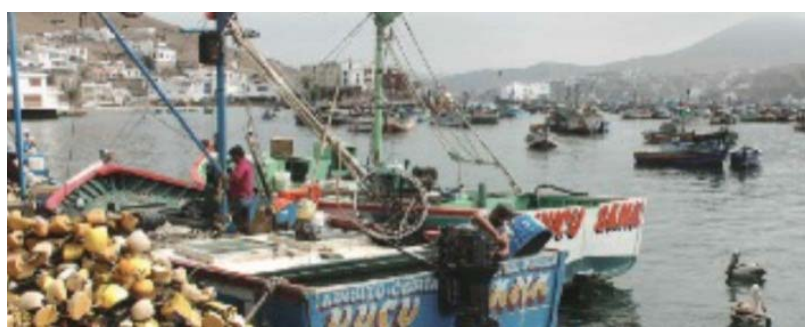

La secuencia marítima del muelle de pescadores es realizar las cargas necesarias para embarcar en el mismo muelle, preparar e motor y las redes necesarias para salir a flote.

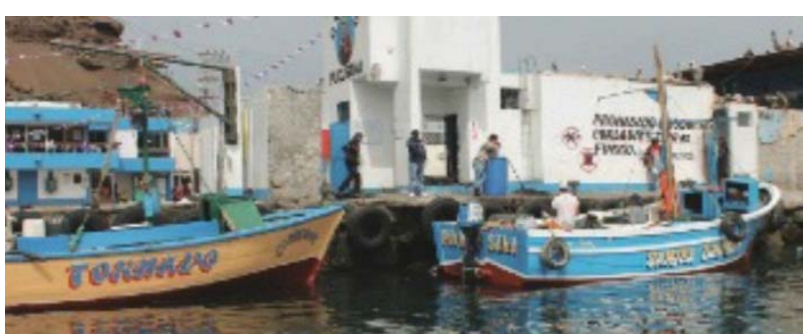
Luego se carga el bote con gasolina en un pequeño puesto colindante al muelle y finalmente luego de tener todo listo se sale al mar para pescar y obtener productos marítimos que serán en algunos casos para el consumo propio y otros para comercializar

Si bien cuenta con un orden claro, estos espacios no cuentan con la infrestructura necesaria para poder realizar sus labores de la mejor manera, de igual manera la falta de mantenimiento de los espacios ha generado que el lugar se vea descuidado y en mal estado 


\subsection{Levantamiento fotografico}

Figura 194: Terminal pesquero desde el mar 1

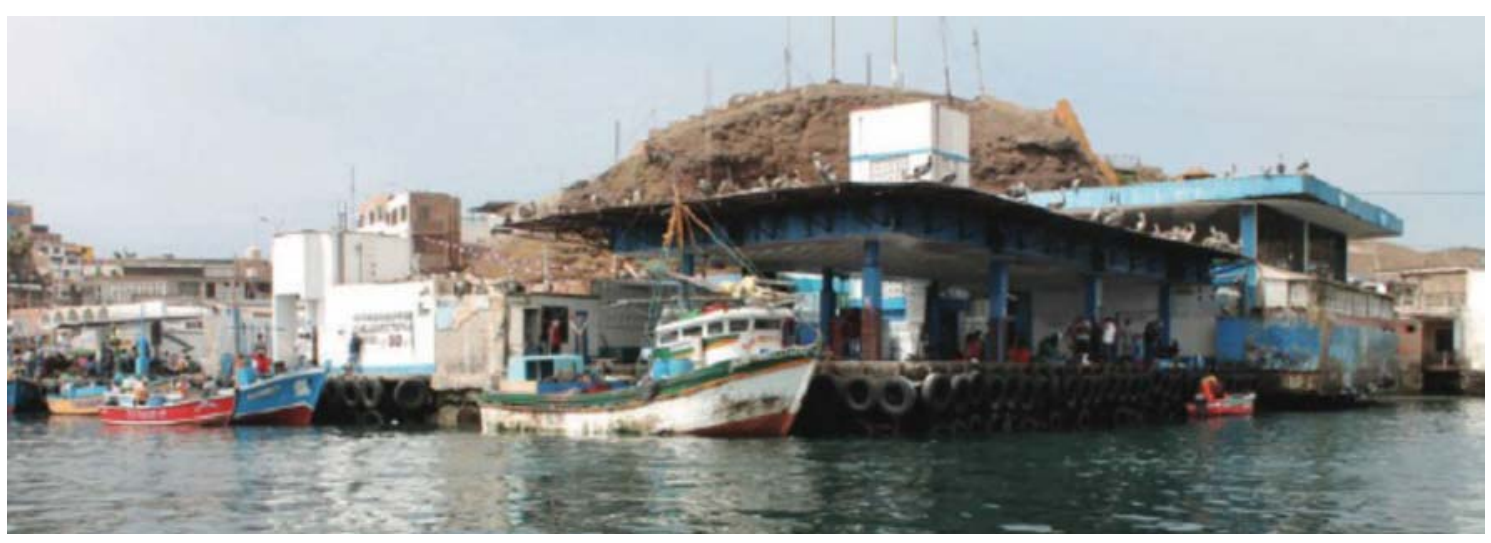

Fuente : Propio

Figura 195: Terminal pesquero desde el mar 2

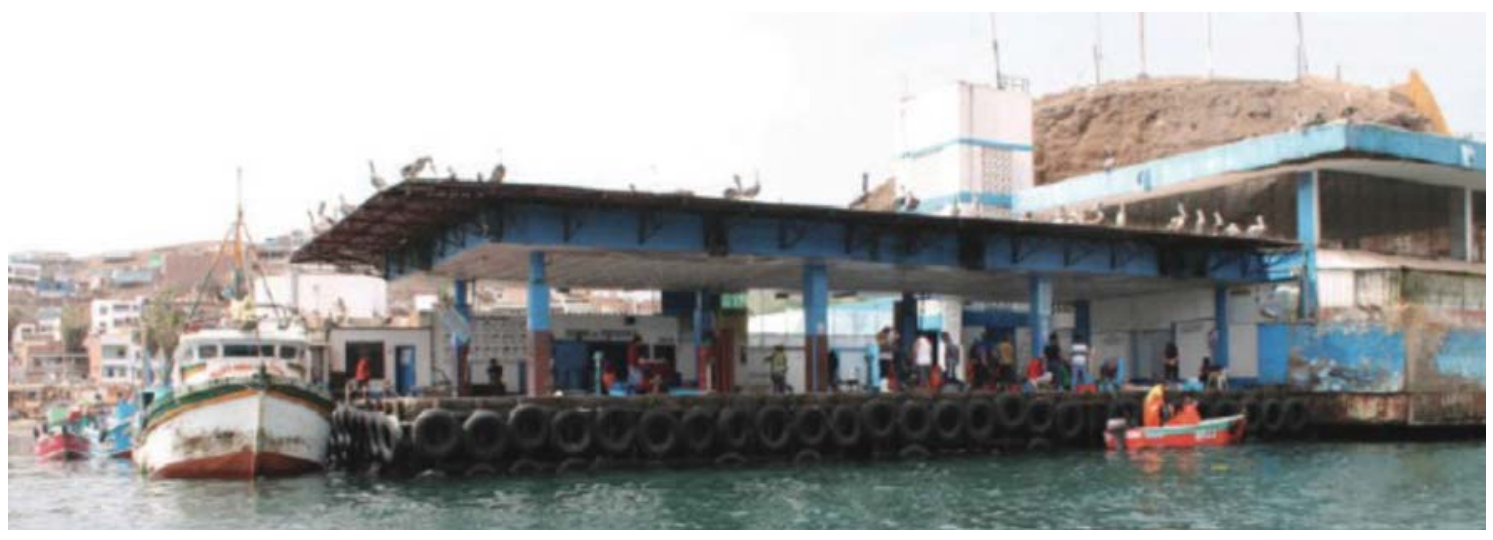

Fuente : Propio

Figura 196: Terminal pesquero desde el mar 3

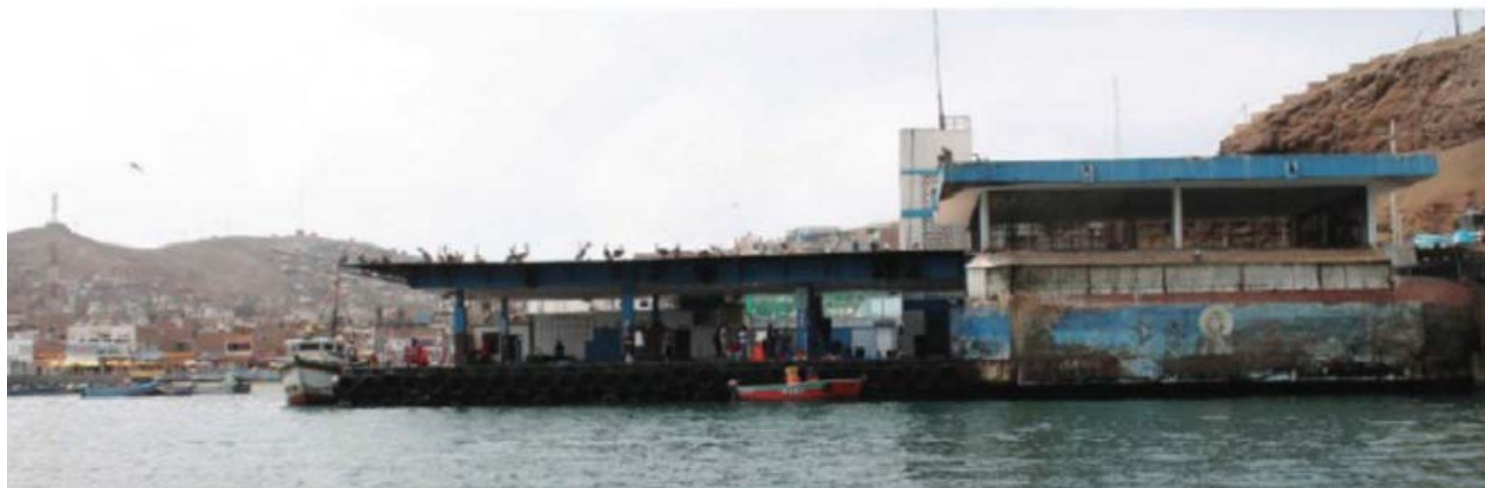

Fuente : Propio 


\section{Capítulo 6. Usuario}

\subsection{Definición de los Usuarios}

La buena ejecución del proyecto: El nuevo terminal pesquero y complejo cultural de la gastronomía peruana es necesario analizar los usuarios tanto internos como externos. Los internos serán los trabajadores que realizarán labores tanto en el terminal, como es el caso de los pescadores, como en el complejo cultura, conformado por dos partes una cultural y otra gastronómica, ambos casos con personal capacitado para hacer de la experiencia la más enriquecedora posible para el visitante.

Los externos por otro lado serán los visitantes de todas las edades que lleguen al proyecto para identificarse con el entorno y conocerlo desde un aspecto histórico y con una trascendencia en la historia fascinante desde tiempos remotos. Los visitantes serán tanto locales como extranjeros, se busca que por medio de la experiencia el usuario pueda identificarse y poder valorar las cualidades que presenta el distrito y las oportunidades hacia el desarrollo que presenta el lugar y el Perú en general en el ámbito gastronómico, reconocer los orígenes de los platos y las mezclas de sabores que vienen desde años atrás por mezclas de culturas que serán narradas y entendida por los guías que la contaran, la museografía que los orientara y los espacios que ayudan a enfatizar los espacios hacia un conocimiento optimo de él.

\section{ESTADISTICAS DE LOS USARIOS DEL DISTRITO}

- El $42 \%$ es pobre tanto monetaria como no monetaria

- El 40\& se dedica a la pesca artesanal, el resto comerciantes y relacionados a la actividad pesquera

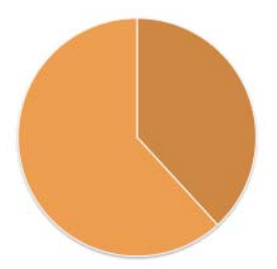

\section{¿QUIÉNES SON?}

Se propone que los usuarios internos sean los mismo habitantes de Pucusana que lleguen al proyecto en busca de oportunidades, sean capacitados y luego contratados para realizar labores y así fomentar la economía del distrito, adicionalmente se contratara a personal especializado en ámbito cultural y gastronómico para que sean los guías del complejo y orienten al publico en un mayor conocimiento. 
TIPOS DE USUARIOS:

\begin{tabular}{ll}
\multicolumn{1}{c}{ USARIOS } \\
\multicolumn{1}{|c}{ INTERNOS } & \multicolumn{1}{c|}{ EXTERNOS } \\
\hline & \\
PERSONAL ADMNISTRATIVO & VISITANTES \\
PERSONAL DE SEGURIDAD Y CONTROL & PROOVEDORES \\
PERSONAL DE CONTROL & TRANSPORTISTAS \\
PERSONAL DE APOYO & \\
PERSONAL DE MANTENIMIENTO & \\
PERSONAL DE SERVICIO &
\end{tabular}

\subsubsection{Informacion Cuantitativa}

- Población total de 10.633 habitantes

$50.52 \%$ son hombres

49.48 son mujeres

Figura 197. Radio de influencia del lugar en el contexto urbano

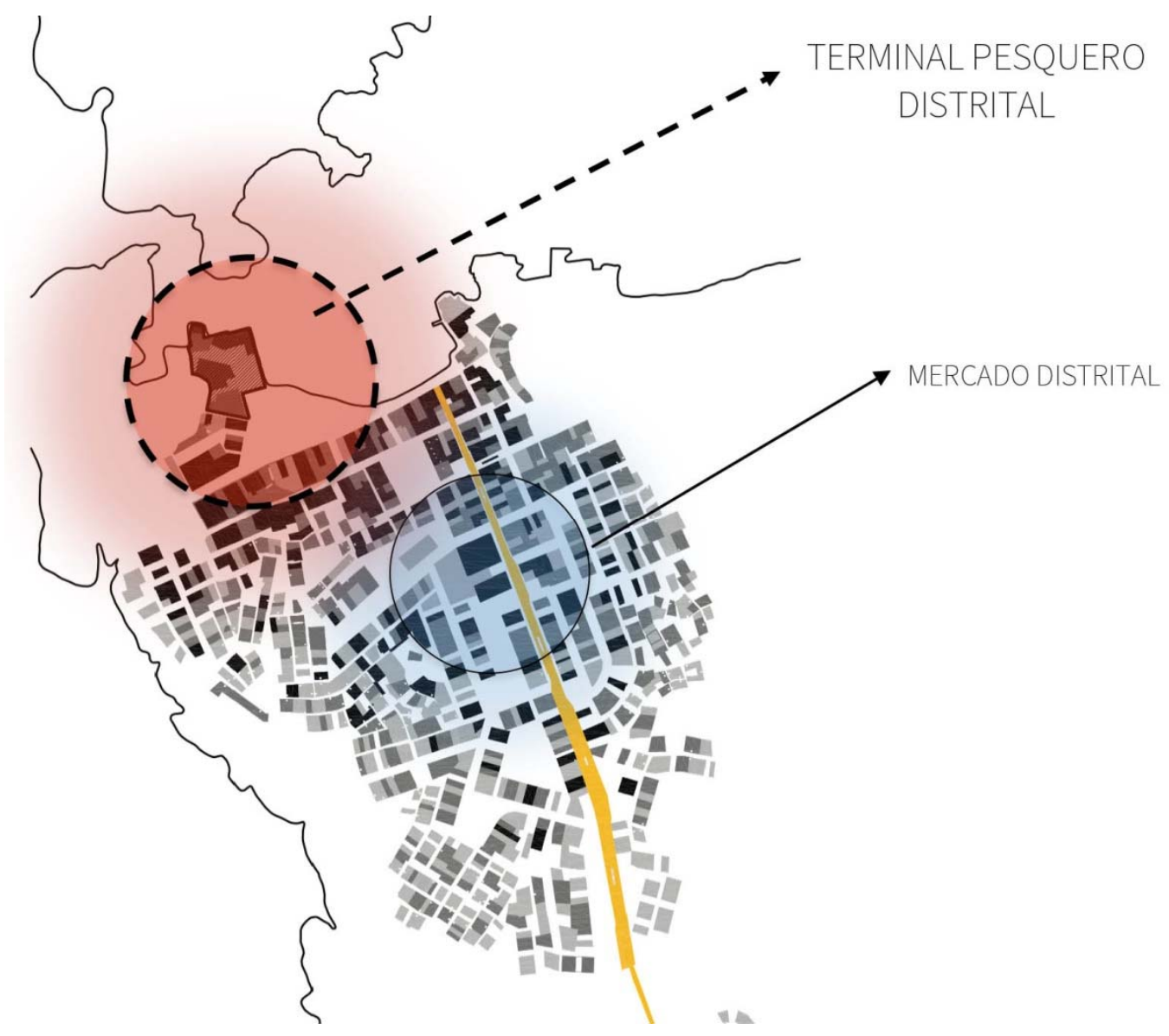

Hay dos puntos en la ciudad que atraen gran influencia poblacional, uno de ellos es el Terminal Pesquero y otro es del mercado de abastos distrital, ambos tienen un flujo muy grande personas que llegan ahí para comprar alimentos y para poder abastecerse de 
elementos que faciliten su vida diaria. En el caso de terminal pesquero en flujo de visitantes si bien una gran parte son locales y llegan ahí para salir a realizar sus labores en la pesca o en el mismo termina, también llegan turistas y visitantes extranjeros, a diferencia que en el mercado distrital que la gran mayoría es de la población local.

Figura 198. Area urbana influenciada

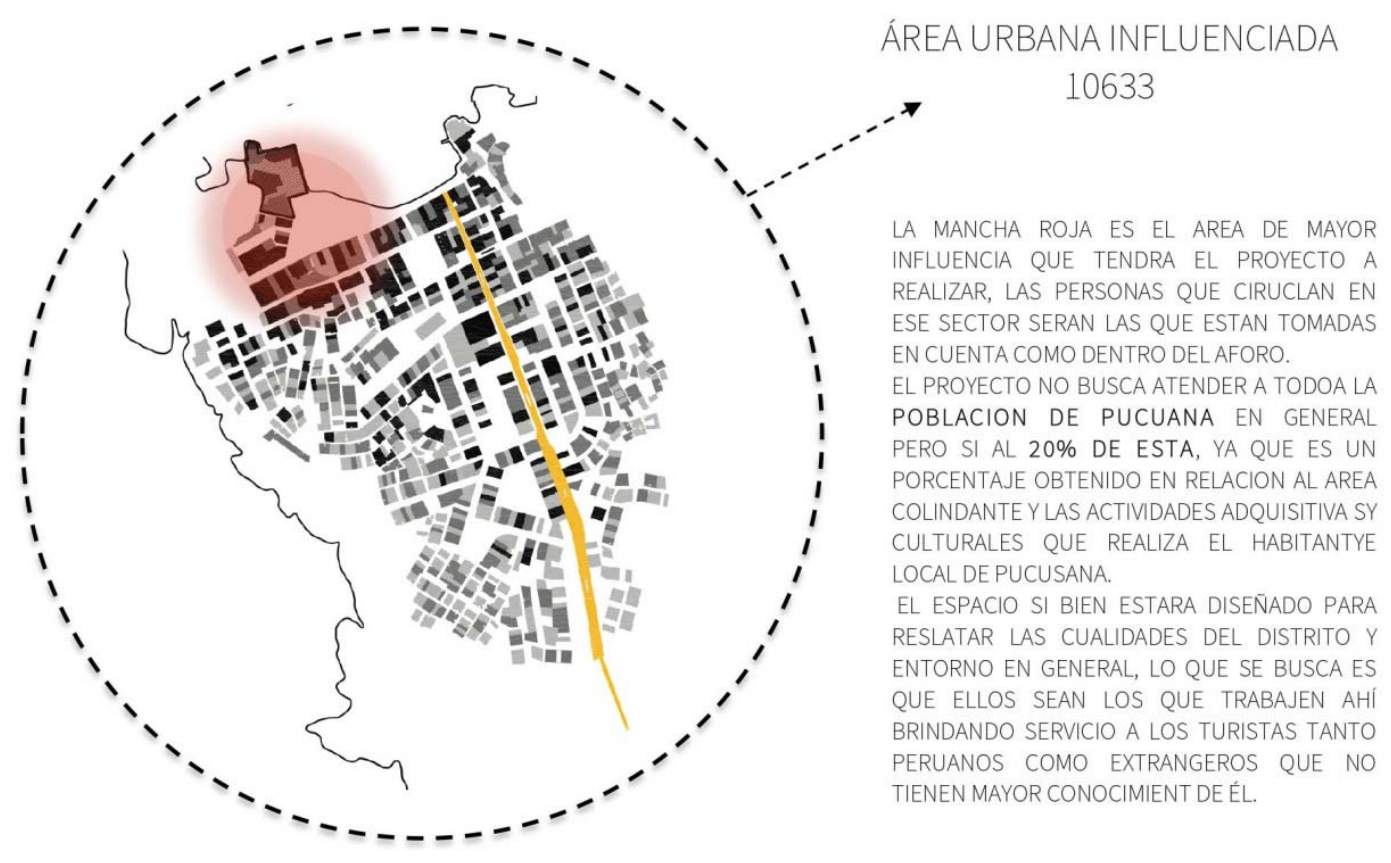

\section{CALCULOS DE USUARIO (2015)}

Poblacion en general distrital y radio de influencia

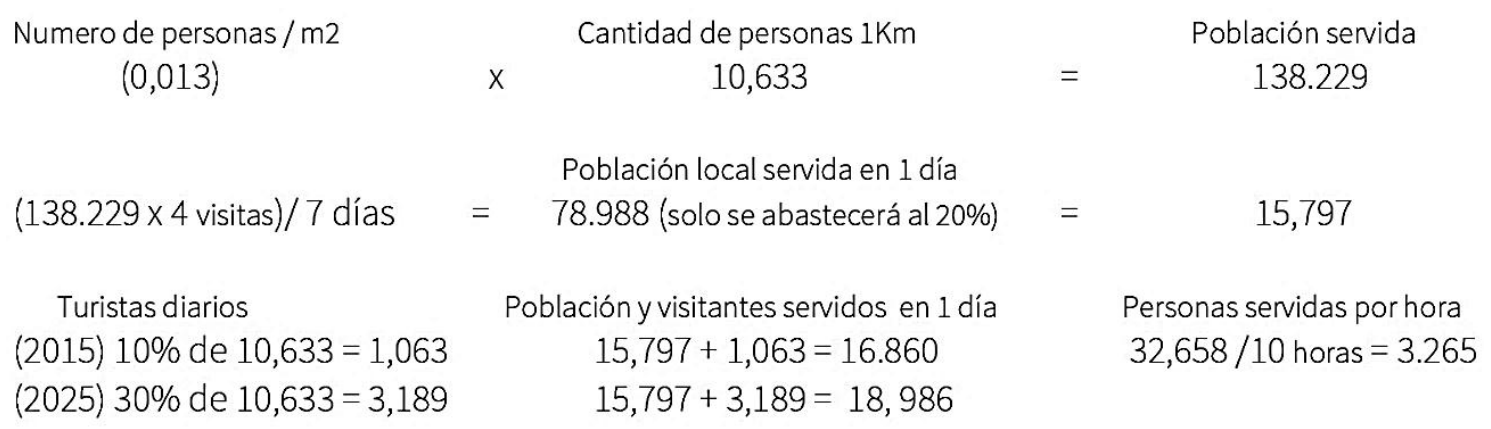

Se estima que para el 2025 el crecimiento turístico aumentará en un 30\%, indicando que la población servida diaria general, entre locales y visitantes llegara a 18,986 por día.

A nivel local el crecimiento poblacional no aumentará, por la falta de espacios para que suceda, sin embargo la infrestructura y paisaje distrital si lo hará, y con ello la consolidación económica a nivel distrital tendrá una visión hacia el progreso, tanto físico como monetario. 


\section{AFOTO TOTAL}

El área total del terreno

$7,682 \mathrm{~m} 2$ m2 por persona según reglamento

$$
2 \mathrm{~m} 2=3.841 \text { personas }
$$

Según la norma A070, data que se necesita para mercado minorista y para galería comercial el espacio de $2 \mathrm{~m} 2$ por persona.

Según la norma para mercado local el numero de puestos varia entre 50 y 250 .

Según el estudio nacional de mercados por cada 15 puestos se atiende a 1000 habitantes. El mercado gastronómico como el mercado de pesca, no buscan satisfacer a todo el publico en general que llegue al complejo; el proyecto esta planteado como un espacio cultural de interacción y que estará acompañado de la gastronomía como hilo conductor. No es necesario consumirlo para poder conocer su historia y sus grandes tradiciones.

Es por ello que el proyecto propone 30 puestos de comida gastronómica y 15 de venta de pescado. Atendiendo así a un total de 2.800 visitantes diarios.

Puestos de venta gastronómica.

30 puestos -2000 personas abastecida

Puestos de venta de pescado

12 puestos -800 personas abastecida

Para el complejo cultural el general se busca atender a todo el público en general a los 18.986 visitantes aproximados que el proyecto a realizar atenderá. Tanto el espacio cultural, el terminal pesquero, el mercado de pesca y el mercado gastronómico serán espacios determinados por distintos usos pero que en todo momento se complementarán y estarán en constante relación tanto espacial como funcionalmente.

Se estima que el personal interno diario será de unas 2000 personas distribuida entre los espacios anteriormente mencionados. Estos tendrán distintos horarios y flujos para poder realizar sus labores correctamente.

En el cuadro anexo se explican los tipos de usuario, sus flujos y edades para poder tener un panorama general de las circulaciones del proyecto y de los futuros espacios a diseñar en torno a ello.
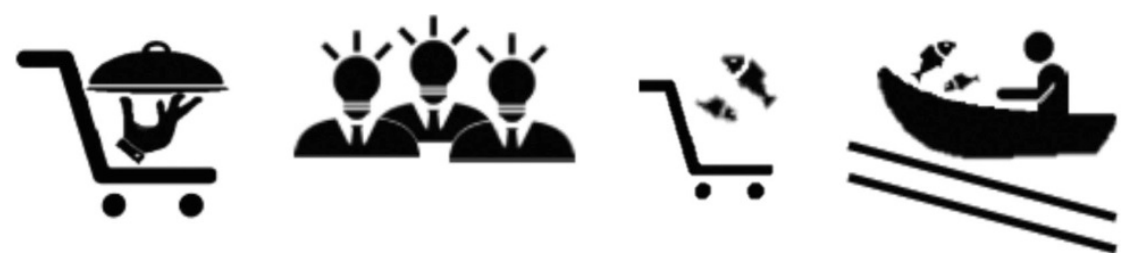


\subsubsection{Numero y tipos de usuario}

\section{CUADRO RESUMEN DEL NUMERO Y TIPO DE USUARIO}

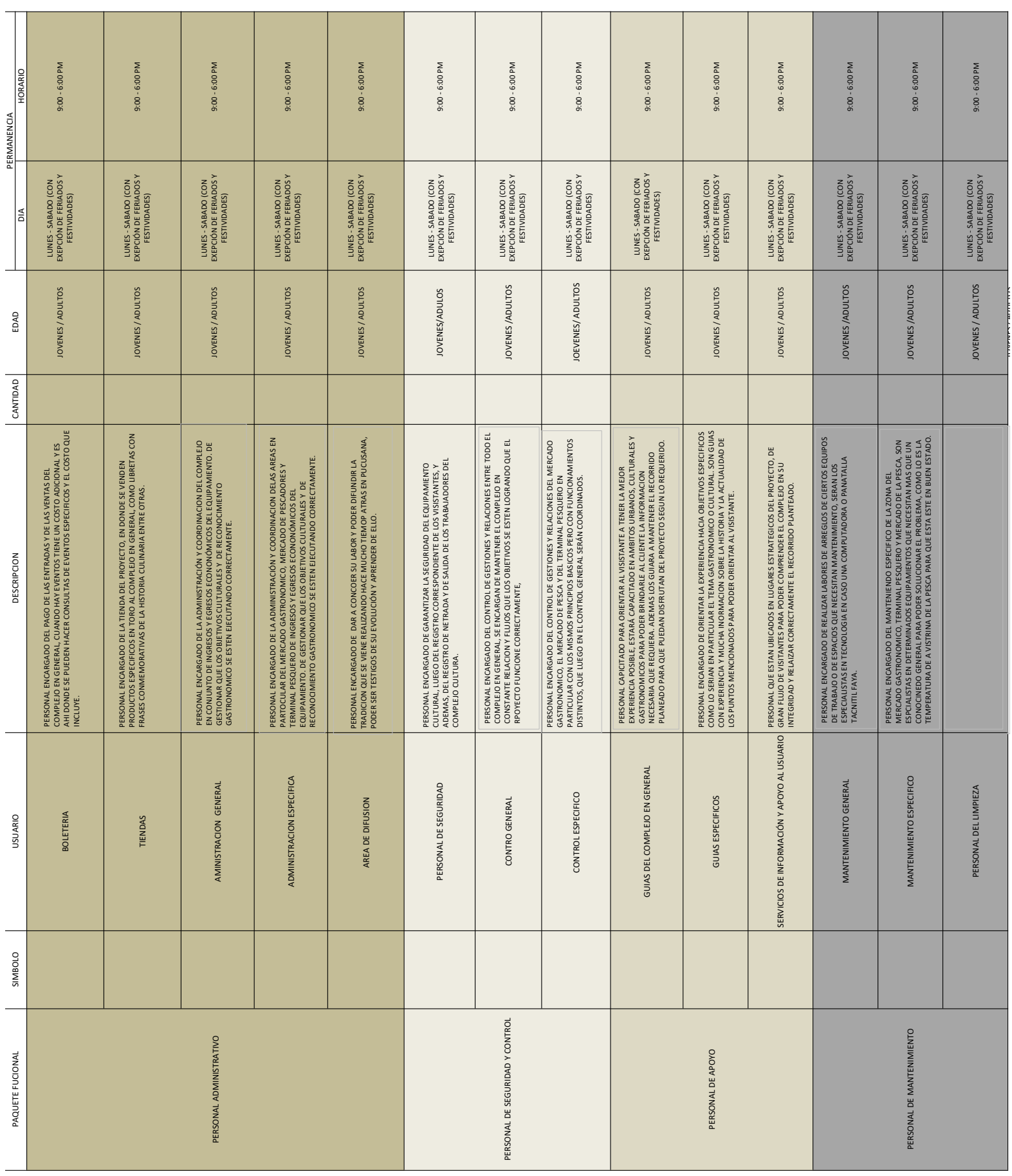




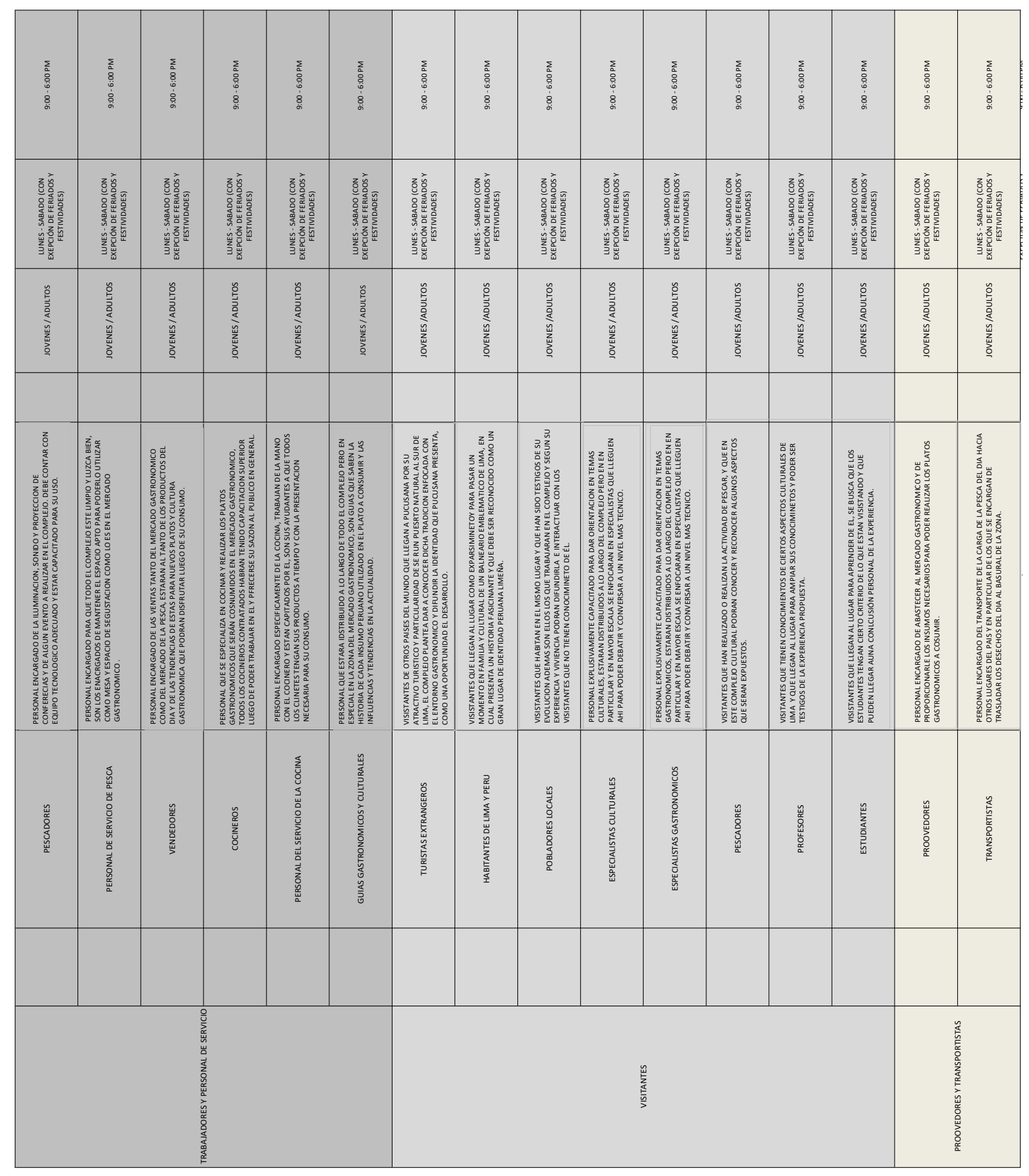




\subsubsection{Informacion cualitativa}

\subsubsection{Flujos y necesidades del Usuario}

\section{USUARIOS INTERNOS}

- PERSONAL ADMINISTRATIVO

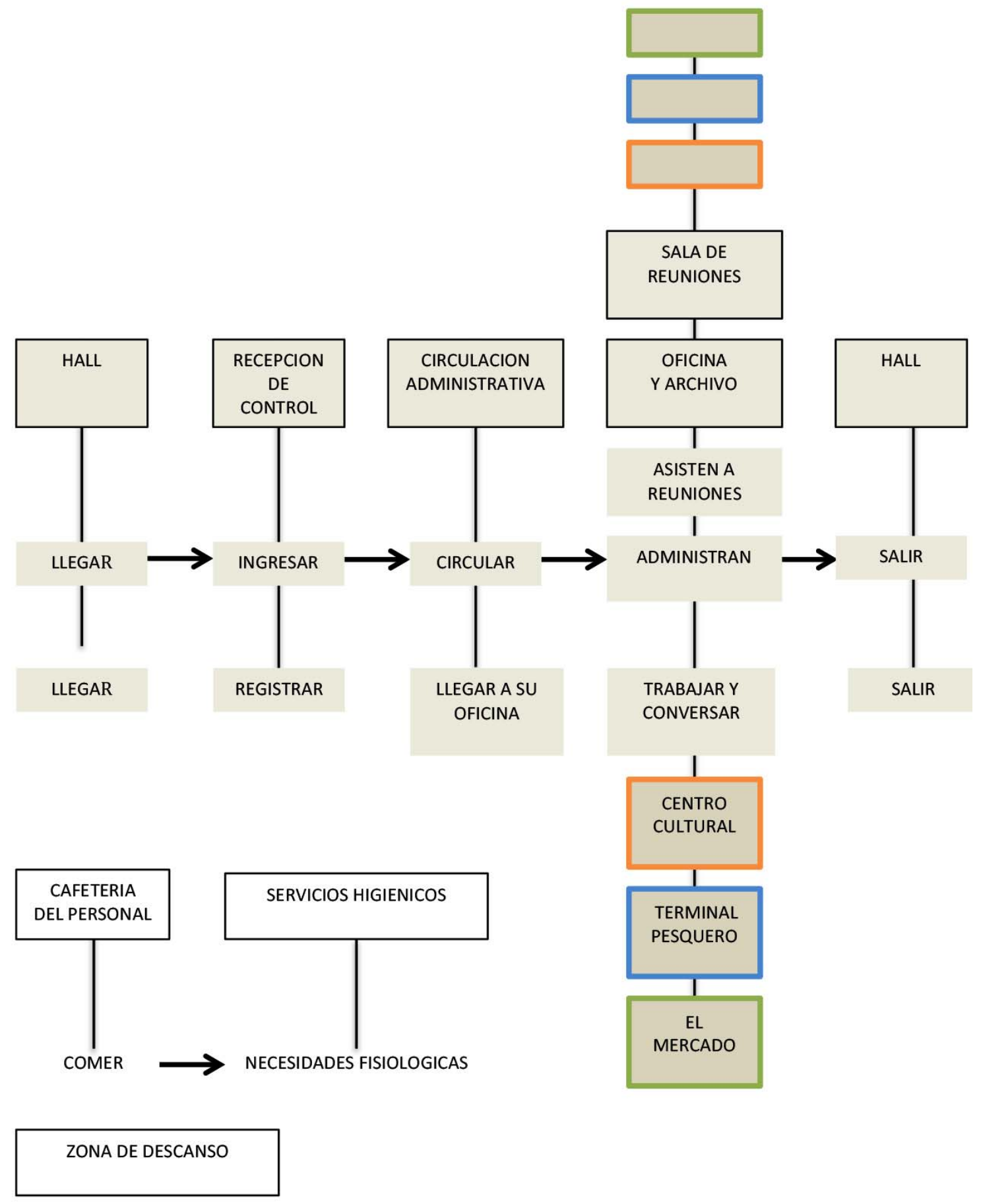


- PERSONAL DE SEGURIDAD Y CONTROL

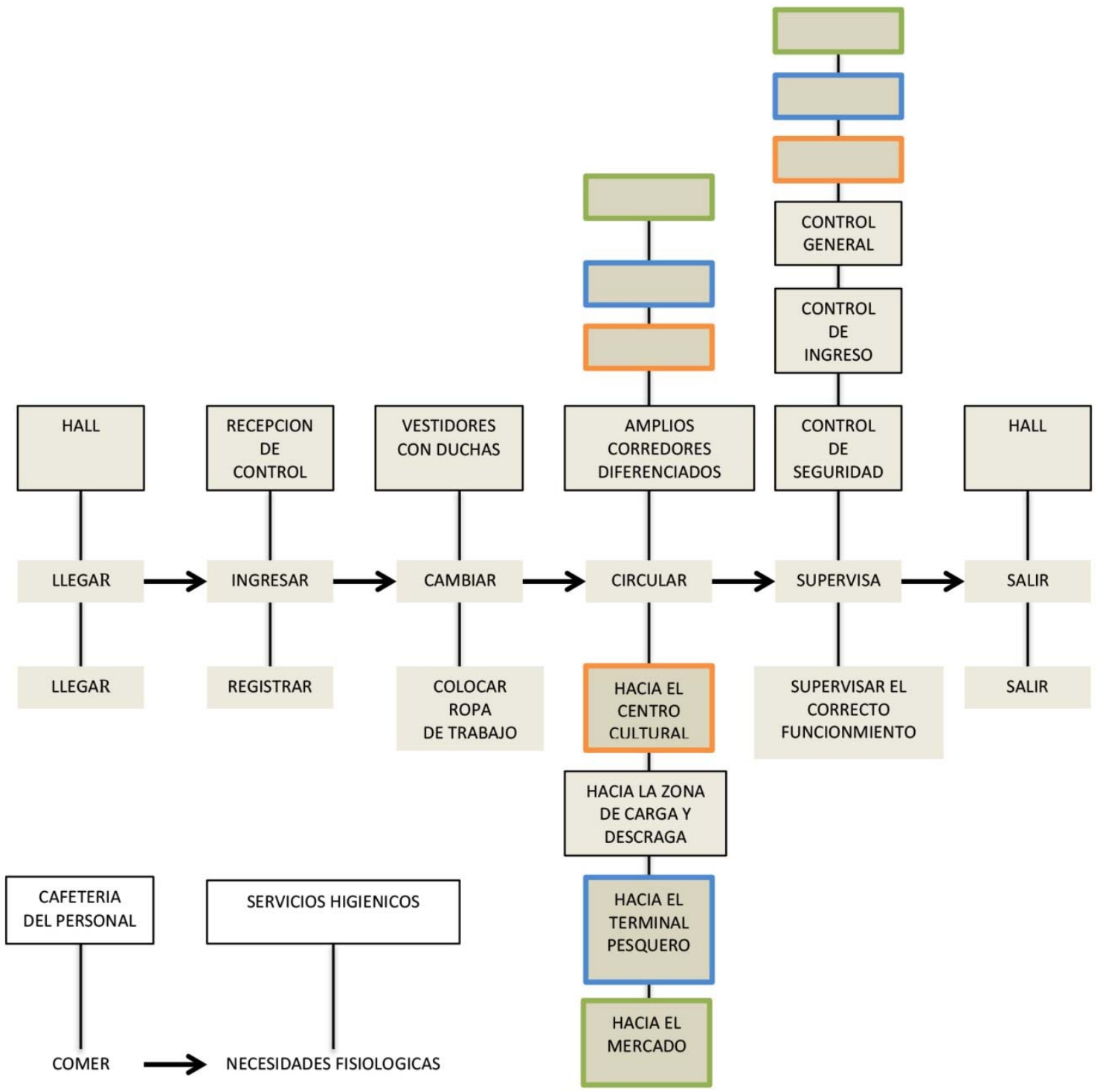


- PERSONAL DE APOYO

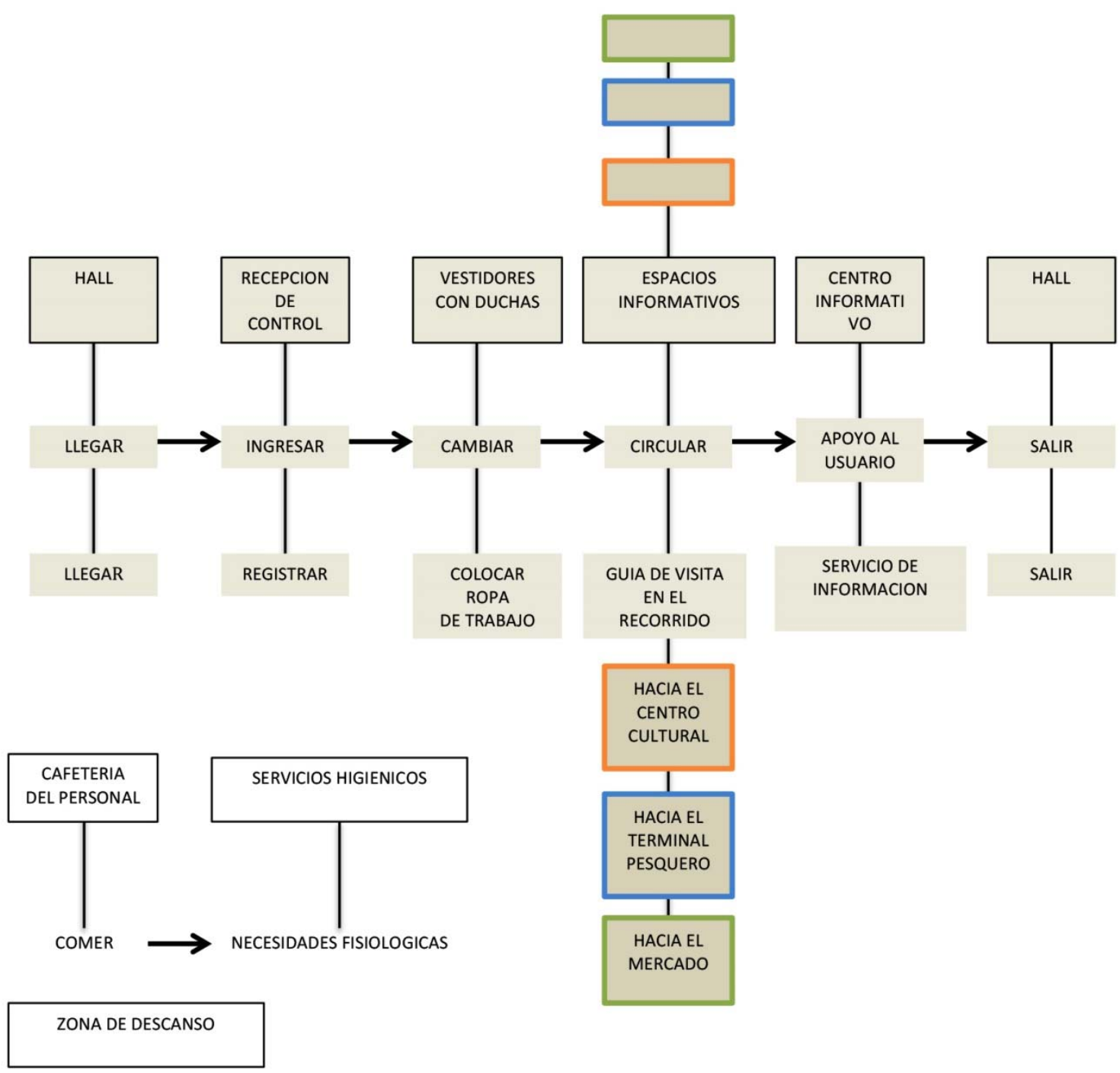


- PERSONAL DE MANTENIMIENTO

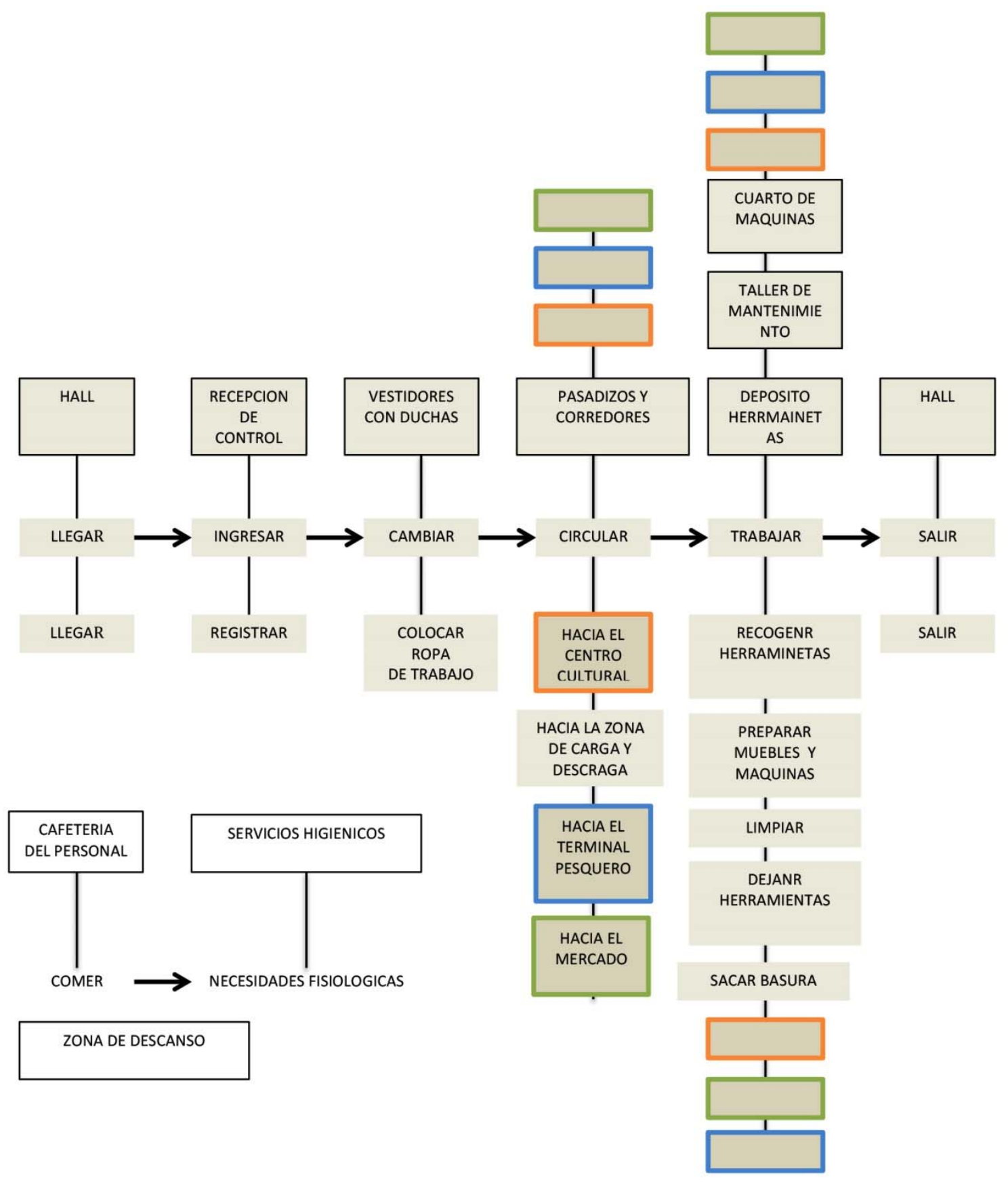


- TRABAJADORES Y PERSONAL DE SERVICIO

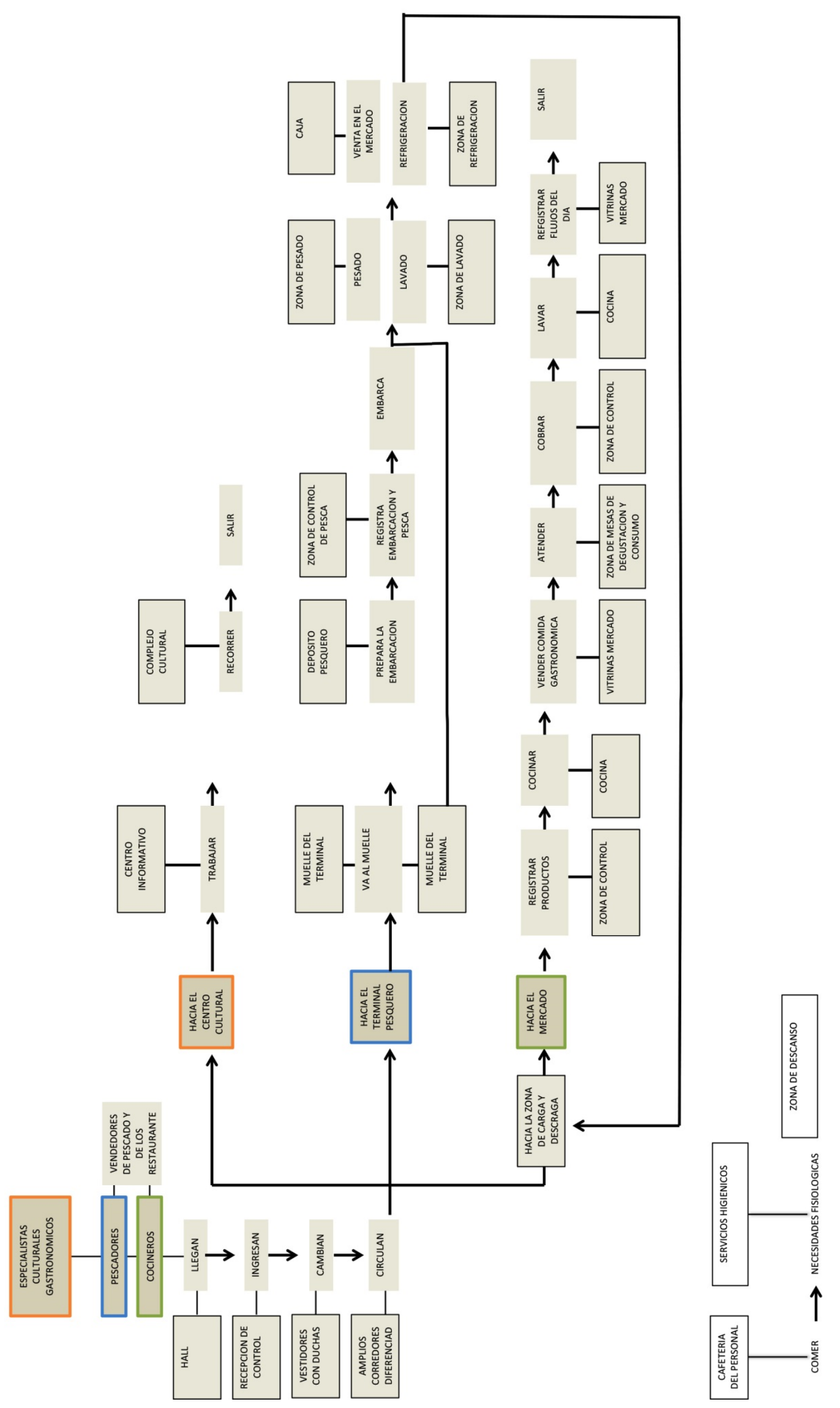




\section{USUARIOS EXTERNOS}

- VISITANTES

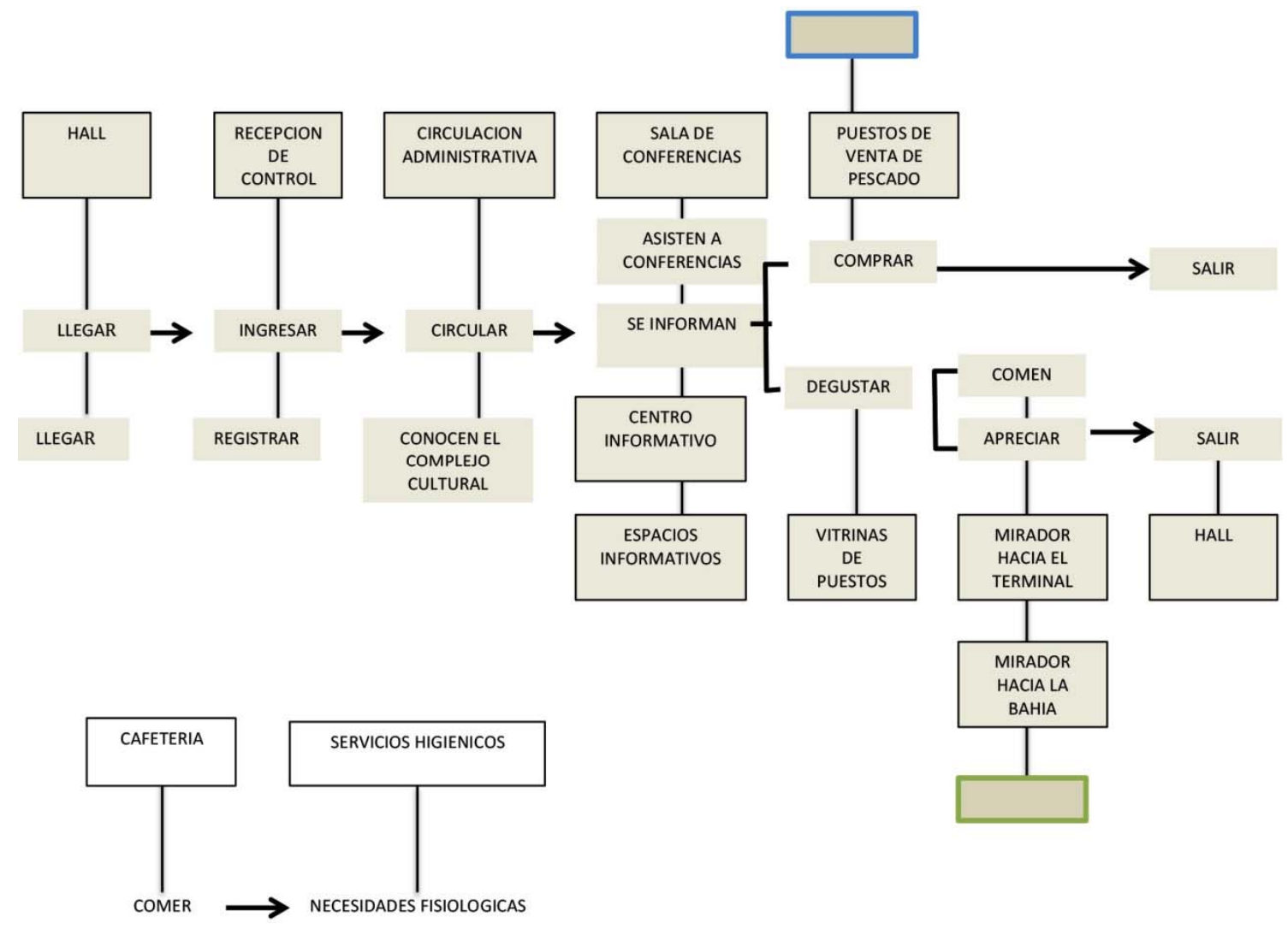

- PROVEEDORES

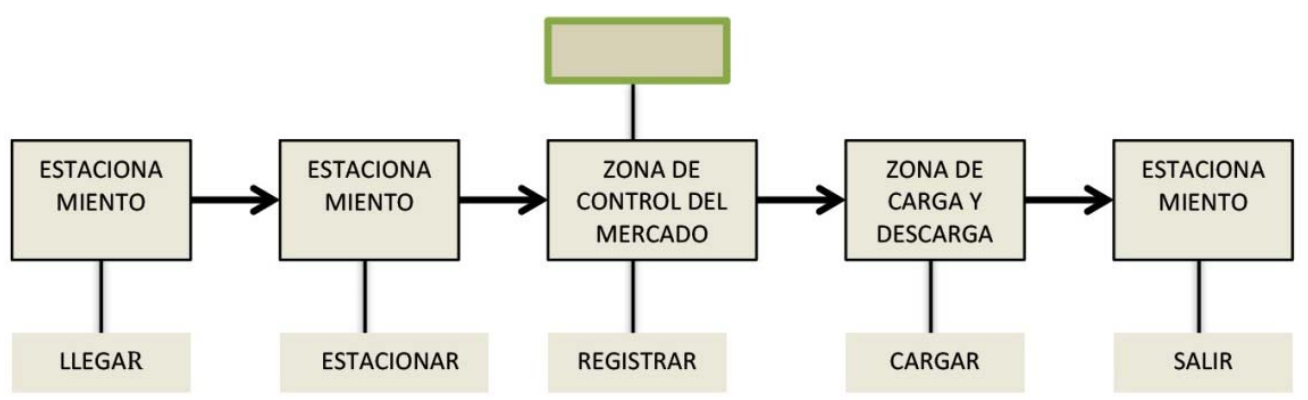

- TRANSPORTISTAS

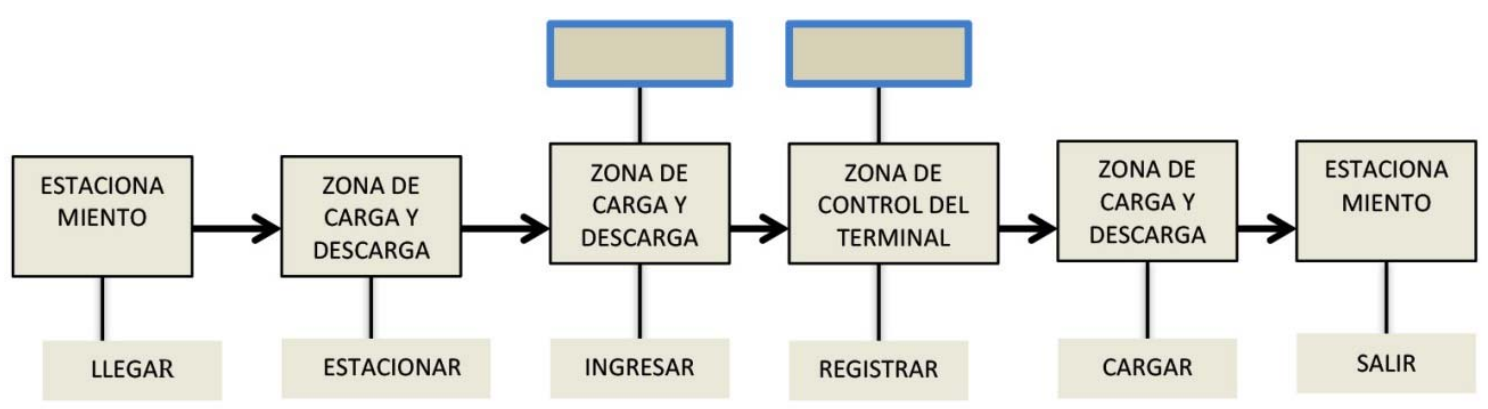




\section{Capítulo 7. Programación Arquitectonica}

\subsection{Organigrama Institucional}

El organigrama institucional está relacionado a las organizaciones de la administración y funcionamiento en general del proyecto a realizar, estará jerarquizado en su gran mayoría de una manera horizontal para que todos los trabajadores puedan mantener relación entre ellos y poder complementarse.

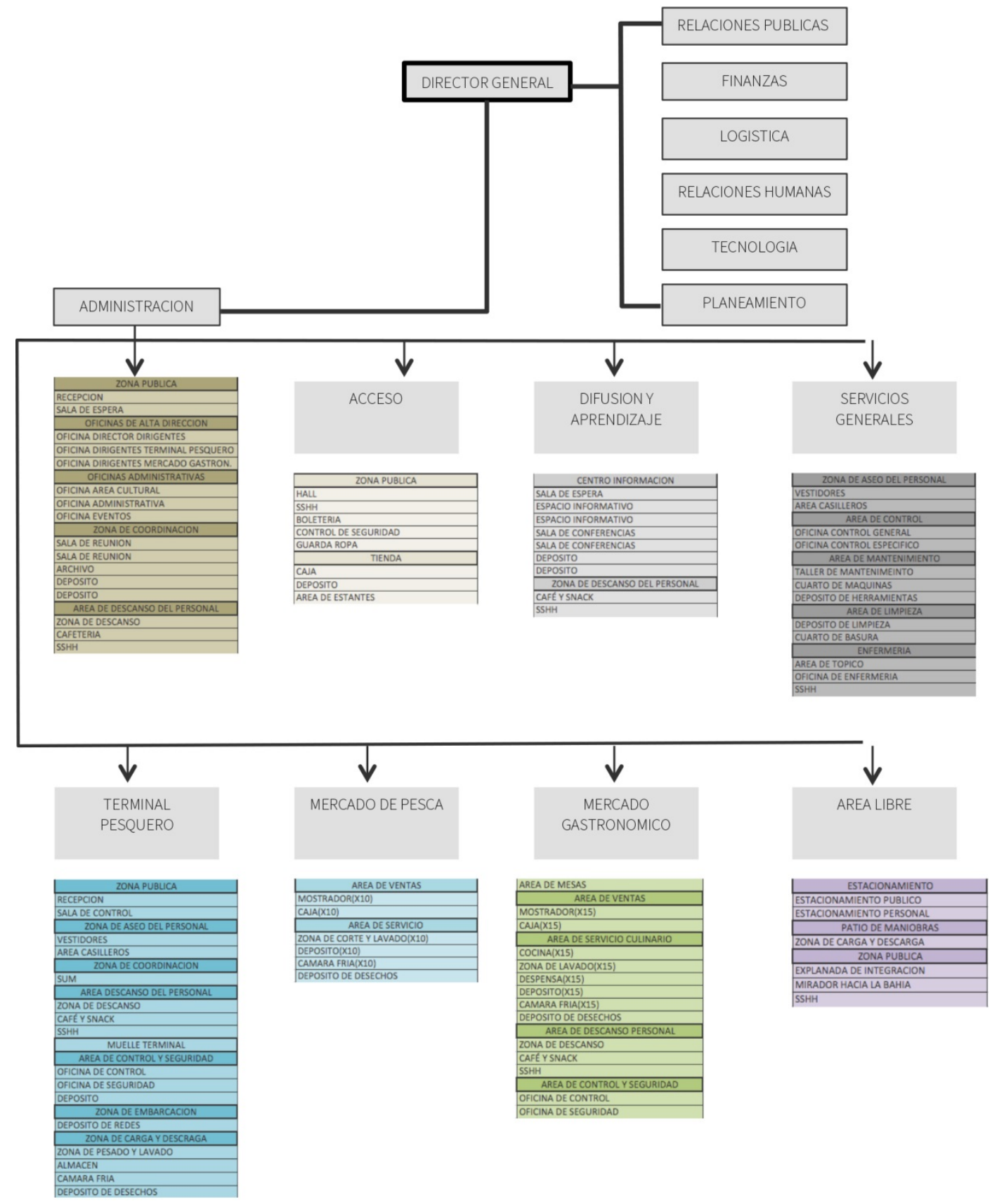




\subsection{Definicion de Paquetes Funcionales}

\subsubsection{Diagramas de interrelación entre paquetes funcionaes}

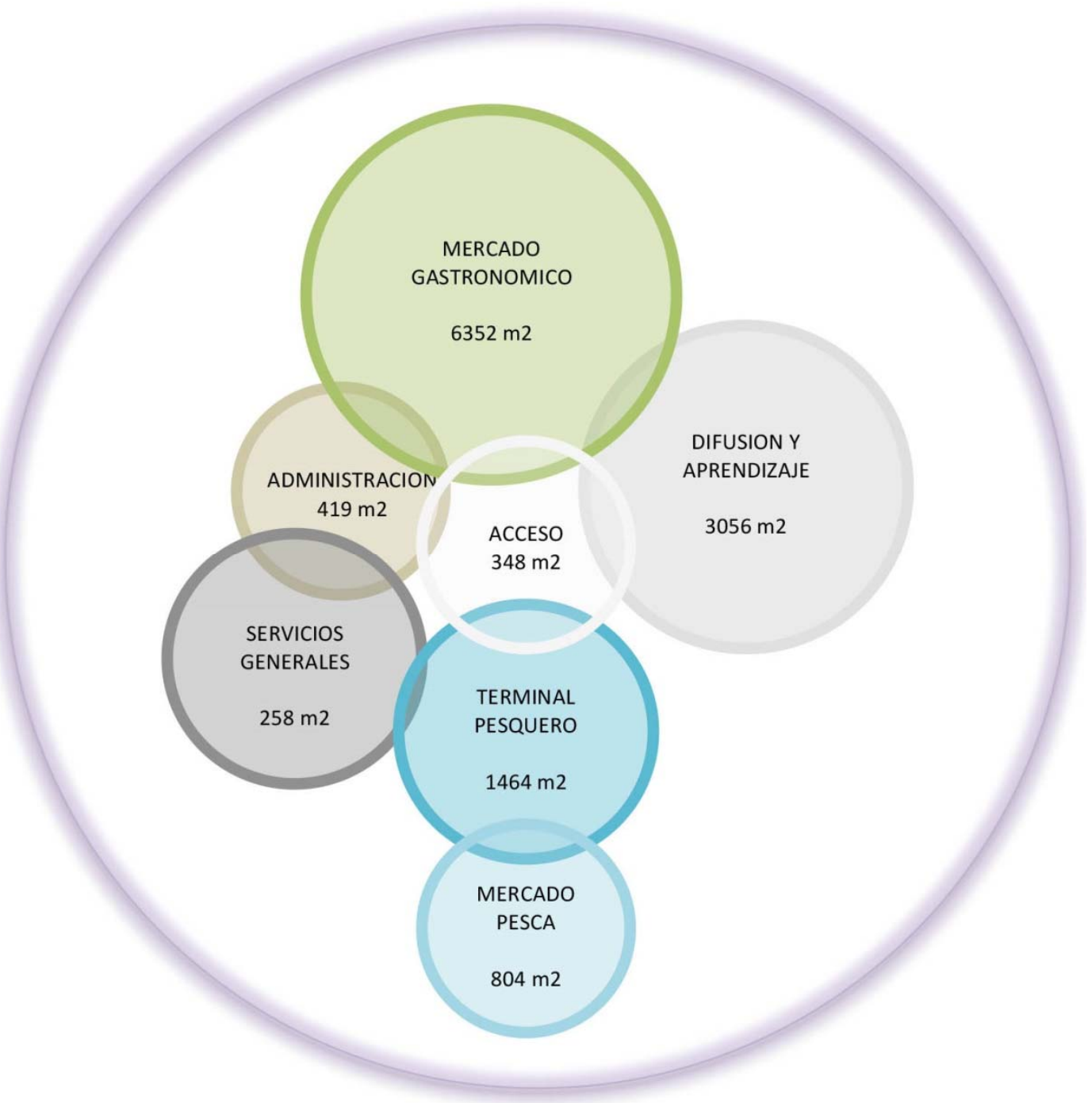

\subsubsection{Cercanias y lejanias de los ambientes y paquetes funcionales}

Se analizaran los distintos cuadros respecto a sus cercanías y lejanías y relaciones en circulación entre los espacios. Para concluir se ha diseñado un organigrama general con la fusión de todos los espacios para tener una visión panorámica y mas amplia en conjunto.

- Paquete funcional - administrativo

- Paquete funcional - acceso

- Paquete funcional - difusion y aprendizaje 
- Paquete funcional - servicio general

- Paquete funcional - terminal pesquero

- Paquete funcional - mercado de pesca

- Paquete funcional - mercado gastronomico

- Paquete funcional - area libre

- Cuadro general

\subsection{Organigrama de los Paquetes Funcionales}

PAQUETE FUNCIONAL - ADMINISTRATIVO

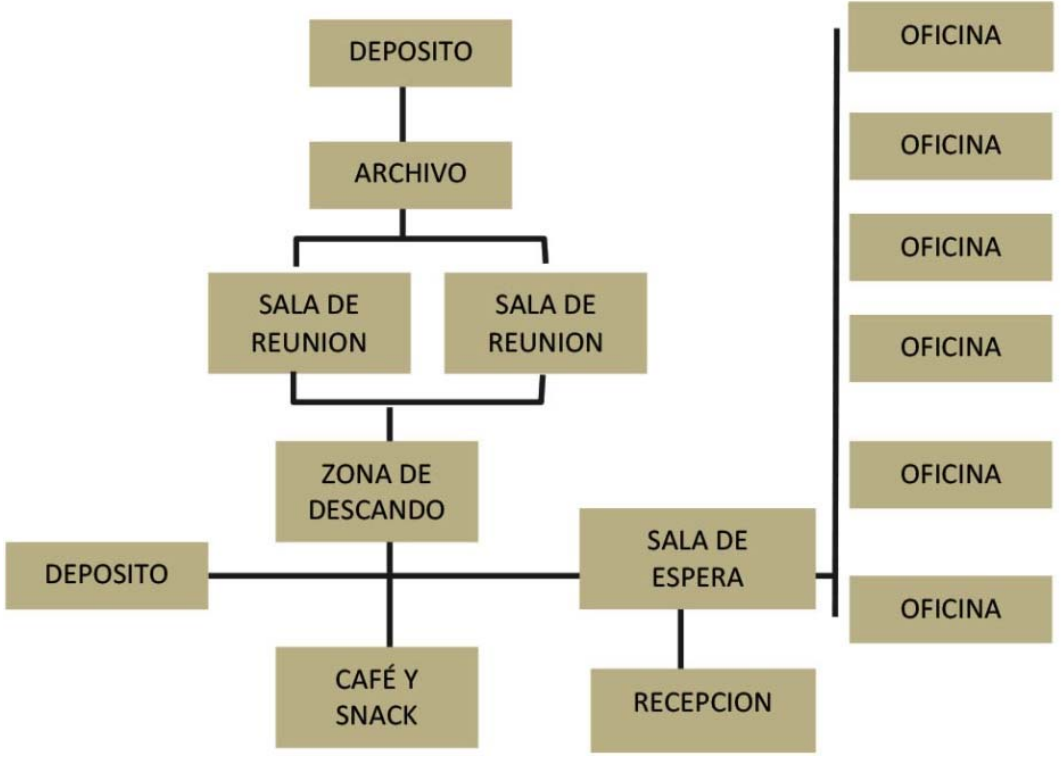

PAQUETE FUNCIONAL - ACCESO

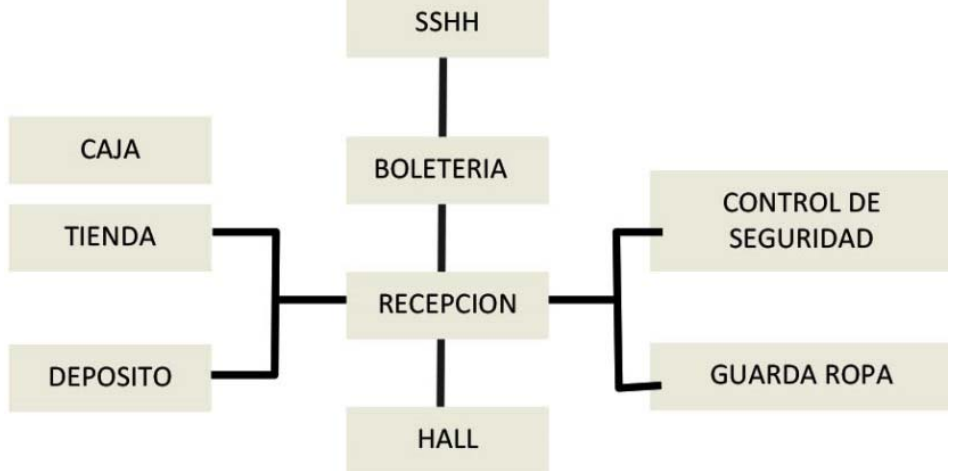


PAQUETE FUNCIONAL - DIFUSION Y APRENDIZAJE

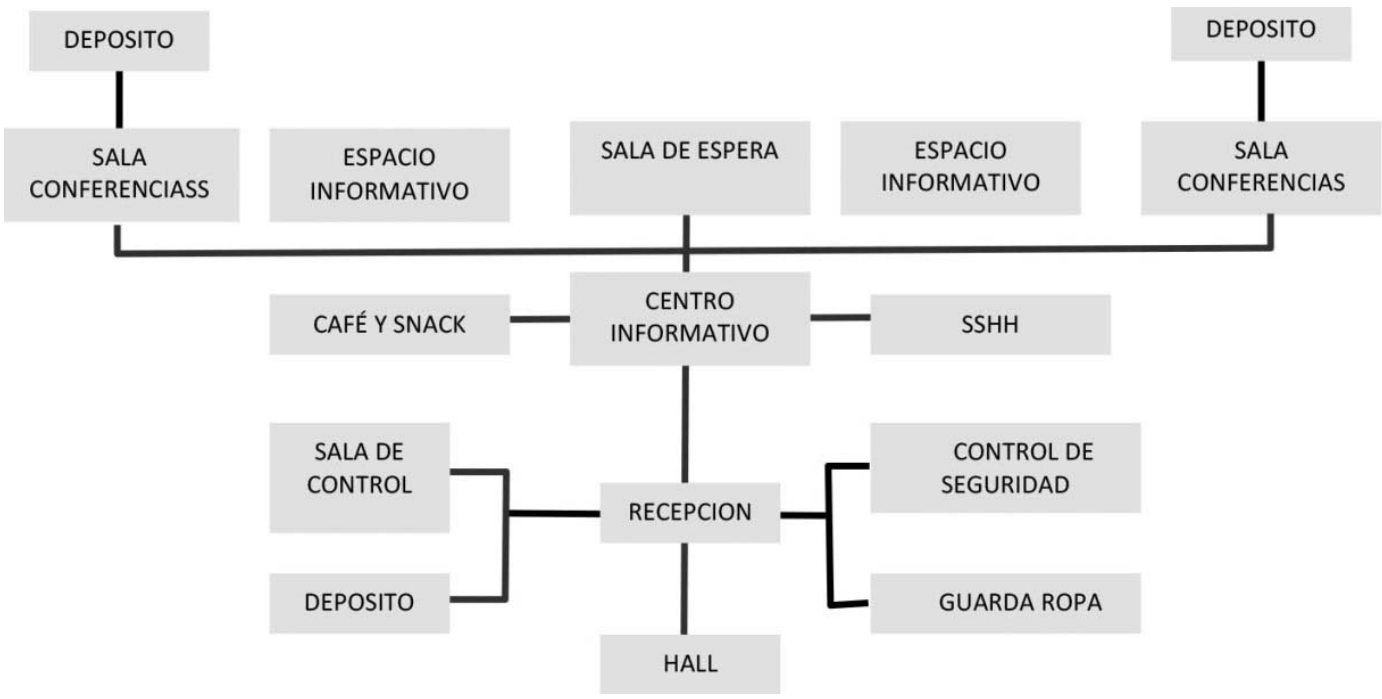

PAQUETE FUNCIONAL - SERVICIO GENERAL

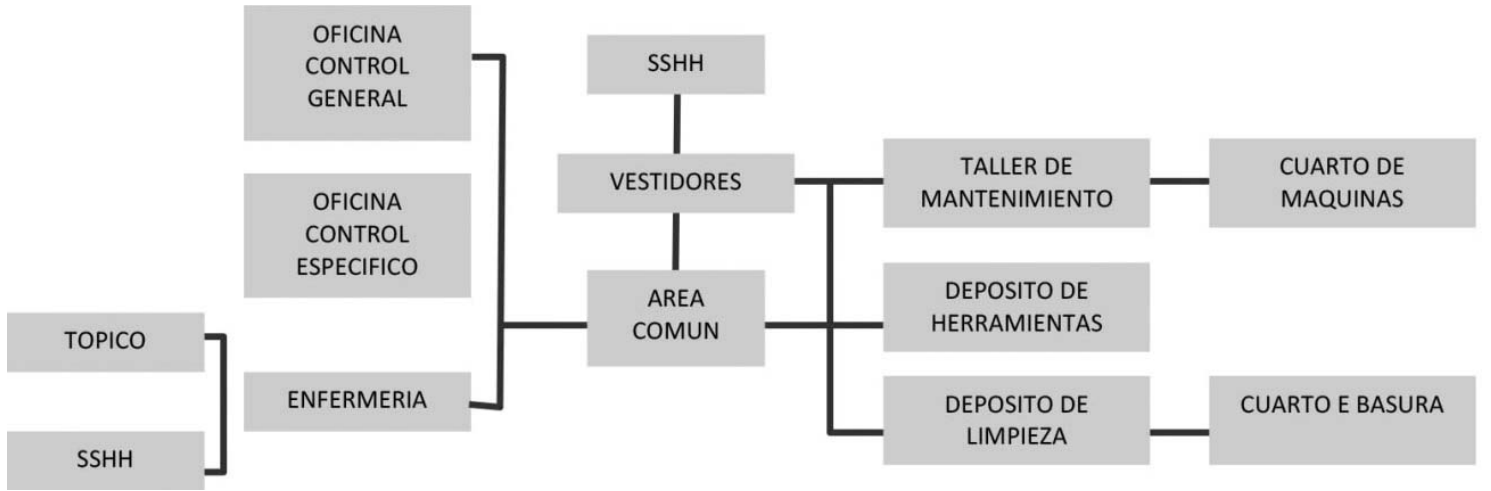

PAQUETE FUNCIONAL - TERMINAL PESQUERO

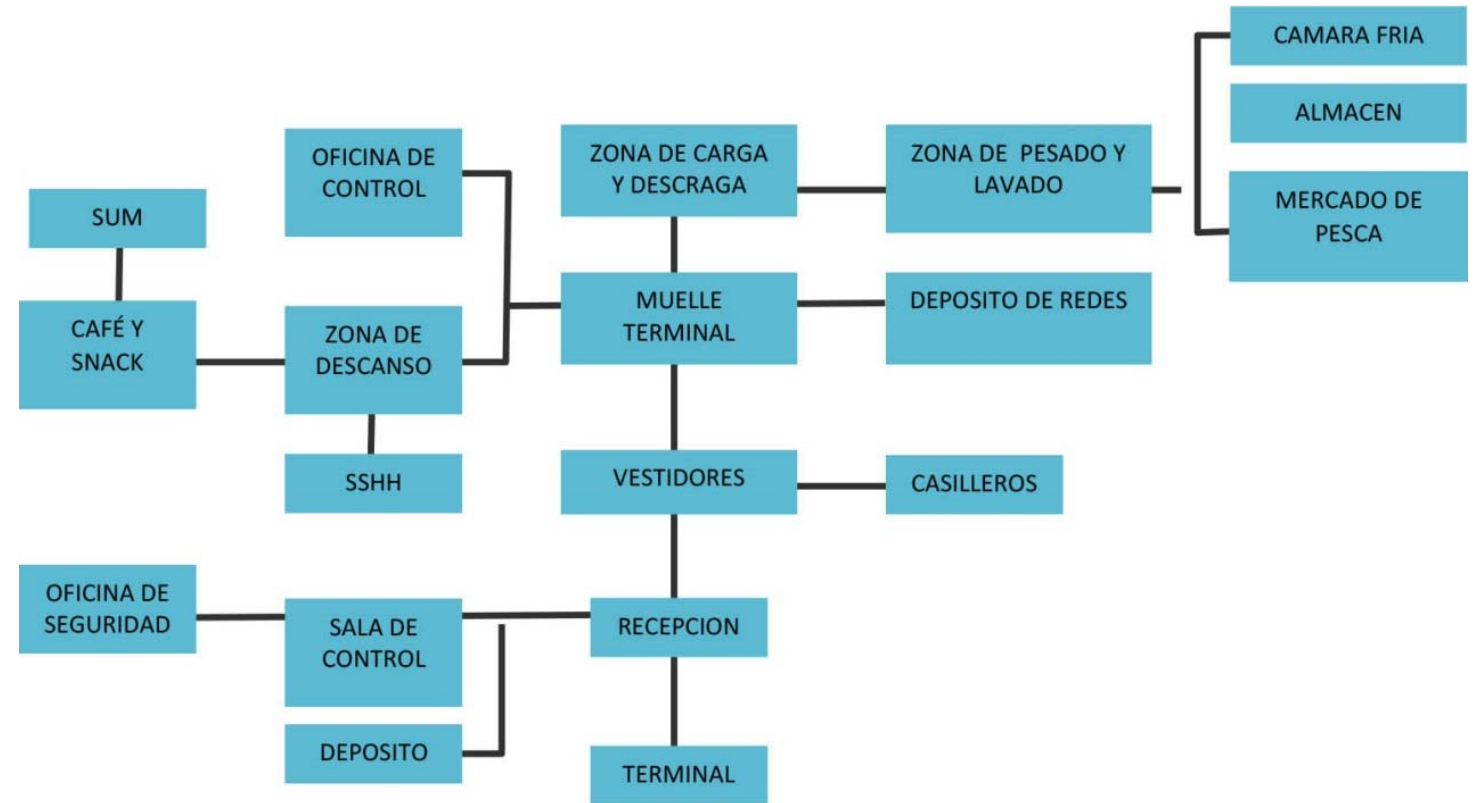


PAQUETE FUNCIONAL - MERCADO DE PESCA

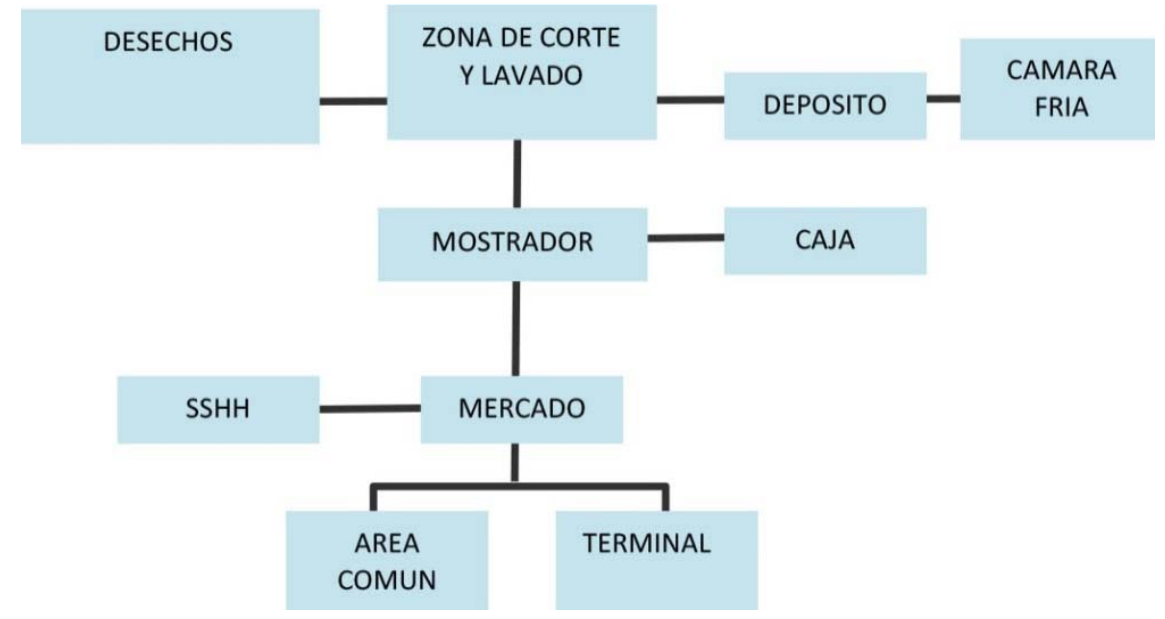

\section{PAQUETE FUNCIONAL - MERCADO GASTRONOMICO}

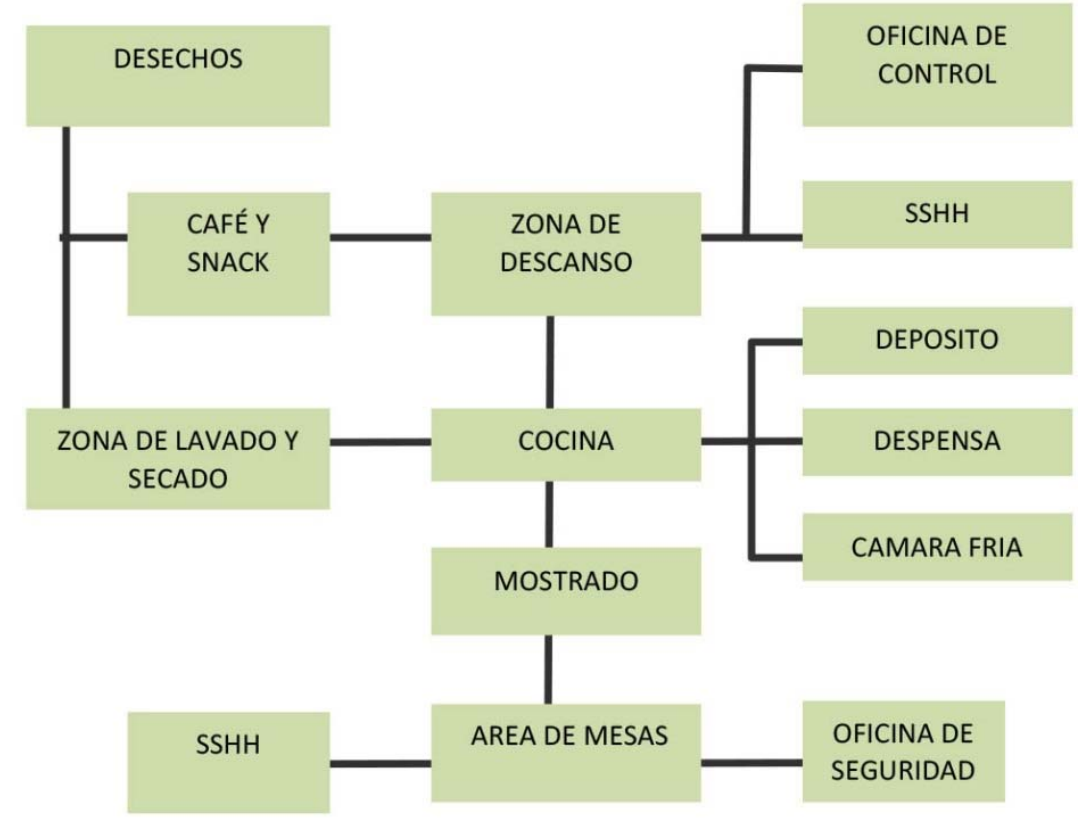

PAQUETE FUNCIONAL - AREA LIBRE

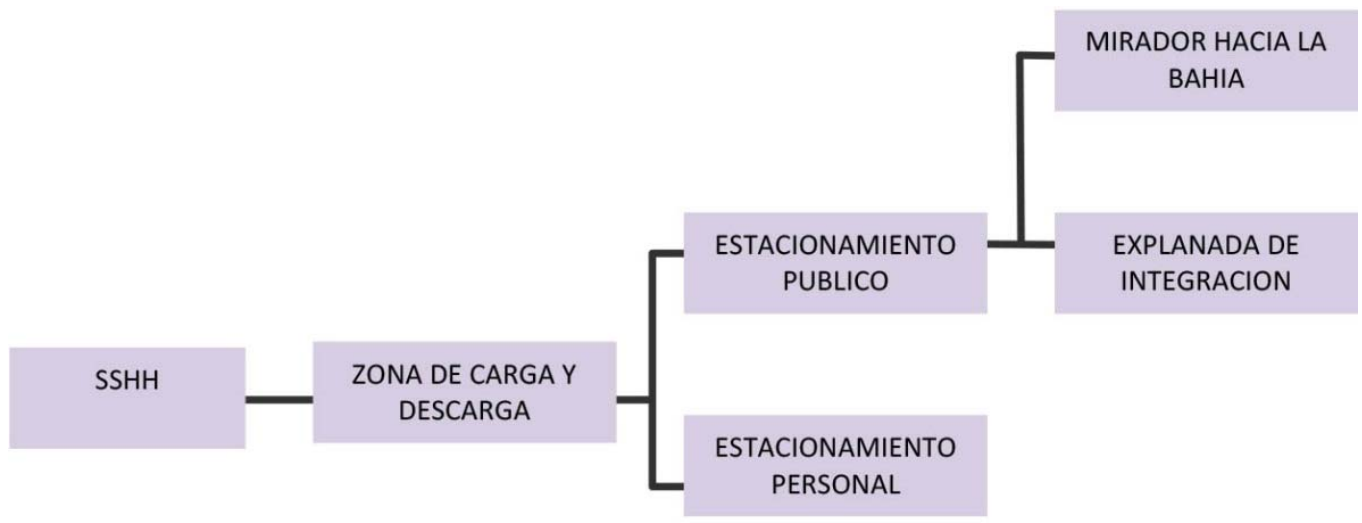




\subsection{Analisis de Normativa aplicable al Proyecto}
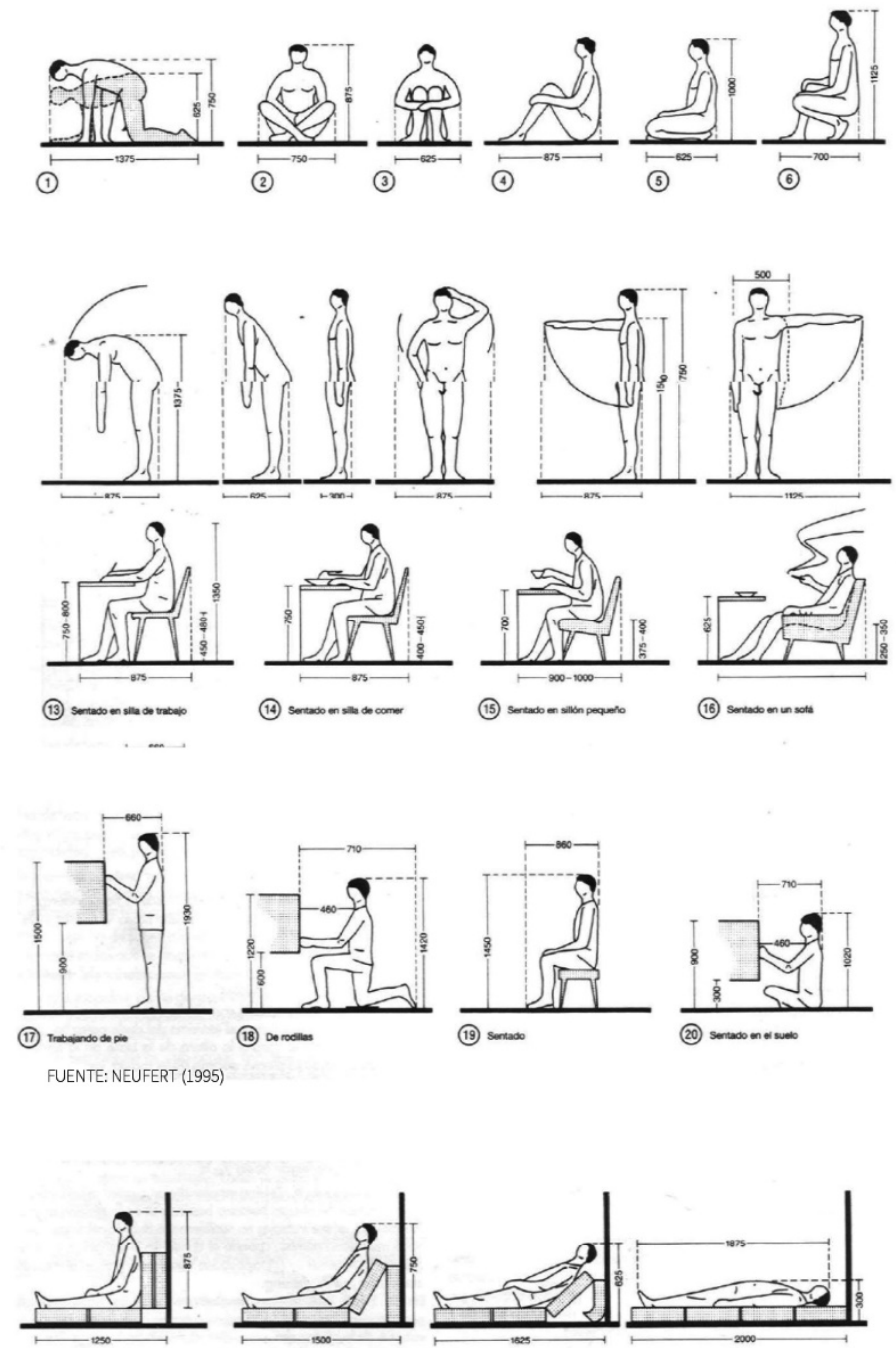

(21)

FUENTE: NEUFERT (1995)
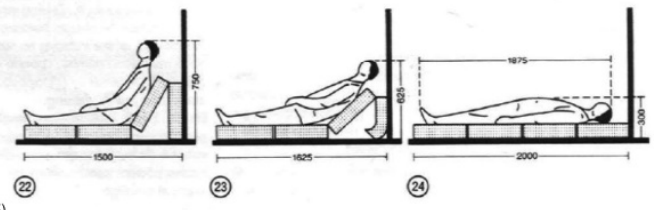

(11) Pare esperas larges
13) Paso normal

FUENTE: NEUFERT (1995)

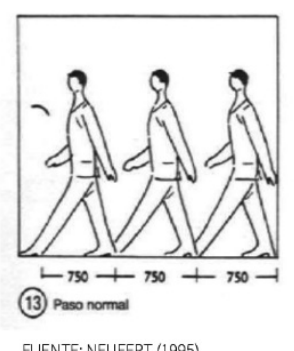

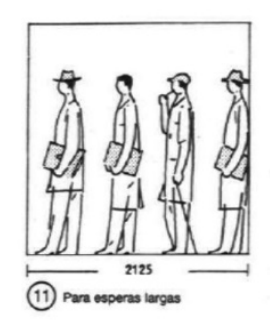

\section{(23)}

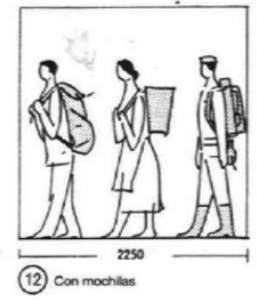

Se analizan las medidas respectivas del cuerpo humano en distintas posiciones para poder determinar el espacio que ocupan mientras realizan sus labores y funciones.

Se tendrán en cuenta dichas medidas para poder diseñar tanto los espacios de trabajo como los espacios interactivas del museo.

Es importante enfatizar al usuario de acuerdo a sus necesidades y a su desplazamiento en el espacio, se tendrá en cuenta el espacio que ocupa un usuario discapacitada ya que el proyecto abarca a todo tipo de usuario sin exclusión alguna, además los visitantes, en algunos casos llegarán acompañados de mochilas como de carteras o otros equipajes que también ocupan espacios y deben ser tomados en cuenta para el diseño arquitectónico.

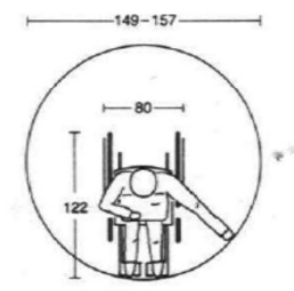

(12) Espacio minimo de giro 

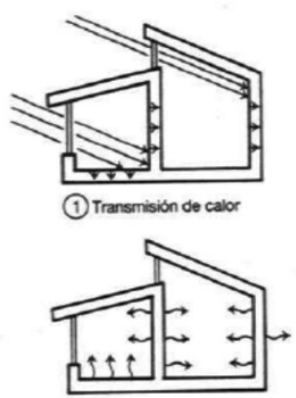

(3) Radiacion de caliox
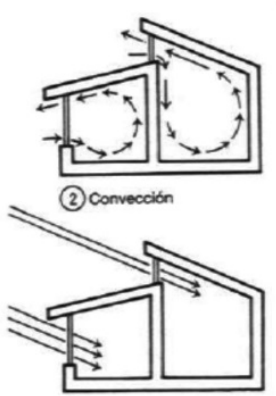

(4) Colector

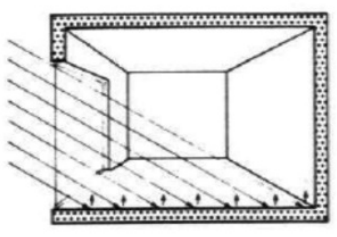
(9) Aprovechamiento directo de la ener-
gia solar a través de las superficies
acristaladas

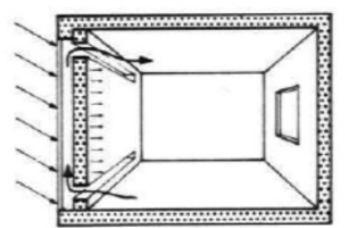

(10) Aprovechamiento indirecto de la Trombe

\section{FUENTE: NEUFERT (1995)}

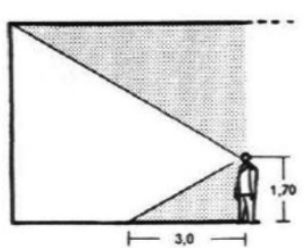

(2) Los espacios altos solo se pueden aprehender moviendo er ojo hacia

Debido a la posición relativa del ojo, un edificio contemplado desde arriba parece mas alto que contemplado desde abajo. El tema perceptivo será tomado en cuenta para el diseño espacial.

1) Aprovechamiento de la energia solar en función de la inclinación

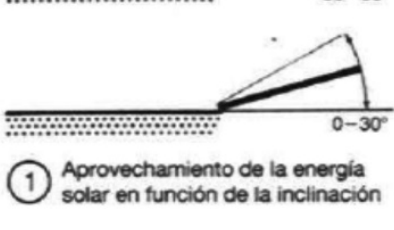

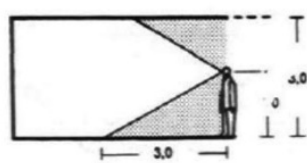

(1) Los espacios bajos pueden percien reposol

$\frac{1}{30-60^{\circ}}$

La iluminación natural en el espacio, será aprovechada considerablemente en el espacio, es por ello que se analizan las características que influyen en el para poder diseñarlas correctamente. Se busca aprovechar al máximo para poder ahorrar energía. Se proponen grandes mamparas en el entorno del complejo para poder contemplar el entorno a la ves orientarlas correctamente para poder iluminar el espacio correctamente.

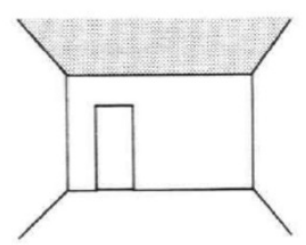

(5) Los colores oscuros pesan. Las habitaciones parecen mas bajas cuando el techo

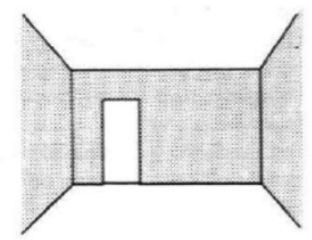

\section{(6) Los colores claros elevan. Las ha-} do las paredes se pintan de color
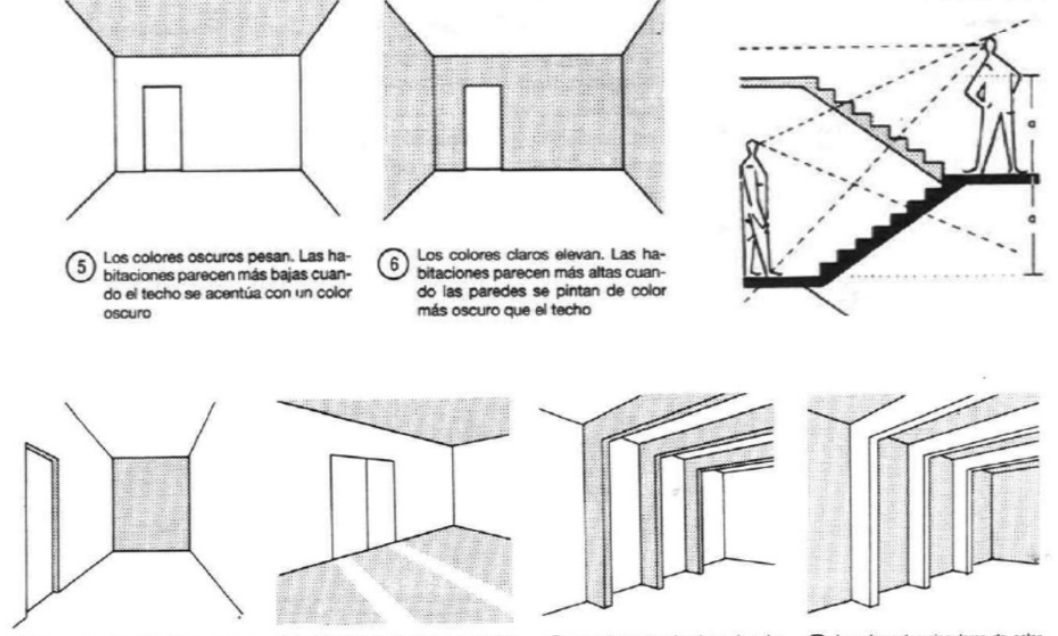

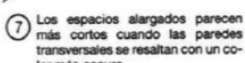

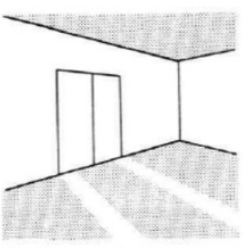

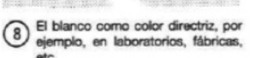

Tass oscino

FUENTE: NEUFERT (1995)

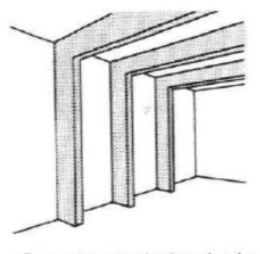

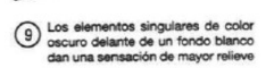

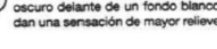

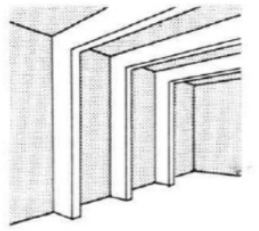

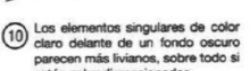

Las percepciones visuales del color serán tomadas en cuenta también para el diseño arquitectónico, es importante como el color influye en el espacio y debe ser analizado para poder incentivar al visitante a poder hacer una reflexión sobre lo recorrido y el contexto en el que se encuentra destacando sus cualidades oportunidades desarrollo 
La iluminación artificial es necesaria en algunos casos para enfatizar el espacio que se busca resaltar, además en la noche la luz natural no permite recorrer el edificio correctamente es por ello que se utilizaran distintos tipos de iluminación para poder cumplir con los objetivos, la iluminación estará distribuida en la parte superior del espacio, en el techo, como en la pared además se tendrá en cuenta la intensidad de la luz para poder generar un contrasté entre los distintos espacios a recorrer.

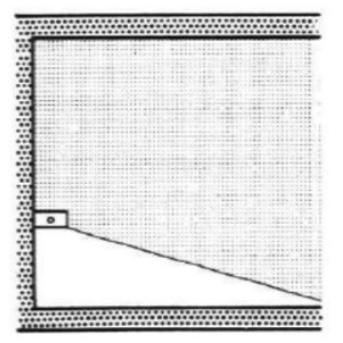

(9) Bañador de suelo

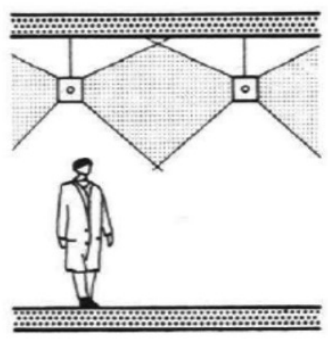

(7) lluminación directa-indirecta

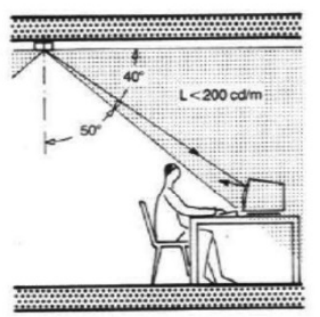

(3) Las luminarias que pueden producir reflejos, deben tener menor dens:irradiación

FUENTE: NEUFERT (1995)

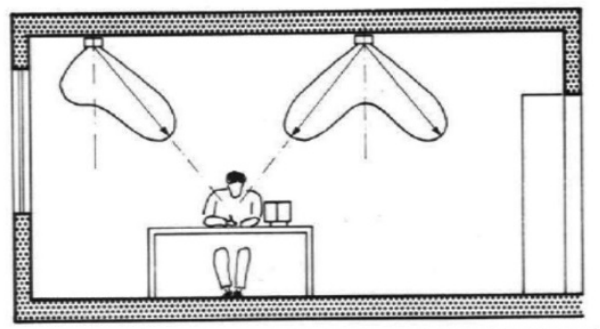

(1) Emplazamiento correcto de las luminarias respecto al puesto de trabajo; ilumi-

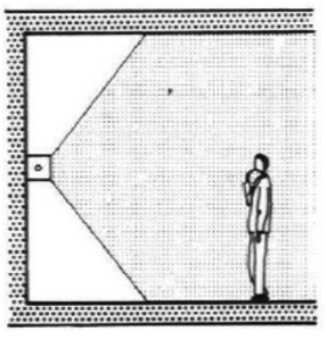

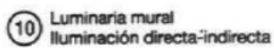

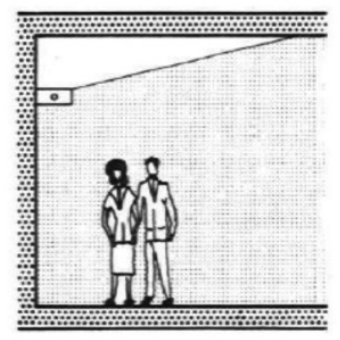

(8) Bañador de techo

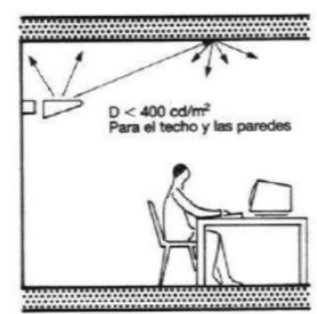

(4) Densidad luminica de una iluminaDensidad luminica
ción indirecta

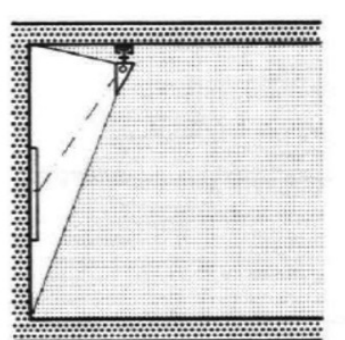

(11) Baflador de pared en rall electrifcado

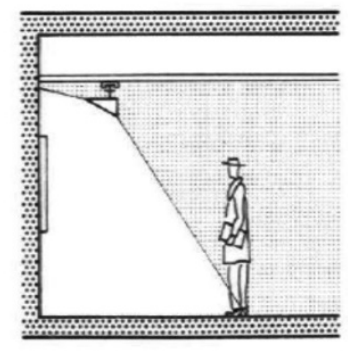

(3) Bañador de pared y suelo en rail electrificado

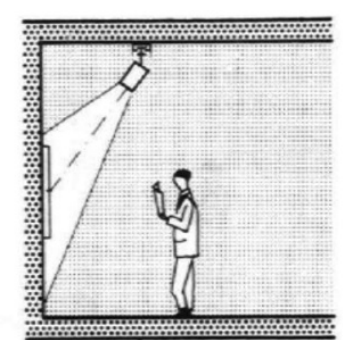

(12) Proyector en rall electrificado

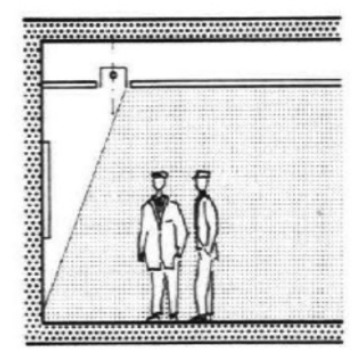

(4) Bañador de pared

En los espacios cerrados, sean de oficinas, talleres o salas, la luz artificial también será propuesta. Es importante saber determinar la cantidad de iluminación que se necesitara dependiendo de la función del usuario en el. En algunos casos se aprovechará la luz natural durante el día, y exclusivamente durante la noche, la luz artificial.
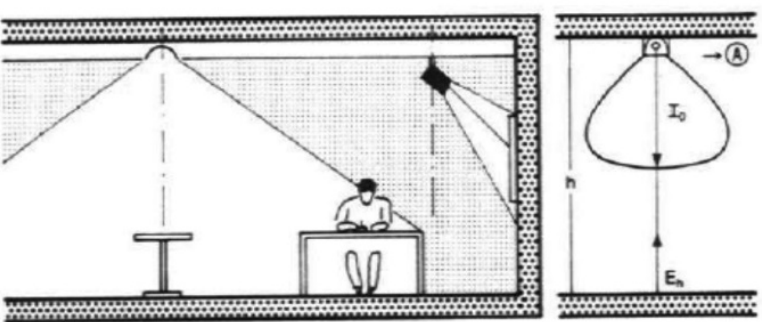


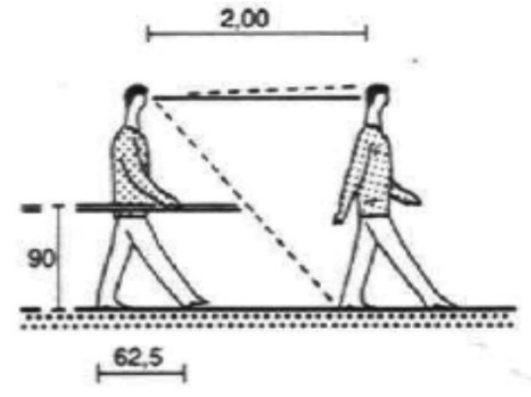

(1) Longitud del paso de una persona adulta sobre una superf. horizontal

FUENTE: NEUFERT (1995)

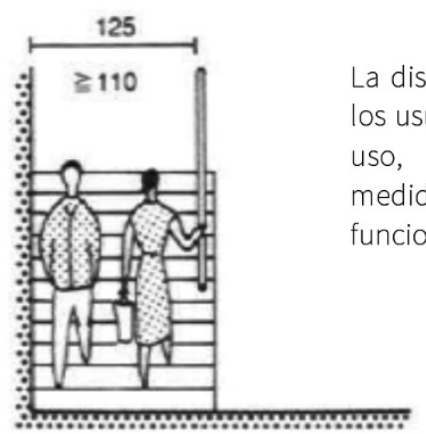

(12) Escaleras en las que pueden cruzarse dos personas

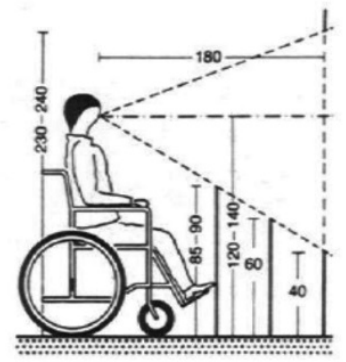

(8) Junto $a$ una ventana

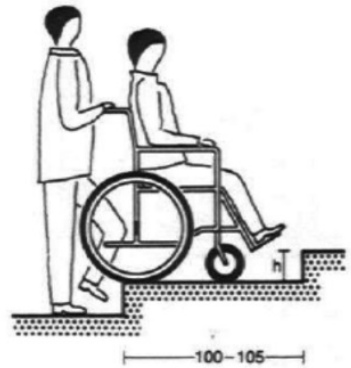

(6) En una escalera

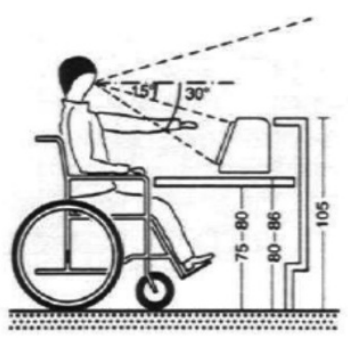

(7) Espacio de trabajo delante de un

Las visuales del usuario discapacitado son distintas, es por ello que se analiza la diferencia para poder diseñar los espacios para todos con equidad, adicional a ello el espacio de escaleras deberá tener una rampa para que lo pueda recorrer correctamente, en algunos casos el uso de escaleras eléctricas será la mejor alternativa para poder llegar a todos los espacios, como lo será para el mercado gastronómico. El espacio mínimo de ancho de una escalera eléctrica es de $80 \mathrm{~cm}$, pero en este caso de propondrá la escalera de $1.50 \mathrm{~m}$ de ancho de para poder entrar dos personas cómodamente y en caso sea necesario, un discapacitado en silla de ruedas.

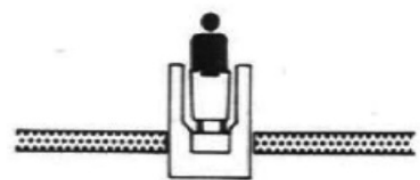

(5) Una persona con carrito de compra $60 \mathrm{~cm}$ anchura $(80 \mathrm{~cm})$

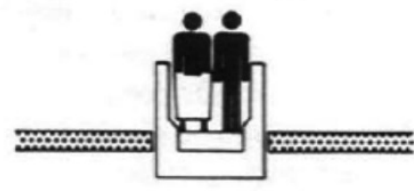

(6) Dos personas $1 \mathrm{~m}$ de anchura

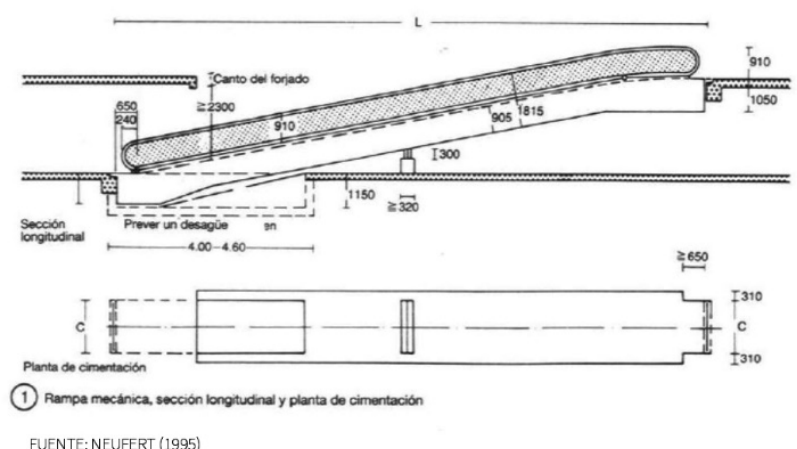

FUENTE: NEUFERT (1995) 


\subsection{Estudio de Antropometria y Mobiliario General}

Las siguientes láminas estarán destinadas a dar a conocer la descripción de los ambientes funcionales que el programa presente, se analizarán en particular los espacios más importantes del proyecto con mobiliario y equipamiento necesario para su funcionamiento.

La secuencia de análisis será tanto en planta como en corte con condicionantes del ambiente tanto de ventilación como iluminación además se hará un énfasis en el usuario que recorre el espacio especificando su circulación en el.

Las conexiones que tendrá con el resto de ambientes se mencionarán dando una idea de cómo se están proponiendo los espacios en el diseño del proyecto, siempre de la mano con la normativa del Reglamento Nacional de Edificaciones y del Neufert como los referentes principales normativos, adicional a ello se adjuntarán imágenes referenciales de proyectos existentes para dar a conocer la volumetría espacial que se propone.

Los espacios a desarrollar serán los siguientes:

- Espacio informativo

- Sala de conferencias

- Sum de pescadores

- Muelle terminal

- Deposito de redes
- Mostrador del mercado de pesca

- Zona de lavado y corte

- Mostrador del mercado gastronomico

- Cocina

- Zona de craga y descarga

Al finalizar el análisis cuantitativo y cualitativo de los distintos espacios funcionales se hará un comentario sobre ello, adicionalmente a las condicionantes de diseño que serán tomadas en cuenta luego del análisis, siempre enfocando el proyecto en su contexto su entono natural, en constante relación tanto especial como funcional con el entorno.

Se busca que el proyecto resalte las cualidades del lugar y mas bien las evoque y no compita con ella dando a conocer sus fortalezas y oportunidades.

El espacio del terminal pesquero además de funcionar como tal con el equipamiento necesario para su correcto funcionamiento luego del análisis previo ya explicado, en adicional a ello servirá como vitrina dentro del complejo y en todo momento el visitante que recorra el espacio podrá apreciar la actividad pesquera se realiza en el distrito, la cual es la principal fuente económica del lugar y además actividad por la cual el distrito dio origine y se fue consolidando siendo hoy lo que refleja. 


\subsection{Analisis Cuantitativo y Cualitativo de los Espacios Funcionales}

\subsubsection{Espacio informativo}

Espacio que pertenece al paquete funcional de Difusión y Aprendizaje, el espacio esta destinad para atender al usuario en caso tenga dudas sobre el recorrido del complejo y el funcionamiento de este. Además el espacio proporcionara a través de pantallas táctiles interactivas información sobre la historia del distrito y sobre las valores gastronómicos del sector y de todo el Perú.

Cuenta con iluminación que enfatiza los espacios interactivos tanto desde la parte superior como desde la parte inferior. Pero la gran mayoría de iluminación es natural ya que se representara como un espacio dentro de un gran espacio cultural que lo engloba.

Cuenta con un área de $24 \mathrm{~m} 2$ ( $4 \mathrm{~m}$ de largo, $6 \mathrm{~m}$ de ancho y $3 \mathrm{~m}$ de altura).

Atiende a un aforo de 12 personas. Distribuidas en los diferentes equipamientos que este espacio presenta. ( $2 \mathrm{~m} 2 /$ personas)

Figura 199: Referente espacio expositivo 1 y 2
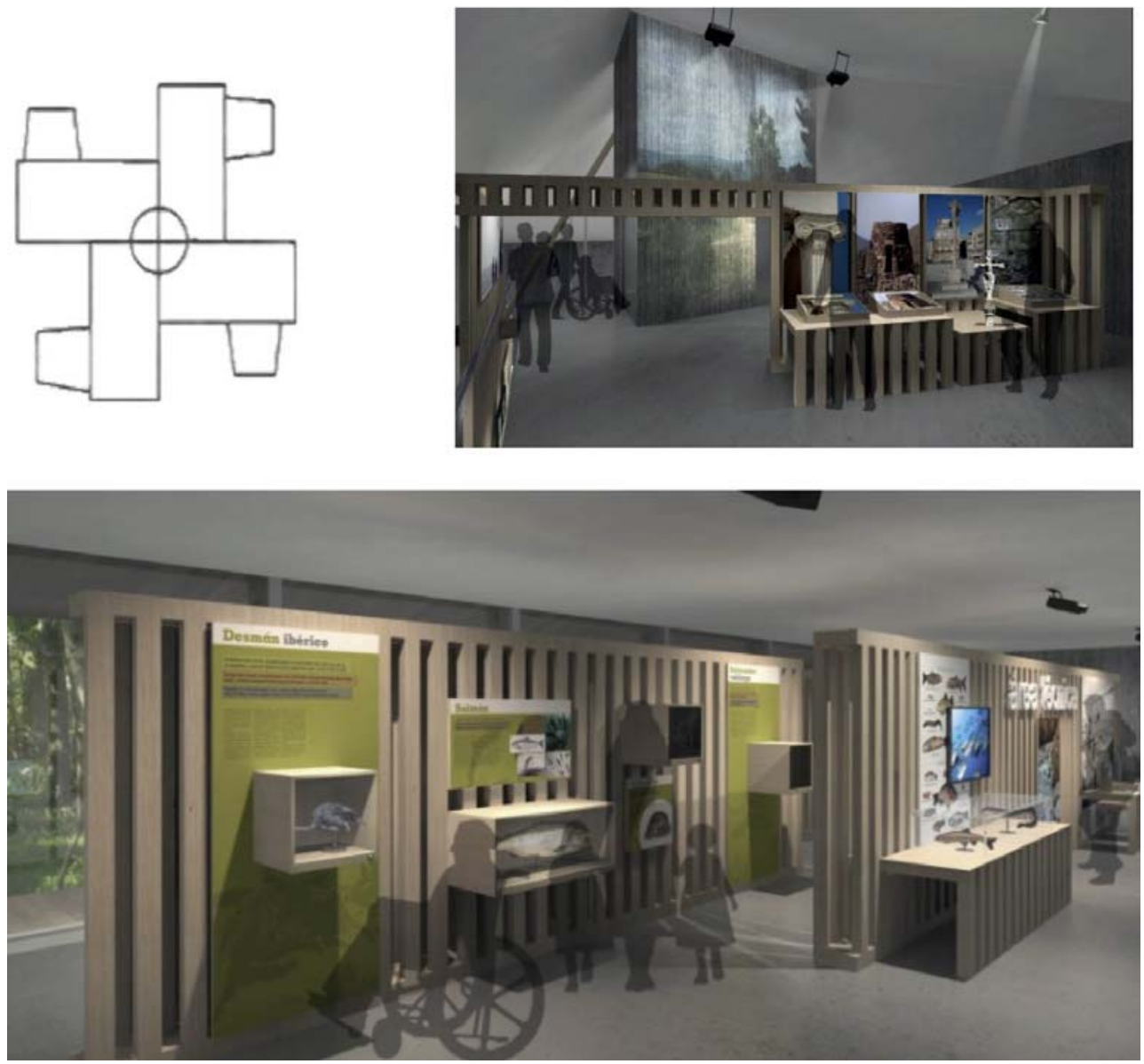


\subsubsection{Sala de conferencias}

Espacio que pertenece al paquete funcional de administración, el espacio esta destinado para atender a los trabajadores del proyecto que realizan conferencias para poder dar a conocer sus labores. Sirve de espacio de integración y en todo momento se fomenta el dialogo y la interacción.

Cuenta con una iluminación acorde para que todos los espectadores puedan ver la exposición o conferencia de manera optima, esta iluminación es artificial ahorrativa en la parte superior del techo, y en los bordes de las escaleras por un tema se seguridad, se igual manera cuenta con iluminación natural en la parte alta del muro de los lados para poder ahorrar energía en caso el día sea soleado y no sea necesario el uso de iluminación artificial.

Cuenta con un mobiliario de aire acondicionado y con instalaciones de proyección y computadora para poder realizar las explicaciones correspondientes.

Cuenta con un área de $30 \mathrm{~m} 2$ ( $6 \mathrm{~m}$ de largo, $5 \mathrm{~m}$ de ancho y $3 \mathrm{~m}$ de altura). Y en adicional el área de las butacas.

Atiende a un aforo de 15 personas. ( $2 \mathrm{~m} 2 /$ persona).

Figura 200: Referencia de sala de conferencias y detalle de butacas
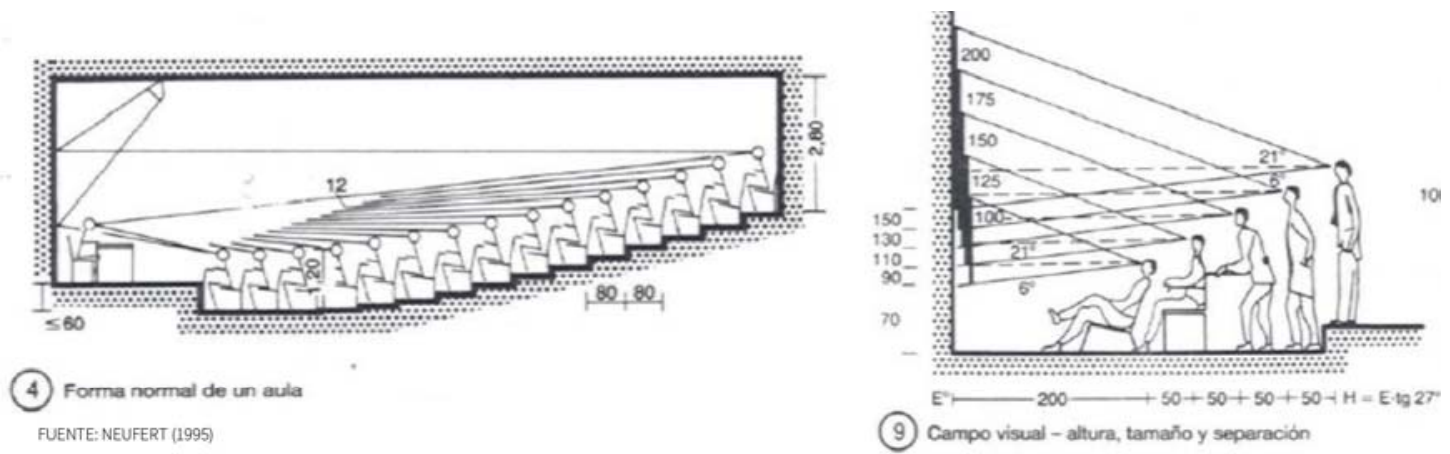

(9) Campo visual - altura, tamaño y separación

FUENTE: NEUFERT (1995)
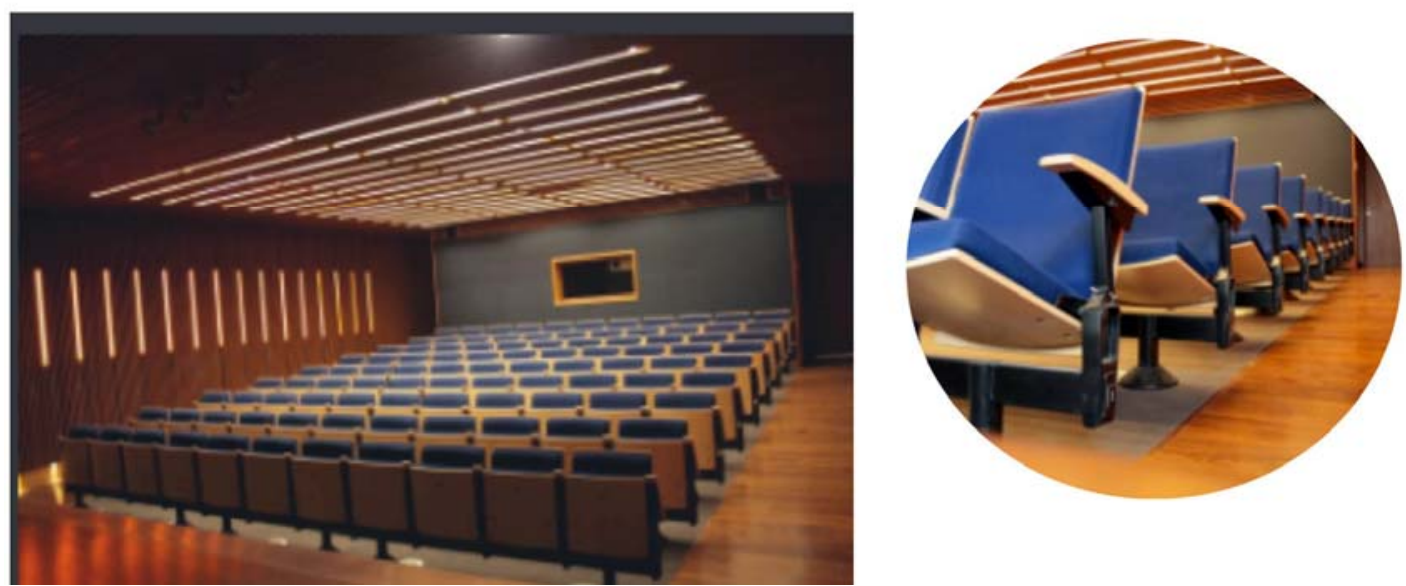


\subsubsection{SUM}

Espacio que pertenece al paquete funcional de terminal pesquero, esta destinado como un espacio de usos múltiples en el cual se pueden realizar distintas actividades sean de conferencias, de interacción participativa de los pescadores, de reportes e incluso de conferencias. El espacio es para reuniones propias de los pescadores y de las coordinaciones del mismo terminal y muelle de pescadores.

Cuenta con una iluminación natural y artificial en ambos casos ubicados según la orientación del sol para que su funcionamiento sea el optimo. Cuenta con mobiliario como lo es un proyectos, una mesa central de reunión con sillas en el perímetro y dos computadores en caso sean requeridos.

Cuenta con un área de $40 \mathrm{~m} 2$ ( $8 \mathrm{~m}$ de largo, $5 \mathrm{~m}$ de ancho y $2.6 \mathrm{~m}$ de altura).

Atiende a un aforo de 20 personas. ( $2 \mathrm{~m} 2$ /persona)

Figura 201: Referencia del SUM 1 y SUM 2
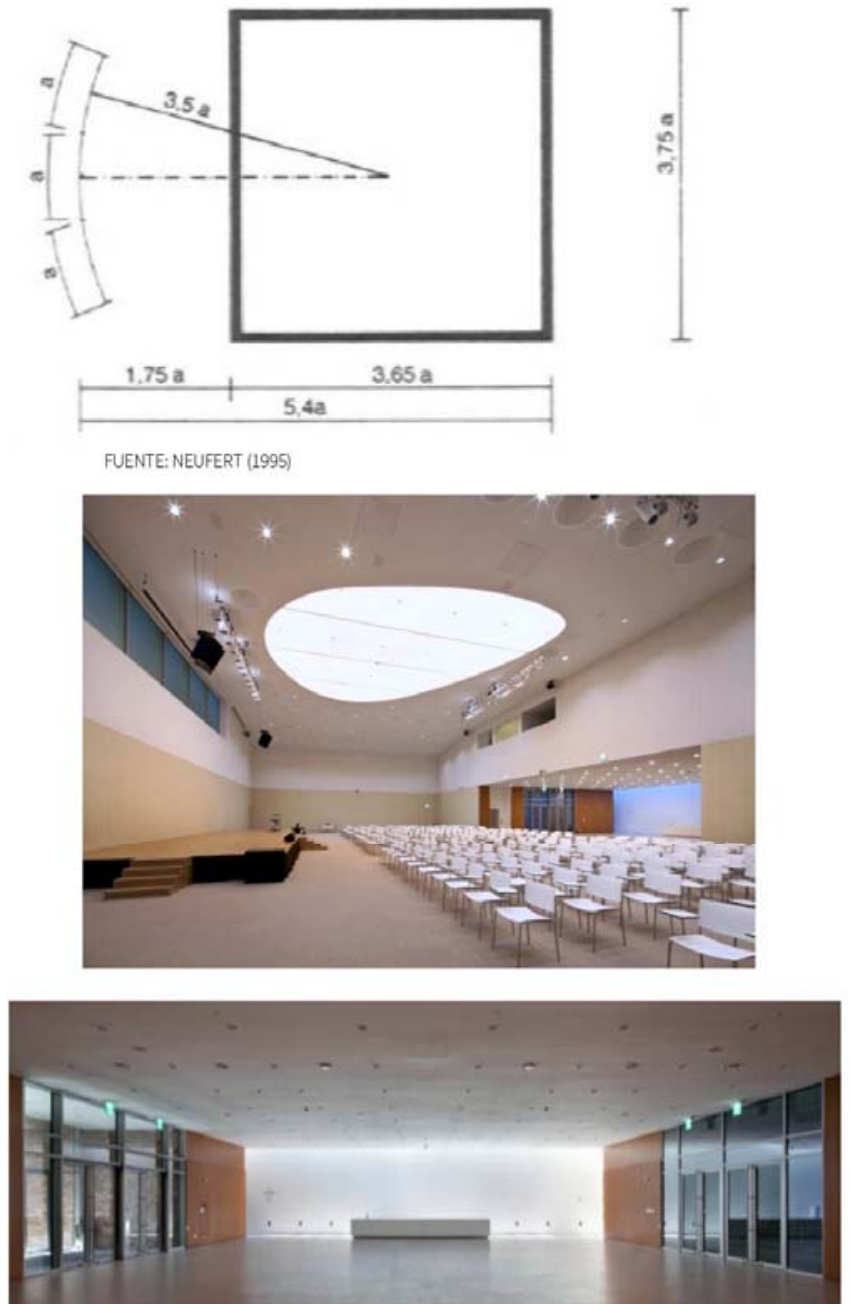

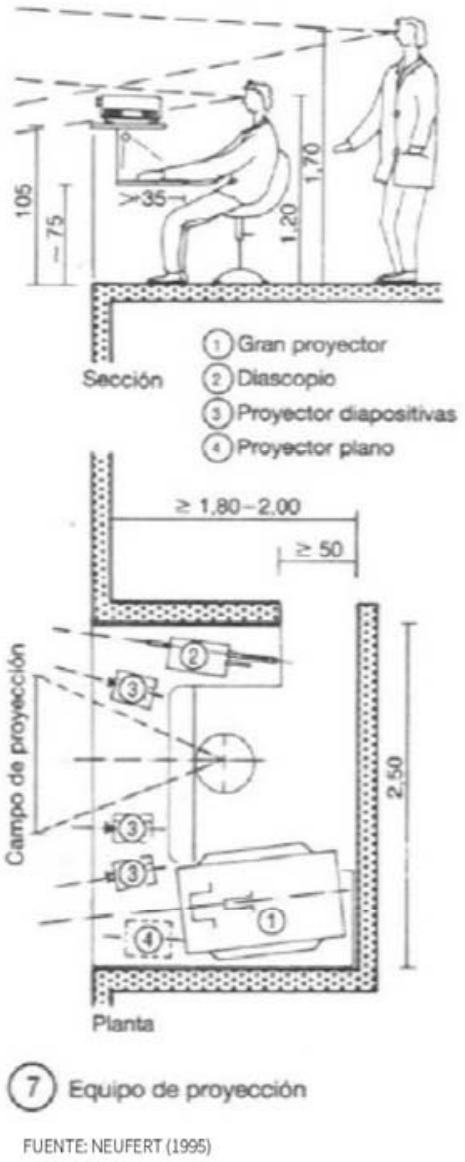




\subsubsection{Muelle terminal}

\section{- DEPOSITO DE REDES}

Espacio que pertenece al paquete funcional de terminal pesquero, esta destinado como un espacio de usos particulares de embarque y desembarque de los botes para realizar la pesca del día, el espacio cuenta con bollas y prolongaciones del muelle hacia el mar que limitan el espacio y que orientan al pescador a generar un circuito y no cruzarse con las demás embarcaciones.

Cuenta con una iluminación natural y el espacio esta totalmente abierto a la periferia, limita con el la plataforma de control y el nexo entre el mar y la edificación.

Cuenta con un área de $120 \mathrm{~m} 2$ ( $20 \mathrm{~m}$ de largo, $6 \mathrm{~m}$ de ancho).

Atiende a un aforo de 60 personas. ( $2 \mathrm{~m} 2$ /persona)

Figura 202: Referencia de Muelle de terminal
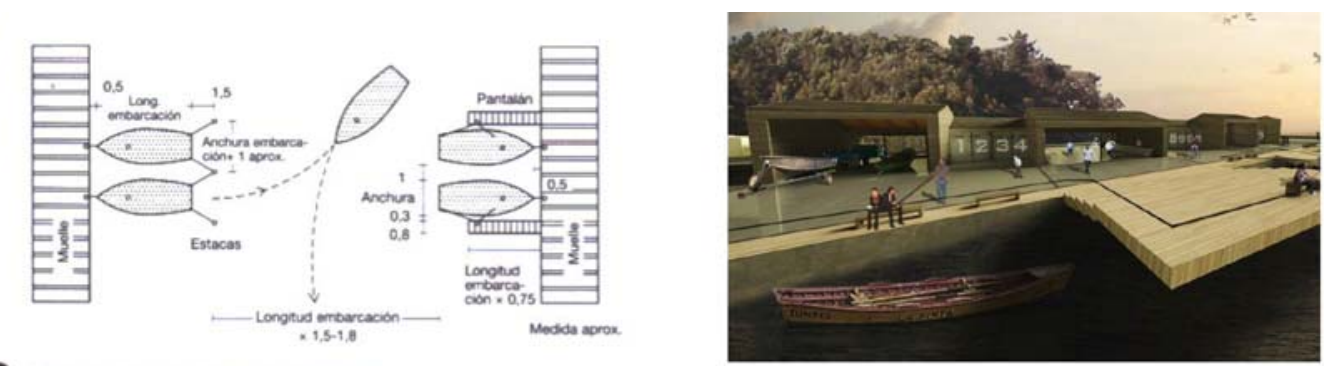

Espacio de maniobra entre dos embarcaderos

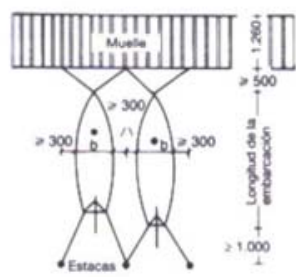

(2) Amarres para embarcacior
entre muello y estacas

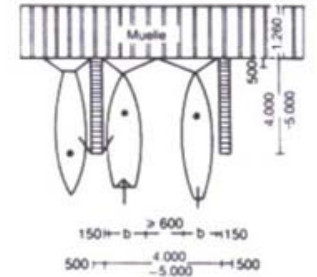

Amarres en diagonal para embarcaciones entre muello
y estacas

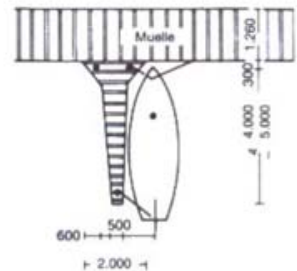

(4) Amarre de embarcaciones en $Y$

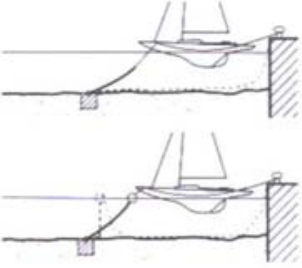

Fondeo con muerto con $y \sin$ boya FUENTE: NEUFERT (1995)

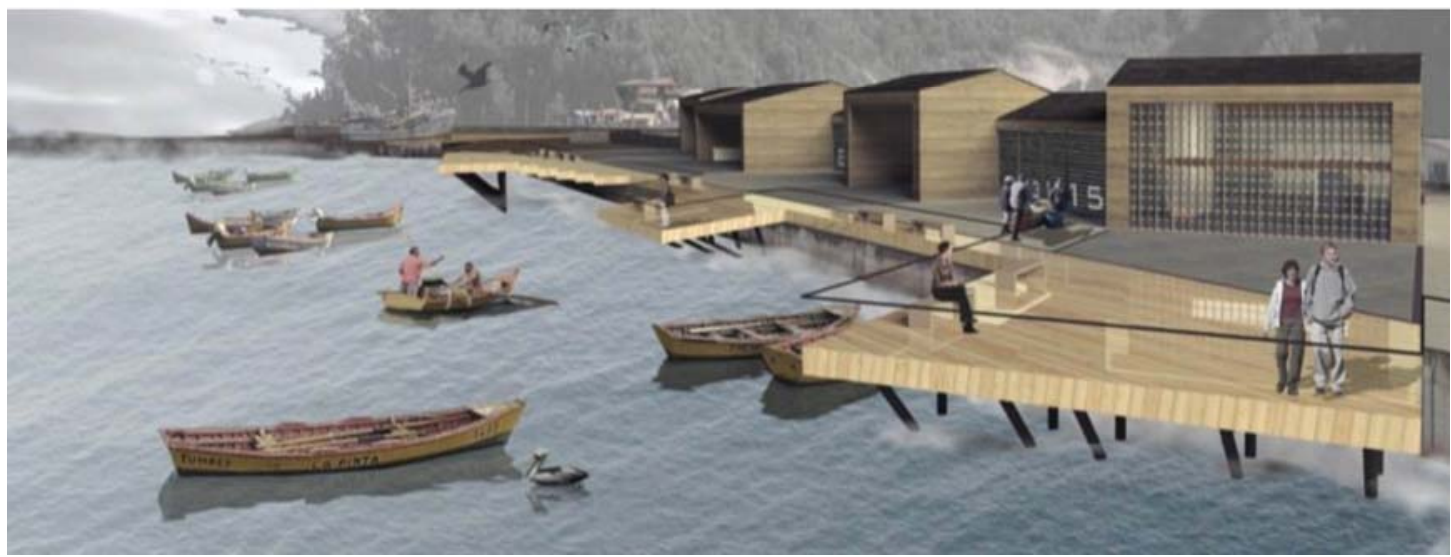

Fuente: Archdaily 


\subsubsection{Mostrador mercado de pesca}

\section{- ZONA DE CORTE Y LAVADO}

Espacio que pertenece al paquete funcional de mercado de pesca, esta destinado a la venta del pescado del día, por medio de espacios en los cuales se ofrecen el producto lavado y cortado según el cliente lo requiera,

Cuenta con una iluminación natural y según la orientación del sol para que su funcionamiento sea el optimo. Cuenta con mobiliario como vitrinas de la pesca del día, con una zona de corte y lavado para poder entregar el producto y una zona de cobranza, en la cual esta la caja y el cobrador.

Cuenta con un área de $15 \mathrm{~m} 2$ ( $5 \mathrm{~m}$ de largo, $3 \mathrm{~m}$ de ancho y $3 \mathrm{~m}$ de altura).

Atiende a un aforo de 6 personas. El mercado cuenta con 12 mostradores. En total el aforo del mercado es de 400 personas.

Figura 203: Referencia de Mercado de Pesca
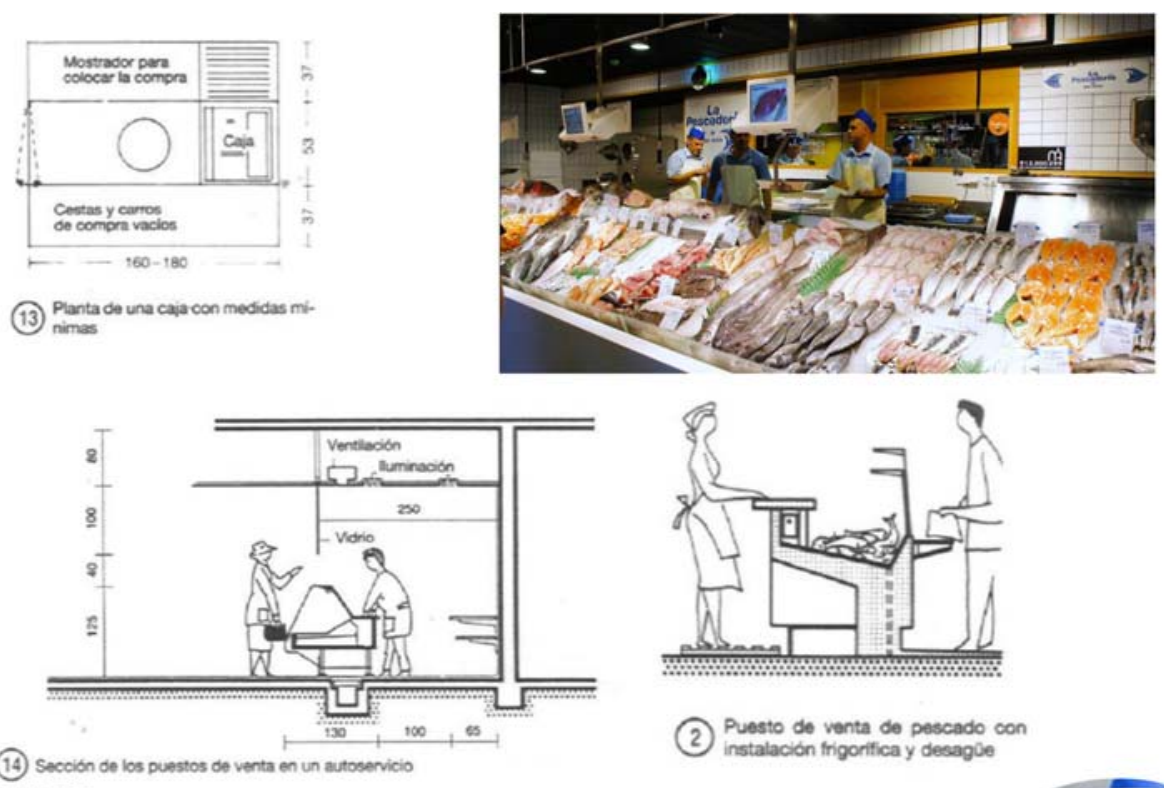

(2) Puesto de venta de pescado con (14) Sección de los puestos de venta en un autoservicio FUENTE: NEUFERT (1995

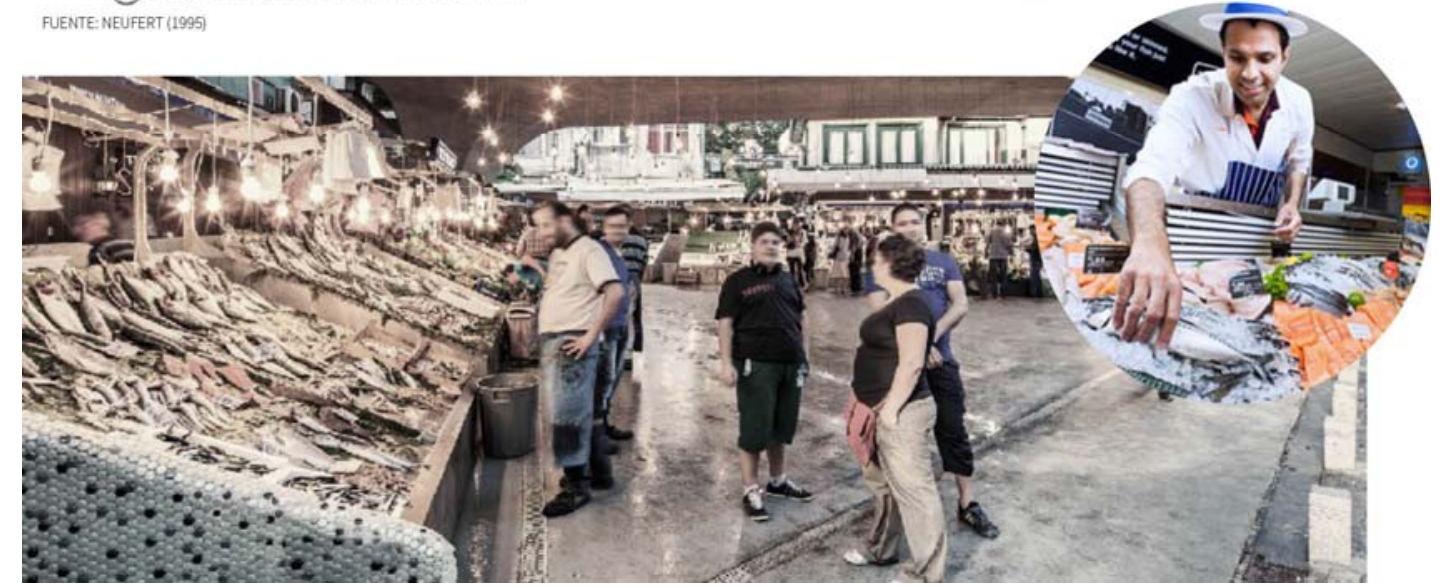

Fuente : Archdaily 


\subsubsection{Mostrador del mercado gastronomico}

Espacio que pertenece al paquete funcional de mercado gastronómico, esta destinado a la venta de platos gastronómicos de la pesca del día y de otros platos típicos peruanos, el mostrador exclusivamente ofrece los platos para degustarlos y poder comprarlos en caso quieran consumirlos en el área de restaurante colindante a los mostradores y en constante relación.

Cuenta con una iluminación natural y artificial para enfatizar ciertas zonas. El espacio busca conectar la experiencia gastronómica con lo adquirido en el recorrido cultural y a la ves con el entorno paisajista y natural en el que se encuentra el visitante.

Cuenta con un área de $15 \mathrm{~m} 2$ ( $5 \mathrm{~m}$ de largo, $3 \mathrm{~m}$ de ancho y $4 \mathrm{~m}$ de altura).

Atiende a un aforo de 6 personas. El mercado cuenta con 30 mostradores. En total el aforo del mercado es de 3176 personas.

Figura 204: Referencia de Mercado Gatronomico - comedor, puestos y espacialidad
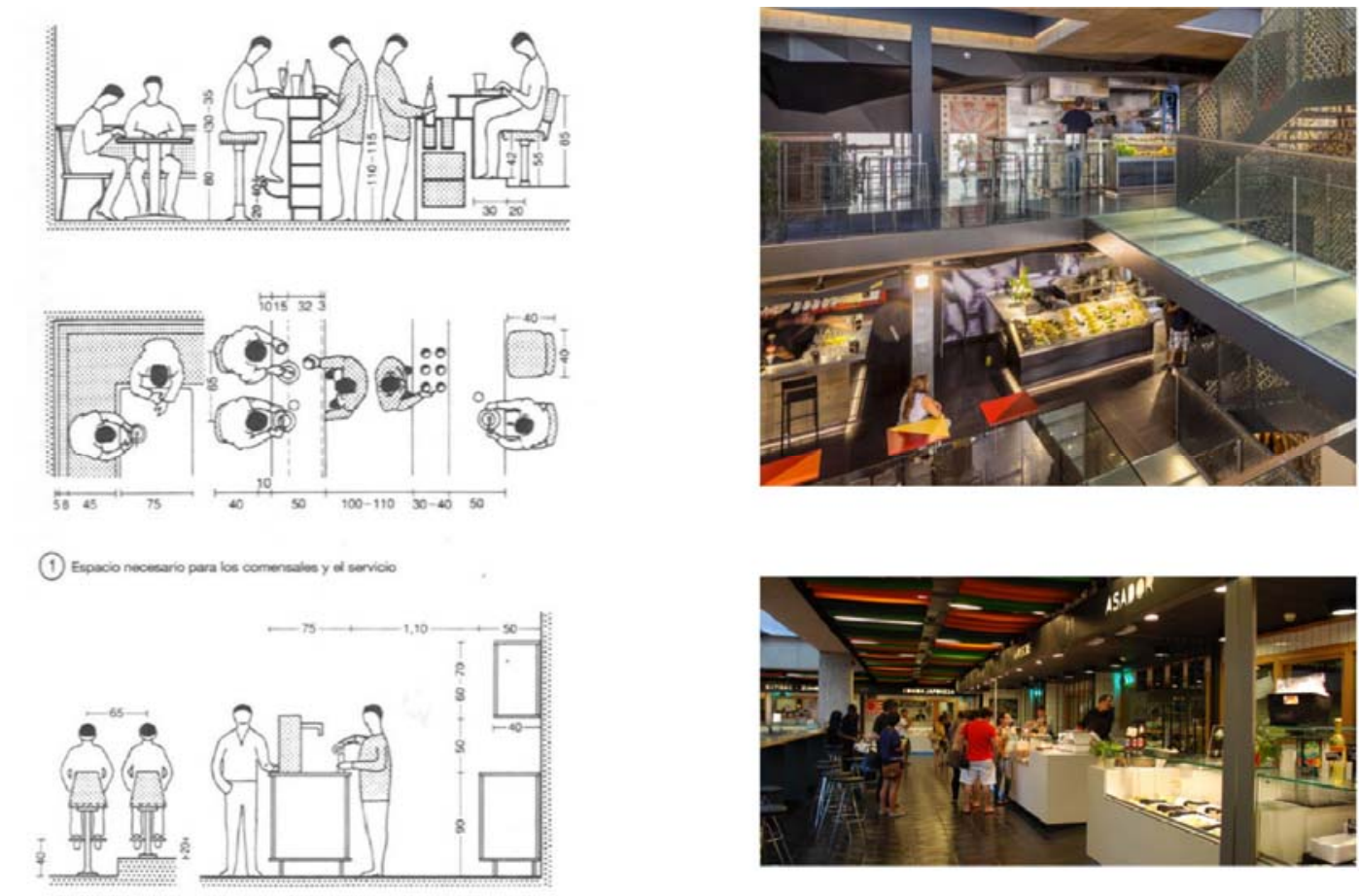

FUENTE: NEUFERT (1995)

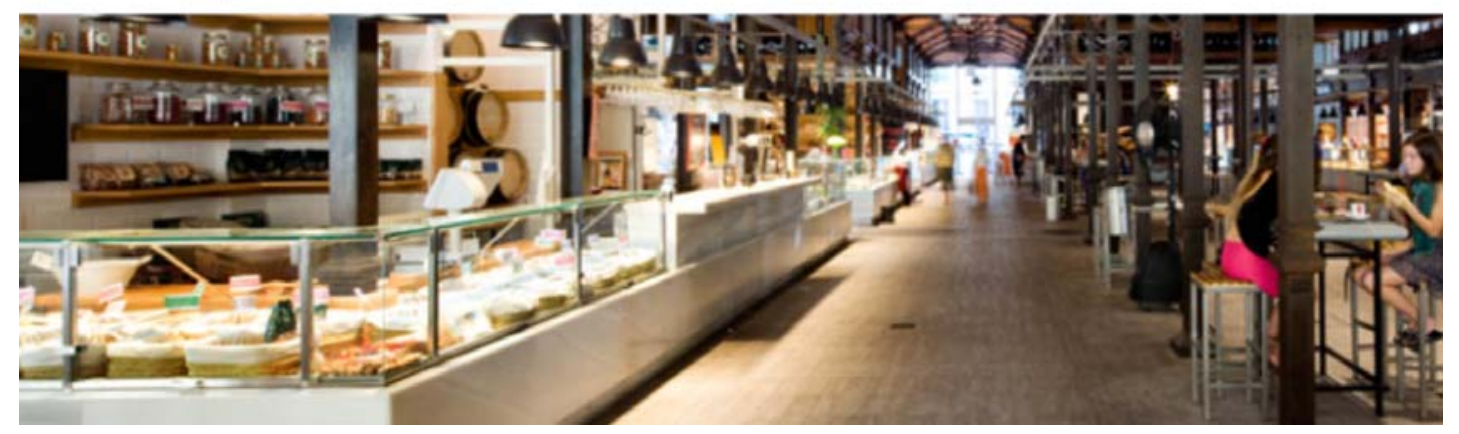

Fuente : Archdaily 


\subsubsection{Cocina del mercado gastronomico}

Espacio que pertenece al paquete funcional de mercado gastronómico, esta destinado a realizar las labores de ejecución de los platos gastronómicos que el visitante solicita, será preparado por un cocinero y ayudantes que hagan de los platos, platos exquisitos que despierten los sentidos hacia la cultura culinaria y gastronómica que el Perú caracteriza. Cuenta una iluminación natural y artificial en caso se requiera, cuenta con cámaras extractoras de olores, y de flujos de aire para poder mantener el ambiente fresco y a una temperatura amigable para poder transcurrir en el. Cuenta con mobiliario de refrigeración, tablas inodoras entre otras que hacen de los platos, un producto optimo para la demanda actual.

Cuenta con un área de $30 \mathrm{~m} 2$ ( $5 \mathrm{~m}$ de largo, $4 \mathrm{~m}$ de ancho y $4 \mathrm{~m}$ de altura). Adjunto a el se encuentran las zonas de deposito, lavado, almacenes, entre otros.

Atiende a un aforo de 5 personas.

Figura 205: Referencia - Cocina del Mercado Gatronomico
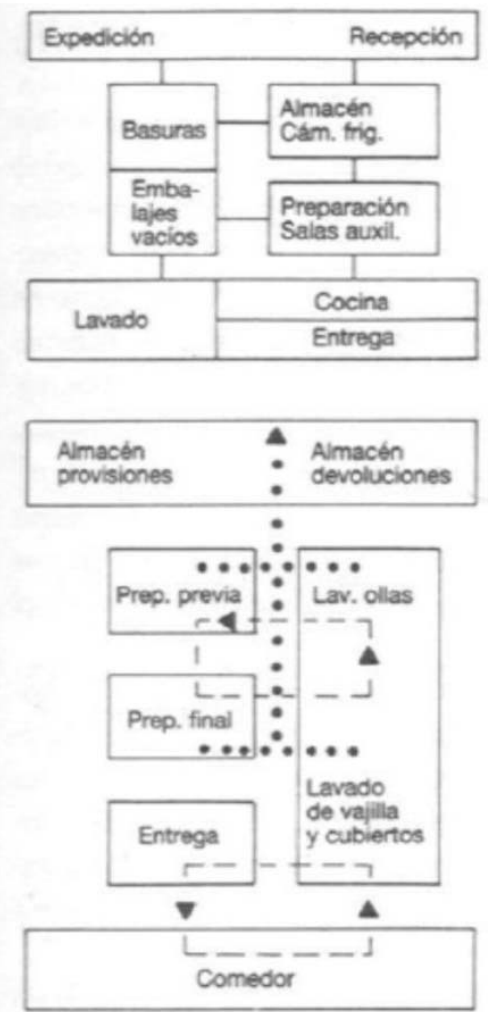

- Flujo de alimentos

-.- Flujo de basuras

- - Recomido de los contenedores

- Recorrido de la vaiplla

(1) Cocina de un restaurante. Funcio-

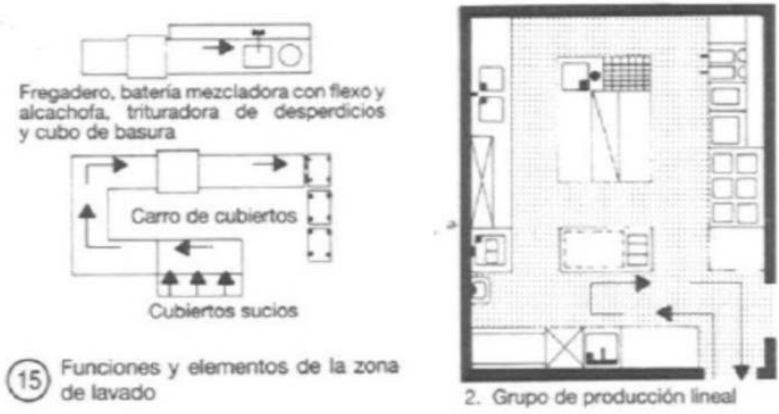

FUENTE: NEUFERT (1995)

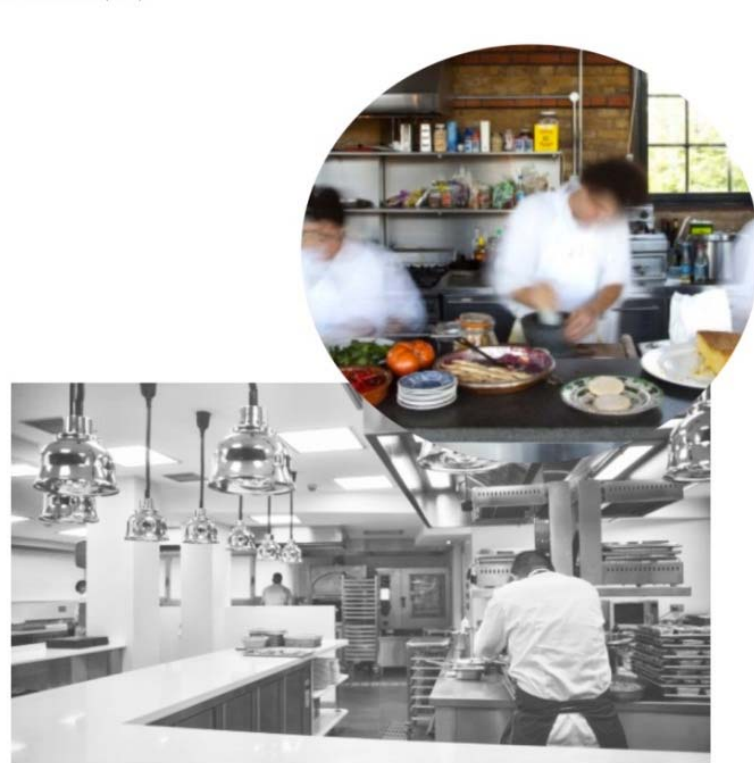

Fuente : Archdaily 


\subsubsection{Zona de carga y descarga}

Espacio que pertenece al paquete funcional de área libre, es el espacio en el cual los camiones llegan a abastecer el mercado gastronómico y a llevarse los productos restantes de la pesca del día que serán distribuidos en distintos mercados minoristas del país.

Cuenta con un área de $400 \mathrm{~m} 2$

Atiende a un aforo de 200 personas. Pero 50 trabajaran en su funcionamiento.

Figura 206: Referencia - Patio de Carga y descarga Mercado Gatronomico
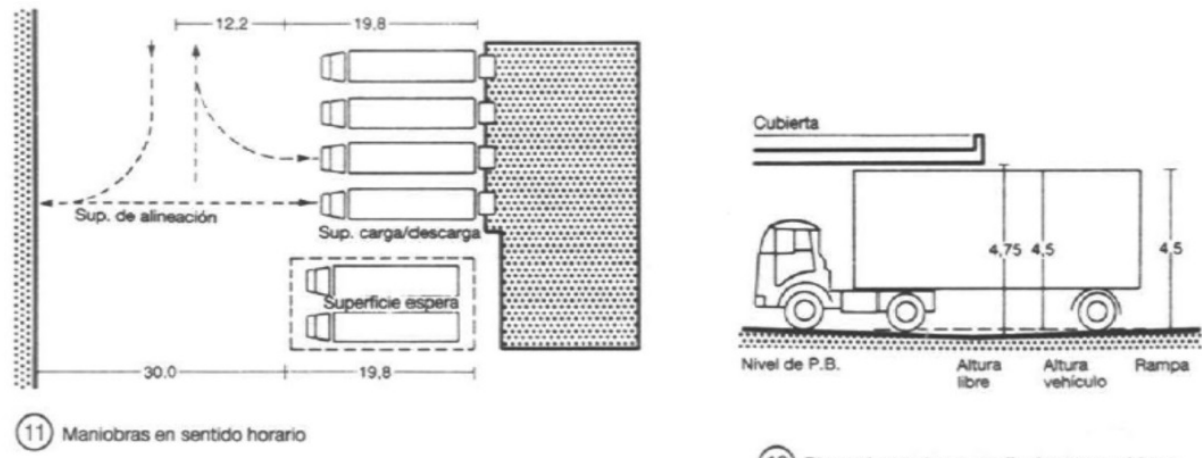

(11) Maniobras en sentido horario

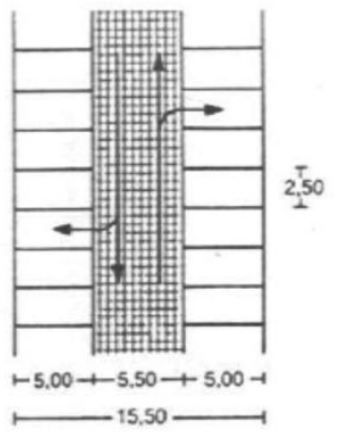

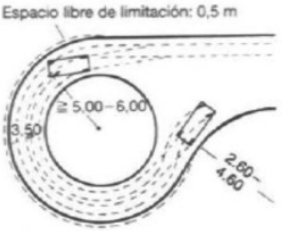

2) Plazoleta de cambio de sentido FUENTE: NEUFERT (1995)

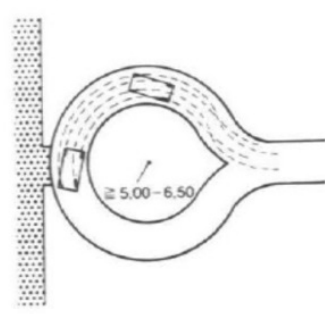

(3) Plazoleta circular de cambio de de giro $\geq 5-6.50 \mathrm{~m}$

Aparcamiento a $90^{\circ}$, desde ambos sentidos. Anchura de las plazas: $2,50 \mathrm{~m}$

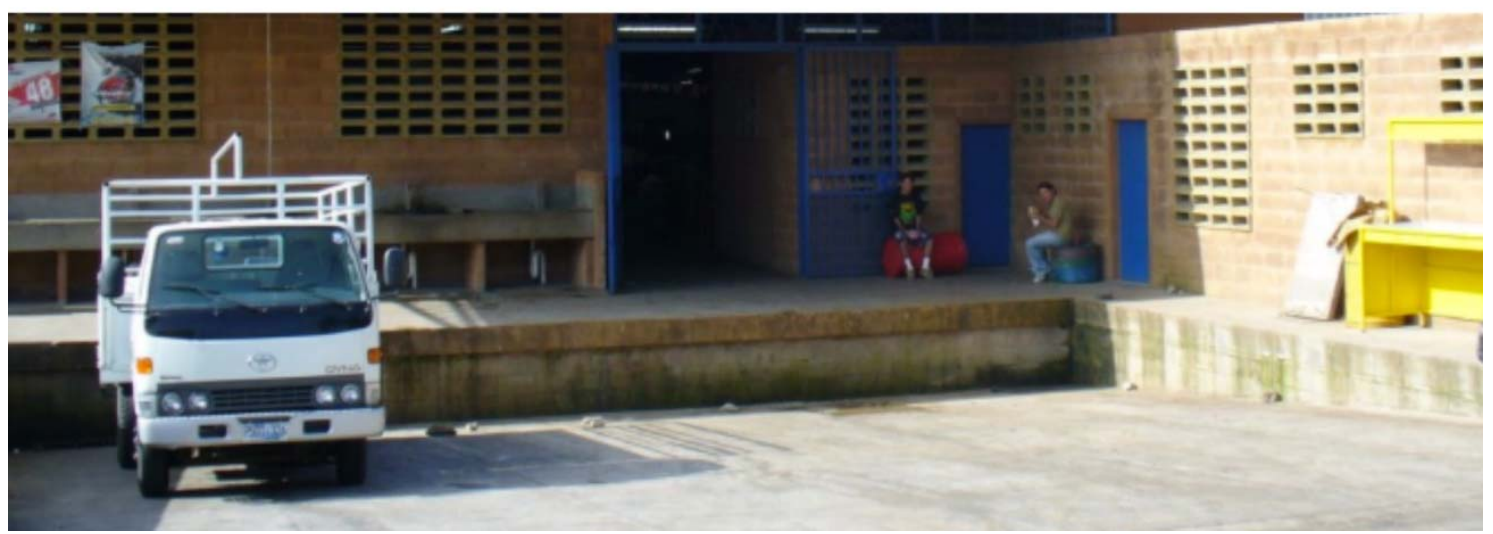




\subsection{Cuadro de areas}

\subsubsection{Listado y número de personas por ambiente}

\begin{tabular}{|c|c|c|c|c|c|}
\hline \multirow[b]{2}{*}{ PAQUETE FUNCIONAL } & \multirow[b]{2}{*}{ AMBIENTES /SUB AMBIENTES } & \multirow[b]{2}{*}{ AFORO (UN.) } & \multicolumn{3}{|c|}{ ASPECTOS CUANTITATIVOS } \\
\hline & & & CANTIDAD(UN.) & AREA(UN.)m2 & AREA TOTAL \\
\hline \multirow{23}{*}{ ADMINISTRACION } & ZONA PUBLICA & & & & \\
\hline & RECEPCION & 3 & 1 & 14 & 14 \\
\hline & SALA DE ESPERA & 10 & 1 & 15 & 15 \\
\hline & OFICINAS DE ALTA DIRECCION & & & & \\
\hline & OFICINA DIRECTOR DIRIGENTES & 2 & 1 & 20 & 20 \\
\hline & OFICINA DIRIGENTES TERMINAL PESQUERO & 3 & 1 & 20 & 20 \\
\hline & OFICINA DIRIGENTES MERCADO GASTRON. & 3 & 1 & 20 & 20 \\
\hline & OFICINAS ADMINISTRATIVAS & & & & \\
\hline & OFICINA AREA CULTURAL & 3 & 1 & 20 & 20 \\
\hline & OFICINA ADMINISTRATIVA & 5 & 1 & 30 & 30 \\
\hline & OFICINA EVENTOS & 3 & 1 & 20 & 20 \\
\hline & ZONA DE COORDINACION & & & & \\
\hline & SALA DE REUNION & 15 & 1 & 40 & 40 \\
\hline & SALA DE REUNION & 15 & 1 & 40 & 40 \\
\hline & ARCHIVO & 3 & 1 & 20 & 20 \\
\hline & DEPOSITO & 3 & 1 & 15 & 15 \\
\hline & DEPOSITO & 3 & 1 & 15 & 15 \\
\hline & AREA DE DESCANSO DEL PERSONAL & & & & \\
\hline & ZONA DE DESCANSO & 40 & 1 & 80 & 80 \\
\hline & CAFETERIA & 40 & 1 & 20 & 20 \\
\hline & SSHH & 10 & 1 & 30 & 30 \\
\hline & SUBTOTAL & 161 & & & 419 \\
\hline & CIRCULACION Y MUROS (30\%) & & & & 125.7 \\
\hline \multirow{13}{*}{ ACCESO } & & & & & \\
\hline & ZONA PUBLICA & & & & \\
\hline & HALL & 60 & 1 & 84 & 84 \\
\hline & SSHH & 40 & 1 & 70 & 70 \\
\hline & BOLETERIA & 5 & 1 & 15 & 15 \\
\hline & CONTROL DE SEGURIDAD & 3 & 1 & 12 & 12 \\
\hline & GUARDA ROPA & 4 & 1 & 45 & 45 \\
\hline & TIENDA & & 1 & & \\
\hline & CAJA & 3 & 1 & 20 & 20 \\
\hline & DEPOSITO & 3 & 1 & 12 & 12 \\
\hline & AREA DE ESTANTES & 15 & 1 & 90 & 90 \\
\hline & SUBTOTAL & 133 & & & 348 \\
\hline & CIRCULACION Y MUROS (30\%) & & & & 104.4 \\
\hline \multirow{13}{*}{ DIFUSION /APRENDIZAJE } & CENTRO INFORMACION & & 1 & 2800 & 2800 \\
\hline & SALA DE ESPERA & 20 & 1 & 24 & 24 \\
\hline & ESPACIO INFORMATIVO & 40 & 1 & 24 & 24 \\
\hline & ESPACIO INFORMATIVO & 40 & 1 & 24 & 24 \\
\hline & SALA DE CONFERENCIAS & 30 & 1 & 56 & 56 \\
\hline & SALA DE CONFERENCIAS & 30 & 1 & 56 & 56 \\
\hline & DEPOSITO & 5 & 1 & 15 & 15 \\
\hline & DEPOSITO & 5 & 1 & 15 & 15 \\
\hline & ZONA DE DESCANSO DEL PERSONAL & & & & \\
\hline & CAFÉ Y SNACK & 20 & 1 & 12 & 12 \\
\hline & SSHH & 10 & 1 & 30 & 30 \\
\hline & SUBTOTAL & 200 & & & 3056 \\
\hline & CIRCULACION Y MUROS (30\%) & & & & 916.8 \\
\hline \multirow{20}{*}{ SERVICIOS GENERALES } & & & & & \\
\hline & ZONA DE ASEO DEL PERSONAL & & & & \\
\hline & VESTIDORES & 40 & 1 & 30 & 30 \\
\hline & AREA CASILLEROS & 40 & 1 & 15 & 15 \\
\hline & AREA DE CONTROL & & & & \\
\hline & OFICINA CONTROL GENERAL & 2 & 1 & 30 & 30 \\
\hline & OFICINA CONTROL ESPECIFICO & 3 & 1 & 20 & 20 \\
\hline & AREA DE MANTENIMIENTO & & & & \\
\hline & TALLER DE MANTENIMEINTO & 12 & 1 & 30 & 30 \\
\hline & CUARTO DE MAQUINAS & 3 & 1 & 15 & 15 \\
\hline & DEPOSITO DE HERRAMIENTAS & 5 & 1 & 20 & 20 \\
\hline & AREA DE LIMPIEZA & & & & \\
\hline & DEPOSITO DE LIMPIEZA & 3 & 1 & 20 & 20 \\
\hline & CUARTO DE BASURA & 2 & 1 & 12 & 12 \\
\hline & ENFERMERIA & & & & \\
\hline & AREA DE TOPICO & 10 & 1 & 45 & 45 \\
\hline & OFICINA DE ENFERMERIA & 10 & 1 & 9 & 9 \\
\hline & SSHH & 10 & 1 & 12 & 12 \\
\hline & SUBTOTAL & 140 & & & 258 \\
\hline & CIRCULACION Y MUROS (30\%) & & & & 77.4 \\
\hline
\end{tabular}




\subsubsection{Area por ambiente, por paquete funcional y area total construida}

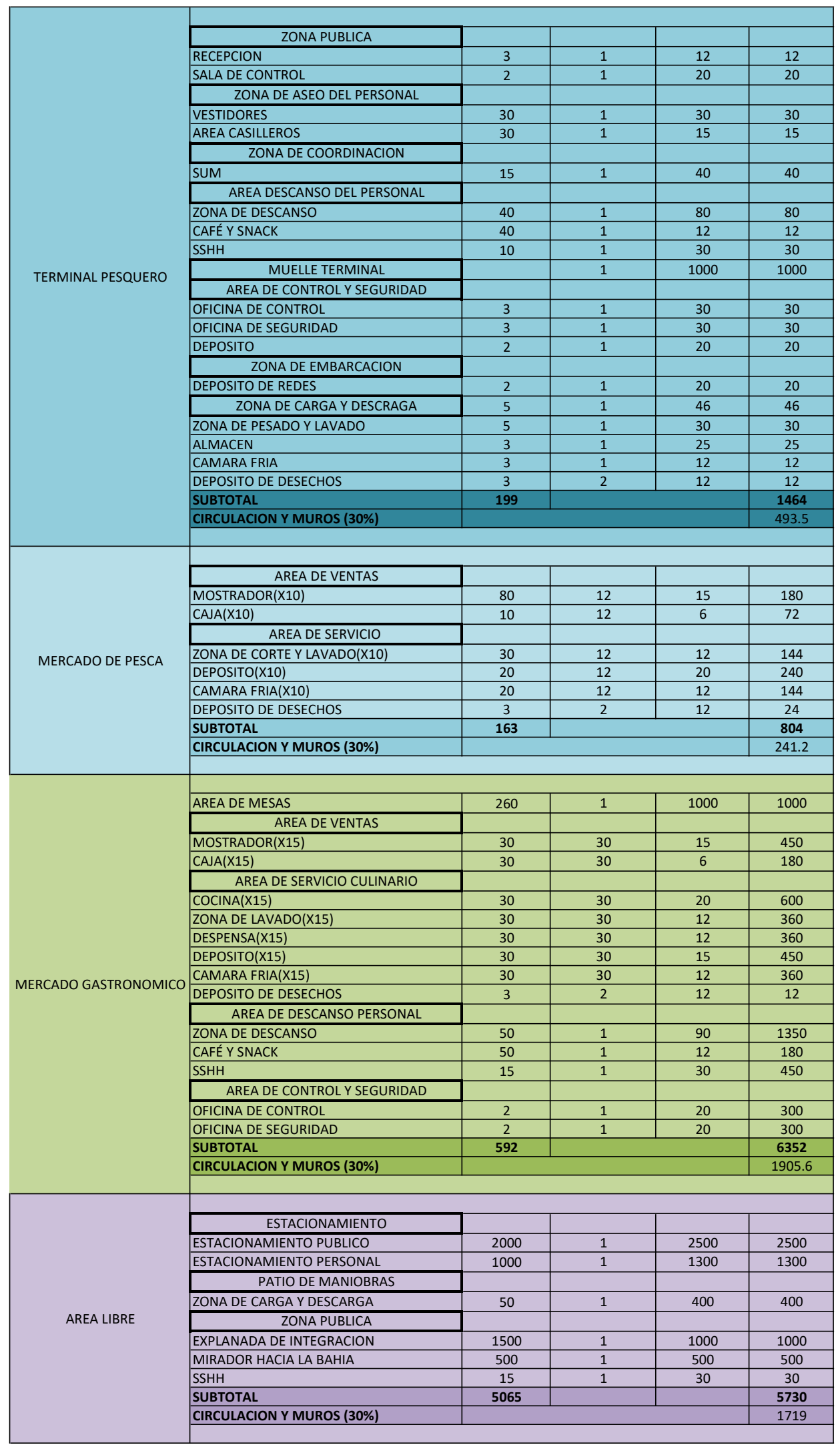


7.8. Cuadro resumen de areas por paquete funcional y area total construida

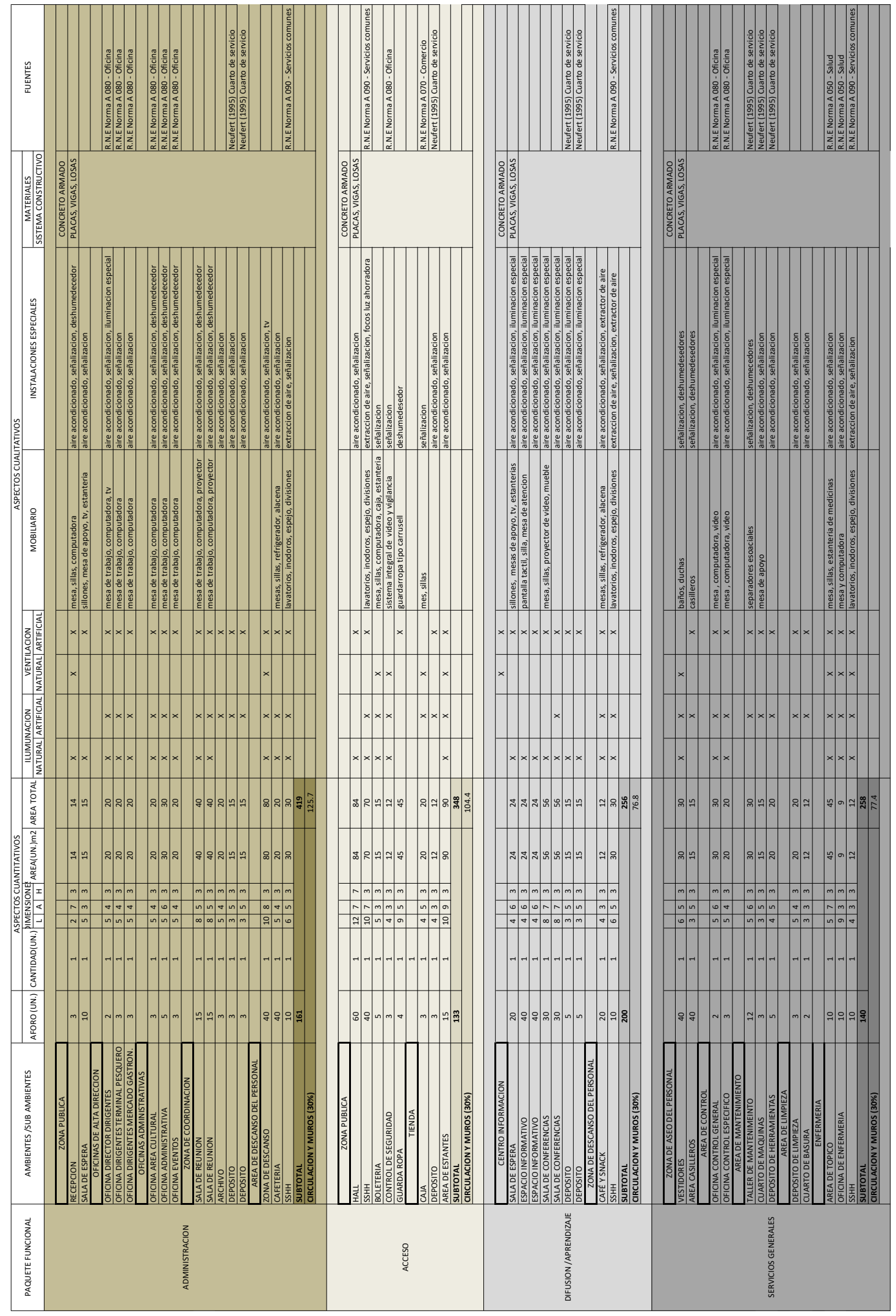




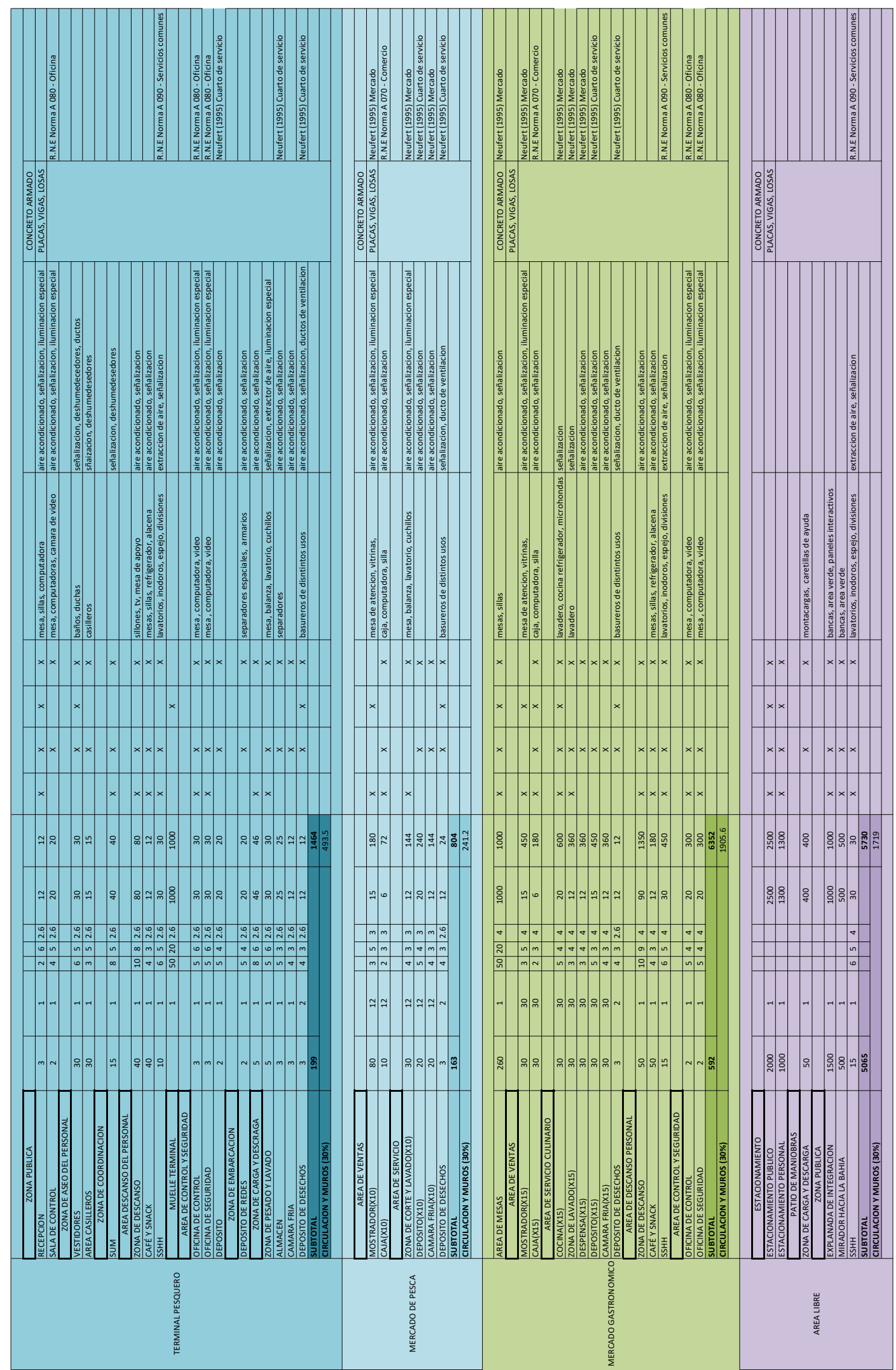




\subsection{Cuadro Resumen}

\begin{tabular}{|c|c|c|c|}
\hline PAQUETE FUNCIONAL & AMBIENTES /SUB AMBIENTES & AFORO (UN.) & AREA TOTAL \\
\hline \multirow[b]{2}{*}{ ADMINISTRACION } & SUBTOTAL & 161 & 419 \\
\hline & CIRCULACION Y MUROS (30\%) & & 125.7 \\
\hline \multirow{2}{*}{ ACCESO } & SUBTOTAL & 133 & 348 \\
\hline & CIRCULACION Y MUROS (30\%) & & 104.4 \\
\hline \multirow{3}{*}{ DIFUSION Y APRENDIZAJE } & GIDTRA & & \\
\hline & 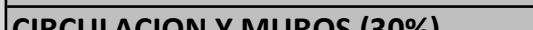 & & 768 \\
\hline & & - & \\
\hline \multirow{3}{*}{ SERVICIOS GENERALES } & & & \\
\hline & SUBTOTAL & 140 & 258 \\
\hline & CIRCULACION Y MUROS (30\%) & & 77.4 \\
\hline \multirow{2}{*}{ TERMINAL PESQUERO } & SUBTOTAL & 199 & 584 \\
\hline & CIRCULACION Y MUROS (30\%) & & 493.5 \\
\hline \multirow{2}{*}{ MERCADO DE PESCA } & SUBTOTAL & 163 & 804 \\
\hline & CIRCULACION Y MUROS (30\%) & & 241.2 \\
\hline \multirow{3}{*}{ MERCADO GASTRONOMICO } & & & \\
\hline & SUBTOTAL & 631 & 6352 \\
\hline & CIRCULACION Y MUROS (30\%) & & 1905.6 \\
\hline \multirow{2}{*}{ AREA LIBRE } & SUBTOTAL & 5065 & 5730 \\
\hline & CIRCULACION Y MUROS (30\%) & & 1719 \\
\hline \multirow{3}{*}{ TOTAL } & & & \\
\hline & & 6,698 & 13,689 \\
\hline & & & 4.106 \\
\hline
\end{tabular}


DATOS - SUSTENTACIÓN

\section{PAQUETES FUNCIONALES}

\begin{tabular}{|c|c|c|c|c|c|}
\hline SERVICIOS & ADMINISTRACIÓN & CULTURAL & TERMINAL PESQUERO & MERCADO DE PESCA & $\begin{array}{c}\text { MERCADO } \\
\text { GASTRONOMICO }\end{array}$ \\
\hline 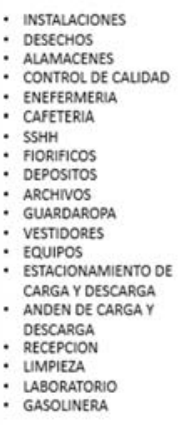 & 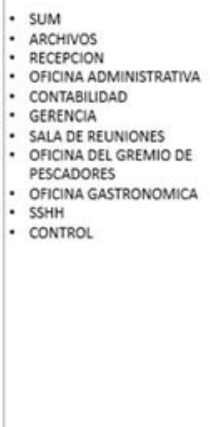 & $\begin{array}{l}\text { : EXPOSICION FOTOGRAFICA } \\
\text { EXPOSICION GASTRONOMICA } \\
\text { EXPOSICION TEMPORA } \\
\text { : EXPOSICOON PERMAMENTE } \\
\text { ESPACIO EXPOSITIVO } \\
\text { MUNICIPAL } \\
\text { EXPOSICION DE ARTESANIAS }\end{array}$ & 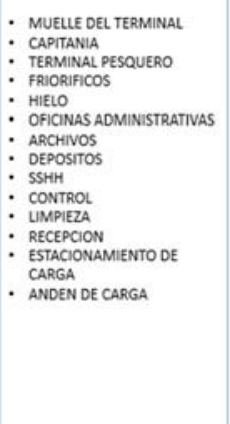 & $\begin{array}{l}\text { - PUESTOS DE VENTA DE } \\
\text { PESCADO Y MARISCOS } \\
\text { - PUESTOS DE VENTA DE } \\
\text { CEVICHE } \\
\text { - ALMACEN DE INSUMOS } \\
\text { - HIELL } \\
\text { - SSHH } \\
\text { CONTROL } \\
\text { COMEDOR }\end{array}$ & 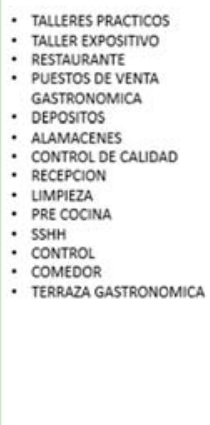 \\
\hline $232 \mathrm{~m} 2$ & $2,555 \mathrm{~m} 2$ & $816 \mathrm{~m} 2$ & $1,565 \mathrm{~m} 2$ & $1631 \mathrm{~m} 2$ & $2514 \mathrm{~m} 2$ \\
\hline \multicolumn{2}{|c|}{$\begin{array}{c}\text { AREA TOTAL DEL } \\
\text { TERRENO }\end{array}$} & $\begin{array}{l}\text { AREA TOTAL } \\
\text { CONSTRUIDA }\end{array}$ & $\begin{array}{l}\text { AREA TOTAL } \\
\text { LIBRE }\end{array}$ & \multicolumn{2}{|c|}{$\begin{array}{l}\text { AREA TOTAL DEL } \\
\text { PROYECTO }\end{array}$} \\
\hline \multicolumn{2}{|c|}{$8,473.44 \mathrm{~m} 2$} & $9,313.14 \mathrm{~m} 2$ & $2,793.9 \mathrm{~m} 2$ & \multicolumn{2}{|c|}{$12,107 \mathrm{~m} 2$} \\
\hline
\end{tabular}

SERVICIOS

ADMINISTRACIÓN

CULTURAL

TERMINAL PESQUERO

MERCADO DE PESCA

MERCADO GASTRONOMICO

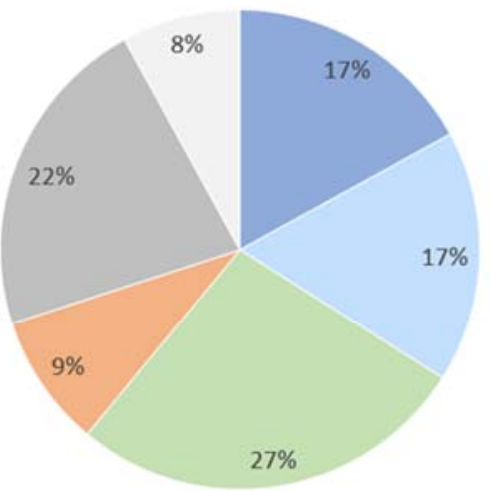

\begin{tabular}{|cccc|}
\hline $\begin{array}{c}\text { AREA TOTAL DEL } \\
\text { TERRENO }\end{array}$ & $\begin{array}{c}\text { AREA TOTAL } \\
\text { CONSTRUIDA }\end{array}$ & $\begin{array}{c}\text { AREA TOTAL } \\
\text { LIBRE }\end{array}$ & $\begin{array}{c}\text { AREA TOTAL DEL } \\
\text { PROYECTO }\end{array}$ \\
\hline $8,473.44 \mathrm{~m} 2$ & $9,313.14 \mathrm{~m} 2$ & $2,793.9 \mathrm{~m} 2$ & $12,107 \mathrm{~m} 2$ \\
\hline
\end{tabular}




\section{Capítulo 8. Conclusiones}

\section{CAPITULO 1 - INTRODUCCION}

En primer lugar, Lima la capital del Perú es una ciudad que presenta un problema muy grande de centralismo, el $80 \%$ de la población es migrante o hijo de emigrante lo cual genera un contraste cultural de personas que llegaron en busca de oportunidades y que hoy en día forman la ciudad de lima, con una diversidad cultural muy variada, este acontecimiento ha generado que el sentimiento de identidad se pierda . En segundo lugar, en los bordes de la ciudad no se han implementado correctamente para satisfacer las necesidades del crecimiento urbano en los últimos años careciendo de infraestructuras educativas y culturales que complementen la actividad comercial generando nuevas centralidad y tercero el turismo no se encuentra articulado en la ciudad, no hay un recorrido que te permita conocer los distintos puntos de la ciudad para poder reconocerlo en su conjunto. Es por ello que se plantea Al sur de lima El Nuevo Terminal Pesquero y Complejo Cultural de la Gastronomia Peruana. El terminal pesquero será el lugar característico del distrito, el gran escenario de identidad y origen distrital, generando identidad en el sector. El complejo cultural de la gastronomía se propone como un recorrido culinario con espacios culturales y gastronómicos que hagan del lugar un lugar de orgullo, fomentando el orgullo nacional. La gastronomía se plantea como el hilo conductor de la experiencia, y la arquitectura como metabolismo para poder mantener todos los espacios en constante relación, complementándose.

\section{CAPITULO 2 - MARCO REFERENCIAL}

Se analizo el marco referencial para poder determinar la historia de la tipología, en este caso la pesca artesanal es una actividad que se realiza hace muchos años, es una de las principales fuentes de alimentos desde años remotos, generando tradiciones que hasta hoy en día se practican. Esta actividad es visto por los trabajadores y pescadores que transcurren en él como un orgullo de emprendimiento, es una gran fuente económica que los ha hecho salir adelante y mejorar su calidad de vida. Además la evolución que ha tenido en su proceso de consumo, desde la extracción hasta el plato, es notable en los últimos años y les ha servido a ellos para poder ampliar su mercado.

CAPITULO 3 - ANALISIS CRITICO DE LOS PROYECTOS REFERENCIALES 
Los proyectos referenciales han sido analizados para poder tener ejemplos de proyectos que han sido planteados con la misma tipología, funcionalidad o incluso equipamientos que podrán ser utilizados en el proyecto a desarrollar. En este caso se analizaron dos proyectos de centros culturales, dos mercados gastronómicos, un terminal pesquero y un espacio de tratamiento paisajista y cultural en el borde hacia el mar. Todos ellos desde una visión arquitectónica y con un criterio critico, valorando sus cualidades como debilidades, para poder aprender de ellos y hacer de nuestros proyectos los mas óptimos posibles, tomando conciencia de lo existente.

\section{CAPITULO 4 - EL LUGAR}

Pucusana es un distrito al sur de lima, con muchas tradiciones que han sido preservadas hasta el día de hoy, presenta un entorno natural paisajista muy hermoso y no se ha sabido valorar con el tiempo, no tienen equipamientos ni infrestructura necesaria para repotenciar la zona pueblo del distrito y poder hacer de el un gran polo turístico, tanto cultural como de ocio y esparcimiento y general. Es importante que su actividad de mayor fuente económica es la pesquera, es por ello que se plantea un espacio ene 1 cual evoque dicha actividad, con un recorrido cultural narrando su origen y historia y como podría ser y es un lugar de desarrollo hacia el fututo.

\section{CAPITULO 5 - EXPEDIENTE URBANO}

El expediente urbano se analizo detalladamente para poder entender el funcionamiento y espacialidad del entorno directo del terreno, tanto el flujo de las personas de el como los espacios utilizados en su perímetro que hacen de este un lugar emblemático distrital. Se tomaran en cuenta dichas actividades de los pobladores para poder implementarlas en el proyecto a desarrollar. Cuenta con espacios como el terminal pesquero mismo, el muelle de pescadores y una gran plaza publica, entre otros que serán repotenciadas y vueltas a diseñar para poder hacer de estos espacios, lugares con diseños arquitectónicos contemporáneos con espacialidades coherentes a su entorno y que sublimen el puerto natural que el distrito caracteriza.

\section{CAPITULO 6 - EL USARIO}

El usuario del proyecto si bien esta enfocado a la población misma, en una gran parte se busca que sean ellos los que trabajen en el, con capacitación previa para que atreves de su experiencia puedan contarle a los visitantes los detalles que el distrito presenta, se 
busca que se sientan orgullosos de sus orígenes y las oportunidades que este presenta. El visitante podrá recorrerlo destacando su visual en los espacios mas importantes del entorno y se busca hacer un reflexión luego de la experiencia. Atenderá a todo el publico en general, desde niños hasta jóvenes, especialistas como profesionales estarán invitados a disfrutar la nueva experiencia cultura y gastronómica que el distrito va a ofrecer.

\section{CAPITULO 7 - PROGRAMACION ARQUITECTONICA}

El programa arquitectónico fue planteado para determinar los espacios a diseñar en el proyecto, de acuerdo a sus usos y necesidades tanto del personal interno como del externo. Se buscan espacios interactivos. un programa variado para poder satisfacer las necesidades múltiples que se dan en este espacio, desde el área de trabajo del personal interno, del área comercial tanto del mercado del terminal pesquero como del mercado gastronómico, cultural y de recreación para los visitantes y pobladores de la zona. Se busca generar un proyecto sostenible, que cuide el medio ambiente y ayude a su preservación.

\subsection{Diagnostico}

Habiendo investigado y analizado el actual terminal pesquero y entono cultural que el distrito presenta, se puede concluir que el lugar no cuenta no equipamiento necesario para hacer de estas actividades, actividades de desarrollo hacia el futuro, el distrito se ha mantenido en el tiempo dentro de su escala productiva, sin embargo las tradiciones distritales se han mantenido y hasta hoy se ven desde que llegas al distrito. No se ha sabido aprovechar las oportunidades que tiene para desarrollarse tanto económicamente, urbanamente y paisajísticamente. Además la identidad que el distrito presenta no se ha sabido trasmitir ya que el paisaje esta dañado incluso en el borde hacia la bahía, con comercio informal hace que el visitante no pueda apreciar las cualidades que el lugar caracteriza. Además el crecimiento urbano a incrementado desarticuladamente, lo cual ha generado que las calles no presentan un orden cogerente con su conjunto y las conexiones no sean claras para una clara permeabilidad distrital, el malecón se encuentra aislado en el conjunto teniendo pocas alternativas de acceso vehicular hacia el, siendo estas las vías con mayor comercio en la zonas bajas e las viviendas, dejando de lado la periferia distrital, quedándose en precariedad y pocas posibilidades de desarrollo. Además el distrito no 
cuente con espacios públicos de interacción tanto del habitante como del visitante que llega al distrito para conocer sus tradiciones.

En conclusión el proyecto propone contribuir a las distintas problemáticas, aprendiendo de ellas con el objetivo de mejorar el distrito en general, repotenciar sus atractivos y poder hacer de este un gran polo turístico tanto para el Perú como para e 1 mundo.

\subsection{Conceptos y Criterios de Diseño}

- Urbanos

- Entorno

- Arquitectonico

- Funcionales

- Ambientales

- Climaticos

- Espaciales

URBANOS ENTORNO

Figura 207: Terreno del proyecto

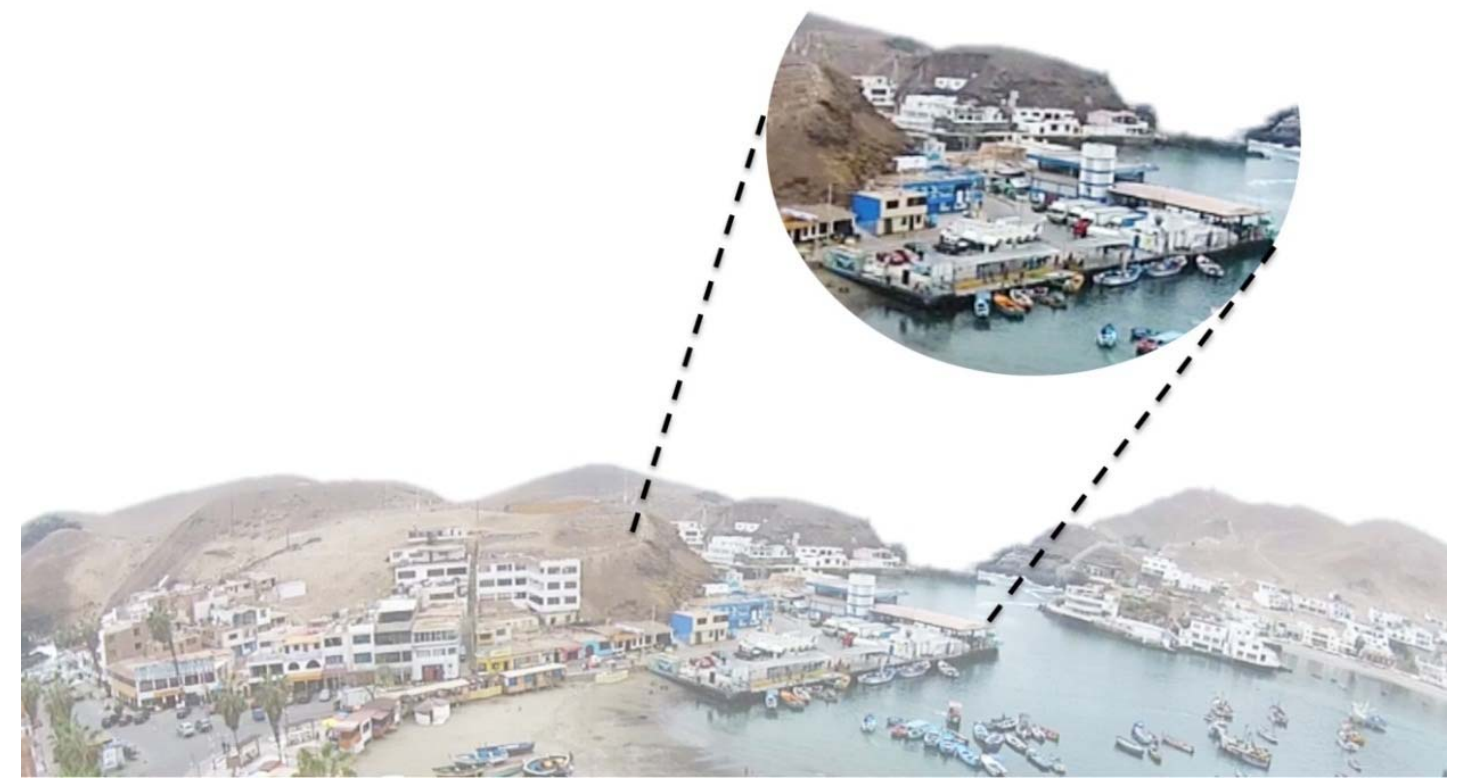

Fuente : Elaboración propia 


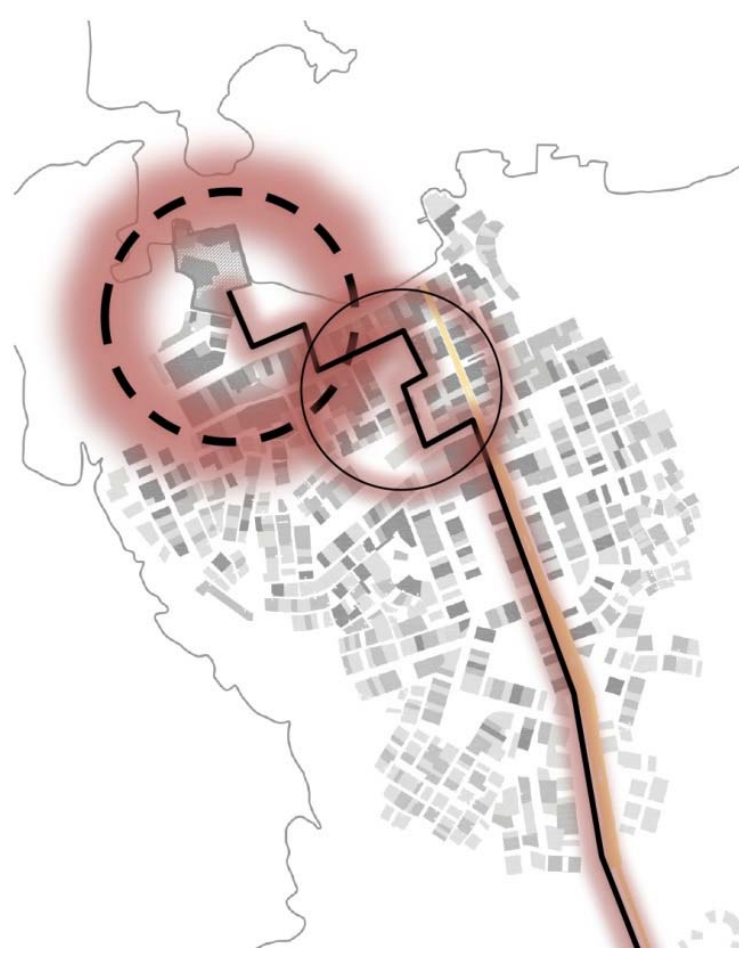

URBANOS

El proyecto estará acompañado de un planteamiento urbano, desde la zona de acceso y salida de la zona pueblo del distrito hasta el malecón, y lugar done se desarrollará el proyecto.

Se propone primero una vía principal, la Av Lima, dotándola de infrestructura con arbustos en la zona central de moda tal que invite al turista a su amplio y optimo recorrido en él. Segundo, mejorar la zona comercial del distrito, re organizando los espacios para evitar el comercio informal en las veredas, y tercero hacer del proyecto un gran foco distrital para el Perú y para el mundo, re activando todo el sector y haciendo del limite hacia el mar un lugar trascendente para el visitante dotándolo de equipamiento para su amplio recorrido como sillas, alamedas y buenas conexiones y orientaciones para que el turista pueda aprovechar el lugar al máximo.

\section{ENTORNO}

El entorno directo del proyecto estará enfocado en los paisajes que caracteriza el lugar, tanto urbano como natural, dentro del complejo se diseñaran espacios de planta libre con materialidad trasparente, permitiendo al visitante insertarse en el territorio y poder reconocerlo y valorarlo, la información historia y cultural estará diseñada para hacer de la experiencia, la mas optima posible de manera didáctica e interactiva.

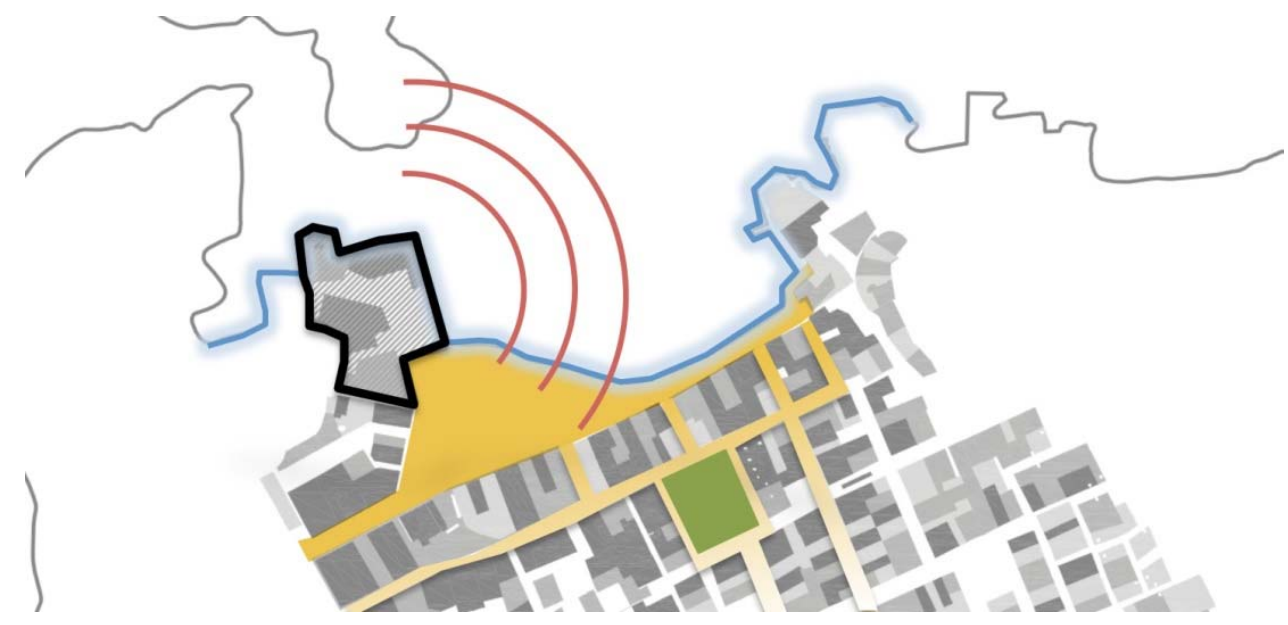




\section{ARQUITECTONICO}

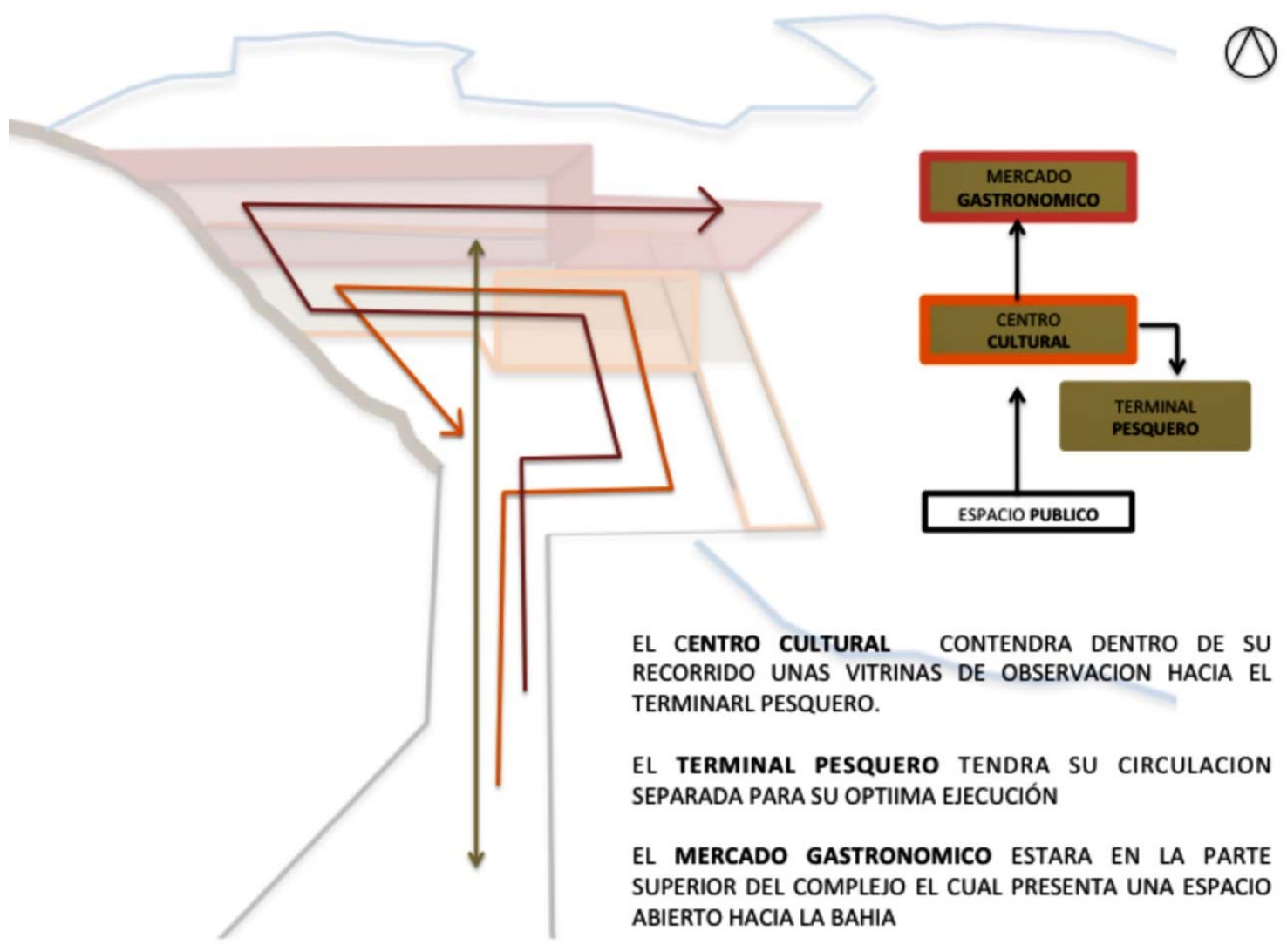

\section{FUNCIONALES}

En las fachadas donde cae el sol, la materialidad del proyecto permitirá que entre la luz en el espacio, el vidrio tendrá protección auto reflejante, se propone un tipo de celosía que permita entrar el viento de una manera moderada, para ventilar el ambiente.

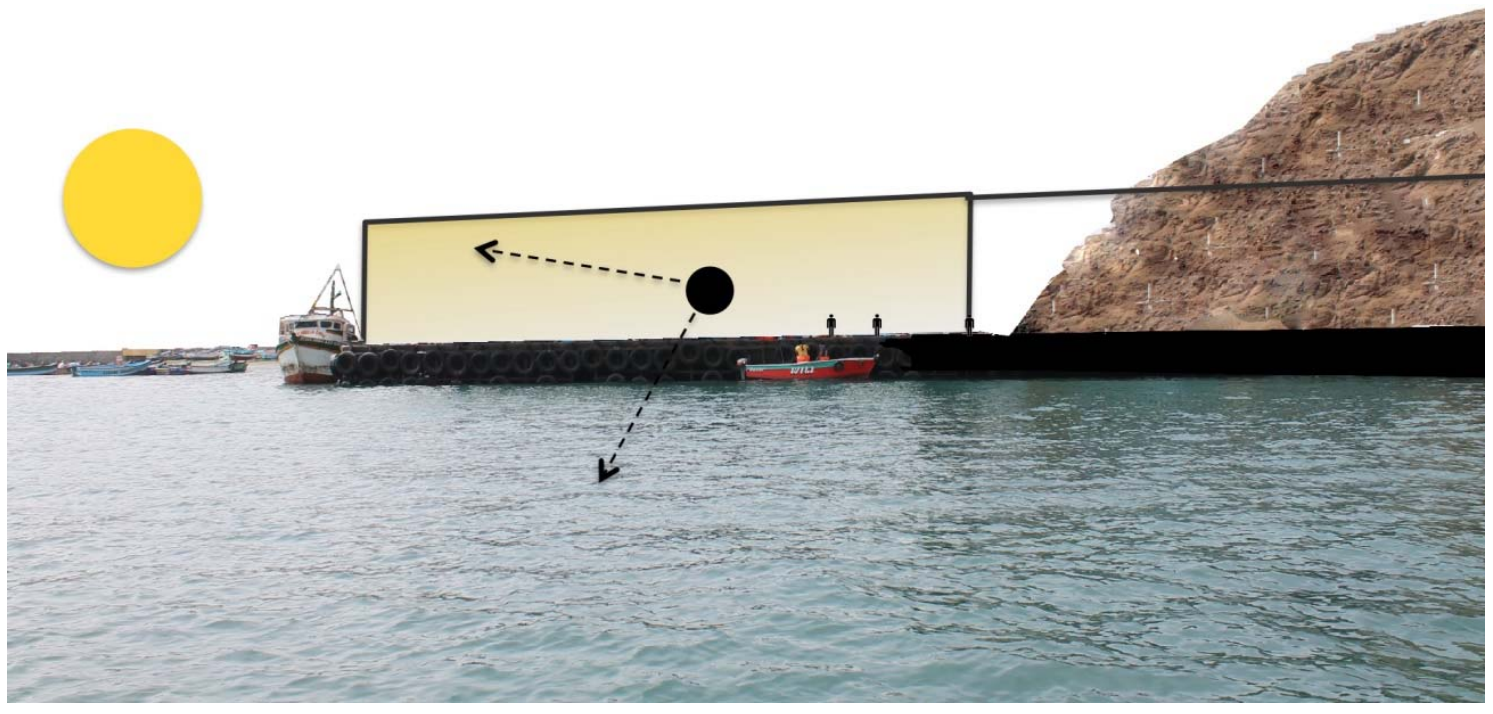




\section{CLIMATICOS}

Los factores climáticos del lugar influirán mucho en el proyecto, por su ubicación en la punta del puerto natural, los vientos son mayores y la marea subirá en ciertas temporadas del año, es por ello que se plantea un retiro del borde para prever en caso de algún imprevisto.
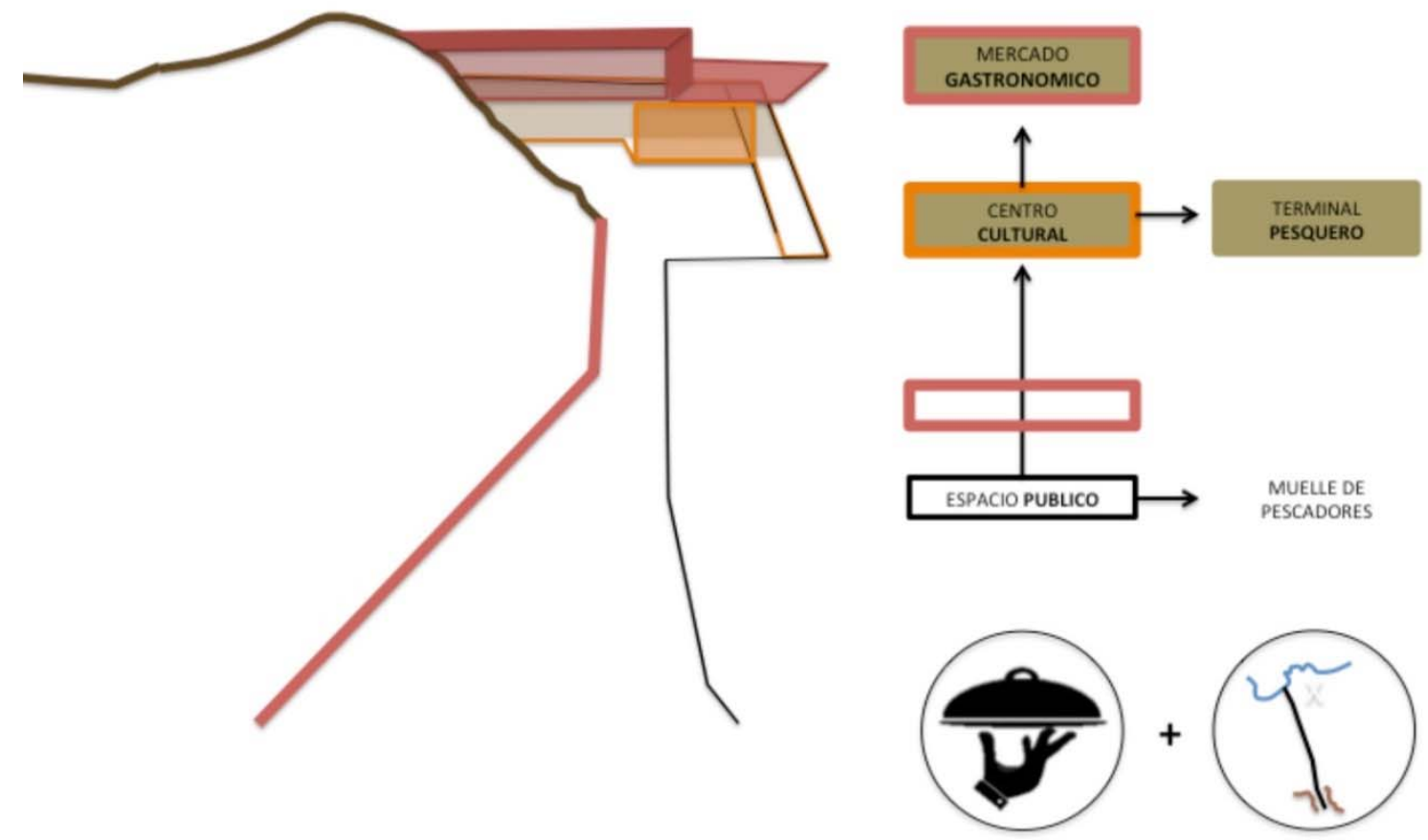

\section{ESPACIALES}

Los espacios estarán distribuidos según su función, todos se conectaran y estarán en contante relación. En la parte superior se ubicara el mercado gastronómico y en la parte inferior el centro cultural y el terminal pesquero, el mercado tendrá una zona de restaurantes los cuales tendrán visuales hacia el terminal.

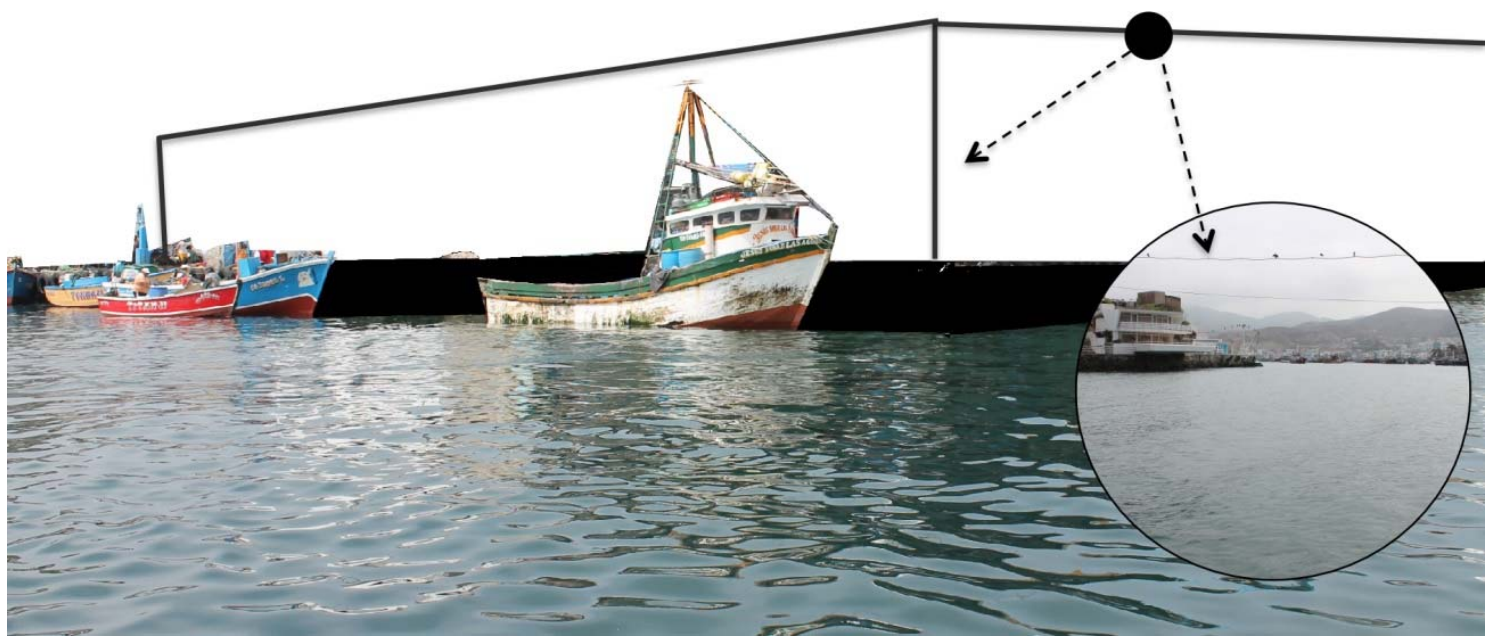




\section{BIBLIOGRAFIA}

Foglia, María Elena; Goytia de Moisset de Espanes, Noemí, LA CUADRICULA EN EL DESARROLLO DE LA CIUDAD HISPANOAMERICANA, EL CASO DE CÓRDOBA 18101916, Tomo II, Córdoba.

García Canclini, nestor, CULTURAS HÍBRIDAS, ESTRATEGIAS PARA ENTRAR Y SALIR DE LA CIUDAD MODERNA, ed. Paidós, Barlcelona, 2001.

Jaramillo, Samuel; Cuervo, Luis Mauricio, URBANIZACIÓN LATINOAMERICANA, NUEVAS PERSPECTIVAS, ed. ESCALA, 1993.

Lynch, Kevin, “LA IMAGEN DE LA CIUDAD”, ed. Gili, SA, Barcelona, 1984/1998.

Lynch, Kevin, “LA ADMINISTRACIÓN DEL PAISAJE”, ed. Norma, Colombia, 1992.

Naselli César, "DE CIUDADES, FORMAS Y PAISAJES”, ed.Arquna, Asunción, Paraguay, 1987.

Naselli César, "LOS ESCENARIOS DE LA ESCRITURA DEL PAISAJE”, Cesar Naselli, Actas Red de Hipótesis de Paisaje, 2002, ed. I+P, 2003.

Solà-Morales Rubió, Ignasi de, PRESENTE Y FUTUROS. LA ARQUITECTURA EN LAS CIUDADES, AA. VV., Presen- te y futuros. Arquitectura en las grandes ciudades, Barcelona: Colegio de Arquitectos de Catalunya / Centro de Cultura Contemporánea, 1996, 10-23.

Schneider Jochem; "NUEVOS PAISAJES NUEVOS TERRITORIOS”, Editorial Actar, Museo de Arte Contemporá- neo de Barcelona, Barcelona, julio 1997.

ZUBIATE, Manuel (consulta Setiembre 2015). "Desarrollo de la Costa Verde" http://manuelzubiatearq.blogspot.pe/2010/10/desarrollo-de-la-costa-verde.html LERNER, Jaime (consulta Agosto 2015) "Acupuntura Urbana" https://puexplora.files.wordpress.com/2011/03/acupuntura-urbana-jaime-lerner.pdf MEDICINA di Paolo, Jorge Amadeo (2010) (consulta Setiembre 2015) El Sistema de turismo en el distrito de Pucusana, como gestión empresarial: una propuesta para elevar el nivel socio económico de la población local (tésis de maestría en Administración con mención en Gestión Empresarial) Lima, Universidad Nacional Mayor de San Marcos.

http://cybertesis.unmsm.edu.pe/xmlui/bitstream/handle/cybertesis/419/Medicina_dj.pdf?sequenc $\mathrm{e}=1$

ARQUITECTURA Y GASTRONOMIA (consulta Setiembre 2015) Prensa y difusión de Sociedad Peruana de Gastronomía - Apega. http://www.apega.pe/noticias/prensa-ydifusion/arquitectura-y-gastronomia.html

APEGA Cocina Peruana - Gastronomía Peruana al 2021 (consulta Agosto 2015) http://www.apega.pe/descargas/contenido/115-apega-cocina-peruana.pdf

LEONARDO LOAYZA, Richard Angelo - blog sobre gastronomía peruana (2009) Universidad Católica - La Travesía del Fantasma (consulta Agosto 2015) 
http://blog.pucp.edu.pe/blog/latravesiadelfantasma/2009/05/07/gastronomia-peruana-singularexpresion-de-la-identidad-cultural/

MIYASHIRO, Jaime y otros. Crecimiento de Lima hacia el Sur. Documento de Urbano. (consulta Setiembre 2015). http://www.urbano.org.pe/downloads/documento/Crecimiento $\% 20 \mathrm{de} \% 20 \mathrm{Lima} \% 20$ hacia $\% 20 \mathrm{el}$ $\% 20$ Sur pdf

GAZTELUMENDI. Simposio de gastronomía (consulta Agosto 2015) http://www.paeria.es/simposigastronomia/pdf/p_igaztelumendi.pdf

LERNER, Jaime. Acupuntura Urbana (2011) (consulta Agosto 2015). https://puexplora.files.wordpress.com/2011/03/acupuntura-urbana-jaime-lerner.pdf Plan de desarrollo concertado de la Municipalidad de Pucusana. Planes de Desarrollo (consulta Setiembre 2015). http://www.imp.gob.pe/images/IMP\%20\%20PLANES\%20DE\%20DESARROLLO\%20MUNI CIPAL/pucusana_plan_de_desarrollo_concertado.pdf Los mejores mercados gastronómicos del mundo (España) (consulta Setiembre 2015) http://listas.20minutos.es/lista/los-mejores-mercados-gastronomicos-del-mundo-396380/ ORREGO, Juan Luis (2009) Blog Universidad Católica. Los balnearios del sur de Lima Pucusana (consulta Agosto 2015).

http://blog.pucp.edu.pe/blog/juanluisorrego/2009/01/12/los-balnearios-del-sur-de-limapucusana/

Profs. Rita Bruschi y César Cutinella (2009) Material extra Reduambiental (consulta Agosto 2015). http://www.reduambiental.edu.uy/wp-content/uploads/2009/12/01-material-extra.pdf COLAUTTI, Viviana (2013) "La Articulación como estrategia proyectual”. Revista Habitat (Argentina) (consulta Agosto 2015). http://www.habitatinclusivo.com.ar/revista/wpcontent/uploads/2013/02/la_articulacion_como_estrategia_proyectual.pdf

CONTE, Ricardo Omar. "Los Nodos como elementos relevantes de la imagen pública de la ciudad de Formosa" (consulta Setiembre 2015). http://www.usal.edu.ar/archivos/geousal/otros/nodos.pdf 